\title{
On the Origin of Cryptic Species:
}

Insights from the Stygocapitella species complex

\author{
José Cerca
}

Thesis submitted for the degree of Philosophiae Doctor

Natural History Museum

Faculty of Mathematics and Natural Sciences

University of Oslo 

"The beauty and brilliancy of this insect are indescribable, and none but a naturalist can understand the intense excitement I experienced when I at length captured it. On taking it out of my net and opening the glorious wings, my heart began to beat violently, the blood rushed to my head, and I felt much more like fainting than I have done when in apprehension of immediate death. I had a headache the rest of the day, so great was the excitement produced by what will appear to most people a very inadequate cause."

Alfred Russel Wallace 

"Em cada esquina um amigo, em cada rosto igualdade."

(In each corner a friend, in each face equality)

José Afonso - Zeca 

"Não sou nada.

Nunca serei nada.

Não posso querer ser nada.

À parte disso, tenho em mim todos os sonhos do mundo."

(I am nobody.

I will never be anything.

I cannot desire to be anything.

Other than this, I hold every dream in the world.) 



\section{Contents}

Acknowledgements

Page 1

List of manuscripts and appendices included

Page 5

Summary

Page 7

Introduction

Page 9

Methods and materials

Page 13

Main findings and Discussion

Page 21

References

Page 46

Manuscripts and appendices

Page 57 

José Cerca - On the Origin of Cryptic Species: Insights from the Stygocapitella species complex

\section{Acknowledgments}

I belong to a lineage from Portugal's rural interior. Growing up in an isolated city in the interior of the country, I never had many goals or ambitions. As a 17-year-old I took a 'career and intelligence test' which pointed out that I had an IQ far lower than the world average. Going to University was not a tough choice though - everyone else did it, and it was only natural that I followed the herd. My first choice was Sports' science, but by the time I had made my choice I had already missed the mandatory physical exams. Back then, I had a supportive biology teacher who helped me understand that I was passionate about biology. I went to University to study biology with no concrete goal in mind, but knew I would be happy becoming a biology high-school teacher. During my period at the University of Coimbra I met incredible people who helped me, stimulated me, and trained me - I developed a liking for plant taxonomy and eventually did a MSc in pollinator ecology. During those years I took a liking to student politics and debating which helped me mature. It was not until I read for my MSc thesis that I understood that I felt like a fish out of water doing ecology. During that period, I heard a talk of Rosemary Gillespie (ESEB 2013) on adaptive radiation of spiders which helped me understand I was truly passionate about evolutionary biology. Following my MSc, I was unemployed for a year. I felt undone and spent my time trying to read up on evolutionary biology. I read Nosil's Ecological Speciation and Schulter's The Ecology of Adaptive Radiation, which made me understand - that's where I want to go. I want to work with evolution and its interface with ecology and morphology and other domains. Having a background in taxonomy and in ecology, in a time where evolutionary biology was being transformed by the 'genomicsrevolution', I could not find a position. I had no network, no support or advice, and did not even understand what I had to do (or the skills to learn) to secure a position. My year of unemployment (note, I took some not-so-relevant jobs) started weighting and defeating me. Nobody was willing to take someone without a skillset in bioinformatics, let alone without much genetics-lab experience. I applied to nearly 40 positions before I took my current position in Oslo.

This background fuels my ambition to work as hard as I can to prove my abilities to myself and to the world. But it also highlights the role of those who believed in me and helped me become who I am. To you, I could not be more grateful. There is not a single day that goes by that I do not acknowledge how lucky I am in having found something that I am so passionate about, and for having had the support to mature and to navigate my way to evolutionary biology. I was lucky I had food, a roof, a bed and a peaceful environment to grow. That being said, I do not think acknowledgements should be laid in paper. Acknowledgements should be done on a daily basis, embodied through caring actions and words, smiles and celebrating each other's success. I thus write these words for personal memories, but also to make sure that in the midst of all our cultural differences, you understand how deeply grateful I am to all of you.

First, and foremost, I am thankful to my main supervisor Torsten H. Struck. I cannot thank you enough for believing in my potential from the beginning. For accepting that you had to train me and that you had to be patient. You invested an incredible amount of time in me - helping me in the lab, discussing 
José Cerca - On the Origin of Cryptic Species: Insights from the Stygocapitella species complex

PCR-gel results as the photography came out, letters of recommendation, grant proposals, in the field, in the terminal, in manuscripts, research ideas, talks and posters. There are many lessons I have learnt from you, but most importantly, you have taught me to always have a high ethical standard - that piece of rigor that separates excellent science from shenanigans. I hope one day I become a scientist like you and make you proud that I came from your laboratory. To Mark Ravinet, for all your advice and support. Hearing how you faced the adversities of your career, and your advice on navigating through graduate school made me spend 4 years admiring you. To Lutz Bachmann, for hours and hours of advice - which made me think twice, and perhaps even become less reckless. To Hugo de Boer for all your time, advice and encouragement. Your ambition and strategy-minded thinking will always be a reference (and a lesson) to me. To Dimitar Dimitrov for your friendship, advice, collaboration and mentorship. It was truly great to have regular lunches with you, as well as to learn from you. To Mike Nowak, for always having an open door. To Günter Purschke for all your support as my co-advisor and expertise in invertebrate morphology. To Mark Blaxter and Julian Catchen for receiving me and treating me as one of your own. I hope to carry a bit of Torsten, MarkR, Lutz, Hugo, Mike, Dimitar, Günter, MarkB, Julian with me.

To everyone who has helped me building up this thesis. This includes the three lab warlocks Lisbeth, Jarl Andreas and Audun for your kind support in laboratory work. To Christian Meyer for helping in sampling and photographing worms. To those who provided me with laboratory space, funding or help in obtaining specimens including Andrew Mackie, Claudia Miller, Christer Erséus, Gustav Paulay, Henning Reiss, Inês Modesto, Lis Lindal Jørgensen, Natalyia Budaeva, Nicola Pennisi, Tim Worsfold, Vasily Radashevsky, and relevant funding bodies.

To my kind and supportive girlfriend Tora Kjærnes Knutsen, who I want to spend my life next to. For all your love and comprehension (i.e. wasted summer holidays, lonely weeks and weekends). À minha mãe e ao meu pai, porque apesar de pensarmos de forma diferente, eu sempre vos amei. Aos meus avós, que estariam em lágrimas por terem criado 'um doutor'. Ao meu irmão Luis Nuno por tanto ser besta como bestial, mas por estar sempre presente quando preciso. To my close friends who kept me going and made me constantly feel saudade (Wikipedia translation: 'deep emotional state of nostalgic or profound melancholic longing for an absent something or someone that one cares for and/or loves (...). One English translation of the word is missingness, although it might not convey the feeling of deep emotion attached to the word "saudade"'). It is not easy to fight alone and I felt the weight of distance was counteracted by your messages and caring support. Thank you urso-Manso (por estares sempre presente quando preciso, e por juntos sermos as duas maiores, mas mais felizes, bestas do mundo), Ruizinho (possas - porque não conseguiria ser feliz sem mandar postas contigo!), Eli (por seres um amor e um grande apoio; já sabes, se o Rui não der..), Ivo (o iron-palhaço que me deu sempre casa e apoio sempre que precisei - mesmo quando não tinha tempo), Rocha (pelo constante apoio, desde que nascemos e até aos nossos últimos dias), Chichorro (pelo apoio e entendimento nesta jornada de doutoramento), Pardal (por estares constantemente preocupada comigo), Maria Palma (por teres sempre uma palavra carinhosa), 
José Cerca - On the Origin of Cryptic Species: Insights from the Stygocapitella species complex

MafaldaJ (por me teres acompanhado desde sempre e me entenderes como ninguém), Paula e Pedro (olhem que vou precisar de espaço no vosso casamento - obrigado por estarem sempre presentes), MafaldaM (por me diagnosticares que sou obcessivo-compulsivo, hiperactivo e ter um défice de atenção - e por aturares toda uma pancada nestes anos), Lucas (por partilharmos ambição e 'background' e crescermos lado-a-lado), David (pela nossa amizade de infância e por ter orgulho das tuas causas), Tiago da Rapoula (possas, tu sabes - sem ti eu não seria eu), Tiago orelhas (por estares sempre presente), restantes ursos do C.d.B. (porque posso estar no cú do mundo, mas jamais terei um grupo de amigos como vocês), Carolina e Bárbara Xavier (bem, não sei. A Bárbara não entrou no parlamento, portanto não sei se quero continuar a ser vosso amigo.. pelo vosso apoio!), Nuno do museu (por te lembrares sempre de mim e me quereres sempre bem), Biotecnólogos da Floresta (por quererem sempre o meu bem), Inês Modesta (pela amizade e por aturares com cada coisa), 'mana' Bea (pelo teu entendimento, apoio e carinho), Deisy (por todo o teu apoio e entendimento), Fátima (for your support), Nicolas (for constant support and friendship), and Cindy (how would I have made it without you in the past two years? You were one of my most fundamental pillars and I have no words to say how much your friendship means to me). Your love, friendship, charisma, and kindness kept me running. Finally, to Luisa Queiroz, António Pereira Coutinho, Paulo Ramos, Isabel Costa, and Rubén Torices for having believed in me when nobody else did, for being an instrumental part of the story above, and for helping me become who I am today.

To my Norwegian friends. Ann-Helén, for all your comradeship and understanding of my world. Thank you for having regular lunches and drinking coffee with me - You know I enjoyed every second of it, and missed having you around every time I left Oslo. The experience at the museum would not have been the same without you. To Siri, for being overwhelmingly present, positive and kind. My four years in Oslo would not have been the same without you. You have become one of my best friends and strongest source of support in these years. To Trude, for being always being supportive, and for hearing my constant rants and complaints in coffee breaks during the last three years. For becoming one of my best friends and such an important support in this four-year journey. To Silje, for being contagiously positive, encouraging and always being able to cheer me up. To the four of you, I really hope our time in Oslo is not over. To Vincent, Irene, Brecht, Marius and Abel for all the good moments in the museum, to Aleks, Sigrid and Sergey for the great times in Oslo. To Luís Morgado for being my best friend in Oslo. You always knew how I felt, and always knew what to say, possibly due to our similar worldview, upbringing in Portugal, and ambition - como é que um gajo sobrevive em Oslo sem ti, pá?

Finally, to all kind people I met throughout my four-year journey in meetings, conferences, courses and seminars. Alexandra, Lene, Marie, Marco and Kerry, thank you for chatting regularly with me, trying to meet outside conferences, in between flights and courses. To my friends in Illinois and Edinburgh including Angel, George and your friends, Niraj, Chris and Jane, Andrea, Jessica. You made my time in Edinburgh and Illinois worthwhile. 
José Cerca - On the Origin of Cryptic Species: Insights from the Stygocapitella species complex

'Em cada esquina, um Amigo' (tr. In each corner, a friend)

To all of you, thank you.. 


\section{Manuscripts included as part of this thesis}

1. T. H. Struck, J. L. Feder, M. Bendiksby, S. Birkeland, J. Cerca, V. I. Gusarov, S. Kistenich, et al. 2018. Finding evolutionary processes hidden in cryptic species. Trends in Ecology \& Evolution: 3, 33: 153-163.

2. J. Cerca, G. Purschke, and T. H. Struck. 2018. Marine connectivity dynamics: clarifying cosmopolitan distributions of marine interstitial invertebrates and the meiofauna paradox. Marine Biology 165: 123.

3. J. Cerca, C. Meyer, D. Stateczny, D. Siemon, J. Wegbrod, G. Purschke, D. Dimitrov, and T. H. Struck. Deceleration of morphological evolution in a cryptic species complex and its links to paleontological stasis. Accepted in Evolution.

4. J. Cerca, C. Meyer, G. Purschke, and T. H. Struck. Delimitation of cryptic species drastically reduces the geographical of marine interstitial ghost-worms (Stygocapitella; Annelida, Sedentaria). Minor revision submitted - Accepted in Molecular Phylogenetics and Evolution

5. J. Cerca, M. Ravinet, M. Nowak, T. H. Struck. Big data in biodiversity: genome-level data (ddRADseq) suggests a complex evolutionary history in a morphologically similar cryptic species complex, which is not revealed by few molecular markers. manuscript format

\section{Appendices including non-peer reviewed replies and book chapters}

1. T. H. Struck, J. L. Feder, M. Bendiksby, S. Birkeland, J. Cerca, V. I. Gusarov, S. Kistenich, et al. 2018. Cryptic Species - More Than Terminological Chaos: A Reply to Heethoff. Trends in Ecology \& Evolution: 3, 33: 310-312.

2. T. H. Struck, J. Cerca, 2019. Cryptic Species and Their Evolutionary Significance. eLS 1-9. 
José Cerca - On the Origin of Cryptic Species: Insights from the Stygocapitella species complex 
José Cerca - On the Origin of Cryptic Species: Insights from the Stygocapitella species complex

\section{Summary}

The revolution of DNA sequencing in biology unveiled unrecognised genetic diversity in previously established species - cryptic species. Recent evidence suggests that cryptic species may represent an important, yet overlooked, component of biodiversity. Despite this, current definitions of cryptic species have led to the interpretation that this unrecognised diversity stems from artefacts from classifying and delimiting species, that is, deficiently delimited species. This view has fuelled the interpretation that cryptic species do not exist in nature.

As part of this thesis, I challenge this view by suggesting that cryptic species are morphologically identical or quasi-identical species. I provide a framework to identify cryptic species, specifically focused on teasing apart 'taxonomic artefacts' and morphologically identical species (i.e. cryptic species). This framework involves a two-step process consisting of a regular species delimitation, followed by a rigorous investigation of morphological divergence (Struck et al., 2018b, 2018a; Struck and Cerca, 2019).

I apply this framework to the Stygocapitella species complex (manuscripts 3-5). Species belonging to the Stygocapitella species complex were estimated to have diverged $\sim 250$ millions of years ago, despite being morphologically very similar (Struck et al., 2017). As part of my thesis, I have collected Stygocapitella from every continental coast in the Northern Hemisphere and studied genetic and morphological divergence among these populations. I find several reproductively isolated Stygocapitella species to be morphologically similar, some living in sympatry. Comparing to closely related annelid taxa, I show that Stygocapitella is morphologically slow evolving (manuscript 3). Based on genetic and morphological divergence, I describe 8 new Styoocapitella species (manuscript 4) and discuss the implications of the detection of cryptic species in biogeography, evolutionary biology, paleontology and systematics (manuscripts 3-5). I optimized and applied a whole-genome amplification protocol together with double-digestion Restriction Associated DNA sequencing (ddRADseq), showing that three morphologically similar Stygocapitella have a complex demographic history (manuscript 5). Finally, I provide a literature survey which demonstrates that the discovery of cryptic species in the meiofauna leads to the reduction of the distribution of the originally described species (Cerca et al., 2018).

My thesis broadly shows that cryptic species represent an important, yet overlooked component of biodiversity. Deceleration of morphological evolution has the potential to bridge the gap between paleontological stasis and extant cryptic species complexes. I find that failing to detect cryptic species results in the overlook biogeographic breaks and in the inflation of species' distributions. I discuss the importance of understanding and describing cryptic species in evolutionary biology, systematics, paleontology and biogeography. 
José Cerca - On the Origin of Cryptic Species: Insights from the Stygocapitella species complex 
José Cerca - On the Origin of Cryptic Species: Insights from the Stygocapitella species complex

\section{Introduction}

\section{Biological diversity}

Describing and delimiting biodiversity is one of the most arduous tasks in biology, due to the diversity and complexity of life. Facing severe underfunding, the resources and funding needed to collect, describe and preserve organisms jeopardizes our ability to understand natural history biodiversity. However, facing global biodiversity losses, environmental changes and human destruction of habitats, studying and cataloguing biodiversity is of fundamental importance and urgency as we will leave a less diverse planet to future generations.

The species is the fundamental unit to characterize, delimit and understand biodiversity, serving as a pillar to obtain general inferences on patterns and processes in various disciplines including ecology, evolution, and biogeography. Biodiversity research is currently undergoing major changes and progress, driven by the recent revolutions of DNA barcoding and High-Throughput Sequencing. DNA barcodes, that is a species-specific DNA identifier, have become a standardized and practical approach to delimit species. Each species is customarily associated with a "DNA barcode", which allows a fast, and somehow reliable identification of a species, without requiring much taxonomic expertise. However, the application of this process has revealed a hidden layer of diversity within previously established species.

\section{Biological diversity and cryptic species}

The upheaval of DNA sequencing in biology uncovered unrecognised genetic diversity in previously established species - cryptic species (Bickford et al., 2007; Fišer et al., 2018; Struck et al., 2018a). Cryptic species have been found in all major biological groups (Hawksworth and Lücking, 2017; Leasi and Norenburg, 2016; Payo et al., 2013; Singer et al., 2018; Surveswaran et al., 2018; Wada et al., 2013), including well studied groups such as primates (Hotaling et al., 2016), amphibia, reptiles and crustaceans (Pérez-Ponce de León and Poulin, 2016). In some cases, the discovery of cryptic species involved more than ten overlooked lineages, some of them occurring in sympatry (Kon et al., 2007). Estimations of cryptic species in the sea include numbers as high as 9,000 - 35,000 species (Appeltans et al., 2012), hence potentially representing a substantial, yet hidden, fraction of biodiversity.

Cryptic species were defined as "two or more distinct species that are erroneously classified (and hidden) under one species name." (Bickford et al., 2007). This definition has been widely accepted and cited, having become the most commonly used definition. However, it has recently prompted criticism because it focuses on the taxonomic history of the species complex (Korshunova et al., 2019, 2017). For example, rates of cryptic species are expected to be higher in groups whose 'taxonomic schools' favoured a conservative approach to delimitating species (traditionally called the "lumpers"), as opposed to those prone to splitting species (the "splitters") (Endersby, 2009). In this way, rates and the occurrence of cryptic species could reflect a taxonomic artefact, rather than an underlying biological phenomenon, 
José Cerca - On the Origin of Cryptic Species: Insights from the Stygocapitella species complex

leading to the opinion that the term cryptic species should be avoided, or used as a temporary formalization of the problems associated with delineation of species complexes (Korshunova et al., 2019, 2017).

An opposing view is to consider cryptic species as the outcome of biological processes leading to slow morphological evolution (Chenuil et al., 2019; Fišer et al., 2018). Biological species are expected to remain morphologically similar under 'morphological stasis', in scenarios of stabilizing selection for morphology (Futuyma, 2010; Hansen and Houle, 2004), hybridization (Futuyma, 2010), due to particularities of their ecosystems and habitats (Sheldon, 1996), or facing constraints to evolution (Futuyma, 2010; Hansen and Houle, 2004; Maynard Smith et al., 1985). In such scenarios, species are expected to remain similar due to the extrinsic (i.e. ecology, habitat, biotic and abiotic interactions) and intrinsic properties (i.e. developmental constraints, genetic constraints) of their biology, in opposition to being taxonomic artefacts. However, morphological stasis has received attention mostly in the paleontological literature as part of the theory of punctuated equilibrium (Eldredge and Gould, 1972). As a result, morphological stasis has received attention mostly from theoretical models, paleontological data and commentaries (Estes and Arnold, 2007; Futuyma, 2005; Hansen, 1997; Hansen and Houle, 2004; Voje et al., 2018), leaving a gap between these and extant taxa (but see Wada et al., 2013; Swift et al., 2016).

\section{The interstitial environment and cryptic meiofaunal species}

A group of organisms with a particularly high incidence of cryptic species is the meiofauna living in interstitial sediments (Giere, 2009; Jörger and Schrödl, 2013). 'Meiofauna' usually refers to organisms living in the interstitial environment or the space available between sand grains, and is defined by sizes approximately between $22 \mu \mathrm{m}$ and $1000 \mu \mathrm{m}$. These organisms were first described in the $19^{\text {th }}$ century (Dujardin, 1851; Lovén, 1844), yet their diversity remained unappreciated for decades. Today we know that sediments in beaches are inhabited by a bewildering diversity of animal groups, with 23 out of the 34 metazoan phyla having meiofaunal representatives and four animal phyla being exclusively meiofaunal (Gnathostomulida, Kinorhyncha, Loricifera and Micrognathozoa) (Giere, 2009). The meiofauna is usually considered as distinct from micro- and from macro-fauna, being its own independent ecological evolutionary unit (Giere, 2009). Its adaptations to the spatially restricted interstitial environment are its most remarkable and distinctive set of traits. The 'meiofaunal syndrome' (Brenzinger et al., 2013; Jörger et al., 2014) describes the general uniform, elongated, worm-like body shape and overall simplified external organization with adhesive structures, a set of traits well-adapted to life in the sediment (Giere, 2009).

The small size of the meiofauna and the absence of pelagic larvae have led biologists to describe these organisms as sedentary and having limited dispersal capacities (Danielopol and Wouters, 1992; Giere, 2009; Sterrer, 1973). This contrasts with their wide distribution ranges, often encompassing whole continental coastlines, being amphi-oceanic or even cosmopolitan (Cerca et al., 2018; Gerlach, 1977; Giere, 2009; Jörger et al., 2012; Kajihara et al., 2015; Sterrer, 1973; Westheide, 1977; Westheide and Rieger, 1987) 
José Cerca - On the Origin of Cryptic Species: Insights from the Stygocapitella species complex

- a contradiction which became known as the 'meiofauna paradox' (Cerca et al., 2018; Giere, 2009). Recent evidence suggests that the presence of cryptic species (i.e. hidden diversity) may lead to the inflation of species distribution (Derycke et al., 2013; Jörger and Schrödl, 2013; Leasi and Norenburg, 2014). In such scenario, species living in separate coastlines would represent different species, but would have been identified as a single cosmopolitan species (Westheide, 2005, 1991).

\section{The Stygocapitella study system}

The Stygocapitella (Annelida: Orbiniidae) genus comprises 3 species of interstitial annelids (Figure 1). The genus was originally described by Knöllner (1934), along with the formal description of the species Stygocapitella subterranea based on individuals collected from Baltic coastline of Germany. Stygocapitella subterranea was posteriorly reported in Sweden, the Mediterranean (French and Tunisian coastlines), the Black Sea (Romanian coast), in both coastlines of North America, and in New Zealand (Purschke et al., 2019; Riser, 1980; Westheide, 2008, 1990), becoming recognized as a cosmopolitan distributed species. However, the application of RAPDs uncovered a phylogeographic pattern, with phylogenetic analyses separating specimens from the Atlantic from those from the Pacific, and further breaking specimens from the distinct North Atlantic coastlines (Schmidt and Westheide, 2000). Struck et al. (2017) described two new Stygocapitella species based on specimens from South Africa and Australia, suggesting that individuals from different coastlines represent cryptic species, and estimated that the time of divergence among some cryptic species might be as old as $290 \mathrm{MY}$. These evidences suggest that the lineages found by Schmidt and Westheide (2000) could potentially represent cryptic species, and the 'cosmopolitan' distribution of Stygocapitella could be a result from considering multiple cryptic species as a single species. Additionally, Struck et al (2017) reported that these three species were morphologically quasi-identical, only distinct by the presence-absence of specific chaetae. Stygocapitella thus stands out as an excellent study system to understand rates of morphological and genetic evolution, as well as to understand the impacts of cryptic species for systematics, biogeography and evolutionary biology.

\section{Objectives and major questions addressed}

The main objective of this thesis is to understand whether cryptic species are a mere taxonomic artefact, or whether they are by-products of biological phenomena. To do so, I propose:

Objective 1 A new framework to delimit cryptic species (Struck et al., 2018a, 2018b);

Objective 2 The application of this framework to the Stygocapitella species complex;

Objective 3 The investigation of rates of morphological and genetic evolution in Stygocapitella using phylogenetic and population genetic tools (manuscripts 3-5). 
José Cerca - On the Origin of Cryptic Species: Insights from the Stygocapitella species complex

Objective 4 To fully understand the impact of cryptic species in various disciplines of biology, a literature survey to understand the incidence of cryptic species in meiofauna, and its contribution to the 'meiofauna paradox' (Cerca et al., 2018).
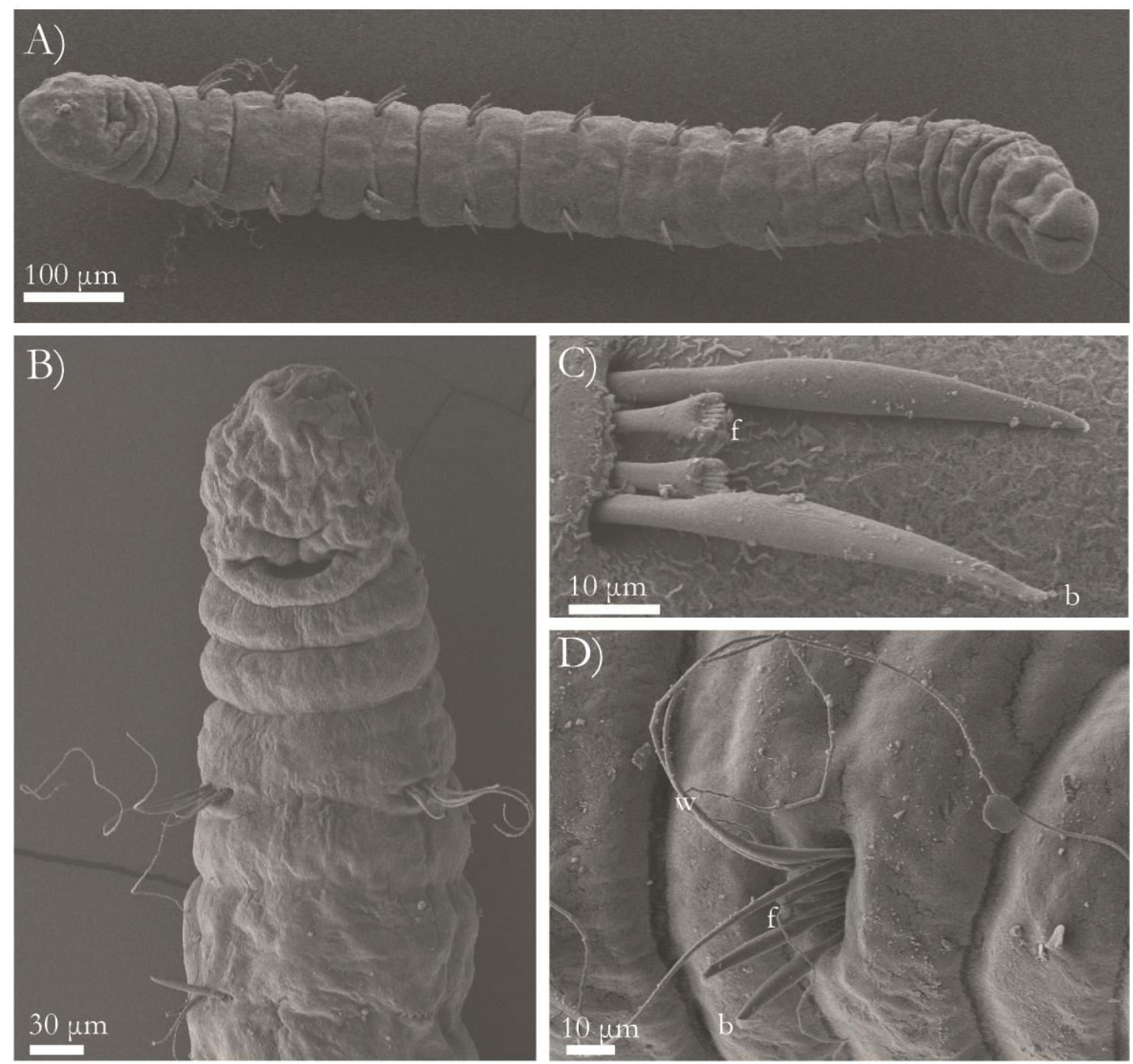

Figure 1. Scanning Electron Microscopy of Stygocapitella spp. including (A) photos of a complete organism, (B) the prostomium, (C) the chaetal pattern found in every Stygocapitella species in segments 3-10, and (D) the characteristic whip-like chaeta. Magnification is provided for each photo. (A) Whole organism photograph of Stygocapitella furcata sp. nov. from the $4^{\text {th }}$ of July Beach, Friday Harbor (WA), USA. (B) Prostomium and first two segments of Stygocapitella berniei sp. nov. from Roche Harbor, Friday Harbor (WA), USA. (C) Abdominal chaetal pattern of Stygocapitella josemariobrancoi sp. nov. consisting of a bilimbate (b), two forked (f), and a bilimbate chaetae. This pattern is common to the $3^{\text {rd }}-10^{\text {th }}$ segment of every Stygocapitella species. Photograph from a specimen from Gravesend, UK. (D) First segment chaetae of Stygocapitella josemariobrancoi sp. nov. with a chaetal pattern consisting of two whip-like chaetae (w), two forked chaetae (f), and two bilimbate chaetae (b). Specimen from Plymouth, UK. 
José Cerca - On the Origin of Cryptic Species: Insights from the Stygocapitella species complex

\section{Methods and materials}

To meet the proposed objectives, I have conducted two literature reviews (Cerca et al., 2018; Struck et al., 2018a) and analysed empirical data (manuscripts 3-5). We conducted literature reviews to understand the impact of cryptic species in various disciplines, justify the need for the new framework, and present a novel framework. The empirical data included morphological, genetic and genomic data and focused on the Stygocapitella genus (Figure 1). My results reveal the usefulness and practicality of the established theoretical framework.

Literature review on cryptic species as part of manuscript 1 (Struck et al., 2018a)

On June 172016 we searched for 'cryptic sp*' and downloaded a list of all papers in the ISI Web of Science database. In total, we obtained a list of 6,002 papers from which we scored 606 papers $(10 \%)$. For each paper, we scored the use of molecular data (i.e. whether it was used or not; whether it included mitochondrial, plastid or nuclear data; the number of obtained loci; whether genome level data had been obtained; quantification of genetic divergence; the use of an outgroup taxa; the use of molecular data; the use fossil-calibration), morphological data (including if it was statistically analyzed and if differences in morphology were found), the use other phenotypic data, the definition of cryptic species, taxa, and whether any species had been described.

\section{Literature review on the meiofauna paradox as part of manuscript 2 (Cerca et al., 2018)}

We did a literature review to understand whether and how the presence and the discovery of cryptic species influenced the distribution of meiofaunal taxa. This survey was carried on June 6th 2018, using the following search terms in ISI Web of Knowledge: "(meiofauna* OR meiobenth* OR Gnathostomulida OR Kinorhyncha OR Loricifera) AND (marine OR Atlantic OR Pacific OR Indian OR Arctic OR Antarctic OR "Southern Ocean") AND (molecular OR cryptic OR paradox OR taxonom* OR dispersal OR phylo* OR biogeo* OR distribut*)". This yielded a total of 1,069 publications, from which we were unable to obtain 16, either due to paywalls (8), being meeting abstracts (3), not being found in google, google scholar or research gate (5). We downloaded and analyzed the abstract and main results of the remaining 1,053 publications, which resulted in the removal of 302 publications because they were written in a language other than English, did not focus primarily on metazoan-meiofaunal taxa, marine areas or did not present new data (i.e. reviews, perspectives and methods papers). The complete list of papers is provided in Supplementary Table 1 as part of Cerca et al. (2018).

In the remaining 752 papers, we scored discipline (i.e. Ecology, Evolution, Biogeography, Taxonomy, Development, Physiology, Review or Perspective, Paleontology), taxa (i.e. Phylum and Species), the use of molecular and morphological data, occurrence of cryptic and pseudo-cryptic species (i.e. if these species had been formally described and the number of species), difficulties of taxonomical characterization (i.e. low-morphology problem), distribution range before and after the study, geographical 
José Cerca - On the Origin of Cryptic Species: Insights from the Stygocapitella species complex

area studied (i.e. the nearest continent or coastline; including Africa, Antarctica, Australia, Asia, Europe, North and Center America, and South America), sediment depth (supra-littoral, intertidal, subtidal from the low water line to a depth of $200 \mathrm{~m}$, or deep sea below $200 \mathrm{~m}$ ), occurrence of pelagic larvae, description of the habitat, and the approach to understand dispersal (i.e. experimental or descriptive). To score these fields we defined a specific set of rules which included: (i) we only registered changes in species distributions (before and after study) only if the study provided unambiguous information about the species distribution before and after the study; (ii) when a study focused on more than 2 genera or species, we registered species as NA; (iii) we only considered the use of morphological methods when a study analyzed morphological traits, and not only use it as a means of species identification; (iv) range distribution was considered "local" if it was only known from a restricted area (e.g., coastline of one country), "regional" if present at an entire coastline (e.g., all Europe), "amphi-oceanic" if present in both sides of an ocean and "cosmopolitan" if present in more than one ocean; (v) "phylum" included every phyla studied, even if only one individual from a particular phylum was mentioned; (vi) in micro- and mesocosms, we considered the geographical area with respect to where sediments or water samples were collected; (vii) when a new species was described, regional range was recorded as "NA" before the study and local, regional, amphi-oceanic, or cosmopolitan afterwards.

\section{Fieldwork}

Stygocapitella specimens are usually found above the high-water line of stable, sheltered gravel or sandy beaches. We selected sampling sites based on previous records available to us, and by inspecting promising beach areas using google maps (Figure 2 A-G). Upon selection of a sampling site, we dug a hole every meter from the high-water line to the foot of the dune (Figure $2 \mathrm{H}$ ). In each hole, we dug to about 1 meter deep and collected samples every $15 \mathrm{~cm}$ height (volume of $375 \mathrm{~cm}^{3}$ ), until approximately 60-75 centimetres depth. Interstitial invertebrates, including Stygocapitella, were anesthetized and extracted from the sediment using the $\mathrm{MgCl}_{2}$ method and sorted under a dissecting microscope (Figure $2 \mathrm{I}$ ) (Westheide and Purschke, 1988). Stygocapitella is easily identified by the presence of two whip-like chaetae in its first segment. After identification, specimens were preserved either for molecular biology or morphological analyses, either by preservation in 70\% ethanol or in SPAFG following Westheide and Purschke (1988). A total of 33 sites spanning every coastline in the Northern Hemisphere were included for this study (Figure $2 \mathrm{~A}-\mathrm{G})$.

\section{DNA extraction and Sanger sequencing as part of manuscripts 3-5}

A detailed account of the molecular methods can be found in manuscripts 3-4. We extracted DNA from individual Stygocapitella specimens either using a phenol-chloroform or a column-based (E. Z. Kit) approach. We used standard PCR amplification together with Sanger sequencing to sequence the mitochondrial genes Cytochrome c oxidase subunit I (COI) and 16S ribosomal RNA (16S), and the nuclear genes $18 \mathrm{~S}$ ribosomal RNA (18S) and Internal transcribed spacer-1 (ITS1). Nuclear markers and 
José Cerca - On the Origin of Cryptic Species: Insights from the Stygocapitella species complex

COI were amplified using the QIAGEN® Multiplex PCR Kit (Qiagen, Hilden, Germany) in a solution containing multiplex mix, Q-solution, forward and reverse primer, genomic DNA and deionized water. $16 \mathrm{~S}$ was amplified using a solution which included $\mathrm{H}_{2} \mathrm{O}, 10 \mathrm{x}$ PCR Buffer I (with $\mathrm{MgCl}_{2}$ added), BSA, dNTPs, forward and reverse primer and amplitaq gold. For COI, we used LCO1490-JJ and HCO2198-JJ as primers (Astrin and Stüben, 2008), and for 18S 18e (Hillis and Dixon, 1991) and 18R1779 (Struck et al., 2002). For ITS1, we used the species-specific primers Stygo_ITS1_F and Stygo_ITS1_R, and for 16S 16SarL (Palumbi et al., 1991) and 16S_AN-R (Zanol et al., 2010). Exceptionally, we used polyLCO and polyHCO (Lobo et al., 2016) to amplify COI in Atlantic-American populations. Purified PCR fragments using a 10x dilution of a phosphatase-exonuclease mix were Sanger-sequenced. The $18 \mathrm{~S}$ fragment required internal sequencing primers, which included 18r, 18L (Hillis and Dixon, 1991), 18F997 (Struck et al., 2002) and 18SF3_Stygo (Struck et al., 2017). After sequencing, sequences were assembled using Geneious
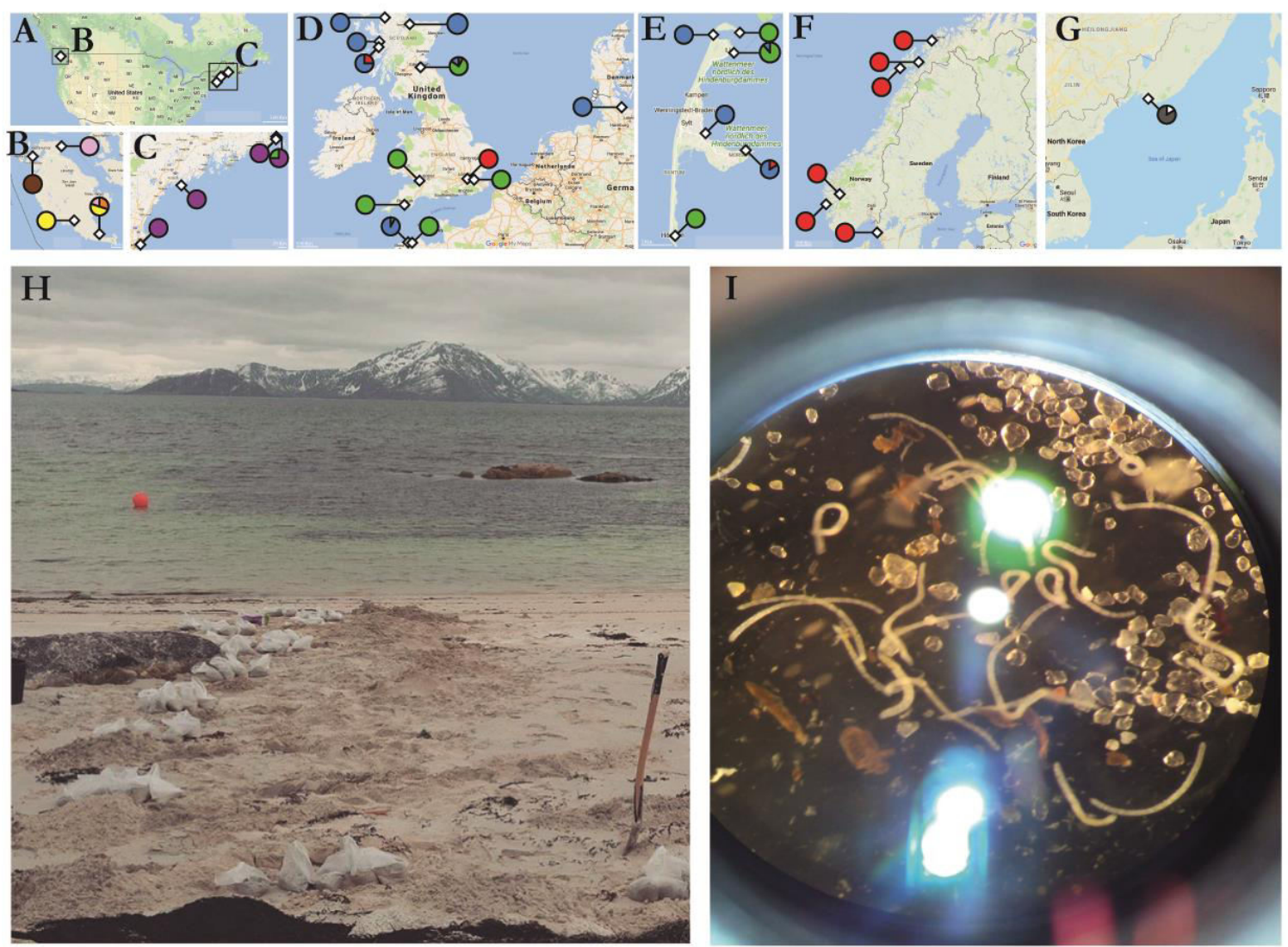

Figure 2. Sampling locations (A-G), a sampling site $(H)$, and view through the dissecting microscope (I). Sampling locations in North America include the (A) North American Pacific coastline, in specific the (B) San Juan Island (WA, USA), and the (C) Atlantic coastline of the USA (ME, MA). Sampling locations in Europe include the (D) UK, France and Germany, (E) the island of Sylt in Germany, (F) and Norway and Sweden. Sampling in (G) Far-East Russia was done in Volchanets (Russia). For GPS coordinates see Supplementary table 1 included as part of manuscript 4. Circles denote lineages collected: Orange - Stygocapitella furcata sp. nov.; Yellow - Stygocapitella Spec. A (undescribed); Brown - Stygocapitella berniei sp. nov.; Pink - Stygocapitella americae sp. nov.; Purple - Stygocapitella westheidei sp. nov.; Red - Stygocapitella zecai sp. nov.; Blue - Stygocapitella subterranea; Green Stygocapitella josemariobrancoi sp. nov.; Grey - Stygocapitella budaevae sp. nov.; White - Stygocapitella pacifica sp. nov.. Circles with multiple colors identify sympatric areas. (H) Sampling site in Andøya (Vesterålen), Northern Norway. (I) Meiofauna under the stereomicroscope. 
José Cerca - On the Origin of Cryptic Species: Insights from the Stygocapitella species complex

(v6.8.1). The ends of sequences were first automatically, and then manually trimmed to remove primer sequences. Each consensus sequence was visually checked and blasted using NCBI database.

\section{Sanger sequencing as part of manuscripts 3-5}

We assembled sequenced Forward and Reverse reads into high-quality sequences using Geneious (v6.8.1). After assembling, each sequence was visually checked, and sequences of poor quality were discarded, and ends with poor quality trimmed. Sequences were then BLASTED using the NCBI database to guarantee that no contamination occurred in the dataset. Sequence alignment was done using mafft v7.310 (Katoh and Standley, 2013). COI, 16S and 18 S sequences were aligned with a maximum of 1,000 iterations and using the local pair alignment algorithm (Katoh and Standley, 2013). ITS1 sequences required a different approach due to the occurrence of multiple gaps and tandem repeats (sequences ranged from $750-1600 \mathrm{bp}$ ). As we were not able to align the full ITS1 data, we removed sequences longer than $1100 \mathrm{bp}$. Removal of these sequences allowed aligning the remaining sequences using the global pair alignment algorithm as part of mafft, which accounts for gap-rich sequences.

Double Digestion Restriction Associated Digestion sequencing (ddRADseq) as part of manuscript 5

To obtain a genome-level dataset we combined a whole-genome amplification approach (WGA) (Golombek et al., 2013) with a Double Digestion Restriction Associated Digestion sequencing protocol (ddRADseq) (Peterson et al., 2012). Building up on results from manuscripts 3-4, we selected specimens from three morphologically-similar cryptic species occurring in the Atlantic, which form a monophyletic clade (Stygocapitella subterranea, S. josemariobrancoi sp. nov., S. westheidei sp. nov.). A WGA approach was necessary due to the low DNA concentration yielded by the extractions, and permitted increasing the amount of genomic DNA of the organisms. To amplify the DNA, we used the Illustra GenomiPhi HY DNA Amplification Kit (GE Healthcare Life Science) and followed the manufacturer's instructions. This method essentially relies on the activity of the Phi29 DNA polymerase in combination with random sequence hexamer-primers. This polymerase synthesizes DNA in an isothermal process, thus increasing the amount of DNA in a sample.

The amplified genomic DNA was then normalized and used for a ddRAD library preparation. First, we digested the DNA using the restriction enzymes Pst-I HF and MseI, using a mix of the Cutsmart buffer, enzymes and DNA. We purified the product using ampure-beads to remove enzymes and salts, and eluted DNA in purified water. Second, we ligated adaptors to the digested DNA, using a DNA-ligase, ligase buffer and illumina adapters with barcodes. Third, we ran a size-selection step using Blue Pippin using the BDF2010 (100-600 bp cassette) selecting for fragments sized between 300-600 bp. Fourth, we did a library amplification step by doing 18 PCR cycles. These samples were then sent for Illumina Sequencing on an Illumina Hi-Seq 6000. 
José Cerca - On the Origin of Cryptic Species: Insights from the Stygocapitella species complex

\section{Morphology data collection as part of manuscripts 3-4}

We quantified morphological divergence using morphological measurements based on light microscopy photos. First, we fixed individuals in the field in 70\% ethanol and photographed these at 10X amplification in the laboratory. Whole-organism photographs were stitched together using photoshop and we measured body length and width, prostomium length and width, and pygidium length and width using ImageJ. We measured these traits in a total of 133 individuals including 11 specimens of Stygocapitella minuta and 10 specimens of S. australis (Struck et al., 2017), and 112 from S. subterranea. However, we split Stygocapitella subterranea into nine different new species, and measurements from 112 specimens included six from an unassigned pacific clade, seven individuals from $S$. berniei sp. nov., seven individuals from $S$. americae sp. nov., nine from $S$. westheidei sp. nov., 14 from $S$. zecai sp. nov., 24 from S. subterranea, 30 from $S$. josemariobrancoi sp. nov., eight from $S$. budaevae sp. nov. and two from $S$. pacifica sp. nov..

To complement morphological measurements, we looked for morphological differences in detail using Scanning Electron Microscopy (SEM). Specimens were rinsed in phosphate buffer, then treated with a buffered $1 \% \mathrm{OsO}_{4}$ solution for one hour at ambient temperature, and dehydrated in a graded ethanol series starting in 30\% ethanol and finishing in 100\% ethanol. Dehydrated specimens were then critically-point-dried with $\mathrm{CO}_{2}$, mounted on aluminium stubs and sputter-coated with platinum. Based on the photographs obtained using a Zeiss Auriga field emission SEM we determined number of segments with chaetae (chaetiger) and the type and number of chaetae in each chaetiger.

To understand the rates of morphological evolution within Stygocapitella, we compared these with those from closely related groups (Struck et al., 2015). We selected 12 species from Orbiniidae and 11 Nerillidae, for which morphological and molecular datasets exist (Bleidorn et al., 2009; Struck et al., 2015; Worsaae, 2005; Zrzavý et al., 2009), and which have a similar degree of genetic divergence (Struck et al., 2015). The integration of this data led to a morphological data matrix consisting of 32 species (nine from Stygocapitella (including the newly described species), 11 from Nerillidae, and 12 from Orbiniidae) and a total of 75 morphological characters.

\section{Phylogenetic and molecular clock analyses as part of manuscript 3-5}

We downloaded Orbiniidae outgroup sequences from GenBank. These, together with the Stygocapitella data, were aligned using mafft as described above. After alignment, we concatenated the dataset using FASconCAT (Kück and Meusemann, 2010), and ran a partitioned Maximum Likelihood (ML) using IQ-tree (Chernomor et al., 2016; Hoang et al., 2017; Nguyen et al., 2015), defining an automatic determination of the best substitution model for each gene independently. To obtain complementary evidence, we ran a Bayesian tree using BEAST v2 using COI and 18S (Bouckaert et al., 2014). To do so, we used IQ-tree's ModelFinder to determine which substitution models best fit the dataset (Kalyaanamoorthy et al., 2017). After model selection, we fit TNe+I for $18 \mathrm{~S}$ and TIM+F+I+G4 for $\mathrm{COI}(\mathrm{F}=$ Empirical base frequencies; $\mathrm{I}=$ Invariable sites; $\mathrm{G}=$ Gamma model). A relaxed, log-normal 
José Cerca - On the Origin of Cryptic Species: Insights from the Stygocapitella species complex

clock was applied with a substitution rate of 0.0001425 for 18 S (Struck et al., 2017) and 0.0176 for COI (Lehmacher et al., 2016). A birth-death model was applied and a MCMC chain run for 100,000,000 generations sampling every 100,000 generation. Convergence was confirmed using Tracer (Rambaut et al., 2007). A Maximum Credibility Consensus Tree was obtained using TreeAnnotator, with a $10 \%$ burnin (Bouckaert et al., 2014). Finally, to verify the congruence in the dataset we obtained maximum likelihood trees for each gene separately.

\section{Haplotype network as part of manuscript 4}

We built haplotype networks of COI, 16S, 18S and ITS1 using TCS (Clement et al., 2000). We calculated a 95\% connection limit to partition the dataset and considered gaps as "fifth state" to account for indels. Graphical representation was done with tcsBU (Múrias Dos Santos et al., 2015) and using Adobe Illustrator.

\section{Species delimitation methods as part of manuscript 4}

We adopted several approaches to do species delimitation following best practices (Carstens et al., 2013). These include a General Mixed Yule Coalescent (GMYC) model (ran online at https://species.hits.org/gmyc/; (Fujisawa and Barraclough, 2013)), a Bayesian Poisson tree processes (bPTP) model (ran online at https://species.h-its.org/ptp/; (Zhang et al., 2013), a 16S- and COI-based 95\% connection limit using TCS (Clement et al., 2000), a posterior cut-off at 0.9 following the generated Bayesian tree and a bootstrap cut-off of $95 \%$ after the ML tree. To understand how well morphology is able to tease species apart we followed a "morphological species concept", focusing on delimiting species based on the presence of certain chaetal types on the $1^{\text {st }}, 2^{\text {nd }}, 3^{\text {rd }}$ and consecutive segments - the only diagnostic features we were able to obtain in our data.

\section{Morphological data analysis as part of manuscripts 3-4}

Using the morphological data of Stygocapitella, we used general linear models (GLM), Least Square Means Analyses (Lenth, 2013), PCA and Multidimensional Morphological Disparity (MMD) indices (Struck et al., 2017) to quantify morphological differences. For each measurement, we fit a GLM model, using measurement as the dependent variable and the assigned "species" as a categorical and independent variable. Because GLM models do not allow assessing differences between categorical variables (i.e. "species" in this analysis), we used a Least Square Means approach that provides pairwise statistical comparisons between the categorical variables. We conducted a principal component analyses using all 6 measurements, using the function prcomp included in R's stats-package (R Core Team, 2013). Finally, we applied the MMD index as done in (Struck et al., 2017). This index quantifies the total difference between two individuals, across the totality of all considered principal components. Plotting of results was done using the ggplot2 package (Wickham, 2016) and the Hmisc package (Harrell Jr and Many Others, 2019). 
José Cerca - On the Origin of Cryptic Species: Insights from the Stygocapitella species complex

Using the data comprising Stygocapitella, Nerillidae, and Orbiniidae, we did a PCA using the "FactoMineR" package (Lê et al., 2008), obtained the values from the first 18 principal components, which together explain 99.07\% of the variation, and determined MMD indices (Struck et al., 2017). We tested whether MMD indices were statistically different between Stygocapitella, Nerillidae and Orbiniidae using Tukey's HSD and pairwise students' T tests.

To fully contrast morphological and molecular evolution, we compiled a dataset of $18 \mathrm{~S}$ sequences for the Stygocapitella species, together with those from Orbiniidae and Nerillidae. $18 \mathrm{~S}$ is the slowest evolving gene in the dataset, being thus ideal to analyse distantly related lineages. Based on this dataset, we reconstructed a Maximum Likelihood tree using IQ-Tree (as described above), and obtained pairwise genetic distances between species using MEGA (Kumar et al., 2016). Pairwise MMD indices were plotted against the corresponding pairwise genetic distances using the the R package "ggplot2" (Wickham, 2016), and fitting a 'loess smoothed fit regression' including confidence regions. Lastly, we mapped the morphological characters on the ML tree using Mesquite version 3.51 with the ML reconstruction option. We counted the number of changes occurring at each branch, and plotted these on the ML tree to quantify the number of total changes per branch.

\section{ddRADseq data analysis as part of manuscript 5}

We obtained a total of 1,277,919,764 reads as a result of two Illumina sequencing lanes (including forward and reverse reads). Using the "process radtags" script, included as part of the STACKS pipeline v2.2 (Rochette et al., 2019; Rochette and Catchen, 2017), we quality-checked reads, discarding those of poor quality. From the original pool of reads, "process radtags" discarded 107,830,588 due to ambiguous barcode $(8.4 \%), 802,222$ due to low quality $(>0.1 \%)$, and 270,174,154 due to ambiguous RAD-tag drops (21.1\%), retaining $899,112,800$ reads $(70.4 \%)$. Retained reads were then assembled to stacks (ustacks), which were used to build a catalog (cstacks) for variant calling (sstacks), we then transposed the data so it is oriented by locus (tsv2bam) and re-called variants in the whole data (gstacks). Following best practices (Paris et al., 2017), we selected stacks with, at the most, 3 variants (single nucleotide polymorphisms; SNPs). To improve the number of retrieved loci and reduce missingness, we ran STACKS for each population independently. This allowed reducing phylogenetic distance and teasing apart between allelic drop-out due to phylogenetic distance as opposed to drop-out due to poor library preparation (Maurstad et al, in prep). Finally, we obtained variant-call format files and fasta-files for data analysis using the "populations" module included as part of STACKS, restricting variants to being present in at least $50 \%$ of a population (-r 50) and being present in at least 8 populations (-p 8).

\section{Phylogenetic analysis as part of manuscript 5}

The fasta consisting of the complete radseq locus, comprising 4,737 loci from 70 individuals (12 individuals were removed based on missingness - see below on population genomics) were used in a phylogenetic analysis. These loci were concatenated to a super-matrix consisting of 1,487,496 bp using 
José Cerca - On the Origin of Cryptic Species: Insights from the Stygocapitella species complex

FASconCAT (Kück and Meusemann, 2010), which was used to build a phylogenetic tree IQ-tree (Chernomor et al., 2016; Nguyen et al., 2015). We defined an automatic determination of the best substitution model for each locus independently, using default values (Hoang et al., 2017). To guarantee that clades were not grouped following patterns of missing data, we obtained the $\%$ of missing data using Base Composition Calculation (BaCoCa) (Kück and Struck, 2014), and plotted these values along the tree using the R package “ape” (Paradis and Schliep, 2018).

\section{Population genomics as part of manuscript 5}

We obtained a variant-call format file (.vcf) with single nucleotide polymorphisms (SNPs) from STACKS. We pruned polymorphisms based on coverage (minimum depth of 10, maximum depth of 100) and minimum allele frequency (removing variants with $>0.05 \%$ ) using vcftools v0.1.13 (Danecek et al., 2011). After this, we removed 12 individuals which had missingness values above $90 \%$ (i.e. $<10 \%$ of the SNPs present) using vcftools and pruned the dataset for linkage by writing a Unix script to keep a single variant per RAD locus. Pruning the data resulted in a dataset of 3,428 SNPs. We analysed the partitioning of genetic variation using PCA, a Multidimensional Scaling (MDS) and STRUCTURE (Falush et al., 2003). As a complement to the phylogenetic analysis, we did a network analysis of the dataset using SplitsTree v4 based on the variant files (Huson and Bryant, 2006).

We analysed the demographic history of the three species (including Stygocapitella westheidei sp. nov., S. subterranea and S. josemariobrancoi sp. nov.) using Site-frequency-spectrum (SFS) coalescent-based simulations as implemented in fastsimcoal v2.6 (Excoffier et al., 2013). This method allows modelling arbitrary scenarios, and provides estimates of several parameters including population size, migration matrixes, time of coalescence in number of generations, population growth and recession rates, which can explain the observed SFS. To implement these simulations, we used the obtained phylogeny, with $S$. subterranea and $S$. westheidei sp. nov. as sister species, and S. josemariobrancoi sp. nov. as the sister to these two. Given the phylogeny, we defined models such as no gene flow, ancient gene flow (between $S$. josemariobrancoi sp. nov. and the common ancestor of S. subterranea and S. westheidei sp. nov.), constant gene flow (between any branch), geographic geneflow (similar as the ancient geneflow, but with modern gene flow between the sympatric S. subterranea and S. josemariobrancoi sp. nov.), or modern geneflow (gene flow between the three species), modern gene flow between $S$. josemariobrancoi sp. nov. and S. subterranea, modern gene flow between $S$. josemariobrancoi sp. nov. and S. westheidei sp. nov., and modern gene flow between S. westheidei sp. nov. and S. subterranea. Each model was run for 10,000 iterations, and the best fitting model was evaluated using a likelihood approach. The obtained parameters associated with the best model were then assessed by means of 100 bootstrap replicates. 
José Cerca - On the Origin of Cryptic Species: Insights from the Stygocapitella species complex

\section{Main findings and Discussion}

\section{Summary of main findings}

This thesis provides a framework to delimit cryptic species, and describes the deceleration of morphological evolution in the Stygocapitella cryptic species complex. Building upon the developed framework, I provide evidence for the impact of cryptic species in marine biogeography, with reference to the 'meiofauna paradox'. I find that missing cryptic species can obscure biogeographic breaks and inflate species' distributions.

Focusing on the Stygocapitella species complex, I delimit 8 new species, some being morphologically identical. Despite the infered time of divergence of $\sim 270 \mathrm{MY}$ (but notice the confidence interval) of the species complex, very few morphological differences occur in this species complex, thereby being one of the most prominent cases of morphological deceleration in a cryptic species complex. Using genome-level data I found a degree of admixture between species in the Atlantic, potentially due to incomplete lineage sorting, ancient admixture or symplesiomorphic evolution.

For the rest of this discussion I will refer to cryptic species as morphologically identical or quasiidentical species, and distinguish these from poorly delimited species (taxonomic artefacts).

\section{A new framework to understand and delimit cryptic species}

The most commonly used definition of cryptic species states that "[cryptic species are] two or more distinct species that are erroneously classified (and hidden) under one species name" (Bickford et al., 2007). As I have suggested as part of Struck et al. (2018a, 2018b) and Struck and Cerca (2019), this definition does not separate poorly delimited species (i.e. due to overlooked characters) from morphologically similar species. This separation is of fundamental importance to understand morphological similarity and the deceleration of morphological evolution in nature. For example, clear morphological differences were identified between populations of the Marphysa sanguinea complex (Elgetany et al., 2018). Populations are genetically and morphologically distinct, and it was recently concluded that these represent, in fact, different cryptic species given its degree of genetic divergence (Elgetany et al., 2018). Strictly under the definition of Bickford et al., these are two distinct species that were erroneously classified under a single species name (Bickford et al., 2007), and therefore, they have to be classified as cryptic species, despite clear-cut (yet overlooked) morphological differences (Elgetany et al., 2018). On the other hand, morphologically similar Polygordius species cannot be considered cryptic species because their original description was based on the continental coastline populations occurred (RameyBalci et al., 2012). Using genetic and morphological assessments, Ramey-Balci et al have confirmed that the originally described species are indeed genetically distinct and adults are morphologically identical (RameyBalci et al., 2012). However, strictly under the Bickford et al. definition, this complex of morphologically similar species could not be considered as cryptic species, because they were not 'under one species name' 
José Cerca - On the Origin of Cryptic Species: Insights from the Stygocapitella species complex

in the past (Ramey-Balc1 et al., 2018). This exposes the arbitrary nature of this definition, and invites for a reassessment of the definition of cryptic species (Struck et al., 2018a, 2018b; Struck and Cerca, 2019).

The separation between species complex which are morphologically identical (i.e. cryptic species), from those which have originated from 'taxonomic artefacts' is not possible when the focus of the delimitation lies in the taxonomic history (Cerca et al., 2018). 'Taxonomic artefacts' are defined as poorly delimited species included as part of a species complex. I have shown as part of Cerca et al. (2018), that problems in species delimitation may stem from various causes, including: (i) sloppy taxonomic practices; (ii) the use of taxonomic keys from European and American regions in developing countries (Hutchings and Kupriyanova, 2018); (iii) development of new methods, which uncover previously concealed traits; and (iv) the low morphology problem, that is, the absence of traits with systematic value (Klautau et al., 1999; van Oppen et al., 1996). In any case, the distinction between morphologically similar species, or those resulting from taxonomic artefacts is an important distinction to understand biodiversity, but also to understand underlying evolutionary phenomena (see below) (Pante et al., 2015; Struck et al., 2018a).

The suggested framework to identify cryptic species included as part of Struck et al. (2018a, 2018b) and Struck and Cerca (2019), consists in a two-step model. First, a species delimitation step should be done, benefiting from all sources of data including behaviour, morphology, physiological and molecular data when relevant or possible. This is not different from any regular species delimitation step, benefiting from scrupulous practice and the inclusion of various sources of data. The second step consists in diagnosing the 'cryptic' status, that is, in showing that species are morphologically more similar than one would expect, given the time of divergence. This step requires estimates of the time of divergence and genetic divergence, as provided by molecular clock and fossil data approaches. Estimates from closely related taxa (i.e. outgroups) will benefit this comparative outlook by providing potential traits which should warrant special attention, such as those under selection or divergence.

While the application of this framework allows distinguishing between taxonomic artefacts from lineages which are morphologically similar, it also encourages better taxonomic practices for species delimitation and systematics in general (Struck et al., 2018a, 2018b; Struck and Cerca, 2019). Indeed, I have found that many cryptic species are identified without clarity (Struck et al., 2018a). In a survey consisting of 606 papers, I have found that only 14\% of the papers included an explicit definition of cryptic species; a majority ( $84.2 \%$ ) of studies use molecular data, but a substantial part used only a single DNA-marker (35.5\%), and less than half (42.7\%) included morphological data.

Nonetheless, this proposed framework has met criticism (Heethoff, 2018; Korshunova et al., 2019). Critics have suggested that the discovery of cryptic species results from the incompatibility of species 'complexes' in applied taxonomy' (Heethoff, 2018), being an artificial blend between morphological and genetic species concepts (Heethoff, 2018). Other sources of criticism have suggested that the degree of morphological similarity remains ambiguous and that this approach requires a very 
José Cerca - On the Origin of Cryptic Species: Insights from the Stygocapitella species complex

scrupulous and detailed systematic approach (Korshunova et al., 2019), and hence cryptic species should be considered as a temporary problem of the taxonomy of a species complex. I have responded to these criticisms by highlighting evidence of morphologically similar species to occur in nature (Struck and Cerca, 2019), by pointing out Heethoff's misconceptions in mixing the grey-zone of speciation and recentlydistinguished species (Struck et al., 2018b), as well as by uncovering the underlying mechanisms of deceleration of morphological evolution after scrupulous taxonomy (manuscripts 3-4).

\section{Deceleration of morphological evolution}

Deceleration of morphological evolution occurs when two closely-related lineages remain morphologically similar after speciation (Struck et al., 2018a; manuscript 3). For instance, when contrasting morphological and genetic evolution (Figure 3), four potential scenarios are identified: 1) cases of fastpaced morphological evolution in recently divergent lineages, such as adaptive radiation and character displacement (orange area in Figure 3); 2) cases where morphological disparity follows genetic divergence and vice-versa (light green area in Figure 2); 3) cases where speciation has occurred recently, and morphological differences have not accumulated, but are likely to accumulate (dark green area in Figure 2); and 4) cases where morphological evolution is clearly deccelerated, as expected in cryptic species (blue area in Figure 2) (Struck et al., 2018a).

Multiple causes can underlie the deceleration of morphological divergence. On one hand, speciation is not necessarily accompanied by morphological divergence, being potentially guided by differences in behaviour, immunity or physiology (Lee and Frost, 2002a; Novo et al., 2012, 2010; Struck et al., 2018a). On the other hand, species can remain morphologically similar due to stabilizing selection (Charlesworth et al., 1982; Futuyma, 2010; Hansen and Houle, 2004), niche conservatism and tracking (Futuyma, 2015, 2010), fluctuating ecological conditions (Futuyma, 2015, 2010, 1987; Sheldon, 1996; Smith et al., 2011), lack of new ecological interactions (Nordbotten and Stenseth, 2016), constraints (Charlesworth et al., 1982; Futuyma, 2010; Hansen and Houle, 2004; Maynard Smith et al., 1985; Smith et al., 2011; Wagner and Schwenk, 2000), recurrent bottlenecks (Futuyma, 2010), physiological or behavioural adaptation (Futuyma, 2010; Lassance et al., 2019; Lee and Frost, 2002b), and the influence of particular environments and environmental conditions (Futuyma, 2010, 1987; Giere, 2009; Gueriau et al., 2016; Westheide, 1977; Westheide and Rieger, 1987). Importantly, many of these scenarios have been discussed in terms of paleontological stasis, but a thorough investigation of the mechanisms and extent of these factor still remains elusive (manuscript 3 ). 


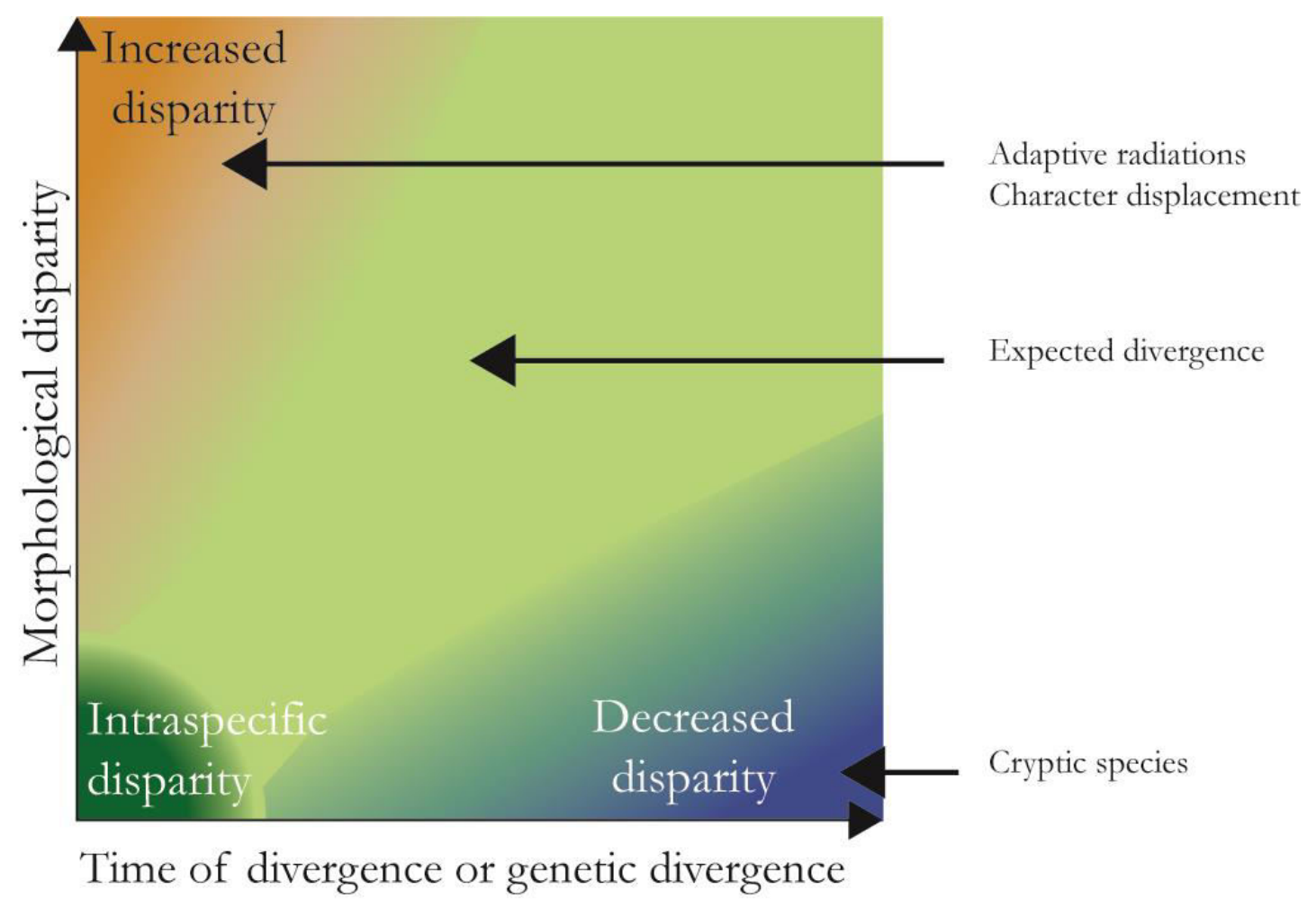

Figure 3. Conceptual framework for understanding genetic divergence and morphological disparity, following (Struck et al., 2018a). The x-axis represents the time of divergence between taxa since their most recent common ancestor given by estimates of genetic divergence. The y axis represents morphological disparity. Intraspecific variation (i.e. polymorphism) within a species is depicted by the dark green area in the lower left corner of the figure. Morphological disparity between taxa relative to sister species is expected to increase proportionately with divergence time (light green area). Morphological disparity could increase at a significantly higher rates in cases such as adaptive radiations (orange area in the upper left corner of the figure). Alternatively, morphological disparity could be substantially lower than expected over time (blue area in the lower right corner), the hallmark of cryptic species.

\section{Four ways to become cryptic}

I have suggested four scenarios to underlie cryptic species, including recent divergence (Panel A in Figure 4), convergent evolution (Panel B, Figure 4), parallel evolution (Panel C, Figure 4) and morphological stasis (Panel D, Figure 4). These are discussed below.

Recent divergence without morphological differentiation (Panel A, Figure 4) include species which have only recently diverged, but remain morphologically similar (Struck et al., 2018a; Struck and Cerca, 2019). One example is the Anopheles species complex, where the " $\mathrm{M}$ " and " $\mathrm{S}$ " forms were recognised as being at an early stage of ecological speciation (Reidenbach et al., 2012). These two forms explore different habitats, with the M-form mainly exploiting stable larval habitats with many stressors, and the S-form exploiting unpolluted, predator-free ephemeral habitats associated with rainfall (Reidenbach et al., 2012). This is an extremely relevant example of a cryptic species delimitation-problem extending outside fundamental fields of biology because not every morphologically-similar species is 
capable of transmitting malaria (Erlank et al., 2018). Other cases of recent speciation without morphological evolution could result from selection acting upon behavioural immunological, physiological, reproductive traits (Struck et al., 2018a).

\section{A) Recent divergence}

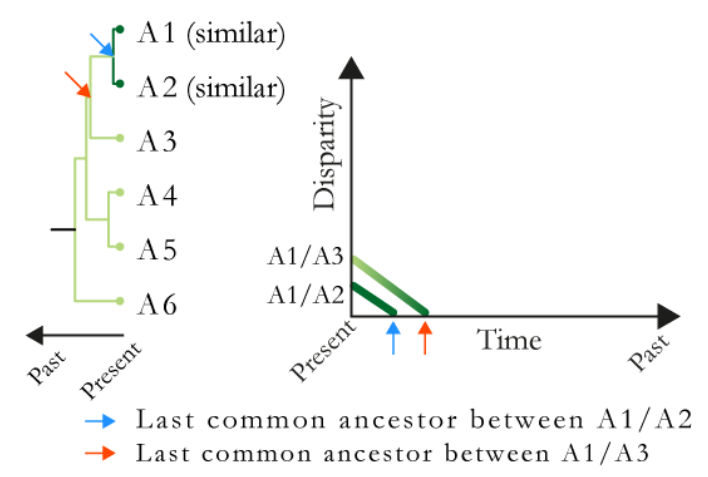

B) Parallel evolution

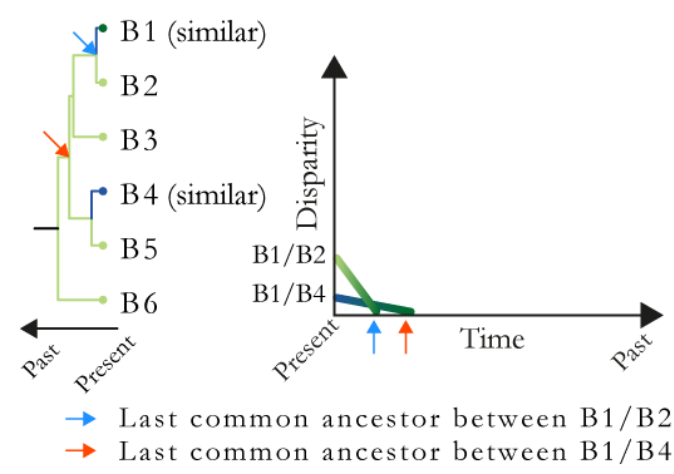

\section{C) Convergent evolution}

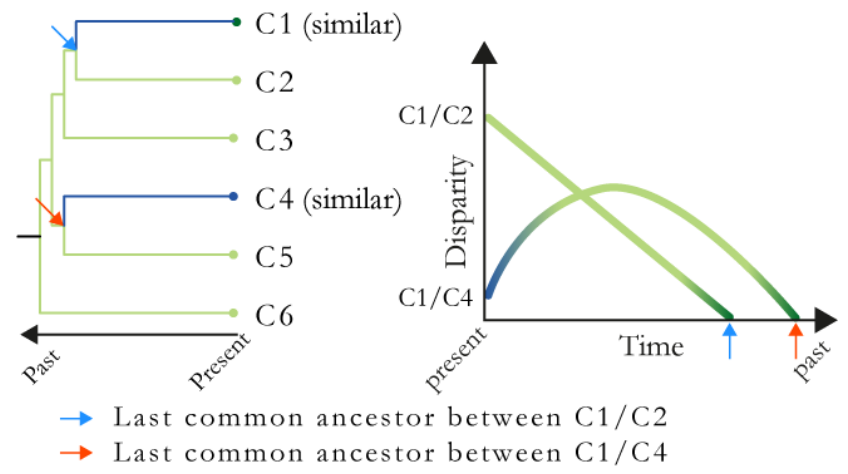

D) Morphological stasis

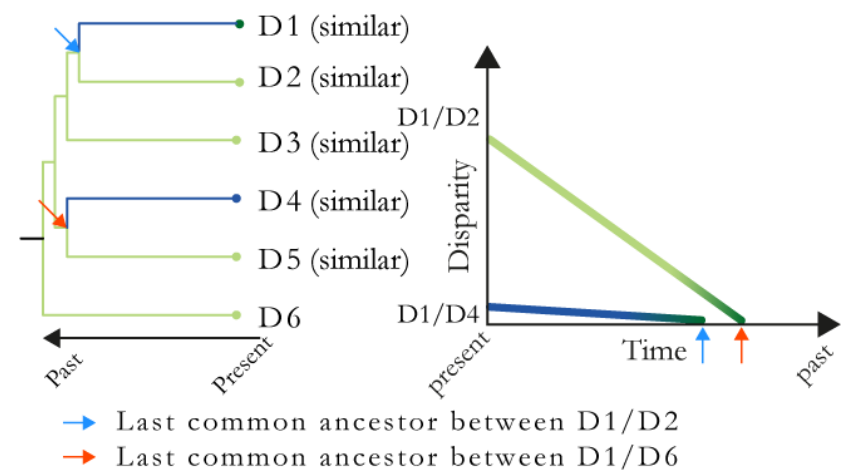

Figure 4. Expected signatures of recent divergence (A), parallel evolution (B), convergent evolution (C) and morphological stasis (D) that may lead to cryptic species. The colours of lines in phylogenies and graphs correspond to the different areas in Figure 3. Species with similar morphotypes are denoted by '(similar)'. Panels to the left (cladogram) denote the phylogenetic relationships among taxa, while the panels to the right (Disparity as a function of time graphic) depict the evolution of morphological disparity through time for pairs of cryptic and non-cryptic species (e.g., A1/ A2 vs. A1/A3). (A) Recent divergence: cryptic species have only recently diverged from each other, being thus closely related. However, the rate of morphological disparity is not necessarily substantially different from that for non-cryptic species. (B) Parallel evolution: cryptic species are not sister species, however the rate of morphological disparity for non-cryptic species is much greater than that for cryptic species. Disparity between non-cryptic species evolved from the dark to the light green area, disparity between cryptic species progressed into the dark blue area of Figure 3. (C) Convergent evolution: cryptic species are not closely related to each other. Initially, morphological disparity for cryptic species can accumulate in a manner similar to that for non-cryptic species. However, at some point, morphological disparity decreases for the cryptic species. Hence, in their past the level of disparity of the cryptic species was first within the light green area of Figure 3, but then evolved toward the dark blue area associated with the low level of disparity of cryptic species. (D) Stasis: the cryptic species are closely related to each other or are part of a species complex which diverged a long time ago. In comparison with non-cryptic species, the rate of morphological change is substantially reduced. Image adapted from (Struck et al., 2018a). 
José Cerca - On the Origin of Cryptic Species: Insights from the Stygocapitella species complex

The second and third discussed scenarios include evolutionary convergence and parallelism (Panel B \& C, Figure 4) (Struck et al., 2018a; Struck and Cerca, 2019; Swift et al., 2016). The distinction between convergence and parallelism comes from considering an 'ancestral set of traits', that is, if the ancestral set of traits is different for a given species complex, it is considered a case of convergence, otherwise it is a case of parallelism (Struck et al., 2018a; Swift et al., 2016). The Mastigias species complex (Scyphozoa) is an example where parallelism and convergence occur (Swift et al., 2016). Different species with an 'oceanic phenotype' have independently colonized several marine salt water lakes, which have formed as a result of rising sea levels after the last glacial maxima (Swift et al., 2016). Modern species found in these lakes have evolved a 'lake-phenotype'. Parallelism in this system occurs when a group of 'lake-phenotype' species share a common ancestor with the same 'oceanic-phenotype' species, whereas convergence occurs when two 'lake-phenotype' have different 'oceanic-phenotype' ancestors (Struck et al., 2018a; Swift et al., 2016).

The fourth scenario proposed for the evolution of cryptic species is morphological stasis (Panel D, Figure 4), wherein closely related species display severely decelerated rates of morphological evolution throughout a long period (Struck et al., 2018a; Swift et al., 2016; Wada et al., 2013). One clear-cut example of cryptic species under stasis include the Cavernacmella snails (Wada et al., 2013). Several Cavernacmella species remained morphologically identical for the last 3 million years. However, several lineages have accumulated differences in shell morphology only in the last few thousands of years (Wada et al., 2013). Morphologically divergent lineages have colonized and inhabit limestone outcrop groups (Wada et al., 2013). This highlights the role of ecology in driving shifts of morphological evolution (i.e. acceleration and deceleration), as in cases of adaptive radiation (Gillespie, 2004; Losos, 2010). The Stygocapitella species complex is another potential case of stasis (see below) (Struck et al., 2017).

Strictly speaking, the cases of recent divergence, parallel and convergent evolution do not contribute to our understanding of morphological deceleration. In recent divergence morphological change can be relatively dormant and lag genetic divergence. In parallel and convergent evolution morphological disparity has occurred in the past. Despite this, these cases indicate that reduced morphological disparity and the lack of morphological evolution are distinct features of cryptic species.

\section{Incidence of cryptic species in meiofauna and the 'meiofauna paradox'}

The 'meiofauna paradox' describes the inconsistency between the wide distribution and the presumed limited dispersal abilities of interstitial invertebrates (Cerca et al., 2018; Giere, 2009). This is best discussed in two separate components: dispersal abilities and distribution (Cerca et al., 2018). I have demonstrated that there is paramount experimental evidence for meiofaunal dispersal (Arroyo et al., 2006; Boeckner et al., 2009; Callens et al., 2012; Commito and Tita, 2002; Cristoni et al., 2004; Cuvelier et al., 2014; De Meester et al., 2015, 2012; Fonsêca-Genevois et al., 2006; Gallucci et al., 2008; Gobin and Warwick, 2006; Guilini et al., 2011; Gwyther and Fairweather, 2005; Hooper and Davenport, 2006; 
José Cerca - On the Origin of Cryptic Species: Insights from the Stygocapitella species complex

Junkins et al., 2006; Lins et al., 2013; Mcfarlane et al., 2013; Mevenkamp et al., 2016; Pugh, 1996; Schratzberger et al., 2000; Teasdale et al., 2004; Thistle, 2003; Thomas and Lana, 2011; J. Ullberg and Ólafsson, 2003; Jörgen Ullberg and Ólafsson, 2003). However, this evidence is in clear contrast with historically defined hypotheses and ideas which have shaped the literature, yet that lack evidence (Christiansen and Fenchel, 1979; Danielopol and Wouters, 1992; Kieneke et al., 2012; Sterrer, 1973; Westheide and Hass-Cordes, 2001).

With regards to 'distribution', I found that there is a high incidence of cryptic species, which interferes with the estimation of meiofaunal species' distribution range (Cerca et al., 2018). When analysing the literature (752 papers), I found that the discovery of cryptic species, led to species distribution rantes to remain unchanged in 40 papers, increase in 25, and decrease in 22. However, when analysing based on the number of species, 82 species remained unchanged, 112 increased their distribution, and 160 decreased their distribution (Cerca et al., 2018). The decrease of the distribution range is linked to the discovery of cryptic species, which were typically localized to a given area. Nemertea was the phylum where the discovery of cryptic species had a bigger impact. 72 species were reported with decreased distributions, 0 with increased distributions and 13 with unchanged distributions (Leasi and Norenburg, 2016, 2014; Tulchinsky et al., 2012). Chaetognatha, Chordata, Cnidaria, Gnathostomulida, Hemichordata, Echinodermata, Entoprotoa, Loricifera, Priapulida and Tardigrada had 0 species with decreased distributions (Cerca et al., 2018). However, these numbers are likely to reflect sampling efforts and the application of molecular tools to species identification and delimitation. For instance, from the aforementioned list of phyla without decreases in range distribution, only 7 studies applied molecular tools ( 2 studies in Gnathostomulida, 1 study in Priapulida, and 4 studies in Tardigrada).

While very few papers $(61,<10 \%)$ applied molecular tools, those which did found a high number of cryptic species. This is in line with previous suggestions that the meiofauna has an high incidence of cryptic species (Fontaneto et al., 2015; Jörger and Schrödl, 2013; Leasi et al., 2013). While I could not distinguish which particular cases result from taxonomic artefacts or due to biological phenomena, I have suggested that high numbers are likely to stem from high rates of morphological stasis, likely due to stabilizing selection on morphology as a result of the restricted space available in the interstium (Schmidt and Westheide, 2000; Sterrer, 1973; Westheide and Rieger, 1987), but also due to the natural degree of convergence resulting from simplified external appendices, elongated worm-like body shape and external adhesive structure - the 'meiofaunal syndrome' (Brenzinger et al., 2013; Jörger et al., 2014).

Finally, I have suggested a roadmap for future meiofauna research on the meiofauna paradox (Cerca et al., 2018). I suggested that future research should: (i) focus on understanding morphological similarity, including (ii) the rates of stasis and convergence and (iii) on the selective pressures leading to it; (iv) understand dispersal capacities of meiofaunal taxa both empirically and experimentally; (v) understand the factors underlying the distribution of a species or group of species, with particular focus on life-history and contribution of specific traits; (vi) have a strong taxonomic component, focusing on describing new 
José Cerca - On the Origin of Cryptic Species: Insights from the Stygocapitella species complex

species using morphology and molecular data; and (vii) using metabarcoding and metatranscriptomic tools to understand whether species are present in the water column, including the stage of development in which dispersal occurs (i.e. using transcriptomic data).

Finally, I have highlighted the Stygocapitella cryptic species complex as a promising study system to address questions on species distributions and morphological similarity. Considering the existence of multiple and world-wide records (Riser, 1984; Schmidt and Westheide, 2000), as well as evidence for potential morphological deceleration (Struck et al., 2017). 


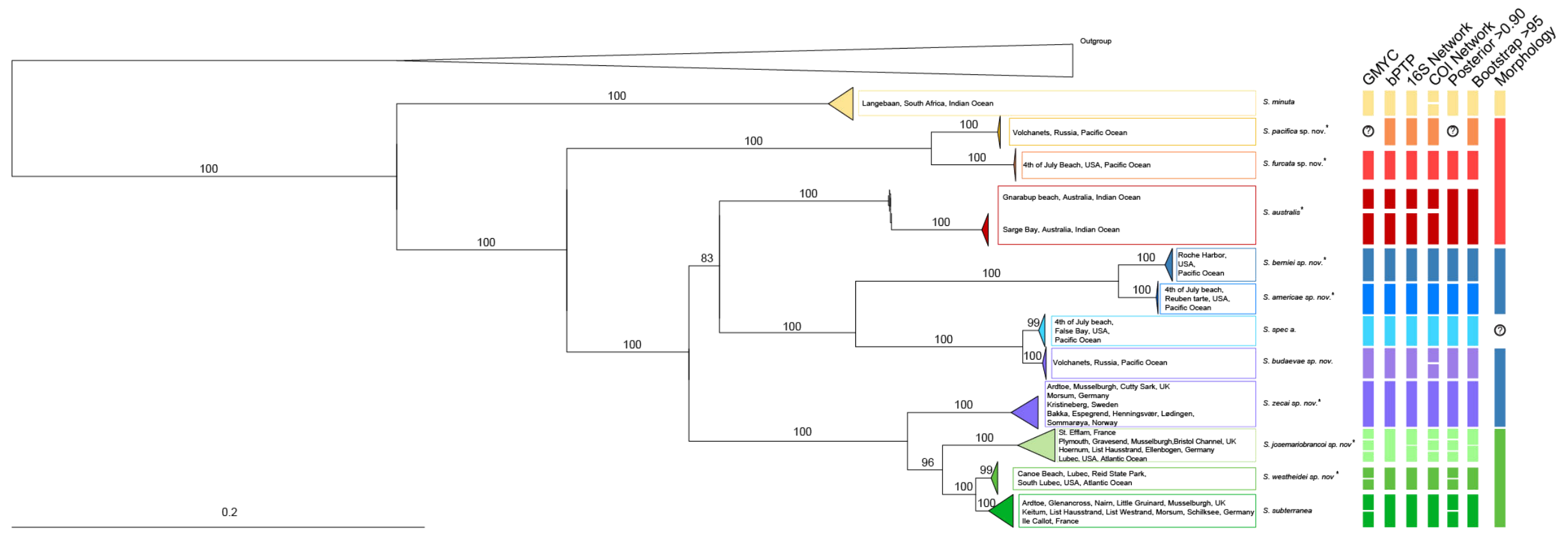

Figure 5. Maximum likelihood phylogeny and species delimitation included as part of manuscript 4. The phylogenetic tree was obtained using a partitioned dataset including COI, 16S, 18S and ITS1 sequences. Bootstrap support is included for each branch. Substitutions per site are shown in the scale bar. Species names and sampling locations are included after each edge. Species delimitation analysis include: bPTP (Bayesian Poisson Tree Processes), 16S network, COI network, posterior probabilities of $>0.90$, Generalized Mixed Yule Coalescent Approach (GMYC), bootstrap support $>95$ and morphology (chaetal composition). Question marks highlight cases where models did not run: because I had only one specimen for the final Bayesian analysis, I was unable to obtain posterior probabilities and to run GMYC (question mark in GMYC and posterior columns); question mark in morphology indicates the species, for which I was unable to obtain Scanning Electron Microscopy photographs. Species followed by an asterisk $(*)$ represent species, which were previously considered as $S$. subterranea (sensu lacto) 
José Cerca - On the Origin of Cryptic Species: Insights from the Stygocapitella species complex

\section{The Stygocapitella species complex - application of the framework to delimit cryptic species}

We have proposed a two-step framework to identify and cryptic species, consisting of a custom species delimitation, followed by the identification of the cryptic status (Struck et al., 2018a, 2018b; Struck and Cerca, 2019). The Stygocapitella genus has three described species including S. subterranea (cosmopolitan species), S. australis (found in Australia) and S. minuta (found in South Africa) (Knöllner, 1934; Purschke et al., 2019; Schmidt and Westheide, 2000; Struck et al., 2017). I have collected Stygocapitella in multiple coastlines (Figure 2) and studied morphological and genetic divergence. The application of several complementary approaches to delimit Stygocapitella species, as suggested by best practices (Carstens et al., 2013), including genetic (haplotype networks, Generalized Mixed Yule Coalescent Approach, Bayesian Poisson Tree Processes, Maximum Likelihood, Posterior probability) and morphological data has led us to suggest 8 new species. Based on this, and on formal action to describe these species (manuscript 4), I will refer to the 8 new Stygocapitella species after their new taxonomic identities: S. pacifica sp. nov., S. furcata sp. nov., S. berniei sp. nov., S. americae sp. nov., S. budaevae sp. nov., S. zecai sp. nov., S. josemariobrancoi sp. nov., and $S$. westheidei sp. nov.. One further species remains undescribed due to the lack of type-material to describe the species, and will hence be referred to as Stygocapitella spec. A. To avoid over splitting, I have opted for a conservative approach to delimitate species, that is, for a given clade, if one approach suggested this as a single species, while other approaches as more than one species, I regarded this as a single species. Finally, I applied a monophyly-criterium, that is, recognized species had to be retrieved as monophyletic, and strongly supported in phylogenetic reconstructions.

In total, I used 353 specimens from 33 sites to obtain genetic data for Stygocapitella. This dataset consisted of 332 16S, 273 COI, 125 18S and 177 ITS1 sequences. Generally, the approaches to delimitate the Stygocapitella species were concordant (Figure 5), suggesting at the most 16 species (GMYC algorithm), and at least 13 (bPTP algorithm). Every approach using genetic data suggests that that $S$. americae sp. nov., S. berniei sp. nov., S. furcata sp. nov., S. pacifica sp. nov., S. spec. A, and S. zecai sp. nov. all represent single taxonomic units. Stygocapitella minuta and $S$. budaevae sp. nov. are considered as single species in every genetics-based approach, with the exception of the COI haplotype network which suggest the presence of two species in each of these lineages (Figure 5). GMYC, bPTP, and network approaches suggest that $S$. australis represent two separate species, yet I take no taxonomic action as any potentially delimitated species could be paraphyletic (Figure 5). 


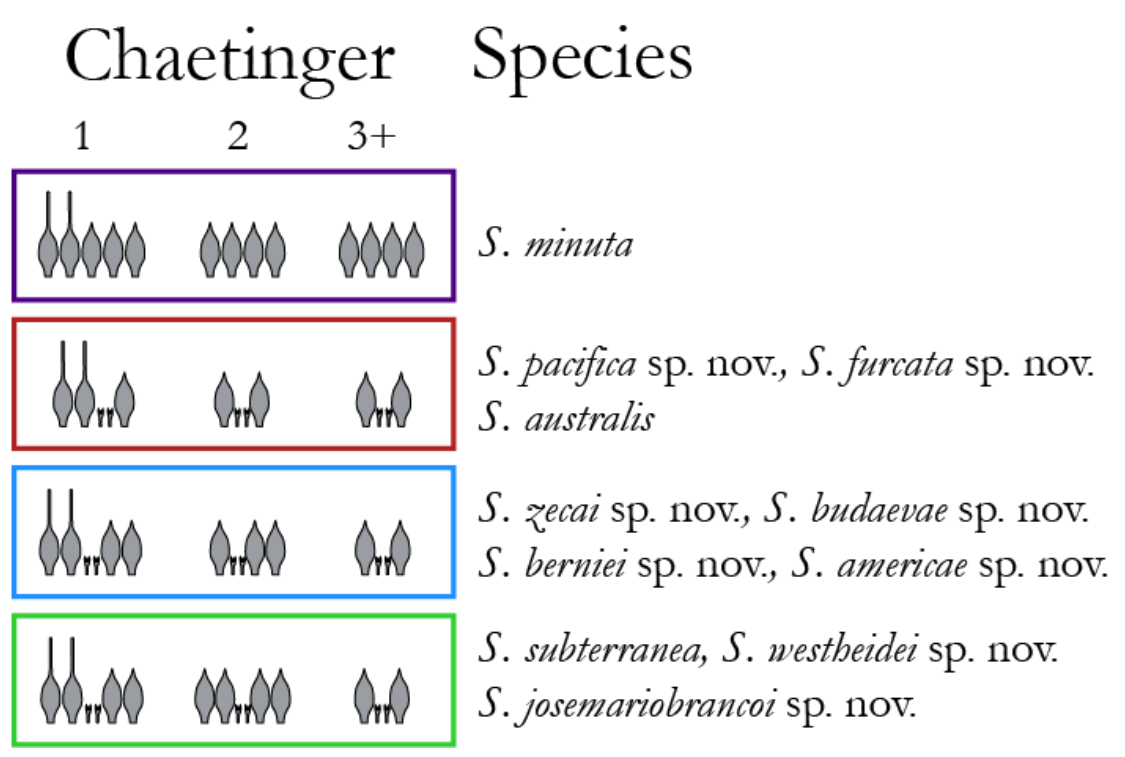

Figure 6. Four Stygocapitella morphotypes based on chaetal pattern and composition. Species are given on the right of each morphotype. Chaetal composition is given for the first (1), second (2) and third and consecutive $(3+)$ chaetae. The first morphotype is composed by two whip-like chaetae and three bilimbate chaetae in the first chaetinger and four bilimbates in the second chaetinger (purple), and is found in $S$. minuta. The second morphotype consists of two whip-like, two forked and one bilimbate chaetae in the first chaetinger, and one bilimbate, two forked and one bilimbate chaetae in the second chaetiger (red). It is present in S. pacifica sp. nov., S. furcata sp. nov., S. australis. The third morphotype consist of two whip-like, two forked and two bilimbate chaetae in the first chaetinger and two bilimbate, two forked and two bilimbate chaetae in the second chaetiger (blue). It is present in Stygocapitella berniei sp. nov., S. americae sp. nov., S. budaevae sp. nov., S. zecai sp. nov. The fourth morphotype is identified by two whip-like, two forked and two bilimbate chaetae in the first chaetinger, and one bilimbate chaetae, two forked and two bilimbate chaetae in the second chaetiger (green). This morphotype is present in $S$. josemariobrancoi sp. nov., S. westheidei sp. nov., and S. subterranea.

After species delimitation (Figure 5), one should provide estimates of morphological evolution by focusing on detecting differences between species (Figures 6-9). After analyzing Scanning Electron Microscopic photos, I found four morphotypes (Figures 6-7), based on the only variable external characters found in Stygocapitella, that is, the chaetae present in chaetingers (Figure 6). I will refer to different morphotypes as the purple, red, blue and green morphotype, as shown in Figures 6 and 7. The red phenotype is composed of two whip-like, two forked and one bilimbate chaetae in the first chaetinger, and one bilimbate, two forked and one bilimbate chaetae in the second chaetiger. It is present in species from the Pacific and Indic Oceans including S. pacifica sp. nov., S. furcata sp. nov., S. australis. The blue morphotype is composed by two whip-like, two forked and two bilimbate chaetae in the first chaetinger and two bilimbate, two forked and two bilimbate chaetae in the second chaetiger. It is present in species living in the Pacific Ocean including S. berniei sp. nov., S. americae sp. nov., S. budaevae sp. nov., and in the Atlantic species $S$. zecai sp. nov. The green morphotype is identified by two whip-like, two forked and two bilimbate chaetae in the first chaetinger and one bilimbate chaetae, two forked and two bilimbate chaetae in the second chaetiger. It is found in the Atlantic species $S$. josemariobrancoi sp. nov., S. westheidei sp. nov., and S. subterranea. I did not find any diagnostic trait within morphotypes (Figure 7), and quantitative morphological measurements are unable to separate species in morphotype (Figures 8-9). 


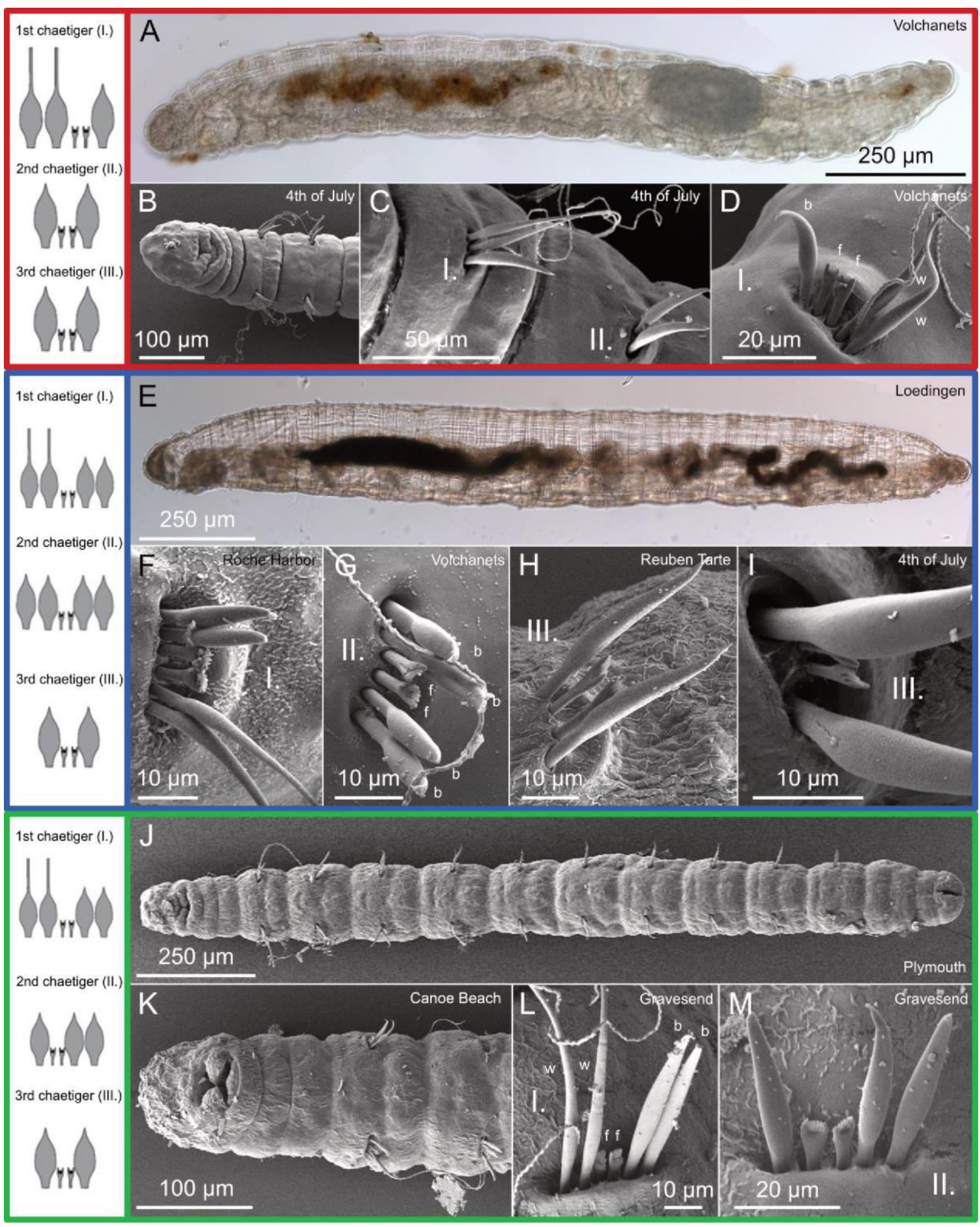

Figure 7. Scanning electron microscopy and light microscopy images of Stygocapitella individuals. The three morphotypes are represented in different colors (red, blue and green boxes) and shown on the left pannels; A) Light microscopy photograph of S. pacifica sp. nov.. B \& C) SEM images of S. furcata sp. nov. with first (I.) and second (II.) chaetae bearing chaetiger. D) 1st chaetiger of $S$. pacifica sp. nov. with 2 whip-like (w), two forked (f) and 1 bilimbate (b) chaetae. E) Light microscopy photograph of $S$. zecai sp. nov.. F) 1 st chaetiger of $S$. berniei sp. nov. with 2 whip-like, 2 forked and 2 bilimbate chaetae. G) 2nd chaetiger of $S$. budaevae sp. nov. with 2 bilimbate (b), 2 forked (f) and 2 bilimbate (b) chaetae. H) 3rd chaetiger of S. americae sp. nov.. I) 3rd chaetiger of Stygocapitella from 4th of July Beach. J) SEM images of whole S. josemariobrancoi sp. nov.. K) Anterior end of $S$. westheidei sp. nov.. L \& M) First two chaetigers of S. josemariobrancoi sp. nov.. 1st chaetiger with 2 whip-like (w), 2 forked (f) and 2 bilimbate (b) chaetae. 2nd chaetiger with 1 bilimbate (b), two forked (f) and 2 bilimbate (b) chaetae. 
José Cerca - On the Origin of Cryptic Species: Insights from the Stygocapitella species complex

I explored quantitative differences by measuring body length and width, prostomium length and width, and pygidium length and width (Figure 8). General Linear Models demonstrate significant differences in measurements: body length (Likelihood Ratio Test scaled dev. $=124.72, p<0.001$ ), body width $($ LRT scaled dev. $=118.3, p<0.001)$, prostomium length $($ LRT scaled dev. $=76.5, p<0.001)$, prostomium width (LRT scaled dev. $=122.8, p<0.001)$, pygidium length (LRT scaled dev. $=45.4, p<$ 0.001 ), and pygidium width (LRT scaled dev. $=140.5, p<0.001$ ). Results from the morphological measurements show that pairwise differences in body length between species are also roughly reflected in the remaining five measurements (Figure 8) and thus, I will concentrate on body length in the following section. S. minuta is significantly shorter in body length (mean 1046.88; SD 76.29) than every other species, with the exception of S. pacifica sp. nov. (mean 1261.47; SD 52.21) and S. budaevae sp. nov. (mean 1368.49; SD 164.53). For the red morphotype (Figure 6), S. pacifica sp. nov. is smaller than S. australis (mean 1933.61; SD 218.01), but this difference is not statistically significant. For blue morphotype (Figure 6), S. budaevae sp. nov. has the shortest body length, followed by S. berniei sp. nov. (mean 2006.98; SD 436.99), whereas $S$. americae sp. nov. (mean 2550.4; SD 229.74) has the largest body length, followed by $S$. zecai sp. nov. (mean 2238.23; SD 322.48). For the green morphotype (Figure 6), S. josemariobrancoi sp. nov. (mean 2409.7; SD 472.15) is clearly the longest species, while S. subterranea (mean 1703.7; SD 380.68) and S. westheidei sp. nov. (mean 1820.2; SD 293.68) have overlapping body lengths. Accordingly, S. josemariobrancoi sp. nov. is significantly different from S. subterranea and S. westheidei sp. nov., but the latter two are not separated from each other.
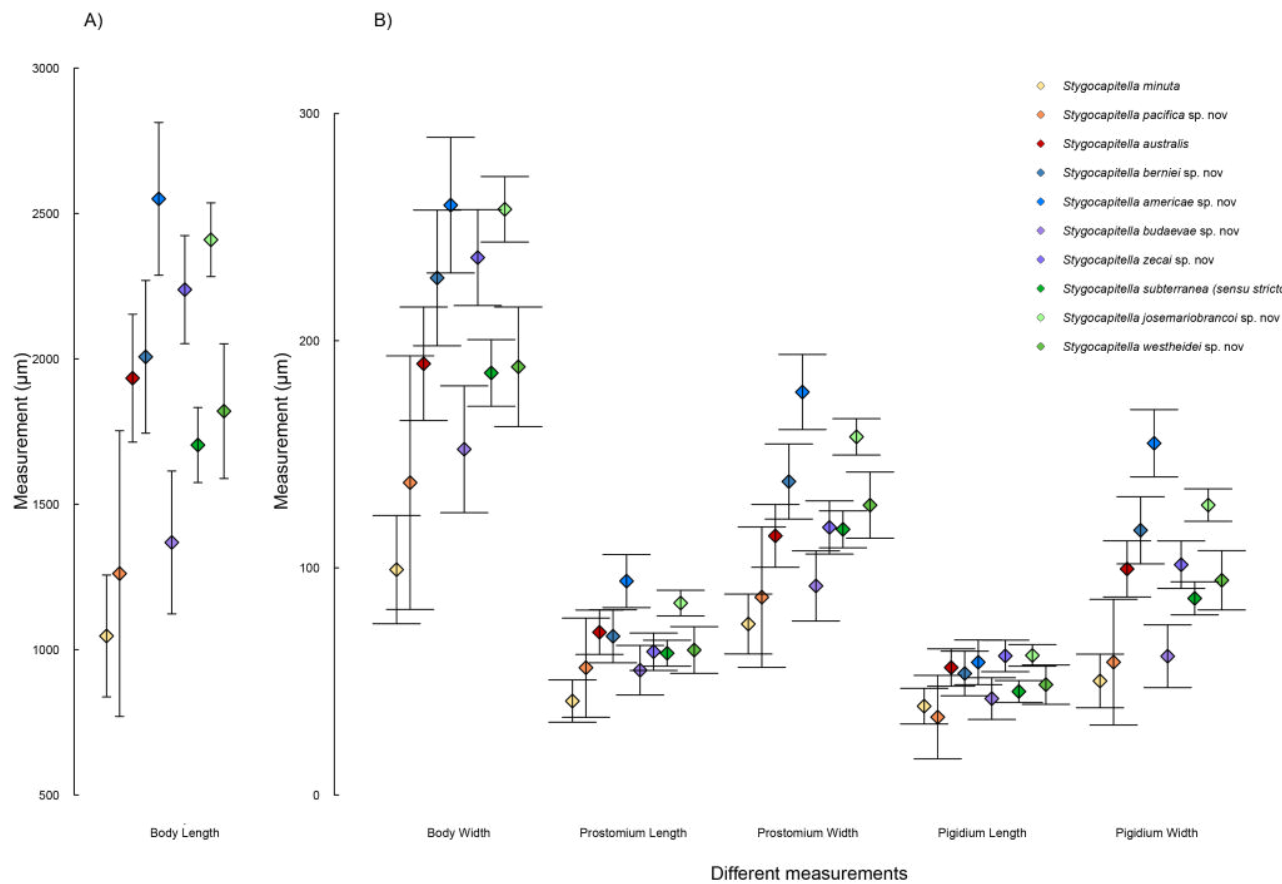

Figure 8. Morphometric analysis of Stygocapitella. Panel A displays body length measurements ( $\mu \mathrm{m})$ and panel B) displays body width, prostomium length and width, and pygidium length and width $(\mu \mathrm{m})$. Each species is displayed with different colours (see legend on the top-right corner). Stygocapitella subterannea is labeled as sensu stricto due to the revised status (see manuscript 4). 
José Cerca - On the Origin of Cryptic Species: Insights from the Stygocapitella species complex

Using principal component analyses, the first principal component separates only S. minuta from the remaining species (PC1 explains $75.4 \%$ of the variance; Figure 9A). The second principal component explained $11.9 \%$ of the variance, and the third axis explained $5.4 \%$. Neither the $2^{\text {nd }}$, neither the $3^{\text {rd }}$ axis separated any of the species (data for the third component is not shown). When considering variance within morphotypes, the results are slightly more informative. In the red morphotype, S. pacifica sp. nov. is separated from S. australis based on the first principal component (Figure 9B). However, S. pacifica sp. nov. is only represented by two specimens and more data is needed for a reliable species separation. In the blue morphotype, the first principal component separates $S$. budaevae sp. nov. from the remaining species (Figure 9C). S. zecai sp. nov. is separated from S. americae sp. nov. based on the first two principal components, but both overlap substantially with $S$. berniei sp. nov.. For the green morphotype all three species overlap substantially, and they cannot be separated based on the PCA analysis (Figure 9D). This is not due to the lack of data as these are the three species with highest number of sampled specimens.

In sum, genetic evidence suggests that the Stygocapitella genus is composed of at least 12 species. However, only four morphotypes, based on chaetal number and composition, exist.
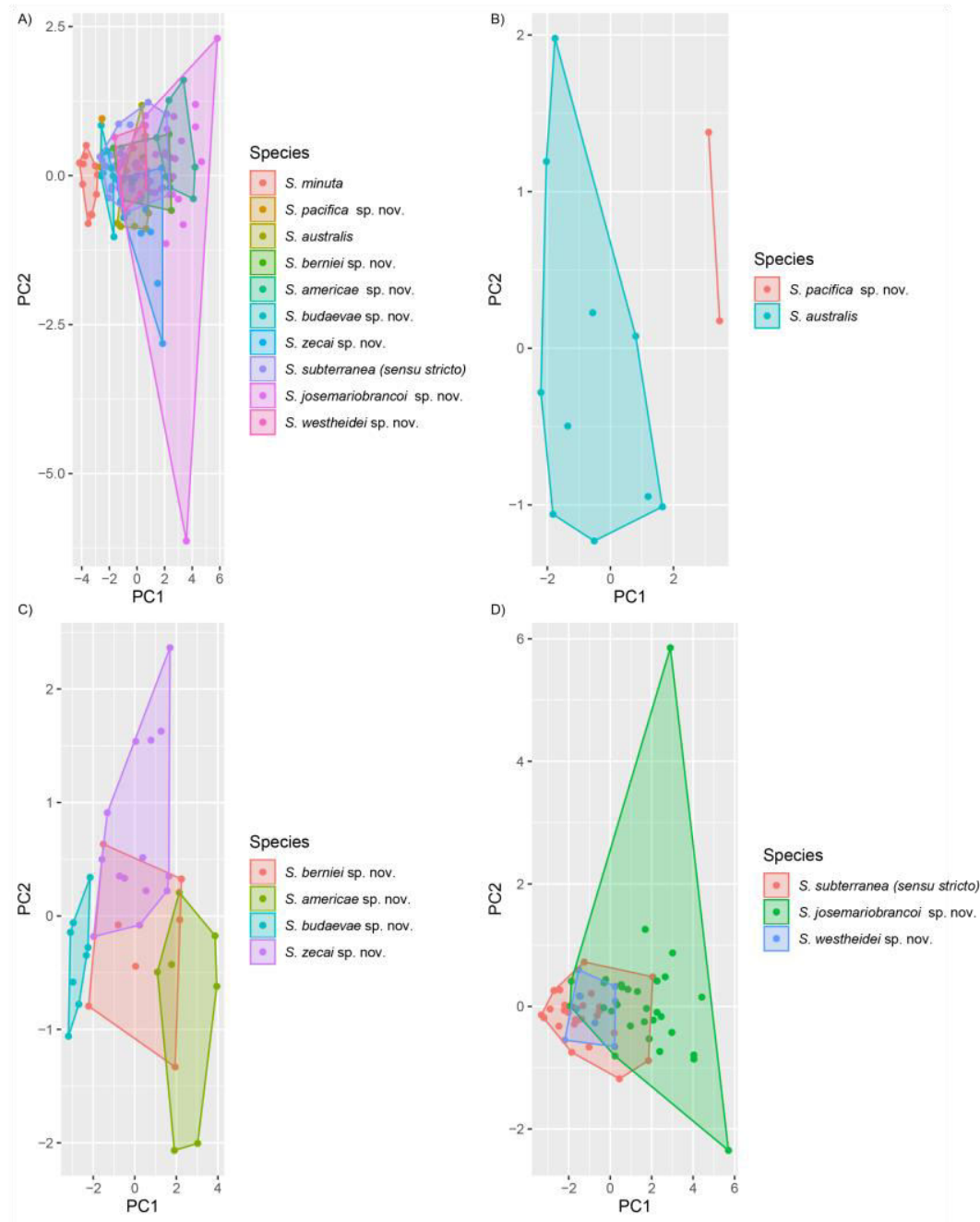

Figure 9. Principal component analysis comprising morphological measurements of Stygocapitella. Every panel displays the first two principal components (PC1-PC2). Panel A) displays all species. Panel B) displays the red morphotype, Pannel C) the blue morphotype and D) the green morphotype. 
José Cerca - On the Origin of Cryptic Species: Insights from the Stygocapitella species complex

\section{The Stygocapitella species complex - application of the framework to understand species' distributions}

The splitting of $S$. subterranea into nine new species with substantialy decreased distributions suggests that overlooking cryptic species leads to an inflation of the distribution of marine organisms (manuscript 4; Knowlton, 2000, 1993), being in line with evidence from the survey carried for meiofaunal taxa (Cerca et al., 2018). Stygocapitella subterranea was previously described as a cosmopolitan species (Riser, 1984; Schmidt and Westheide, 2000), yet the described species are present only in one coastline (Figures $2 A-G, 5)$. The only exception is $S$. josemariobrancoi, which is present in the North American coastline of the Atlantic Ocean and the European coastline. However, given the mitochondrial similarity of specimens found at both coastlines, I suspect that these might represent a recent human translocation (Radziejewska et al., 2006).

\section{Stygocapitella species complex - morphological deceleration and stasis}

I contrasted morphological disparity in a dataset comprising Stygocapitella, Nerellidae and Orbiniidae (Figures 10-11). Mapping of 75 morphological characters on a maximum likelihood tree revealed that morphological evolution in Styoocapitella is relatively slower to that of nerillids and orbiniids (Figure 10). In a total of 16 branches, only 4 have morphological changes in Stygocapitella, while in nerillids and orbiniids, only 1 and 3 branches have no differences, respectively. In Stygocapitella, there is an average of 0.5 changes per branch, whereas in nerillids, there is an average of 4.1 morphological changes per branch, and only six branches showed three or less changes. In orbiniids, there is an average of 2.8 changes per branch, eight branches only have one to three morphological changes, and 10 branches have four to eight changes (Figure 10).

Decomposition of morphological variance in a principal component analysis (Figure 11A) shows that Nerillidae, Orbiniidae and Stygocapitella are clearly separated from each other (PC1 and PC2 together explain $64.4 \%$ of the variance). Clearly, Nerillidae and Orbiniidae occupy a substantially larger morphospace area than Stygocapitella (Figure 11A). Multidimensional morphological disparity (MMD) shows that this difference is not restricted to the first principal components, but holds up for the first 18 principal components (manuscript 4). MMD indices of Stygocapitella had a mean of 1.14 (Figure 11B), with a standard deviation of 1.28. The MMD indices of Nerillids had a mean of 7.21 with a standard deviation of 2.76. For orbiniids the mean was 7.46 with a standard deviation of 3.29 values (Figure 11B). Boxplot representations of the MMD distribution show that the quartiles of Stygocapitella do not overlap with the quartiles belonging to Nerillidae and Orbiniidae, while they overlap completely (Figure 11B). Tukey's HSD and students' T-tests show that morphological disparity in Stygocapitella is significantly lower in comparison to both Nerillidae and Orbiniidae $(p<0.000001)$, while there is no significant difference between Nerillidae and Orbiniidae (Tukey's HSD: $p=0.7343163$; students' T: $p=0.45$ ). 
José Cerca - On the Origin of Cryptic Species: Insights from the Stygocapitella species complex

Plotting of MMD indices against pairwise genetic distances, in these groups (Figure 11C) indicates that lower MMD values in Stygocapitella are not an artefact of the arbitrary above species taxonomical ranks (i.e. Stygocapitella is a genus; Nerillidae and Orbiniidae are families). In Stygocapitella, MMD indices remain between 0 and 1 until a pairwise genetic distance of 0.025 . These values increase slightly above 4 only at higher molecular distances. In clear contrast, MMD indices in Nerillidae and Orbiniidae vary between 5 and 10 at relatively shallow genetic distances of $<0.01$ (Figure 11C). Morphological disparity in these lineages remains at high levels with increasing genetic distances and only a few outliers display disparity values as low as Stygocapitella.

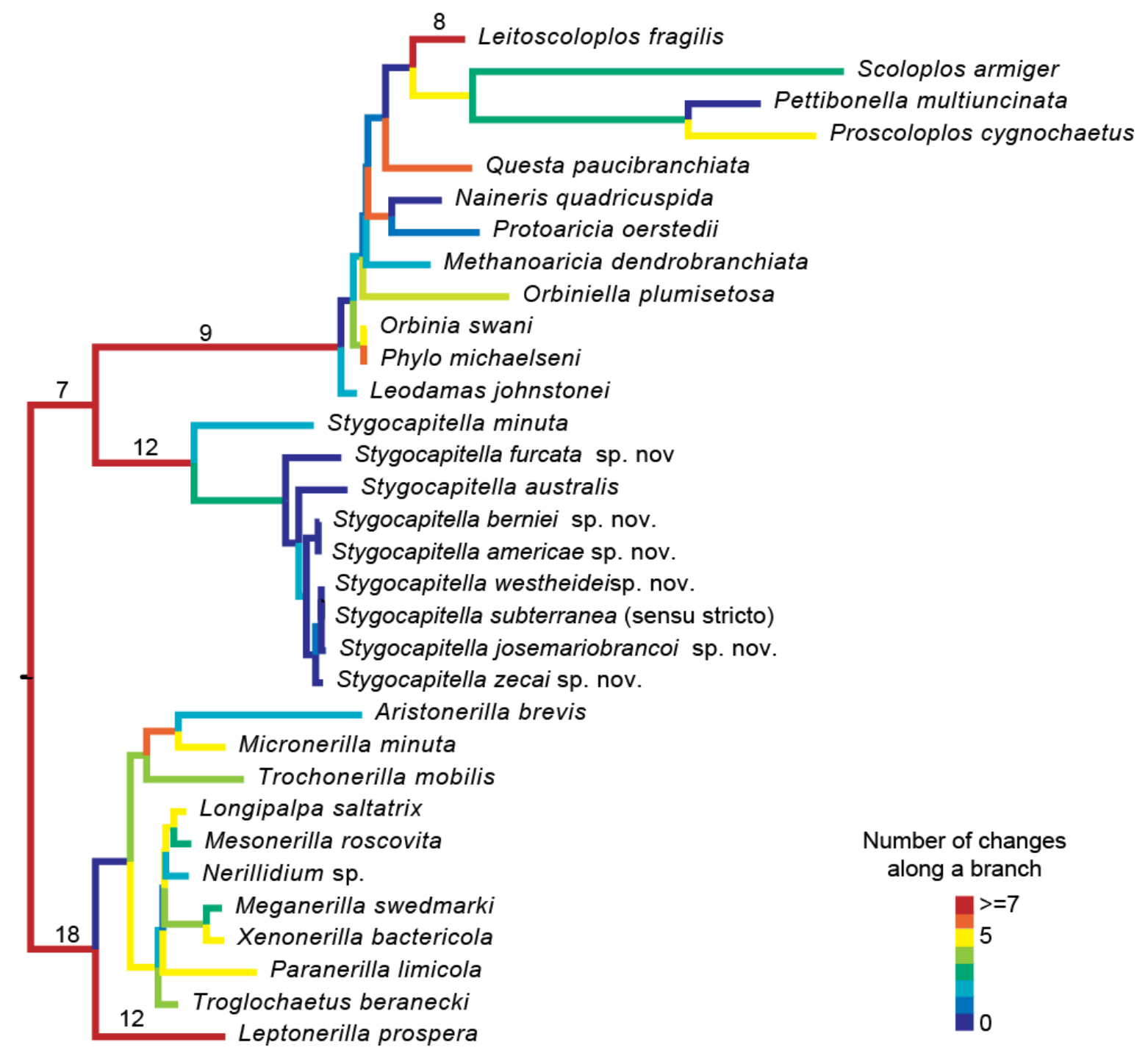

Figure 10. Mapping of character evolution in Stygocapitella (Parergodrilidae), Orbiniidae and Nerillidae. Tree topology is based on a 18S ML phylogeny (manuscript 3). The number of changes along branches are based on a matrix comprising 75 morphological characters, and are portrayed in different colours (see left-bottommost corner). Zero corresponds to no change occurring along the branch. The number of changes along a branch $>7$ is shown on top of the branch. 
A

C

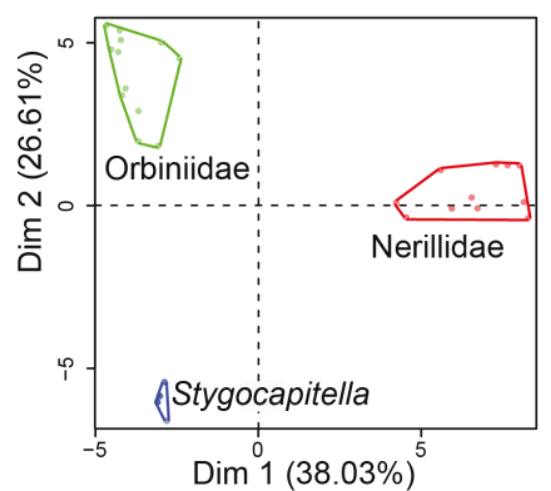

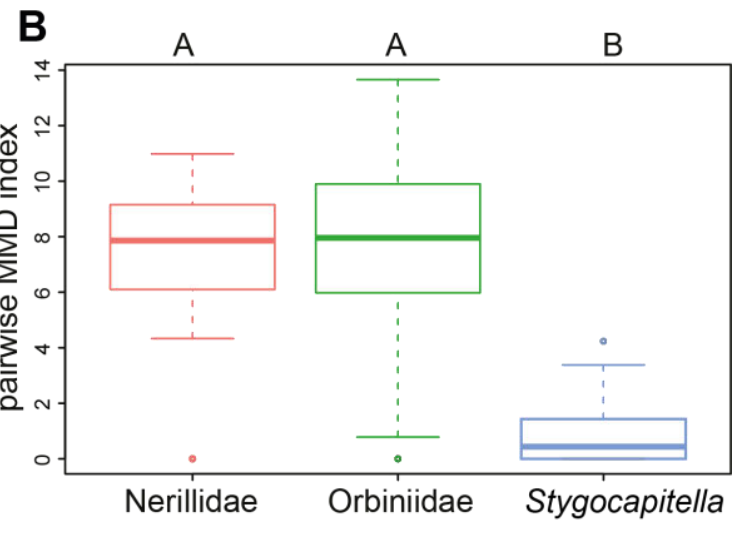

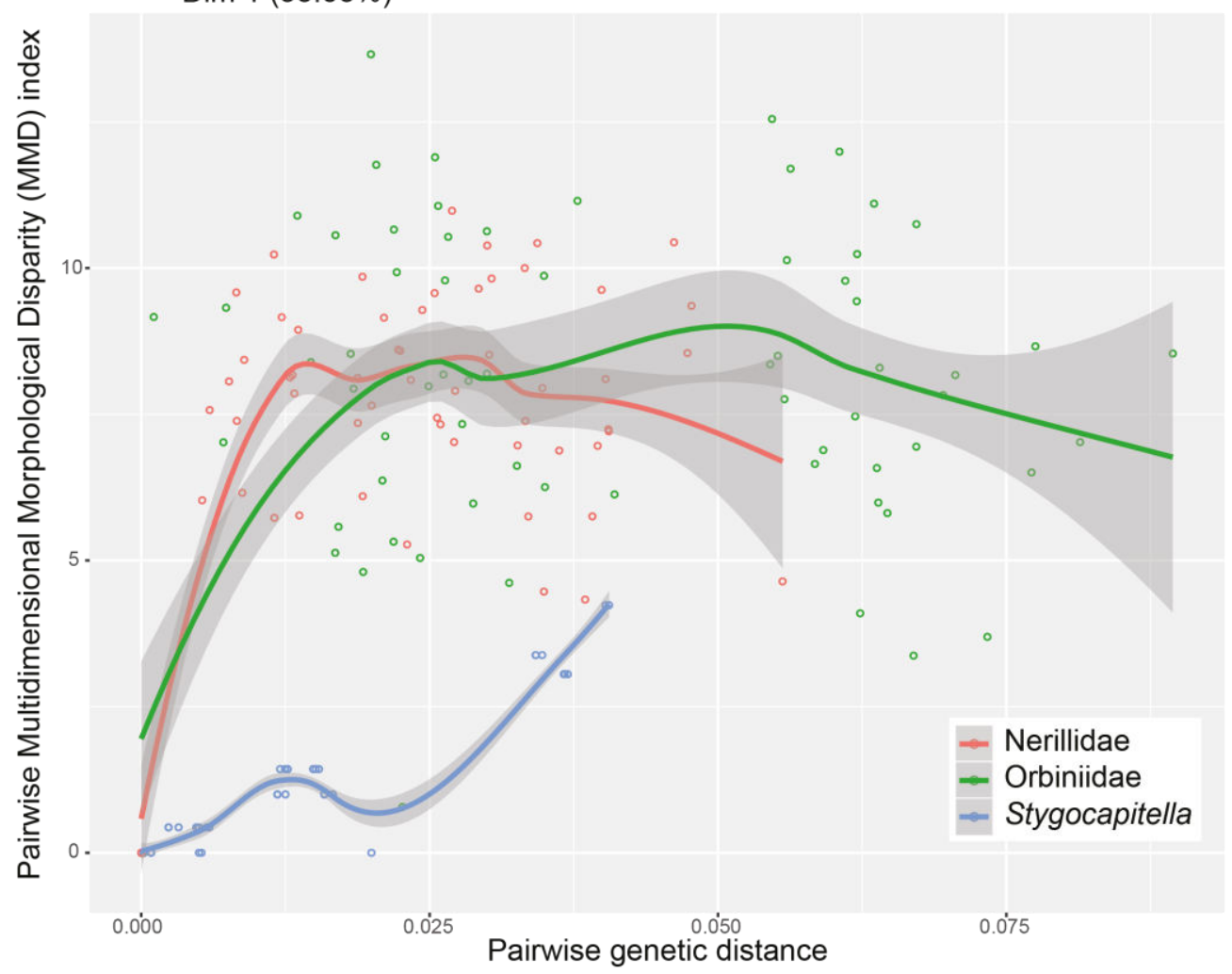

Figure 11. Principal Component (PC) analysis and Multidimensional Morphological Disparity (MMD) index results among Stygocapitella, Orbiniidae and Nerillidae. A) PC analysis of the 75 morphological characters. The first PC explains $38.03 \%$ of the variation and the second explains $26.61 \%$. B) Pairwise differences in the MMD index. Outliers are represented by single dots above or below the confidence intervals. Groups which are not significantly different are signed by same letter (top of the box plot). C) Plotting of the pairwise MMD indices against the pairwise genetic distance in $18 \mathrm{~S}$ shows that at relatively big genetic distances, Stygocapitella displays a lower morphological disparity than the remaining taxa.

I plotted an ancestral state reconstruction on a time-calibrated tree using time estimates based on a molecular clock analysis (Figure 12). These results suggest that Stygocapitella spp. Started to diverge about $\sim 275$ million years ago. Two morphologically similar species, namely S. australis and S. furcata sp. nov. have potentially diverged 140 million years ago. The blue morphotype is likely to have appeared about $18 \mathrm{MY}$ ago (confidence intervals range between $5-37 \mathrm{MY}$ ) (Figure 12) and corresponds to S. subterranea, $S$. westheidei sp. nov. and S. josemariobrancoi sp. nov.. The green morphotype was reconstructed as the ancestral 
José Cerca - On the Origin of Cryptic Species: Insights from the Stygocapitella species complex

condition for a clade comprising $S$. zecai sp. nov., S. bermiei sp. nov., and $S$. americae sp. nov, as well as for $S$. subterranea, S. westheidei sp. nov. and S. josemariobrancoi sp. nov. (Figure 12). The age of divergence for this clade (also including S. spec. A, which no morphological data was obtained) was estimated to be about 64 MY (33 - 104 MY) ago (Figure 12). Finally, the red morphotype was reconstructed as the ancestral state for the whole radiation, except for S. minuta, and it was dated at ca. $140 \mathrm{MY}$ (75 - $205 \mathrm{MY}$ ) (Figure 12). The age for Stygocapitella spp. was dated at about 275 MY (124 - 438 MY), being congruent with previous estimates on a substantially smaller dataset based only on 3 species (S. subterranea, S. minuta and S. australis) and on 18S (Struck et al., 2017) which estimated an age of 270 MY for the whole complex and 83 MY for the split of $S$. australis from S. subterranea. When considering the $95 \%$ confidence interval (not shown in Figure 12), the red morphotype has been maintained for at least $75 \mathrm{MY}$, and the green for at least $33 \mathrm{MY}$ and the blue for at least $5 \mathrm{MY}$. Long-term morphological stasis is evident (manuscript 3).

Morphological stasis is defined by the retention of a given ancestral character state over an extended period (Struck et al., 2018a). Retention of a given ancestral character, and the reduction of variation can potentially be achieved by scenarios of niche conservatism and tracking (Futuyma, 2015, 2010), fluctuating ecological conditions (Futuyma, 2015, 2010, 1987; Sheldon, 1996; Smith et al., 2011), stabilizing selection (Charlesworth et al., 1982; Futuyma, 2010; Hansen and Houle, 2004), constraints (Charlesworth et al., 1982; Futuyma, 2010; Hansen and Houle, 2004; Maynard Smith et al., 1985; Smith et al., 2011; Wagner and Schwenk, 2000), the influence of particular environments and environmental conditions (Futuyma, 2010, 1987; Giere, 2009; Gueriau et al., 2016; Westheide, 1977; Westheide and Rieger, 1987), recurrent bottlenecks (Futuyma, 2010), physiological or behavioural adaptation (Futuyma, 2010; Lassance et al., 2019; Lee and Frost, 2002b), and lack of new ecological interactions (Nordbotten and Stenseth, 2016). Below, we consider a potential scenario to explain stasis in Stygocapitella. However, we warrant data including ecological, developmental, genome-level to potentially confirm any scenario. 


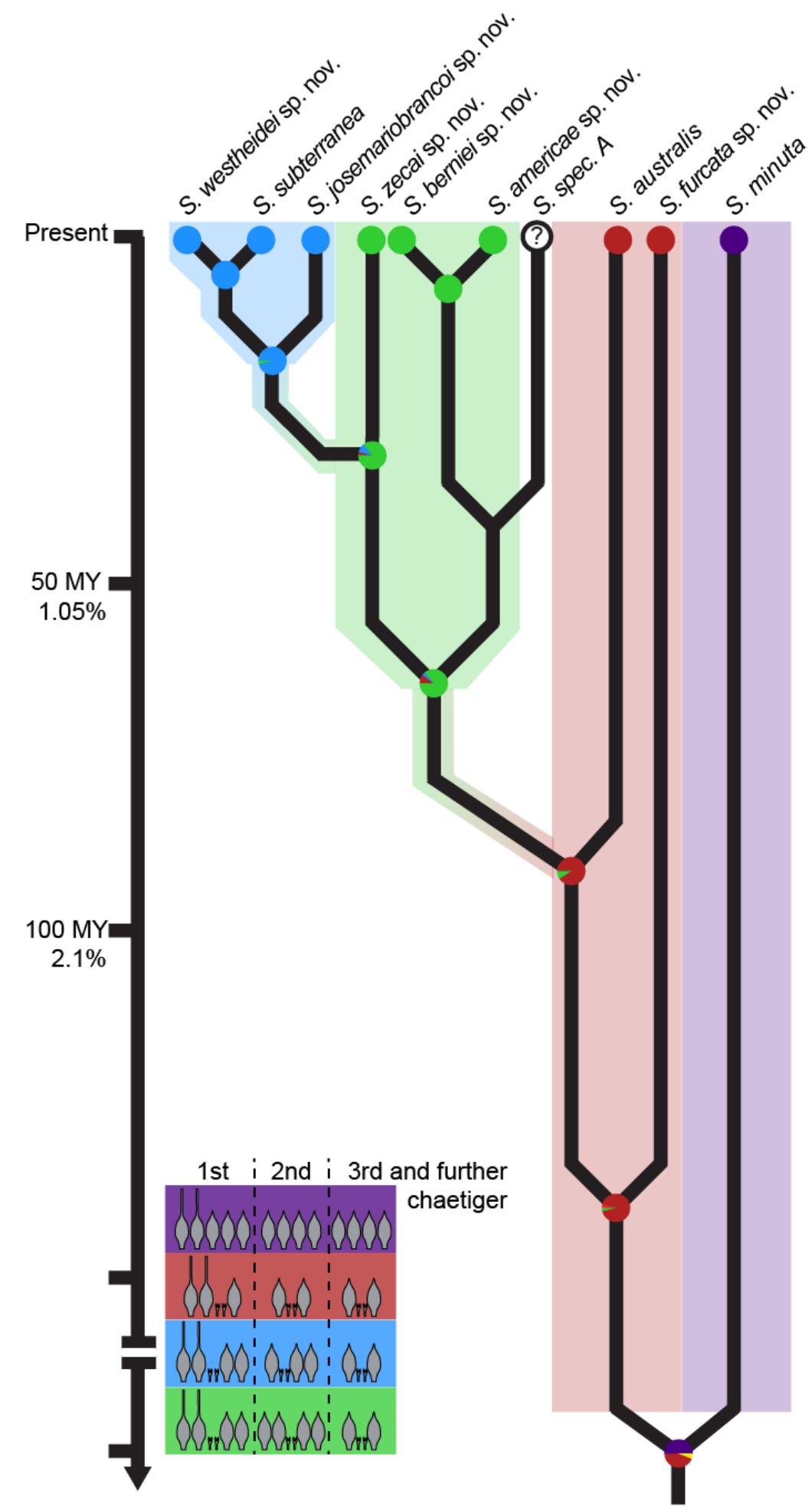

Figure 12. Tree-like representation of the evolution of the four Stygocapitella morphotypes. Circles in the tree nodes follow differences at the chaetigers, as displayed in Figure 6. Node-colour at terminal branches represent morphological assignment of the studied species, whereas nodes in intermediate positions were obtained based on an ancestral character reconstruction. Time at the y axis is based on the molecular clock analyses. Morphological transitions between morphotypes are shown by transitioning colours. Tree topology is based on a ML phylogeny (Figure 5). Pie charts at nodes denote ancestral state reconstructions using a ML approach. Percentages refer to genetic divergence in $18 \mathrm{~S}(0.0002127 / \mathrm{MY})$. 
José Cerca - On the Origin of Cryptic Species: Insights from the Stygocapitella species complex

It has been suggested that stasis can result from a combination of niche conservatism, niche tracking and the occurrence of fluctuating ecological dynamics (Futuyma, 2010; Lindholm, 2014; Sheldon, 1996). In such a scenario, species are expected to (i) remain in the same environment; (ii) be able to track new areas of that given environment; and (iii) fluctuations in abiotic conditions could occur in short-term, but being stable on the long term. The Stygocapitella genus seems to have remained for an extended period in sandy beaches, considering the combination of times of divergence (Figure 12), and the fact that the most distantly related species live in beaches. This is in line with the argumentation stating that the colonization of the space between the space grains requires a high degree of specialization, which could 'lock' interstitial organisms to this environment (Westheide, 1987). This is indeed one of the defining features of the meiofauna, that is the 'meiofauna syndrome', which describes organisms as having an array of convergent features including small body sizes, flat and broad or vermiform-elongated body shapes (Brenzinger et al., 2013; Cerca et al., 2018; Jörger et al., 2014). The idea behind niche tracking is that species are able to persist in their own niche, and remain under the same selective pressures (Futuyma, 2010; Gueriau et al., 2016; Hansen and Houle, 2004; Smith et al., 2011). Given the relative stability of interstitial habitats over geological times, the interstitial realm could represent a "hyperstable niche" (Appeltans et al., 2012; Hansen and Houle, 2004) or one where the core sets of environmental conditions are always present somewhere (Giere, 2009; Noodt, 1974). This is observed on our data as I find multiple instances of dispersal, and the maintenance of wide distributions in different Stygocapitella species, potentially suggesting a strong dispersal capacity (Figures 5,12-13; see below). For instance, S. subterranea and S. josemariobrancoi sp. nov. have wide distributions ranging from Scotland, to Germany and France, with haplotypes occurring over long distances (Figure 13). The phylogeny of Stygocapitella displays a biogeographic signal related to oceanic water bodies, with several oceanic transitions being observed (Figure 5). This is in line with evidence for wide distributions of meiofaunal nemerteans (Leasi and Norenburg, 2016, 2014), xenacoelomorphans (Meyer-Wachsmuth et al., 2014), nematodes (Derycke et al., 2008) and molluscs (Jörger et al., 2012). Finally, fluctuations in ecological conditions are expected to promote stasis by selecting 'morphologically-idle' species (Sheldon, 1996). Fluctuating conditions seem to occur rapidly in the sediments ( $\mathrm{pH}$, salinity and moisture), yet conditions have been potentially similar for millions of years (Giere, 2009; Noodt, 1974). The interstitial habitat could, thus, be considered as constantly changing, yet as a long term stable environment (Giere, 2009; Westheide, 1977; Westheide and Rieger, 1987), as suggested by the "plus ça change, plus c'est la même chose" model (French for 'The more it changes, the more it is the same') (Sheldon, 1996). The combination of these three scenarios may explain stasis in interstitial organisms and in Stygocapitella, but further data should be collected to substantiate these conclusions. 
José Cerca - On the Origin of Cryptic Species: Insights from the Stygocapitella species complex

\section{Stygocapitella species complex - evolutionary history}

Stygocapitella species maintain wide distributions suggesting wide dispersal capacities, with no association between population structure and geography. For example, $S$. zecai sp. nov. is distributed from Northern Norway to England, and one of its 16S haplotypes is shared among specimens from Henningsvær and Lødingen (Northern Norway), Ardtoe (Western Scotland) and Cutty Sark (England) suggesting that no population structure occurs for about $\sim 2000 \mathrm{~km}$ distance (Figure 13). Stygocapitella subterranea and S. josemariobrancoi sp. nov. have wide distributions ranging from Scotland, Germany and France, with a similar pattern of haplotypes occurring over long distances (Figure 13). Stygocapitella westheidei sp. nov. has one single $16 \mathrm{~S}$ haplotype along the entire North-western Atlantic coastline in the USA, spanning ca. $450 \mathrm{~km}$ (Figure 13).

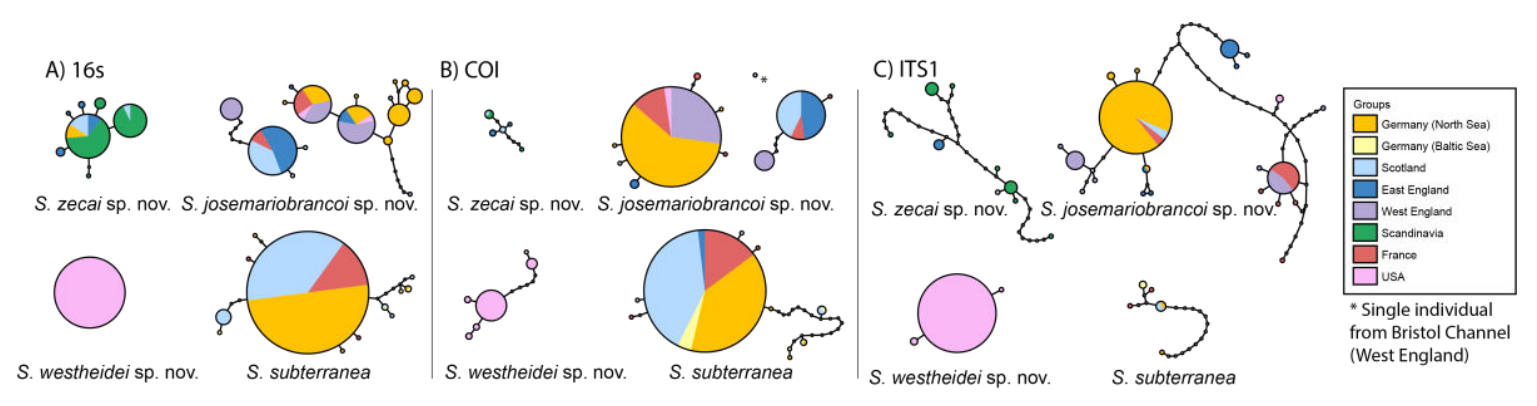

Figure 13. Haplotype networks of the species occurring in the Atlantic Ocean (S. zecai sp. nov., S. subterranea, S. westheidei sp. nov., S. josemariobrancoi sp. nov.). Data includes (A) the mitochondrial $16 \mathrm{~S}$ and (B) COI, and the nuclear gene ITS1. Haplotype sp. nov. networks are colored based on countries and regions.

The phylogeny of Stygocapitella displays a biogeographic signal related to the oceans. Northern Atlantic species form a monophyletic group (Figure 5). However, the North-American distributed S. westheidei sp. nov. is nested within the remaining Atlantic species which occur in Europe. The Northern Atlantic group is closely related to the species present in the Indo-Pacific Oceans, indicating that a transition from the Indo-Pacific to the Atlantic has occurred only once. Interestingly, I find evidence for two groups of sister species occurring in opposite sides of the Northern Pacific Ocean, with S. furcata sp. nov. and S. pacifica sp. nov., as well as Stygocapitella spec. A and S. budaevae sp. nov. occurring in Northern America and Russia, respectively. This suggests that the ancient lineages of each pair speciated allopatrically following vicariance or could transverse the Pacific Ocean (Figure 5). The Australian species, S. australis, is closely related to the Northern Pacific ones, while $S$. minuta, from South Africa, is the first to branch off in the phylogenetic tree (Figure 5). This suggests that at least two equatorial transitions must have occurred.

Two major hypotheses have been suggested to explain the distribution of meiofaunal groups. These include the 'strict vicariance hypothesis', which states that meiofaunal taxa are poor dispersers, and the 'long-distance dispersal hypothesis' which states that meiofaunal taxa are indeed capable of dispersing. Evidence gathered from my thesis is congruent with a previous analysis (Struck et al., 2017), which 
José Cerca - On the Origin of Cryptic Species: Insights from the Stygocapitella species complex

together suggest that a strict vicariance hypothesis does neither fit the observed distribution patterns nor the phylogeny of Stygocapitella. I find evidence for several events of long-distance dispersal (Westheide, 1991, 1977), which have an important role in establishing new populations across oceans and spreading along coastlines (Derycke et al., 2008; Schmidt and Westheide, 2000).

Two specimens collected in Lubec (Maine, USA) were identified as S. josemariobrancoi sp. nov.

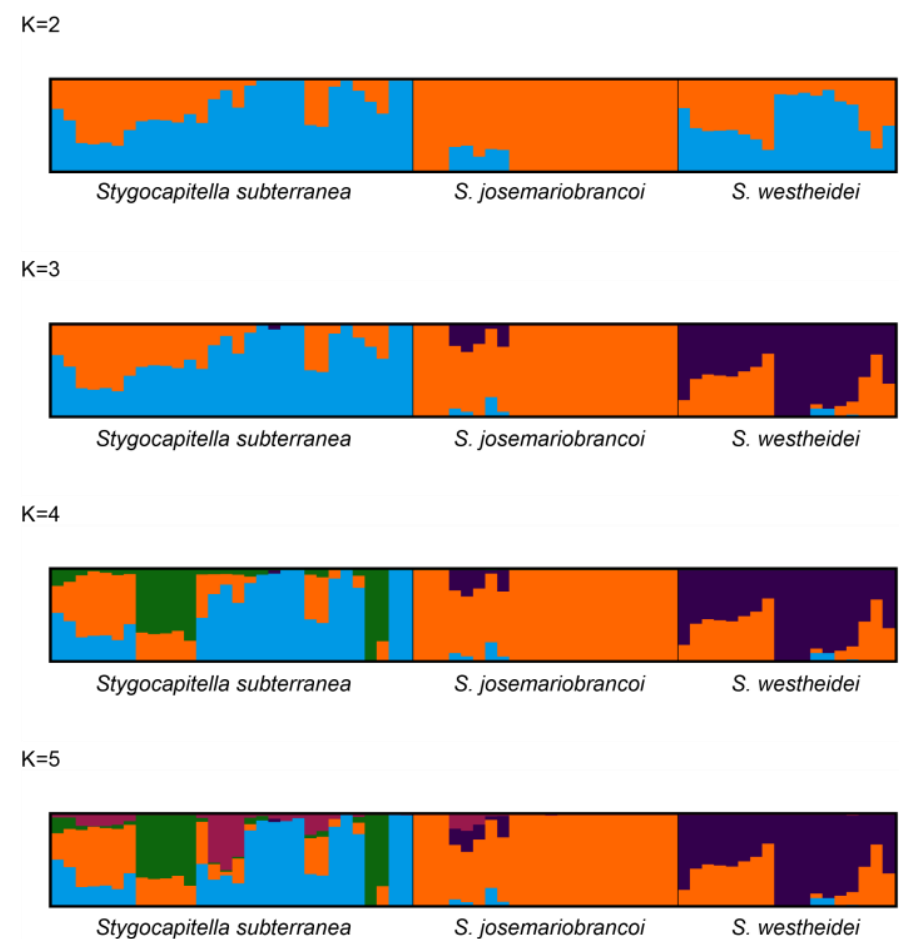

Figure 14. Structure analysis of 3,428 single-nucleotide-polymorphisms (SNPs) based on the ddRAD dataset. Different K's represent different number of clusters fit in different analyses. Stygocapitella subterranea, S. josemariobrancoi and $S$. westheidei are consecutively plotted from left to right. $\mathrm{K}=3$ was the best supported $\mathrm{K}$ (manuscript 5).

using molecular tools (Figure 2A, 5). This species is elsewhere present in Northern Europe. The specimens from Lubec share a 16S haplotype with specimens from England, France and Germany, suggesting a very recent dispersal event possibly due to trans-Atlantic trade.

However, the application of double digestion Restriction-Associated DNA Digestion Sequencing (ddRAD) together with a whole genome amplification (WGA) approach, suggest shared genetic variation among S. stubterranea, S. westheidei, and S. josemariobrancoi (Figures 14-16). While WGA includes a certain amount of bias in the form of palindromes (Warris et al., 2018) and missingness (de Medeiros and Farrell, 2018), these challenges are surmounted by stringent filtering of the data (de Medeiros and Farrell, 2018; manuscript 5). Evidence from shared genetic variation comes from structure analyses (Figure 14), the phylogenomic tree (Figure 15) and coalescent simulations based on the Site-Frequency-Spectrum (Figure 16). Strictly spoken, the phylogenomic-based tree analysis shows that the species are non-monophyletic 


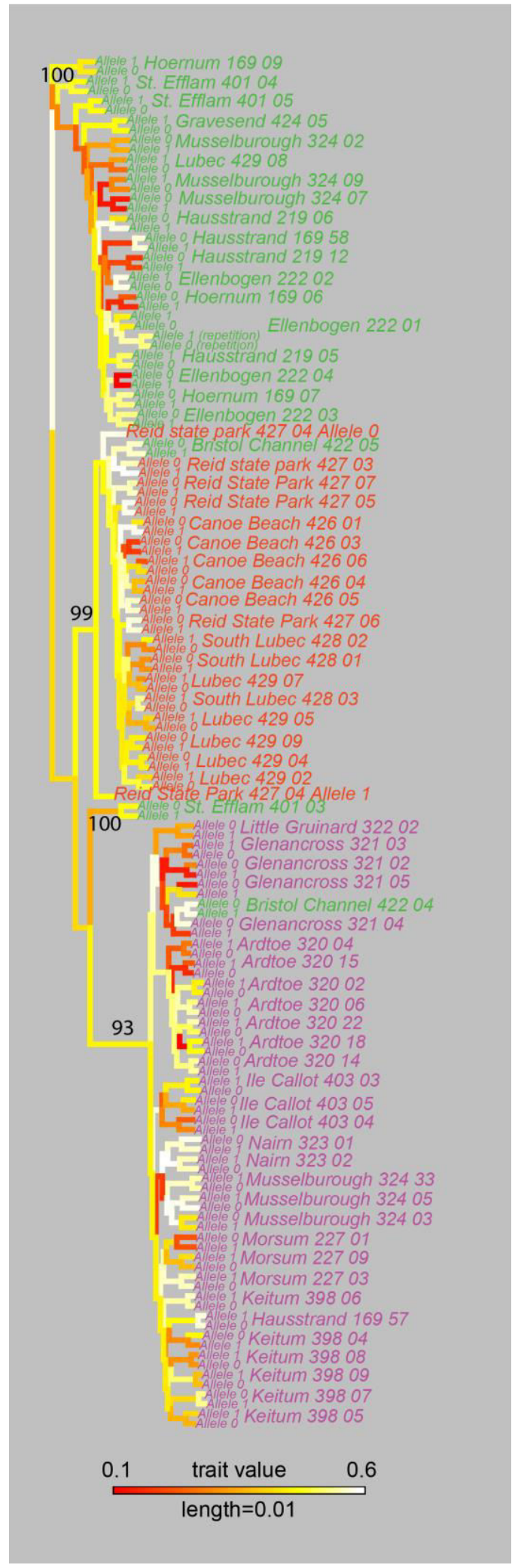

Figure 15. Phylogenomic tree consisting of 4,737 RADseq locus. Bootstrap support for the three species are given on top of the branches. Colours follow species with Stygocapitella subterranea being represented in purple, S. josemariobrancoi in green, and $S$. westheidei inorange. Colours on the tree topology represent missingness $(10 \%$ missing data in red; $60 \%$ missing data in white). The sample Ellenbogen222_01 was included twice to test for data quality.
(Figure 15). In this tree, specimens from $S$. josemariobrancoi sp. nov. form a monophyletic clade, but some individuals are nested in the branches of $S$. subterranea and S. westheidei sp. nov. (Figure 15). Genome-level data thus suggests that some degree of admixture, incomplete lineage sorting or symplesiomorphic variation. This is confirmed in demographic analyses (Figure 16). The most supported demographic scenarios include the "Ancient gene flow", the "No Gene Flow" and the "Modern Geneflow between $S$. subterranea and $S$. westheidei sp. nov." (modern refers to currently existing lineages). When evaluating parameter files for these three scenarios, ancient geneflow suggests that the coalescent events have occurred 1,130,483 generations ago (S. subterranea, S. westheidei $\mathrm{sp}$. nov.) and 12,816,687 generations ago ( $S$. josemariobrancoi sp. nov., and the most common ancestor branch between $S$. subterranea and $S$. westheidei sp. nov.). The "No gene flow scenario" suggests that the coalescence have occurred 205,937 generations ago and 7,482,922 generations ago, and the "Modern Geneflow between Stygocapitella subterranea and S. westheidei" suggest these have occurred 3,759 and 31,853 generations ago. Considering a generation time of 1 year in Stygocapitella (Günter Purschke, pers. comm.), the "Ancient gene flow" scenario is in agreement with molecular clock approaches (manuscript 4).

These results suggest that selected markers might limit the study of the evolutionary history of a given clade but 
cryptic species in the Stygocapitella can likely be determined by a combination of mitochondrial and nuclear markers (manuscript 5). However, complex demographic histories, likely comprising incomplete lineage sorting, admixture between ancestral lineages, or symplesiomorphies are overlooked by a limited number of selected markers and are only revealed by thousands of individual markers. This is in agreement with the evidence that suggests that the application of a limited amount of markers, typically mitochondrial markers can overlook deep splits in lineages (Dincă et al., 2019; Giska et al., 2015; Hinojosa et al., 2019), introgression (Toews and Brelsford, 2012), and incomplete lineage sorting (Toews and Brelsford, 2012).
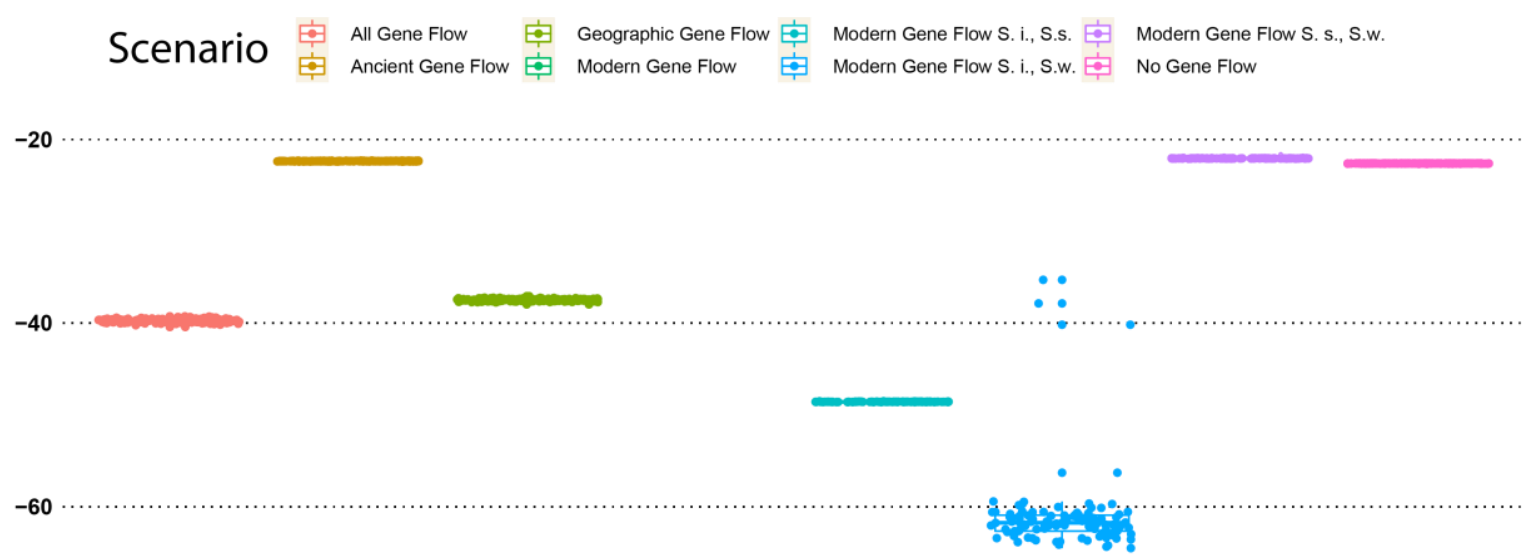

$-80$
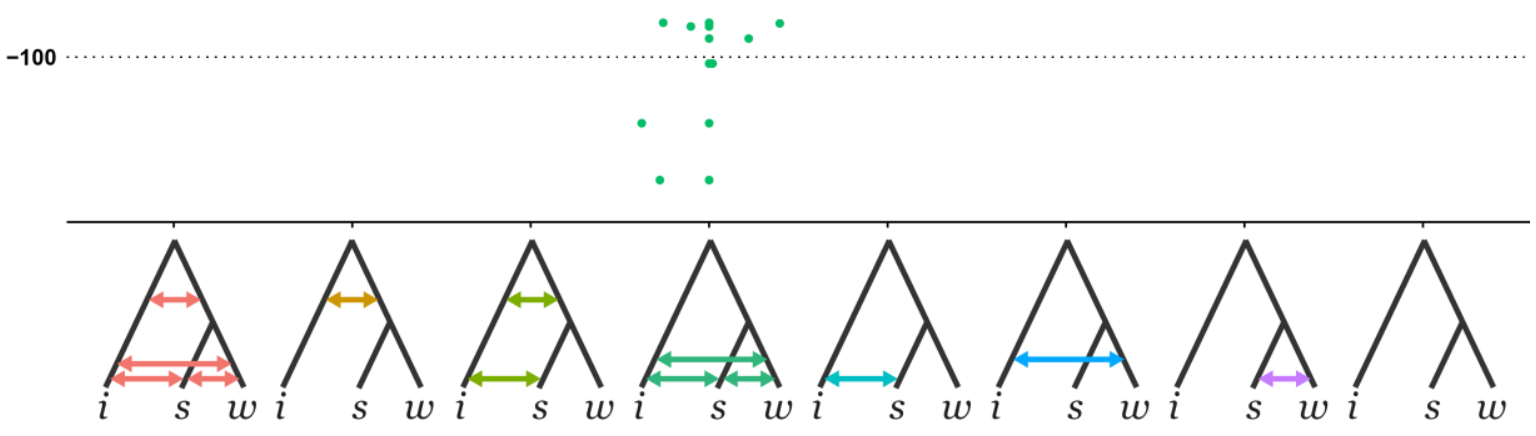

Figure 16. Demographic scenarios used for coalescent simulations based on the Site Frequency Spectrum. In the $\mathrm{X}$ axis, different scenarios are modelled. In the $\mathrm{Y}$ axis, the likelihood of each scenario is displayed. Modelled gene flow is given by arrows as displayed in the cladograms bellow each scenario. From left to right, scenarios include 1) all gene flow (gene flow between all lineages); 2) ancient gene flow (gene flow in the ancestral lineage of $S$. josemariobrancoi sp. nov., S. subterranea and S. westheidei sp. nov.); 3) geographic gene flow (geneflow between potentially para/sympatric lineages; 4) modern gene flow (between all currently existing lineages); 5) gene flow between $S$. josemariobrancoi sp. nov. and S. subterranea; 6) geneflow between $S$. josemariobrancoi sp. nov., $S$. westheidei sp. nov.; 7) geneflow between $S$. subterranea, $S$. westheidei sp. nov.; 8) no gene flow.

\section{The importance of 'cryptic biodiversity'}

The detection of cryptic species has been raising in recent years with the advent and application of DNA barcoding (Struck et al., 2018a). Some estimations suggest that there are around 9,000-36,000 
José Cerca - On the Origin of Cryptic Species: Insights from the Stygocapitella species complex

cryptic species in the seas, comprising a total of $3-12 \%$ of life in oceans (Appeltans et al., 2012). Understanding which groups are more prone to have decelerated morphologies and hence more overlooked species becomes thus important in a time of global extinctions and human-induced climatic changes. This hidden layer of biodiversity is likely to affect ecological parameters such as community composition (Chenuil et al., 2019), the determination of species' evolutionary history (Hinojosa et al., 2019), estimates of paleontological rates of evolution (Alizon et al., 2008), estimation of biogeographic breaks (Weber et al., 2019), and in species' conservation (Bernardo, 2011). Future works should focus on quantifying the numbers of cryptic species by habitats and in different branches in the tree of life (PérezPonce de León and Poulin, 2016), and should focus on detecting cryptic species in lineages affected by extinction and in habitats facing fragmentation, destruction or climate change.

\section{Conclusions}

Biological forms have evolved to occupy nearly every environment in our planet, displaying an astonishing diversity of forms, traits and strategies. Morphological diversity has inspired generations of biologists, being at the heart of the passion we hold for biology. 'Evolvability' (i.e. the ability to evolve new traits) is seen as a measure of biological success, and as a desired feature of any system (Weiss, 2011). All of this has rendered ideas of 'invariability', 'deceleration' or 'stasis' as dubious or as bad observations. However, the occurrence of cryptic species is becoming more relevant and more prominent in recent years (Struck et al., 2018a). Cryptic species potentially represent an important component of biodiversity, and warrant further attention.

As part of this thesis, I have provided a framework to understand and identify cryptic species. This framework focuses on the biological history of the species complex, rather than on human-error (i.e. taxonomic artefacts). With reference to the 'meiofauna paradox', I have provided an example of how overlooking cryptic species can bias estimations of species distribution and confound species' biogeography. Focusing on the Stygocapitella cryptic species complex, I have shown that it has decelerated rates of morphological evolution relatively to closely related taxa. The description of 8 new species has reduced the distribution of Stygocapitella subterranea from cosmopolitan to only being present in the European coastlines. Some of these species are morphologically undisguisable using quantitative tools (i.e. Scanning Electron Microscopy), or various measurements. Furthermore, genomic data suggests that a complex of morphologically similar Stygocapitella species have a potentially complex demographic history.

Future research should focus on quantifying the occurrence of cryptic species in in different lineages of the tree of life. It should also further our knowledge on the mechanisms leading to the deceleration of morphological evolution and, in particular, the extreme example of stasis. These approaches will benefit from the integration of decades of research of paleontological stasis, together with modern genomic tools including population genomics, phylogenomics and comparative genomics. 
José Cerca - On the Origin of Cryptic Species: Insights from the Stygocapitella species complex

\section{References}

Alizon, S., Kucera, M., Jansen, V., 2008. Competition between cryptic species explains variations in rates of lineage evolution. Proc. Natl. Acad. Sci. U. S. A. 105, 12382-12386.

https://doi.org/10.1073/pnas.0805039105

Appeltans, W., Ahyong, S.T., Anderson, G., Angel, M. V., Artois, T., Bailly, N., Bamber, R., Barber, A., Bartsch, I., Berta, A., Błazewicz-Paszkowycz, M., Bock, P., Boxshall, G., Boyko, C.B., Brandão, S.N., Bray, R.A., Bruce, N.L., Cairns, S.D., Chan, T.Y., Cheng, L., Collins, A.G., Cribb, T., Curini-Galletti, M., Dahdouh-Guebas, F., Davie, P.J.F., Dawson, M.N., De Clerck, O., Decock, W., De Grave, S., De Voogd, N.J., Domning, D.P., Emig, C.C., Erséus, C., Eschmeyer, W., Fauchald, K., Fautin, D.G., Feist, S.W., Fransen, C.H.J.M., Furuya, H., Garcia-Alvarez, O., Gerken, S., Gibson, D., Gittenberger, A., Gofas, S., Gómez-Daglio, L., Gordon, D.P., Guiry, M.D., Hernandez, F., Hoeksema, B.W., Hopcroft, R.R., Jaume, D., Kirk, P., Koedam, N., Koenemann, S., Kolb, J.B., Kristensen, R.M., Kroh, A., Lambert, G., Lazarus, D.B., Lemaitre, R., Longshaw, M., Lowry, J., MacPherson, E., Madin, L.P., Mah, C., Mapstone, G., McLaughlin, P.A., Mees, J., Meland, K., Messing, C.G., Mills, C.E., Molodtsova, T.N., Mooi, R., Neuhaus, B., Ng, P.K.L., Nielsen, C., Norenburg, J., Opresko, D.M., Osawa, M., Paulay, G., Perrin, W., Pilger, J.F., Poore, G.C.B., Pugh, P., Read, G.B., Reimer, J.D., Rius, M., Rocha, R.M., Saiz-Salinas, J.I., Scarabino, V., Schierwater, B., Schmidt-Rhaesa, A., Schnabel, K.E., Schotte, M., Schuchert, P., Schwabe, E., Segers, H., Self-Sullivan, C., Shenkar, N., Siegel, V., Sterrer, W., Stöhr, S., Swalla, B., Tasker, M.L., Thuesen, E. V., Timm, T., Todaro, M.A., Turon, X., Tyler, S., Uetz, P., Van Der Land, J., Vanhoorne, B., Van Ofwegen, L.P., Van Soest, R.W.M., Vanaverbeke, J., Walker-Smith, G., Walter, T.C., Warren, A., Williams, G.C., Wilson, S.P., Costello, M.J., 2012. The magnitude of global marine species diversity. Curr. Biol. 22, 2189-2202. https://doi.org/10.1016/j.cub.2012.09.036

Arroyo, N.L., Aarnio, K., Bonsdorff, E., 2006. Drifting algae as a means of re-colonizing defaunated sediments in the Baltic Sea. A short-term microcosm study. Hydrobiologia 554, 83-95. https://doi.org/10.1007/s10750-005-1008-5

Astrin, J.J., Stüben, P.E., 2008. Phylogeny in cryptic weevils: Molecules, morphology and new genera of western Palaearctic Cryptorhynchinae (Coleoptera: Curculionidae). Invertebr. Syst. 22, 503-522. https://doi.org/10.1071/IS07057

Bernardo, J., 2011. A critical appraisal of the meaning and diagnosability of cryptic evolutionary diversity, and its implications for conservation in the face of climate change. Clim. Chang. Ecol. Syst. 380-438. https://doi.org/10.1017/CBO9780511974540.019

Bickford, D., Lohman, D.J., Sodhi, N.S., Ng, P.K.L., Meier, R., Winker, K., Ingram, K.K., Das, I., 2007. Cryptic species as a window on diversity and conservation. Trends Ecol. Evol. 22, 148-155. https://doi.org/10.1016/j.tree.2006.11.004

Bleidorn, C., Hill, N., Erséus, C., Tiedemann, R., 2009. On the role of character loss in orbiniid phylogeny (Annelida): Molecules vs. morphology. Mol. Phylogenet. Evol. 52, 57-69. https://doi.org/10.1016/j.ympev.2009.03.022

Boeckner, M.J., Sharma, J., Proctor, H.C., 2009. Revisiting the meiofauna paradox: Dispersal and colonization of nematodes and other meiofaunal organisms in low- and high-energy environments. Hydrobiologia 624, 91-106. https://doi.org/10.1007/s10750-008-9669-5

Bouckaert, R., Heled, J., Kühnert, D., Vaughan, T., Wu, C.H., Xie, D., Suchard, M.A., Rambaut, A., Drummond, A.J., 2014. BEAST 2: A software platform for bayesian evolutionary analysis. PLoS Comput. Biol. 10, 1-6. https://doi.org/10.1371/journal.pcbi.1003537

Brenzinger, B., Haszprunar, G., Schrödl, M., 2013. At the limits of a successful body plan - 3D microanatomy, histology and evolution of Helminthope (Mollusca: Heterobranchia: Rhodopemorpha), the most worm-like gastropod. Front. Zool. 10, 37. https://doi.org/10.1186/1742-9994-10-37 
José Cerca - On the Origin of Cryptic Species: Insights from the Stygocapitella species complex

Callens, M., Gheerardyn, H., Ndraro, S.G.M., De Troch, M., Vanreusel, A., 2012. Harpacticoid copepod colonization of coral fragments in a tropical reef lagoon (Zanzibar, Tanzania). J. Mar. Biol. Assoc. United Kingdom 92, 1535-1545. https://doi.org/10.1017/S0025315411001597

Carstens, B.C., Pelletier, T.A., Reid, N.M., Satler, J.D., 2013. How to fail at species delimitation. Mol. Ecol. 22, 4369-4383. https://doi.org/10.1111/mec.12413

Cerca, J., Purschke, G., Struck, T.H., 2018. Marine connectivity dynamics: clarifying cosmopolitan distributions of marine interstitial invertebrates and the meiofauna paradox. Mar. Biol. 165, 123. https://doi.org/10.1007/s00227-018-3383-2

Charlesworth, B., Lande, R., Slatkin, M., 1982. A Neo-Darwinian commentary on macroevolution. Evolution (N. Y). 36, 474-498.

Chenuil, A., Cahill, A.E., Délémontey, N., Luc, E.D.S. du, Hadrien, Fanton, 2019. Problems and questions posed by cryptic species. A framework to guide future studies. pp. 77-106. https://doi.org/10.1007/978-3-030-10991-2

Chernomor, O., Von Haeseler, A., Minh, B.Q., 2016. Terrace aware data structure for phylogenomic inference from supermatrices. Syst. Biol. 65, 997-1008. https://doi.org/10.1093/sysbio/syw037

Christiansen, F.B., Fenchel, T.M., 1979. Evolution of marine invertebrate reproductive patterns. Theor. Popul. Biol. 16, 267-282. https://doi.org/10.1016/0040-5809(79)90017-0

Clement, M., Posada, D., Crandall, K.A., 2000. TCS: a computer program to estimate gene genealogies. Mol. Ecol. 9, 1657-1660. https://doi.org/10.1046/j.1365-294x.2000.01020.x

Commito, J.A., Tita, G., 2002. Differential dispersal rates in an intertidal meiofauna assemblage. J. Exp. Mar. Bio. Ecol. 268, 237-256. https://doi.org/10.1016/S0022-0981(01)00386-0

Cristoni, C., Colangelo, M.A., Ceccherelli, V.U., 2004. Spatial scale and meiobenthic copepod recolonisation: Testing the effect of disturbance size in a seagrass habitat. J. Exp. Mar. Bio. Ecol. 298, 49-70. https://doi.org/10.1016/j.jembe.2003.08.005

Cuvelier, D., Beesau, J., Ivanenko, V.N., Zeppilli, D., Sarradin, P.M., Sarrazin, J., 2014. First insights into macro- and meiofaunal colonisation patterns on paired wood/slate substrata at Atlantic deep-sea hydrothermal vents. Deep. Res. Part I Oceanogr. Res. Pap. 87, 70-81. https://doi.org/10.1016/j.dsr.2014.02.008

Danecek, P., Auton, A., Abecasis, G., Albers, C.A., Banks, E., DePristo, M.A., Handsaker, R.E., Lunter, G., Marth, G.T., Sherry, S.T., McVean, G., Durbin, R., 2011. The variant call format and VCFtools. Bioinformatics 27, 2156-2158. https://doi.org/10.1093/bioinformatics/btr330

Danielopol, D.A.N., Wouters, K., 1992. Evolutionary (Paleo)biology of marine interstitial ostracoda. Geobios 25, 207-211.

de Medeiros, B.A.S., Farrell, B.D., 2018. Whole genome amplification in double-digest RAD-seq results in adequate libraries but fewer sequenced loci. PeerJ. https://doi.org/10.7717/peerj.5089

De Meester, N., Derycke, S., Moens, T., 2012. Differences in time until dispersal between cryptic species of a marine nematode species complex. PLoS One 7, 1-8.

https://doi.org/10.1371/journal.pone.0042674

De Meester, N., Derycke, S., Rigaux, A., Moens, T., 2015. Active dispersal is differentially affected by inter- and intraspecific competition in closely related nematode species. Oikos 124, 561-570. https://doi.org/10.1111/oik.01779

Derycke, S., Backeljau, T., Moens, T., 2013. Dispersal and gene flow in free-living marine nematodes. Front. Zool. 10, 1. https://doi.org/10.1186/1742-9994-10-1 
José Cerca - On the Origin of Cryptic Species: Insights from the Stygocapitella species complex

Derycke, S., Remerie, T., Backeljau, T., Vierstraete, A., Vanfleteren, J., Vincx, M., Moens, T., 2008. Phylogeography of the Rhabditis (Pellioditis) marina species complex: Evidence for long-distance dispersal, and for range expansions and restricted gene flow in the northeast Atlantic. Mol. Ecol. 17, 3306-3322. https://doi.org/10.1111/j.1365-294X.2008.03846.x

Dincă, V., Lee, K.M., Vila, R., Mutanen, M., 2019. The conundrum of species delimitation: a genomic perspective on a mitogenetically super-variable butterfly. Proc. Biol. Sci. 286.

Dujardin, F., 1851. Sur un petit animal marin, l'Echinodère, formant un type intermédiaire entre les Crustacés et les Vers. Ann Sci Nat Zool. 3, 158-160.

Eldredge, N., Gould, S.J., 1972. Punctuated Equilibria: An alternative to phylogetic gradualism, in: Schopf, T.J.M. (Ed.), Models in Paleobiology. Freeman, Cooper and Co., San Francisco., pp. 82-115.

Elgetany, A.H., El-Ghobashy, A.E., Ghoneim, A.M., Struck, T.H., 2018. Description of a new species of the genus marphysa (Eunicidae), Marphysa aegypti sp.n., based on molecular and morphological evidence. Invertebr. Zool. 15, 71-84. https://doi.org/10.15298/invertzool.15.1.05

Endersby, J., 2009. Lumpers and splitters: Darwin, Hooker, and the search for order. Science (80-. ). 326, 1496-1499. https://doi.org/10.1126/science.1165915

Erlank, E., Koekemoer, L.L., Coetzee, M., 2018. The importance of morphological identification of African anopheline mosquitoes (Diptera: Culicidae) for malaria control programmes. Malar. J. 17, 1 7. https://doi.org/10.1186/s12936-018-2189-5

Estes, S., Arnold, S.J., 2007. Resolving the paradox of stasis: models with stabilizing selection explain evolutionary divergence on all timescales. Am. Nat. 169, 227-244. https://doi.org/10.1086/510633

Excoffier, L., Dupanloup, I., Huerta-Sánchez, E., Sousa, V.C., Foll, M., 2013. Robust Demographic Inference from Genomic and SNP Data. PLoS Genet. 9. https://doi.org/10.1371/journal.pgen.1003905

Falush, D., Stephens, M., Pritchard, J.K., 2003. Inference of population structure using multilocus genotype data: Linked loci and correlated allele frequencies. Genetics 164, 1567-1587. https://doi.org/10.1111/j.1471-8286.2007.01758.x

Fišer, C., Robinson, C.T., Malard, F., 2018. Cryptic species as a window into the paradigm shift of the species concept. Mol. Ecol. 27, 613-635. https://doi.org/10.1111/mec.14486

Fonsêca-Genevois, V. da, Somerfield, P.J., Neves, M.H.B., Coutinho, R., Moens, T., 2006. Colonization and early succession on artificial hard substrata by meiofauna. Mar. Biol. 148, 1039-1050. https://doi.org/10.1007/s00227-005-0145-8

Fontaneto, D., Flot, J.F., Tang, C.Q., 2015. Guidelines for DNA taxonomy, with a focus on the meiofauna. Mar. Biodivers. 45, 433-451. https://doi.org/10.1007/s12526-015-0319-7

Fujisawa, T., Barraclough, T.G., 2013. Delimiting species using single-locus data and the generalized mixed yule coalescent approach: A revised method and evaluation on simulated data sets. Syst. Biol. 62, 707-724. https://doi.org/10.1093/sysbio/syt033

Futuyma, D., 2005. Evolution, Evolution. Sinauer Associates, Inc, Sunderland, MA. https://doi.org/10.1007/s13398-014-0173-7.2

Futuyma, D.J., 2015. Can modern evolutionary theory explain macroevolution?, in: Macroevolution. pp. 29-86. https:// doi.org/10.5860/choice.192898

Futuyma, D.J., 2010. Evolutionary constraint and ecological consequences. Evolution (N. Y). 64, 18651884. https://doi.org/10.1111/j.1558-5646.2010.00960.x 
José Cerca - On the Origin of Cryptic Species: Insights from the Stygocapitella species complex

Futuyma, D.J., 1987. On the role of species in anagenesis. Am. Nat. 130, 465-473.

Gallucci, F., Moens, T., Vanreusel, A., Fonseca, G., 2008. Active colonisation of disturbed sediments by deep-sea nematodes: Evidence for the patch mosaic model. Mar. Ecol. Prog. Ser. 367, 173-183. https://doi.org/10.3354/meps07537

Gerlach, S.A., 1977. Means of meiofauna dispersal., in: The Meiofauna Species in Time and Space. Mikrofauna Meeresbod. pp. 89-103.

Giere, O., 2009. Meiobenthology: the microscopic motile fauna of aquatic sediments, 2nd ed. SpringlerVerlag, Berlin Heidelberg. https://doi.org/10.1016/0022-0981(94)90135-X

Gillespie, R., 2004. Community assembly through adaptive radiation in Hawaiian spiders. Science (80-. ). 303, 356-360.

Giska, I., Sechi, P., Babik, W., 2015. Deeply divergent sympatric mitochondrial lineages of the earthworm Lumbricus rubellus are not reproductively isolated. BMC Evol. Biol. 15, 217. https://doi.org/10.1186/s12862-015-0488-9

Gobin, J.F., Warwick, R.M., 2006. Geographical variation in species diversity: A comparison of marine polychaetes and nematodes. J. Exp. Mar. Bio. Ecol. 330, 234-244. https://doi.org/10.1016/j.jembe.2005.12.030

Golombek, A., Tobergte, S., Nesnidal, M.P., Purschke, G., Struck, T.H., 2013. Mitochondrial genomes to the rescue - Diurodrilidae in the myzostomid trap. Mol. Phylogenet. Evol. 68, 312-326.

Gueriau, P., Rabet, N., Clément, G., Lagebro, L., Vannier, J., Briggs, D.E.G., Charbonnier, S., Olive, S., Béthoux, O., 2016. A 365-million-year-old freshwater community reveals morphological and ecological stasis in branchiopod crustaceans. Curr. Biol. 26, 383-390. https://doi.org/10.1016/j.cub.2015.12.039

Guilini, K., Soltwedel, T., van Oevelen, D., Vanreusel, A., 2011. Deep-sea nematodes actively colonise sediments, irrespective of the presence of a pulse of organic matter: Results from an in-situ experiment. PLoS One 6. https://doi.org/10.1371/journal.pone.0018912

Gwyther, J., Fairweather, P.G., 2005. Meiofaunal recruitment to mimic pneumatophores in a cooltemperate mangrove forest: spatial context and biofilm effects. J. Exp. Mar. Bio. Ecol. 317, 69-85. https://doi.org/10.1016/j.jembe.2004.11.012

Hansen, T.F., 1997. Stabilizing selection and the comparative analysis of adaptation. Evolution (N. Y). 51, $1341-1351$.

Hansen, T.F., Houle, D., 2004. Evolvability, stabilizing selection, and the problem of stasis, in: Pigliucci, M., Preston, K. (Eds.), Phenotypic Integration: Studying the Ecology and Evolution of Complex Phenotypes. Oxford University Press, New York, pp. 130-154.

Harrell Jr, F.E., Many Others, contributions from, 2019. Hmisc: Harrell Miscellaneous. R package.

Hawksworth, D.L., Lücking, R., 2017. Fungal diversity revisited : 2.2 to 3.8 million species. Microbiol. Spetrum 5, 1-17. https://doi.org/10.1128/microbiolspec.FUNK-0052-2016.Correspondence

Heethoff, M., 2018. Cryptic species - Conceptual or terminological chaos? A response to Struck et al. Trends Ecol. Evol. 33, 2018. https://doi.org/10.1016/j.tree.2018.02.006

Hillis, D.M., Dixon, M.T., 1991. Ribosomal DNA: Molecular evolution and phylogenetic inference. Q. Rev. Biol. 66, 411-453.

Hinojosa, J.C., Koubínová, D., Szenteczki, M.A., Pitteloud, C., Dincă, V., Alvarez, N., Vila, R., 2019. A mirage of cryptic species: Genomics uncover striking mitonuclear discordance in the butterfly 
José Cerca - On the Origin of Cryptic Species: Insights from the Stygocapitella species complex

Thymelicus sylvestris . Mol. Ecol. 1-12. https://doi.org/10.1111/mec.15153

Hoang, D.T., Chernomor, O., von Haeseler, A., Quang Minh, B., Sy Vinh, L., 2017. Ufboot2: Improving the ultrafast bootstrap approximation 35, 518-522. https://doi.org/10.5281/zenodo.854445

Hooper, G.J., Davenport, J., 2006. Epifaunal composition and fractal dimensions of intertidal marine macroalgae in relation to emersion. J. Mar. Biol. Assoc. United Kingdom 86, 1297-1304. https://doi.org/10.1017/S0025315406014329

Hotaling, S., Foley, M.E., Lawrence, N.M., Bocanegra, J., Blanco, M.B., Rasoloarison, R., Kappeler, P.M., Barrett, M.A., Yoder, A.D., Weisrock, D.W., 2016. Species discovery and validation in a cryptic radiation of endangered primates: Coalescent-based species delimitation in Madagascar's mouse lemurs. Mol. Ecol. 25, 2029-2045. https://doi.org/10.1111/mec.13604

Huson, D.H., Bryant, D., 2006. Application of phylogenetic networks in evolutionary studies. Mol. Biol. Evol. 23, 254-267. https://doi.org/10.1093/molbev/msj030

Hutchings, P., Kupriyanova, E., 2018. Cosmopolitan polychaetes - fact or fiction? Personal and historical perspectives. Invertebr. Syst. 32, 1-9. https://doi.org/https://doi.org/10.1071/IS17035

Jörger, K.M., Neusser, T.P., Brenzinger, B., Schrödl, M., 2014. Exploring the diversity of mesopsammic gastropods: how to collect, identify, and delimitate small and elusive sea slugs? Am. Malacol. Bull. 32, 290-307. https://doi.org/10.4003/006.032.0205

Jörger, K.M., Norenburg, J.L., Wilson, N.G., Schrödl, M., 2012. Barcoding against a paradox? Combined molecular species delineations reveal multiple cryptic lineages in elusive meiofaunal sea slugs. BMC Evol. Biol. 12, 245. https://doi.org/10.1186/1471-2148-12-245

Jörger, K.M., Schrödl, M., 2013. How to describe a cryptic species? Practical challenges of molecular taxonomy. Front. Zool. 10, 59. https://doi.org/10.1186/1742-9994-10-59

Junkins, R., Kelaher, B., Levinton, J., 2006. Contributions of adult oligochaete emigration and immigration in a dynamic soft-sediment community. J. Exp. Mar. Bio. Ecol. 330, 208-220.

https://doi.org/10.1016/j.jembe.2005.12.028

Kajihara, H., Ikoma, M., Yamasaki, H., Hiruta, S.F., 2015. Trilobodrilus itoi sp. nov., with a re-description of T. nipponicus (Annelida: Dinophilidae) and a molecular phylogeny of the genus. Zoolog. Sci. 32, 405417. https://doi.org/10.2108/zs140251

Kalyaanamoorthy, S., Minh, B.Q., Wong, T.K.F., Von Haeseler, A., Jermiin, L.S., 2017. ModelFinder: Fast model selection for accurate phylogenetic estimates. Nat. Methods 14, 587-589.

https://doi.org/10.1038/nmeth.4285

Katoh, K., Standley, D.M., 2013. MAFFT multiple sequence alignment software version 7: Improvements in performance and usability. Mol. Biol. Evol. 30, 772-780. https://doi.org/10.1093/molbev/mst010

Kieneke, A., Martínez Arbizu, P.M., Fontaneto, D., 2012. Spatially structured populations with a low level of cryptic diversity in European marine Gastrotricha. Mol. Ecol. 21, 1239-54.

https://doi.org/10.1111/j.1365-294X.2011.05421.x

Klautau, M., Russo, C.A.M., Lazoski, C., Boury-esnault, N., Thorpe, J.P., Sole-cava, A.M., Klautau, M., Russo, C.A.M., Lazoski, C., Boury-esnault, N., John, P., Solt-cava, A.M., 1999. Does cosmopolitanism result from overconservative systematics? A case study using the marine sponge Chondrilla nucula. Evolution (N. Y). 53, 1414-1422.

Knöllner, F., 1934. Stypocapitella subterranea nov.gen. nov.spec. Schriften der Naturwissenschaftlichen Vereins für Schleswig-Holstein 20, 468-472. 
José Cerca - On the Origin of Cryptic Species: Insights from the Stygocapitella species complex

Knowlton, N., 2000. Molecular genetic analyses of species boundaries in the sea. Hydrobiologia 420, $73-$ 90. https:// doi.org/10.1023/A:1003933603879

Knowlton, N., 1993. Sibling species in the sea. Annu. Rev. Ecol. Syst. 24, 189-216.

Kon, T., Yoshino, T., Mukai, T., Nishida, M., 2007. DNA sequences identify numerous cryptic species of the vertebrate: A lesson from the gobioid fish Schindleria. Mol. Phylogenet. Evol. 44, 53-62. https://doi.org/10.1016/j.ympev.2006.12.007

Korshunova, T., Martynov, A., Bakken, T., Picton, B., 2017. External diversity is restrained by internal conservatism: New nudibranch mollusc contributes to the cryptic species problem. Zool. Scr. 46, 683-692. https://doi.org/10.1111/zsc.12253

Korshunova, T., Picton, B., Furfaro, G., Mariottini, P., Pontes, M., Prkić, J., Fletcher, K., Malmberg, K., Lundin, K., Martynov, A., 2019. Multilevel fine-scale diversity challenges the 'cryptic species' concept. Sci. Rep. 9, 6732. https://doi.org/10.1038/s41598-019-42297-5

Kück, P., Meusemann, K., 2010. FASconCAT: Convenient handling of data matrices. Mol. Phylogenet. Evol. 56, 1115-1118. https://doi.org/10.1016/j.ympev.2010.04.024

Kück, P., Struck, T.H., 2014. BaCoCa - A heuristic software tool for the parallel assessment of sequence biases in hundreds of gene and taxon partitions. Mol. Phylogenet. Evol. 70, 94-98. https://doi.org/10.1016/j.ympev.2013.09.011

Kumar, S., Stecher, G., Tamura, K., 2016. MEGA7: Molecular Evolutionary Genetics Analysis Version 7.0 for Bigger Datasets. Mol. Biol. Evol. 33, 1870-1874. https://doi.org/10.1093/molbev/msw054

Lassance, J.M., Svensson, G.P., Kozlov, M. V., Francke, W., Löfstedt, C., 2019. Pheromones and barcoding delimit boundaries between cryptic species in the primitive moth genus Eriocrania (Lepidoptera: Eriocraniidae). J. Chem. Ecol. 45, 429-439. https://doi.org/10.1007/s10886-01901076-2

Lê, S., Josse, J., Husson, F., 2008. FactoMineR: An R Package for Multivariate Analysis. J. Stat. Softw. 25, 253-8. https://doi.org/10.1016/j.envint.2008.06.007

Leasi, F., Norenburg, J.L., 2016. At least some meiofaunal species are not everywhere. Indication of geographic, ecological and geological barriers affecting the dispersion of species of Ototyphlonemertes (Nemertea, Hoplonemertea). Mol. Ecol. 25, 1381-1397. https://doi.org/10.1111/mec.13568

Leasi, F., Norenburg, J.L., 2014. The necessity of DNA taxonomy to reveal cryptic diversity and spatial distribution of meiofauna, with a focus on Nemertea. PLoS One 9.

https://doi.org/10.1371/journal.pone.0104385

Leasi, F., Tang, C.Q., De Smet, W.H., Fontaneto, D., 2013. Cryptic diversity with wide salinity tolerance in the putative euryhaline Testudinella clypeata (Rotifera, Monogononta). Zool. J. Linn. Soc. 168, 1728. https:// doi.org/10.1111/zoj.12020

Lee, C.E., Frost, B.W., 2002a. Morphological stasis in the Eurytemora affinis species complex (Copepoda: Temoridae). Hydrobiologia 480, 111-128. https://doi.org/10.1023/A:1021293203512

Lee, C.E., Frost, B.W., 2002b. Morphological stasis in the Eurytemora affinis species complex (Copepoda: Temoridae), in: Hydrobiologia. pp. 111-128. https://doi.org/10.1023/A:1021293203512

Lehmacher, C., Ramey-balci, P.A., Wolff, L.I., Fiege, D., 2016. Ultrastructural differences in presumed photoreceptive organs and molecular data as a means for species discrimination in Polygordius (Annelida, Protodriliformia , Polygordiidae). Org. Divers. Evol. https://doi.org/10.1007/s13127016-0272-8

Lenth, R. V., 2013. Lsmeans: Least-squares means. R package version 1.10-4. http://CRAN.R- 
José Cerca - On the Origin of Cryptic Species: Insights from the Stygocapitella species complex

project.org/package=lsmeans [WWW Document].

Lindholm, M., 2014. Morphologically conservative but physiologically diverse: The mode of stasis in Anostraca (Crustacea: Branchiopoda). Evol. Biol. 41, 503-507. https://doi.org/10.1007/s11692014-9283-6

Lins, L., Vanreusel, A., van Campenhout, J., Ingels, J., 2013. Selective settlement of deep-sea canyon nematodes after resuspension - an experimental approach. J. Exp. Mar. Bio. Ecol. 441, 110-116. https://doi.org/10.1016/j.jembe.2013.01.021

Lobo, J., Teixeira, M.A.L., Borges, L.M.S., Ferreira, M.S.G., Hollatz, C., Gomes, P.T., Sousa, R., Ravara, A., Costa, M.H., Costa, F.O., 2016. Starting a DNA barcode reference library for shallow water polychaetes from the southern European Atlantic coast. Mol. Ecol. Resour. 16, 298-313. https://doi.org/10.1111/1755-0998.12441

Losos, J.B., 2010. Adaptive Radiation, Ecological Opportunity, and Evolutionary Determinism. Am. Nat. 175, 623-639. https://doi.org/10.1086/652433

Lovén, S., 1844. Chaetoderma, ett nytt masksläkte n.g. Öfvers K. Vetenskaps-Akad Förh 1, 116+pl.112.

Maynard Smith, J., Burian, R., Kauffman, S., Alberch, P., Campbell, J., Goodwin, B., Lande, R., Raup, D., Wolpert, L., 1985. Developmental constraints and evolution. Q. Rev. Biol. 60, 265-287.

Mcfarlane, C.B.A., Drolet, D., BArbeau, M.A., Hamilton, D.J., Ollerhead, J., 2013. Dispersal of marine benthic invertebrates through ice rafting. Ecology 94, 250-256.

Mevenkamp, L., Van Campenhout, J., Vanreusel, A., 2016. Experimental evidence for selective settlement of meiofauna from two distinct environments after sediment suspension. J. Exp. Mar. Bio. Ecol. 474, 195-203. https://doi.org/10.1016/j.jembe.2015.10.005

Meyer-Wachsmuth, I., Curini Galletti, M., Jondelius, U., 2014. Hyper-cryptic marine meiofauna: Species complexes in Nemertodermatida. PLoS One 9. https://doi.org/10.1371/journal.pone.0107688

Múrias Dos Santos, A., Cabezas, M.P., Tavares, A.I., Xavier, R., Branco, M., 2015. TcsBU: A tool to extend TCS network layout and visualization. Bioinformatics 32, 627-628. https://doi.org/10.1093/bioinformatics/btv636

Nguyen, L.T., Schmidt, H.A., Von Haeseler, A., Minh, B.Q., 2015. IQ-TREE: A fast and effective stochastic algorithm for estimating maximum-likelihood phylogenies. Mol. Biol. Evol. 32, 268-274. https://doi.org/10.1093/molbev/msu300

Noodt, W., 1974. Anpassungen an interstielle Bedingungen: ein faktor in der evolution höherer taxa der Crustacea. Faun.-ökol. Mitt 4, 445-452.

Nordbotten, J.M., Stenseth, N.C., 2016. Asymmetric ecological conditions favor Red-Queen type of continued evolution over stasis. Proc. Natl. Acad. Sci. U. S. A. 113, 1847-52. https://doi.org/10.1073/pnas.1525395113

Novo, M., Almodóvar, A., Fernández, R., Trigo, D., Dáaz-Cosán, D.J., Giribet, G., 2012. Appearances can be deceptive: Different diversification patterns within a group of mediterranean earthworms (Oligochaeta, Hormogastridae). Mol. Ecol. 21, 3776-3793. https://doi.org/10.1111/j.1365294X.2012.05648.x

Novo, M., Almodóvar, A., Fernández, R., Trigo, D., Díaz Cosín, D.J., 2010. Cryptic speciation of hormogastrid earthworms revealed by mitochondrial and nuclear data. Mol. Phylogenet. Evol. 56, 507-512. https://doi.org/10.1016/j.ympev.2010.04.010

Palumbi, S., Martin, A., Romano, S., McMillan, W.O., Stice, L., Grabowski, G., 1991. The simple fool's guide to PCR, version 2 . 
José Cerca - On the Origin of Cryptic Species: Insights from the Stygocapitella species complex

Pante, E., Puillandre, N., Viricel, A., Arnaud-Haond, S., Aurelle, D., Castelin, M., Chenuil, A., Destombe, C., Forcioli, D., Valero, M., Viard, F., Samadi, S., 2015. Species are hypotheses: avoid connectivity assessments based on pillars of sand. Mol. Ecol. 24, 525-544. https://doi.org/10.1111/mec.13048

Paradis, E., Schliep, K., 2018. Ape 5.0: An environment for modern phylogenetics and evolutionary analyses in R. Bioinformatics 35, 526-528. https://doi.org/10.1093/bioinformatics/bty633

Paris, J.R., Stevens, J.R., Catchen, J.M., 2017. Lost in parameter space: a road map for stacks. Methods Ecol. Evol. 8, 1360-1373. https://doi.org/10.1111/2041-210X.12775

Payo, D.A., Leliaert, F., Verbruggen, H., D’hondt, S., Calumpong, H.P., De Clerck, O., 2013. Extensive cryptic species diversity and fine-scale endemism in the marine red alga Portieria in the Philippines. Proc. R. Soc. B Biol. Sci. 280, 20122660-20122660. https://doi.org/10.1098/rspb.2012.2660

Pérez-Ponce de León, G., Poulin, R., 2016. Taxonomic distribution of cryptic diversity among metazoans: not so homogeneous after all. Biol. Lett. 12, 20160371. https://doi.org/10.1098/rsbl.2016.0371

Peterson, B.K., Weber, J.N., Kay, E.H., Fisher, H.S., Hoekstra, H.E., 2012. Double digest RADseq: An inexpensive method for de novo SNP discovery and genotyping in model and non-model species. PLoS One 7. https://doi.org/10.1371/journal.pone.0037135

Pugh, P.J.A., 1996. Using Artificial Substrata to Monitor How Cryptofaunal Acari Colonize Littoral Algae on Sub-antarctic South Georgia. Acarologia 37, 188-200.

Purschke, G., Böggemann, M., Westheide, W., 2019. Parergodrilidae Reisinger, 1925, in: Purschke, G., Böggemann, M., Westheide, W. (Eds.), Annelida, Volume 1: Annelida Basal Groups and Pleistoannelida, Sedentaria. De Gruyter, Berlin, Boston, pp. 237-250.

R Core Team, 2013. R: A language and environment for statistical computing. R Foundation for Statistical Computing, Vienna, Austria. URL http://www.R-project.org/. [WWWW Document].

Radziejewska, T., Gruszka, P., Rokicka-Praxmajer, J., 2006. A home away from home: A meiobenthic assemblage in a ship's ballast water tank sediment. Oceanologia 48, 259-265.

Rambaut, A., Drummond, A.J., Suchard, M.A., 2007. Tracer v1.6.

Ramey-Balci, P., Fiege, D., Purschke, G., 2012. Polygordiida: Polygordiidae Czerniavsky, 1881., in: Handbook of Zoology. Berlin, Boston.

Ramey-Balc1, P., Fiege, D., Struck, T.H., 2018. Molecular phylogeny, morphology, and distribution of Polygordius (Polychaeta: Polygordiidae) in the Atlantic and Mediterranean. Mol. Phylogenet. Evol. 127, 919-930. https://doi.org/10.1016/j.ympev.2018.06.039

Reidenbach, K.R., Neafsey, D.E., Costantini, C., Sagnon, N., Simard, F., Ragland, G.J., Egan, S.P., Feder, J.L., Muskavitch, M.A.T., Besansky, N.J., 2012. Patterns of Genomic Differentiation between Ecologically Differentiated M and S Forms of Anopheles gambiae in West and Central Africa. Genome Biol. Evol. 4, 1202-1212. https://doi.org/10.1093/gbe/evs095

Riser, N.W., 1984. General observations on the intertidal interstitial fauna of New Zealand. Tane 30, 239_ 250.

Riser, N.W., 1980. The aberrant polychaete Stygocapitella from some American beaches. Wasmann J. Biol. $38,10-17$.

Rochette, N., Rivera-Colón, A., Catchen, J.M., 2019. Stacks2: Analytical methods for paired-end sequencing improve RADseq-based population genomics. Mol. Ecol. https://doi.org/10.1111/mec.15253

Rochette, N.C., Catchen, J.M., 2017. Deriving genotypes from RAD-seq short-read data using Stacks. Nat. 
José Cerca - On the Origin of Cryptic Species: Insights from the Stygocapitella species complex

Protoc. 12, 2640-2659. https://doi.org/10.1038/nprot.2017.123

Schmidt, H., Westheide, W., 2000. Are the meiofaunal polychaetes Hesionides arenaria and Stygocapitella subterranea true cosmopolitan species? - results of RAPD-PCR investigations. Zool. Scr. 29, 17-27. https://doi.org/doi:10.1046/j.1463-6409.2000.00026.x

Schratzberger, M., Rees, H.L., Boyd, S.E., 2000. Effects of simulated deposition of dredged material on structure of nematode assemblages - the role of burial. Mar. Biol. 136, 519-530.

Sheldon, P.R., 1996. Plus ça change - A model for stasis and evolution in different environments. Palaeogeogr. Palaeoclimatol. Palaeoecol. 127, 209-227. https://doi.org/10.1016/S00310182(96)00096-X

Singer, D., Kosakyan, A., Seppey, C.V.W., Pillonel, A., Fernández, L.D., Fontaneto, D., Mitchell, E.A.D., Lara, E., 2018. Environmental filtering and phylogenetic clustering correlate with the distribution patterns of cryptic protist species. Ecology 99, 904-914. https://doi.org/10.1002/ecy.2161

Smith, K.L., Harmon, L.J., Shoo, L.P., Melville, J., 2011. Evidence of constrained phenotypic evolution in a cryptic species complex of agamid lizards. Evolution (N. Y). 65, 976-992. https://doi.org/10.1111/j.1558-5646.2010.01211.x

Sterrer, W., 1973. Plate tectonics as a mechanism for dispersal and speciation in interstitial sand fauna. Netherlands J. Sea Res. 7, 200-222.

Struck, T.H., Cerca, J., 2019. Cryptic species and their Evolutionary significance. eLS 1-9. https://doi.org/10.1002/9780470015902.a0028292

Struck, T.H., Feder, J.L., Bendiksby, M., Birkeland, S., Cerca, J., Gusarov, V.I., Kistenich, S., Larsson, K.H., Liow, L.H., Nowak, M.D., Stedje, B., Bachmann, L., Dimitrov, D., 2018a. Finding evolutionary processes hidden in cryptic species. Trends Ecol. Evol. 1-11. https://doi.org/10.1016/j.tree.2017.11.007

Struck, T.H., Feder, J.L., Bendiksby, M., Birkeland, S., Cerca, J., Gusarov, V.I., Kistenich, S., Larsson, K.H.H., Liow, L.H., Nowak, M.D., Stedje, B., Bachmann, L., Dimitrov, D., 2018b. Cryptic Species More Than Terminological Chaos: A Reply to Heethoff. Trends Ecol. Evol. 33, 310-312. https://doi.org/10.1016/j.tree.2018.02.008

Struck, T.H., Golombek, A., Weigert, A., Franke, F.A., Westheide, W., Purschke, G., Bleidorn, C., Halanych, K.M., 2015. The evolution of annelids reveals two adaptive routes to the interstitial realm. Curr. Biol. 1-7. https://doi.org/10.1016/j.cub.2015.06.007

Struck, T.H., Koczula, J., Stateczny, D., Meyer, C., Purschke, G., 2017. Two new species in the annelid genus Stygocapitella (Orbiniida, Parergodrilidae) with comments on their biogeography. Zootaxa 4286, 301-332. https://doi.org/10.11646/zootaxa.4286.3.1

Struck, T.H., Westheide, W., Purschke, G., 2002. Progenesis in Eunicida ("Polychaeta," Annelida) Separate evolutionary events? Evidence from molecular data. Mol. Phylogenet. Evol. 25, 190-199. https://doi.org/10.1016/S1055-7903(02)00231-2

Surveswaran, S., Gowda, V., Sun, M., 2018. Using an integrated approach to identify cryptic species, divergence patterns and hybrid species in Asian ladies' tresses orchids (Spiranthes, Orchidaceae). Mol. Phylogenet. Evol. 124, 106-121. https://doi.org/10.1016/j.ympev.2018.02.025

Swift, H.F., Daglio, L.G., Dawson, M.N., 2016. Three routes to crypsis: stasis, convergence, and parallelism in the Mastigias species complex (Scyphozoa, Rhizostomeae). Mol. Phylogenet. Evol. 99, 103-115. https://doi.org/10.1016/j.ympev.2016.02.013

Teasdale, M., Vopel, K., Thistle, D., 2004. The timing of benthic copepod emergence. Limnol. Oceanogr. 49, 884-889. 
José Cerca - On the Origin of Cryptic Species: Insights from the Stygocapitella species complex

Thistle, D., 2003. Harpacticoid copepod emergence at a shelf site in summer and winter: Implications for hydrodynamic and mating hypotheses. Mar. Ecol. Prog. Ser. 248, 177-185.

https://doi.org/10.3354/meps248177

Thomas, M.C., Lana, P.C., 2011. A new look into the small-scale dispersal of free-living marine nematodes. Zoologia 28, 449-456. https://doi.org/10.1590/S1984-46702011000400006

Toews, D.P.L., Brelsford, A., 2012. The biogeography of mitochondrial and nuclear discordance in animals. Mol. Ecol. 21, 3907-3930. https://doi.org/10.1111/j.1365-294X.2012.05664.x

Tulchinsky, A.Y., Norenburg, J.L., Turbeville, J.M., 2012. Phylogeography of the marine interstitial nemertean Ototyphlonemertes parmula (Nemertea, Hoplonemertea) reveals cryptic diversity and high dispersal potential. Mar. Biol. 159, 661-674. https://doi.org/10.1007/s00227-011-1844-y

Ullberg, J., Ólafsson, E., 2003. Effects of biological disturbance by Monoporeia affinis (Amphipoda) on small-scale migration of marine nematodes in low-energy soft sediments. Mar. Biol. 143, 867-874. https://doi.org/10.1007/s00227-003-1139-z

Ullberg, Jörgen, Ólafsson, E., 2003. Free-living marine nematodes actively choose habitat when descending from the water column. Mar. Ecol. Prog. Ser. 250, 141-149. https://doi.org/10.3354/meps260141

van Oppen, M.J.H., Klerk, H., Olsen, J.L., Stam, W.T., 1996. Hidden diversity in marine algae: some examples of genetic variation below the species level. J. Mar. Biol. Assoc. United Kingdom 76, 239242.

Voje, K.L., Starrfelt, J., Liow, L.H., 2018. Model adequacy and microevolutionary explanations for stasis in the fossil record. Am. Nat. 191, 000-000. https://doi.org/10.1086/696265

Wada, S., Kameda, Y., Chiba, S., 2013. Long-term stasis and short-term divergence in the phenotypes of microsnails on oceanic islands. Mol. Ecol. 22, 4801-10. https://doi.org/10.1111/mec.12427

Wagner, G.P., Schwenk, K., 2000. Evolutionarily stable configurations: Functional integration and the evolution of phenotypic stability, in: Hecht, M.K., Macintyre, R.J., Clegg, M.T. (Eds.), Evolutionary Biology. Springer US, Boston, MA, pp. 155-217.

Warris, S., Schijlen, E., van de Geest, H., Vegesna, R., Hesselink, T., Te Lintel Hekkert, B., Sanchez Perez, G., Medvedev, P., Makova, K.D., de Ridder, D., 2018. Correcting palindromes in long reads after whole-genome amplification. BMC Genomics 19, 798. https://doi.org/10.1186/s12864-018-5164-1

Weber, A.A.-T., Stöhr, S., Chenuil, A., 2019. Species delimitation in the presence of strong incomplete lineage sorting and hybridization. Mol. Phylogenet. Evol. 131, 240218.

https://doi.org/10.1101/240218

Weiss, A.M., 2011. The evolution of evolution: reconciling the problem of stability. Evol. Biol. 38, 42-51. https://doi.org/10.1007/s11692-010-9099-y

Westheide, W., 2008. Polychaetes: Interstitial families., 2nd Editio. ed. Field Studies Council, Shrewsbury, $169 \mathrm{pp}$.

Westheide, W., 2005. Meiofauna geographic distribution: vicariance and dispersal. Meiofauna Mar. 14, 201-207.

Westheide, W., 1991. The meiofauna of the Galapagos: a review, in: Mathew J. James (Ed.), Galápagos Marine Invertebrates. Springler, New York, pp. 37-69.

Westheide, W., 1990. Polychaetes: interstitial families. Keys and notes for the identification of the species., Universal. ed. 
José Cerca - On the Origin of Cryptic Species: Insights from the Stygocapitella species complex

Westheide, W., 1987. Progenesis as a principle in meiofauna evolution. J. Nat. Hist. 21, 843-854. https://doi.org/10.1080/00222938700770501

Westheide, W., 1977. The geographical distribution of interstitial polychaetes. Mikrofauna Meeresb. 61, 287-302.

Westheide, W., Hass-Cordes, E., 2001. Molecular taxonomy: description of a cryptic Petitia species (Polychaeta : Syllidae) from the island of Mahe (Seychelles, Indian Ocean) using RAPD markers and ITS2 sequences. J. Zool. Syst. Evol. Res. 39, 103-111.

Westheide, W., Purschke, G., 1988. Organism processing, in: Higgins, R.P., Thiel, H. (Eds.), Introduction to the Study of Meiofauna. Smithsonian Institution Press, Washington, pp. 146-160.

Westheide, W., Rieger, R.M., 1987. Systematics of the amphiatlantic Micropbthalmus listensis species-group (Polychaeta: Hesionidae): facts and concepts for reconstruction of phylogeny and speciation. Zeitschrift für Zool. Syst. und Evol. 25, 12-39.

Wickham, H., 2016. ggplot2: Elegant Graphics for Data Analysis. Springer-Verlag, New York.

Worsaae, K., 2005. Phylogeny of Nerillidae (Polychaeta, Annelida) as inferred from combined 18S rDNA and morphological data. Cladistics 21, 143-162. https://doi.org/10.1111/j.1096-0031.2005.00058.x

Zanol, J., Halanych, K.M., Struck, T.H., Fauchald, K., 2010. Phylogeny of the bristle worm family Eunicidae (Eunicida, Annelida) and the phylogenetic utility of noncongruent 16S, COI and $18 \mathrm{~S}$ in combined analyses. Mol. Phylogenet. Evol. 55, 660-676.

https://doi.org/10.1016/j.ympev.2009.12.024

Zhang, J., Kapli, P., Pavlidis, P., Stamatakis, A., 2013. A general species delimitation method with applications to phylogenetic placements. Bioinformatics 29, 2869-2876.

https://doi.org/10.1093/bioinformatics/btt499

Zrzavý, J., Ř́ha, P., Piálek, L., Janouškovec, J., 2009. Phylogeny of Annelida (Lophotrochozoa): Totalevidence analysis of morphology and six genes. BMC Evol. Biol. 9, 1-14.

https://doi.org/10.1186/1471-2148-9-189 
José Cerca - On the Origin of Cryptic Species: Insights from the Stygocapitella species complex

Manuscripts 1-5 
José Cerca - On the Origin of Cryptic Species: Insights from the Stygocapitella species complex

\section{Manuscript 1}

Finding evolutionary processes hidden in cryptic species 


\section{Opinion \\ Finding Evolutionary Processes Hidden in Cryptic Species}

Torsten H. Struck, ${ }^{1, \star}$ Jeffrey L. Feder, ${ }^{2}$ Mika Bendiksby, ${ }^{1,3}$ Siri Birkeland, ${ }^{1}$ José Cerca, ${ }^{1}$ Vladimir I. Gusarov, ${ }^{1}$ Sonja Kistenich, ${ }^{1}$ Karl-Henrik Larsson, ${ }^{1}$ Lee Hsiang Liow, ${ }^{1,4}$ Michael D. Nowak, ${ }^{1}$ Brita Stedje, ${ }^{1}$ Lutz Bachmann, ${ }^{1}$ and Dimitar Dimitrov ${ }^{1,5}$

Cryptic species could represent a substantial fraction of biodiversity. However, inconsistent definitions and taxonomic treatment of cryptic species prevent informed estimates of their contribution to biodiversity and impede our understanding of their evolutionary and ecological significance. We propose a conceptual framework that recognizes cryptic species based on their low levels of phenotypic (morphological) disparity relative to their degree of genetic differentiation and divergence times as compared with non-cryptic species. We discuss how application of a more rigorous definition of cryptic species in taxonomic practice will lead to more accurate estimates of their prevalence in nature, better understanding of their distribution patterns on the tree of life, and increased abilities to resolve the processes underlying their evolution.

\section{Cryptic Species - Taxonomic Oddities or Biologically Relevant Entities?}

'Cryptic species' is a common and increasingly used term that refers to taxa that cannot readily be distinguished morphologically, yet evidence indicates they are on different evolutionary trajectories (Box 1). While researchers may not be able to visually recognize cryptic species as different species, the organisms can. Cryptic species are found on all major branches of the tree of life and probably represent a significant portion of undiscovered biodiversity [1-4]. As such, cryptic species might significantly add to our understanding of biodiversity, calling for increased conservation efforts [2,4-9]. Cryptic species are also important because they serve as an intellectual bridge connecting the study of taxonomy and phylogenetic pattern with ecosystems functioning, evolutionary processes, and macroevolutionary trends, including speciation, parallelism (see Glossary), convergence, and stasis. However, problems with the definition, among others the linkage to the species' taxonomic nomenclature history, and inconsistencies in the use of the term 'cryptic species' make it difficult to draw firm conclusions about their prevalence in nature and their implications for ecology and evolution.

Here, we discuss the general problem of defining cryptic species based on a literature survey that revealed the wide latitude in what researchers call cryptic species. Some authors have even suggested considering cryptic species as a temporary formalization problem of species delineation, rather than as a natural phenomenon [10]. To help mitigate the problem, we propose a more rigorous, multidimensional, and interdisciplinary approach for cryptic species. The approach focuses on better quantifying the extent of phenotypic disparity of taxa compared with the degree to which they have genetically diverged and exchanged genes (have evolved reproductive isolation). Standardizing the delineation of cryptic species will facilitate investigations into several outstanding questions concerning their biological significance (see Outstanding Questions). It will also lead to a better characterization and

\section{Highlights}

Current definitions of cryptic species are inconsistent and can lead to biased estimates of species diversity.

Cryptic species are often implied to represent taxa displaying low phenotypic disparity in relation to divergence time, but this relationship is usually not formally quantified.

Here we propose a quantitative framework, which provides a formal characterization of the intuitive concept of cryptic species.

The proposed framework facilitates understanding of evolutionary processes leading to and resulting from cryptic species and provides a basis for estimates and modeling of occurrences of cryptic species across taxa and environments.

The framework fosters a shift from pattern- to process-driven research concerning cryptic species.

${ }^{1}$ Natural History Museum, University of Oslo, 0318 Oslo, Norway ${ }^{2}$ Department of Biological Sciences, University of Notre Dame, Notre Dame, IN 46556, USA

${ }^{3}$ NTNU University Museum,

Norwegian University of Science and Technology, 7491 Trondheim, Norway ${ }^{4}$ Centre for Ecological \& Evolutionary Synthesis (CEES), Department of Biosciences, University of Oslo, 0316 Oslo, Norway

${ }^{5}$ Current address: Center for Macroecology, Evolution and Climate, Natural History Museum of Denmark, University of Copenhagen, Copenhagen, Denmark 


\section{Trends in Ecology \& Evolution}

\section{Box 1. Cryptic Species: History and Definitions}

The English clergyman William Derham reported cryptic species in the avian genus Phylloscopus as early as 1718 [58]. Cryptic species have thus been recognized for several hundred years. In the last few decades the number of publications referring to cryptic species has increased dramatically (Figure IA), likely due to more researchers in the field and the increased use of genetic methods to distinguish taxa (Figure IB and, for example, [5,10]). However, criteria used in the literature to designate taxa as cryptic have often been vague and nonuniform. In the few cases where an explicit definition has been stated, the wording is often similar to that of Bickford et al. [5]: Cryptic species are 'two or more distinct species that are erroneously classified (and hidden) under one species name'. This taxonomy-based definition is often elaborated upon to highlight that cryptic species are morphologically indistinguishable [5,35]. Others have included an additional requirement of genetic divergence or distinctiveness between cryptic species ([15]; see Supplemental Table S4 online for a list of definitions). How genetically diverged populations must be to be considered cryptic species is usually not specified, but one can assume that this will be of the same magnitude as for non-cryptic species (e.g., a certain barcode gap) [5]. By contrast, several definitions seem to mostly follow trends and concepts related to the research topic of the paper or field of the researcher. For example, in speciation research, definitions tend to highlight reproductive isolation and the biological species concept [37]. Mayr [59], for instance, defined cryptic species as 'morphologically similar or identical natural populations that are reproductively isolated'. Other terms such as 'semi-cryptic', 'pseudo-cryptic', 'sibling', and 'hypercryptic' indicating different degrees of 'crypticity' have also been proposed [10], complicating the debate of the biological relevance of cryptic species. Regardless, our literature survey (Box 2) revealed that many cryptic species have been defined based on molecular data and taxonomic history, with little regard for actually quantifying morphological disparity.
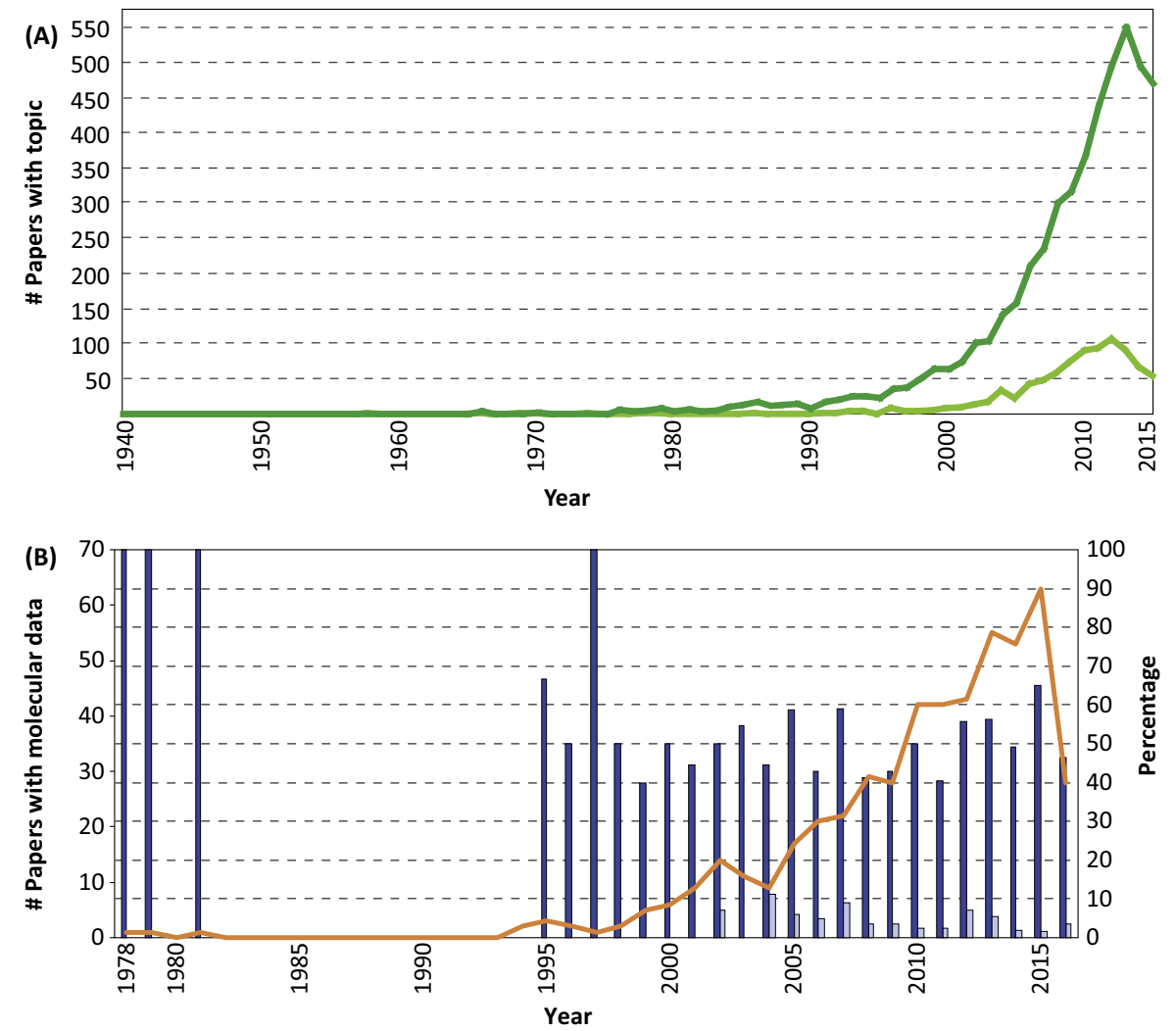

Trends in Ecology \& Evolution

Figure I. Scientific Publications on the Subject of Cryptic Species since 1940. (A) The number of papers found with the search term 'cryptic speci”' (dark green line) and 'cryptic speciation' (light green). Of note is the marked increase in publications since 1990. (B) The number of papers included in the literature survey (Box 2) that included molecular data in the study (orange line) is also increasing similar to the overall numbers in A. Dark blue bars indicate the percentages of molecular papers that analyzed more than one genetic marker and light blue bars indicate studies based on genomic data. Note that these percentages are not increasing through time.
${ }^{*}$ Correspondence:

t.h.struck@nhm.uio.no (T.. Struck). 


\section{Trends in Ecology \& Evolution}

\section{CellPress}

understanding of the different types of cryptic species, from recently diverged to phylogenetically distant taxa. In doing so, conclusions concerning (i) evolutionary parallelism, convergence, and stasis; (ii) the role that cryptic species play in ecosystem functioning; and (iii) factors initiating and contributing to speciation can be more confidently accepted.

\section{The Problem of Definition in Theory and Practice}

Cryptic species have generated both taxonomic and evolutionary ambiguity. A frequently cited definition of cryptic species [5] describes them as two or more distinct species that were earlier classified as one. Hence, cryptic species are defined based only on their taxonomic nomenclature history. However, this is unsatisfactory because various biological factors or taxonomic artifacts might result in erroneous species lumping. In addition, it offers no guidance for how morphologically similar or by how many characters species should differ to be considered as cryptic. Moreover, one of the longest and most contentious debates in evolution concerns what constitutes a species. If biologists cannot even agree on what to consider different species, then how can we reach consensus on what represents cryptic species?

Our literature survey of 606 studies indicates that the lack of philosophical clarity translates into a serious empirical problem in the operational designation of cryptic species (Box 2, see Supplemental Material and Tables S1-S4 online). For example, 47\% of them, even though claiming cryptic species status for taxa, presented no phenotypic data, while $25.3 \%$ reported at least one trait differing between cryptic species. Thus, morphological similarity is subjectively evaluated and rarely quantified to address how similar cryptic species are [11-13]. Moreover, nonmorphological phenotypes, such as behavior, were seldom considered (Box 2). In this regard, cryptic species designation was often pattern driven with a focus on morphological characters discriminating taxa and little else. When several phenotypic traits were assessed, analyses seldom extended to species beyond the focal cryptic species. This is relevant because rates of morphological evolution for cryptic 'ingroup' taxa should be substantially (statistically) reduced compared with non-cryptic taxa to be considered cryptic.

\section{Box 2. Characteristics of Published Studies of Cryptic Species}

Our literature survey was based on the ISI Web of Science 'Life Sciences' database, using the search term 'cryptic speci*' for 'Topic' on June 17, 2016. The initial search returned 6002 entries (see Supplemental Table S1 online), from which approximately $15 \%$ were discarded as they were either not research papers, did not use our search term in a taxonomic context, or were not written in English. From the remaining publications, 606 were randomly chosen (see Supplemental Table S2 online) and assessed according to (i) how cryptic species were defined; (ii) whether and which types of genetic markers were scored; (iii) the analyses conducted; and (iv) the conclusions that could be drawn (see Supplemental Material and Table S3 online for additional details). For these 606 papers, $72.4 \%$ involved animals, $7.5 \%$ plants, $10.1 \%$ fungi, and $6.4 \%$ other groups, including protozoans. Only $14.0 \%$ of the studies explicitly referred to a specific definition of the term 'cryptic species', indicating the degree of subjectivity in the field. Moreover, according to the Code, species - including cryptic ones - are only valid when accompanied by a formal description. However, only $19.3 \%$ of the studies provided such formal descriptions. This low number can be indicative of uncertainties of the species status, ignorance of taxonomic practice, or that the species were formally described elsewhere.

The majority of studies (84.2\%) provided molecular data, but many (35.5\%) used only one locus. In comparison, only $42.7 \%$ of the studies included explicit analyses of morphological data and $23.9 \%$ other phenotypic traits. Overall, $56.6 \%$ of the studies targeted mitochondrial loci and $52.6 \%$ nuclear markers. Of the studies using nuclear data, $48.3 \%$ contained results for multiple loci. Very few studies included genome-scale data (3.1\%). The relative numbers of studies with more than one marker or genomic data have not increased in recent years (see Figure IB in Box 1). Most studies (73.9\%) provided an estimate of genetic divergence of some form (e.g., distance estimates or phylograms) and included congeneric species in the comparison (61.4\%). However, only $16.0 \%$ of the studies applied genetic dating methods to estimate the time to the MRCA and only $4.3 \%$ used fossil calibrations.

\section{Glossary}

Convergence: independent evolution of a derived character state between taxa from different ancestral traits [41].

Disparity: the morphological or phenotypic difference between taxa [60].

\section{Most recent common ancestor}

(MRCA): the last ancestor genetically shared by a group of individuals. Parallelism: independent evolution of a character state in different taxa from a similar and shared ancestral trait [41].

Pattern-driven research: research focusing on the detection of biological patterns in empirical data. Process-driven research: research focusing on the underlying processes generating observed patterns. Stasis: retention of the same ancestral character state over an extended period [41].

Symplesiomorphy: character state of the MRCA present in descendant taxa. 


\section{Trends in Ecology \& Evolution}

The genetic data provided in the surveyed studies were also of limited utility in cryptic species delineation. Of the 606 studies, 35.5\% based cryptic species designation on only a single molecular marker, most often from the plastid or mitochondrion, and lacked information on phenotypic disparity. Only $15.4 \%$ of the surveyed studies combined different types of molecular markers with morphological and/or other phenotypic data, and compared genetic divergence of the cryptic taxa with other congeneric non-cryptic species. The results show that there is remarkable inconsistency in the operational designation of 'cryptic species' $[5,14,15]$ and huge variation in the applied analytical rigor [11,16-21]. Taxonomic practice for identifying cryptic species thus requires attention if the term is to be useful for comparative studies.

With recent advances in high-throughput DNA sequencing, visualization/microscopy, and statistical analytical tools, there are no technological or methodological impediments restricting higher standards in the empirical investigation of cryptic species [22,23]. This is important as informed estimates of species diversity and speciation rates are crucial for understanding evolutionary processes and ecosystem functioning, and for developing effective conservation strategies and sustainable usage of ecosystem services [2,4-9]. Cryptic species are one component of these estimates. Estimates of cryptic biodiversity based on vague definitions are of little help and, like undiscovered species or lack of species lists, will be counterproductive. For example, in ecology and conservation research, cryptic species are usually taken at face value based on the original reports. In particular, studies investigating patterns of cryptic species distribution across habitats, taxonomic groups, or life history strategies are often based on meta-analyses [5,24-28]. Given the shaky foundation in which cryptic species appear to be subjectively defined, it is difficult to place much confidence in the conclusions drawn from such meta-analyses. Sympatric cryptic species might, for example, contradict the ecological paradigm of competitive exclusion $[29,30]$, but based on the current state it remains difficult to decide whether this is specifically or generally true. Similar considerations apply to studies of parallelism, convergence, and stasis. Without better standardization of the designation of cryptic species including details about phenotypic variation, levels of genomic differentiation, and divergence times, it remains difficult to make proper inference about evolutionary processes. Such standardizations as suggested herein will substantially improve comparability across lineages, as taxonomic nomenclature traditions are replaced with studies quantifying variation in a similar manner within and across groups.

\section{The Conceptual Framework}

Accurate pattern- and process-driven research on cryptic species is possible. However, to accomplish this, a sound and consistent foundation for defining cryptic species is needed. We do not pretend to solve the cryptic species problem completely here, but offer a conceptual framework to alleviate the problem by combining phenotypic disparity and genetic divergence. The latter serving as a proxy for reduced gene flow and an estimate of the time since divergence from the most recent common ancestor (MRCA). By doing so, we emphasize the importance of reduced gene flow between taxa and the establishment of reproductive isolation between sexually reproducing populations relative to the extent to which they have changed in morphological and other phenotypic characters. As we explain later, this approach facilitates studies of parallelism, convergence, and speciation. The proposed framework provides a yardstick for the standardization of cryptic species descriptions without getting too entangled in the issue of species concepts. We concentrate on sexually reproducing organisms, for which a metric of gene flow and divergence time versus phenotypic disparity are key considerations.

Our conceptual framework highlights two important elements for defining cryptic species (Figure 1). First, species have to be distinguishable, for example, as statistically separable 


\section{Trends in Ecology \& Evolution}

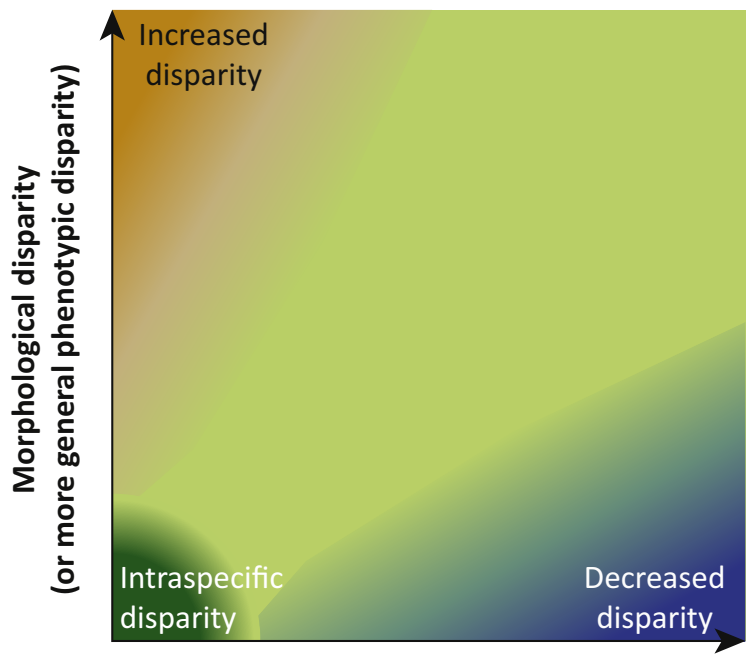

Divergence time or genetic divergence

Trends in Ecology \& Evolution

Figure 1. Our Conceptual Framework for Cryptic Species. The $x$ axis represents the time of divergence between taxa since their most recent common ancestor approximated by genetic divergence. The $y$ axis represents phenotypic (morphological) disparity. Intraspecific variation (polymorphism) within a taxon is depicted by the dark green area in the lower left corner of the figure. The null hypothesis is that morphological disparity between taxa relative to sister species should increase proportionately with divergence time (light green area). However, morphological disparity could increase at a significantly higher rate than the null expectation due to, for example, a recent adaptive radiation (orange area in the upper left corner of the figure). Alternatively, morphological disparity could also be substantially lower than expected over time (blue area in the lower right corner), the hallmark of cryptic species.

and diverged genotypic clusters of individuals (reflecting reproductive isolation) that do not form diagnostic morphological clusters. Although estimates of reproductive isolation in nature are only truly possible for taxa that geographically overlap, data from laboratory crosses, when technically feasible, and other information can be used to help gauge the level of gene flow and reproductive isolation. One major consideration is the time point when diverging populations are considered as being genetically and reproductively distinguishable species (e.g., [31-35]), as this will affect conclusions about recently diverged species. Consequently, cases, where populations exhibit sufficient gene flow to not cluster distinctively using methods like STRUCTURE or genetic network analyses, should be considered, if at all, as races or ecotypes [34,36], rather than cryptic species [37].

Second, the temporal dimension of cryptic species should be recognized by their showing of statistically lower degrees of phenotypic (or more specifically morphological) disparity than noncryptic relatives given similar divergence time estimates from their MRCAs (Figure 1). By placing morphological disparity directly in relation to time (genetic divergence), recognition of cryptic species can become divorced from taxonomic nomenclature traditions based on the numbers of previously recognized species (e.g., lumpers vs. splitters), and debates about levels of 'crypticity' [10] more nuanced.

Although these two components of defining cryptic species seem self-evident, they are seldom adequately performed to allow for quantitative comparisons. For example, the temporal dimension is frequently ignored [38-40] and, of the 606 studies in our survey, only 3.3\% and $4.5 \%$ of the reported divergence events could confidently be regarded as young or old, 


\section{Trends in Ecology \& Evolution}

respectively. For accurately determining genetic divergence, genome-wide sequence data are highly preferred for any group of taxa. However, very few studies applied genome-scale data (Box 2) $[18,23]$. Uniparentally inherited markers, such as the mitochondrial cytochrome oxidase subunit I gene (COI) - the target marker for DNA barcoding in animals - do not provide a comprehensive assessment of gene flow and reproductive isolation. There are several examples of high genetic divergence in $\mathrm{COI}$ that reflect deep population structure rather than species differences [18].

More importantly, to identify and quantify species that are cryptic from those that are not, detailed information about phenotypic disparity has to be related to genetic divergence, levels of gene flow, and reproductive isolation. Therefore, population to species-level morphological variation needs to be explicitly quantified to measure morphological disparity among cryptic species and their relatives as, for example, done in [41-43]. Available species descriptions can provide a good starting point for such morphological comparisons, providing information on both discrete and continuous characters. Depending on the data, appropriate methods for the quantification of morphological variation are available, including geometric morphometrics [44], landmark-free approaches such as the generalized Procrustes surface analysis [45], and multivariate analysis like nonmetric multidimensional scaling [46]. These methods and clustering, principal component, and discriminant function analyses should be employed to assess whether populations can be statistically distinguished from another or not. In addition, statistical tools like disparity through time plots [47] allow for testing whether morphological disparity between hypothesized cryptic taxa is significantly lower than expected given a null random walk expectation of drift. Tests of rate variation (e.g., variance ratio test) among hypothesized cryptic and non-cryptic lineages can also indicate whether morphological and other phenotypic traits (e.g., those related to behavior, life history, and physiology) deviate significantly from neutral expectation to statistically support cryptic species status for taxa. Note that hybridization has the potential to complicate analyses by reducing phenotypic disparity below levels seen for allopatric or completely reproductively isolated populations. However, it can generally be expected that proportional reductions in the level of genomic divergence would compensate for this and help to maintain the standardization of cryptic species delineation.

Currently, there are no studies that adhere completely to the proposed framework. There are several examples, however, where most of the requirements are fulfilled, for example, in studies of unicellular eukaryotes [48], cnidarians [41], annelids [42], mollusks [43], vertebrates [46], and plants [49]. However, the primary focus of these studies has been to find diagnostic characters. Phenotypic disparity was usually not cast in relation to other non-cryptic taxa and/or genetic divergence. One reason for this is that detailed examination of phenotypic and genetic variation in a comparative context, as proposed here, is time-consuming and not practical for projects whose primary focus is not the delineation of cryptic species (but then they should also refrain from assigning them). However, accurate rather than quick science is what should be aimed for, and when conducted properly, the proposed framework will provide the rigor to move beyond suggestive evidence to full and more standardized recognition of cryptic species.

\section{Evolutionary Processes and Cryptic Species}

Given a standardized and more accurate characterization of cryptic species, it is possible to examine their ecological and evolutionary implications in greater depth and with more confidence. For example, one question of interest is the extent to which cryptic species represent recently diverged versus more distantly related taxa. Other questions concerning evolutionary processes like parallelism, stasis, and convergence that are often considered primarily with respect to single traits [50-52] could also be extended to investigate whole phenotypes by 


\section{Trends in Ecology \& Evolution}

more robust analysis of cryptic species. In this regard, underlying selective regimes might be expected to be more pronounced or generally constrained to impact the entire (or nearly entire) suite of phenotypic traits [53], to which the term 'cryptic speciation' has been misleadingly applied in recent years (Figure IA). We examine these questions in the following section.

\section{Recent Divergence}

In this case, hypothesized cryptic species are sister taxa or members of a species complex with short divergence times, which are too recent for substantial morphological differences to accumulate $[37,54,55]$ (Figure 2A). In many of these instances, the rate of accumulation of morphological disparity might actually not differ significantly from older non-cryptic species (Figure 2A). In speciation research it is commonly assumed that in the early stages of speciation selection acts largely on physiological, immunological, reproductive, or behavioral traits rather than on morphology $[16,17,19]$. Hence, for very young species, similarity in morphology might not be unexpected and it could take additional time to visually observe differences between taxa [10]. However, recently diverged taxa showing significantly lower rates of morphological disparity might be constrained by stabilizing selection and represent early stages of stasis.

\section{Parallelism}

Cryptic species that evolved by parallelism are not sister taxa, but are phylogenetically separated from each other to such a degree that their similarity can no longer be considered symplesiomorphic, but rather independently evolved from morphologically similar ancestors (Figure 2B). In comparison to more closely related and younger non-cryptic species, morphological disparity changes less as the cryptic species evolve from one similar morphotype to another similar one (Figure 2B). However, if the evolution of the new morphotype in one lineage precedes the other lineage in time, morphological disparity will first increase and then decrease again (similar to the plot in Figure 2C). Regardless, ancestral character state reconstructions are important to distinguish between recent divergence, convergence, or parallelism, and to assess and test rates of morphological change. Swift et al. [41], for example, showed that similar morphologies for lake species evolved by parallelism in closely related scyphozoan species. Confirmation of parallelism begs the question of whether similar morphotypes evolved due to intrinsic (e.g., developmental or genetic constraints) or extrinsic factors (e.g., deterministic environmental pressures) confining the available morphospace to only one selectively advantageous solution.

\section{Convergence}

In this case, cryptic species are not closely related and their morphological similarity results from independent evolution of morphologically dissimilar ancestors (Figure 2C). At early stages of divergence, cryptic and non-cryptic species pairs are expected to show similar rates of morphological differentiation. However, at some point in time the cryptic species pairs would begin to converge morphologically (Figure 2C). Convergence as a mechanism for cryptic species is rare, but has been reported in the deep sea [56]. In contrast to parallelism, intrinsic factors are expected to be less important for convergence than extrinsic ones, as convergent evolution is assumed to have started from different genetic and developmental backgrounds.

\section{Stasis}

Under stasis, cryptic species are sister taxa or members of a complex that retain a high degree of morphological similarity over extended periods (Figure 2D). Hence, symplesiomorphies prevail for millions of years, and significantly longer than expected by random drift. For example, 


\section{Trends in Ecology \& Evolution}

(A)

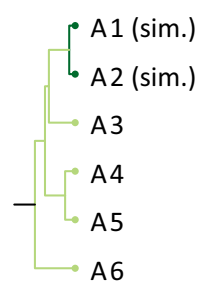

(B)

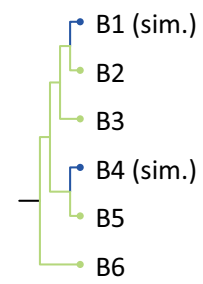

(C)
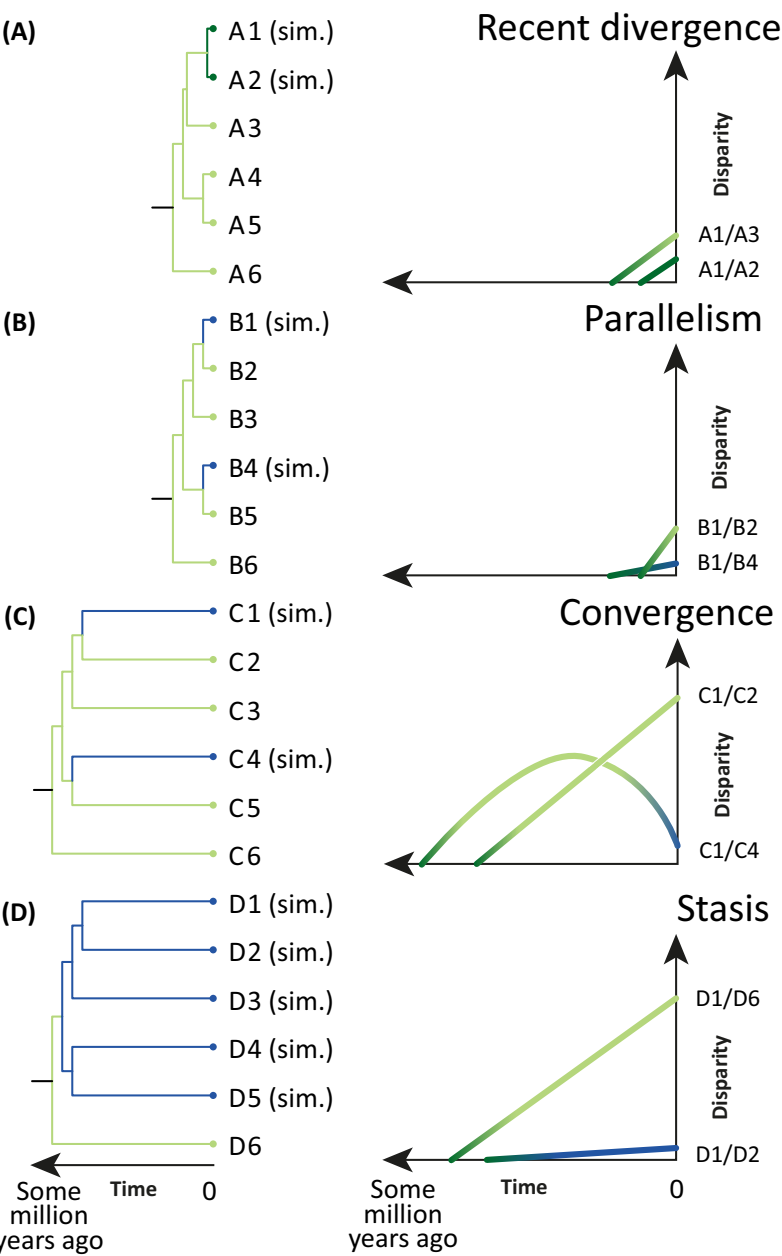

$$
\text { years ago }
$$

years ago

Trends in Ecology \& Evolution

Figure 2. Expected Signatures of Four Evolutionary Processes That Can Lead to Cryptic Species. The colors of lines in phylogenies and graphs correspond to the different areas in Figure 1 and species with similar (identical) morphotypes denoted with 'sim.'. Panels on the left denote the phylogenetic relationships among taxa, while the panels to the right depict the evolution of morphological disparity through time for pairs of cryptic and non-cryptic species (e.g., A1/ A2 vs. A1/A3). (A) Recent divergence: cryptic species are very closely related and only recently diverged from each other. However, the rate of morphological disparity is not necessarily substantially different from that for non-cryptic species and, as such, these taxa may not actually represent cryptic species. The supposed cryptic species might indeed be on a trajectory, which with time might lead from the borders of the dark green area to the light green area in Figure 1. (B) Parallelism: the cryptic species are not very closely related to each other and the rate of morphological disparity for noncryptic species is much greater than that for cryptic species. While disparity between non-cryptic species evolved from the dark to the light green area, disparity between the cryptic species progressed into the dark blue area of Figure 1. (C) Convergence: the cryptic species are also not closely related to each other. Initially, morphological disparity for cryptic species can change in a manner similar to that for the non-cryptic species pair. However, at some point, morphological disparity decreases for the cryptic species, while continuing to increase between non-cryptic taxa. Hence, in their past the level of disparity of the cryptic species was first within the light green area of Figure 1, but then evolved toward the dark blue area associated with the low level of disparity of cryptic species. (D) Stasis: the cryptic species are closely related to each other or are part of a species complex and diverged a long time ago. In comparison with non-cryptic species, the rate of morphological change is substantially reduced, as cryptic species evolved from the dark green to the dark blue area of Figure 1. 


\section{Trends in Ecology \& Evolution}

one cryptic complex of annelid worms has been shown to display little morphological variation over tens of millions of years [42]. The lack of morphological diversification could result from low standing genetic variation and/or developmental constraints on the morphospace [5,57]. It is also possible that the ecology of taxa showing stasis has remained relatively constant through time and strong stabilizing selection has retained a common, shared morphology. This raises the question of whether cryptic species tend to be ecological generalists versus specialists, the answer to which might hinge on how common adaptation to different environments underlies speciation and depends on morphological change.

\section{Concluding Remarks}

Current research practices regarding cryptic species require change. There is much insight to be gained by standardizing and increasing the rigor in the way that cryptic species are defined and studied. Current practices, however, do not allow firm conclusions to be made concerning the number and significance of cryptic species in nature or the evolutionary processes associated with them. Indeed, given the results of our literature survey it is likely that many reported cryptic species should not be considered as such. Consequently, there is a need for careful re-analyses of many proposed cryptic species complexes with more rigorous criteria to better assess their true prevalence in nature. We propose an interdisciplinary approach that involves combining comprehensive data on genomic and phenotypic traits to statistically test for significant differences in rates of phenotypic disparity (e.g., morphological disparity) between cryptic and non-cryptic species. This approach will standardize the designation of cryptic species in the literature for taxonomic and comparative purposes; eliminate the history of taxonomic nomenclature as a consideration; and enable meta-analyses based on comparisons involving taxa categorized as displaying similar versus differing levels of disparity, periods of divergence, and degree of reproductive isolation. Adopting the approaches we advocate will provide a more sound basis for policy making in conservation biology and make it possible to address a number of questions involving evolutionary parallelism, convergence, and stasis associated with cryptic species (see Outstanding Questions), helping to reveal the biological meaning hidden in cryptic species. Conducted across lineages, general principles and accurate predictions, for example, to what extent cryptic species prevail in certain groups or are affected by climate change can be deduced.

\section{Acknowledgments}

We would like to thank the Natural History Museum of the University of Oslo for funding and Sarah Samadi and Gene Hunt for discussion on the subject. We also appreciate the comments of three anonymous reviewers. This is NHM Evolutionary Genomics Lab contribution No. 7.

\section{Supplemental Information}

Supplemental information associated with this article can be found online at https://doi.org/10.1016/j.tree.2017.11.007.

\section{References}

1. Jörger, K. and Schrödl, M. (2013) How to describe a cryptic species? Practical challenges of molecular taxonomy. Front. Zool. 10, 59

2. Pante, E. et al. (2015) Species are hypotheses: avoid connectivity assessments based on pillars of sand. Mol. Ecol. 24, 525-544

3. Loxdale, H.D. et al. (2016) Known knowns and unknowns in biology. Biol. J. Linn. Soc. 117, 386-398

4. Nygren, A. (2013) Cryptic polychaete diversity: a review. Zool. Scr. 43, 172-183

5. Bickford, D. et al. (2007) Cryptic species as a window on diversity and conservation. Trends Ecol. Evol. 22, 148-155
6. Alizon, S. et al. (2008) Competition between cryptic species explains variations in rates of lineage evolution. Proc. Natl. Acad.

7. Nadler, S.A. and Perez-Ponce de Leon, G. (2011) Integrating molecular and morphological approaches for characterizing parasite cryptic species: implications for parasitology. Parasitology 138, 1688-1709

8. Boykin, L.M. et al. (2012) Species delimitation and global biosecurity. Evol. Bioinform. 8, 1-37

9. Krug, P.J. et al. (2013) Integrative species delimitation in photosynthetic sea slugs reveals twenty candidate species in three nominal taxa studied for drug discovery, plastid symbiosis or biological control. Mol. Phylogenet. Evol. 69, 1101-1119 Sci. U. S. A. 105, 12382-12386

\section{Outstanding Questions}

What is the general relationship between phenotypic disparity and reproductive isolation and genetic divergence through time?

Do thresholds of phenotypic disparity indicating the presence of cryptic species exist or is the relationship a continuum, with taxa lying in the tail of the distribution warranting cryptic species status?

Which methods for assessing phenotypic disparity and their significance are most universally applicable and most powerful with regard to discerning cryptic species?

Is it possible to establish an a priori best-practice strategy for defining cryptic species across a broad range of diverse taxonomic groups?

Are there more cryptic species in certain branches of the tree of life, among taxa with certain life histories (e.g., generalists vs. specialists), or in certain habitats?

Which cryptic species are the results of recent speciation, parallelism, convergence, or stasis, and how common are they?

What are the relevant intrinsic and extrinsic factors affecting morphological evolution and to what degree do they affect the phenotypic landscape of cryptic species? 


\section{Trends in Ecology \& Evolution}

10. Korshunova, T. et al. (2017) External diversity is restrained by internal conservatism: new nudibranch mollusc contributes to the cryptic species problem. Zool. Scr. 46, 683-692

11. Wu, Z.-Z. et al. (2014) Sequence analysis of mitochondrial ND1 gene can reveal the genetic structure and origin of Bactrocera dorsalis s.s. BMC Evol. Biol. 14, 55

12. Sanchez, G. et al. (2016) Evaluation of the $5^{\prime}$ end of the $16 \mathrm{~S}$ rRNA gene as a DNA barcode marker for the Cephalopoda. Fish Sci. 82, 279-288

13. Schmidt, R.C. et al. (2016) High levels of endemism in suckermouth catfishes (Mochokidae: Chiloglanis) from the Upper Guinean forests of West Africa. Mol. Phylogenet. Evol. 100, 199-205

14. Wang, Y. et al. (2014) Morphology, molecular genetics, and bioacoustics support two new sympatric Xenophrys toads (Amphibia: Anura: Megophryidae) in Southeast China. PLoS One 9, e93075

15. Van Campenhout, J. et al. (2016) Transcription, signaling receptor activity, oxidative phosphorylation, and fatty acid metabolism mediate the presence of closely related species in distinct intertidal and cold-seep habitats. Genome Biol. Evol. 8, 51-69

16. Bensch, S. et al. (2004) Linkage between nuclear and mitochondrial DNA sequences in avian malaria parasites: multiple cases of cryptic speciation? Evolution 58, 1617-1621

17. Damm, S. et al. (2010) An integrative approach to species discovery in odonates: from character-based DNA barcoding to ecology. Mol. Ecol. 19, 3881-3893

18. Giska, I. et al. (2015) Deeply divergent sympatric mitochondrial lineages of the earthworm Lumbricus rubellus are not reproductively isolated. BMC Evol. Biol. 15, 217

19. Derycke, S. et al. (2016) Coexisting cryptic species of the Litoditis marina complex (Nematoda) show differential resource use and have distinct microbiomes with high intraspecific variability. Mol. Ecol. 25, 2093-2110

20. Karanovic, T. et al. (2016) Cryptic species or inadequate taxonomy? Implementation of 2D geometric morphometrics based on integumental organs as landmarks for delimitation and description of copepod taxa. Syst. Biol. 65, 304-327

21. Razkin, O. et al. (2017) Species delimitation for cryptic species complexes: case study of Pyramidula (Gastropoda, Pulmonata). Zool. Scr. 46, 55-72

22. Richards, S. (2015) It's more than stamp collecting: how genome sequencing can unify biological research. Trends Genet. 31 $411-421$

23. Janzen, D.H. et al. (2017) Nuclear genomes distinguish cryptic species suggested by their DNA barcodes and ecology. Proc. Natl. Acad. Sci. U. S. A. 114, 8313-8318

24. Pfenninger, M. and Schwenk, K. (2007) Cryptic animal species are homogeneously distributed among taxa and biogeographical regions. BMC Evol. Biol. 7, 121

25. Poulin, R. and Pérez-Ponce de León, G. (2017) Global analysis reveals that cryptic diversity is linked with habitat but not mode of life. J. Evol. Biol. 30, 641-649

26. Perez-Ponce de Leon, G. and Poulin, R. (2016) Taxonomic distribution of cryptic diversity among metazoans: not so homogeneous after all. Biol. Lett. 12, 20160371

27. Adams, M. et al. (2014) Global biodiversity assessment and hyper-cryptic species complexes: more than one species of elephant in the room? Syst. Biol. 63, 518-533

28. Skoracka, A. et al. (2015) Cryptic speciation in the Acari: a function of species lifestyles or our ability to separate species? Exp. Appl. Acarol. 67, 165-182

29. Chesson, P. (1991) A need for niches. Trends Ecol. Evol. 6, 26-28

30. Gause, G.F. (1934) The Struggle for Existence, Hafner Publishing Company

31. Norris, R.D. and Hull, P.M. (2012) The temporal dimension of marine speciation. Evol. Ecol. 26, 393-415

32. The Marie Curie SPECIATION Network (2012) What do we need to know about speciation? Trends Ecol. Evol. 27, 27-39
33. De Queiroz, K. (2007) Species concepts and species delimitation. Syst. Biol. 56, 879-886

34. Roux, C. et al. (2016) Shedding light on the grey zone of speciation along a continuum of genomic divergence. PLOS Biol. 14, e2000234

35. Bernardo, J. et al. (2011) A critical appraisal of the meaning and diagnosability of cryptic evolutionary diversity, and its implications for conservation in the face of climate change. In Climate Change, Ecology and Systematics (Hodkinson, T.R., ed.), pp. 380-438, Cambridge University Press

36. Sukumaran, J. and Knowles, L.L. (2017) Multispecies coalescent delimits structure, not species. Proc. Natl. Acad. Sci. U. S. A. 114 1607-1612

37. Reidenbach, K.R. et al. (2012) Patterns of genomic differentiation between ecologically differentiated M and S forms of Anopheles gambiae in West and Central Africa. Genome Biol. Evol. 4 1202-1212

38. Harder, A.M. et al. (2016) Diversity and distribution within the sea spider genus Pallenopsis (Chelicerata: Pycnogonida) in the Western Antarctic as revealed by mitochondrial DNA. Polar Biol. 39, 677-688

39. Sauvage, T. et al. (2016) A metabarcoding framework for facilitated survey of endolithic phototrophs with tufA. BMC Ecol. 16, 8

40. Williams, J.T. and Viviani, J. (2016) Pseudogramma polyacantha complex (Serranidae, tribe Grammistini): DNA barcoding results lead to the discovery of three cryptic species, including two new species from French Polynesia. Zootaxa 4111, 15

41. Swift, H.F. et al. (2016) Three routes to crypsis: stasis, convergence, and parallelism in the Mastigias species complex (Scyphozoa, Rhizostomeae). Mol. Phylogenet. Evol. 99, 103-115

42. Struck, T.H. et al. (2017) Two new species in the annelid genus Stygocapitella (Orbiniida, Parergodrilidae) with comments on their biogeography. Zootaxa 4286, 301-332

43. Wada, S. et al. (2013) Long-term stasis and short-term diver gence in the phenotypes of microsnails on oceanic islands. $\mathrm{Mol}$. Ecol. 22, 4801-4810

44. Bookstein, F.L. (1991) Morphometric Tools for Landmark Data. Geometry and Biology, Cambridge University Press

45. Pomidor, B.J. et al. (2016) A landmark-free method for threedimensional shape analysis. PLoS One 11, e0150368

46. Shirley, M.H. et al. (2014) Rigorous approaches to species delimitation have significant implications for African crocodilian systematics and conservation. Proc. Biol. Sci. 281, 20132483

47. Harmon, L.J. et al. (2003) Tempo and mode of evolutionary radiation in iguanian lizards. Science 301, 961-964

48. Krenek, S. et al. (2015) New Paramecium (Ciliophora, Oligohymenophorea) congeners shape our view on its biodiversity. Org. Divers. Evol. 15, 215-233

49. Vigalondo, B. et al. (2015) Unmasking cryptic species: morphometric and phylogenetic analyses of the Ibero-North African Linaria incarnata complex. Bot. J. Linn. Soc. 177, 395-417

50. Huang, S. et al. (2015) Convergence, divergence, and parallelism in marine biodiversity trends: integrating present-day and fossil data. Proc. Natl. Acad. Sci. U. S. A. 112, 4903-4908

51. Hunt, G. et al. (2015) Simple versus complex models of trait evolution and stasis as a response to environmental change. Proc. Natl. Acad. Sci. U. S. A. 112, 4885-4890

52. Ralph, P.L. and Coop, G. (2015) Convergent evolution during local adaptation to patchy landscapes. PLoS Genet. 11, e1005630

53. Futuyma, D.J. (2010) Evolutionary constraint and ecological consequences. Evolution 64, 1865-1884

54. Knowlton, N. (1993) Sibling species in the sea. Annu. Rev. Ecol. Syst. 24, 189-216

55. Gustafsson, A.L.S. et al. (2014) Genetics of cryptic speciation within an arctic mustard, Draba nivalis. PLoS One 9, e93834

56. Vrijenhoek, R.C. (2009) Cryptic species, phenotypic plasticity, and complex life histories: assessing deep-sea faunal diversity 


\section{Trends in Ecology \& Evolution}

with molecular markers. Deep Sea Res. Part II Top. Stud. Oceanogr. 56, 1713-1723

57. Appeltans, W. et al. (2012) The magnitude of global marine species diversity. Curr. Biol. 22, 2189-2202

58. Winker, K. (2005) Sibling species were first recognized by William Derham (1718). Auk 122, 706-707
59. Mayr, E. (1970) Populations, Species, and Evolution: An Abridgment of Animal Species and Evolution, Belknap Press of Harvard University Press

60. Wills, M.A. et al. (2001) Morphological disparity: a primer. In Fossils, Phylogeny, and Form: An Analytical Approach (Adrain, J.M., ed.), pp. 55-144, Kluwer Academic/Plenum Publishers 
José Cerca - On the Origin of Cryptic Species: Insights from the Stygocapitella species complex

\section{Supplementary data for manuscript 1}

The supplementary data for this manuscript can be found online in https://doi.org/10.1016/j.tree.2017.11.007 
José Cerca - On the Origin of Cryptic Species: Insights from the Stygocapitella species complex

\section{Manuscript 2}

Marine connectivity dynamics: clarifying cosmopolitan distributions of marine interstitial invertebrates and the meiofauna paradox 


\title{
Marine connectivity dynamics: clarifying cosmopolitan distributions of marine interstitial invertebrates and the meiofauna paradox
}

\author{
José Cerca ${ }^{1}\left[\right.$ - Günter Purschke ${ }^{2}$ Torsten H. Struck ${ }^{1}$
}

Received: 25 September 2017 / Accepted: 2 July 2018

(c) Springer-Verlag GmbH Germany, part of Springer Nature 2018

\begin{abstract}
Many interstitial species were first described as widely distributed, often cosmopolitan or amphi-oceanic, contrasting with descriptions of a sedentary life style and the general absence of pelagic dispersal stages. These inconsistencies became known as the "meiofauna paradox". In this review, we present a literature review investigating these inconsistencies and address the assumptions of the meiofauna paradox. We break the paradox down to two aspects including species distribution and dispersal. Focusing on distribution, we demonstrate that wide distributions are seldom given and false records likely stem from biological phenomena like stasis or recent speciation. These phenomena account for morphological similarity, ultimately represented by the pronounced occurrence of cryptic species with restricted distribution ranges. Additionally, taxonomic artefacts such as the erroneous application of taxonomic keys contribute to the report of widely distributed species. Considering dispersal, we point out the mismatch between traditional assumptions of meiofaunal sedentarism and growing experimental and empirical evidences suggesting higher dispersal potential. These evidences include not only indications for dispersal by pelagic stages, but further consider ecological and life-history traits in shaping distribution ranges. We conclude that the meiofauna paradox sensu stricto most likely does not exist and provide a roadmap for future research, suggesting a focus on morphological similarity and marine connectivity. Meiofaunal research should concentrate on evolutionary factors resulting in morphological similarity, improving the taxonomic resolution of species complexes and conducting more sophisticated experimental experiments to meiofaunal dispersal. In all cases, meiofaunal research will benefit from highthroughput sequencing such as genome scanning approaches, metagenomics or metatranscriptomics.
\end{abstract}

\section{Introduction}

Few environments would seem more homogeneous and lifeless than an extensive area of sandy sediments. Accordingly, the interstitium or the space between the sand grains was overlooked as a potential source of biological diversity for

Responsible Editor: S. Connell.

Reviewed by Undisclosed experts.

Electronic supplementary material The online version of this article (https://doi.org/10.1007/s00227-018-3383-2) contains supplementary material, which is available to authorized users.

José Cerca

jose.cerca@gmail.com

1 Frontiers of Evolutionary Zoology Research Group, Natural History Museum, University of Oslo, Oslo, Norway

2 Fachbereich Biologie/Chemie, Universität Osnabrück, Osnabrück, Germany a long time. The first meiofaunal organisms were described in the 19th century (e.g., Lovén 1844; Dujardin 1851) and while this diversity was recognized it was not further considered (Giard 1904). The first naturalist who began to uncover this diversity was Remane (1933). He studied the fauna of the so-called coastal groundwater of sandy beaches by digging holes into the sand and collecting floating animals from the accumulating brackish ground water using small landing nets- the common collecting method in those times. Thus, owing to an error-prone sampling strategy, meiofauna organisms were assumed to only inhabit the groundwater. Later on, evidence accumulated suggesting that these organisms in fact inhabited the spaces between the sand grains in areas of moist sand and that the coastal groundwater itself only contained very few individuals, if any. These new findings initiated an intensive phase in meiofaunal research, leading to thousands of publications in many fields of zoology (for reviews see Higgins and Thiel 1988; Giere 2009) and uncovered an astonishing diversity, whereby a mere teaspoon of marine sediment or of sand in a beach could yield a 
bewildering biological diversity (Fig. 1; Fenchel 1978; Giere 2009). Today we know that marine sediments anywhere in between the supralittoral to the deep sea are inhabited by a considerably diverse meiofaunal diversity. The fauna living in the space between sand grains is also generally known as interstitial fauna (Giere 2009), and the terms meiofauna and interstitial species are often used synonymously in the literature. In this way, although officially classified by sizes passing through sieves ranging from $22-44 \mu \mathrm{m}$ to $500-1000 \mu \mathrm{m}$ (Giere 2009; Zeppilli et al. 2015), these ranges represent just a convenient (yet arbitrary) definition. For instance, several interstitial species are considerably larger than $1000 \mu \mathrm{m}$ such as the well-known annelid Polygordius and hence, strictly spoken, do not belong to the meiofauna. On the other hand, some meiofauna are not strictly interstitial, as they burrow through the sediment due to the small open space available. They are nonetheless referred to as interstitial (e.g., some Nerillidae species (Annelida) living in muddy sediments). In this review, we concentrate on both marine meiofaunal and interstitial species and consider them synonymously as it is the case in the literature. In the following sections, we refer to them as meiofauna for consistency with the literature, where this term is more commonly used than interstitial.

Out of the approximately 34 metazoan phyla, 23 have at least some meiofaunal representatives, and four, namely Gnathostomulida, Kinorhyncha, Loricifera and Micrognathozoa, are exclusively meiofaunal (Fenchel 1978; Sands et al. 2008; Giere 2009; Zeppilli et al. 2015; Figs. 1a-r, 2), but so far, no marine representatives are known for Micrognathozoa. Meiofauna is usually considered as an independent ecological evolutionary unit (Giere 2009) and its adaptation to the spatially restricted interstitial environment is the group's most prominent and distinctive feature. Indeed, the meiofauna's unique type of form has been coined the "meiofaunal syndrome" (Brenzinger et al. 2013; Jörger et al. 2014), which is generally characterized by an uniform, elongated, worm-like body shape and usually simplified external organization with adhesive structures for attachment to sand grains (Giere 2009). Hence generally, on first sight their appearance seems often to be that of simple-bodied organisms.

The combination of small size and the absence of pelagic larvae in some species have led meiofauna biologists to describe these organisms as sedentary (i.e., limited dispersal capacities) and to suggest severely restricted distribution rates (Giere 2009). At the same time, a substantial number of species were described with distribution ranges encompassing whole continental coast lines, amphi-oceanic, or even cosmopolitan (Sterrer 1973; Gerlach 1977; Westheide 1977, 2005; Westheide and Rieger 1987; Giere 2009; Jörger et al. 2012). This contradiction became known as the "meiofauna paradox" (Sterrer 1973; Gerlach 1977; Westheide 1977; Boeckner et al. 2009; Giere 2009). Several alternative dispersal hypotheses were suggested to account for this inconsistency. For instance, dispersal models considering either stepping stone, or infrequent occasions of long-distance transport of a few individuals (such as birdmediated dispersal, rafting on drifting material or recent accidental dispersal by humans) were suggested (Gerlach 1977; Westheide 1991; von Soosten et al. 1998). Alternatively, vicariance-driven hypotheses focusing on Pangea's division and subsequent continental drift (i.e., successive vicariance events) have been put forward to account for the meiofauna paradox (Sterrer 1973). Part of this discussion considers vicariance and dispersal as mutually exclusive. Following Giere (2009), this paradox can be summarized into two questions: (1) "Why are so many meiofaunal taxa from distant areas so similar despite their limited means of dispersal?" and (2) "How can meiofauna have bridged oceans and occupied distinct shores in the absence of large populations and competitive propagative stages?".

In this review of the meiofauna paradox, we present a literature survey focusing on distribution ranges and meiofaunal dispersal and how these contribute to a modern understanding of this paradox. We consider marine metazoan species from beach shores to the deep sea. Additionally, we consider the distribution range of a species as the geographic area within which a species has genetic cohesiveness is maintained by gene flow (Klautau et al. 1999). Having Giere's (2009) questions in mind, we address this paradox into two slightly more general questions both relating to dispersal and distribution range of meiofauna species. First, we ask: "Why are so many meiofaunal taxa from distant areas so similar?". We reframe this question considering that morphological similarity across wide distribution ranges might not hinge only upon dispersal capacity, but also on other biological phenomena, as well as non-biological aspects like observers' bias. By tackling morphological similarity, we discuss that distribution ranges are often inflated as a synergetic by-product of taxonomic challenges, sampling biases and the occurrence of cryptic species. Second, we address "How can meiofauna have bridged oceans and occupied distinct shores in the absence of propagative stages?". Meiofaunal population sizes are largely unknown as their local distribution is often patchy and possibly subject to enhanced extinction-colonization dynamics (i.e., metapopulation dynamics) and hence it cannot be determined if large populations are present. Moreover, dispersal over long distances does not depend exclusively on large populations. Considering this question, we address the disparity between historical literature on dispersal and vicariance and the recent experimental and empirical evidence of meiofauna dispersal. We demonstrate that both our empirical and experimental knowledge about meiofauna dispersal is still relatively limited for general conclusions. Based on these evidences, we conclude that the meiofauna paradox in the strict sense most 

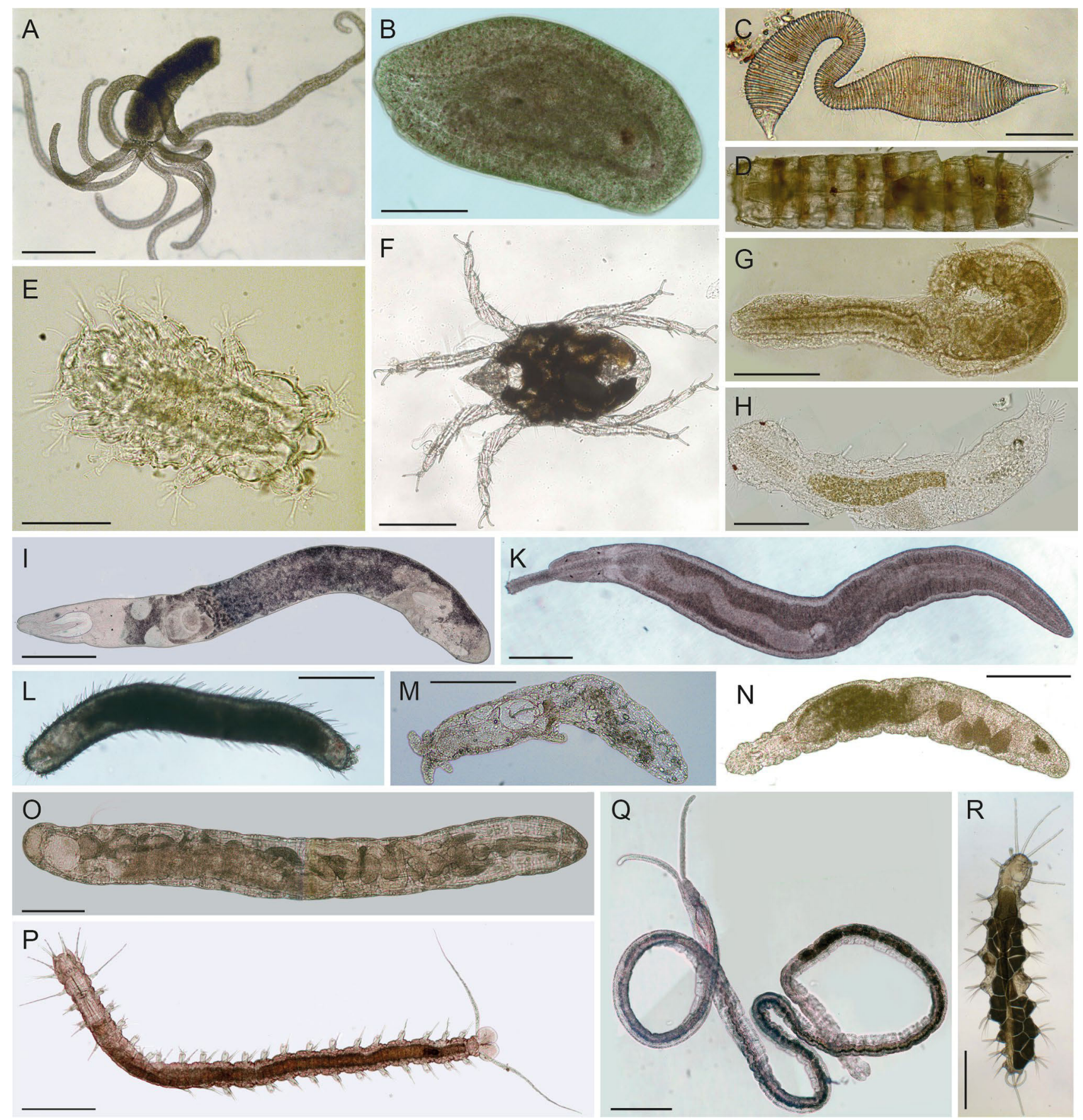

Fig. 1 Meiofauna diversity shown by examples from a variety of higher taxa. Light micrographs from living animals, originals. a Cnidaria: Halammohydra octopodides Remane, 1927 (Hydrozoa). b Xenacoelomorpha: Symsagittifera roscoffensis (Graff, 1891) (Acoela, Bursalia). c-f Ecdysozoa. c Metepsilonema hagmeieri (Stauffer, 1924) (Cycloneuralia, Nematoda, Chromadorea). d An undetermined Kinorhynch (Cycloneuralia, Kinorhyncha). e Batillipes mirus Richters, 1909 (Tardigrada, Heterotardigrada). f Halacarellus subterraneus Schulz, 1933 (Arthropoda, Chelicerata, Acari). g-r Spiralia. g Turbanella sp. Schultze, 1853 (Gastrotricha, Macrodasyida). h Dactylopodola baltica (Remane, 1926) (Gastrotricha, Macrodasyida). i Proschizorhynchus gullmarensis Karling, 1950 (Platyhelminthes,
Neoophora, Kalyptorhynchia). k-r Lophotrochozoa. Prostomatella arenicola Friedrich, 1935 (Nemertini, Monostylifera). $\mathbf{l}$ undescribed Pholidoskepia. m Microhedyle glandulifera (Kowalevsky, 1901) (Mollusca, Gastropoda, Opisthobranchia). n Trilobodrilus axi Westheide, 1967 (Annelida, Sedentaria, Orbiniidae). o Stygocapitella subterranea Knöllner, 1934 (Annelida, Sedentaria, Orbiniidae). p Hesionides arenaria Friedrich, 1937 (Annelida, Errantia, Phyllodocida). q Protodriloides chaetifer (Remane, 1926) (Annelida, Errantia, Protodrilida). $\mathbf{r}$ Nerilla antennata Schmidt, 1848 (Annelida, Errantia). Scales in $\mathbf{a}, \mathbf{b}, \mathbf{f}, \mathbf{i}, \mathbf{m}, \mathbf{n}, \mathbf{o}, \mathbf{p} 250 \mu \mathrm{m}$; in $\mathbf{c}, \mathbf{d}, \mathbf{e}, \mathbf{g}, \mathbf{h}, \mathbf{l} 100 \mu \mathrm{m}$; in $\mathbf{k}$, q, $\mathbf{r} 500 \mu \mathrm{m}$ 
Fig. 2 Meiofaunal representatives across the animal phylogeny. Clades with meiofaunal representatives are highlighted in green. Exclusively meiofaunal clades are highlighted in yellow. Tree topology reproduced after Dunn et al. (2014)

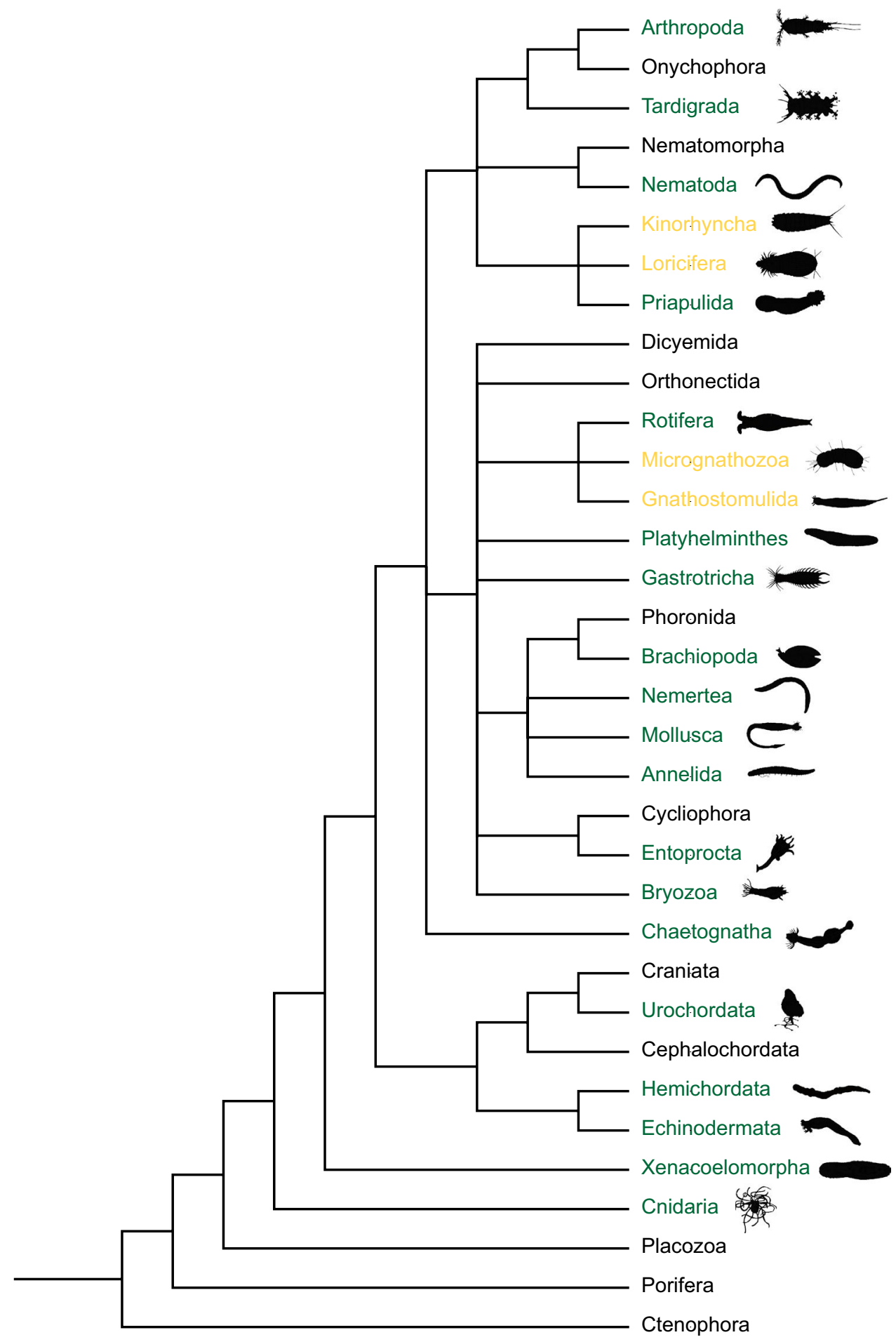

likely does not exist and provide a roadmap for future directions of research on meiofauna dispersal and distribution.

\section{Literature survey: description and general results}

On June 6, 2018 we searched ISI Web of Science using the following combination of search terms: "(meiofauna* OR meiobenth* OR Gnathostomulida OR Kinorhyncha OR Loricifera) AND (marine OR Atlantic OR Pacific OR 
Indian OR Arctic OR Antarctic OR "Southern Ocean") AND (molecular OR cryptic OR paradox OR taxonom* OR dispersal OR phylo* OR biogeo* OR distribut*)". This search yielded 1069 publications. While we were unable to obtain 16 articles mostly due to the presence of paywalls and indexed meeting abstracts on ISI, we assessed the abstracts and results of the remaining 1053 (Supplementary Table 1). After this preliminary assessment, we excluded 302 publications because they did not focus on marine, metazoan or meiofaunal organisms or they were not written in English (for a through list of criteria see Supplementary Material). The remaining 751 contributions were scored for taxa, discipline, use of molecular or morphological methods, occurrence of cryptic and pseudocryptic species, geographical location including depth and habitat description, as well as if there was an experimental approach to test for meiofauna dispersal (for a complete list of scoring criteria see Supplementary Material).

The majority of the captured papers corresponded to taxonomic (235) or ecological studies (488; Table 1). Surprisingly, only seven studies focused specifically on the evolution of meiofaunal species (one on Annelida, two on Arthropoda, two on Kinorhyncha, one on Nematoda and one on Platyhelminthes; Table 1). Herein, we consider publications as "evolution" in the strict sense of the discipline "Evolutionary Biology" by focusing on understanding evolutionary processes such as speciation and on population genetics (i.e., performing explicit tests of demography and gene flow). This allows us to differentiate these publications from studies of other disciplines like taxonomy or systematics also addressing the species' evolution. Similarly, development (12 papers), physiology (15) and palaeontology (4) were also underrepresented. Most studies focused on nematodes and arthropods, primarily harpacticoid copepods (Table 1), reflecting their overall abundance and their availability as ecological indicators (407 out of 447 papers dealing with nematodes and 303 out of 357 of the studies on Arthropoda were ecological studies).

The uneven representation of arthropods and nematodes is not as pronounced in taxonomy or biogeography as in ecological research. In total, 48 studies focused on biogeography and 235 focused on taxonomy (Table 1). This survey was unable to detect any taxonomic or biogeographical study focusing on Chaetognatha or Echinodermata. Most taxonomic studies were performed in Arthropoda (46), Gastrotricha (50), Kinorhyncha (26), Nematoda (39), Platyhelminthes (23) and Tardigrada (21). Studies in biogeography included Annelida (7), Arthropoda (15), Chordata (1), Cnidaria (2), Gastrotricha (6), Gnathostomulida (1), Kinorhyncha (3), Loricifera (1), Mollusca (2), Nematoda (13), Nemertea (3), Platyhelminthes (5), Rotifera (3), Tardigrada (2) and Xenacoelomorpha (2). Most of the studies were performed around European (327), North and Central American (157) and Asian (141) coastlines and waters. Coastlines and waters adjacent to Antarctica (35), Africa (54), Australia (51) and South America (75) are less well-studied. Regarding depth distribution, 359 papers focused on shallow-subtidal to a depth of 200 metres, 212 focused on the deep sea (below $200 \mathrm{~m}$ ) and 202 intertidal areas. In contrast, only 14 studies investigated species from supralittoral areas (Table 1).

Most taxonomical studies described new species (135), while relatively few, often only implicitly, reported on the distribution range of meiofaunal species (Table 2). Of these, 40 papers reported an unchanged distribution of some of the focal taxa (accounting for 82 species), 25 reported an increase of distribution (including 112 species) and 22 a decrease of distribution (including 160 species). Only 27 papers used a combination of molecular and morphological data to assess species delineation (Todaro et al. 1996, 2014; Curini-Galletti and Puccinelli 1998; Westheide and HassCordes 2001; De Ley et al. 2005; Sterrer and Sørensen 2006; Suatoni et al. 2006; Leasi and Todaro 2007; Casu et al. 2009; Neusser et al. 2011; Eder et al. 2011; Kieneke et al. 2012; Jörger et al. 2012; Leasi et al. 2013; Jörger and Schrödl 2013; Rundell and Leander 2014; Di Domenico et al. 2014; Kånneby et al. 2015; Smythe 2015; Dal Zotto 2015; Kajihara et al. 2015; Karanovic et al. 2016; Sánchez et al. 2016; Tanaka and Ohtsuka 2016; Kieneke and Nikoukar 2017; Atherton and Jondelius 2018; Van Steenkiste et al. 2018), with 16 additional papers using molecular data only (Schmidt and Westheide 2000; Bhadury et al. 2006; Todaro et al. 2006; Casu and Curini-Galletti 2006; Bik et al. 2010, 2012; Gruber-Vodicka et al. 2011; Tulchinsky et al. 2012; Baldrighi et al. 2013; Yamasaki et al. 2014; Fonseca et al. 2014; Leasi and Norenburg 2014, 2016; Meyer-Wachsmuth et al. 2014; Scarpa et al. 2015; Sahraean et al. 2017). Moreover, 14 papers mentioned difficulties in morphological characterization of the considered taxa (we refer to this issue as the low-morphology problem, see below). The occurrence of cryptic or pseudocryptic species was reported in 32 papers. Finally, only 25 studies performed experimental approaches to understand meiofaunal dispersal (Supplementary Table 2).

These results point to several trends in meiofaunal research. European, North and Central American and Asian coastlines are the most well-studied, potentially as an outcome from scientific traditions in these continents. Additionally, deep-sea research is well-represented with about $20 \%$ of the works focusing on this area, yet the majority of works was still done on shallow-subtidal areas (from low-water line to 200 metres depth). Taxonomy and ecology are the most vibrant disciplines in meiofaunal works. The potential skew towards Nematoda and Arthropoda research is most pronounced in ecological surveys, while Gastrotricha, Kinorhyncha, Platyhelminthes, and Tardigrada are especially well-represented in taxonomy. Moreover, 


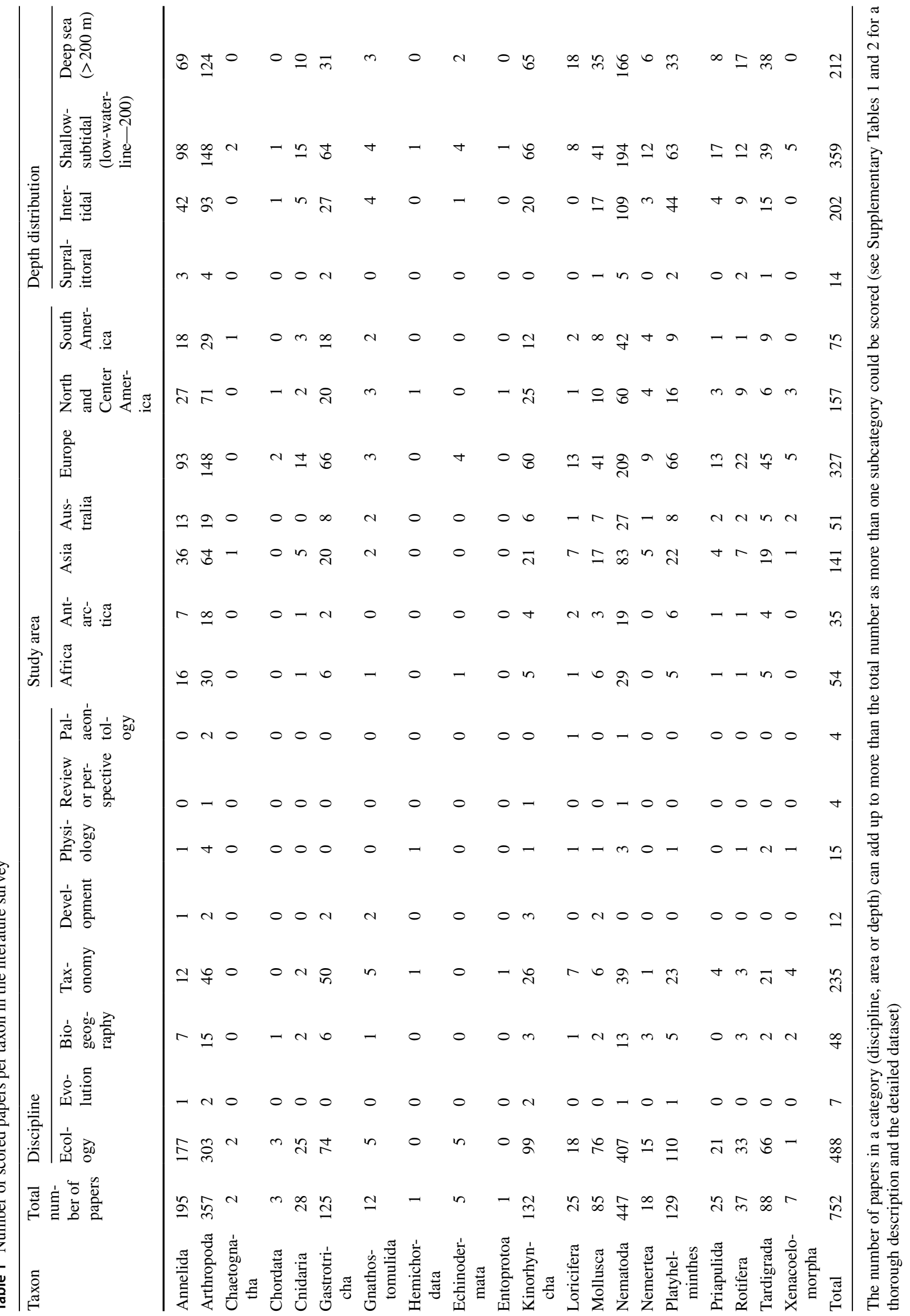




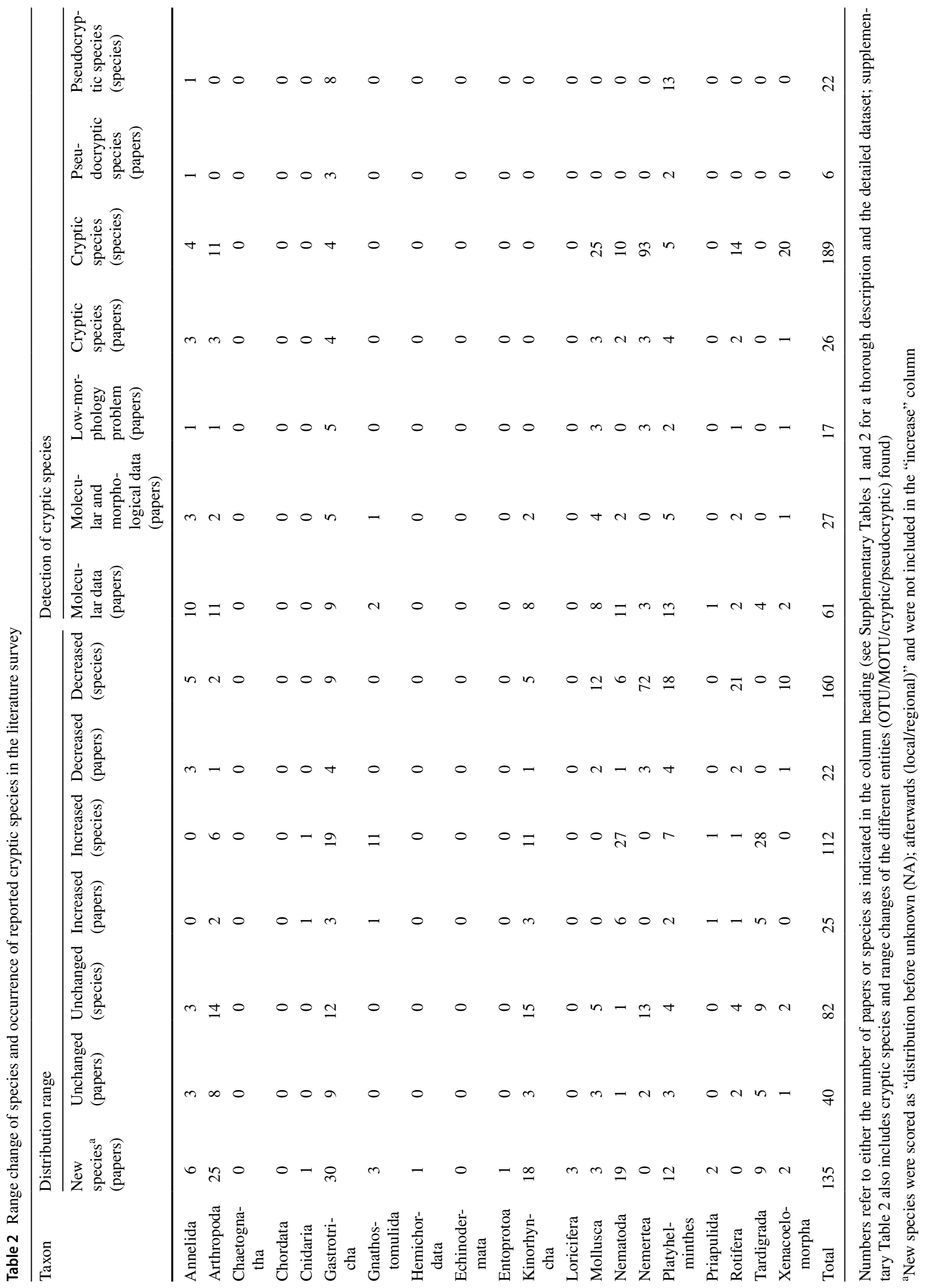


the surveyed ecological studies did not at all focus on or address geographical distribution as well as the meiofauna paradox. Hence, these studies were irrelevant with respect to the subject of this review. Given the considered studies, the incidence of cryptic species seems high and few studies have explicitly focused on uncovering the distribution of meiofaunal species (Table 2). In the next section, we discuss some of these results more exhaustively.

\section{"Why are so many meiofaunal taxa from distant areas so similar?"}

A considerably high number of meiofaunal species descriptions include distribution ranges encompassing whole continental coastlines, amphi-oceanic, or even cosmopolitan (Sterrer 1973; Gerlach 1977; Westheide 1977, 2005; Westheide and Rieger 1987; Giere 2009). While many of these descriptions were registered in early decades of meiofauna research, valuable insights provided by detailed morphological reanalyses and approaches such as molecular taxonomy and phylogeography clearly contrasted these records. Hence, Giere's first question (2009) of "similarity" between meiofaunal taxa is here considered based on biological phenomena resulting in the lack of accumulation of morphological differences between reproductively isolated species as well as difficulties in characterization and identification of meiofauna.

In recent years, the unveiling of "cryptic species" has become commonplace in meiofauna taxa, especially for those with presumed wide geographic ranges (Todaro et al. 1996; von Soosten et al. 1998; Schmidt and Westheide 2000; Rocha-Olivares et al. 2001; Casu and Curini-Galletti 2004; Derycke et al. 2005, 2006, 2012, 2013, 2016; Suatoni et al. 2006; De Meester et al. 2012; Tulchinsky et al. 2012; Jörger et al. 2012; Kieneke et al. 2012; Leasi and Norenburg 2016; Meyer-Wachsmuth et al. 2014; Van Campenhout et al. 2014; Leasi and Norenburg 2014). We consider cryptic species as species which demonstrate a high degree of molecular divergence, despite no recognizable morphological differentiation (Struck et al. 2018b). The presented literature survey showed that most of the studies using both molecular and morphological data detected either cryptic or pseudocryptic species (Table 2). In total, 189 cryptic species within Annelida, Arthropoda, Gastrotricha, Mollusca, Nematoda, Nemertea, Platyhelminthes, Rotifera and Xenacoelomorpha were recorded (Curini-Galletti and Puccinelli 1998; Schmidt and Westheide 2000; Rocha-Olivares et al. 2001; Westheide and Hass-Cordes 2001; Casu and Curini-Galletti 2006; Suatoni et al. 2006; Jouin-Toulmond and Gambi 2007; Casu et al. 2009; Leasi and Todaro 2009; Neusser et al. 2011; Kieneke et al. 2012; Tulchinsky et al. 2012; De Meester et al. 2012, 2015; Jörger et al. 2012; Leasi et al. 2013; Jörger and Schrödl 2013; Leasi and Norenburg 2014, 2016; MeyerWachsmuth et al. 2014; Karanovic et al. 2016; Muenter and Kieneke 2017; Sahraean et al. 2017; Kieneke and Nikoukar 2017; Van Steenkiste et al. 2018). Interestingly, the number of cryptic species is highly uneven across the studied taxa. While some studies captured an overwhelming number of cryptic species within established morphospecies or species complexes of Acoelomorpha, Nemertea, Mollusca and Rotifera (Suatoni et al. 2006; Jörger et al. 2012; Leasi et al. 2013; Leasi and Norenburg 2014, 2016; Meyer-Wachsmuth et al. 2014), other studies found only a few cryptic species within complexes of Annelida, Gastrotricha and Platyhelminthes (Schmidt and Westheide 2000; Casu et al. 2009; Kieneke et al. 2012; Kieneke and Nikoukar 2017) (Table 2). However, the uneven discovery of cryptic species does not necessarily reflect differences in occurrence of cryptic species between taxa, but rather the study's efforts. For example, the two papers addressing cryptic species in Nemertea (Leasi and Norenburg 2014, 2016) investigate several species complexes, while the ones on rotifers (Suatoni et al. 2006; Leasi et al. 2013) focus on a single species complex each (Supplementary Table 2).

Following the aforementioned definition of cryptic species, these can be considered as the result of phenomena such as recent speciation, parallelism, convergence and morphological stasis (Wada et al. 2013; Swift et al. 2016; Struck et al. 2018a, b). Several of these have been reported in meiofauna, highlighting these species as possible systems addressing questions of phenotypic conservation. Cases of recent speciation where morphological differentiation lags behind reproductive isolation have not yet been explicitly proposed in meiofauna, but numerous cases of cryptic species in our survey are likely to represent such cases (Casu et al. 2009; Jörger et al. 2012; Kieneke et al. 2012; Leasi et al. 2013; Leasi and Norenburg 2014, 2016; MeyerWachsmuth et al. 2014; Karanovic et al. 2016; Kieneke and Nikoukar 2017). In contrast, parallelism and convergent evolution have been explicitly suggested for some interstitial gastropods (Brenzinger et al. 2013; Jörger et al. 2014). Morphological stasis arises as the most common explicit explanation, possibly resulting from stabilizing selection on morphology due to the restricted space available in the interstitial environment (Sterrer 1973; Westheide and Rieger 1987; von Soosten et al. 1998; Schmidt and Westheide 2000; Hansen and Houle 2004; Futuyma 2010).

Although the pronounced phenotypic similarity opens venues in evolutionary research, the occurrence of cryptic species or overlooked diversity can also stem from the difficulty of characterizing and identifying meiofauna. For instance, the general paucity of traits with systematic value or inadequate morphological criteria poses a challenge to morphology-based taxonomic practices, eventually resulting in the synonymization of several species into a widely 
distributed, cosmopolitan species (Sterrer 1973). This problem has been framed as the "low-morphology problem" and has been thoroughly discussed in algae and corals where molecular approaches have been suggested as a more reliable approach to species delimitation (van Oppen et al. 1996; Klautau et al. 1999). Indeed, 17 studies applying explicitly molecular and/or morphological methods directly reported or discussed issues related to difficulties of morphologicaloriented practices in species delimitation in meiofauna. These studies spanned several phyla, including gastrotrichs, annelids, platyhelminths, nemerteans, molluscs, rotifers, xenacoelomorphs and arthropods (Todaro et al. 1996; Casu and Curini-Galletti 2006; Jouin-Toulmond and Gambi 2007; Casu et al. 2009; Leasi and Todaro 2009; Neusser et al. 2011; Tulchinsky et al. 2012; Jörger et al. 2012; Kieneke et al. 2012; Leasi et al. 2013; Jörger and Schrödl 2013; Meyer-Wachsmuth et al. 2014; Leasi and Norenburg 2014, 2016; Karanovic et al. 2016; Muenter and Kieneke 2017; Kieneke and Nikoukar 2017); Table 2).

Similarly, although the presence of cryptic species should be considered alongside with a strict sense of absence of morphological differentiation between species, re-analyses of meiofaunal species have uncovered overlooked morphological differences for some species (e.g., Pietsch and Westheide 1985; Westheide and Rieger 1987; Curini-Galletti and Puccinelli 1998; Rocha-Olivares et al. 2001; Casu and Curini-Galletti 2006; Jouin-Toulmond and Gambi 2007; Casu et al. 2009; Leasi and Todaro 2009; Garlitska et al. 2012; Muenter and Kieneke 2017; Struck et al. 2017). Species with morphological differences found after reinvestigations are usually named 'pseudocryptic species' (which can be considered as morphologically unrecognised species). For example, differences in setation were found within the cosmopolitan harpacticoid copepod Nannopus palustris (Arthropoda; Garlitska et al. 2012). Likewise, overlooked differences in the muscular system correspond with genetic differentiation within the Xenotrichula intermedia species complex (Gastrotricha; Leasi and Todaro 2009; Muenter and Kieneke 2017). For the annelid Stygocapitella subterranea complex slight differences in the chaetal composition of the first two chaetigers were re-evaluated as constituting species-specific differences in the light of molecular data and in contrast to previous conclusions (Struck et al. 2017).

The breadth of changes in distribution range before and after a study captured by the literature survey also revealed trends in meiofaunal research (Supplementary Table 3; Table 2). In the survey, we report 25 studies whose focus species increased its distribution (considering the established categories, including regional, amphi-oceanic and cosmopolitan). In common, none of these studies employed molecular approaches and relied explicitly or implicitly on morphological data only (e.g., Villora-Moreno and Grimaldi 1993; Chatterjee et al. 2000; Delogu et al. 2008; Dal Zotto and Todaro 2016;
Clausen 2000; Prasath et al. 2017). In sharp contrast, studies reporting a decrease of a range distribution generally employed molecular methods (Table 2; Supplementary Tables 2-3; e.g., Curini-Galletti and Puccinelli 1998; Schmidt and Westheide 2000; Jörger et al. 2012; Leasi et al. 2013; Meyer-Wachsmuth et al. 2014; Karanovic et al. 2016; Leasi and Norenburg 2016; Kieneke and Nikoukar 2017; Sahraean et al. 2017). For example, the six cryptic species uncovered within the Terschellingia longicaudata species complex (Nematoda) decreased the overall distribution of a formerly cosmopolitan species to two clades occurring in Bahrain, one in Taiwan, one in the UK and Mexico (amphi-oceanic), one in the UK and one cosmopoli$\tan .40$ studies reported unchanged distributions (Table 2). A conclusion from these results is the necessity of molecular-oriented methods in species identification. Additionally, changes in distribution rather reflected the usage of methods than taxa. Within Xenacoelomorpha, Mollusca, Nemertea, Platyhelminthes, and Rotifera, there was a tendency for decreased or unchanged distribution ranges. In contrast, for Gastrotricha, Kinorhyncha, Nematoda and Tardigrada we found an increase. Yet, this cannot be related to the taxa themselves, but rather to the methodology used. Taxa with reduced ranges are also the ones with high numbers of cryptic or pseudocryptic species (Table 2).

Added to the limited available morphological traits for species delimitation and the presence of morphologically similar species, sampling biases might also contribute to the erroneous assumption of a cosmopolitan distribution of a species. Information on species distribution is often biased by sampling localities and intensity (Leasi and Norenburg 2016; Garraffoni and Balsamo 2017; Rinaldo et al. 2017). For instance, the higher diversity of meiofaunal species from European waters likely reflects a sampling artefact due to research traditions (Fontaneto et al. 2009; Jörger et al. 2014). Due to this bias, the report of species from understudied areas is often based on the inappropriate usage of species descriptions or taxonomic keys from Europe due to lack of such information for the study area. This is a common problem in modern taxonomy and not restricted to meiofauna only. Application of keys originating from different regions is likely to result in inappropriate assignment of species (Hutchings and Kupriyanova 2018). For instance, our survey potentially captured some papers wherein British keys were used following surveys in India and Thailand (Zawierucha et al. 2013; Ansari et al. 2015a, b, 2016, 2017; Prasath et al. 2017) and, maybe not surprisingly, these suggest an increased species distribution (Supplementary Table 3). 


\section{Conclusions regarding "Why are so many meiofaunal taxa from distant areas so similar?"}

Considering the prevalence of cryptic species complexes and the subsequent reduction in distribution ranges in studies employing molecular investigations, the distribution of most meiofauna species seems clearly inflated as complexes of cryptic species consists of several, independent distributions, currently interpreted as a single distribution range (Casu and Curini-Galletti 2004; Derycke et al. 2005; Andrade et al. 2011; Tulchinsky et al. 2012; Leasi and Norenburg 2014). Our survey showed that cosmopolitan or, at least, amphi-oceanic distributions of most meiofauna species seldom occur and that increases in distribution range are not supported by molecular approaches. Therefore, the taxonomic identity and assumed wide distribution ranges of many meiofauna species assumed to be examples of the 'meiofauna paradox' is not verified (Schmidt and Westheide 2000; Casu and Curini-Galletti 2006; Suatoni et al. 2006; Casu et al. 2009; Tulchinsky et al. 2012; Jörger et al. 2012; Kieneke et al. 2012; Leasi et al. 2013; Leasi and Norenburg 2014, 2016; MeyerWachsmuth et al. 2014; Karanovic et al. 2016; Sahraean et al. 2017; Kieneke and Nikoukar 2017). Careful reinvestigations, including detailed morphological and molecular analyses should resolve the paradox of widespread species. Hence, in the strictest sense the meiofauna paradox, that meiofauna species with limited dispersal capacities exhibit wide distribution ranges, does not seem to exist or only to a substantially lower degree than assumed before.

Nonetheless, the original observations associated with the meiofauna paradox, that widely distributed complexes of species exhibit very high degrees of morphological similarity, poses intriguing research topics. Clearly, morphological and genetic diversity seem to evolve at different paces in meiofaunal species, as suggested by the high degree of morphological conservatism. Although the provided discussions did not directly give a single and clear answer to the overall similarity between meiofaunal species complexes, it suggests that this question is indeed prominent. First, this requires that the evolutionary history and hence the taxonomy of the study system is firmly established as the basis for future research efforts. While many taxonomists have been aware of these problems, species identifications should include DNA sequences as molecular fingerprints as well as ideally the determination of the level of gene flow at the genomic level.

Additionally, besides the presence of restricted gene flow it has also to be shown that the degree of morphological similarity is as high as assumed (Struck et al. 2018b). Some degree of assumed similarity might arise from neglecting certain morphological character traits a priori (e.g., due to taxonomic tradition), that might actually help to delimitate the species and hence decrease the morphological similarity. Indeed, new developments and approaches in morphological measurements such as detailed anatomical examinations and 3D modelling, other high-resolution microscopy techniques or morphometrics might provide further resolution (Leasi and Todaro 2009; Neusser et al. 2009, 2011; Jörger et al. 2014; Struck et al. 2017). Additional and so far overlooked characters might also decrease the overall similarity in some cases (Knowlton 1993; Méndez et al. 2000; Andrade et al. 2011; Garlitska et al. 2012). Revalidation of characters in this respect could also include other phenotypic characters such as chemical traits, as most marine species rely on chemical cues for mate choice and ecological interactions (Knowlton 1993; Derycke et al. 2008) or the microbiome (Derycke et al. 2016).

If it can be shown that the homogenising effect of gene flow is not present or minimal due to the presence of reproductive isolation, the shown overall morphological or even phenotypic similarity could indicate an adaptive value of this conservatism. As suggested, phenomena such as recent speciation, parallelism, convergence and morphological stasis might account for this (Wada et al. 2013; Swift et al. 2016; Struck et al. 2018b), but further research is needed to unveil the contributions of these phenomena and the selective forces driving them as well as to determine the adaptive value of morphological conservatism (for further details please see the road map below).

\section{"How can meiofauna have bridged oceans and occupied distinct shores in the absence of propagative stages?"}

Dispersal and vicariance are generally discussed as the two major forces underlying the distribution range of meiofauna species. Both hold a fundamental role in shaping ecological and evolutionary dynamics of populations and species as they influence habitat colonization, genetic cohesion of species across space, competition and, in the case of dispersal, facilitate or hamper local adaptation (Knowlton 1993; Ronce 2007; Derycke et al. 2013; De Meester et al. 2015; Baco et al. 2016; Mevenkamp et al. 2016). Ronce (2007) defined dispersal as "any movement of individuals or propagules with potential consequences for gene flow across space". Vicariance can be regarded as the establishment of barriers, whether biotic or abiotic, to dispersal and hence gene flow.

Several lines of evidence provide support for dispersal ability in meiofauna. The presented survey included 25 works which directly tested for meiofauna dispersal with experimental approaches (Supplementary Table 2). 
Generally, these experimental and empirical evidences show that certain meiofauna organisms (including annelids, arthropods, gastropods, kinorhynchs, nematodes, molluscs, platyhelminths, rotifers and tardigrades; Supplementary Table 2) are regularly found drifting in the water column, rafting on algae or ice or are able to colonize sediment traps and have a selective settlement (Pugh 1996; Schratzberger et al. 2000; Commito and Tita 2002; Thistle 2003; Ullberg and Ólafsson 2003a, b; Teasdale et al. 2004; Cristoni et al. 2004; Gwyther and Fairweather 2005; Arroyo et al. 2006; Gobin and Warwick 2006; Hooper and Davenport 2006; Junkins et al. 2006; da Fonsêca-Genevois et al. 2006; Gallucci et al. 2008; Boeckner et al. 2009; Guilini et al. 2011; Thomas and Lana 2011; Callens et al. 2012; De Meester et al. 2012, 2015; Lins et al. 2013; Mcfarlane et al. 2013; Cuvelier et al. 2014; Mevenkamp et al. 2016).

Presence in the water column can result from sediment erosion (Hagerman and Rieger 1981; Palmer 1988) or through active dispersal as a response to unexpected threats (such as predator attack), changing conditions (such as environmental deterioration, overcrowding, competition), winter migration or nocturnal emergence (Palmer and Gust 1985; Armonies 1990, 1994; Giere 2009). For example, polychaetes and harpacticoid copepods colonize nearby cages more rapidly and abundantly than those farther away (Boeckner et al. 2009). Rates of up to $80 \%$ of emergence were reported in harpacticoid copepods (Sedlacek and Thistle 2006). While in the water column, meiofauna can be transported as far as 10 kilometres by erosive tidal currents (Hagerman and Rieger 1981) and members of all meiobenthic taxa have been found in the water column (Armonies 1990). However, all these experimental studies are hampered by the fact that they could not differentiate between local recruitment and long-distance dispersal as they were based on morphological data only. Generally, the conclusions in these studies were therefore conservative and assumed that the detected meiofauna species were only locally recruited from the adjacent sediments.

Besides water column transport, meiofauna dispersal can occur by drifting macroalgae, ice, large floating islands and marine snow (microbial processes and mucus secretions; Fenchel 1978; Westheide 1991; Shanks and Walters 1997; Barnes 2002; Derycke et al. 2008; Giere 2009; de Meester et al. 2012; Tulchinsky et al. 2012; Mcfarlane et al. 2013; Mevenkamp et al. 2016). The dispersal of eggs attached to sand grains (Fenchel 1978) or "buoyant" eggs rather than individuals has also been suggested (Giere 2009; Zeppilli et al. 2011). For example, marine gastrotrichs attach their fertilized eggs directly to sand grains, making dispersal via current sediment plausible (Giere 2009; Kieneke et al. 2012). Considering the evidence for both water column transport and drift, water movements such as currents and flows could become invaluable sources of information when studying meiofauna distribution and dispersal. For example, currents influence genetic structuring in marine nematodes, where population genetic differentiation (i.e., $\mathrm{F}_{\mathrm{ST}}$ values) is often uncorrelated with distance (Derycke et al. 2013). Additionally, wet ballast sand in ships potentially influences meiofaunal dispersal by human activities and could account for dispersal over hundreds of kilometres, but evidence thus far is sparse (Radziejewska et al. 2006; Giere 2009). Moreover, the possibility of stepping-stone dispersal using sea mounts has also been discussed (George and Schminke 2002; George 2013; Packmor and Riedl 2016). However, the evidence for dispersal in these studies was only indirect as they were derived from biogeographic patterns without direct testing of the means of dispersal using, for example, experimental approaches.

In contrast to all this cumulating direct or indirect evidence of dispersal, meiofaunal organisms are often considered to be one of the most sedentary of the marine faunas with virtually no capacity for dispersal (Sterrer 1973; Christiansen and Fenchel 1979; Westheide and Hass-Cordes 2001; Kieneke et al. 2012). For example, Sterrer (1973) stated that the "development, morphology and biology all seem designed to assure one thing: that the organism never leaves its interstitial environment"; while Danielopol and Wouters (1992) suggested that "they are supposed to disperse very slowly and only with or through the sediments as they have no pelagic life stages". Hence, ideas stating that meiofaunal organisms are poor dispersers influenced the general understanding, hypothesis testing and discussion of meiofaunal dispersal modes (Giere 2009). This viewpoint is further supported by the above finding that the supposed wide distribution ranges of meiofaunal are indeed the cumulated distribution ranges of species complexes and the distribution range is often substantially reduced for each species in this complex when molecular data are applied (see above, Table 2 and Supplementary Table 3).

Along this trend, antagonising views were often either dismissed, neglected or ignored (Palmer and Gust 1985) and the dispersal-distribution discussion narrowed to focus almost exclusively on the absence of pelagic larvae. This is generally in accordance with the remaining marine biology literature. Marine species without pelagic larval dispersal are generally expected to have smaller distribution ranges and higher genetic differentiation between populations than species with such stages, which are thought to ultimately connect populations at larger spatial scales and thus lowering genetic differentiation (Knowlton 1993; Kelly and Palumbi 2010; Baco et al. 2016). As a result, much research has been dedicated to understand larval developmental patterns, duration of pelagic larval stage and larval behaviour (Jokiel 1990; Bhaud and Duchêne 1995). However, evidence against the general applicability of this intuitive scheme (pelagic vs. non-pelagic) has accumulated over the 
years. Several studies demonstrated cases of non-pelagic dispersed organisms with highly homogeneous haplotype networks occupying surprisingly wide ranges; on the other hand, other studies reported pelagic dispersed species with clear population structuring, for example, due to local settlement of larva within in the vicinities of the parents (Jokiel 1990; Kyle and Boulding 2000; Colborn et al. 2001; Sponer and Roy 2002; Lester and Ruttenberg 2005; Johnson and Black 2006; Cowen et al. 2007; Lester et al. 2007; Hellberg 2009; Boissin et al. 2015). Hence, dispersal is not the sole, perfect proxy of the distribution range of marine species in general and several other circumstances and particularities can impact distribution ranges such as niche breadth, environmental tolerance, body size, population abundance, latitude, environmental variably at different spatial and temporal scales like substrate type or wave exposure, occurrence of environmental gradients, reproductive strategy, fecundity, lifecycle duration, and physiological constraints (Gaylord and Gaines 2000; Lester and Ruttenberg 2005; Lester et al. 2007; White et al. 2009; Sanford and Kelly 2011). Focusing on meiofauna, some of these factors and concepts have been discussed in the literature, mostly following discoveries of inconsistent and confounding patterns in species' range distribution (Andrade et al. 2011; Tulchinsky et al. 2012). For example, Derycke et al. (2013) suggest that life-history characteristics are important in determining the genetic structure of nematode populations. Similarly, the genetic structure of Pellioditis marina might be best explained by its life-history characteristics of a short generation time, high colonization potential and evolutionary potential for local adaptation (Derycke et al. 2005). Furthermore, evidence for rare longdistance dispersal events stems also from the highly similar composition and high diversity of the meiofauna of the Galapagos Islands with other parts of the world (Westheide 1977, 1991). The same may hold truth for colonization of other islands of volcanic origin.

Vicariance has also been proposed not only to explain the establishment of barriers to dispersal as evidenced by the reduced distribution ranges (Table 2), but also as a responsible force underlying the present distributions of meiofaunal species. In specific, the distribution of meiofaunal taxa was suggested to reflect the movement of the tectonic plates and with that the continental landmasses with their coastlines (Sterrer 1973). Arguably, Sterrer overemphasized the importance of this mechanism, and dismissed dispersal (due to the absence of pelagic larval stages) as a viable mechanism, rendering both as mutually exclusive (Sterrer 1973). When considering variation of species distributions through time, the severe differences in geological and climatological events have to be accounted for (Norris and Hull 2012), as these influence population connectivity and distribution ranges in complex ways, both at macro- and microgeological scales.
For example, glacial periods resulted in a decrease of the sea level, leading to changes of coastal geography (e.g., increase in island mass) including closure of seaways which were open in interglacial periods. Likewise, temperature, oxygen and salinity gradients were affected by these changes. It is not surprising to assume that the evolutionary history, regardless of the dispersal abilities of ecological communities was severely affected throughout time by such events (Dawson 2001). Hence, considering the registered variance of climatological, sea level and geological changes throughout the last $\sim 500$ million years, focusing exclusively on vicariance is misleading. Accordingly, none of the studies mentioned above using molecular data supported the hypothesis that the distribution was exclusively the result of plate tectonic events. Indeed, climatic oscillations such as intermittent glacial-interglacial periods resulted in bottlenecks, recent founder-events, and local extinctions in some meiofaunal species (Taylor et al. 1998; Derycke et al. 2005, 2008, 2013; Casu and Curini-Galletti 2006; Tulchinsky et al. 2012). For the gastrotrich Turbanella cornuta, Kieneke et al. (2012) found that the most likely colonization to the Baltic Sea was via water connections and corresponding currents about 10,000 years ago rather than by the recent connectivity routes. Moreover, instances of long-distance dispersal within the Northeast Atlantic could be found in other Turbanella species. A recent study focusing on the annelid genus Stygocapitella demonstrated that considering a strict vicariance hypothesis does not fit meiofauna dispersal (Struck et al. 2017). Applying the vicariance hypothesis strictly would require that the southern species be separated 450 million years ago in the Ordovician with the beginning formation of the Paleo-Tethys Ocean (Fig. 3). Hence, ancient dispersal events (Fig. 3) are more likely, possibly in combination with vicariant events establishing barriers of dispersal (Struck et al. 2017). Furthermore, Derycke et al. (2013) discussed hypotheses considering dispersal and gene flow of free-living meiofaunal nematodes and stressed the importance of historical events in shaping the genetic pattern of marine nematodes, showing that land mass drift, sea level rise and glacial cycles influenced population structuring and distribution of the nematode Litoditis marina. From this, they concluded that the evolutionary history of this cryptic species complex is only thoroughly understood when historical events are considered alongside aspects of dispersal. In conclusion, climatological and geological events affect meiofauna distribution and dispersal. 


\section{Strict vicariance}
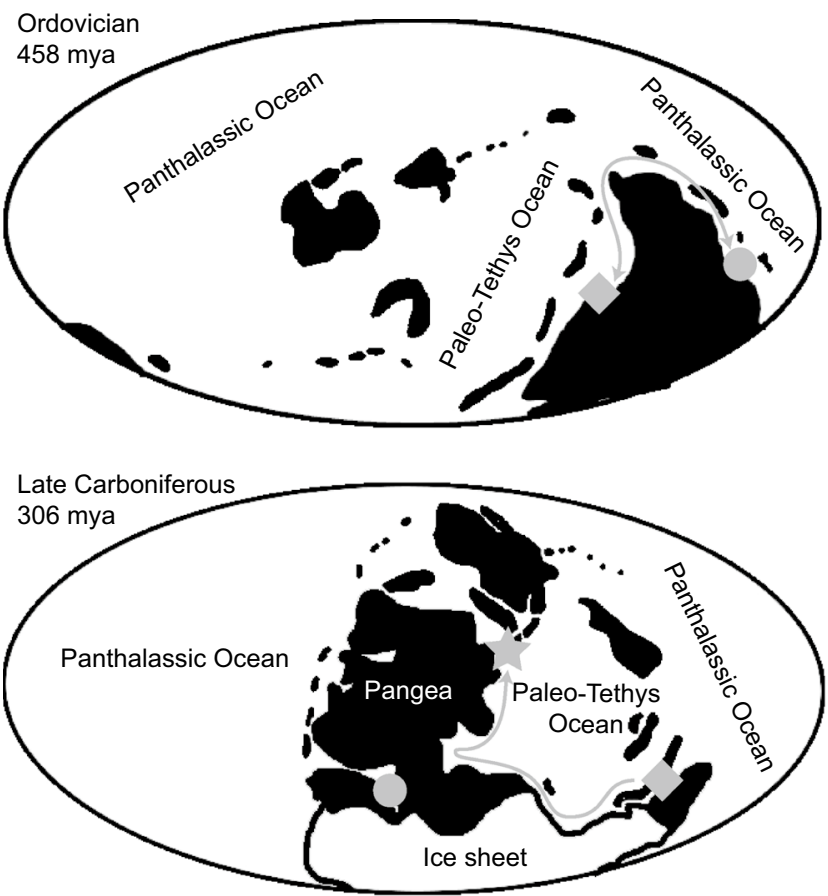

Ancient dispersal
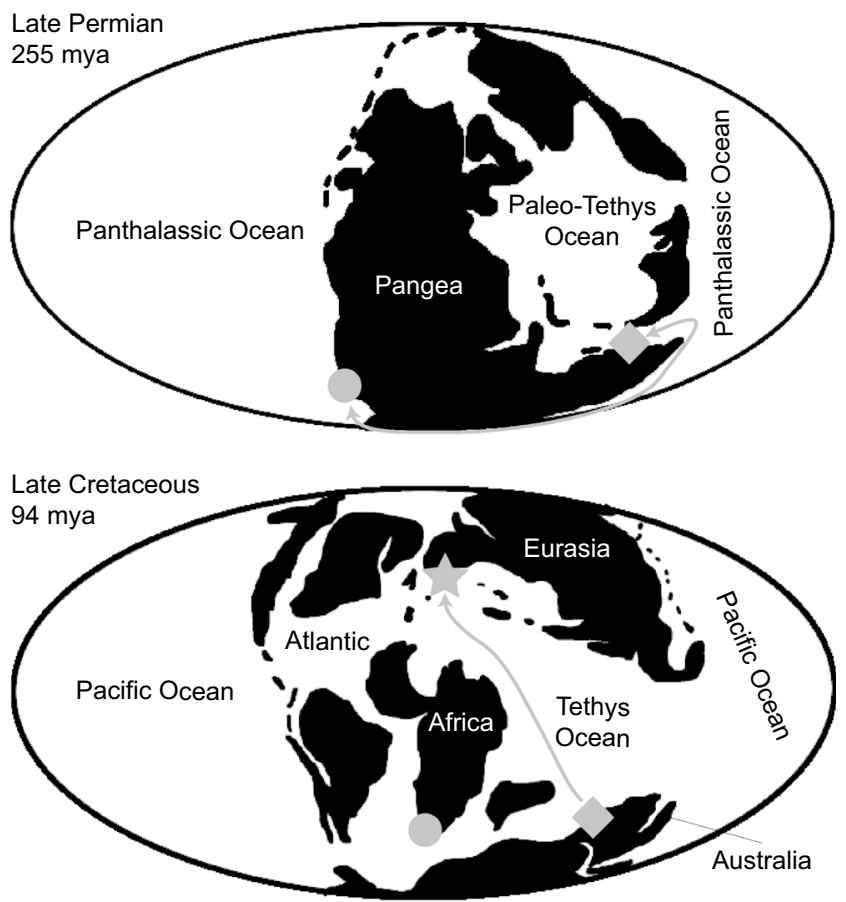

Recent distribution

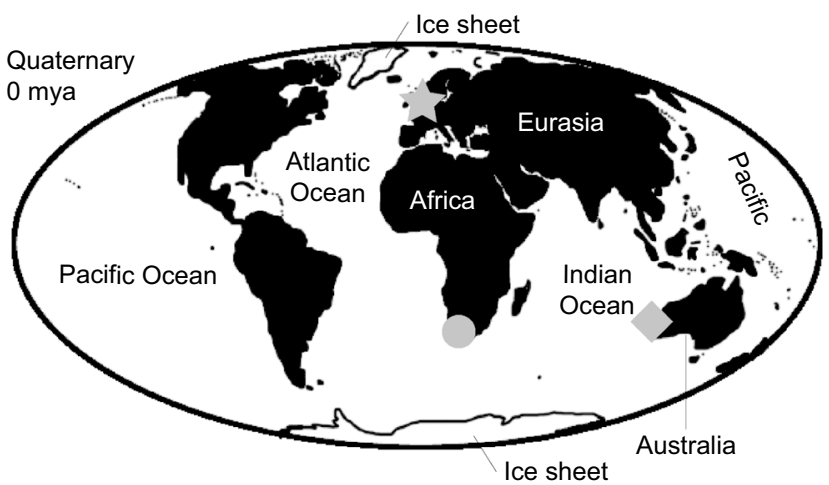

Fig. 3 Two scenarios explaining the distribution of three species of Stygocapitella investigated by Struck et al. (2017). The left upper two panels show a strictly vicariant scenario, the right upper two show ancient dispersal and the lowest the recent distribution. Arrows indi-

\section{Conclusions on "How can meiofauna have bridged oceans and occupied distinct shores in the absence of propagative stages?"}

A cornerstone of the 'meiofauna paradox' is the expectation of low dispersal of meiofaunal invertebrates. There is an increasing body of experimental and empirical evidence, which clearly contrasts this view. Meiofaunal dispersal, not specifically tied to any restrained evolutionary lineage or taxonomic clade, has been clearly demonstrated. Dispersal abilities seem to account for the distribution of lineages throughout considerably large areas. Nevertheless, this cate possible dispersal routes either via plate tectonics or long-distance dispersal. Paleomaps modified from Scotese (2002). Star, population of $S$. subterranea; diamond, population of $S$ australis; circle, population of $S$. minuta should not be confounded by the ability to maintain cosmopolitan distributions. The expectations of low dispersal seem to emerge from historical views based on the dichotomous presence/absence view on pelagic larval dispersal. The presence of pelagic dispersal plays a role in dispersal and species distribution, but it is not the only considered variable. Meiofaunal biologists should explore the ecological roles and life-history traits of the species to understand the distribution of a species. Ecological and life-history traits effectively affect dispersal and the range distribution of individuals and are seldom considered. Moreover, the inclusion of vicariant events and ancient dispersal routes can explain 
the recent distribution of meiofaunal organisms. However, vicariance should not be considered the sole driver of meiofaunal distribution. Only few studies on meiofauna have been conducted so far, which accounted for both (Westheide 2005). Therefore, general conclusions for meiofauna dispersal as not being possible must be regarded as idiosyncratic for the time being.

Future empirical studies on the dispersal of meiofaunal organisms should concentrate on deciphering the contributions of dispersal and vicariance on the recent distribution at several geographic and temporal scales. This will allow more general conclusions regarding dispersal potential, time scales of dispersal and speciation as well as associated processes, especially if these studies are conducted for a broad range of the meiofaunal biodiversity. Empirical data providing indirect evidence of dispersal routes should be complemented by experimental approaches to directly test dispersal capacities, which allow assessing the difference between local recruiters and long-distance dispersers (for further details please see the road map below).

Moreover, analyses of metapopulation dynamics have gained popularity in marine ecological studies (Wares et al. 2001; Kritzer and Sale 2004; Cowen et al. 2007), and have been frequently applied to meiofaunal organisms (Derycke et al. 2006, 2007a, b, 2008; Andrade et al. 2011; Leasi and Norenburg 2016). The complexity and dynamics of meiofauna populations through time and space make them suitable for such analyses. Suitable habitats often consist of relatively small (metre scale) isolated patches of sediment, which are separated from each other by distances of several metres to even hundreds of kilometres of inhospitable habitat (Tulchinsky et al. 2012; Leasi and Norenburg 2016). This often results in mosaic-like population patterns, which are best addressed by taking metapopulation dynamics into account.

\section{Roadmap for meiofauna research: directions of future research}

The wide geographical distribution (including cosmopolitanism) of many marine species has puzzled researchers and resulted in the prevalence of several paradoxes. Examples are the extended pelagic stage of some species with restricted distributions (Colborn et al. 2001), the community composition of Rockall (Johannesson 1988 ) or the cosmopolitan distribution of marine species without free-living larvae (Sponer and Roy 2002). These paradoxes stem from sampling and taxonomic complications and the meiofauna paradox is no exception to these difficulties. Here, we discussed that the meiofauna paradox likely stems from pre-established, historically defined hypotheses, pre-concepts of sea connectivity dynamics and the presence of cryptic species as well as difficulties and biases in meiofauna sampling and collection, identification and characterization. As pointed out in the literature survey, recent evidences indicate that the meiofauna paradox and its underlying assumptions including the wide distribution and low dispersal capability of meiofaunal organisms are not met. First, a considerable amount of studies focusing on cosmopolitan species and applying molecular methods uncovered underlying diversity (cryptic species) often with limited distribution ranges. Hence, the assumption of wide distribution is not given. Second, the limited dispersal capacity seems questionable and a remnant of historical literature. Nonetheless, even though the meiofauna paradox in its strictest sense does most likely not exist, certain aspects of the paradox pose interesting research venues. As such, facing the future we suggest that Giere's (2009) questions concerning the meiofauna paradox should be considered in terms of morphological similarity and marine connectivity.

To understand phenotypic conservatism, both evolutionary and taxonomic approaches are needed. Future studies should focus on unveiling the selective pressures resulting in phenotypic similarity of meiofaunal species. Overall similarity in meiofauna and its underlying processes warrants potentially interesting evolutionary phenomena (i.e., morphological stasis, recent speciation, parallel or convergent evolution). In the age of 'high-throughput sequencing', genomic scans such as RADseq, anchored hydrid enrichment (AHE), ultra-conserved elements (UCE) or genome re-sequencing in combination with de novo genome assemblies of meiofaunal species will open unprecedented gates to understand the evolutionary history, connectivity, adaptation and selective regimes affecting meiofaunal organisms. Surprisingly though, the provided literature survey captured only seven studies focusing on evolutionary biology (Schmidt and Westheide 1999; Rocha-Olivares et al. 2001; Denis et al. 2009; Yamasaki et al. 2014; Scarpa et al. 2015; Smythe 2015; Rands $\varnothing$ et al. 2018) out of a total of 751 studies. Meiofaunal species represent ideal systems to understand selective pressures on cryptic species complexes and deceleration of phenotypic evolution (as generally suggested by Struck et al. 2018a, b). Even though meiofaunal organisms are of small size, recent advantages in whole genome amplification techniques allow working with individual specimens (e.g., Golombek et al. 2013, 2015). On the other hand, the small size can be a potential advantage when investigating the similarity of the whole phenotype as a more complete assessment of the whole phenotype is possible. If such studies are combined with nested sampling strategies of populations and species of a complex as well as of morphological slightly different sister species, selective regimes at different taxonomical levels such as between populations, cryptic species and non-cryptic species can be revealed. 
In addition to this evolutionary approach, discovery and description of meiofaunal species should be prioritized, as only a broad taxonomic basis will allow for solid general conclusions about evolutionary processes, speciation and biogeographic history and selective regimes as well as provide the necessary phylogenetic framework for the evolutionary studies. Taxonomic efforts should include DNA sequences when describing species, as these allow a better detection of distribution ranges as discussed above. Guidelines for DNA taxonomy with a focus on meiofauna have been published (Fontaneto et al. 2015). Additionally, the overall phenotype of the meiofaunal species should be described in as much detail as possible, as this will provide the basis to assess similarities across species boundaries. Indeed, following our discussion, a thorough understanding of meiofaunal species' distributions is inevitable to understand the scale and range that meiofaunal species can maintain connectivity. The unravelling of cryptic species, resulting from the overall phenotypic similarity, will help understanding potential barriers of gene flow including historical barriers. Additionally, the discovery of cryptic species will open further research venues such as physiological variability (de Meester et al. 2011) and distribution along ecological gradients. Hence, investment in classical taxonomic research like species characterization and development of identification keys in understudied areas should be a priority of meiofaunal research, likely yielding the discovery of endemic species or species with a more restricted distribution (Garraffoni and Balsamo 2017).

To tackle marine connectivity, both empirical and experimental approaches should be adopted. Empirical research on dispersal and distribution of meiofaunal organisms can apply the methodology outlined above for evolutionary and taxonomic approaches. If an adequate sampling regime is performed, the produced data will be able to tackle questions concerning connectivity, demography and biogeography. Hence, the sampling strategy should be inclusive to both possible vicariance and dispersal events for the group of interest. The dispersal potential of meiofaunal organisms and the influence of vicariant events can then be addressed more thoroughly and systematically in time, space and taxonomic breadth. This includes assessing dispersal potential empirically at local and regional scales, which are potentially affected by historic events like glaciations, comparing sister species pairs with only very few differing biological properties as well as using metapopulation models to get a better fit of the reality of meiofaunal population structure. A strong focus of research is recently on intertidal to shallow-subtidal habitats. However, to achieve a more thorough understanding, marine connectivity research on supralittoral and deep sea habitats should also be emphasized, also having in mind that these could have been temporal habitats in the past. Moreover, genome-scale data are preferable over few molecular markers if possible, as they allow a more accurate assessment of both recent and historic gene flow and hence dispersal capacity based on fewer specimens due to the increased sampling size.

In contrast, only a minority of the surveyed literature directly tested for meiofaunal dispersal in experimental settings. While challenging historical expectations, these works are vital to understand the means of meiofauna connectivity, dispersal and distribution. Considering recent technological advances, the inclusion of DNA sequences on species detection in such studies using metagenomic and metatranscriptomic approaches will enable future works to test for dispersal of meiofauna more accurately (Fonseca et al. 2014; Carugati et al. 2015; Leray and Knowlton 2015, 2016). For example, collecting environmental DNA samples of sediments at various depths and from the adjacent 'pelagic realm' can provide insights if the present meiofaunal species in the pelagic realm are only locally recruited or if specimens from more distant populations are also present. Additionally, metatranscriptomic approaches have the potential to determine which stages of development are responsible for dispersal. However, to validate such approaches, appropriate databases must be established, including genetic and transcriptomic markers specific for certain developmental stages. Therefore, at the present stage, priority should be given to projects compiling such comprehensive databases.

Acknowledgements The authors are indebted to two anonymous reviewers and Diego Fontaneto whose comments have considerably improved the original manuscript. JC is grateful to Zeca Afonso (among other thinkers) for inspiration ("Em cada esquina um amigo; Em cada rosto igualdade"). This is NHM Evolutionary Genomics Lab contribution No. 10.

\section{Compliance with ethical standards}

Ethical approval All authors have approved the submitted manuscript

Conflict of interest The authors declare that they have no conflict of interest.

Human animal rights statement This article does not contain any studies with animals performed by any of the authors.

\section{References}

Andrade SCS, Norenburg JL, Solferini VN (2011) Worms without borders: genetic diversity patterns in four Brazilian Ototyphlonemertes species (Nemertea, Hoplonemertea). Mar Biol 158:2109_ 2124. https://doi.org/10.1007/s00227-011-1718-3

Ansari KGMT, Pattnaik AK, Rastogi G, Bhadury P (2015a) An inventory of free-living marine nematodes from Asia's largest coastal lagoon, Chilika, India. Wetl Ecol Manag 23:881-890. https://doi. org/10.1007/s11273-015-9426-2 
Ansari KGMT, Lyla PS, Khan SA (2015b) New distributional records of free-living marine nematodes from Indian waters I. Chromadorids. Indian J Geo Mar Sci 44:756-765

Ansari KGMT, Lyla PS, Khan SA (2016) New distributional records of free-living marine nematodes from Indian waters II. Monhysterids. Indian J Geo-Marine Sci 45:342-351

Ansari KGMT, Lyla PS, Ajmal Khan S (2017) New distributional records of free-living marine nematodes from Indian waters III. Microlaimids and Laptolaimids. Indian J Geo Mar Sci $46: 155-162$

Armonies W (1990) Short-term changes of meiofaunal abundance in intertidal sediments. Helgoländer Meeresuntersuchungen 386:375-386

Armonies W (1994) Drifting meio- and macrobenthic invertebrates on tidal flats in Königshafen: a review. Helgoländer Meeresuntersuchungen 48:299-320. https://doi.org/10.1007/BF02367043

Arroyo NL, Aarnio K, Bonsdorff E (2006) Drifting algae as a means of re-colonizing defaunated sediments in the Baltic Sea. A shortterm microcosm study. Hydrobiologia 554:83-95. https://doi. org/10.1007/s10750-005-1008-5

Atherton S, Jondelius U (2018) Microstomum (Platyhelminthes, Macrostomorpha, Microstomidae) from the Swedish west coast: two new species and a population description. Eur J Taxon. https:// doi.org/10.5852/ejt.2018.398

Baco AR, Etter RJ, Ribeiro PA, von der Heyden S, Beerli P, Kinlan BP (2016) A synthesis of genetic connectivity in deep-sea fauna and implications for marine reserve design. Mol Ecol 25:3276-3298. https://doi.org/10.1111/mec.13689

Baldrighi E, Aliani S, Conversi A, Lavaleye M, Borghini M, Manini E (2013) From microbes to macrofauna: an integrated study of deep benthic communities and their response to environmental variables along the Malta Escarpment (Ionian Sea). Sci Mar 77:625-639. https://doi.org/10.3989/scimar.03811.03b

Barnes DKA (2002) Invasions by marine life on plastic debris. Nature 416:808-809. https://doi.org/10.1038/416808a

Bhadury P, Austen MC, Bilton DT, Lambshead PJD, Rogers AD, Smerdon GR (2006) Molecular detection of marine nematodes from environmental samples: overcoming eukaryotic interference. Aquat Microb Ecol 44:97-103. https://doi.org/10.3354/ ame 044097

Bhaud M, Duchêne J (1995) Change from planktonic to benthic development: is life cycle evolution an adaptive answer to the constraints of dispersal? Oceanol Acta 19:335-346

Bik HM, Thomas WK, Lunt DH, Lambshead PJD (2010) Low endemism, continued deep-shallow interchanges, and evidence for cosmopolitan distributions in free-living marine nematodes (order Enoplida). BMC Evol Biol 10:389. https://doi. org/10.1186/1471-2148-10-389

Bik HM, Sung W, De Ley P, Baldwin JG, Sharma J, Rocha-Olivares A, Thomas WK (2012) Metagenetic community analysis of microbial eukaryotes illuminates biogeographic patterns in deep-sea and shallow water sediments. Mol Ecol 21:1048-1059. https:// doi.org/10.1111/j.1365-294X.2011.05297.x

Boeckner MJ, Sharma J, Proctor HC (2009) Revisiting the meiofauna paradox: dispersal and colonization of nematodes and other meiofaunal organisms in low- and high-energy environments. Hydrobiologia 624:91-106. https://doi.org/10.1007/s10750-008-9669-5

Boissin E, Egea E, Féral JP, Chenuil A (2015) Contrasting population genetic structures in Amphipholis squamata, a complex of brooding, self-reproducing sister species sharing life history traits. Mar Ecol Prog Ser 539:165-177. https://doi.org/10.3354/meps11480

Brenzinger B, Haszprunar G, Schrödl M (2013) At the limits of a successful body plan-3D microanatomy, histology and evolution of Helminthope (Mollusca: Heterobranchia: Rhodopemorpha), the most worm-like gastropod. Front Zool 10:37. https://doi. org/10.1186/1742-9994-10-37
Callens M, Gheerardyn H, Ndraro SGM, De Troch M, Vanreusel A (2012) Harpacticoid copepod colonization of coral fragments in a tropical reef lagoon (Zanzibar, Tanzania). J Mar Biol Assoc UK 92:1535-1545. https://doi.org/10.1017/S0025315411001597

Carugati L, Corinaldesi C, Dell A, Danovaro R (2015) Marine genomics metagenetic tools for the census of marine meiofaunal biodiversity: an overview. Mar Genom 24:11-20. https://doi. org/10.1016/j.margen.2015.04.010

Casu M, Curini-Galletti M (2004) Sibling species in interstitial flatworms: a case study using Monocelis lineata (Proseriata: Monocelididae). Mar Biol 145:669-679. https://doi.org/10.1007/ s00227-004-1367-x

Casu M, Curini-Galletti M (2006) Genetic evidence for the existence of cryptic species in the mesopsammic flatworm Pseudomonocelis ophiocephala (Rhabditophora: Proseriata). Biol J Linn Soc 87:553-576. https://doi.org/10.1111/j.1095-8312.2006.00588.x

Casu M, Lai T, Sanna D, Cossu P, Curini-Galletti M (2009) An integrative approach to the taxonomy of the pigmented European Pseudomonocelis meixner, 1943 (Platyhelminthes: Proseriata). Biol J Linn Soc 98:907-922. https://doi.org/10.111 1/j.1095-8312.2009.01316.x

Chatterjee T, Troch M De (2000) Halacaridae (Acari) from Gazi Bay (Kenya): description and biogeography of three new and two known species. Hydrobiologia 427:177-194. https://doi. org/10.1023/A:1003979629889

Christiansen FB, Fenchel TM (1979) Evolution of marine invertebrate reproductive patterns. Theor Popul Biol 16:267-282. https://doi. org/10.1016/0040-5809(79)90017-0

Clausen C (2000) Gastrotricha macrodasyida from the Troms $\varnothing$ region, northern Norway. Sarsia 85:357-384. https://doi. org/10.1080/00364827.2000.10414588

Colborn J, Crabtree RE, Shaklee JB, Pfeiler E, Bowen BW (2001) The evolutionary enigma of bonefishes (Albula spp.): cryptic species and ancient separations in a globally distributed shorefish. Evolution (N Y) 55:807-820. https://doi. org/10.1111/j.0014-3820.2001.tb00816.x

Commito JA, Tita G (2002) Differential dispersal rates in an intertidal meiofauna assemblage. J Exp Mar Bio Ecol 268:237-256. https ://doi.org/10.1016/S0022-0981(01)00386-0

Cowen RK, Gawarkiewicz G, Pineda J, Thorrold SR, Werner FE (2007) Population connectivity in marine systems. Oceanography 20:14-21. https://doi.org/10.1126/science.1122039

Cristoni C, Colangelo MA, Ceccherelli VU (2004) Spatial scale and meiobenthic copepod recolonisation: testing the effect of disturbance size in a seagrass habitat. J Exp Mar Bio Ecol 298:49-70. https://doi.org/10.1016/j.jembe.2003.08.005

Curini-Galletti M, Puccinelli I (1998) The Gyratrix hermaphroditus species complex (Kalyptorhynchia: Polycystididae) in marine habitats of eastern Australia. Hydrobiologia 383:287-298. https ://doi.org/10.1023/A:1003456102035

Cuvelier D, Beesau J, Ivanenko VN, Zeppilli D, Sarradin PM, Sarrazin J (2014) First insights into macro- and meiofaunal colonisation patterns on paired wood/slate substrata at Atlantic deep-sea hydrothermal vents. Deep Res Part I Oceanogr Res Pap 87:7081. https://doi.org/10.1016/j.dsr.2014.02.008

da Fonsêca-Genevois V, Somerfield PJ, Neves MHB, Coutinho R, Moens T (2006) Colonization and early succession on artificial hard substrata by meiofauna. Mar Biol 148:1039-1050. https:// doi.org/10.1007/s00227-005-0145-8

Dal Zotto M (2015) Antygomonas caeciliae, a new kinorhynch from the Mediterranean Sea, with report of mitochondrial genetic data for the phylum. Mar Biol Res 11:689-702. https://doi. org/10.1080/17451000.2015.1007872

Dal Zotto M, Todaro MA (2016) Kinorhyncha from Italy, a revision of the current checklist and an account of the recent investigations. Zool Anz 265:90-107. https://doi.org/10.1016/j.jcz.2016.01.004 
Danielopol DAN, Wouters K (1992) Evolutionary (Paleo)biology of marine interstitial ostracoda. Geobios 25:207-211

Dawson MN (2001) Phylogeography in coastal marine animals: a solution from California? J Biogeogr 28:723-736

De Ley P, De Ley IT, Morris K, Abebe E, Mundo-Ocampo M, Yoder M, Heras J, Waumann D, Rocha-Olivares A, Jay Burr AH, Baldwin JG, Thomas WK (2005) An integrated approach to fast and informative morphological vouchering of nematodes for applications in molecular barcoding. Philos Trans R Soc B Biol Sci 360:1945-1958. https://doi.org/10.1098/rstb.2005.1726

de Meester N, Derycke S, Bonte D, Moens T (2011) Salinity effects on the coexistence of cryptic species: a case study on marine nematodes. Mar Biol 158:2717-2726. https://doi.org/10.1007/ s00227-011-1769-5

De Meester N, Derycke S, Moens T (2012) Differences in time until dispersal between cryptic species of a marine nematode species complex. PLoS One 7:1-8. https://doi.org/10.1371/journ al.pone. 0042674

De Meester N, Derycke S, Rigaux A, Moens T (2015) Active dispersal is differentially affected by inter- and intraspecific competition in closely related nematode species. Oikos 124:561-570. https ://doi.org/10.1111/oik.01779

Delogu V, Casu M, Curini-Galletti M (2008) The genera Parotoplana Meixner, 1938 and Parotoplanella Ax, 1956 (Platyhelminthes: Proseriata) in southern Spain. J Nat Hist 42:157-176. https://doi. org/10.1080/00222930701840696

Denis F, Ravallec R, Pavillon J-F, Van Wormhoudt A (2009) Genetic differentiation of Atlantic populations of the intertidal copepod Tigriopus brevicornis. Sci Mar 73:579-587. https://doi. org/10.3989/scimar.2009.73n3579

Derycke S, Remerie T, Vierstraete A, Backeljau T, Vanfleteren JR, Vincx M, Moens T (2005) Mitochondrial DNA variation and cryptic speciation within the free-living marine nematode $\mathrm{Pel}$ lioditis marina. Mar Ecol Prog Ser 300:91-103. https://doi. org/10.3354/meps300091

Derycke S, Backeljau T, Vlaeminck C, Vierstraete A, Vanfleteren J, Vincx M, Moens T (2006) Seasonal dynamics of population genetic structure in cryptic taxa of the Pellioditis marina complex (Nematoda: Rhabditida). Genetica 128:307-321. https://doi. org/10.1007/s10709-006-6944-0

Derycke S, Van Vynckt R, Vanoverbeke J, Vincx M, Moens T (2007a) Colonization patterns of Nematoda on decomposing algae in the estuarine environment: community assembly and genetic structure of the dominant species Pellioditis marina. Limnol Oceanogr 52:992-1001. https://doi.org/10.4319/lo.2007.52.3.0992

Derycke S, Backeljau T, Vlaeminck C, Vierstraete A, Vanfleteren J, Vincx M, Moens T (2007b) Spatiotemporal analysis of population genetic structure in Geomonhystera disjuncta (Nematoda, Monhysteridae) reveals high levels of molecular diversity. Mar Biol 151:1799-1812. https://doi.org/10.1007/s00227-007-0609-0

Derycke S, Remerie T, Backeljau T, Vierstraete A, Vanfleteren J, Vincx M, Moens T (2008) Phylogeography of the Rhabditis (Pellioditis) marina species complex: evidence for long-distance dispersal, and for range expansions and restricted gene flow in the northeast Atlantic. Mol Ecol 17:3306-3322. https://doi.org/10.1111/ j.1365-294X.2008.03846.x

Derycke S, Sheibani Tezerji R, Rigaux A, Moens T (2012) Investigating the ecology and evolution of cryptic marine nematode species through quantitative real-time PCR of the ribosomal ITS region. Mol Ecol Resour 12:607-619. https://doi.org/10.111 1/j.1755-0998.2012.03128.x

Derycke S, Backeljau T, Moens T (2013) Dispersal and gene flow in free-living marine nematodes. Front Zool 10:1. https://doi. org/10.1186/1742-9994-10-1

Derycke S, De Meester N, Rigaux A, Creer S, Bik H, Thomas W, Moens T (2016) Coexisting cryptic species of the Litoditis marina complex (Nematoda) show differential resource use and have distinct microbiomes with high intraspecific variability. Mol Ecol. https://doi.org/10.1111/mec.13597

Di Domenico M, Martínez A, Lana P, Worsaae K (2014) Molecular and morphological phylogeny of Saccocirridae (Annelida) reveals two cosmopolitan clades with specific habitat preferences. Mol Phylogenet Evol 75:202-218. https://doi.org/10.1016/j.ympev .2014 .02 .003

Dujardin F (1851) Sur un petit animal marin, l'Echinodère, formant un type intermédiaire entre les Crustacés et les Vers. Ann Sci Nat Zool 3:158-160

Dunn CW, Giribet G, Edgecombe GD, Hejnol A (2014) Animal phylogeny and its evolutionary implications. Annu Rev Ecol Syst 45:371-395. https://doi.org/10.1146/annurev-ecolsys-12021 3-091627

Eder B, Schrödl M, Jörger KM (2011) Systematics and redescription of the European meiofaunal slug Microhedyle glandulifera (Kowalevsky, 1901) (Heterobranchia: Acochlidia): Evidence from molecules and morphology. J Molluscan Stud 77:388-400. https:// doi.org/10.1093/mollus/eyr030

Fenchel TM (1978) The ecology of micro- and meiobenthos. Annu Rev Ecol Syst 9:99-121

Fonseca VG, Carvalho GR, Nichols B, Quince C, Johnson HF, Neill SP, Lambshead JD, Thomas WK, Power DM, Creer S (2014) Metagenetic analysis of patterns of distribution and diversity of marine meiobenthic eukaryotes. Glob Ecol Biogeogr 23:12931302. https://doi.org/10.1111/geb.12223

Fontaneto D, Kaya M, Herniou EA, Barraclough TG (2009) Extreme levels of hidden diversity in microscopic animals (Rotifera) revealed by DNA taxonomy. Mol Phylogenet Evol 53:182-189. https://doi.org/10.1016/j.ympev.2009.04.011

Fontaneto D, Flot JF, Tang CQ (2015) Guidelines for DNA taxonomy, with a focus on the meiofauna. Mar Biodivers 45:433-451. https ://doi.org/10.1007/s12526-015-0319-7

Futuyma DJ (2010) Evolutionary constraint and ecological consequences. Evolution (N Y) 64:1865-1884. https://doi.org/10.11 11/j.1558-5646.2010.00960.x

Gallucci F, Moens T, Vanreusel A, Fonseca G (2008) Active colonisation of disturbed sediments by deep-sea nematodes: evidence for the patch mosaic model. Mar Ecol Prog Ser 367:173-183. https ://doi.org/10.3354/meps07537

Garlitska L, Neretina T, Schepetov D, Mugue N, De Troch M, Baguley JG, Azovsky A (2012) Cryptic diversity of the "cosmopolitan" harpacticoid copepod Nannopus palustris: genetic and morphological evidence. Mol Ecol 21:5336-5347. https://doi. org/10.1111/mec.12016

Garraffoni ARS, Balsamo M (2017) Is the ubiquitous distribution real for marine gastrotrichs? Detection of areas of endemism using Parsimony Analysis of Endemicity (PAE). Proc Biol Soc Wash 130:197-210. https://doi.org/10.2988/17-00011

Gaylord B, Gaines SD (2000) Temperature or transport? Range limits in marine species mediated solely by flow. Am Nat 155:769-789. https://doi.org/10.1086/303357

George KH (2013) Faunistic research on metazoan meiofauna from seamounts-a review. Meiofauna Mar 20:1-32

George KH, Schminke HK (2002) Harpacticoida (Crustacea, Copepoda) of the Great Meteor Seamount, with first conclusions as to the origin of the plateau fauna. Mar Biol 141:887-895. https:// doi.org/10.1007/s00227-002-0878-6

Gerlach SA (1977) Means of meiofauna dispersal. In: Sterrer W, Ax $\mathrm{P}$ (eds) The meiofauna species in time and space. Mikrofauna Meeresbod, vol 61, pp 89-103

Giard A (1904) Sur une faunule charactéristique des sables à diatomées d'Ambleteuse. C R Séanc Soc Biol Paris 56:107-165

Giere O (2009) Meiobenthology: the microscopic motile fauna of aquatic sediments, 2nd edn. Springler-Verlag, Berlin Heidelberg 
Gobin JF, Warwick RM (2006) Geographical variation in species diversity: a comparison of marine polychaetes and nematodes. J Exp Mar Bio Ecol 330:234-244. https://doi.org/10.1016/j. jembe.2005.12.030

Golombek A, Tobergte S, Nesnidal MP, Purschke G, Struck TH (2013) Mitochondrial genomes to the rescue-diurodrilidae in the myzostomid trap. Mol Phylogenet Evol 68:312-326

Golombek A, Tobergte S, Struck TH (2015) Elucidating the phylogenetic position of Gnathostomulida and first mitochondrial genomes of Gnathostomulida, Gastrotricha and Polycladida (Platyhelminthes). Mol Phylogenet Evol 86:49-63. https:// doi.org/10.1016/j.ympev.2015.02.013

Gruber-Vodicka HR, Dirks U, Leisch N, Baranyi C, Stoecker K, Bulgheresi S, Heindl NR, Horn M, Lott C, Loy A, Wagner M, Ott J (2011) Paracatenula, an ancient symbiosis between thiotrophic Alphaproteobacteria and catenulid flatworms. Proc Natl Acad Sci 108:12078-12083. https://doi.org/10.1073/pnas.11053 47108

Guilini K, Soltwedel T, van Oevelen D, Vanreusel A (2011) Deep-sea nematodes actively colonise sediments, irrespective of the presence of a pulse of organic matter: results from an in situ experiment. PLoS One. https://doi.org/10.1371/journal.pone.0018912

Gwyther J, Fairweather PG (2005) Meiofaunal recruitment to mimic pneumatophores in a cool-temperate mangrove forest: spatial context and biofilm effects. J Exp Mar Bio Ecol 317:69-85. https ://doi.org/10.1016/j.jembe.2004.11.012

Hagerman GM, Rieger RM (1981) Dispersal of benthic meiofauna by wave and current action in Bogue sound, North Carolina, USA. Mar Ecol 2:245-270. https://doi.org/10.1111/j.1439-0485.1981. tb00099.x

Hansen TF, Houle D (2004) Evolvability, stabilizing selection, and the problem of stasis. In: Pigliucci M, Preston K (eds) Phenotypic integration: studying the ecology and evolution of complex phenotypes. Oxford University Press, New York, pp 130-154

Hellberg ME (2009) Gene flow and isolation among populations of marine animals. Annu Rev Ecol Evol Syst 40:291-310. https:// doi.org/10.1146/annurev.ecolsys.110308.120223

Higgins RP, Thiel H (1988) Introduction to the study of meiofauna. Smithsonian Institution Press, Washington

Hooper GJ, Davenport J (2006) Epifaunal composition and fractal dimensions of intertidal marine macroalgae in relation to emersion. J Mar Biol Assoc UK 86:1297-1304. https://doi. org/10.1017/S0025315406014329

Hutchings P, Kupriyanova E (2018) Cosmopolitan polychaetes-fact or fiction? Personal and historical perspectives. Invertebr Syst 32:1-9. https://doi.org/10.1071/IS17035

Johannesson K (1988) The paradox of Rockall: why is a brooding gastropod (Littorina saxatilis) more widespread than one having a planktonic larval dispersal stage (L. littorea)? Mar Biol 99:507-513. https://doi.org/10.1007/BF00392558

Johnson MS, Black R (2006) Islands increase genetic subdivision and disrupt patterns of connectivity of intertidal snails in a complex archipelago. Evolution (N Y) 60:2498-2506. https://doi. org/10.1111/j.0014-3820.2006.tb01885.x

Jokiel PL (1990) Long-distance dispersal by rafting: reemergence of an old hypothesis. Endeavour 14:66-73

Jörger KM, Schrödl M (2013) How to describe a cryptic species? Practical challenges of molecular taxonomy. Front Zool 10:59. https ://doi.org/10.1186/1742-9994-10-59

Jörger KM, Norenburg JL, Wilson NG, Schrödl M (2012) Barcoding against a paradox? Combined molecular species delineations reveal multiple cryptic lineages in elusive meiofaunal sea slugs. BMC Evol Biol 12:245. https://doi. org/10.1186/1471-2148-12-245

Jörger KM, Neusser TP, Brenzinger B, Schrödl M (2014) Exploring the diversity of mesopsammic gastropods: how to collect, identify, and delimitate small and elusive sea slugs? Am Malacol Bull 32:290-307. https://doi.org/10.4003/006.032.0205

Jouin-Toulmond C, Gambi MC (2007) Description of Saccocirrus goodrichi sp. nov. (Annelida: Polychaeta: Saccocirridae), a new Mediterranean species and new data on the chaetae of S. papillocercus and S. major. Cah Biol Mar 48:381-390

Junkins R, Kelaher B, Levinton J (2006) Contributions of adult oligochaete emigration and immigration in a dynamic soft-sediment community. J Exp Mar Bio Ecol 330:208-220. https://doi. org/10.1016/j.jembe.2005.12.028

Kajihara H, Ikoma M, Yamasaki H, Hiruta SF (2015) Trilobodrilus itoi sp. nov., with a re-description of $T$. nipponicus (Annelida: Dinophilidae) and a molecular phylogeny of the genus. Zool Sci 32:405-417. https://doi.org/10.2108/zs140251

Kånneby T, Bernvi DC, Jondelius U (2015) Distribution, delimitation and description of species of Archaphanostoma (Acoela). Zool Scr 44:218-231. https://doi.org/10.1111/zsc.12092

Karanovic I, Tanaka H, Tsukagoshi A (2016) Congruence between male upper lip morphology and molecular phylogeny in Parapolycope (Ostracoda), with two new species from Korea Congruence between male upper lip morphology and molecular phylogeny in Parapolycope (Ostracoda), with two new species from. Invertebr Syst 30:231-254

Kelly RP, Palumbi SR (2010) Genetic structure among 50 species of the northeastern pacific rocky intertidal community. PLoS One. https://doi.org/10.1371/journal.pone.0008594

Kieneke A, Nikoukar H (2017) Integrative morphological and molecular investigation of Turbanella hyalina Schultze, 1853 (Gastrotricha: Macrodasyida), including a redescription of the species. Zool Anz 267:168-186. https://doi.org/10.1016/j. jcz.2017.03.005

Kieneke A, Martínez Arbizu PM, Fontaneto D (2012) Spatially structured populations with a low level of cryptic diversity in European marine Gastrotricha. Mol Ecol 21:1239-1254. https://doi. org/10.1111/j.1365-294X.2011.05421.x

Klautau M, Russo CAM, Lazoski C, Boury-esnault N, Thorpe JP, Solecava AM, Klautau M, Russo CAM, Lazoski C, Boury-esnault N, John P, Solt-cava AM (1999) Does cosmopolitanism result from overconservative systematics? A case study using the marine sponge Chondrilla nucula. Evolution (N Y) 53:1414-1422

Knowlton N (1993) Sibling species in the sea. Annu Rev Ecol Syst 24:189-216

Kritzer JP, Sale PF (2004) Metapopulation ecology in the sea: from Levins' model to marine ecology and fisheries science. Fish Fish 5:131-140. https://doi.org/10.1111/J.1467-2979.2004.00131.X

Kyle CJ, Boulding EG (2000) Comparative population genetic structure of marine gastropods (Littorina spp.) with and without pelagic larval dispersal. Mar Biol 137:835-845. https://doi.org/10.1007/ s002270000412

Leasi F, Norenburg JL (2014) The necessity of DNA taxonomy to reveal cryptic diversity and spatial distribution of meiofauna, with a focus on Nemertea. PLoS One. https://doi.org/10.1371/ journal.pone. 0104385

Leasi F, Norenburg JL (2016) At least some meiofaunal species are not everywhere. Indication of geographic, ecological and geological barriers affecting the dispersion of species of Ototyphlonemertes (Nemertea, Hoplonemertea). Mol Ecol 25:1381-1397. https:// doi.org/10.1111/mec. 13568

Leasi F, Todaro MA (2007) The Muscular system of Musellifer delamarei and other chaetonotidans with implication for the phylogeny and systematisation of the Paucitubulatina (Gastrotricha). Biol J Linn Soc 94:379-398

Leasi F, Todaro MA (2009) Meiofaunal cryptic species revealed by confocal microscopy: the case of Xenotrichula intermedia (Gastrotricha). Mar Biol 156:1335-1346. https://doi.org/10.1007/ s00227-009-1175-4 
Leasi F, Tang CQ, De Smet WH, Fontaneto D (2013) Cryptic diversity with wide salinity tolerance in the putative euryhaline Testudinella clypeata (Rotifera, Monogononta). Zool J Linn Soc 168:17-28. https://doi.org/10.1111/zoj.12020

Leray M, Knowlton N (2015) DNA barcoding and metabarcoding of standardized samples reveal patterns of marine benthic diversity. Proc Natl Acad Sci 2014:201424997. https://doi. org/10.1073/pnas.1424997112

Leray M, Knowlton N (2016) Censusing marine eukaryotic diversity in the twenty-first century. Philos Trans R Soc B Biol Sci 371:20150331. https://doi.org/10.1098/rstb.2015.0331

Lester SE, Ruttenberg BI (2005) The relationship between pelagic larval duration and range size in tropical reef fishes: a synthetic analysis. Proc Biol Sci 272:585-591. https://doi.org/10.1098/ rspb.2004.2985

Lester SE, Ruttenberg BI, Gaines SD, Kinlan BP (2007) The relationship between dispersal ability and geographic range size. Ecol Lett 10:745-758. https://doi.org/10.111 1/j.1461-0248.2007.01070.x

Lins L, Vanreusel A, van Campenhout J, Ingels J (2013) Selective settlement of deep-sea canyon nematodes after resuspensionan experimental approach. J Exp Mar Bio Ecol 441:110-116. https://doi.org/10.1016/j.jembe.2013.01.021

Lovén S (1844) Chaetoderma, ett nytt masksläkte n.g. Öfvers K Vetenskaps-Akad Förh 1:116+ pl.112

Mcfarlane CBA, Drolet D, Barbeau MA, Hamilton DJ, Ollerhead J (2013) Dispersal of marine benthic invertebrates through ice rafting. Ecology 94:250-256

Méndez N, Linke-Gamenick I, Forbes VE (2000) Variability in reproductive mode and larval development within the Capitella capitata species complex. Invertebr Reprod Dev 38:131-142. https://doi.org/10.1080/07924259.2000.9652448

Mevenkamp L, Van Campenhout J, Vanreusel A (2016) Experimental evidence for selective settlement of meiofauna from two distinct environments after sediment suspension. J Exp Mar Bio Ecol 474:195-203. https://doi.org/10.1016/j.jembe .2015 .10 .005

Meyer-Wachsmuth I, Curini Galletti M, Jondelius U (2014) Hypercryptic marine meiofauna: species complexes in Nemertodermatida. PLoS One. https://doi.org/10.1371/journal.pone.01076 88

Muenter L, Kieneke A (2017) Novel myo-anatomical insights to the Xenotrichula intermedia species complex (Gastrotricha: Paucitubulatina): Implications for a pan-European species and reconsideration of muscle homology among Paucitubulatina. Proc Biol Soc Wash 130:165-185. https://doi.org/10.2988/17-00013

Neusser TP, Heß M, Schrödl M (2009) Tiny but complex - interactive 3D visualization of the interstitial acochlidian gastropod Pseudunela cornuta (Challis, 1970). Front Zool. https://doi. org/10.1186/1742-9994-6-20

Neusser TP, Jörger KM, Schrödl M (2011) Cryptic species in tropic sands-interactive 3D anatomy, molecular phylogeny and evolution of meiofaunal Pseudunelidae (Gastropoda, Acochlidia). PLoS One. https://doi.org/10.1371/journal.pone.0023313

Norris RD, Hull PM (2012) The temporal dimension of marine speciation. Evol Ecol 26:393-415. https://doi.org/10.1007/s1068 2-011-9488-4

Packmor J, Riedl T (2016) Records of Normanellidae Lang, 1944 (Copepoda, Harpacticoida) from Madeira island support the hypothetical role of seamounts and oceanic islands as "stepping stones" in the dispersal of marine meiofauna. Mar Biodivers 46:861-877. https://doi.org/10.1007/s12526-016-0448-7

Palmer M (1988) Dispersal of marine meiofauna: a review and conceptual model explaining passive transport and active emergence with implications for recruitment. Mar Ecol Prog Ser 48:81-91. https://doi.org/10.3354/meps048081
Palmer MA, Gust G (1985) Dispersal of meiofauna in a turbulent tidal creek. J Mar Res 43:179-210. https://doi.org/10.1357/00222 4085788437280

Pietsch A, Westheide W (1985) Ultrastructural investigations of presumed photoreceptors as a means of discrimination and identificafion of closely related species of the genus Microphtbalmus (Polychaeta, Hesionidae). Zoomorphology 105:265-276

Prasath D, Balasubramaniam J, Marimuthu P, Jayaraj KA (2017) New record of two free-living marine nematode species, Sphaerolaimus balticus and Sphaerolaimus islandicus (Nematoda: Sphaerolaimaidae) from Sipphighat mangrove region, South Andaman. Indian J Geo Mar Sci 46:1105-1109

Pugh PJA (1996) Using artificial substrata to monitor how cryptofaunal acari colonize littoral algae on sub-antarctic south Georgia. Acarologia 37:188-200

Radziejewska T, Gruszka P, Rokicka-Praxmajer J (2006) A home away from home: a meiobenthic assemblage in a ship's ballast water tank sediment. Oceanologia 48:259-265

Rands $\varnothing$ PV, Domenico MD, Herranz M, Lorenzen ED, Sørensen MV (2018) Population genetic structure of the intertidal kinorhynch Echinoderes marthae (Kinorhyncha; Cyclorhagida; Echinoderidae) across the São Sebastião Channel, Brazil. Proc Biol Soc Wash 131:36-46. https://doi.org/10.2988/17-00005

Remane A (1933) Verteilung und organisation der benthonischen mikrofauna der Kieler Bucht. Wissenschaftliche Meeresuntersuchungen 21:161-221

Rinaldo A, Garraffoni S, Araújo TQ (2017) Phylogeny of Pseudostomella Swedmark, 1956 (Gastrotricha: Macrodasyida) base on morphological data and first insights on the historical biogeography of Thaumastodermatidae. Proc Biol Soc Wash 130:222-238. https://doi.org/10.2988/17-00014

Rocha-Olivares A, Fleeger JW, Foltz DW (2001) Decoupling of molecular and morphological evolution in deep lineages of a meiobenthic Harpacticoid Copepod. Mol Biol Evol 18:1088-1102. https ://doi.org/10.1093/oxfordjournals.molbev.a003880

Ronce O (2007) How does it feel to be like a rolling stone? Ten questions about dispersal evolution. Annu Rev Ecol Evol Syst 38:231-253. https://doi.org/10.1146/annurev.ecolsys.38.09120 6.095611

Rundell RJ, Leander BS (2014) Molecular examination of kalyptorhynch diversity (Platyhelminthes: Rhabdocoela), including descriptions of five meiofaunal species from the north-eastern Pacific Ocean. J Mar Biol Assoc UK 94:499-514. https://doi. org/10.1017/S0025315413001471

Sahraean N, Van Campenhout J, Rigaux A, Mosallanejad H, Leliaert F, Moens T (2017) Lack of population genetic structure in the marine nematodes Ptycholaimellus pandispiculatus and Terschellingia longicaudata in beaches of the Persian Gulf, Iran. Mar Ecol. https://doi.org/10.1111/maec.12426

Sánchez N, Yamasaki H, Pardos F, Sørensen MV, Martínez A (2016) Morphology disentangles the systematics of a ubiquitous but elusive meiofaunal group (Kinorhyncha: Pycnophyidae). Cladistics 32:479-505. https://doi.org/10.1111/cla.12143

Sands CJ, Convey P, Linse K, McInnes SJ (2008) Assessing meiofaunal variation among individuals utilising morphological and molecular approaches: an example using the Tardigrada. BMC Ecol 8:7. https://doi.org/10.1186/1472-6785-8-7

Sanford E, Kelly MW (2011) Local adaptation in marine invertebrates. Annu Rev Mar Sci 3:509-537. https://doi.org/10.1146/annurevmarine-120709-142756

Scarpa F, Cossu P, Sanna D, Lai T, Norenburg JL, Curini-Galletti M, Casu M (2015) An 18S and 28S-based clock calibration for marine Proseriata (Platyhelminthes). J Exp Mar Bio Ecol 463:22-31. https://doi.org/10.1016/j.jembe.2014.10.020

Schmidt H, Westheide W (1999) Genetic relationships (RAPDPCR) between geographically separated populations of the 
"cosmopolitan" interstitial polychaete Hesionides gohari (Hesionidae) and the evolutionary origin of the freshwater species Hesionides riegerorum. Biol Bull 196:216-226. https://doi. org/10.2307/1542567

Schmidt H, Westheide W (2000) Are the meiofaunal polychaetes Hesionides arenaria and Stygocapitella subterranea true cosmopolitan species?-results of RAPD-PCR investigations. Zool Scr 29:17-27. https://doi.org/10.1046/j.1463-6409.2000.00026 . $\mathrm{x}$

Schratzberger M, Rees HL, Boyd SE (2000) Effects of simulated deposition of dredged material on structure of nematode assemblages - the role of burial. Mar Biol 136:519-530

Scotese CR (2002) PALEOMAP project website. http://www.scote se.com. Accessed May 2017

Sedlacek L, Thistle D (2006) Emergence on the continental shelf: differences among species and between microhabitats. Mar Ecol Prog Ser 311:29-36

Shanks AL, Walters K (1997) Holoplankton, meroplankton, and meiofauna associated with marine snow. Mar Ecol Prog Ser $156: 75-86$

Smythe AB (2015) Evolution of feeding structures in the marine nematode order Enoplida. Integr Comp Biol 55:228-240. https://doi. org/10.1093/icb/icv043

Sponer R, Roy MS (2002) Phylogeographic analysis of the brooding brittle star Amphipholis squamata (Echinodermata) along the coast of New Zealand reveals high cryptic genetic variation and cryptic dispersal potential. Evolution (N Y) 56:1954-1967

Sterrer W (1973) Plate tectonics as a mechanism for dispersal and speciation in interstitial sand fauna. Neth J Sea Res 7:200-222

Sterrer W, Sørensen MV (2006) Chirognathia dracula gen. et spec. nov. (Gnathostomulida) from the west coast of North America. Mar Biol Res 2:296-302. https://doi.org/10.1080/1745100060 0895013

Struck TH, Koczula J, Stateczny D, Meyer C, Purschke G (2017) Two new species in the annelid genus Stygocapitella (Orbiniida, Parergodrilidae) with comments on their biogeography. Zootaxa 4286:301-332. https://doi.org/10.11646/zootaxa.4286.3.1

Struck TH, Feder JL, Bendiksby M, Birkeland S, Cerca J, Gusarov VI, Kistenich S, Larsson K-H, Liow LH, Nowak MD, Stedje B, Bachmann L, Dimitrov D (2018a) Cryptic species-more than terminological chaos: a reply to heethoff. Trends Ecol Evol 33:310-312. https://doi.org/10.1016/j.tree.2018.02.008

Struck TH, Feder JL, Bendiksby M, Birkeland S, Cerca J, Gusarov VI, Kistenich S, Larsson K-H, Liow LH, Nowak MD, Stedje B, Bachmann L, Dimitrov D (2018b) Finding evolutionary processes hidden in cryptic species. Trends Ecol Evol. https://doi. org/10.1016/j.tree.2017.11.007

Suatoni E, Vicario S, Rice S, Snell T, Caccone A (2006) An analysis of species boundaries and biogeographic patterns in a cryptic species complex: the rotifer-Brachionus plicatilis. Mol Phylogenet Evol 41:86-98. https://doi.org/10.1016/j.ympev.2006.04.025

Swift HF, Daglio LG, Dawson MN (2016) Three routes to crypsis: stasis, convergence, and parallelism in the Mastigias species complex (Scyphozoa, Rhizostomeae). Mol Phylogenet Evol 99:103-115. https://doi.org/10.1016/j.ympev.2016.02.013

Tanaka H, Ohtsuka S (2016) Historical biogeography of the genus Polycopissa (Ostracoda: Myodocopa: Cladocopina), with the description and DNA barcode of the second Indo-Pacific species from the Seto Inland Sea. Mar Biodivers 46:625-640. https ://doi.org/10.1007/s12526-015-0412-y

Taylor DJ, Finston TL, Hebert PDN (1998) Biogeography of a widespread freshwater crustacean: pseudocongruence and cryptic endemism in the North American Daphnia laevis complex. Evolution (N Y) 52:1648-1670

Teasdale M, Vopel K, Thistle D (2004) The timing of benthic copepod emergence. Limnol Oceanogr 49:884-889
Thistle D (2003) Harpacticoid copepod emergence at a shelf site in summer and winter: implications for hydrodynamic and mating hypotheses. Mar Ecol Prog Ser 248:177-185. https://doi. org/10.3354/meps248177

Thomas MC, Lana PC (2011) A new look into the small-scale dispersal of free-living marine nematodes. Zoologia 28:449-456. https:// doi.org/10.1590/S1984-46702011000400006

Todaro MA, Fleeger JW, Hu YP, Hrincevich AW, Foltz DW (1996) Are meiofaunal species cosmopolitan? Morphological and molecular analysis of Xenotrichula intermedia (Gastrotricha: Chaetonotida). Mar Biol 125:735-742

Todaro MA, Telford MJ, Lockyer AE, Littlewood DTJ (2006) Interrelationships of the Gastrotricha and their place among the Metazoa inferred from 18S rRNA genes. Zool Scr 35:251-259. https://doi. org/10.1111/j.1463-6409.2006.00228.x

Todaro MA, Leasi F, Hochberg R (2014) A new species, genus and family of marine Gastrotricha from Jamaica, with a phylogenetic analysis of Macrodasyida based on molecular data. Syst Biodivers 12:473-488. https://doi.org/10.1080/14772000.2014.942718

Tulchinsky AY, Norenburg JL, Turbeville JM (2012) Phylogeography of the marine interstitial nemertean Ototyphlonemertes parmula (Nemertea, Hoplonemertea) reveals cryptic diversity and high dispersal potential. Mar Biol 159:661-674. https://doi. org/10.1007/s00227-011-1844-y

Ullberg J, Ólafsson E (2003a) Effects of biological disturbance by Monoporeia affinis (Amphipoda) on small-scale migration of marine nematodes in low-energy soft sediments. Mar Biol 143:867-874. https://doi.org/10.1007/s00227-003-1139-z

Ullberg J, Ólafsson E (2003b) Free-living marine nematodes actively choose habitat when descending from the water column. Mar Ecol Prog Ser 250:141-149. https://doi.org/10.3354/meps260141

Van Campenhout J, Derycke S, Moens T, Vanreusel A (2014) Differences in life-histories refute ecological equivalence of cryptic species and provide clues to the origin of bathyal Halomonhystera (Nematoda). PLoS One. https://doi.org/10.1371/journ al.pone.0111889

van Oppen MJH, Klerk H, Olsen JL, Stam WT (1996) Hidden diversity in marine algae: some examples of genetic variation below the species level. J Mar Biol Assoc UK 76:239-242

Van Steenkiste NWL, Herbert ER, Leander BS (2018) Species diversity in the marine microturbellarian Astrotorhynchus bifidus sensu lato (Platyhelminthes: Rhabdocoela) from the Northeast Pacific Ocean. Mol Phylogenet Evol 120:259-273. https://doi. org/10.1016/j.ympev.2017.12.012

Villora-Moreno S, de Grimaldi SZ (1993) Redescription and ecology of Batillipes phreaticus Renaud-Debyser, 1959 (Arthrotardigrada, Batillipedidae) in the gulf of Valencia (western mediterranean). Cah Biol Mar 34:387-399

von Soosten C, Schmidt H, Westheide W (1998) Genetic variability and relationships among geographically widely separated populations of Petitia amphophthalma (Polychaeta: Syllidae). Results from RAPD-PCR investigations. Mar Biol 131:659-669. https://doi. org/10.1007/s002270050358

Wada S, Kameda Y, Chiba S (2013) Long-term stasis and short-term divergence in the phenotypes of microsnails on oceanic islands. Mol Ecol 22:4801-4810. https://doi.org/10.1111/mec.12427

Wares JP, Gianes SD, Cunningham CW (2001) A comparative study of asymmetric migration events across a marine biogeographic boundary. Evolution (N Y) 55:295-306

Westheide W (1977) The geographical distribution of interstitial polychaetes. Mikrofauna Meeresb 61:287-302

Westheide W (1991) The meiofauna of the galapagos: a review. In: James Mathew J (ed) Galápagos marine invertebrates. Springler, New York, pp 37-69

Westheide W (2005) Meiofauna geographic distribution: vicariance and dispersal. Meiofauna Mar 14:201-207 
Westheide W, Hass-Cordes E (2001) Molecular taxonomy: description of a cryptic Petitia species (Polychaeta: Syllidae) from the island of Mahe (Seychelles, Indian Ocean) using RAPD markers and ITS2 sequences. J Zool Syst Evol Res 39:103-111

Westheide W, Rieger RM (1987) Systematics of the amphiatlantic Microphthalmus listensis species-group (Polychaeta: Hesionidae): facts and concepts for reconstruction of phylogeny and speciation. Zeitschrift für Zool Syst und Evol 25:12-39

White TA, Stefanni S, Stamford J, Hoelzel AR (2009) Unexpected panmixia in a long-lived, deep-sea fish with well-defined spawning habitat and relatively low fecundity. Mol Ecol 18:2563-2573. https://doi.org/10.1111/j.1365-294X.2009.04218.x

Yamasaki H, Hiruta SF, Kajihara H, Dick MH (2014) Two Kinorhynch species (Cyclorhagida, Echinoderidae, Echinoderes) show different distribution patterns across Tsugaru Strait, Northern Japan. Zool Sci 31:421-429. https://doi.org/10.2108/zs140011

Zawierucha K, Grzelak K, Kotwicki L, Michalczyk Ł, Kaczmarek Ł (2013) Batillipes pennaki Marcus, 1946, a new addition to the
Thai Tardigrade fauna, with an overview of literature on the species. Pak J Zool 45:801-808

Zeppilli D, Vanreusel A, Danovaro R (2011) Cosmopolitanism and biogeography of the genus Manganonema (Nematoda: Monhysterida) in the deep sea. Animals 1:291-305. https://doi. org/10.3390/ani1030291

Zeppilli D, Sarrazin J, Leduc D, Arbizu PM, Fontaneto D, Fontanier C, Gooday AJ, Kristensen RM, Ivanenko VN, Sørensen MV, Vanreusel A, Thébault J, Mea M, Allio N, Andro T, Arvigo A, Castrec J, Danielo M, Foulon V, Fumeron R, Hermabessiere L, Hulot V, James T, Langonne-Augen R, Le Bot T, Long M, Mahabror D, Morel Q, Pantalos M, Pouplard E, Raimondeau L, Rio-Cabello A, Seite S, Traisnel G, Urvoy K, Van Der Stegen T, Weyand M, Fernandes D (2015) Is the meiofauna a good indicator for climate change and anthropogenic impacts? Mar Biodivers 45:505-535. https://doi.org/10.1007/s12526-015-0359-z 
José Cerca - On the Origin of Cryptic Species: Insights from the Stygocapitella species complex

\section{Supplementary data for manuscript 2}

The supplementary data for this manuscript can be found online in https://doi.org/10.1007/s00227-018-3383-2 
José Cerca - On the Origin of Cryptic Species: Insights from the Stygocapitella species complex

\section{Manuscript 3}

Deceleration of morphological evolution in a cryptic species complex and its links to paleontological stasis 


\section{Title:}

2 Deceleration of morphological evolution in a cryptic species complex and its link to paleontological stasis

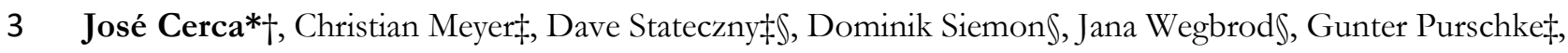

4 Dimitar Dimitrov\#, Torsten H. Struck $\dagger$

$5 \quad *$ Corresponding author: José Cerca; jose.cerca@gmail.com; ORCID 0000-0001-7788-4367

6 † Frontiers of Evolutionary Zoology Research Group, Natural History Museum, University of Oslo, 0562

7 Oslo, Norway

$8 \ddagger$ Zoology and Developmental Biology, Department of Biology and Chemistry, University of Osnabrueck, 9 Barbarastr. 11, 49069 Osnabrueck, Germany

10 \Zoological Research Museum Alexander Koenig, Adenauerallee 160, 53113 Bonn, Germany

11 \# Department of Natural History, University Museum of Bergen, University of Bergen, P.O. Box 7800,

125020 Bergen, Norway

13 Keywords:

14 Stasis; Speciation; Sibling species; Morphological acceleration; Morphological evolution; adaptive radiation 
Deceleration of morphological evolution in a cryptic species complex and its link to paleontological stasis

\section{Abstract:}

Morphological stasis or the absence of morphological change is a well-known phenomenon in the paleontological record, yet it is poorly integrated with neontological evidence. Recent evidence suggests that cryptic species complexes may remain morphologically identical due to morphological stasis. Here, we describe a case of long-term stasis in the Stygocapitella cryptic species complex (Parergodrilidae, Orbiniida, Annelida). Using phylogenetic methods and morphological data, we find that rates of morphological evolution in Stygocapitella are significantly slower than in closely related taxa (Nerillidae, Orbiniidae). Assessment of quantitative and qualitative morphology revealed the presence of four morphotypes with only subtle differences, while molecular data supports 10 reproductively isolated clades. Notably, estimates for the time of Stygocapitella species divergence range from $\sim 275$ million years to $\sim 18$ million years, including one case of two morphologically similar species which have diverged about 140 million years ago. These findings provide evidence for morphological deceleration and long-term morphological stasis in Stygocapitella, and that speciation is not necessarily accompanied by morphological changes. The deceleration of morphological divergence in Stygocapitella can be potentially linked to niche conservatism and tracking, coupled with the fluctuating dynamics of the interstitial environment, or genetic constraints due to progenetic evolution. Finally, we conclude that failing to integrate speciation without morphological evolution in paleontology may bias estimates of rates of speciation and morphological evolution.

\section{Introduction}

The occurrence of morphological stasis, defined as little or no morphological evolution over extended periods of time, remains a controversial topic in evolutionary biology (Futuyma 2010). Morphological variation is seen as a desired feature of any biological system and its absence is often interpreted as a potential failure to capture variation (Weiss 2011). Lineages with higher evolvability are expected to occupy broader range of habitats more quickly and efficiently, ultimately replacing less labile groups (Rabosky and Adams 2012) and hence, cases of low-evolvability and morphological stasis are expected to be exceptionally uncommon. Despite this, examples of morphological stasis are commonplace in the fossil record (Cheetham 1986; Futuyma 2005, 2010; Frame et al. 2007; Hunt et al. 2008; Hunt and Rabosky 2014; Voje et al. 2018), where series of invariant morphotypes occur at diverse time-scales in different organismal groups (Cheetham 1986; Hunt 2007).

A theory which aims to explain the occurrence of long periods of stasis is the punctuated equilibrium (Eldredge 1971; Eldredge and Gould 1972). In its essence, punctuated equilibrium suggests that species undergo long periods of morphological stasis, which are disrupted by rapid change during 
speciation (Eldredge and Gould 1972; Futuyma 2005). The postulation that morphological evolution occurs exclusively during speciation implies that adaptive and selective processes are insignificant during substantial parts of the evolutionary histories of species (e.g. (Stanley 1975)), and challenged the accumulating evidence of the emerging 'modern synthesis' (Futuyma 2005; Hunt and Rabosky 2014). While the modern synthesis-punctuated equilibrium debate lasted for about 2 decades, over the years paleontological evidence was aligned with the major processes suggested by the modern synthesis: selection, drift, mutation and gene flow (Hunt and Rabosky 2014). However, the conciliation of stasis with these processes was never thoroughly achieved. On one hand, researchers have argued that stasis could result either from biases in the paleontological evidence due to, for example, taphonomical biases (Kidwell and Holland 2002; Pennell et al. 2014), or either be due to the lack of statistical or sampling resolution (Frame et al. 2007; Voje 2016). On the other hand, competing views have focused on developing theoretical frameworks underlying the deceleration of morphological evolution which include scenarios of stabilizing selection (Charlesworth et al. 1982; Hansen and Houle 2004; Futuyma 2010), niche conservatism and tracking (Futuyma 2010, 2015), fluctuating ecological conditions (Futuyma 1987, 2010, 2015; Sheldon 1996; Smith et al. 2011), lack of new ecological interactions (Nordbotten and Stenseth 2016), constraints (Charlesworth et al. 1982; Maynard Smith et al. 1985; Wagner and Schwenk 2000; Hansen and Houle 2004; Futuyma 2010; Smith et al. 2011), recurrent bottlenecks (Futuyma 2010), physiological or behavioural adaptation (Lee and Frost 2002; Futuyma 2010; Lassance et al. 2019), and the influence of particular environments and environmental conditions (Westheide 1977; Futuyma 1987, 2010; Westheide and Rieger 1987; Giere 2009; Gueriau et al. 2016).

One suggested way of integrating components of punctuated equilibrium and modern synthesis can result from variation in rates of anagenetic and cladogenetic change (Futuyma 1987, 2015). If a cladogenetic event (speciation) occurs, and posterior anagenetic changes are slowed or non-existent, daughter species will be similar in morphology. While this idea is plausible, it cannot be tested in the paleontological record because paleontological species are diagnosed based on morphology alone and rely on the evolution of morphological differences (Jackson and Cheetham 1999; Aze et al. 2011; Strotz and Allen 2013). If daughter species are morphologically similar, these estimations will be biased. A solution to this problem is the combination of molecular phylogenetic tools coupled with morphological data in lineages displaying stasis (Bokma 2002, 2008; Mattila and Bokma 2008; Katz 2018). For example, Katz (2019) argues that integrating evidence from palaeontology, paleobiology and molecular phylogenetics is the key to understand the early-burst of the Angiosperms. Applying a holistic approach to the problem of stasis could potentially provide a link between paleontological evidence and evolutionary studies based on neontological evidence. Cryptic species complexes are a potential target for such approach. Morphological stasis has been suggested to occur in extant cryptic species complexes - different species which are similar in morphology (Wada et al. 2013; Swift et al. 2016; Cerca et al. 2018; Struck et al. 2018). Cryptic species have been found widespread across the tree of life (Pfenninger and Schwenk 2007; Pérez-Ponce de León and Poulin 2016), and are being discovered at a faster pace. Matching morphological stasis as seen in 
cryptic species and paleontological stasis may provide the possibility to test for phylogenetic signatures of stasis in closely related extant taxa (Mattila and Bokma 2008) and offer the possibility to quantify gene flow and genetic divergence in these complexes (Sheldon 1996; Futuyma 2010; Hunt and Rabosky 2014). In cryptic species, morphological evolution can be potentially decelerated, if adaptive pressures focus on physiological, behavioural or biochemical traits that have no bearing on morphology (Gómez et al. 2002; Lee and Frost 2002; Novo et al. 2010, 2012; Struck et al. 2018; Lassance et al. 2019). Despite this potential, currently described cryptic species complexes are relatively young, contrasting with fossil record evidence which suggest long-lasting stasis. A promising system to close this gap is the Stygocapitella cryptic species complex (Parergodrilidae, Orbiniida, Annelida), which until recently was thought to consist of a singlespecies with a worldwide distribution (Schmidt and Westheide 2000; Struck et al. 2017). Recent evidence suggests that pronounced periods of stasis are intertwined with slight changes in morphology (Struck et al. 2017). However, this work focused on a limited set of species and populations with slight morphological differences, hence lacking resolution to describe morphological and genetic evolution. Here, we present an extended sampling of this genus, with special emphasis on the Northern hemisphere. Specifically, we determine genetic and morphological divergences in the Stygocapitella cryptic species complex and in closely related taxa.

\section{Material and methods}

\section{Sample collection, identification and preservation}

Stygocapitella is an interstitial annelid, generally found around the high-water line of stable, sheltered gravel or sandy beaches (Purschke 2018) (Fig. 1). In each sampling location, we collected sediment samples by drawing transects from the high-water line to the foot of the dune. Every one meter, we dug a one-meter deep hole and, in each of these, we collected approximately $375 \mathrm{~cm}^{3}$ of sediment every $15 \mathrm{~cm}$-depth. Afterwards, we extracted Stygocapitella specimens under dissecting microscope using the $\mathrm{MgCl}_{2}$ method (Westheide and Purschke 1988). For this study a total of 33 sites across the Northern hemisphere were sampled (Fig. 2, Suppl. Table S1 \& S2). Specimens used for molecular biology were preserved in 95\% ethanol and for morphological analyses in sucrose-picric acid-paraformaldehydeglutaraldehyde (SPAFG) following Westheide and Purschke (1988) (Suppl. Table S1,3-4).

\section{Molecular biology}

Genomic DNA was extracted using phenol-chloroform or the E.Z.N.A Tissue DNA Kit (Omega Bio-Tek). The nuclear markers $18 \mathrm{~S}$ and ITS1 and the mitochondrial CO1 were amplified with the QIAGEN® Multiplex PCR Kit (Qiagen, Hilden, Germany) in a $10 \mu \mathrm{l}$ reaction-mix containing $5 \mu$ l of multiplex mix, $1 \mu \mathrm{l}$ Q-solution, $0.8 \mu \mathrm{l} 10 \mu \mathrm{M}$ of both forward and reverse primer, $1 \mu \mathrm{l}$ genomic DNA and $1.4 \mu \mathrm{l}$ deionized water. For the mitochondrial gene $16 \mathrm{~S}$, a $25 \mu \mathrm{l}$ reaction-mix included $15.2 \mu \mathrm{l}$ of $\mathrm{H}_{2} \mathrm{O}, 2.5$ 
$\mu$ l of 10X PCR Buffer I (with $\mathrm{MgCl}_{2}$ added; Applied Biosystems), $2.5 \mu$ l of BSA, $0.5 \mu$ l of 10mM dNTPs, $1.6 \mu \mathrm{l} 10 \mu \mathrm{M}$ of both forward and reverse primer and $0.13 \mu \mathrm{l}$ of amplitaq gold (Applied Biosystems). The following primers have been used: LCO1490-JJ (CHACWAAYCATAAAGATARYGG) \& HCO2198-JJ (AWACTTCVGGRTGVCCAAARAATCA; both (Astrin and Stüben 2008)) for COI, 18e (CTGGTTGATCCTGCCAGT; (Hillis and Dixon 1991)) \& 18R1779 (TGTTACCGACTTTTACTTCCTCTA; (Struck et al. 2002)) for 18S, species-specific primers Stygo_ITS1_F (TGTTGATTACGTCCCTGCCC) \& Stygo_ITS1_R (GTCAACCGACCCTGAGACAG) for ITS1 and 16SarL (CGCCTGTTTATCAAAAACAT; (Palumbi et al. 1991) \& 16S_AN-R (GCTTACGCCGGTCTGAACTCAG; (Zanol et al. 2010)) for 16S. The only exceptions were the American populations for COI, where we used polyLCO (GAYTATWTTCAACAAATCATAAAGATATTGG) \& polyHCO (TAMACTTCWGGGTGACCAAARAATC; both (Lobo et al. 2016)). PCR conditions for ITS1 included the following protocol (initial denaturation: $15^{\prime} 95^{\circ} \mathrm{C}$; 40 cycles: $30^{\prime \prime} 95^{\circ} \mathrm{C}, 30^{\prime \prime} 66^{\circ} \mathrm{C}, 1^{\prime} 72^{\circ} \mathrm{C}$; final elongation: $20^{\prime} 72^{\circ} \mathrm{C}$ ), for $16 \mathrm{~S}$ a touchdown one (initial denaturation: $15^{\prime} 95^{\circ} \mathrm{C} ; 40$ cycles: $30^{\prime \prime} 94^{\circ} \mathrm{C}, 30^{\prime \prime}$ $51^{\circ} \mathrm{C}$ (touchdown: $-0.2^{\circ} \mathrm{C}$ per cycle), $2^{\prime} 65^{\circ} \mathrm{C}$; final elongation: $7^{\prime} 65^{\circ} \mathrm{C}$ ), for $18 \mathrm{~S}$ a touchdown/touch-up (initial denaturation: $15^{\prime} 95^{\circ} \mathrm{C} ; 15$ cycles: $35^{\prime \prime} 94^{\circ} \mathrm{C}, 90^{\prime \prime} 55^{\circ} \mathrm{C}$ (touchdown: $-1^{\circ} \mathrm{C}$ per cycle), $2.5^{\prime} 72^{\circ} \mathrm{C} ; 25$ cycles: $35^{\prime \prime} 94^{\circ} \mathrm{C}, 90^{\prime \prime} 50^{\circ} \mathrm{C}, 2.5^{\prime} 72^{\circ} \mathrm{C}$; final elongation: $10^{\prime} 72^{\circ} \mathrm{C}$ ), and for $\mathrm{COI}$ the same (initial denaturation: $15^{\prime} 95^{\circ} \mathrm{C}$; 15 cycles: $35^{\prime \prime} 94^{\circ} \mathrm{C}, 90^{\prime \prime} 55^{\circ} \mathrm{C}$ (touchdown: $-1^{\circ} \mathrm{C}$ per cycle), $1.5^{\prime} 72^{\circ} \mathrm{C} ; 25$ cycles: $35^{\prime \prime} 94^{\circ} \mathrm{C}, 90^{\prime \prime} 50^{\circ} \mathrm{C}, 1.5^{\prime} 72^{\circ} \mathrm{C}$; final elongation: $10^{\prime} 72^{\circ} \mathrm{C}$ ). PCR fragments were purified using a phosphatase-exonuclease mix and Sanger-sequenced by Macrogen Europe. Given the length of the 18S fragment, four additional sequencing primers were included: 18r (CTCTAAT'TT'T'TCAAAGTAAAC), 18L (AGCTCTCAATCTGTCAATCCT; both (Hillis and Dixon 1991)), 18F997 (TTCGAAGACGATCAGATACCG; (Struck et al. 2002)) \& 18SF3_Stygo (CCTCGGGATTGGAATGAGTAC; (Struck et al. 2017). After sequencing, all sequences were assembled and the ends automatically trimmed using Geneious (v6.8.1). The quality of the assembly of each sequence was visually checked and each consensus sequence screened for contamination by doing NCBI megablast searches against the complete non-redundant database.

\section{Phylogenetic and molecular clock analyses}

Details about amplified markers as well as outgroups obtained from GenBank are provided in Suppl. Table S1. The sequences of each gene were aligned with mafft v7.310 using a maximum of 1,000 iterations and the accurate localpair algorithm (Katoh and Standley 2013). ITS1 was aligned using the genafpair algorithm, which is optimized for gappy sequences. After alignment, both ends of the sequences were trimmed until the first position without missing data. These datasets were concatenated with FASconCAT v1.1 (Kück and Meusemann 2010). A partitioned Maximum Likelihood (ML) analysis of the concatenated dataset was performed using IQ-tree v1.5.5 (Nguyen et al. 2015) with an automatic determination of the best substitution model for each gene, 300 initial parsimony trees, 15 best trees 
retained during search and 1,000 bootstrap replicates. Similar settings were used for ML analyses of each gene independently.

Molecular clock analyses were conducted using BEAST v2.4.7 (Bouckaert et al. 2014). We used IQ-tree's ModelFinder to determine which substitution models best fit the dataset (Kalyaanamoorthy et al. 2017). After performing several runs using combinations of different prior models and genes, we selected CO1 and $18 \mathrm{~S}$ for the final dating analysis because both genes are commonly used for molecular dating of annelids and showed best chain convergence and effective sampling sizes. BEAST was run with linked trees using a TN93 model with equal frequencies for 18S and HKY with estimated frequencies and a $\Gamma$ distribution with four categories for CO1. As no fossil record is known for these taxa, we selected a relaxed, log-normal clock to account for rate heterogeneity across lineages and mean values of 0.0001425 and 0.0176 as substitution rates per million year for $18 \mathrm{~S}$ and COI, respectively (Escalante and Ayala 1995; Pérez-Losada et al. 2004; Struck et al. 2017). We applied a birth-death model and constrained the in-group as monophyletic. A MCMC was run for one billion generations, sampling every $100,000^{\text {th }}$ generation. We confirmed chain convergence using Tracer v1.6 (Rambaut et al. 2007), with a 1\% burn-in threshold. A Maximum Credibility Consensus Tree was obtained using TreeAnnotator (Bouckaert et al. 2014). Considering the potential biases and criticism of molecular clock approaches, we limit our interpretation of these results.

\section{Genetic diversity}

To validate the established lineages, we performed an "Automatic Barcode Gap Discovery" analysis using the ABGD web interface (https://bioinfo.mnhn.fr/abi/public/abgd/) with the COI data (i.e. the "animal barcode"). ABGD analysis was run using the default settings (0.001 > Prior Intraspecific divergence $<0.1 ; 10$ steps; 1.5 relative gap width; 20 bins for distance distribution; JC69 distance).

Polymorphic sites, haplotype diversity, sampling variation and Tajima's D were calculated using DNAsp v6.10.01 (Rozas et al. 2017) and the 16S marker, as it has the highest coverage of species and populations. For the isolation-by-distance test, we applied a mantel test in R using the "ade4" package (Dray and Dufour 2007). For this test, we selected the sequences for each of the four Atlantic species separately, and realigned each individual gene dataset using mafft as previously described. Pairwise F $_{\text {ST }}$ were obtained with DNAsp. The least distance between each pair of sites was calculated using google maps' "measure distance" function. After this, we modified the distance line by adding points until the minimum distance between two sites would not cross any landmass. The obtained $\mathrm{F}_{\text {ST }}$ values and geographic distances between sites were used to compute a mantel test based on 9,999 replicates using the “ade4” R package (Dray and Dufour 2007). For the EA_C we excluded the two American specimens to ensure that the test is not dominated by the long distance to these two specimens, as evidence shows that these might be a result of accidental human translocation (Radziejewska et al. 2006). 
Morphological divergence was evaluated by Scanning Electron Microscopy (SEM) and morphometrics. Due to the small size of the specimens, we were unable to genotype and obtain morphological data of the same individual (Westheide and Hass-Cordes 2001). Individuals used in morphological studies were identified indirectly based on the investigated site. For SEM, specimens were transferred to a buffered $1 \% \mathrm{OsO}_{4}$ solution for one hour at ambient temperature and dehydrated in a graded ethanol series from $30 \%$ to $100 \%$. Dehydrated specimens were critically-point-dried with $\mathrm{CO}_{2}$, mounted on aluminium stubs, sputter coated with platinum and examined with a Zeiss Auriga field emission SEM. In total we investigated 73 specimens from 16 sites ( 4.5 specimens per from: Langebaan, Sarge Bay, Gnarabup Beach, Roche Harbor, Reuben State Park, $4^{\text {th }}$ of July Beach, Canoe Beach, Lubec, Lødingen, Henningsvær, Schilksee, île Callot, List, Bristol Channel, Gravesend, and Plymouth; Suppl. Table S3). For morphometrics, quantitative measurements of sexually mature specimens were carried out based on pictures taken under a light microscope at an amplification of 10X. Images were assembled using Adobe Photoshop and morphometric traits measured in ImageJ. These included 6 body size characteristics: body length and width, prostomium length and width, and pygidium length and width; of a total of 123 individuals from 18 sites ( $\sim 7$ specimens per site; Langebaan, Sarge Bay, Gnarabup Beach, Roche Harbor, Reuben State Park, 4th of July Beach, Canoe Beach, Lubec, Lødingen, Henningsvær, Schilksee, Île Callot, Glenancross, Keitum, Bristol Channel, Gravesend, Plymouth, and Ellenbogen; Suppl. Table S4).

\section{Rates of morphological and molecular evolution}

First, we analysed which morphological characters are variable and/or fixed within the Stygocapitella species complex. We did this to obtain character states for each lineage, and to assess the degree of variability among and across lineages. After this initial assessment, we analysed (i) the number of segments with chaetae; and (ii) the number and pattern of chaetal type in each individual chaetiger (Suppl. Table S3). Only the first and the second chaetiger displayed variance in chaetal pattern, and hence the third and following segments were coded only once. Based on this information, we investigated rates of morphological evolution within Stygocapitella by means of an ancestral state reconstruction and by a regression of morphological data and pairwise genetic differences. We obtained ancestral state reconstructions by mapping morphological characters on a tree topology derived from the ML and Bayesian analyses above using Mesquite version 3.51. We applied both ML and parsimony reconstructions. In addition, we determined Multidimensional Morphological Disparity (MMD) indices within and between species as described in Struck et al. (2017). In brief, this method relies on the decomposition of variance through a principal component analyses (PCA). Using both discrete morphological and morphometric data, we performed a PCA using the function "prcomp" included in the basic R package "stats" (R Core Team 2013). In both cases the first four principal components were selected for the MMD calculations as they accounted for $>99 \%$ of the variance. The MMD indices were plotted against the uncorrelated genetic 
distances of the $18 \mathrm{~S}$ gene within and between Stygocapitella species, which we obtained using MEGA X (Kumar et al. 2018), by applying 500 bootstrap replications, the TN93 model, and a $\Gamma$-distribution.

After this, we compared the rate of morphological evolution within Stygocapitella to other closely related groups within Orbiniida (Struck et al. 2015). To do so, we selected 12 species from Orbiniidae and 11 Nerillidae for which morphological and molecular datasets exist (Worsaae 2005; Bleidorn et al. 2009) (Suppl. Tables S5-7). Importantly, both these taxa and Stygocapitella have a similar degree of genetic divergence (Struck et al., 2015). Conveniently, Orbiniidae comprises both in faunal and interstitial species, while Nerillidae consists exclusively of interstitial species such as Stygocapitella. The integration of the morphological records obtained herein and the records from the literature (Worsaae 2005; Bleidorn et al. 2009; Zrzavý et al. 2009; Struck et al. 2015) led to a morphological data matrix consisting of 32 species (9 from Stygocapitella, 11 from Nerillidae, and 12 from Orbiniidae) and 75 morphological characters (Suppl. Tables S5-6). We then conducted a PCA analysis of this dataset using the PCA option of the "FactoMineR" package (Lê et al. 2008). Based on first 18 principal components, which together explain 99.07\% of the variation in the dataset, we determined MMD indices between species within Stygocapitella, Orbiniidae and Nerillidae separately, and tested if they were statistically different to each other using Tukey's HSD and pairwise students' $T$ tests.

To contrast morphological and molecular evolution, we compiled a dataset of $18 \mathrm{~S}$ sequences for each species (Suppl. Table S7). Considering that 18S was the slowest evolving gene in the dataset, this gene is the ideal gene to analyse distantly related lineages. Based on this dataset, we reconstructed a ML tree using IQ-Tree (as described above) and obtained pairwise genetic distances between species. Pairwise MMD indices were plotted against the corresponding pairwise genetic distances using the "ggplot" function of the R package "ggplot2" (Wickham 2016) with a loess smoothed fit regression including confidence regions. Finally, we mapped the morphological characters on the ML tree using Mesquite version 3.51 with the ML reconstruction option. We counted the number of changes occurring in each branch, and plotted these on the ML tree to quantify the number of total changes per branch.

\section{Ecological data}

Bioclimatic variables were downloaded from the world-climatic database using the "raster" R package (Hijmans 2014). Nineteen variables were downloaded with a 2.5 minutes of a degree resolution (21.62 $\mathrm{m}^{2}$ at the equator) for each of the sampling sites. Because of the extensive sampling effort in the Eastern Atlantic, we subsampled sites in which only one species occurred. Ideally, we would include variables such as granularity, $\mathrm{pH}$, moisture content - but this was not possible at this stage given the requirement of specialized equipment which was not available at the sampled sites across the entire globe. Additionally, given the strong short-term fluctuations of these parameters (Giere 2009), a comprehensive dataset may only be obtained after repeated and long-term measurements over several years, accounting for events such as heavy rains and stormy weather. "Species" was treated as the dependent variable and 
each of the 19 climatic variables as an independent variable. Because species is a multinomial variable, we fitted a multinominal logistic regression using the R package "nnet" (Venables and Ripley 2002). After fitting each model, we performed a least squares means analysis using the R package "lsmeans" (Lenth 2013). We evaluated species-presence pairwise contrasts using F-ratios and its associated $P$-value.

\section{Results}

\section{Number of Stygocapitella species}

We obtained sequences from four gene markers (i.e., 16S, COI, 18S \& ITS1) for 301 Stygocapitella subterranea, 12 S. australis and 18 S. minuta specimens from 32 sites, as well as five orbiniid outgroups (Suppl. Table S1). The concatenated dataset comprised 4,081 nucleotide positions. Both maximum likelihood (Suppl. Fig. S1) and Bayesian analyses (Fig. 3) of the concatenated molecular data resulted in the same topology. Ten well supported species were found with bootstrap values $\geq 95$ and posterior probabilities $\geq 0.95$ except for the Eastern Atlantic species B (EA_B) (bootstrap value $=87$, posterior probability $=$ 0.81). All species except $S$. subterranea, S. australis and S. minuta, are new and formal description is pending. Relationships among species received high support with only two cases of bootstrap values $<95$. Singlegene phylogenies retrieved the same species as the concatenated datasets (Suppl. Table S8; Suppl. Fig. S1S5). The highly conserved $18 \mathrm{~S}$ gene was unable to unambiguously distinguish the most recent divergence between closely related species (Suppl. Fig. S2). In congruence with the phylogenetic analysis, the barcoding analyses (ABGD) found an intraspecific maximal distance of 0.031581 for COI and the recursive partitioning found eight species within S. subterranea.

The three species occurring in Europe, WA and EA_C in North America, as well as EP_D, EP_C and EP_B in the Pacific Ocean occur in sympatry at a total of seven out of 32 sites (Figs. 1 \& 2), often cooccurring within the same handful of sand. For example, three of the four Eastern Pacific species cooccur at the $4^{\text {th }}$ of July beach and all three Eastern Atlantic species are found at Musselburgh.

\section{Ancestral state reconstruction}

The eight discrete morphological characters present in Stygocapitella (out of a total of 75 assessed characters; Fig. 1) exhibited interindividual and interspecific variation. Ancestral character reconstructions of these discrete morphological characters suggest the occurrence of four distinct morphotypes based on the number of chaetigers and the number of specific chaetae in certain chaetigers (Fig. 4A; Suppl. Fig. S6). Morphotype \#1 (red in Fig. 4) is restricted to S. minuta. Besides having only eight chaetigers, the first chaetiger of \#1 has two whip-like chaetae and three bilimbate chaetae. All following chaetigers have four bilimbate chaetae. While \#1 is considerably distinct, the other three morphotypes are very similar to each other. All three (\#2,\#3,\#4) have 10 chaetigers and possess an additional chaetal type, forked chaetae. Morphotype \#2, observed in S. australis, in specimens from $4^{\text {th }}$ of July beach and in one specimen from Plymouth in EA_C consists of two whip-like, two forked and one bilimbate chaeta in the first chaetiger 
and two bilimbate and two forked in the rest (green in Fig. 4; Suppl. Figs. S6-7). In comparison to \#2, \#3 has one additional bilimbate chaeta in the first and second chaetigers (Fig. 4; Suppl. Fig. S6). This morphotype is observed in EA_B, EA_C and WA as well as in some specimens of EA_A and the Eastern Pacific. Finally, \#4 has one additional bilimbate chaetae in the second chaetiger when compared with \#3 and is present in the Eastern Pacific, in EA_A and in one specimen from Gravesend in EA_C (yellow in Fig. 4; Suppl. Fig. S6). The ancestral state reconstructions unambiguously reveal that \#1 is the ancestral condition for S. minuta, \#2 for EP_A and S. australis, \#3 for EP_C, EP_D and EA_A, and \#4 for EA_B, EA_C and WA.

These results show that the Stygocapitella species complex is composed of several cryptic species as the majority of species are presently morphologically indistinguishable. Only $S$. minuta can be distinguished from the remaining species having a particularly distinct morphology. The remaining species display morphologies which are not species-exclusive, and differences between the three morphologies are minimal (Fig. 4; Suppl. Fig. S7 - blue; green; yellow morphotypes). The maximal difference is three additional bilimbate chaetae in a total of 44 chaetae for \#4 in comparison to \#2.

\section{Morphological disparity within Stygocapitella}

We obtained estimates of morphological disparity within the Stygocapitella cryptic complex and compared these to estimates from two closely related taxa. Mapping of the 75 morphological characters on the 18S ML tree shows that morphological evolution in Stygocapitella is slower when compared to nerillids and orbiniids (Fig. 4B). Indeed, in a total of 16 branches, only 4 are associated with morphological changes in Stygocapitella, while nerillids and orbiniids display changes at 19 out of 20 and 18 out of 22 branches, respectively. Within Stygocapitella we found one branch showing three, two branches displaying two, and a single branch with one morphological change. This translates to an average of 0.5 changes per branch in Stygocapitella. In contrast, when considering branches with changes in nerillids, only six showed three or less changes, while 13 had between four to 12 changes, totaling to an average of 4.1 morphological changes per branch. Orbiniids displayed eight branches with one to three morphological changes and 10 branches with four to eight changes (Fig. 4B). The average number of changes per branch in orbiniids is 2.8. Thus, in Stygocapitella not only the percentage of branches with no changes is higher, but also the amount of change along a branch is considerably smaller considering both the average and the maximum number of changes.

Principal component analysis shows that Nerillidae, Orbiniidae and Styocapitella are clearly separated from each other (PC1 and PC2 together explain 64.4\% of the variance). In addition to this, Nerillidae and Orbiniidae occupy a substantially larger morphospace area than Stygocapitella (Fig. 5A). MMD analysis shows that this difference is not restricted to the first principal components, but holds up for the first 18 principal components. MMD indices of Stygocapitella had a mean value of 1.14 with a standard deviation of 1.28 and a median of 0.41 . For nerillids, the mean was 7.21 with a standard deviation 

of 2.76 and median of 7.86 and for orbiniids it was 7.46 with 3.29 and 7.96 , respectively. Boxplots of the distributions of the MMD indices show that the quartiles of Stygocapitella do not overlap with the quartiles belonging to Nerillidae and Orbiniidae, while these two overlap completely (Fig. 5B). Accordingly, Tukey's HSD and students' T-tests show that morphological disparity in Stygocapitella is significantly lower in comparison to both Nerillidae and Orbiniidae $(P<0.000001$ in all cases), while there is no significant difference in morphological disparity between Nerillidae and Orbiniidae (Tukey's HSD: $P=0.7343163$; students' T: $P=0.45)$.

Plotting of the MMD indices against pairwise genetic distances in Stygocapitella, nerillids and orbiniids (Fig. 5C) indicates that lower MMD values in Stygocapitella are not an artefact of taxonomical ranks (Stygocapitella is a genus; Nerillidae and Orbiniidae are families). In Stygocapitella MMD indices remain between 0 and 1 until a pairwise genetic distance of 0.025 . These values increase slightly to about 4 only at higher molecular distances. This is in agreement with the mapping of morphological change along the $18 \mathrm{~S}$ ML tree (Fig. 4B) where two branches (out of four having morphological changes) comprise five of the eight morphological changes that were reconstructed in Stygocapitella. In clear contrast, MMD indices in Nerillidae and Orbiniidae vary between 5 and 10 at relatively shallow genetic distances of $(<0.01$; Fig. 5C). Morphological disparity in these lineages remains at high levels with increasing genetic distances and only a few outliers display disparity values as low as Stygocapitella. These outliers are at genetic distances of 0.0375 . Hence, independent of the genetic distance, morphological disparity in nerillids and orbiniids is on average 2-8 times higher than in Stygocapitella (Fig. 5C). Complementarily, we calculated MMD indices for discrete morphological traits and for the morphometric data in the Stygocapitella complex while taking the interindividual variation into account and plotted these against genetic distances in 18S (Suppl. Fig. S7). Considering only MMD indices, morphotype \#2, \#3, and \#4 cannot be separated from each other neither in discrete traits nor in morphometrics. Morphotype \#1 is clearly set apart from the remaining three but only when considering discrete characters (Suppl. Fig. 7A). When considering morphometric characters, morphotype \#1 partially overlaps with the remaining three (Suppl. Fig. 7B). Hence, as above, the morphological similarity across different Stygocapitella species is high. Nonetheless, when considering both genetic distances and MMD together we find three clearly separated clusters. The only exceptions being morphotypes \#3 and \#4. Despite the very low morphological disparity high genetic divergence can be observed between species with different morphotypes indicating that speciation in the Stygocapitella complex is not accompanied by morphological changes given the characters analyzed herein.

Finally, we plotted the results of the ancestral state reconstruction (Suppl. Fig. S6) on a timecalibrated tree using the time estimates obtained from the molecular clock analysis (Fig. 3; Suppl. Fig. S6). These results suggest that morphotype \#3 is the ancestral condition of EA_B, EA_C and WA and that these three species diverged about 18 MY (5 - 37 MY) ago (Fig 4A; Suppl. Fig. S6). Morphotype \#4 was reconstructed as the ancestral condition for a clade comprising EA_A, EP_C, EP_D, as well as for EA_B, EA_C and WA (Suppl. Fig. S6). The age of divergence for this clade (also including EP_B, for which no 
morphological data was obtained) was estimated to be about 64 MY (33 - 104 MY) ago (Fig. 4A). Finally, morphotype \#2 was reconstructed as the ancestral state for the whole radiation, except for S. minuta, and it was dated at ca. 140 MY (75 - 205 MY) (Fig 4A; Suppl. Fig. S6). The age for Stygocapitella spp. was dated at about $275 \mathrm{MY}(124-438 \mathrm{MY})$. These dates are congruent with previous estimates on a substantially smaller dataset based only on 18 S (Struck et al. 2017) which calculated an age of 270 MY for the whole complex and $83 \mathrm{MY}$ for the split of $S$. australis from $S$. subterranea. Hence, even though different morphotypes can be detected, long-term morphological stasis is evident. When considering the $95 \%$ confidence interval, morphotype \#2 has been maintained for at least $75 \mathrm{MY}$, and \#3 and \#4 for at least 5 and $33 \mathrm{MY}$, respectively. To put the degree of these morphological variations into perspective, even when considering the absolute lowest estimated minimal divergence time for \#2 of about $75 \mathrm{MY}$, only four morphological differences evolved in Stygocapitella, while almost the whole radiation of mammals took place during the same time interval.

\section{Demographic changes and ecological separation}

We focused on the Atlantic species for the analyses addressing potential ecological drivers of morphological stasis such as niche conservatism and/or the occurrence of fluctuating ecological dynamics (Sheldon 1996; Futuyma 2010; Lindholm 2014). However, analyses at the macro-climatic scale using 19 variables found no statistical differences in the ecological preferences within and among the species (Suppl. Table S9), with $P$-values being generally $>0.70$. The lowest observed $P$-value was $P=0.22$, for the comparison between EA_B and EA_C for annual mean temperature.

To investigate potential causes of stasis including niche tracking and reduction of standing genetic variation we assessed the dispersal capacity of different Stygocapitella species. Phylogenetic reconstructions indicate that at least five trans-oceanic dispersal events (two across the Pacific Ocean and three across the Atlantic) are necessary to explain present-day distribution. This includes historical transitions, as well as modern translocations potentially due to human activity (Fig. 3, Suppl. Fig. S1). Using Tajima's D we found indications for reduction in genetic diversity in several populations $(\mathrm{D}<0$ or populations with no polymorphism; Suppl. Table S10) including Bakka, Henningsvær, Kristineberg, and Lødingen as part of EA_A, Glenancross, Île Callot, Keitum, Morsum, and Nairn as part of EA_B, and Bristol Channel, Ellenbogen, Hörnum, Musselburgh, and St. Efflam as part of EA_C. Except for Henningsvær (EA_A), Keitum (EA_B), Ellenbogen, Hörnum, Musselburgh, and St. Efflam (EA_C), all other populations had significant $P$-values or had only a single haplotype. Finally, signatures of balancing selection or population contraction were detected for Cutty Sark (EA_A), Ardtoe (EA_B), Gravesend, List and Plymouth (EA_C) but none of these were significant (D > 0; Suppl. Table S10).

\section{Discussion}

\section{New perspective on morphological evolution}


To the best of our knowledge, this study describes the longest occurrence of stasis in cryptic species complexes known to date. It substantially exceeds results from other cryptic species complexes which uncovered patterns of morphological stasis over a few millions of years. For instance, independent lineages of Cavernacmella snails have remained morphologically similar despite estimates of species divergence of about 3 MY ago (Wada et al. 2013) and Mastigias jellyfish have remained morphologically similar for 6 MY (Swift et al. 2016). In about 275 MY, the Stygocapitella complex evolved at least 10 reproductively isolated species with only with minor morphological differences. Reproductive isolation of these species can be indirectly inferred by complete congruence of independently evolving genetic markers, even when several species occur in sympatry (Coyne and Orr 2004), by species-specific ITS1 length (Suppl. Fig. S8), and by the ABGD analysis.

Rates of morphological evolution are best described as a continuum with two ends represented by 'acceleration' and 'deceleration' (e.g., Stuck et al 2018). In such framework, cryptic species complexes represent cases of substantially decelerated morphological evolution. This is evident when comparing Stygocapitella to closely related taxa which demonstrate substantially faster rates of morphological evolution (Fig. 4b). On the other end of the spectrum, accelerated morphological evolution occurs in, for instance, adaptive radiations (Gillespie 2004; Simões et al. 2016) and in character displacement (Brown and Wilson 1956). Generally, increase in rates of morphological evolution seem to be connected with the availability of ecological niches (Gillespie 2004; Losos 2010). Between these extremes, one finds cases where morphological divergence follows genetic divergence or where changes are not as pronounced as in adaptive radiations or conserved in cryptic species complexes. A continuum view will be most informative to future works in morphological evolution which should seek to understand the causes leading to shifts in the pace of morphological evolution (acceleration and deceleration), but also lineage-level morphological evolvability and constraints.

Variations in the rate of morphological change (i.e. acceleration or deceleration/stasis) are likely due to selective pressures, but also 'drift in morphology'. Selection can lead to the evolution of new morphologies, but it can also act to conserve a morphotype (Lynch 1990; Smith et al. 2011; Lidgard and Love 2018). Similar to molecular evolution, the absence of selection or a weak selective pressure on a particular morphotype or trait would lead to "neutral non-adaptive change" (Lynch 1990; Smith et al. 2011). Neutral non-adaptive change occurs when separate populations or species (reproductively isolated or not) accumulate differences in morphology by chance. This could result, for instance, due to random fluctuations in the mean value of a given trait or morphology or fixation of a different trait.

\section{Punctuated Equilibrium}

Stasis in Stygocapitella is occasionally interrupted by pulses of quantitative and qualitative change, as predicted by punctuated equilibrium (Eldredge and Gould 1972). It is important to note that due to the 
lack of fossil data, and due to the few events of morphological change, we cannot infer the exact tempo and mode of morphological evolution in this group. Morphological changes could have occurred either along with speciation events as predicted by the original formulation of the punctuated equilibrium, or they could have occurred in a series of subsequent changes as predicted by gradualism (Mattila and Bokma 2008; Landis and Schraiber 2017). In any case, this is in line with suggestions of punctuated equilibriumlike patterns described in biology, in molecular evolution (Pagel et al. 2006), molecular phylogenies (Bokma 2008), mammal body mass evolution (Mattila and Bokma 2008), and paleontological studies such as the armor development shifts between adaptive peaks in the three-spined stickleback which fits the punctuated equilibrium model (Hunt et al. 2008). Similar to Stygocapitella, the evolutionary patterns of other cryptic species complexes such as the Cavernacmella snails (Wada et al. 2013) and the Mastigias jelly fish (Swift et al. 2016) are best explained by stasis in combination with occasional morphological change in some lineages. In Cavernacmella, several species remain morphologically similar, while five became morphologically distinct. Morphological differences in these five lineages seem to be associated with the colonization of limestone outcrops (Wada et al. 2013). This colonization event led to the accumulation of differences in shell morphology in few thousands years despite the evidence for 3 million years long stasis in C. minima lineages. This suggests that there are no constraints preventing the evolution of new shell shapes, and that shifts in the pace of morphological evolution could be linked to the ecology or habitat of Cavernacmella species, similar to adaptive radiations (Losos 2010). Similarly, in the Mastigias species complex, stasis in oceanic offshore species is repeatedly interrupted following independent colonization of marine coastal lakes. Both examples suggest that some degree of stabilizing selection on morphology occurs and when a group of individuals colonizes a new environment, there is a release of the selective pressure leading to the appearance of morphological differences. In Stygocapitella, we could not find macroecological differences within three morphologically similar species (EA_B, EA_C and WA), and between them and the morphologically distinct species (EA_A). However, our analyses do not include potentially relevant micro-ecological parameters affecting the interstitial environment such as granularity, salinity or moisture distribution (Giere, 2009).

Cryptic species strongly support the hypothesis that speciation is not necessarily coupled with morphological change (Rabosky and Adams 2012; Wada et al. 2013). In Stygocapitella 12 out of 16 branches are not associated with morphological change in the assessed characters. In addition, the occurrence of speciation without morphological change adds a layer of complexity to the relationship between speciation, extinction and morphological evolution (Alizon et al. 2008; Silvestro et al. 2018; Katz 2019). Failure to integrate speciation without morphological evolution in paleontology may bias estimates of rates of speciation and morphological evolution (see (Alizon et al. 2008). Because in paleontology a "species" is defined based on morphological differences (Futuyma 1987) and considering the evidence for the widespread occurrence of cryptic species (Pfenninger and Schwenk 2007; Pérez-Ponce de León and Poulin 2016), paleontological estimates of speciation and extinction could be wrong and simply reflect rates of morphological change through time. To mitigate this, we suggest that, when possible, researchers 
should obtain ratios of cryptic species in extant taxa when focusing on a given paleontological group. For instance, accounting for the presence of cryptic species in marine microplankton fossils demonstrates that the lumping of several cryptic species overestimates the amount of variation within morphospecies, and leads to an apparent slow-down of the rates of evolution (Alizon et al. 2008).

While rates of anagenesis and cladogenesis have been estimated in the paleontological record (Jackson and Cheetham 1999; Aze et al. 2011; Strotz and Allen 2013), variation of these rates has received less attention. Stygocapitella has two nodes (in a total of eight) associated with more than one morphological change, a single node with a single morphological change and five nodes without any change. This implies that at least five speciation events (i.e. cladogenesis) have occurred without any change in the characters assessed. Additionally, considering that S. australis and EP_A share the same morphotype but branch off consecutively, the two subsequent morphological changes occurring in this clade had to be anagenetic. Futuyma (1987) has argued that if variation occurs in rates of anagenesis and cladogenesis, it could result in a pulsated pattern. This is seen in Stygocapitella, where we observe that anagenetic changes are lower than the rate of cladogenesis, which results in a pattern of "pulsated changes" between morphotypes.

A recent review has argued that discussions about living fossils would benefit from shifting from pattern-description to the causes underlying consistency in morphology through time (Lidgard and Love 2018). This is similar to the recently proposed views for cryptic species (Struck et al. 2018). Considering that morphological deceleration occurs in both cryptic species and living fossils, and that it may be due to the same underlying forces, the integration of cryptic species and living fossils could be accomplished under a synthesis of morphological deceleration and stasis. Indeed, cases of long-term stasis in cryptic species could represent living fossils, given a paleontological record (Lidgard and Love 2018). Our results show that some Stygocapitella species have been morphologically identical in the assessed characters for at least 50 million years and if there was a fossil record for these lineages, it is very likely that extant species would have been considered living fossils.

\section{Morphological stasis}

Selection is, likely, the force that maintains highly similar/identical morphologies in Stygocapitella species. This may be due to the special properties of the interstitial realm (the space between sand grains) (Noodt 1974; Westheide 1977, 1987; Giere 2009). The interstitial environment is characterized by limited and three-dimensionally structured space, and by constant changes in chemistry due to tides, wave action, seasonal changes, weather conditions, salinity, temperature and input of organic matter. While these factors vary extensively on short time scales (daily and seasonally), it has been shown that abiotic conditions within the interstitial realm have not changed for millions of years (Noodt 1974; Westheide 1977; Westheide and Rieger 1987; Giere 2009). This is in agreement with the 'plus ça change, plus c'est la même chose' model by Sheldon (1996), which states that taxa inhabiting environments with severe short- 
term abiotic fluctuations, yet stable in the long-term can display stasis. In this model, species are expected to be efficient niche trackers, ultimately resulting in niche conservatism and stasis. Fluctuating conditions have been shown to occur in areas where the three European Stygocapitella species occur (i.e., Sylt, Schilksee and Tromsø) (Schmidt 1968, 1969, 1970, 1972a, b). Furthermore, given their mitochondrial divergence (Suppl. Figs. S4-5), Stygocapitella species seem to be efficient niche trackers, capable of finding new areas where their habitat occurs. This is shown by their broad distribution ranges, for example, in several populations all individuals have the same haplotype, despite the long-distance between sites. While this is a potential scenario, our attempt to test for reduction in genetic diversity, as a result of recurrent bottlenecks and founder effects (as suggested for meiofauna) did not reveal any general pattern (Andrade et al. 2011; Derycke et al. 2013). If this was the case, absence of standing genetic variation would diminish the potential for selection to act, and potentially drive morphological stasis (Futuyma 2010), yet this must be confirmed using genome-level data. Importantly, the Nerillidae, which are also interstitial, do not exhibit signs of stasis, and hence not every taxa inhabiting the interstitial environment is under stasis.

\section{Conclusions}

The Stygocapitella cryptic species complex is characterized by decelerated rates of morphological evolution and by long-periods of morphological stasis. In about 275 MYs the Stygocapitella complex evolved at least 10 reproductively isolated species, but only four distinct morphotypes with few differences. This highlights that morphological evolution should be represented as a continuum (from accelerated to decelerated) and suggests that the Stygocapitella cryptic species complex is one of the most extreme examples for morphological deceleration. Even though we cannot provide conclusive evidence about the causes of stasis in Stygocapitella, stasis is likely maintained by niche-conservatism coupled with the ability to track favourable habitats. On the other hand, the comparison with other interstitial species shows that the interstitial realm per se is not causing stasis. The increasing numbers of publications describing the occurrence of cryptic species suggest that speciation without morphological changes might be commonplace, and that the presence of morphologically-similar species can bias paleontological rates of speciation, extinction, anagenesis and cladogenesis.

\section{Acknowledgments}

We are grateful to Gustav Paulay, Claudia E. Mills, Bernadette Holthuis and Tim Miller for field site suggestions in the USA, and to Tim Worsfold, Andy Mackie, Henning Reiss, Lis Jørgensen for laboratory space in the UK and Norway. We thank Lisbeth Thorbek for her assistance in sequencing, Nataliya Budaeva for primer suggestions and Inês Modesto for fieldwork support in Northern Norway. We are grateful to Peter Wagner and to three anonymous reviewers whose comments substantially improved the manuscript. We acknowledge the use of Norwegian national e-infrastructure for highperformance computing and storage via the projects NN9408K and NS9408K, respectively. JC is grateful 
to José Mário Branco (“É um lindo sonho para viver; Quando toda a gente assim quiser”), and to Chris Booth and Jane Lewis for late-night discussions about punctuated equilibrium. Fieldwork was partly funded by the Ragen Award from Friday Harbor Laboratories and a Den Grevelige HjelmstjerneRosencroneske Stiftelse ved UiOslo (JC) and by the EU Assemble program (THS). A Forbio travel-grant 548 led JC to Osnabrück to take Light Microscopy and SEM photographs with GP and CM. We thank Kjetil

549 Voje and Lutz Bachmann for reading and commenting a previous version of this manuscript. This is

550 NHM Evolutionary Genomics lab contribution nr X.

\section{References}

552

Alizon S, Kucera M, Jansen V (2008) Competition between cryptic species explains variations in rates of lineage evolution. Proc Natl Acad Sci U S A 105:12382-12386. doi: 10.1073/pnas.0805039105

Andrade SCS, Norenburg JL, Solferini VN (2011) Worms without borders: Genetic diversity patterns in four Brazilian Ototyphlonemertes species (Nemertea, Hoplonemertea). Mar Biol 158:2109-2124. doi: 10.1007/s00227-011-1718-3

Astrin JJ, Stüben PE (2008) Phylogeny in cryptic weevils: Molecules, morphology and new genera of western Palaearctic Cryptorhynchinae (Coleoptera: Curculionidae). Invertebr Syst 22:503-522. doi: 10.1071/IS07057

Aze T, Ezard THG, Purvis A, et al (2011) A phylogeny of Cenozoic macroperforate planktonic foraminifera from fossil data. Biol Rev 86:900-927. doi: 10.1111/j.1469-185X.2011.00178.x

Bleidorn C, Hill N, Erséus C, Tiedemann R (2009) On the role of character loss in orbiniid phylogeny (Annelida): Molecules vs. morphology. Mol Phylogenet Evol 52:57-69. doi: 10.1016/j.ympev.2009.03.022

Bokma F (2002) Detection of punctuated equilibrium from molecular phylogenies. J Evol Biol 15:10481056. doi: 10.1046/j.1420-9101.2002.00458.x

Bokma F (2008) Detection of "punctuated equilibrium" by Bayesian estimation of speciation and extinction rates, ancestral character states, and rates of anagenetic and cladogenetic evolution on a molecular phylogeny. Evolution (N Y) 62:2718-2726. doi: 10.1111/j.1558-5646.2008.00492.x

Bouckaert R, Heled J, Kühnert D, et al (2014) BEAST 2: A software platform for bayesian evolutionary analysis. PLoS Comput Biol 10:1-6. doi: 10.1371/journal.pcbi.1003537

Brown WL, Wilson EO (1956) Character Displacement. Syst Zool 5:49. doi: 10.2307/2411924

Cerca J, Purschke G, Struck TH (2018) Marine connectivity dynamics: clarifying cosmopolitan distributions of marine interstitial invertebrates and the meiofauna paradox. Mar Biol 165:123. doi: 10.1007/s00227-018-3383-2 
Charlesworth B, Lande R, Slatkin M (1982) A Neo-Darwinian commentary on macroevolution. Evolution (N Y) 36:474-498

Cheetham AH (1986) Tempo of evolution in a Neogene Bryozoan: Rates of morphologic change within and across species boundaries. Paleobiology 12:190-202

Coyne J, Orr H (2004) Speciation. Sinauer Associates, Sunderland, MA

Derycke S, Backeljau T, Moens T (2013) Dispersal and gene flow in free-living marine nematodes. Front Zool 10:1. doi: 10.1186/1742-9994-10-1

Dray S, Dufour A-B (2007) The ade4 package: Implementing the duality diagram for ecologists. J Stat Softw 22:. doi: 10.18637/jss.v022.i04

Eldredge N (1971) The allopatric model and phylogeny in Paleozoic invertebrates. Evolution (N Y) 25:156-167

Eldredge N, Gould SJ (1972) Punctuated Equilibria: An alternative to phylogetic gradualism. In: Schopf TJM (ed) Models in paleobiology. Freeman, Cooper and Co., San Francisco., pp 82-115

Escalante AA, Ayala FJ (1995) Evolutionary origin of Plasmodium and other Apicomplexa based on rRNA genes. Proc Natl Acad Sci 92:5793-5797. doi: 10.1073/pnas.92.13.5793

Frame K, Hunt G, Roy K (2007) Intertidal meiofaunal biodiversity with respect to different algal habitats: A test using phytal ostracodes from Southern California. Hydrobiologia 586:331-342. doi: 10.1007/s10750-007-0707-5

Futuyma D (2005) Evolution. Sinauer Associates, Inc, Sunderland, MA

Futuyma DJ (2010) Evolutionary constraint and ecological consequences. Evolution (N Y) 64:1865-1884. doi: 10.1111/j.1558-5646.2010.00960.x

Futuyma DJ (2015) Can modern evolutionary theory explain macroevolution? In: Macroevolution. pp 29_ 86

Futuyma DJ (1987) On the role of species in anagenesis. Am Nat 130:465-473

Giere O (2009) Meiobenthology: the microscopic motile fauna of aquatic sediments, 2nd edn. SpringlerVerlag, Berlin Heidelberg

Gillespie R (2004) Community assembly through adaptive radiation in Hawaiian spiders. Science (80- ) 303:356-360

Gómez A, Serra M, Carvalho GR, et al (2002) Speciation in ancient cryptic species complexes: evidence 

from the molecular phylogeny of Brachionus plicatilis (Rotifera). Evolution (N Y) 56:1431-1444. doi: 10.1554/0014-3820(2002)056[1431:SIACSC]2.0.CO;2

Gueriau P, Rabet N, Clément G, et al (2016) A 365-million-year-old freshwater community reveals morphological and ecological stasis in branchiopod crustaceans. Curr Biol 26:383-390. doi: 10.1016/j.cub.2015.12.039

Hansen TF, Houle D (2004) Evolvability, stabilizing selection, and the problem of stasis. In: Pigliucci M, Preston K (eds) Phenotypic integration: studying the ecology and evolution of complex phenotypes. Oxford University Press, New York, pp 130-154

Hijmans RJ (2014) raster: Geographic data analysis and modeling

Hillis DM, Dixon MT (1991) Ribosomal DNA: Molecular evolution and phylogenetic inference. Q Rev Biol 66:411-453

Hunt G (2007) The relative importance of directional change, random walks, and stasis in the evolution of fossil lineages. Proc Natl Acad Sci 104:18404-18408

Hunt G, Bell MA, Travis MP (2008) Evolution toward a new adaptive optimum: Phenotypic evolution in a fossil stickleback lineage. Evolution (N Y) 62:700-710. doi: 10.1111/j.1558-5646.2007.00310.x

Hunt G, Rabosky DL (2014) Phenotypic evolution in fossil species: pattern and process. Annu Rev Earth Planet Sci 42:421-441. doi: 10.1146/annurev-earth-040809-152524

Jackson JBC, Cheetham AH (1999) Tempo and mode of speciation in the sea. Trends Ecol. Evol. 14:7277

Kalyaanamoorthy S, Minh BQ, Wong TKF, et al (2017) ModelFinder: Fast model selection for accurate phylogenetic estimates. Nat Methods 14:587-589. doi: 10.1038/nmeth.4285

Katoh K, Standley DM (2013) MAFFT multiple sequence alignment software version 7: Improvements in performance and usability. Mol Biol Evol 30:772-780. doi: 10.1093/molbev/mst010

Katz O (2018) Extending the scope of Darwin's “abominable mystery”: Integrative approaches to understanding angiosperm origins and species richness. Ann Bot 121:1-8. doi: 10.1093/aob/mcx109

Katz O (2019) Conflict and complementarity of paleontological and molecular chronologies? Paleobiology 45:7-20. doi: 10.1017/pab.2018.44

Kidwell SM, Holland SM (2002) The quality of the fossil record: Implications for evolutionary analyses. Annu Rev Ecol Syst 33:561-588. doi: 10.1146/annurev.ecolsys.33.030602.152151

Kück P, Meusemann K (2010) FASconCAT: Convenient handling of data matrices. Mol Phylogenet Evol 
Kumar S, Stecher G, Li M, et al (2018) MEGA X: Molecular evolutionary genetics analysis across computing platforms. Mol Biol Evol 35:1547-1549. doi: 10.1093/molbev/msy096

Landis MJ, Schraiber JG (2017) Pulsed evolution shaped modern vertebrate body sizes. Proc Natl Acad Sci 0:201710920. doi: 10.1073/pnas.1710920114

Lassance JM, Svensson GP, Kozlov M V., et al (2019) Pheromones and barcoding delimit boundaries between cryptic species in the primitive moth genus Eriocrania (Lepidoptera: Eriocraniidae). J Chem Ecol 45:429-439. doi: 10.1007/s10886-019-01076-2

Lê S, Josse J, Husson F (2008) FactoMineR: An R Package for Multivariate Analysis. J Stat Softw 25:2538. doi: 10.1016/j.envint.2008.06.007

Lee CE, Frost BW (2002) Morphological stasis in the Eurytemora affinis species complex (Copepoda: Temoridae). In: Hydrobiologia. pp 111-128

Lenth R V. (2013) Lsmeans: Least-squares means. R package version 1.10-4. http:/ CRAN.Rproject.org $/$ package $=1$ smeans

Lidgard S, Love AC (2018) Rethinking living fossils. Bioscience 68:760-770. doi: 10.1093/biosci/biy084 Lindholm M (2014) Morphologically conservative but physiologically diverse: The mode of stasis in Anostraca (Crustacea: Branchiopoda). Evol Biol 41:503-507. doi: 10.1007/s11692-014-9283-6

Lobo J, Teixeira MAL, Borges LMS, et al (2016) Starting a DNA barcode reference library for shallow water polychaetes from the southern European Atlantic coast. Mol Ecol Resour 16:298-313. doi: 10.1111/1755-0998.12441

Losos JB (2010) Adaptive radiation, ecological opportunity and evolutionary determinism. Am Nat 175:623-639. doi: 10.1086/652433

Lynch M (1990) The rate of morphological evolution in Mammals from the standpoint of the neutral expectation. Am Nat 136:727-741

Mattila TM, Bokma F (2008) Extant mammal body masses suggest punctuated equilibrium. Proc R Soc B Biol Sci 275:2195-2199. doi: 10.1098/rspb.2008.0354

Maynard Smith J, Burian R, Kauffman S, et al (1985) Developmental constraints and evolution. Q Rev Biol 60:265-287

Nguyen LT, Schmidt HA, Von Haeseler A, Minh BQ (2015) IQ-TREE: A fast and effective stochastic algorithm for estimating maximum-likelihood phylogenies. Mol Biol Evol 32:268-274. doi: 
666

667

668

669

670

671

672

673

674

675

676

677

678

679

680

681

682

683

684

685

686

687

688

689

690

691

692

693

694

Noodt W (1974) Anpassungen an interstielle Bedingungen: ein faktor in der evolution höherer taxa der Crustacea. Faun-ökol Mitt 4:445-452

Nordbotten JM, Stenseth NC (2016) Asymmetric ecological conditions favor Red-Queen type of continued evolution over stasis. Proc Natl Acad Sci U S A 113:1847-52. doi: $10.1073 /$ pnas. 1525395113

Novo M, Almodóvar A, Fernández R, et al (2012) Appearances can be deceptive: Different diversification patterns within a group of mediterranean earthworms (Oligochaeta, Hormogastridae). Mol Ecol 21:3776-3793. doi: 10.1111/j.1365-294X.2012.05648.x

Novo M, Almodóvar A, Fernández R, et al (2010) Cryptic speciation of hormogastrid earthworms revealed by mitochondrial and nuclear data. Mol Phylogenet Evol 56:507-512. doi: 10.1016/j.ympev.2010.04.010

Pagel M, Venditti C, Meade A (2006) Large punctuational contribution of speciation to evolutionary divergence at the molecular level. Science (80- ) 314:119-121. doi: 10.1029/2005GL023216

Palumbi S, Martin A, Romano S, et al (1991) The simple fool's guide to PCR, version 2.

Pennell MW, Harmon LJ, Uyeda JC (2014) Is there room for punctuated equilibrium in macroevolution? Trends Ecol Evol 29:23-32. doi: 10.1016/j.tree.2013.07.004

Pérez-Losada M, Høeg JT, Crandall KA (2004) Unraveling the evolutionary radiation of the thoracican barnacles using molecular and morphological evidence: A comparison of several divergence time estimation approaches. Syst Biol 53:244-264. doi: 10.1080/10635150490423458

Pérez-Ponce de León G, Poulin R (2016) Taxonomic distribution of cryptic diversity among metazoans: not so homogeneous after all. Biol Lett 12:20160371. doi: 10.1098/rsbl.2016.0371

Pfenninger M, Schwenk K (2007) Cryptic animal species are homogeneously distributed among taxa and biogeographical regions. BMC Evol Biol 7:121. doi: 10.1186/1471-2148-7-121

Purschke G (2018) Parergodrilidae Reisinger, 1925. In: Handbook of Zoology Annelida. Vol. 1 Basal Groups and Pleistoannelida, Sedentaria I. Berlin, pp 223-246

R Core Team (2013) R: A language and environment for statistical computing. R Foundation for Statistical Computing, Vienna, Austria. URL http://www.R-project.org/.

Rabosky DL, Adams DC (2012) Rates of morphological evolution are correlated with species richness in salamanders. Evolution (N Y) 66:1807-1818. doi: 10.5061/dryad.vt41c78j 
Radziejewska T, Gruszka P, Rokicka-Praxmajer J (2006) A home away from home: A meiobenthic assemblage in a ship's ballast water tank sediment. Oceanologia 48:259-265

Rambaut A, Drummond AJ, Suchard MA (2007) Tracer v1.6

Rozas J, Ferrer-Mata A, Sánchez-DelBarrio JC, et al (2017) DnaSP 6: DNA sequence polymorphism analysis of large data sets. Mol Biol Evol 34:3299-3302. doi: 10.1093/molbev/msx248

Schmidt H, Westheide W (2000) Are the meiofaunal polychaetes Hesionides arenaria and Stygocapitella subterranea true cosmopolitan species? - results of RAPD-PCR investigations. Zool Scr 29:17-27. doi: doi:10.1046/j.1463-6409.2000.00026.x

Schmidt P (1968) Die quantitative verteilung und populationsdynamik des mesopsammons am gezeitensandsstrand der Nordseeinsel Sylt - I. Faktorengefüge und biologische Gliederung des Lebensraumes. Int Rev der gesamten Hydrobiol und Hydrogr 53:723-779

Schmidt P (1969) Die quantitative Verteilung und Populationdynamik des Mesopsammons am GezeitenSandstrand der Nordseeinsel Sylt - II. Quantitative verteilung und populationsdynamik einzelner Arten. Int Rev der gesamten Hydrobiol und Hydrogr 54:95-174

Schmidt P (1970) Zonation of the interstitial polychaete Stygocapitella subterranea (Stygocapitellidae) in European sandy beaches. Mar Biol 7:319-323

Schmidt P (1972a) Zonierung und jahreszeitliche Fluktuationen des Mesopsammons im Sandstrand von Schilksee (Kieler Bucht). Mikrofauna des Meeresbodens 10:1-60

Schmidt P (1972b) Zonierung und jahreszeitliche Fluktuationen der interstitiellen Fauna in Sandstränden des Gebiets von Tromsø (Norwegen). Mikrofauna des Meeresbodens 10:81-164

Sheldon PR (1996) Plus ça change - A model for stasis and evolution in different environments. Palaeogeogr Palaeoclimatol Palaeoecol 127:209-227. doi: 10.1016/S0031-0182(96)00096-X

Silvestro D, Warnock RCM, Gavryushkina A, Stadler T (2018) Closing the gap between palaeontological and neontological speciation and extinction rate estimates. Nat Commun 9:5237. doi: 10.1038/s41467-018-07622-y

Simões M, Breitkreuz L, Alvarado M, et al (2016) The Evolving Theory of Evolutionary Radiations. Trends Ecol Evol 31:27-34. doi: 10.1016/j.tree.2015.10.007

Smith KL, Harmon LJ, Shoo LP, Melville J (2011) Evidence of constrained phenotypic evolution in a cryptic species complex of agamid lizards. Evolution (N Y) 65:976-992. doi: 10.1111/j.15585646.2010.01211.x 
Strotz LC, Allen AP (2013) Assessing the role of cladogenesis in macroevolution by integrating fossil and molecular evidence. Proc Natl Acad Sci 110:2904-2909. doi: 10.1073/pnas.1208302110

Struck TH, Feder JL, Bendiksby M, et al (2018) Finding evolutionary processes hidden in cryptic species. Trends Ecol Evol 1-11. doi: 10.1016/j.tree.2017.11.007

Struck TH, Golombek A, Weigert A, et al (2015) The evolution of annelids reveals two adaptive routes to the interstitial realm. Curr Biol 1-7. doi: 10.1016/j.cub.2015.06.007

Struck TH, Koczula J, Stateczny D, et al (2017) Two new species in the annelid genus Stygocapitella (Orbiniida, Parergodrilidae) with comments on their biogeography. Zootaxa 4286:301-332. doi: 10.11646/zootaxa.4286.3.1

Struck TH, Westheide W, Purschke G (2002) Progenesis in Eunicida ("Polychaeta," Annelida) - Separate evolutionary events? Evidence from molecular data. Mol Phylogenet Evol 25:190-199. doi: 10.1016/S1055-7903(02)00231-2

Swift HF, Daglio LG, Dawson MN (2016) Three routes to crypsis: stasis, convergence, and parallelism in the Mastigias species complex (Scyphozoa, Rhizostomeae). Mol Phylogenet Evol 99:103-115. doi: 10.1016/j.ympev.2016.02.013

Venables WN, Ripley B d. (2002) Modern applied Statistics with S, Fourth. Springer, New York

Voje KL (2016) Tempo does not correlate with mode in the fossil record. Evolution (N Y) 70:2678-2689. doi: $10.1111 /$ evo. 13090

Voje KL, Starrfelt J, Liow LH (2018) Model adequacy and microevolutionary explanations for stasis in the fossil record. Am Nat 191:000-000. doi: 10.1086/696265

Wada S, Kameda Y, Chiba S (2013) Long-term stasis and short-term divergence in the phenotypes of microsnails on oceanic islands. Mol Ecol 22:4801-10. doi: 10.1111/mec.12427

Wagner GP, Schwenk K (2000) Evolutionarily stable configurations: Functional integration and the evolution of phenotypic stability. In: Hecht MK, Macintyre RJ, Clegg MT (eds) Evolutionary Biology. Springer US, Boston, MA, pp 155-217

Weiss AM (2011) The evolution of evolution: reconciling the problem of stability. Evol Biol 38:42-51. doi: $10.1007 /$ s11692-010-9099-y

Westheide W (1977) The geographical distribution of interstitial polychaetes. Mikrofauna Meeresb 61:287-302 
Westheide W (1987) Progenesis as a principle in meiofauna evolution. J Nat Hist 21:843-854. doi: $10.1080 / 00222938700770501$

758 759

Westheide W, Hass-Cordes E (2001) Molecular taxonomy: description of a cryptic Petitia species (Polychaeta : Syllidae) from the island of Mahe (Seychelles, Indian Ocean) using RAPD markers and ITS2 sequences. J Zool Syst Evol Res 39:103-111

Westheide W, Purschke G (1988) Organism processing. In: Higgins RP, Thiel H (eds) Introduction to the study of meiofauna. Smithsonian Institution Press, Washington, pp 146-160

Westheide W, Rieger RM (1987) Systematics of the amphiatlantic Micropbthalmus listensis species-group (Polychaeta: Hesionidae): facts and concepts for reconstruction of phylogeny and speciation. Zeitschrift für Zool Syst und Evol 25:12-39

Wickham H (2016) ggplot2: Elegant Graphics for Data Analysis. Springer-Verlag, New York

Worsaae K (2005) Phylogeny of Nerillidae (Polychaeta, Annelida) as inferred from combined 18S rDNA and morphological data. Cladistics 21:143-162. doi: 10.1111/j.1096-0031.2005.00058.x

Zanol J, Halanych KM, Struck TH, Fauchald K (2010) Phylogeny of the bristle worm family Eunicidae (Eunicida, Annelida) and the phylogenetic utility of noncongruent 16S, COI and $18 \mathrm{~S}$ in combined analyses. Mol Phylogenet Evol 55:660-676. doi: 10.1016/j.ympev.2009.12.024

Zrzavý J, Ř́ha P, Piálek L, Janouškovec J (2009) Phylogeny of Annelida (Lophotrochozoa): Totalevidence analysis of morphology and six genes. BMC Evol Biol 9:1-14. doi: 10.1186/1471-2148-9189 

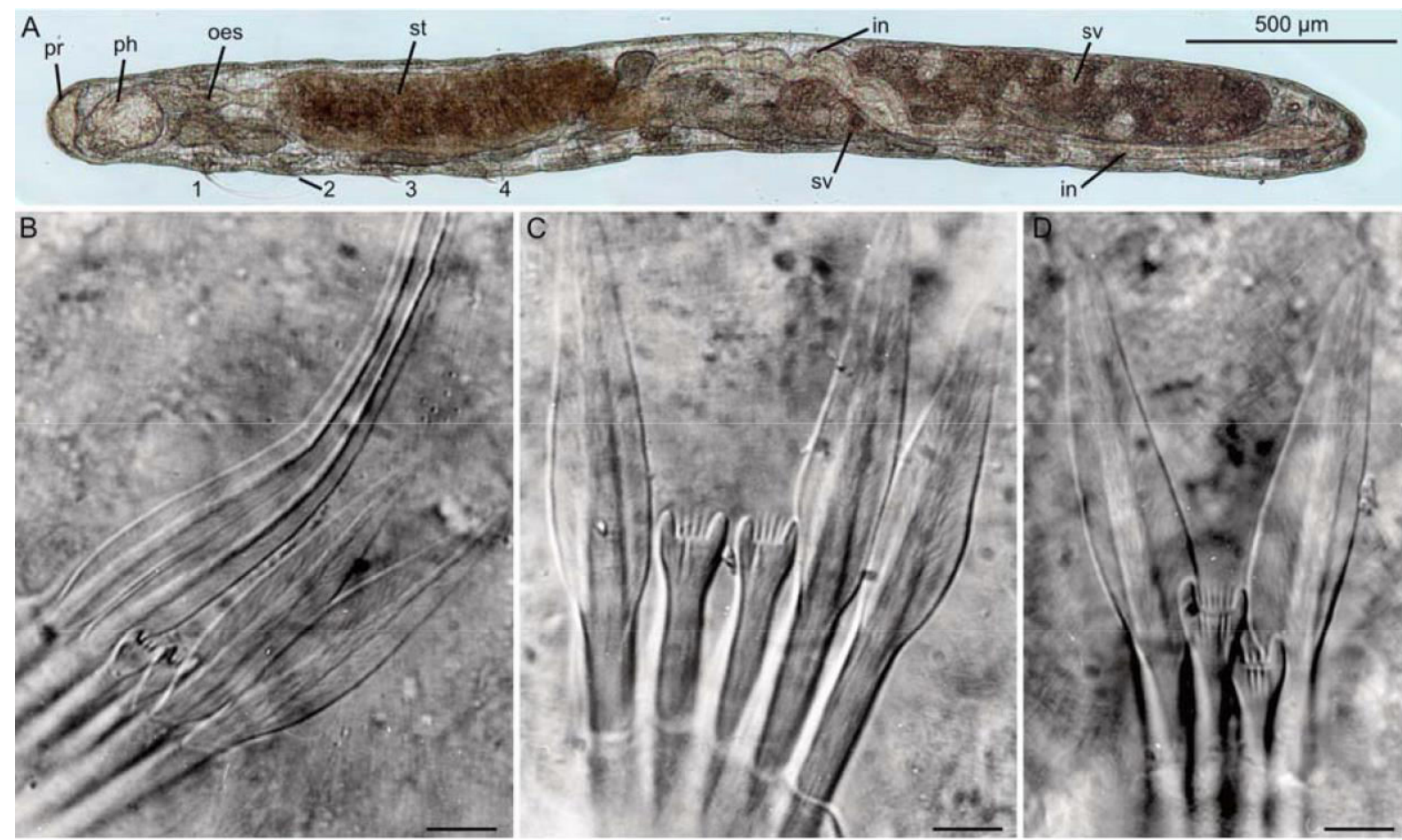

778 Figure 1: Stygocapitella subterranea light microscopy images. A bright field, B-D Normasky interference

779 contrast images. A: Whole-mount of living fully mature male individual with prostomium (pr), pharynx

780 (ph), oesophagus (oes), stomach (st), intestine (in) and seminal vesicle (sv). Numbers one to four indicate

781 the chaetae of the $1^{\text {st }}, 2^{\text {nd }}, 3^{\text {rd }}$, and $4^{\text {th }}$ chaetiger, respectively. The remaining chaetae are not visible.

782 Individual from Weser estuary, Dedesdort, Germany. B: Detail of the left group of chaetae of the 1 st

783 chaetiger (indicated as 1 in A) comprising 2 whip-like, 2forked and 2 bilimbate chaetae. C: $2^{\text {nd }}$ group of

784 chaetae from chaetiger 2 (left side, indicated as 2 in A) comprising 2 forked and 3 bilimbate chaetae $\mathbf{D}$ :

785 Detailed view of one chaetal bundle from chaetigers three to ten (such as $3^{\text {rd }}$ and $4^{\text {th }}$ pair of chaetae

786 indicated as 3 and 4 in A) always comprising 2 forked and 2 bilimbate chaetae - Individuals B-D from

787 North Sea Island of Sylt (List-Hausstrand). Scale bars in B-D $10 \mu \mathrm{m}$. 


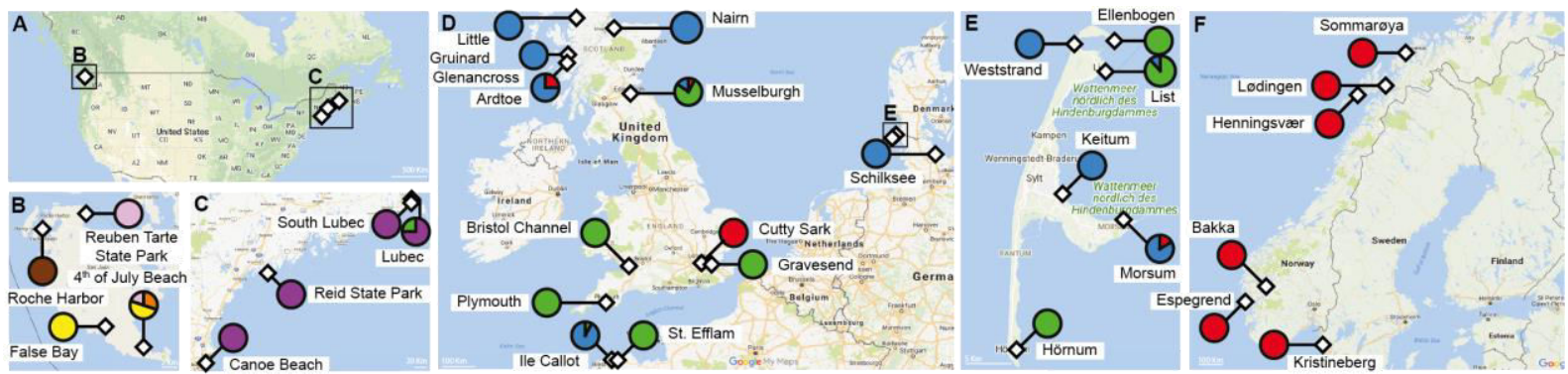

790 Figure 2: Sampling locations included in this study. A) USA; B) San Juan island; C) US Atlantic coastline;

791 D) UK, France and Germany; E) Island of Sylt; F) Norway. Circles denote species given the phylogeny

792 (Fig. 2): Orange (Eastern Pacific species A; EP_A); Yellow (Eastern Pacific species B; EP_B); Brown

793 Pacific Species (Eastern Pacific species C; EP_C); Pink (Eastern Pacific species D; EP_D); Purple

794 (Western Atlantic species; WA); Red (Eastern Atlantic species A; EA_A); Blue (Eastern Atlantic species B;

795 EA_B); Green (Eastern Atlantic species C; EA_C). Circles with several colours identify sympatry. 


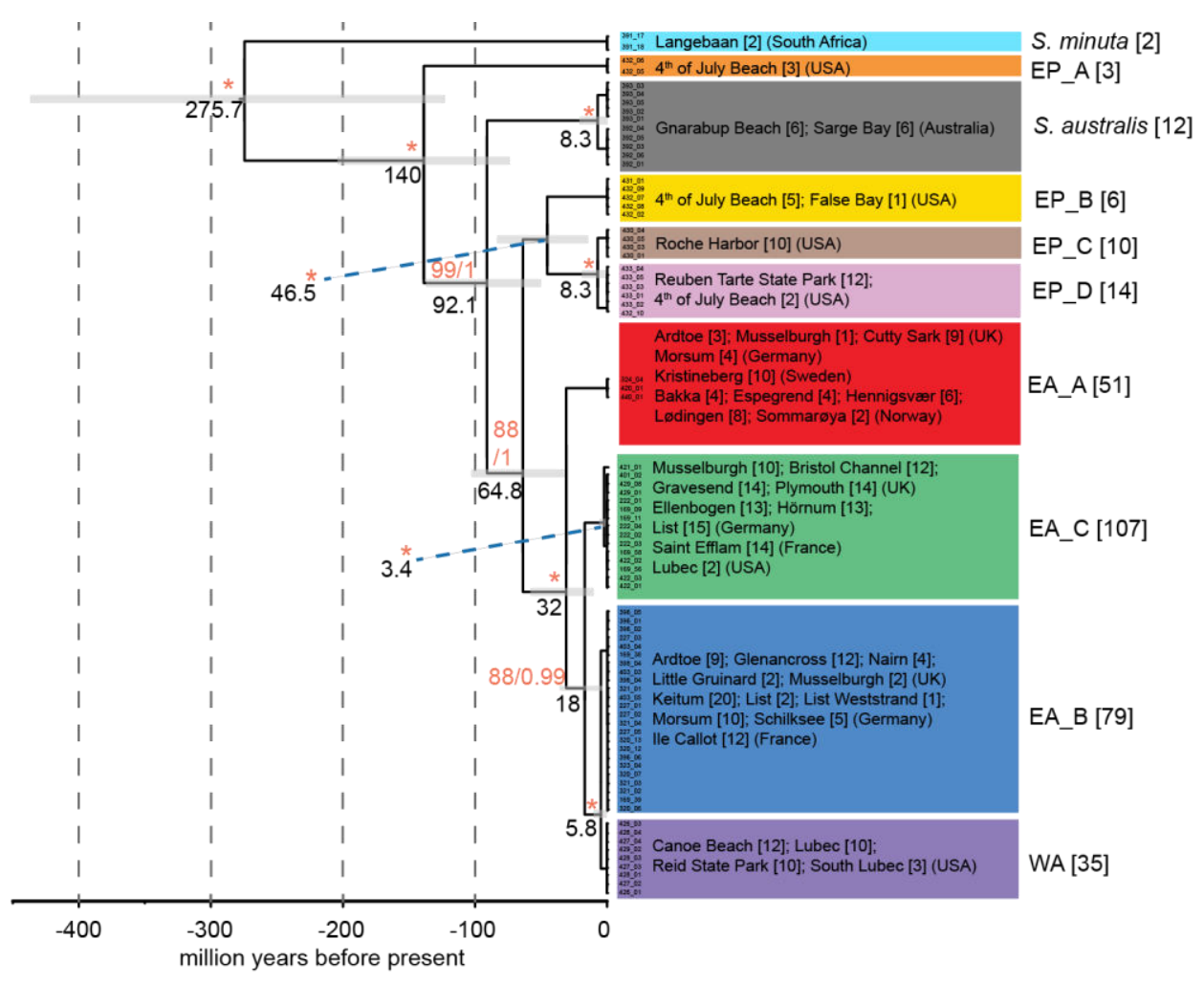

798 Figure 3: Reconstruction of the Bayesian analysis using $18 \mathrm{~S}$ and COI. Results are congruent with the ML

799 phylogeny of the concatenated data of all four markers (Suppl. Fig. S1). Outgroup is not shown. Above

800 basal nodes bootstrap/posterior support (in red) are shown and below the average divergence date; a grey

801 bar shows the $95 \%$ confidence interval. Asterisks $(*)$ indicate a bootstrap value of 100 and a posterior

802 probability of 1 . Numbers in square brackets represent the number of specimens for the site included in

803 the ML analysis. For abbreviations see Fig. 1. 


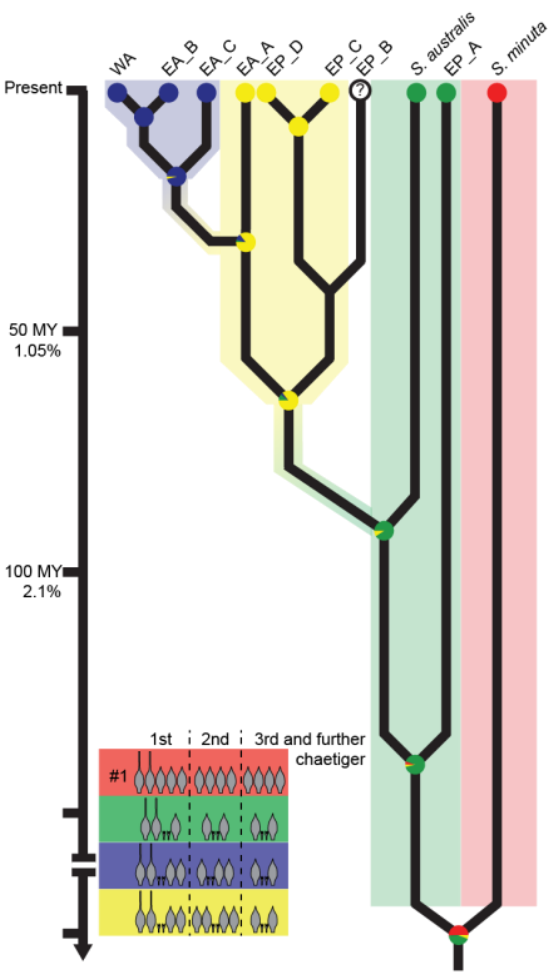

A
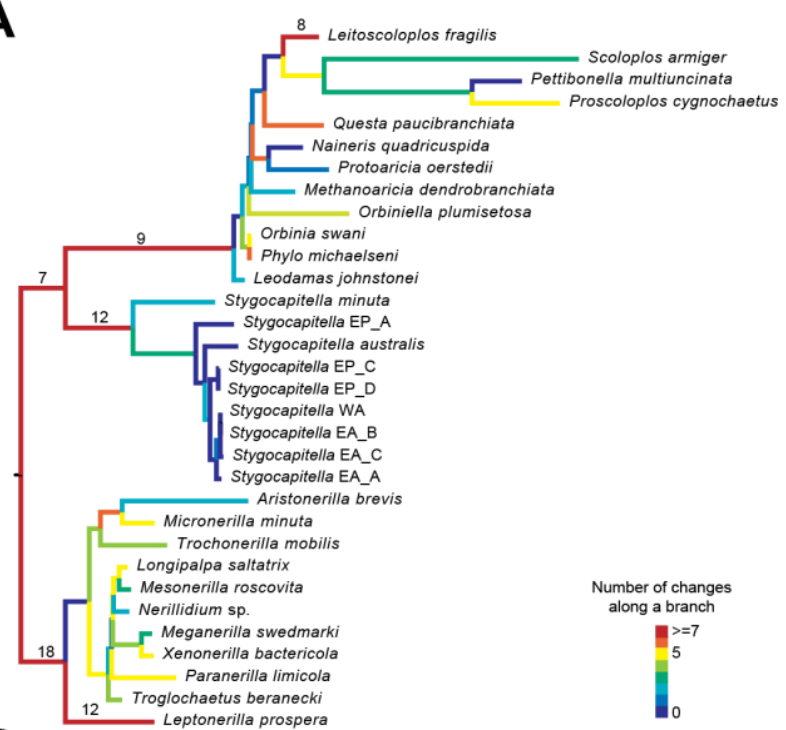

B

806 Figure 4: Morphologic and genetic divergence in Stygocapitella. A) Tree-like representation of the evolution

807 of the four Stygocapitella phenotypes. Morphological assignments follow differences at the chaetigers. Time at the $y$ axis is based on the molecular clock analyses. Morphological transitions between phenotypes are shown by transitioning colours. Tree topology is based on a ML phylogeny (Fig. 2). Pie charts at nodes denote ancestral state reconstructions using a ML approach. Percentages refer to genetic divergence in $18 \mathrm{~S}$ (0.0002127/MY). For abbreviations see Fig. 1. B) Mapping of character evolution in Stygocapitella

812 (Parergodrilidae), Orbiniidae and Nerillidae. Tree topology is based on a 18S ML phylogeny. Number of

813 changes is portrayed in different colours. Zero corresponds to no change occurring along the branch. The

814 number of changes along a branch $\geq 7$ is shown on top of the branch. 
A

C

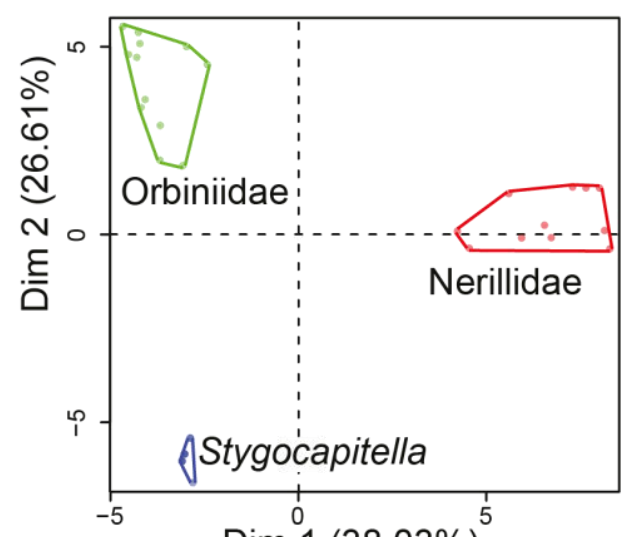

B

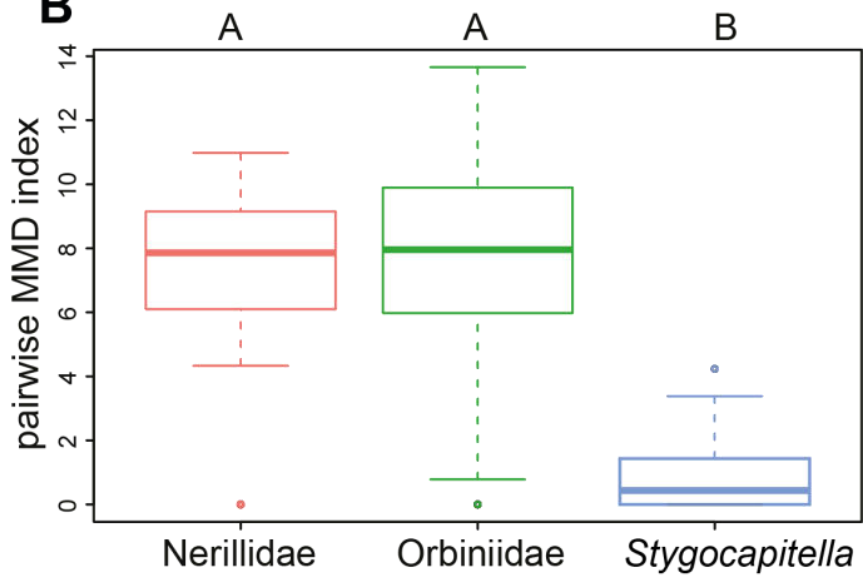

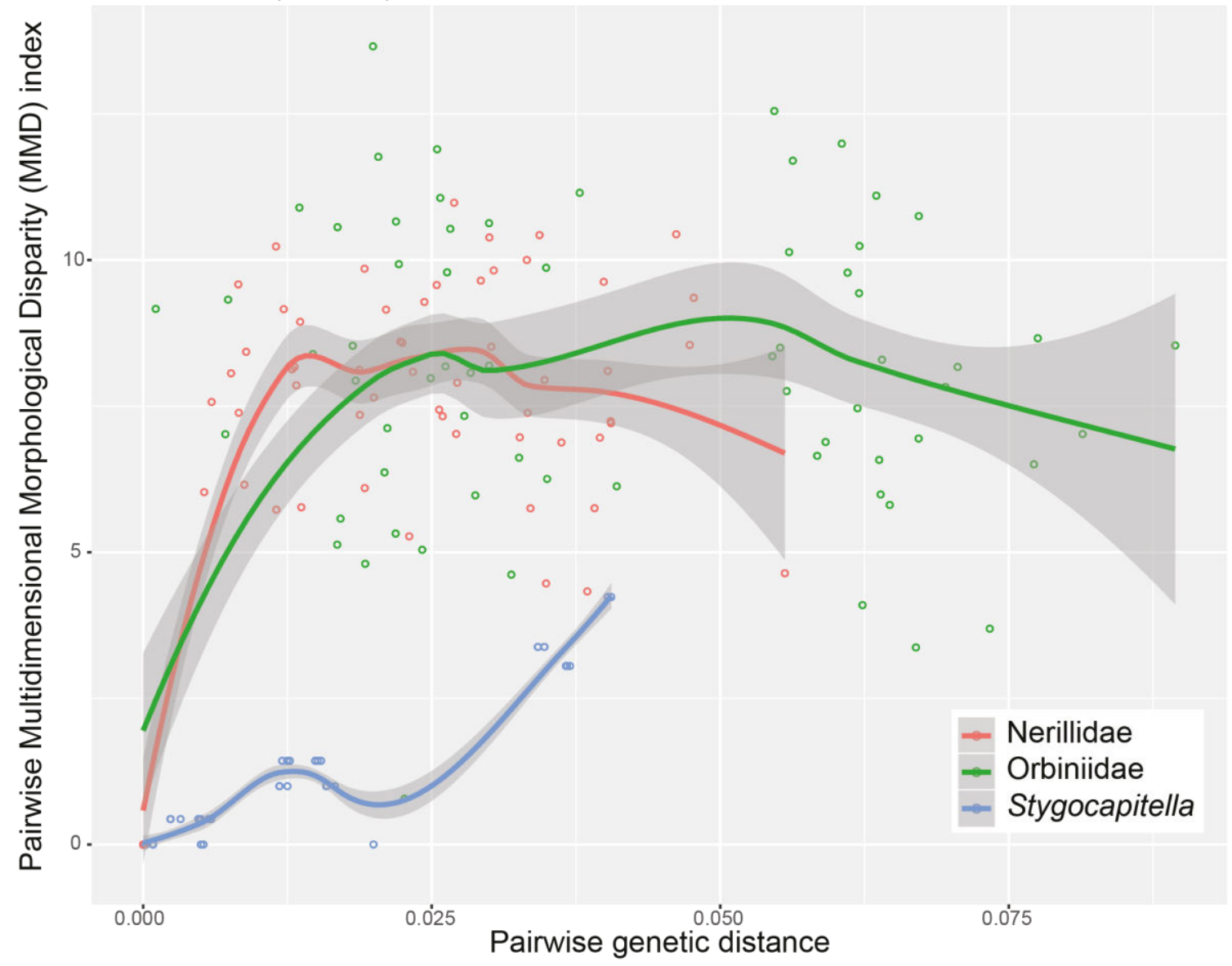

816 Figure 5: Principal Component (PC) analysis and Multidimensional Morphological Disparity (MMD)

817 index results among Stygocapitella, Orbiniidae and Nerillidae. A) PC analysis of the 75 morphological

818 characters. The first PC explains $38.03 \%$ of the variation and the second explains $26.61 \%$. B) Pairwise

819 differences in the MMD index. Outliers are represented by single dots above or below the confidence

820 intervals. Groups which are not significantly different are signed by same letter. C) Plotting of the pairwise

821 MMD indices against the pairwise genetic distance in $18 \mathrm{~S}$. 


\section{Supplementary data for manuscript 3}

Supplementary Table 1. Accession numbers of sequences used for phylogenetic analyses. Sequences obtained for this study are in bold. For information on sampling sites see Supplementary Table 2.

\begin{tabular}{|c|c|c|c|c|c|c|c|}
\hline Taxon & Species & Site & $\begin{array}{l}\text { Sampling } \\
\text { Code }\end{array}$ & COI & $16 S$ & $18 \mathrm{~S}$ & ITS1 \\
\hline \multirow{5}{*}{ Orbiniidae } & Scoloplos acmeceps & & & FJ612519 & FJ612470 & FJ612488 & \\
\hline & Leitoscoloplos bifurcatus & & & KR781456 & KR349351 & KR778793 & \\
\hline & Leitoscoloplos fragilis & & & FJ612498 & AY532341 & AY532360 & \\
\hline & Leitoscoloplos robustus & & & & FJ612457 & FJ612480 & \\
\hline & Leitoscoloplos pugettensis & & & HM473442 & FJ612454 & AY532365 & \\
\hline \multirow[t]{60}{*}{ Parergodrilidae } & Stygocapitella minuta & Langebaan & 327_01 & KY503054 & & & \\
\hline & & Langebaan & $327-02$ & KY503055 & & & \\
\hline & & Langebaan & $327 \_03$ & KY503056 & & & \\
\hline & & Langebaan & $327-04$ & KY503057 & & & \\
\hline & & Langebaan & $327 \_05$ & KY503058 & & & \\
\hline & & Langebaan & $327-06$ & KY503059 & & & \\
\hline & & Langebaan & $327-07$ & KY503060 & & & \\
\hline & & Langebaan & $327-08$ & KY503061 & & & \\
\hline & & Langebaan & $327 \_10$ & KY503062 & & & \\
\hline & & Langebaan & 327_11 & KY503063 & & & \\
\hline & & Langebaan & $327 \_16$ & & & & \\
\hline & & Langebaan & $327 \_17$ & & & & \\
\hline & & Langebaan & $327 \_18$ & & & & \\
\hline & & Langebaan & 327_19 & & & & \\
\hline & & Langebaan & 391_16 & KY503064 & & & \\
\hline & & Langebaan & 391_17 & KY503065 & & KY503075 & \\
\hline & & Langebaan & 391_18 & KY503066 & & KY503076 & \\
\hline & & Langebaan & 391_19 & KY503067 & & & \\
\hline & Stygocapitella australis & Gnarabup Beach & 392_01 & KY503042 & & & \\
\hline & & Gnarabup Beach & 392_03 & KY503043 & & & \\
\hline & & Gnarabup Beach & 392_04 & KY503044 & & & \\
\hline & & Gnarabup Beach & 392_05 & KY503045 & & KY503077 & \\
\hline & & Gnarabup Beach & 392_06 & KY503046 & & & \\
\hline & & Gnarabup Beach & 392_07 & KY503047 & & & \\
\hline & & Sarge Bay & 393_01 & KY503048 & & KY503078 & \\
\hline & & Sarge Bay & 393_02 & KY503049 & & & \\
\hline & & Sarge Bay & 393_03 & KY503050 & & & \\
\hline & & Sarge Bay & 393_04 & KY503051 & & & \\
\hline & & Sarge Bay & $393 \_05$ & KY503052 & & & \\
\hline & & Sarge Bay & 393_06 & KY503053 & & & \\
\hline & Stygocapitella subterranea & 4th July Beach & 432_01 & MN158589 & MN164067 & & MN162714 \\
\hline & & 4th July Beach & 432_02 & MN158382 & MN164061 & MN162897 & MN162736 \\
\hline & & 4th July Beach & 432_03 & MN158612 & MN164343 & MN162996 & MN162886 \\
\hline & & 4th July Beach & 432_04 & & MN164062 & & MN162738 \\
\hline & & 4th July Beach & 432_05 & MN158613 & MN164345 & MN162997 & MN162887 \\
\hline & & 4th July Beach & 432_06 & MN158614 & MN164344 & MN162998 & MN162888 \\
\hline & & 4th July Beach & 432_07 & MN158385 & MN164063 & MN162909 & MN162739 \\
\hline & & 4th July Beach & 432_08 & MN158383 & MN164065 & MN162895 & MN162737 \\
\hline & & 4th July Beach & 432_09 & MN158384 & MN164064 & MN162911 & MN162741 \\
\hline & & 4th July Beach & 432_10 & MN158597 & MN164068 & MN162914 & MN162724 \\
\hline & & Ardtoe & 320_01 & MN158583 & MN164132 & & \\
\hline & & Ardtoe & 320_02 & MN158516 & MN164320 & & \\
\hline & & Ardtoe & 320_03 & & MN164133 & & \\
\hline & & Ardtoe & 320_04 & MN158525 & MN164270 & & \\
\hline & & Ardtoe & 320_05 & MN158584 & MN164134 & & \\
\hline & & Ardtoe & 320_06 & MN158526 & MN164298 & MN162926 & \\
\hline & & Ardtoe & 320_07 & MN158540 & MN164315 & MN162927 & \\
\hline & & Ardtoe & 320_08 & MN158551 & MN164311 & & \\
\hline & & Ardtoe & 320_12 & MN158537 & MN164318 & MN162958 & \\
\hline & & Ardtoe & 320_13 & MN158541 & MN164319 & MN162933 & \\
\hline & & Ardtoe & 320_14 & MN158536 & MN164312 & & \\
\hline & & Ardtoe & 320_15 & MN158523 & MN164299 & & \\
\hline & & Bakka & 439_01 & & MN164090 & MN162985 & \\
\hline & & Bakka & 439_03 & MN158582 & MN164093 & MN162989 & \\
\hline & & Bakka & 439_07 & & MN164091 & & \\
\hline & & Bakka & 439_08 & & MN164094 & & \\
\hline & & Bristol Channel & 422_01 & MN158387 & MN164135 & MN162970 & MN162799 \\
\hline & & Bristol Channel & 422_02 & MN158399 & MN164136 & MN162971 & MN162803 \\
\hline & & Bristol Channel & 422_03 & MN158400 & MN164144 & MN162972 & MN162805 \\
\hline & & Bristol Channel & 422_04 & MN158388 & MN164148 & MN162978 & MN162808 \\
\hline
\end{tabular}




\begin{tabular}{|c|c|c|c|c|c|}
\hline Bristol Channel & 422_05 & MN158413 & MN164176 & & \\
\hline Bristol Channel & 422_06 & MN158401 & MN164183 & & MN162802 \\
\hline Bristol Channel & 422_07 & MN158389 & MN164177 & & MN162800 \\
\hline Bristol Channel & 422_08 & MN158435 & & & MN162804 \\
\hline Bristol Channel & 422_09 & MN158415 & MN164184 & & MN162807 \\
\hline Bristol Channel & 422_10 & MN158480 & MN164200 & & MN162801 \\
\hline Bristol Channel & 422_11 & MN158390 & MN164178 & & MN162806 \\
\hline Bristol Channel & 422_12 & & MN164149 & & \\
\hline Canoe Beach & 426_01 & MN158481 & MN164233 & MN162928 & MN162768 \\
\hline Canoe Beach & 426_02 & MN158503 & & MN162960 & MN162770 \\
\hline Canoe Beach & 426_03 & MN158504 & MN164234 & MN162939 & MN162794 \\
\hline Canoe Beach & 426_04 & MN158502 & MN164235 & MN162948 & MN162784 \\
\hline Canoe Beach & 426_05 & MN158507 & MN164236 & & \\
\hline Canoe Beach & 426_06 & MN158486 & MN164237 & & MN162795 \\
\hline Canoe Beach & 426_07 & MN158501 & MN164254 & & MN162771 \\
\hline Canoe Beach & 426_08 & MN158505 & MN164238 & & MN162785 \\
\hline Canoe Beach & 426_09 & MN158506 & MN164264 & & MN162796 \\
\hline Canoe Beach & 426_10 & & MN164239 & & MN162774 \\
\hline Canoe Beach & 426_11 & & MN164249 & & MN162788 \\
\hline Canoe Beach & 426_12 & & MN164250 & & MN162797 \\
\hline Cutty Sark & 423_01 & & & & MN162869 \\
\hline Cutty Sark & 423_02 & & MN164109 & & MN162870 \\
\hline Cutty Sark & 423_03 & MN158578 & MN164127 & & \\
\hline Cutty Sark & 423_04 & & MN164095 & & \\
\hline Cutty Sark & 423_06 & & MN164128 & & \\
\hline Cutty Sark & 423_07 & MN158579 & MN164110 & & \\
\hline Cutty Sark & 423_08 & MN158580 & MN164111 & & \\
\hline Cutty Sark & $423 \_09$ & & MN164096 & & \\
\hline Cutty Sark & 423_10 & MN158581 & MN164112 & & MN162871 \\
\hline Ellenbogen & 222_01 & MN158440 & MN164199 & MN162982 & MN162809 \\
\hline Ellenbogen & 222_02 & MN158418 & MN164153 & MN162975 & MN162810 \\
\hline Ellenbogen & $222 \_03$ & MN158396 & MN164171 & MN162979 & MN162832 \\
\hline Ellenbogen & 222_04 & MN158416 & MN164142 & MN162984 & MN162811 \\
\hline Ellenbogen & 222_05 & MN158428 & MN164195 & & MN162812 \\
\hline Ellenbogen & 222_06 & MN158419 & & & MN162820 \\
\hline Ellenbogen & 222_07 & MN158412 & & & MN162816 \\
\hline Ellenbogen & 222_08 & MN158421 & MN164154 & & MN162821 \\
\hline Ellenbogen & 222_09 & MN158422 & MN164155 & & \\
\hline Ellenbogen & 222_10 & MN158420 & MN164172 & & \\
\hline Ellenbogen & 222_11 & MN158397 & MN164173 & & \\
\hline Ellenbogen & 222_12 & MN158423 & MN164175 & & \\
\hline Ellenbogen & 222_13 & & MN164143 & & \\
\hline Espegrend & 440_01 & MN158588 & MN164092 & MN162986 & MN162872 \\
\hline Espegrend & 440_02 & & MN164097 & MN162993 & MN162878 \\
\hline Espegrend & 440_03 & & MN164098 & & \\
\hline Espegrend & 440_04 & & MN164113 & & MN162875 \\
\hline False Bay & 431_01 & MN158386 & MN164066 & MN162910 & MN162740 \\
\hline Glenancross & 321_01 & MN158538 & MN164300 & MN162929 & \\
\hline Glenancross & 321_02 & MN158539 & MN164301 & MN162952 & \\
\hline Glenancross & 321_03 & MN158542 & MN164303 & MN162940 & \\
\hline Glenancross & 321_04 & MN158534 & MN164304 & MN162941 & \\
\hline Glenancross & 321_05 & MN158530 & MN164305 & & \\
\hline Glenancross & 321_06 & MN158535 & MN164306 & & \\
\hline Glenancross & 321_07 & & MN164338 & & \\
\hline Glenancross & 321_08 & & MN164302 & & \\
\hline Glenancross & 321_09 & MN158528 & MN164307 & & \\
\hline Glenancross & 321_10 & MN158529 & MN164310 & & \\
\hline Glenancross & 321_11 & MN158517 & MN164308 & & \\
\hline Glenancross & 321_12 & MN158524 & MN164309 & & \\
\hline Gravesend & 424_01 & MN158447 & MN164201 & & MN162842 \\
\hline Gravesend & 424_02 & MN158436 & MN164151 & & \\
\hline Gravesend & 424_03 & MN158463 & MN164211 & & \\
\hline Gravesend & 424_04 & MN158448 & MN164202 & & \\
\hline Gravesend & 424_05 & MN158449 & MN164213 & & MN162843 \\
\hline Gravesend & 424_06 & MN158450 & MN164203 & & MN162846 \\
\hline Gravesend & 424_07 & MN158451 & MN164212 & & MN162841 \\
\hline Gravesend & 424_08 & MN158452 & MN164209 & & MN162848 \\
\hline Gravesend & 424_09 & MN158461 & MN164204 & & MN162849 \\
\hline Gravesend & 424_10 & MN158479 & MN164205 & & MN162844 \\
\hline Gravesend & 424_11 & MN158453 & MN164206 & & MN162838 \\
\hline Gravesend & 424_12 & MN158431 & MN164179 & & MN162847 \\
\hline Gravesend & 424_13 & MN158432 & MN164191 & & MN162840 \\
\hline Gravesend & 424_14 & MN158462 & MN164207 & & MN162845 \\
\hline Henningsvær & 437_01 & & & & MN162885 \\
\hline Henningsvær & 437_02 & & MN164099 & & \\
\hline Henningsvær & 437_03 & & MN164114 & & MN162877 \\
\hline Henningsvær & 437_05 & & MN164105 & & \\
\hline
\end{tabular}




\begin{tabular}{|c|c|c|c|c|c|}
\hline Henningsvær & 437_06 & & MN164100 & & \\
\hline Henningsvær & 437_07 & & MN164103 & & \\
\hline Hörnum & 169_06 & MN158391 & MN164180 & & MN162828 \\
\hline Hörnum & 169_07 & MN158404 & MN164192 & & MN162822 \\
\hline Hörnum & 169_08 & MN158439 & MN164159 & & \\
\hline Hörnum & 169_09 & MN158424 & MN164165 & MN162973 & MN162839 \\
\hline Hörnum & 169_10 & MN158392 & MN164174 & MN162974 & MN162825 \\
\hline Hörnum & 169_11 & MN158441 & & MN162981 & MN162835 \\
\hline Hörnum & 169_12 & MN158433 & MN164190 & MN162977 & \\
\hline Hörnum & 169_13 & MN158393 & MN164198 & & MN162836 \\
\hline Hörnum & 169_14 & & MN164157 & & MN162829 \\
\hline Hörnum & 169_15 & MN158430 & MN164181 & & MN162826 \\
\hline Hörnum & 169_16 & MN158405 & MN164147 & & MN162823 \\
\hline Hörnum & 169_17 & MN158394 & & & MN162830 \\
\hline Île Callot & 210_10 & MN158556 & & & \\
\hline Île Callot & 210_11 & MN158557 & MN164321 & & \\
\hline Île Callot & 210_12 & MN158558 & MN164284 & & MN162766 \\
\hline Île Callot & 210_13 & MN158553 & MN164325 & & \\
\hline Île Callot & 210_14 & MN158566 & MN164291 & & \\
\hline Île Callot & 403_03 & MN158508 & MN164265 & MN162950 & MN162762 \\
\hline Île Callot & 403_04 & MN158567 & MN164266 & MN162942 & \\
\hline Île Callot & 403_05 & MN158509 & MN164267 & MN162930 & \\
\hline Île Callot & 403_06 & & MN164268 & & \\
\hline Île Callot & $403 \_07$ & MN158545 & MN164322 & & \\
\hline Île Callot & 403_08 & MN158554 & MN164273 & & \\
\hline Île Callot & $403 \_09$ & & MN164274 & & \\
\hline Keitum & 169_28 & & MN164282 & & \\
\hline Keitum & 169_29 & MN158561 & MN164283 & & \\
\hline Keitum & $169 \_30$ & MN158569 & MN164287 & & \\
\hline Keitum & 169_31 & & MN164288 & & \\
\hline Keitum & 169_32 & & MN164323 & & \\
\hline Keitum & 169_33 & MN158562 & MN164293 & & \\
\hline Keitum & 169_34 & MN158518 & MN164326 & & \\
\hline Keitum & 169_35 & MN158563 & MN164289 & & \\
\hline Keitum & 169_36 & MN158560 & MN164324 & & \\
\hline Keitum & $169 \_37$ & & MN164295 & MN162953 & \\
\hline Keitum & $169 \_38$ & MN158568 & MN164281 & MN162949 & \\
\hline Keitum & 169_39 & MN158564 & MN164290 & MN162954 & \\
\hline Keitum & 398_04 & MN158510 & MN164275 & MN162956 & \\
\hline Keitum & 398_05 & MN158546 & MN164276 & & \\
\hline Keitum & 398_06 & MN158550 & MN164277 & & \\
\hline Keitum & 398_07 & MN158511 & MN164278 & & \\
\hline Keitum & 398_08 & MN158512 & MN164297 & & \\
\hline Keitum & 398_09 & MN158544 & MN164279 & & \\
\hline Keitum & 398_10 & MN158513 & MN164269 & & MN162763 \\
\hline Keitum & 398_11 & MN158547 & MN164280 & & \\
\hline Kristineberg & 420_01 & MN158585 & MN164115 & MN162987 & \\
\hline Kristineberg & 420_02 & & MN164116 & MN162988 & \\
\hline Kristineberg & 420_03 & & MN164124 & MN162990 & MN162873 \\
\hline Kristineberg & 420_04 & & MN164117 & & MN162880 \\
\hline Kristineberg & 420_05 & MN158586 & MN164118 & & MN162882 \\
\hline Kristineberg & 420_06 & & MN164119 & & MN162881 \\
\hline Kristineberg & 420_07 & & MN164120 & & MN162874 \\
\hline Kristineberg & 420_09 & & MN164125 & & \\
\hline Kristineberg & 420_10 & & MN164122 & & \\
\hline Kristineberg & 420_12 & & MN164123 & & MN162883 \\
\hline List & $169 \_54$ & MN158446 & MN164156 & & MN162837 \\
\hline List & $169 \_55$ & MN158548 & & & \\
\hline List & $169 \_56$ & MN158406 & MN164160 & MN162980 & MN162817 \\
\hline List & $169 \_57$ & MN158571 & MN164337 & & \\
\hline List & $169 \_58$ & MN158417 & MN164164 & MN162976 & MN162813 \\
\hline List & 219_02 & & MN164161 & MN162983 & \\
\hline List & 219_03 & MN158408 & MN164193 & & MN162824 \\
\hline List & 219_04 & & MN164168 & & MN162819 \\
\hline List & 219_05 & MN158442 & MN164170 & & MN162818 \\
\hline List & 219_06 & MN158443 & MN164163 & & MN162814 \\
\hline List & 219_07 & & MN164158 & & MN162827 \\
\hline List & 219_08 & MN158410 & MN164150 & & MN162831 \\
\hline List & 219_09 & & MN164166 & & MN162833 \\
\hline List & 219_10 & MN158425 & MN164169 & & \\
\hline List & 219_11 & MN158427 & & & \\
\hline List & 219_12 & & MN164162 & & \\
\hline List & 219_13 & & MN164182 & & \\
\hline Little Gruinard & 322_01 & MN158576 & MN164314 & & \\
\hline Little Gruinard & $322 \_02$ & MN158577 & MN164335 & & \\
\hline Lødingen & 436_01 & & MN164106 & & \\
\hline Lødingen & 436_02 & & MN164107 & & \\
\hline
\end{tabular}




\begin{tabular}{|c|c|}
\hline Lødingen & 436_03 \\
\hline Lødingen & 436_04 \\
\hline Lødingen & 436_05 \\
\hline Lødingen & 436_07 \\
\hline Lubec & 429_01 \\
\hline Lubec & 429_02 \\
\hline Lubec & 429_03 \\
\hline Lubec & 429_04 \\
\hline Lubec & 429_05 \\
\hline Lubec & 429_06 \\
\hline Lubec & 429_07 \\
\hline Lubec & 429_08 \\
\hline Lubec & 429_09 \\
\hline Lubec & 429_10 \\
\hline Lubec & 429_11 \\
\hline Lubec & 429_12 \\
\hline Morsum & 227_01 \\
\hline Morsum & 227_02 \\
\hline Morsum & 227_03 \\
\hline Morsum & 227_04 \\
\hline Morsum & 227_05 \\
\hline Morsum & 227_06 \\
\hline Morsum & 227_07 \\
\hline Morsum & 227_08 \\
\hline Morsum & 227_09 \\
\hline Morsum & 227_10 \\
\hline Morsum & 227_14 \\
\hline Morsum & 227_15 \\
\hline Musselburgh & 324_01 \\
\hline Musselburgh & 324_02 \\
\hline Musselburgh & 324_03 \\
\hline Musselburgh & 324_04 \\
\hline Musselburgh & 324_05 \\
\hline Musselburgh & 324_06 \\
\hline Musselburgh & 324_07 \\
\hline Musselburgh & 324_08 \\
\hline Musselburgh & 324_09 \\
\hline Musselburgh & 324_10 \\
\hline Musselburgh & 324_11 \\
\hline Musselburgh & 324_12 \\
\hline Musselburgh & 324_52 \\
\hline Nairn & 323_01 \\
\hline Nairn & 323_02 \\
\hline Nairn & 323_03 \\
\hline Nairn & 323_04 \\
\hline Plymouth & 421_01 \\
\hline Plymouth & 421_02 \\
\hline Plymouth & 421_03 \\
\hline Plymouth & 421_04 \\
\hline Plymouth & 421_05 \\
\hline Plymouth & 421_06 \\
\hline Plymouth & 421_07 \\
\hline Plymouth & 421_08 \\
\hline Plymouth & 421_09 \\
\hline Plymouth & 421_10 \\
\hline Plymouth & 421_11 \\
\hline Plymouth & 421_13 \\
\hline Plymouth & 421_14 \\
\hline Plymouth & 421_15 \\
\hline Reid State Park & 427_01 \\
\hline Reid State Park & 427_02 \\
\hline Reid State Park & 427_03 \\
\hline Reid State Park & 427_04 \\
\hline Reid State Park & 427_05 \\
\hline Reid State Park & 427_06 \\
\hline Reid State Park & 427_07 \\
\hline Reid State Park & 427_08 \\
\hline Reid State Park & 427_09 \\
\hline Reid State Park & 427_10 \\
\hline Reuben Tarte & 433_01 \\
\hline Reuben Tarte & 433_02 \\
\hline Reuben Tarte & 433_03 \\
\hline Reuben Tarte & 433_04 \\
\hline Reuben Tarte & 433_05 \\
\hline Reuben Tarte & 433_06 \\
\hline Reuben Tarte & 433_07 \\
\hline Reuben Tarte & 433_08 \\
\hline
\end{tabular}

\begin{tabular}{|c|c|c|c|}
\hline & MN164101 & & MN162884 \\
\hline & MN164102 & & \\
\hline & MN164104 & & \\
\hline & MN164108 & & MN162879 \\
\hline MN158444 & MN164138 & MN162963 & MN162850 \\
\hline MN158482 & & MN162934 & MN162775 \\
\hline & MN164255 & & MN162776 \\
\hline & MN164240 & & \\
\hline & MN164256 & & MN162777 \\
\hline & MN164251 & & MN162778 \\
\hline & & & MN162793 \\
\hline MN158429 & MN164185 & MN162967 & MN162851 \\
\hline MN158490 & MN164257 & & MN162779 \\
\hline MN158489 & MN164241 & & MN162783 \\
\hline MN158483 & MN164242 & & MN162780 \\
\hline MN158497 & MN164258 & & \\
\hline MN158519 & MN164285 & MN162935 & \\
\hline MN158520 & MN164286 & MN162951 & \\
\hline MN158573 & MN164271 & MN162955 & \\
\hline MN158521 & MN164272 & MN162936 & \\
\hline MN158522 & MN164316 & MN162961 & \\
\hline MN158527 & MN164294 & & \\
\hline MN158543 & MN164292 & & \\
\hline MN158555 & MN164340 & & MN162767 \\
\hline & MN164296 & & \\
\hline MN158559 & MN164317 & & \\
\hline & MN164129 & & \\
\hline & MN164130 & & \\
\hline MN158455 & MN164223 & & \\
\hline MN158457 & MN164215 & & \\
\hline MN158565 & MN164331 & & \\
\hline MN158587 & MN164131 & MN162992 & MN162876 \\
\hline MN158549 & MN164332 & & MN162764 \\
\hline MN158466 & MN164216 & & MN162834 \\
\hline MN158458 & MN164217 & & \\
\hline MN158464 & MN164222 & & \\
\hline MN158460 & MN164219 & & \\
\hline MN158459 & MN164220 & & \\
\hline MN158465 & MN164218 & & \\
\hline MN158456 & MN164221 & & \\
\hline MN158468 & MN164208 & & \\
\hline MN158531 & MN164329 & & \\
\hline MN158533 & MN164333 & & \\
\hline MN158552 & MN164330 & & \\
\hline MN158532 & MN164334 & MN162957 & MN162765 \\
\hline MN158471 & MN164224 & MN162964 & MN162852 \\
\hline MN158474 & MN164225 & & \\
\hline MN158473 & MN164228 & & MN162865 \\
\hline MN158438 & MN164186 & & \\
\hline MN158475 & MN164229 & & MN162853 \\
\hline MN158403 & MN164187 & & MN162867 \\
\hline & MN164226 & & \\
\hline MN158472 & MN164232 & & \\
\hline MN158476 & MN164227 & & \\
\hline MN158478 & MN164230 & & MN162862 \\
\hline & MN164188 & & \\
\hline MN158414 & MN164189 & & MN162855 \\
\hline MN158426 & MN164167 & & MN162858 \\
\hline MN158477 & MN164231 & & \\
\hline MN158484 & MN164259 & MN162943 & MN162781 \\
\hline MN158495 & MN164260 & MN162931 & MN162772 \\
\hline MN158487 & MN164243 & MN162937 & MN162773 \\
\hline MN158485 & MN164252 & MN162944 & MN162786 \\
\hline MN158499 & MN164244 & & \\
\hline MN158500 & MN164245 & & MN162787 \\
\hline MN158492 & MN164261 & & MN162789 \\
\hline MN158493 & MN164262 & & MN162792 \\
\hline MN158494 & MN164246 & & MN162798 \\
\hline MN158496 & MN164253 & & MN162782 \\
\hline MN158590 & MN164069 & MN162917 & MN162720 \\
\hline MN158591 & MN164075 & MN162918 & MN162722 \\
\hline MN158599 & MN164070 & MN162915 & MN162715 \\
\hline MN158600 & MN164076 & MN162920 & MN162716 \\
\hline MN158601 & MN164071 & MN162919 & MN162721 \\
\hline MN158592 & MN164077 & & MN162717 \\
\hline MN158593 & MN164078 & & \\
\hline MN158594 & MN164072 & & MN162719 \\
\hline
\end{tabular}




\begin{tabular}{|c|c|c|c|c|c|}
\hline Reuben Tarte & 433_09 & MN158595 & MN164079 & & MN162723 \\
\hline Reuben Tarte & 433_10 & MN158596 & MN164080 & MN162916 & \\
\hline Reuben Tarte & 433_11 & & MN164073 & & MN162725 \\
\hline Reuben Tarte & $433 \_12$ & MN158598 & MN164074 & & MN162718 \\
\hline Roche Harbor & 430_01 & MN158602 & MN164081 & MN162921 & MN162726 \\
\hline Roche Harbor & 430_02 & & & MN162925 & MN162727 \\
\hline Roche Harbor & 430_03 & MN158603 & MN164082 & MN162922 & MN162731 \\
\hline Roche Harbor & 430_04 & MN158604 & MN164083 & MN162923 & MN162728 \\
\hline Roche Harbor & 430_05 & MN158605 & MN164084 & MN162924 & MN162729 \\
\hline Roche Harbor & 430_06 & MN158609 & MN164089 & & MN162735 \\
\hline Roche Harbor & 430_07 & MN158606 & MN164085 & & MN162733 \\
\hline Roche Harbor & 430_08 & MN158608 & MN164086 & & MN162730 \\
\hline Roche Harbor & 430_09 & MN158607 & MN164087 & & MN162734 \\
\hline Roche Harbor & 430_10 & MN158610 & MN164088 & & MN162732 \\
\hline Schilksee & 396_01 & KY503068 & MN164336 & KY503073 & \\
\hline Schilksee & 396_02 & KY503069 & MN164339 & KY503074 & \\
\hline Schilksee & 396_04 & KY503070 & MN164327 & MN162938 & MN162761 \\
\hline Schilksee & 396_05 & KY503071 & MN164313 & MN162962 & MN162760 \\
\hline Schilksee & 396_06 & KY503072 & MN164328 & MN162959 & \\
\hline Sommarøya & 438_01 & & MN164121 & & \\
\hline Sommarøya & 438_02 & & MN164126 & MN162991 & \\
\hline South Lubec & 428_01 & MN158491 & MN164263 & MN162946 & MN162791 \\
\hline South Lubec & 428_02 & MN158498 & MN164247 & MN162969 & MN162790 \\
\hline South Lubec & 428_03 & MN158488 & MN164248 & MN162947 & MN162769 \\
\hline St. Efflam & 210_01 & MN158470 & & & MN162864 \\
\hline St. Efflam & 210_02 & MN158409 & MN164197 & & MN162815 \\
\hline St. Efflam & 210_03 & MN158395 & & & MN162860 \\
\hline St. Efflam & 210_04 & MN158467 & MN164152 & & MN162863 \\
\hline St. Efflam & 210_05 & MN158407 & MN164196 & & \\
\hline St. Efflam & 210_06 & MN158411 & & & MN162856 \\
\hline St. Efflam & 210_07 & & MN164141 & & MN162868 \\
\hline St. Efflam & 401_01 & & MN164139 & MN162968 & MN162861 \\
\hline St. Efflam & 401_02 & MN158398 & MN164140 & MN162966 & MN162854 \\
\hline St. Efflam & 401_03 & MN158454 & MN164214 & MN162965 & \\
\hline St. Efflam & 401_04 & MN158437 & MN164194 & & MN162857 \\
\hline St. Efflam & 401_05 & MN158434 & MN164146 & & \\
\hline St. Efflam & 401_06 & MN158445 & MN164145 & & MN162859 \\
\hline St. Efflam & 401_07 & MN158469 & MN164210 & & MN162866 \\
\hline Weststrand & 169_01 & MN158574 & & & \\
\hline
\end{tabular}


Supplementary Table 2. Sampling locations including GPS coordinates for this work.

\begin{tabular}{llll}
\hline Site & Coastline (Country) & Latitude & Longitude \\
\hline 4th July Beach & Eastern Pacific (USA) & 4846822 & -123.00298 \\
False bay & Eastern Pacific (USA) & 48.49026 & -123.06598 \\
Roche Harbor & Eastern Pacific (USA) & 48.59612 & -123.16999 \\
Reuben Tarte State Park & Eastern Pacific (USA) & 48.61281 & -123.09838 \\
Canoe Beach & Western Atlantic (USA) & 42.41962 & -70.90684 \\
Reid State Park & Western Atlantic (USA) & 43.77628 & -69.73121 \\
Lubec & Western Atlantic (USA) & 44.85482 & -66.98179 \\
South Lubec & Western Atlantic (USA) & 44.82476 & -66.98917 \\
Île Callot & Eastern Atlantic (France) & 48.68713 & -3.92439 \\
Saint Efflam & Eastern Atlantic (France) & 48.684609 & -3.62247 \\
Hörnum & Eastern Atlantic (Germany) & 54.75619 & 8.29466 \\
Morsum & Eastern Atlantic (Germany) & 54.87822 & 8.46527 \\
Ellenbogen & Eastern Atlantic (Germany) & 55.04397 & 8.45172 \\
Keitum & Eastern Atlantic (Germany) & 54.902 & 8.36766 \\
List & Eastern Atlantic (Germany) & 55.01556 & 8.43736 \\
Westland & Eastern Atlantic (Germany) & 55.040667 & 8.386944 \\
Schilksee & Eastern Atlantic (Germany) & 54.42386 & 10.17473 \\
Kristineberg & Eastern Atlantic (Sweden) & 58.24774 & 11.44598 \\
Henningsvær & Eastern Atlantic (Norway) & 68.26079 & 14.26836 \\
Lødingen & Eastern Atlantic (Norway) & 68.56414 & 16.49406 \\
Sommarøya & Eastern Atlantic (Norway) & 69.63179 & 18.02713 \\
Espegrend & Eastern Atlantic (Norway) & 60.26637 & 5.22234 \\
Bristol Channel & Eastern Atlantic (Wales) & 51.39973 & -3.19606 \\
Plymouth & Eastern Atlantic (England) & 50.34861 & -4.20071 \\
Cutty Sark & Eastern Atlantic (England) & 51.48294 & -0.0137 \\
Gravesend & Eastern Atlantic (England) & 51.44443 & 0.37764 \\
Ardtoe & Eastern Atlantic (Scotland) & 56.76923 & -5.88361 \\
Glenancross & Eastern Atlantic (Scotland) & 56.94472 & -5.85347 \\
Nairn & Eastern Atlantic (Scotland) & 57.59653 & -3.84176 \\
Musselburgh & Eastern Atlantic (Scotland) & 55.94645 & -3.07624 \\
Little Gruinard & Eastern Atlantic (Scotland) & 57.85223 & -5.4533 \\
\hline & & & \\
\hline & & & \\
& & &
\end{tabular}


Supplementary Table 3. Discrete morphological characters. Segments $=$ Number of segments with chaetae $(=$ chaetigers); 1 Bilimbate $=$ Number of bilimbate chaetae in chaetiger $1 ; 2$ Bilimbate $=$ Number of bilimbate chaetae in chaetiger 2; 3Bilimbate $=$ Number of bilimbate chaetae in chaetiger 3; 4Bilimbate $=$ Number of bilimbate chaetae in chaetiger 4 and the following ones; 1 Whip $=$ Number of whipped chaetae in chaetiger $1 ; 1$ Forked $=$ Number of forked chaetae in chaetiger $1 ; 2$ Forked $=$ Number of forked chaetae in chaetiger $2 ; 3$ Forked $=$ Number of forked chaetae in chaetiger $3 ; 4$ Forked $=$ Number of forked chaetae in chaetiger 4 and the following ones. If the numbers were different in the left and right parapodium the average values was taken.

\begin{tabular}{|c|c|c|c|c|c|c|c|c|c|c|c|c|c|}
\hline Site & Clade & Individual & ID & 苞 & 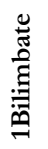 & $\stackrel{\text { : }}{\stackrel{2}{z}}$ & 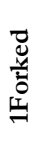 & 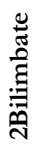 & 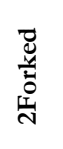 & $\begin{array}{l}\text { Еू⿹ } \\
\text { है } \\
\text { है } \\
\text { लै }\end{array}$ & 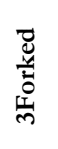 & 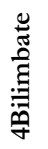 & 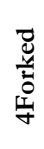 \\
\hline Langebaan & S. minuta & Holotype & SA_LGB_Holo & 8 & 3 & 2 & 0 & 4 & 0 & 4 & 0 & 4 & 0 \\
\hline Langebaan & S. minuta & Lost Male & SA_LGB_LostM1 & 8 & 3 & 2 & 0 & 4 & 0 & 4 & 0 & 4 & 0 \\
\hline Langebaan & S. minuta & Paratype 91 & SA_LGB_ParaF1 & 8 & 3 & 2 & 0 & 4 & 0 & 4 & 0 & 4 & 0 \\
\hline Langebaan & S. minuta & Paratype +2 & SA_LGB_ParaF2 & 8 & 3 & 2 & 0 & 4 & 0 & 4 & 0 & 4 & 0 \\
\hline Langebaan & S. minuta & Paratype +3 & SA_LGB_ParaF3 & 8 & 3 & 2 & 0 & 4 & 0 & 4 & 0 & 4 & 0 \\
\hline Langebaan & S. minuta & Paratype 94 & SA_LGB_ParaF4 & 8 & 3 & 2 & 0 & 4 & 0 & 4 & 0 & 4 & 0 \\
\hline Langebaan & S. minuta & Paratype +5 & SA_LGB_ParaF5 & 8 & 3 & 2 & 0 & 4 & 0 & 4 & 0 & 4 & 0 \\
\hline Langebaan & S. minuta & Paratype 96 & SA_LGB_ParaF6 & 8 & 3 & 2 & 0 & 4 & 0 & 4 & 0 & 4 & 0 \\
\hline Langebaan & S. minuta & Paratype $\delta 1$ & SA_LGB_ParaM1 & 8 & 3 & 2 & 0 & 4 & 0 & 4 & 0 & 4 & 0 \\
\hline Langebaan & S. minuta & Paratype $\delta^{\top} 2$ & SA_LGB_ParaM2 & 8 & 3 & 2 & 0 & 4 & 0 & 4 & 0 & 4 & 0 \\
\hline Langebaan & S. minuta & Paratype $\$ 3$ & SA_LGB_ParaM3 & 8 & 3 & 2 & 0 & 4 & 0 & 4 & 0 & 4 & 0 \\
\hline Langebaan & S. minuta & Paratype $\delta 4$ & SA_LGB_ParaM4 & 8 & 3 & 2 & 0 & 4 & 0 & 4 & 0 & 4 & 0 \\
\hline Gnarabup Beach & S. australis & Holotype & AUS_GNB_HoloM & 10 & 1 & 2 & 2 & 2 & 2 & 2 & 2 & 2 & 2 \\
\hline Gnarabup Beach & S. australis & Paratype +1 & AUS_GNB_ParaF1 & 10 & 1 & 2 & 2 & 2 & 2 & 2 & 2 & 2 & 2 \\
\hline Gnarabup Beach & S. australis & Paratype $\delta 1$ & AUS_GNB_ParaM1 & 10 & 1 & 2 & 2 & 2 & 2 & 2 & 2 & 2 & 2 \\
\hline Gnarabup Beach & S. australis & Paratype $\delta^{\wedge} 2$ & AUS_GNB_ParaM2 & 10 & 1 & 2 & 2 & 2 & 2 & 2 & 2 & 2 & 2 \\
\hline Sarge Bay & S. australis & Paratype +2 & AUS_SAB_ParaF2 & 10 & 1 & 2 & 2 & 2 & 2 & 2 & 2 & 2 & 2 \\
\hline Sarge Bay & S. australis & Paratype 93 & AUS_SAB_ParaF3 & 10 & 1 & 2 & 2 & 2 & 2 & 2 & 2 & 2 & 2 \\
\hline Sarge Bay & S. australis & Paratype 94 & AUS_SAB_ParaF4 & 10 & 1 & 2 & 2 & 2 & 2 & 2 & 2 & 2 & 2 \\
\hline Sarge Bay & S. australis & Paratype +5 & AUS_SAB_ParaF5 & 10 & 1 & 2 & 2 & 2 & 2 & 2 & 2 & 2 & 2 \\
\hline Sarge Bay & S. australis & Paratype $\$ 3$ & AUS_SAB_ParaM3 & 10 & 1 & 2 & 2 & 2 & 2 & 2 & 2 & 2 & 2 \\
\hline Sarge Bay & S. australis & Paratype $\delta 4$ & AUS_SAB_ParaM4 & 10 & 1 & 2 & 2 & 2 & 2 & 2 & 2 & 2 & 2 \\
\hline 4th July Beach & EP_A & Individual 1 & USA_4JB_Ind1 & 10 & 1 & 2 & 2 & 2 & 2 & 2 & 2 & 2 & 2 \\
\hline 4th July Beach & EP_A & Individual 3 & USA_4JB_Ind3 & 10 & 1 & 2 & 2 & 2 & 2 & 2 & 2 & 2 & 2 \\
\hline Roche Harbor & EP_C & Individual 1 & USA_ROH_Ind1 & 10 & 2 & 2 & 2 & 3 & 2 & 2 & 2 & 2 & 2 \\
\hline Roche Harbor & EP_C & Individual 2 & USA_ROH_Ind2 & 10 & 2 & 2 & 2 & 4 & 2 & 2 & 2 & 2 & 2 \\
\hline Roche Harbor & EP_C & Individual 3 & USA_ROH_Ind3 & 10 & 2 & 2.5 & 2 & 4 & 2 & 2 & 2 & 2 & 2 \\
\hline 4th July Beach & EP_D & Individual 4 & USA_4JB_Ind4 & 10 & 2 & 2 & 2 & 3 & 2 & 2 & 2 & 2 & 2 \\
\hline Reuben Tarte & EP_D & Individual 1 & USA_RSP_Ind1 & 10 & 2 & 2 & 2 & 4 & 2 & 2 & 2 & 2 & 2 \\
\hline Reuben Tarte & EP_D & Individual 2 & USA_RSP_Ind2 & 10 & 2 & 2 & 2 & 4 & 2 & 2 & 2 & 2 & 2 \\
\hline Reuben Tarte & EP_D & Individual 4 & USA_RSP_Ind3 & 10 & 2 & 2 & 2 & 4 & 2 & 2 & 2 & 2 & 2 \\
\hline Canoe Beach & WA & Individual 1 & USA_CAB_Ind1 & 10 & 2 & 2 & 2 & 3 & 2 & 2 & 2 & 2 & 2 \\
\hline Canoe Beach & WA & Individual 2 & USA_CAB_Ind2 & 10 & 2 & 2 & 2 & 3 & 2 & 2 & 2 & 2 & 2 \\
\hline Lubec & WA & Individual 1 & USA_LUB_Ind1 & 10 & 2 & 2 & 2 & 3 & 2 & 2 & 2 & 2 & 2 \\
\hline Lubec & WA & Individual 2 & USA_LUB_Ind2 & 10 & 2 & 2 & 2 & 3 & 2 & 2 & 2 & 2 & 2 \\
\hline Lubec & WA & Individual 3 & USA_LUB_Ind3 & 10 & 2 & 2 & 2 & 3 & 2 & 2 & 2 & 2 & 2 \\
\hline Lødingen & EA_A & 436.30 & NOR_LOE_A436.30 & 10 & 2 & 2 & 2 & 3 & 2 & 2 & 2 & 2 & 2 \\
\hline Lødingen & EA_A & 436.32 & NOR_LOE_A436.32 & 10 & 2 & 2 & 2 & 3 & 2 & 2 & 2 & 2 & 2 \\
\hline Lødingen & EA_A & 436.33 & NOR_LOE_A436.33 & 10 & 2 & 2 & 2 & 4 & 1.5 & 2.5 & 1.5 & 2 & 2 \\
\hline Lødingen & EA_A & 436.34 & NOR_LOE_A436.34 & 10 & 2 & 2 & 2 & 3 & 2 & 2 & 2 & 2 & 2 \\
\hline Henningsvær & EA_A & 437.21 & NOR_HEN_A437.21 & 10 & 2 & 2 & 2 & 4 & 2 & 2 & 2 & 2 & 2 \\
\hline Henningsvær & EA_A & 437.22 & NOR_HEN_A437.22 & 10 & 2 & 2 & 2 & 4 & 2 & 2 & 2 & 2 & 2 \\
\hline Henningsvær & EA_A & 437.23 & NOR_HEN_A437.23 & 10 & 2 & 2 & 0 & 4 & 2 & 3 & 0 & 2 & 2 \\
\hline Henningsvær & EA_A & 437.25 & NOR_HEN_A437.25 & 10 & 2 & 2 & 2 & 4 & 2 & 2 & 2 & 2 & 2 \\
\hline Henningsvær & EA_A & 437.28 & NOR_HEN_A437.28 & 10 & 2 & 2 & 2 & 4 & 2 & 2 & 2 & 2 & 2 \\
\hline Henningsvær & EA_A & 437.29 & NOR_HEN_A437.29 & 10 & 2 & 2 & 2 & 4 & 2 & 2 & 2 & 2 & 2 \\
\hline Île Callot & EA_B & Individual 2 & FRA_ILE_Ind2 & 10 & 2 & 2 & 2 & 3 & 2 & 2 & 2 & 2 & 2 \\
\hline Île Callot & EA_B & Individual 3 & FRA_ILE_Ind3 & 10 & 2 & 2 & 2 & 3 & 2 & 2 & 2 & 2 & 2 \\
\hline Île Callot & EA_B & Individual 4 & FRA_ILE_Ind4 & 10 & 2 & 2 & 2 & 3 & 2 & 2 & 2 & 2 & 2 \\
\hline Schilksee & EA_B & Neotype & GER_SCS_NeoF & 10 & 2 & 2 & 2 & 3 & 2 & 2 & 2 & 2 & 2 \\
\hline Schilksee & EA_B & Paratype +1 & GER_SCS_ParaF1 & 10 & 2 & 2 & 2 & 3 & 2 & 2 & 2 & 2 & 2 \\
\hline Schilksee & EA_B & Paratype +2 & GER_SCS_ParaF2 & 10 & 2 & 2 & 2 & 3 & 2 & 2 & 2 & 2 & 2 \\
\hline Schilksee & EA_B & Paratype $\$ 3$ & GER_SCS_ParaM3 & 10 & 2 & 2 & 2 & 3 & 2 & 2 & 2 & 2 & 2 \\
\hline Schilksee & EA_B & Paratype $\delta 4$ & GER_SCS_ParaM4 & 10 & 2 & 2 & 2 & 3 & 2 & 2 & 2 & 2 & 2 \\
\hline List & EA_C & Individual 1 & GER_HAU_Ind1 & 10 & 2 & 2 & 2 & 3 & 2 & 2 & 2 & 2 & 2 \\
\hline List & EA_C & Individual 2 & GER_HAU_Ind2 & 10 & 2 & 2 & 2 & 3 & 2 & 2 & 2 & 2 & 2 \\
\hline List & EA_C & Individual 3 & GER_HAU_Ind3 & 10 & 2 & 2 & 2 & 3 & 2 & 2 & 2 & 2 & 2 \\
\hline List & EA_C & Individual 4 & GER_HAU_Ind4 & 10 & 2 & 2 & 2 & 3 & 2 & 2 & 2 & 2 & 2 \\
\hline
\end{tabular}




\begin{tabular}{|c|c|c|c|c|c|c|c|c|c|c|c|c|c|}
\hline List & EA_C & Individual 5 & GER_HAU_Ind5 & 10 & 2 & 2 & 2 & 3 & 2 & 2 & 2 & 2 & 2 \\
\hline Gravesend & EA_C & Sample 2 Ind. 1 & UK_GRA_Ind2_1 & 10 & 2 & 2 & 2 & 3 & 2 & 2 & 2 & 2 & 2 \\
\hline Gravesend & EA_C & Sample 2 Ind. 2 & UK_GRA_Ind2_2 & 10 & 2 & 3 & 2 & 4 & 2 & 2 & 2 & 2 & 2 \\
\hline Gravesend & EA_C & Sample 2 Ind. 3 & UK_GRA_Ind2_3 & 10 & 2 & 2 & 2 & 3 & 2 & 2 & 2 & 2 & 2 \\
\hline Gravesend & EA_C & Sample 2 Ind. 4 & UK_GRA_Ind2_4 & 10 & 2 & 2 & 2 & 3 & 2 & 2 & 2 & 2 & 2 \\
\hline Gravesend & EA_C & Sample 3 Ind. 1 & UK_GRA_Ind3_1 & 10 & 2 & 2 & 2 & 3 & 2 & 2 & 2 & 2 & 2 \\
\hline Gravesend & EA_C & Sample 3 Ind. 2 & UK_GRA_Ind3_2 & 10 & 2 & 2 & 2 & 3 & 2 & 2 & 2 & 2 & 2 \\
\hline Gravesend & EA_C & Sample 3 Ind. 3 & UK_GRA_Ind3_3 & 10 & 2 & 2 & 2 & 3 & 2 & 2 & 2 & 2 & 2 \\
\hline Gravesend & EA_C & Sample 3 Ind. 4 & UK_GRA_Ind3_4 & 10 & 2 & 2 & 2 & 3 & 2 & 2 & 2 & 2 & 2 \\
\hline Plymouth & EA_C & Individual 1 & UK_PLY_Ind1 & 10 & 1 & 2 & 2 & 2 & 2 & 2 & 2 & 2 & 2 \\
\hline Plymouth & EA_C & Individual 2 & UK_PLY_Ind2 & 10 & 2 & 2 & 2 & 3 & 2 & 2 & 2 & 2 & 2 \\
\hline Plymouth & EA_C & Individual 3 & UK_PLY_Ind3 & 10 & 2 & 2 & 2 & 3 & 2 & 2 & 2 & 2 & 2 \\
\hline Bristol Channel & EA_C & Individual 1 & UK_BCH_Ind1 & 10 & 2 & 2 & 2 & 3 & 2 & 2 & 2 & 2 & 2 \\
\hline Bristol Channel & EA_C & Individual 2 & UK_BCH_Ind2 & 10 & 2 & 2 & 2 & 3 & 2 & 2 & 2 & 2 & 2 \\
\hline Bristol Channel & EA_C & Individual 3 & UK_BCH_Ind3 & 10 & 2 & 2 & 2 & 3 & 2 & 2 & 2 & 2 & 2 \\
\hline
\end{tabular}


Supplementary Table 4. Morphometric measurements. BodyLength = Length of entire body; BodyWidth $=$ Width of entire body; ProstomiumLength $=$ Length of prostomium; ProstomiumWidth $=$ Width of prostomium; PeristomiumLength $=$ Length of peristomium; PeristomiumWidth $=$ Width of peristomium. All measurements are in $\mu \mathrm{m}$.

\begin{tabular}{|c|c|c|c|c|c|c|c|c|c|}
\hline Site & Clade & Individual & ID & 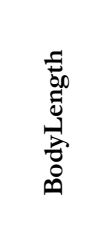 & 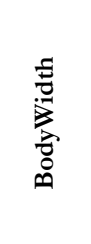 & 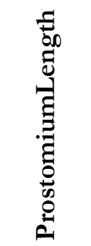 & 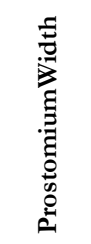 & 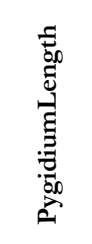 & 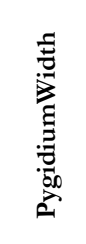 \\
\hline Langebaan & S. minuta & Holotype & SA_LGB_Holo & 1010.74 & 104.54 & 46.6 & 78.89 & 30.95 & 35.21 \\
\hline Langebaan & S. minuta & Lost Male & SA_LGB_LostM1 & 992.34 & 91.11 & 39.61 & 75.01 & 33.51 & 37.7 \\
\hline Langebaan & S. minuta & Paratype +1 & SA_LGB_ParaF1 & 977.69 & 87.79 & 46.46 & 75.88 & 33.13 & 39.6 \\
\hline Langebaan & S. minuta & Paratype 93 & SA_LGB_ParaF3 & 999.66 & 97.2 & 33.13 & 66.02 & 47.41 & 59.72 \\
\hline Langebaan & S. minuta & Paratype 94 & SA_LGB_ParaF4 & 912.97 & 81.1 & 35.07 & 72.96 & 37.35 & 47.75 \\
\hline Langebaan & S. minuta & Paratype 95 & SA_LGB_ParaF5 & 1143.29 & 117.07 & 46.6 & 85.51 & 37.51 & 55.87 \\
\hline Langebaan & S. minuta & Paratype 96 & SA_LGB_ParaF6 & 1059.66 & 89.71 & 39.8 & 52.27 & 30.9 & 38.53 \\
\hline Langebaan & S. minuta & Paratype 1 & SA_LGB_ParaM1 & 1155.68 & 102.67 & 38.44 & 69.19 & 46.86 & 54.27 \\
\hline Langebaan & S. minuta & Paratype 32 & SA_LGB_ParaM2 & 1099 & 110.27 & 43.24 & 85.35 & 44.31 & 63.48 \\
\hline Langebaan & S. minuta & Paratype $\$ 3$ & SA_LGB_ParaM3 & 1117.34 & 110.65 & 47.34 & 90.44 & 40.46 & 62.76 \\
\hline Langebaan & S. minuta & Paratype $\widehat{\delta} 4$ & SA_LGB_ParaM4 & 1047.34 & 99.21 & 38.6 & 76.46 & 47.71 & 57.39 \\
\hline Gnarabup Beach & S. australis & Holotype & AUS_GNB_HoloM & 2019.02 & 209.21 & 73.84 & 115.29 & 67.47 & 123.95 \\
\hline Gnarabup Beach & S. australis & Paratype 91 & AUS_GNB_ParaF1 & 1900.44 & 196.75 & 89.21 & 138.95 & 47.87 & 114.86 \\
\hline Gnarabup Beach & S. australis & Paratype $\delta 1$ & AUS_GNB_ParaM1 & 1808 & 224.39 & 81.89 & 130.51 & 67.19 & 115.27 \\
\hline Gnarabup Beach & S. australis & Paratype $\delta^{2} 2$ & AUS_GNB_ParaM2 & 2312.6 & 235.11 & 80.59 & 131.72 & 37.62 & 84.99 \\
\hline Sarge Bay & S. australis & Paratype 92 & AUS_SAB_ParaF2 & 2008.77 & 202.73 & 76.18 & 104.79 & 53.32 & 89.06 \\
\hline Sarge Bay & S. australis & Paratype 93 & AUS_SAB_ParaF3 & 1650.14 & 172.52 & 64.76 & 104.79 & 49.6 & 84.56 \\
\hline Sarge Bay & S. australis & Paratype 94 & AUS_SAB_ParaF4 & 2130.8 & 185.77 & 54.33 & 113.22 & 61.04 & 106.34 \\
\hline Sarge Bay & S. australis & Paratype 95 & AUS_SAB_ParaF5 & 2079.81 & 204.69 & 69.79 & 114.52 & 57.38 & 117.42 \\
\hline Sarge Bay & S. australis & Paratype 33 & AUS_SAB_ParaM3 & 1804.37 & 145.06 & 59.7 & 98.88 & 60.3 & 75.89 \\
\hline Sarge Bay & S. australis & Paratype $\delta^{2} 4$ & AUS_SAB_ParaM4 & 1622.17 & 122.31 & 66.23 & 87.96 & 59.36 & 82.77 \\
\hline 4th July Beach & EP_A & Individual 2 & USA_4JB_Ind2 & 2075.61 & 283.45 & 143.15 & 240.08 & 71.07 & 126.86 \\
\hline 4th July Beach & EP_A & Individual 3 & USA_4JB_Ind3 & 1669.4 & 200.72 & 87.72 & 111.82 & 37.54 & 82.19 \\
\hline 4th July Beach & EP_A & Individual 4 & USA_4JB_Ind4 & 1837.43 & 214.65 & 79.28 & 137.85 & 68.51 & 84.66 \\
\hline 4th July Beach & EP_A & Individual 5 & USA_4JB_Ind5 & 1718.05 & 218.64 & 78.05 & 130.88 & 55.85 & 86.03 \\
\hline 4th July Beach & EP_A & Individual 6 & USA_4JB_Ind6 & 2535.21 & 308.11 & 104.79 & 177.73 & 77.18 & 123.73 \\
\hline 4th July Beach & EP_A & Individual 7 & USA_4JB_Ind7 & 1217.05 & 154.59 & 84.29 & 108.99 & 27.46 & 89.47 \\
\hline Roche Harbor & EP_C & Individual 1 & USA_ROH_Ind1 & 1342.86 & 166.72 & 60.45 & 106.08 & 39.35 & 74.9 \\
\hline Roche Harbor & EP_C & Individual 2 & USA_ROH_Ind2 & 1874.94 & 203.63 & 42.85 & 86.68 & 47.96 & 101.62 \\
\hline Roche Harbor & EP_C & Individual 3 & USA_ROH_Ind3 & 1680.1 & 216.92 & 58.03 & 125.91 & 50.54 & 95.9 \\
\hline Roche Harbor & EP_C & Individual 4 & USA_ROH_Ind4 & 2406.77 & 273.1 & 81.79 & 162.75 & 70.9 & 143.44 \\
\hline Roche Harbor & EP_C & Individual 5 & USA_ROH_Ind5 & 2326.9 & 226.89 & 95.54 & 182.19 & 54.18 & 145.75 \\
\hline Roche Harbor & EP_C & Individual 6 & USA_ROH_Ind6 & 2552.82 & 273.68 & 91.58 & 148.79 & 63.5 & 138.1 \\
\hline Roche Harbor & EP_C & Individual 7 & USA_ROH_Ind7 & 1864.44 & 232.47 & 58.96 & 153.64 & 47.97 & 116.03 \\
\hline Reuben Tarte & EP_D & Individual 1 & USA_RSP_Ind1 & 2409.03 & 256.93 & 71.27 & 147.03 & 45.67 & 137.85 \\
\hline Reuben Tarte & EP_D & Individual 2 & USA_RSP_Ind 2 & 2787.72 & 261.71 & 78.35 & 165.59 & 64.01 & 131.26 \\
\hline Reuben Tarte & EP_D & Individual 3 & USA_RSP_Ind3 & 2733.84 & 283.71 & 103.84 & 189.07 & 76.45 & 174.35 \\
\hline Reuben Tarte & EP_D & Individual 4 & USA_RSP_Ind4 & 2181.42 & 224.14 & 114.39 & 184.93 & 50.12 & 129.56 \\
\hline Reuben Tarte & EP_D & Individual 5 & USA_RSP_Ind5 & 2787.91 & 284.27 & 95.39 & 197.67 & 65.89 & 200.81 \\
\hline Reuben Tarte & EP_D & Individual 6 & USA_RSP_Ind6 & 2516.54 & 275.45 & 109.05 & 193.42 & 44.71 & 171.26 \\
\hline Reuben Tarte & EP_D & Individual 7 & USA_RSP_Ind7 & 2436.34 & 231.51 & 86.84 & 164.01 & 62.08 & 138.87 \\
\hline Canoe Beach & $\mathrm{WA}^{-}$ & Individual 1 & USA_CAB_Ind1 & 1570.1 & 168.64 & 73.11 & 107.38 & 51.41 & 86.24 \\
\hline Canoe Beach & WA & Individual 2 & USA_CAB_Ind2 & 1632.26 & 182.2 & 66.42 & 105.87 & 59.28 & 72.17 \\
\hline Lubec & WA & Individual 1 & USA_LUB_Ind1 & 2013.09 & 222.07 & 68.53 & 136.84 & 56.89 & 121.91 \\
\hline Lubec & WA & Individual 2 & USA_LUB_Ind2 & 1851.4 & 184.65 & 63.18 & 136.1 & 43.68 & 106.07 \\
\hline Lubec & WA & Individual 3 & USA_LUB_Ind3 & 2227.13 & 198.78 & 71.97 & 168.34 & 43.75 & 98.99 \\
\hline Lubec & WA & Individual 4 & USA_LUB_Ind4 & 1620.44 & 171.11 & 49.22 & 118.02 & 34.88 & 72.28 \\
\hline Lubec & WA & Individual 5 & USA_LUB_Ind5 & 1647.19 & 147.38 & 73.39 & 113.84 & 48.14 & 77.73 \\
\hline Lubec & WA & Individual 6 & USA_LUB_Ind6 & 2298.89 & 237.15 & 56.89 & 139.88 & 51.96 & 116.73 \\
\hline Lubec & WA & Individual 7 & USA_LUB_Ind7 & 1521.28 & 184.64 & 51.68 & 122.04 & 47.11 & 98.58 \\
\hline Lødingen & EA_A & 436.29 & NOR_LOE_A436.29 & 2365.12 & 245.9 & 82.79 & 127.87 & 59.84 & 79.51 \\
\hline Lødingen & EA_A & 436.30 & NOR_LOE_A436.30 & 1766.87 & 198.36 & 49.18 & 105.74 & 52.46 & 69.67 \\
\hline Lødingen & EA_A & 436.31 & NOR_LOE_A436.31 & 2005.23 & 202.46 & 45.08 & 96.72 & 54.92 & 82.79 \\
\hline Lødingen & EA_A & 436.32 & NOR_LOE_A436.32 & 2388.31 & 195.87 & 51.65 & 123.14 & 50 & 80.58 \\
\hline Lødingen & EA_A & 436.33 & NOR_LOE_A436.33 & 2277.61 & 250 & 61.16 & 147.93 & 100.83 & 116.94 \\
\hline Lødingen & EA_A & 436.34 & NOR_LOE_A436.34 & 2456.69 & 241.32 & 73.55 & 112.81 & 83.47 & 123.55 \\
\hline Henningsvær & EA_A & 437.21 & NOR_HEN_A437.21 & 2293.93 & 221.9 & 57.85 & 118.18 & 50 & 83.47 \\
\hline Henningsvær & EA_A & 437.23 & NOR_HEN_A437.23 & 2500.06 & 295.46 & 84.71 & 123.55 & 56.41 & 126.03 \\
\hline Henningsvær & EA_A & 437.24 & NOR_HEN_A437.24 & 2572.16 & 280.99 & 54.55 & 102.07 & 63.64 & 123.97 \\
\hline Henningsvær & EA_A & 437.25 & NOR_HEN_A437.25 & 1876.3 & 198.36 & 85.25 & 121.31 & 65.57 & 114.75 \\
\hline
\end{tabular}




\begin{tabular}{|c|c|c|c|c|c|c|c|c|c|}
\hline Henningsvær & EA_A & 437.26 & NOR_HEN_A437.26 & 2573.28 & 255.37 & 57.85 & 118.18 & 49.59 & 113.22 \\
\hline Henningsvær & EA_A & 437.28 & NOR_HEN_A437.28 & 1514.25 & 170.49 & 50.82 & 108.2 & 45.9 & 81.15 \\
\hline Henningsvær & EA_A & 437.29 & NOR_HEN_A437.29 & 2392.82 & 262.3 & 44.26 & 107.38 & 61.48 & 104.1 \\
\hline Henningsvær & EA_A & 437.30 & NOR_HEN_A437.30 & 2352.62 & 293.44 & 84.43 & 136.07 & 63.12 & 119.67 \\
\hline Schilksee & EA_B & Neotype & GER_SCS_NeoF & 1692.39 & 140.99 & 54.12 & 82.56 & 46.55 & 77.55 \\
\hline Schilksee & EA_B & Paratype +1 & GER_SCS_ParaF1 & 1801.36 & 218.75 & 65.31 & 121.51 & 55.29 & 76.76 \\
\hline Schilksee & EA_B & Paratype 92 & GER_SCS_ParaF2 & 1407.97 & 159.51 & 48.13 & 99.11 & 45.94 & 81.02 \\
\hline Schilksee & EA_B & Paratype $\$ 3$ & GER_SCS_ParaM3 & 1841.37 & 171.13 & 33.07 & 93.32 & 45.23 & 58.33 \\
\hline Schilksee & EA_B & Paratype $\widehat{\delta} 4$ & GER_SCS_ParaM4 & 1608.5 & 185.78 & 61.52 & 109.71 & 33.85 & 80.41 \\
\hline Île Callot & EA_B & Individual 1 & FRA_ILE_Ind1 & 1772.15 & 186.94 & 51.36 & 104.66 & 38.91 & 92.79 \\
\hline Île Callot & EA_B & Individual 2 & FRA_ILE_Ind2 & 2074.69 & 233.75 & 66.39 & 109.72 & 50.68 & 98.79 \\
\hline Île Callot & EA_B & Individual 3 & FRA_ILE_Ind3 & 2329.07 & 277.84 & 79.73 & 152.68 & 64.65 & 160.32 \\
\hline Île Callot & EA_B & Individual 4 & FRA_ILE_Ind4 & 2507.08 & 251.73 & 70.58 & 153.04 & 36.65 & 95.99 \\
\hline Île Callot & EA_B & Individual 5 & FRA_ILE_Ind5 & 2441.76 & 285.81 & 89.96 & 167.84 & 47.14 & 125.71 \\
\hline Île Callot & EA_B & Individual 6 & FRA_ILE_Ind6 & 1958.52 & 233.13 & 72.9 & 140.66 & 45.31 & 118.62 \\
\hline Glenancross & EA_B & 321.51 & UK_GLE_A321.51 & 1352.02 & 204.92 & 88.53 & 126.23 & 43.44 & 78.69 \\
\hline Glenancross & EA_B & 321.52 & UK_GLE_A321.52 & 1277.24 & 217.36 & 54.96 & 114.05 & 45.87 & 63.22 \\
\hline Glenancross & EA_B & 321.53 & UK_GLE_A321.53 & 1617.29 & 183.88 & 66.53 & 121.49 & 45.46 & 82.23 \\
\hline Glenancross & EA_B & 321.55 & UK_GLE_A321.55 & 1219.04 & 143.8 & 54.13 & 91.32 & 39.26 & 54.13 \\
\hline Glenancross & EA_B & 321.56 & UK_GLE_A321.56 & 1201.2 & 142.88 & 54.96 & 102.07 & 42.15 & 61.57 \\
\hline Glenancross & EA_B & 321.57 & UK_GLE_A321.57 & 1545.18 & 176.03 & 51.24 & 104.13 & 39.26 & 60.33 \\
\hline Glenancross & EA_B & 321.59 & UK_GLE_A321.59 & 1358.37 & 185.73 & 52.89 & 104.55 & 42.98 & 76.86 \\
\hline Glenancross & EA_B & 321.60 & UK_GLE_A321.60 & 1099.18 & 121.31 & 45.9 & 105.74 & 36.89 & 63.93 \\
\hline Keitum & EA_B & 398.1_1 & GER_R_KEI_A398.1_1 & 1944.72 & 188.84 & 71.49 & 126.45 & 49.17 & 104.55 \\
\hline Keitum & EA_B & 398.1_2 & GER_KEI_A398.1_2 & 1427.03 & 146.69 & 66.12 & 118.18 & 45.87 & 86.36 \\
\hline Keitum & EA_B & 398.1_3 & GER_KEI_A398.1_3 & 1909.69 & 231.41 & 57.03 & 130.58 & 47.11 & 95.46 \\
\hline Keitum & EA_B & 398.1_4 & GER_KEI_A398.1_4 & 2050.62 & 180.58 & 72.31 & 127.27 & 50.83 & 99.59 \\
\hline Keitum & EA_B & 398.2_1 & GER_KEI_A398.2_1 & 2185.57 & 149.59 & 61.57 & 108.26 & 43.39 & 78.93 \\
\hline Keitum & EA_B & 398.2_2 & GER_KEI_A398.2_2 & 1452 & 151.65 & 61.98 & 111.98 & 45.04 & 83.06 \\
\hline Keitum & EA_B & $398.2 \_3$ & GER_KEI_A398.2_3 & 1921.13 & 161.57 & 64.88 & 117.36 & 48.35 & 84.3 \\
\hline Keitum & EA_B & $398.2 \_4$ & GER_KEI_A398.2_4 & 1401.46 & 135.95 & 63.22 & 108.26 & 44.63 & 82.23 \\
\hline Keitum & EA_B & 398.16 & GER_KEI_A398.16 & 1396.82 & 145.9 & 70.49 & 124.59 & 43.44 & 88.53 \\
\hline Keitum & EA_B & 398.17 & GER_KEI_A398.17 & 1613.95 & 174.79 & 58.68 & 114.46 & 57.85 & 100 \\
\hline Bristol Channel & EA_C & Individual 1 & UK_BCH_Ind1 & 1873.11 & 207.79 & 88.07 & 111.54 & 54.05 & 99.27 \\
\hline Bristol Channel & EA_C & Individual 2 & UK_BCH_Ind2 & 2149.73 & 227.91 & 67.44 & 146.56 & 53.36 & 113.37 \\
\hline Bristol Channel & EA_C & Individual 3 & UK_BCH_Ind3 & 1998.95 & 226.25 & 66.45 & 139.53 & 54.81 & 145.95 \\
\hline Bristol Channel & EA_C & Individual 4 & UK_BCH_Ind4 & 2294.3 & 248.21 & 76.08 & 147.1 & 76.32 & 149.98 \\
\hline Bristol Channel & EA_C & Individual 5 & UK_BCH_Ind5 & 1829.39 & 227.4 & 71.96 & 141.17 & 51.03 & 114.78 \\
\hline Gravesend & EA_C & Individual 1 & UK_GRA_Ind1 & 2661.38 & 338.49 & 84.97 & 164.24 & 64.46 & 105.47 \\
\hline Gravesend & EA_C & Individual 2 & UK_GRA_Ind2 & 2275.83 & 226.1 & 67.52 & 145.55 & 59.35 & 114.8 \\
\hline Gravesend & EA_C & Individual 3 & UK_GRA_Ind3 & 2644.38 & 267.09 & 81.52 & 139.92 & 52.82 & 142.71 \\
\hline Gravesend & EA_C & Individual 4 & UK_GRA_Ind4 & 2637.59 & 291.42 & 90.99 & 161.94 & 59.33 & 144.71 \\
\hline Gravesend & EA_C & Individual 5 & UK_GRA_Ind5 & 2493.57 & 264.58 & 71.32 & 144.94 & 50.62 & 118.22 \\
\hline Gravesend & EA_C & Individual 6 & UK_GRA_Ind6 & 3751.87 & 423.71 & 153.28 & 206.36 & 51.2 & 115.59 \\
\hline Gravesend & EA_C & Individual 7 & UK_GRA_Ind7 & 2549.49 & 189.77 & 63.13 & 115.96 & 56.95 & 97.98 \\
\hline Gravesend & EA_C & Individual 8 & UK_GRA_Ind8 & 2625.56 & 234.9 & 85.71 & 110.32 & 61.09 & 119.39 \\
\hline Gravesend & EA_C & Individual 9 & UK_GRA_Ind9 & 2499.99 & 297.56 & 84.72 & 164.46 & 57.75 & 131.38 \\
\hline Plymouth & EA_C & Individual 1 & UK_PLY_Ind1 & 1595.9 & 169.31 & 47.96 & 106.38 & 41.61 & 97.98 \\
\hline Plymouth & EA_C & Individual 2 & UK_PLY_Ind2 & 1317 & 159.65 & 56.13 & 104.45 & 48.81 & 105.2 \\
\hline Plymouth & EA_C & Individual 3 & UK_PLY_Ind3 & 2903.19 & 284.06 & 89.94 & 161.34 & 77.43 & 153.36 \\
\hline Plymouth & EA_C & Individual 4 & UK_PLY_Ind4 & 1713.76 & 225.3 & 62.55 & 130.77 & 56.28 & 120.45 \\
\hline Plymouth & EA_C & Individual 5 & UK_PLY_Ind5 & 3021.08 & 367.8 & 105.95 & 200.45 & 60.57 & 132.59 \\
\hline Plymouth & EA_C & Individual 6 & UK_PLY_Ind6 & 2093.62 & 229.65 & 77.32 & 133.1 & 39.05 & 123.48 \\
\hline Plymouth & EA_C & Individual 7 & UK_PLY_Ind7 & 2689.28 & 312.04 & 93.96 & 171.86 & 56.55 & 156.02 \\
\hline Ellenbogen & EA_C & Individual 1 & GER_ELLE_Ind1 & 2386.98 & 255.15 & 70.92 & 160.32 & 160.32 & 126.17 \\
\hline Ellenbogen & EA_C & Individual 2 & GER_ELL_Ind2 & 2524.11 & 247.34 & 75.37 & 175.99 & 64.66 & 97.37 \\
\hline Ellenbogen & EA_C & Individual 3 & GER_ELL_Ind3 & 2780.02 & 277.53 & 126.13 & 222.07 & 59.78 & 145.03 \\
\hline Ellenbogen & EA_C & Individual 5 & GER_ELL_Ind5 & 2324.45 & 213.18 & 81.59 & 172.38 & 53.95 & 163.36 \\
\hline Ellenbogen & EA_C & Individual 6 & GER_ELL_Ind6 & 2372.22 & 251.88 & 87.12 & 180.05 & 50.92 & 137.65 \\
\hline Ellenbogen & EA_C & Individual 7 & GER_ELL_Ind7 & 2283.45 & 280.01 & 100.28 & 190.78 & 52.69 & 133 \\
\hline Ellenbogen & EA_C & Individual 8 & GER_ELL_Ind8 & 2674.36 & 270.7 & 92.9 & 183.6 & 73.28 & 127.54 \\
\hline Ellenbogen & EA_C & Individual 9 & GER_ELL_Ind 9 & 2732.56 & 264.3 & 73.54 & 178.41 & 65.86 & 140.89 \\
\hline Ellenbogen & EA_C & Individual 10 & GER_ELL_Ind10 & 2593.88 & 256.32 & 140.17 & 219.23 & 78.67 & 155.39 \\
\hline
\end{tabular}


Supplementary Table 5. List of morphological characters used in the analyses comparing Stygocapitella with Orbiniidae and Nerillidae.

\begin{tabular}{|c|c|c|}
\hline \# & Character & Character states \\
\hline 1 & Segmentation & $\begin{array}{l}0=\text { absent } \\
1=\text { present }\end{array}$ \\
\hline 2 & Size & $\begin{array}{l}0=\text { macrofaunal } \\
1=\text { meiofaunal }\end{array}$ \\
\hline 3 & Numbers of segments & $\begin{array}{l}0=\text { more than ten } \\
1=\text { ten } \\
2=\text { nine } \\
3=\text { eight } \\
4=\text { seven }\end{array}$ \\
\hline 4 & Head structure & $\begin{array}{l}0=\text { prostomium and ring-like peristomium } \\
1=\text { prostomium and two or more ring-like peristomium } \\
2=\text { prostomium and peristomium limited to lips }\end{array}$ \\
\hline 5 & Shape of prostomium & $\begin{array}{l}0=\text { unmodified } \\
1=\text { prostomium narrowly pointed or sharply conical } \\
2=\text { prostomium broadly rounded or truncate on anterior margin } \\
3=\text { prostomium elongate, narrow, rounded anteriorly }\end{array}$ \\
\hline 6 & First body segment & $\begin{array}{l}0=\text { similar to following segments, or more or less reduced } \\
1=\text { surrounding head }\end{array}$ \\
\hline 7 & Chaetae on first body segment & $\begin{array}{l}0=\text { present } \\
1=\text { absent }\end{array}$ \\
\hline 8 & Second body segment & $\begin{array}{l}0=\text { short } \\
1=\text { elongated to form trunk }\end{array}$ \\
\hline 9 & Palps & $\begin{array}{l}0=\text { absent } \\
1=\text { present }\end{array}$ \\
\hline 10 & Palp origin & $\begin{array}{l}0=\text { absent } \\
1=\text { prostomial } \\
2=\text { peristomial }\end{array}$ \\
\hline 11 & Number of palps & $\begin{array}{l}0=\text { absent } \\
1=\text { one pair of palps }\end{array}$ \\
\hline 12 & Median prostomial antenna & $\begin{array}{l}0=\text { absent } \\
1=\text { present }\end{array}$ \\
\hline 13 & Relative length median antenna & $\begin{array}{l}0=\text { absent } \\
1=\text { longer than prostomial width } \\
2=\text { shorter than prostomial width }\end{array}$ \\
\hline 14 & Shape of antennae & $\begin{array}{l}0=\text { absent } \\
1=\text { straight } \\
2=\text { wrinkled }\end{array}$ \\
\hline 15 & Lateral prostomial antennae & $\begin{array}{l}0=\text { absent } \\
1=\text { present }\end{array}$ \\
\hline 16 & Relative length paired antennae & $\begin{array}{l}0=\text { absent } \\
1=\text { longer than palps and prostomial width } \\
2=\text { shorter than palps and prostomial width }\end{array}$ \\
\hline 17 & Palp structure & $\begin{array}{l}0=\text { absent } \\
1=\text { solid }\end{array}$ \\
\hline 18 & Parapodia & $\begin{array}{l}0=\text { absent } \\
1=\text { present }\end{array}$ \\
\hline 19 & Shape of notopodium & $\begin{array}{l}0=\text { absent } \\
1=\text { tori or small lobes } \\
2=\text { prominent lobes }\end{array}$ \\
\hline 20 & Shape of neuropodium & $\begin{array}{l}0=\text { absent } \\
1=\text { tori or small lobes } \\
2=\text { promiment lobes }\end{array}$ \\
\hline 21 & Presence of tori & $\begin{array}{l}0=\text { absent } \\
1=\text { present }\end{array}$ \\
\hline 22 & Dorsal cirri & $\begin{array}{l}0=\text { absent } \\
1=\text { present }\end{array}$ \\
\hline 23 & Ventral cirri & $\begin{array}{l}0=\text { absent } \\
1=\text { present }\end{array}$ \\
\hline 24 & Interramal cirri & $\begin{array}{l}0=\text { absent } \\
1=\text { present }\end{array}$ \\
\hline 25 & IC number per segment & $\begin{array}{l}0=\text { absent } \\
1=\text { double pair } \\
2=\text { single pair } \\
3=\text { single }\end{array}$ \\
\hline 26 & IC first body segment & $\begin{array}{l}0=\text { absent } \\
1=\text { present }\end{array}$ \\
\hline 27 & IC other segments length & $\begin{array}{l}0=\text { absent } \\
1=\text { longer than segment } \\
2=\text { shorter than segment } \\
3=\text { rudimentary }\end{array}$ \\
\hline 28 & $\begin{array}{l}\text { IC other segments relative } \\
\text { length }\end{array}$ & $\begin{array}{l}0=\text { absent } \\
1=\text { increasing towards posterior end }\end{array}$ \\
\hline
\end{tabular}


IC other segments shape

$2=$ similar throughout

$3=$ increasing towards posterior end

$0=$ absent

$1=$ cirriform

2=leaf-shaped

$3=$ bottle-shaped

30

IC last segment

$0=$ absent

$1=$ present

$0=$ absent

$1=$ present

segment

$0=$ absent

$1=$ present

segments

$0=$ absent

$1=$ present

$0=$ absent

$1=$ present

$0=$ absent

$1=$ present

$0=$ absent

$1=$ present

$0=$ absent

$1=$ present

$0=$ absent

$1=$ present

$0=$ absent

$1=$ present

$0=$ absent

$1=$ present

$0=$ absent

$1=$ present

$0=$ absent

$1=$ present

$0=$ absent

$1=$ cirriform

$2=$ wrinkled

$3=$ leaf-shaped

$0=$ absent

$1=$ one pair

$2=$ two or more pairs

$0=$ absent

$1=$ present

$0=$ absent

Prostomial ciliation lateral

$1=$ present groups between lateral antennae and palps

47 Dorsal transverse body ciliation

$0=$ absent

$1=$ present

$0=$ absent

$1=$ two groups of cilia

$2=$ a maximum of more than two groups

$3=$ continuous rows of cilia

$4=$ dorso-lateral bands between parapodia

Ventral transverse body ciliation

$0=$ absent

$1=$ present

$0=$ absent

$1=$ two groups of cilia

$2=$ a maximum of more than two groups

$3=$ continuous rows of cilia

$4=$ ventro-lateral bands between parapodia

$51 \quad$ Nuchal organs

$0=\mathrm{absent}$

$1=$ present

$2=$ internalized

$0=$ pits or grooves

$1=$ other form

$0=$ absent

$1=$ present

$0=$ absent

$1=$ present

$0=$ absent

$1=$ single pair

$2=$ double pair

$0=$ absent

$1=$ present

$0=$ absent

$1=$ single pair

$2=$ double pairs

58

Chaetae

$0=$ absent

$1=$ present 


\begin{tabular}{|c|c|c|}
\hline 59 & Internatized supporting chaetae & $\begin{array}{l}0=\text { absent } \\
1=\text { present }\end{array}$ \\
\hline 60 & Compound chaetae & $\begin{array}{l}0=\text { absent } \\
1=\text { present }\end{array}$ \\
\hline 61 & Compound notochaetae & $\begin{array}{l}0=\text { absent } \\
1=\text { present }\end{array}$ \\
\hline 62 & Uncini hooks & $\begin{array}{l}0=\text { absent } \\
1=\text { present }\end{array}$ \\
\hline 63 & Shape hooks & $\begin{array}{l}0=\text { absent } \\
1=\text { swan-shaped }\end{array}$ \\
\hline 64 & Forked chaetae & $\begin{array}{l}0=\text { absent } \\
1=\text { present }\end{array}$ \\
\hline 65 & Whipped chaetae & $\begin{array}{l}0=\text { absent } \\
1=\text { present }\end{array}$ \\
\hline 66 & $\begin{array}{l}\text { Bilimbate chaetae first body } \\
\text { segment }\end{array}$ & $\begin{array}{l}0=\text { absent } \\
1=\text { one }\end{array}$ \\
\hline 67 & $\begin{array}{l}\text { Bilimbate chaetae second body } \\
\text { segment }\end{array}$ & $\begin{array}{l}2=\text { two } \\
3=\text { three } \\
0=\text { absent } \\
1=\text { two } \\
2=\text { three } \\
3=\text { four }\end{array}$ \\
\hline 68 & $\begin{array}{l}\text { Bilimbate chaetae other body } \\
\text { segment }\end{array}$ & $\begin{array}{l}0=\text { absent } \\
1=\text { two } \\
2=\text { four }\end{array}$ \\
\hline 69 & Crenulated capillary chaetae & $\begin{array}{l}0=\text { absent } \\
1=\text { present }\end{array}$ \\
\hline 70 & $\begin{array}{l}\text { Anterior parapodia thick } \\
\text { modified spines }\end{array}$ & $\begin{array}{l}0=\text { absent } \\
1=\text { present }\end{array}$ \\
\hline 71 & $\begin{array}{l}\text { Thoracic neuropodia special } \\
\text { chaetae }\end{array}$ & $\begin{array}{l}0=\text { absent } \\
1=\text { present }\end{array}$ \\
\hline 72 & Stomodaeum & $\begin{array}{l}0=\text { absent } \\
1=\text { ventral buccal organ }\end{array}$ \\
\hline 73 & Dorsolateral folds & $\begin{array}{l}0=\text { absent } \\
1=\text { present }\end{array}$ \\
\hline 74 & Gut & $\begin{array}{l}0=\text { straight } \\
1=\text { lateral folds }\end{array}$ \\
\hline 75 & Body distinct thorax-abdomen & $\begin{array}{l}0=\text { absent } \\
1=\text { present }\end{array}$ \\
\hline
\end{tabular}


Supplementary Table 6. Data matrix of morphological characters used in the analyses comparing Stygocapitella with Orbiniidae and Nerillidae.

\begin{tabular}{|c|c|c|c|c|c|c|c|c|c|c|c|c|c|c|c|c|c|c|c|c|c|c|c|c|c|c|}
\hline Taxon & Species & 01 & 02 & 03 & 04 & 05 & 06 & 07 & 08 & 09 & 10 & 11 & 12 & 13 & 14 & 15 & 16 & 17 & 18 & 19 & 20 & 21 & 22 & 23 & 24 & 25 \\
\hline \multirow[t]{12}{*}{ Orbiniidae } & Leitoscoloplos fragilis & 1 & 0 & 0 & 0 & 1 & 0 & 0 & 0 & 0 & 0 & 0 & 0 & 0 & 0 & 0 & 0 & 0 & 1 & 2 & 2 & 0 & 0 & 0 & 1 & 3 \\
\hline & Leodamas jobnstonei & 1 & 0 & 0 & 0 & 1 & 0 & 0 & 0 & 0 & 0 & 0 & 0 & 0 & 0 & 0 & 0 & 0 & 1 & 2 & 2 & 0 & 0 & 0 & 0 & 0 \\
\hline & Methanoaricia dendrobranchiata & 1 & 0 & 0 & 2 & 3 & 0 & 0 & 0 & 0 & 0 & 0 & 0 & 0 & 0 & 0 & 0 & 0 & 1 & 2 & 2 & 0 & 0 & 0 & 0 & 0 \\
\hline & Naineris quadricuspida & 1 & 0 & 0 & 0 & 2 & 0 & 0 & 0 & 0 & 0 & 0 & 0 & 0 & 0 & 0 & 0 & 0 & 1 & 2 & 2 & 0 & 0 & 0 & 0 & 0 \\
\hline & Orbinia swani & 1 & 0 & 0 & 0 & 1 & 0 & 0 & 0 & 0 & 0 & 0 & 0 & 0 & 0 & 0 & 0 & 0 & 1 & 2 & 2 & 0 & 0 & 0 & 0 & 0 \\
\hline & Orbiniella plumisetosa & 1 & 0 & 0 & 1 & 2 & 0 & 0 & 0 & 0 & 0 & 0 & 0 & 0 & 0 & 0 & 0 & 0 & 1 & 1 & 1 & 0 & 0 & 0 & 0 & 0 \\
\hline & Pettibonella multiuncinata & 1 & 0 & 0 & 1 & 2 & 0 & 0 & 0 & 0 & 0 & 0 & 0 & 0 & 0 & 0 & 0 & 0 & 1 & 2 & 2 & 0 & 0 & 0 & 0 & 0 \\
\hline & Pbylo michaelseni & 1 & 0 & 0 & 0 & 1 & 0 & 0 & 0 & 0 & 0 & 0 & 0 & 0 & 0 & 0 & 0 & 0 & 1 & 2 & 2 & 0 & 0 & 0 & 1 & 3 \\
\hline & Proscoloplos cygnochaetus & 1 & 0 & 0 & 1 & 2 & 0 & 0 & 0 & 0 & 0 & 0 & 0 & 0 & 0 & 0 & 0 & 0 & 1 & 2 & 2 & 0 & 0 & 0 & 0 & 0 \\
\hline & Protoaricia oerstedii & 1 & 0 & 0 & 1 & 2 & 0 & 0 & 0 & 0 & 0 & 0 & 0 & 0 & 0 & 0 & 0 & 0 & 1 & 2 & 2 & 0 & 0 & 0 & 0 & 0 \\
\hline & Questa paucibranchiata & 1 & 0 & 0 & 0 & 2 & 0 & 0 & 0 & 0 & 0 & 0 & 0 & 0 & 0 & 0 & 0 & 0 & 1 & 1 & 1 & 0 & 0 & 0 & 0 & 0 \\
\hline & Scoloplos armiger & 1 & 0 & 0 & 0 & 1 & 0 & 0 & 0 & 0 & 0 & 0 & 0 & 0 & 0 & 0 & 0 & 0 & 1 & 2 & 2 & 0 & 0 & 0 & 0 & 0 \\
\hline \multirow[t]{9}{*}{ Parergodrilidae } & Stygocapitella minuta & 1 & 0 & 3 & 1 & 2 & 0 & 0 & 0 & 0 & 0 & 0 & 0 & 0 & 0 & 0 & 0 & 0 & 0 & 0 & 0 & 0 & 0 & 0 & 0 & 0 \\
\hline & Stygocapitella australis & 1 & 0 & 1 & 1 & 2 & 0 & 0 & 0 & 0 & 0 & 0 & 0 & 0 & 0 & 0 & 0 & 0 & 0 & 0 & 0 & 0 & 0 & 0 & 0 & 0 \\
\hline & Stygocapitella EP A & 1 & 0 & 1 & 1 & 2 & 0 & 0 & 0 & 0 & 0 & 0 & 0 & 0 & 0 & 0 & 0 & 0 & 0 & 0 & 0 & 0 & 0 & 0 & 0 & 0 \\
\hline & Stygocapitella EP C & 1 & 0 & 1 & 1 & 2 & 0 & 0 & 0 & 0 & 0 & 0 & 0 & 0 & 0 & 0 & 0 & 0 & 0 & 0 & 0 & 0 & 0 & 0 & 0 & 0 \\
\hline & Stygocapitella EP D & 1 & 0 & 1 & 1 & 2 & 0 & 0 & 0 & 0 & 0 & 0 & 0 & 0 & 0 & 0 & 0 & 0 & 0 & 0 & 0 & 0 & 0 & 0 & 0 & 0 \\
\hline & Stygocapitella WA & 1 & 0 & 1 & 1 & 2 & 0 & 0 & 0 & 0 & 0 & 0 & 0 & 0 & 0 & 0 & 0 & 0 & 0 & 0 & 0 & 0 & 0 & 0 & 0 & 0 \\
\hline & Stygocapitella EA A & 1 & 0 & 1 & 1 & 2 & 0 & 0 & 0 & 0 & 0 & 0 & 0 & 0 & 0 & 0 & 0 & 0 & 0 & 0 & 0 & 0 & 0 & 0 & 0 & 0 \\
\hline & Stygocapitella EA B & 1 & 0 & 1 & 1 & 2 & 0 & 0 & 0 & 0 & 0 & 0 & 0 & 0 & 0 & 0 & 0 & 0 & 0 & 0 & 0 & 0 & 0 & 0 & 0 & 0 \\
\hline & Stygocapitella EA C & 1 & 0 & 1 & 1 & 2 & 0 & 0 & 0 & 0 & 0 & 0 & 0 & 0 & 0 & 0 & 0 & 0 & 0 & 0 & 0 & 0 & 0 & 0 & 0 & 0 \\
\hline \multirow[t]{11}{*}{ Nerillidae } & Aristonerilla brevis & 1 & 1 & 4 & 2 & 0 & 0 & 0 & 0 & 1 & 1 & 1 & 1 & 1 & 2 & 1 & 1 & 1 & 1 & 1 & 1 & 0 & 0 & 0 & 1 & 2 \\
\hline & Leptonerilla prospera & 1 & 1 & 2 & 2 & 0 & 0 & 0 & 0 & 1 & 1 & 1 & 1 & 1 & 1 & 1 & 1 & 1 & 1 & 1 & 1 & 0 & 0 & 0 & 1 & 1 \\
\hline & Longipalpa saltatrix & 1 & 1 & 3 & 2 & 0 & 0 & 0 & 0 & 1 & 1 & 1 & 1 & 2 & 1 & 1 & 2 & 1 & 1 & 1 & 1 & 0 & 0 & 0 & 1 & 2 \\
\hline & Meganerilla swedmarki & 1 & 1 & 2 & 2 & 0 & 0 & 0 & 0 & 1 & 1 & 1 & 0 & 0 & 0 & 0 & 0 & 1 & 1 & 1 & 1 & 0 & 0 & 0 & 1 & 2 \\
\hline & Mesonerilla roscovita & 1 & 1 & 2 & 2 & 0 & 0 & 1 & 0 & 1 & 1 & 1 & 1 & 2 & 1 & 1 & 1 & 1 & 1 & 1 & 1 & 0 & 0 & 0 & 1 & 2 \\
\hline & Micronerilla minuta & 1 & 1 & 3 & 2 & 0 & 0 & 0 & 0 & 1 & 1 & 1 & 1 & 1 & 2 & 1 & 1 & 1 & 1 & 1 & 1 & 0 & 0 & 0 & 1 & 1 \\
\hline & Nerillidium $s p$ & 1 & 1 & 3 & 2 & 0 & 0 & 0 & 0 & 1 & 1 & 1 & 0 & 0 & 0 & 1 & 1 & 1 & 1 & 1 & 1 & 0 & 0 & 0 & 1 & 2 \\
\hline & Paranerilla limicola & 1 & 1 & 4 & 2 & 0 & 0 & 0 & 0 & 1 & 1 & 1 & 0 & 0 & 0 & 0 & 0 & 1 & 1 & 1 & 1 & 0 & 0 & 0 & 1 & 2 \\
\hline & Trochonerilla mobilis & 1 & 1 & 3 & 2 & 0 & 0 & 0 & 0 & 1 & 1 & 1 & 1 & 2 & 1 & 1 & 2 & 1 & 1 & 1 & 1 & 0 & 0 & 0 & 1 & 2 \\
\hline & Troglochaetus beranecki & 1 & 1 & 3 & 2 & 0 & 0 & 1 & 0 & 1 & 1 & 1 & 0 & 0 & 0 & 0 & 0 & 1 & 1 & 1 & 1 & 0 & 0 & 0 & 1 & 2 \\
\hline & Xenonerilla bactericola & 1 & 1 & 2 & 2 & 0 & 0 & 1 & 0 & 1 & 1 & 1 & 0 & 0 & 0 & 0 & 0 & 1 & 1 & 1 & 1 & 0 & 0 & 0 & 1 & 2 \\
\hline
\end{tabular}


Supplementary Table 6. Cont.

\begin{tabular}{|c|c|c|c|c|c|c|c|c|c|c|c|c|c|c|c|c|c|c|c|c|c|c|c|c|c|c|}
\hline Taxon & Species & 26 & 27 & 28 & 29 & 30 & 31 & 32 & 33 & 34 & 35 & 36 & 37 & 38 & 39 & 40 & 41 & 42 & 43 & 44 & 45 & 46 & 47 & 48 & 49 & 50 \\
\hline \multirow[t]{12}{*}{ Orbiniidae } & Leitoscoloplos fragilis & 0 & 2 & 3 & 1 & 0 & 1 & 1 & 1 & 0 & 1 & 0 & 0 & 0 & 1 & 1 & 1 & 1 & 1 & 2 & 0 & 0 & 0 & 0 & 0 & 0 \\
\hline & Leodamas jobnstonei & 0 & 0 & 0 & 0 & 0 & 0 & 1 & 1 & 0 & 0 & 0 & 0 & 0 & 1 & 1 & 1 & 1 & 1 & 2 & 0 & 0 & 0 & 0 & 0 & 0 \\
\hline & Methanoaricia dendrobrancbiata & 0 & 0 & 0 & 0 & 0 & 1 & 1 & 0 & 0 & 0 & 0 & 0 & 0 & 1 & 1 & 1 & 1 & 1 & 2 & 0 & 0 & 0 & 0 & 0 & 0 \\
\hline & Naineris quadricuspida & 0 & 0 & 0 & 0 & 0 & 1 & 1 & 1 & 0 & 0 & 0 & 0 & 0 & 1 & 1 & 1 & 1 & 1 & 2 & 0 & 0 & 0 & 0 & 0 & 0 \\
\hline & Orbinia swani & 0 & 0 & 0 & 0 & 0 & 1 & 1 & 1 & 1 & 1 & 0 & 0 & 0 & 1 & 1 & 1 & 1 & 1 & 2 & 0 & 0 & 0 & 0 & 0 & 0 \\
\hline & Orbiniella plumisetosa & 0 & 0 & 0 & 0 & 0 & 0 & 0 & 0 & 0 & 0 & 0 & 0 & 0 & 0 & 1 & 1 & 0 & 0 & 2 & 0 & 0 & 0 & 0 & 0 & 0 \\
\hline & Pettibonella multiuncinata & 0 & 0 & 0 & 0 & 0 & 1 & 1 & 0 & 0 & 0 & 0 & 0 & 0 & 1 & 1 & 1 & 1 & 1 & 2 & 0 & 0 & 0 & 0 & 0 & 0 \\
\hline & Phylo michaelseni & 0 & 2 & 3 & 1 & 0 & 0 & 1 & 1 & 1 & 1 & 0 & 0 & 0 & 1 & 1 & 1 & 1 & 1 & 2 & 0 & 0 & 0 & 0 & 0 & 0 \\
\hline & Proscoloplos cygnochaetus & 0 & 0 & 0 & 0 & 0 & 1 & 1 & 0 & 0 & 0 & 0 & 0 & 0 & 1 & 1 & 1 & 1 & 1 & 2 & 0 & 0 & 0 & 0 & 0 & 0 \\
\hline & Protoaricia oerstedii & 0 & 0 & 0 & 0 & 0 & 1 & 1 & 1 & 0 & 0 & 0 & 0 & 0 & 1 & 1 & 1 & 1 & 1 & 2 & 0 & 0 & 0 & 0 & 0 & 0 \\
\hline & Questa paucibrancbiata & 0 & 0 & 0 & 0 & 0 & 1 & 1 & 0 & 0 & 0 & 1 & 1 & 0 & 1 & 1 & 0 & 1 & 1 & 2 & 0 & 0 & 0 & 0 & 0 & 0 \\
\hline & Scoloplos armiger & 0 & 0 & 0 & 0 & 0 & 1 & 1 & 1 & 0 & 1 & 0 & 0 & 0 & 1 & 1 & 1 & 1 & 1 & 2 & 0 & 0 & 0 & 0 & 0 & 0 \\
\hline \multirow[t]{9}{*}{ Parergodrilidae } & Stygocapitella minuta & 0 & 0 & 0 & 0 & 0 & 0 & 0 & 0 & 0 & 0 & 0 & 0 & 0 & 0 & 0 & 0 & 0 & 0 & 0 & 0 & 0 & 0 & 0 & 0 & 0 \\
\hline & Stygocapitella australis & 0 & 0 & 0 & 0 & 0 & 0 & 0 & 0 & 0 & 0 & 0 & 0 & 0 & 0 & 0 & 0 & 0 & 0 & 0 & 0 & 0 & 0 & 0 & 0 & 0 \\
\hline & Stygocapitella EP A & 0 & 0 & 0 & 0 & 0 & 0 & 0 & 0 & 0 & 0 & 0 & 0 & 0 & 0 & 0 & 0 & 0 & 0 & 0 & 0 & 0 & 0 & 0 & 0 & 0 \\
\hline & Stygocapitella EP C & 0 & 0 & 0 & 0 & 0 & 0 & 0 & 0 & 0 & 0 & 0 & 0 & 0 & 0 & 0 & 0 & 0 & 0 & 0 & 0 & 0 & 0 & 0 & 0 & 0 \\
\hline & Stygocapitella EP D & 0 & 0 & 0 & 0 & 0 & 0 & 0 & 0 & 0 & 0 & 0 & 0 & 0 & 0 & 0 & 0 & 0 & 0 & 0 & 0 & 0 & 0 & 0 & 0 & 0 \\
\hline & Stygocapitella WA & 0 & 0 & 0 & 0 & 0 & 0 & 0 & 0 & 0 & 0 & 0 & 0 & 0 & 0 & 0 & 0 & 0 & 0 & 0 & 0 & 0 & 0 & 0 & 0 & 0 \\
\hline & Stygocapitella EA A & 0 & 0 & 0 & 0 & 0 & 0 & 0 & 0 & 0 & 0 & 0 & 0 & 0 & 0 & 0 & 0 & 0 & 0 & 0 & 0 & 0 & 0 & 0 & 0 & 0 \\
\hline & Stygocapitella EA B & 0 & 0 & 0 & 0 & 0 & 0 & 0 & 0 & 0 & 0 & 0 & 0 & 0 & 0 & 0 & 0 & 0 & 0 & 0 & 0 & 0 & 0 & 0 & 0 & 0 \\
\hline & Stygocapitella EA C & 0 & 0 & 0 & 0 & 0 & 0 & 0 & 0 & 0 & 0 & 0 & 0 & 0 & 0 & 0 & 0 & 0 & 0 & 0 & 0 & 0 & 0 & 0 & 0 & 0 \\
\hline \multirow[t]{11}{*}{ Nerillidae } & Aristonerilla brevis & 0 & 1 & 1 & 1 & 0 & 0 & 0 & 0 & 0 & 0 & 0 & 0 & 0 & 0 & 0 & 0 & 1 & 2 & 1 & 1 & 1 & 1 & 2 & 1 & 2 \\
\hline & Leptonerilla prospera & 1 & 1 & 2 & 1 & 1 & 0 & 0 & 0 & 0 & 0 & 0 & 0 & 0 & 0 & 0 & 0 & 1 & 1 & 1 & 1 & 1 & 1 & 3 & 1 & 3 \\
\hline & Longipalpa saltatrix & 0 & 2 & 1 & 3 & 1 & 0 & 0 & 0 & 0 & 0 & 0 & 0 & 0 & 0 & 0 & 0 & 0 & 0 & 1 & 1 & 1 & 1 & 2 & 1 & 2 \\
\hline & Meganerilla swedmarki & 1 & 2 & 1 & 2 & 1 & 0 & 0 & 0 & 0 & 0 & 0 & 0 & 0 & 0 & 0 & 0 & 1 & 3 & 1 & 1 & 1 & 1 & 4 & 1 & 4 \\
\hline & Mesonerilla roscovita & 1 & 1 & 1 & 1 & 1 & 0 & 0 & 0 & 0 & 0 & 0 & 0 & 0 & 0 & 0 & 0 & 1 & 1 & 1 & 1 & 1 & 1 & 2 & 1 & 2 \\
\hline & Micronerilla minuta & 0 & 1 & 1 & 1 & 0 & 0 & 0 & 0 & 0 & 0 & 0 & 0 & 0 & 0 & 0 & 0 & 1 & 2 & 1 & 1 & 0 & 0 & 0 & 0 & 0 \\
\hline & Nerillidium $s p$ & 1 & 2 & 2 & 1 & 0 & 0 & 0 & 0 & 0 & 0 & 0 & 0 & 0 & 0 & 0 & 0 & 1 & 1 & 1 & 1 & 1 & 1 & 1 & 1 & 2 \\
\hline & Paranerilla limicola & 1 & 3 & 2 & 1 & 1 & 0 & 0 & 0 & 0 & 0 & 0 & 0 & 0 & 0 & 0 & 0 & 1 & 1 & 1 & 1 & 0 & 1 & 3 & 1 & 3 \\
\hline & Trochonerilla mobilis & 0 & 1 & 1 & 1 & 0 & 0 & 0 & 0 & 0 & 0 & 0 & 0 & 0 & 0 & 0 & 0 & 1 & 2 & 1 & 1 & 1 & 1 & 3 & 1 & 3 \\
\hline & Troglochaetus beranecki & 0 & 3 & 2 & 1 & 0 & 0 & 0 & 0 & 0 & 0 & 0 & 0 & 0 & 0 & 0 & 0 & 1 & 0 & 1 & 1 & 1 & 1 & 1 & 0 & 0 \\
\hline & Xenonerilla bactericola & 0 & 2 & 2 & 2 & 1 & 0 & 0 & 0 & 0 & 0 & 0 & 0 & 0 & 0 & 0 & 0 & 1 & 3 & 1 & 1 & 0 & 0 & 0 & 0 & 0 \\
\hline
\end{tabular}


Supplementary Table 6. Cont.

\begin{tabular}{|c|c|c|c|c|c|c|c|c|c|c|c|c|c|c|c|c|c|c|c|c|c|c|c|c|c|c|}
\hline Taxon & Species & 51 & 52 & 53 & 54 & 55 & 56 & 57 & 58 & 59 & 60 & 61 & 62 & 63 & 64 & 65 & 66 & 67 & 68 & 69 & 70 & 71 & 72 & 73 & 74 & 75 \\
\hline \multirow[t]{12}{*}{ Orbiniidae } & Leitoscoloplos fragilis & 1 & 0 & 0 & 0 & 0 & 0 & 0 & 1 & 1 & 0 & $\overline{0}$ & 0 & 0 & 0 & 0 & 0 & 0 & 0 & 1 & 0 & 0 & 1 & 1 & 0 & 1 \\
\hline & Leodamas johnstonei & 1 & 0 & 0 & 0 & 0 & 0 & 0 & 1 & 1 & 0 & 0 & 0 & 0 & 1 & 0 & 0 & 0 & 0 & 1 & 0 & 1 & 1 & 1 & 0 & 1 \\
\hline & Methanoaricia dendrobrancbiata & 1 & 0 & 0 & 0 & 0 & 0 & 0 & 1 & 1 & 0 & 0 & 0 & 0 & 0 & 0 & 0 & 0 & 0 & 1 & 0 & 1 & 1 & 1 & 0 & 0 \\
\hline & Naineris quadricuspida & 1 & 0 & 0 & 1 & 1 & 1 & 1 & 1 & 1 & 0 & 0 & 0 & 0 & 1 & 0 & 0 & 0 & 0 & 1 & 0 & 1 & 1 & 1 & 0 & 1 \\
\hline & Orbinia swani & 1 & 0 & 0 & 1 & 1 & 1 & 1 & 1 & 1 & 0 & 0 & 0 & 0 & 1 & 0 & 0 & 0 & 0 & 1 & 0 & 1 & 1 & 1 & 0 & 1 \\
\hline & Orbiniella plumisetosa & 1 & 0 & 0 & 1 & 1 & 1 & 1 & 1 & 1 & 0 & 0 & 0 & 0 & 0 & 0 & 0 & 0 & 0 & 1 & 0 & 1 & 1 & 1 & 0 & 0 \\
\hline & Pettibonella multiuncinata & 1 & 0 & 0 & 1 & 1 & 1 & 1 & 1 & 1 & 0 & 0 & 1 & 1 & 0 & 0 & 0 & 0 & 0 & 1 & 0 & 1 & 1 & 1 & 0 & 1 \\
\hline & Phylo michaelseni & 1 & 0 & 0 & 0 & 0 & 0 & 0 & 1 & 1 & 0 & 0 & 0 & 0 & 1 & 0 & 0 & 0 & 0 & 1 & 1 & 1 & 1 & 1 & 0 & 1 \\
\hline & Proscoloplos gygnochaetus & 1 & 0 & 0 & 0 & 0 & 0 & 0 & 1 & 1 & 0 & 0 & 1 & 1 & 0 & 0 & 0 & 0 & 0 & 1 & 0 & 1 & 1 & 1 & 0 & 0 \\
\hline & Protoaricia oerstedii & 1 & 0 & 0 & 1 & 1 & 1 & 1 & 1 & 1 & 0 & 0 & 0 & 0 & 1 & 0 & 0 & 0 & 0 & 1 & 0 & 1 & 1 & 1 & 0 & 1 \\
\hline & Questa paucibrancbiata & 1 & 0 & 0 & 0 & 0 & 0 & 0 & 1 & 0 & 0 & 0 & 0 & 0 & 0 & 0 & 0 & 0 & 0 & 1 & 0 & 0 & 1 & 1 & 0 & 1 \\
\hline & Scoloplos armiger & 1 & 0 & 0 & 1 & 1 & 1 & 1 & 1 & 1 & 0 & 0 & 0 & 0 & 0 & 0 & 0 & 0 & 0 & 1 & 0 & 1 & 1 & 1 & 0 & 1 \\
\hline \multirow[t]{9}{*}{ Parergodrilidae } & Stygocapitella minuta & 2 & 0 & 0 & 0 & 0 & 0 & 0 & 1 & 0 & 0 & 0 & 0 & 0 & 0 & 1 & 3 & 3 & 2 & 0 & 0 & 0 & 1 & 0 & 0 & 0 \\
\hline & Stygocapitella australis & 2 & 0 & 0 & 0 & 0 & 0 & 0 & 1 & 0 & 0 & 0 & 0 & 0 & 1 & 1 & 1 & 1 & 1 & 0 & 0 & 0 & 1 & 0 & 0 & 0 \\
\hline & Stygocapitella EP A & 2 & 0 & 0 & 0 & 0 & 0 & 0 & 1 & 0 & 0 & 0 & 0 & 0 & 1 & 1 & 1 & 1 & 1 & 0 & 0 & 0 & 1 & 0 & 0 & 0 \\
\hline & Stygocapitella EP C & 2 & 0 & 0 & 0 & 0 & 0 & 0 & 1 & 0 & 0 & 0 & 0 & 0 & 1 & 1 & 2 & 3 & 1 & 0 & 0 & 0 & 1 & 0 & 0 & 0 \\
\hline & Stygocapitella EP D & 2 & 0 & 0 & 0 & 0 & 0 & 0 & 1 & 0 & 0 & 0 & 0 & 0 & 1 & 1 & 2 & 3 & 1 & 0 & 0 & 0 & 1 & 0 & 0 & 0 \\
\hline & Stygocapitella WA & 2 & 0 & 0 & 0 & 0 & 0 & 0 & 1 & 0 & 0 & 0 & 0 & 0 & 1 & 1 & 2 & 2 & 1 & 0 & 0 & 0 & 1 & 0 & 0 & 0 \\
\hline & Stygocapitella EA A & 2 & 0 & 0 & 0 & 0 & 0 & 0 & 1 & 0 & 0 & 0 & 0 & 0 & 1 & 1 & 2 & 3 & 1 & 0 & 0 & 0 & 1 & 0 & 0 & 0 \\
\hline & Stygocapitella EA B & 2 & 0 & 0 & 0 & 0 & 0 & 0 & 1 & 0 & 0 & 0 & 0 & 0 & 1 & 1 & 2 & 2 & 1 & 0 & 0 & 0 & 1 & 0 & 0 & 0 \\
\hline & Stygocapitella EA C & 2 & 0 & 0 & 0 & 0 & 0 & 0 & 1 & 0 & 0 & 0 & 0 & 0 & 1 & 1 & 2 & 2 & 1 & 0 & 0 & 0 & 1 & 0 & 0 & 0 \\
\hline \multirow[t]{11}{*}{ Nerillidae } & Aristonerilla brevis & 1 & 0 & 0 & 1 & 1 & 1 & 1 & 1 & 0 & 1 & 1 & 0 & 0 & 0 & 0 & 0 & 0 & 0 & 0 & 0 & 0 & 1 & 1 & 0 & 0 \\
\hline & Leptonerilla prospera & 1 & 0 & 0 & 1 & 1 & 1 & 1 & 1 & 0 & 1 & 1 & 0 & 0 & 0 & 0 & 0 & 0 & 0 & 0 & 0 & 0 & 1 & 1 & 0 & 0 \\
\hline & Longipalpa saltatrix & 1 & 0 & 0 & 0 & 0 & 0 & 0 & 1 & 0 & 1 & 1 & 0 & 0 & 0 & 0 & 0 & 0 & 0 & 0 & 0 & 0 & 1 & 1 & 0 & 0 \\
\hline & Meganerilla swedmarki & 1 & 0 & 0 & 0 & 0 & 0 & 0 & 1 & 0 & 0 & 0 & 0 & 0 & 0 & 0 & 0 & 0 & 0 & 0 & 0 & 0 & 1 & 1 & 0 & 0 \\
\hline & Mesonerilla roscovita & 1 & 0 & 0 & 0 & 0 & 0 & 0 & 1 & 0 & 1 & 1 & 0 & 0 & 0 & 0 & 0 & 0 & 0 & 0 & 0 & 0 & 1 & 1 & 0 & 0 \\
\hline & Micronerilla minuta & 1 & 0 & 0 & 1 & 1 & 1 & 1 & 1 & 0 & 1 & 1 & 0 & 0 & 0 & 0 & 0 & 0 & 0 & 0 & 0 & 0 & 1 & 1 & 0 & 0 \\
\hline & Nerillidium sp & 1 & 0 & 0 & 0 & 0 & 0 & 0 & 1 & 0 & 0 & 0 & 0 & 0 & 0 & 0 & 0 & 0 & 0 & 0 & 0 & 0 & 1 & 1 & 0 & 0 \\
\hline & Paranerilla limicola & 1 & 0 & 0 & 0 & 0 & 0 & 0 & 1 & 0 & 1 & 1 & 0 & 0 & 0 & 0 & 0 & 0 & 0 & 0 & 0 & 0 & 1 & 1 & 0 & 0 \\
\hline & Trochonerilla mobilis & 1 & 0 & 0 & 1 & 1 & 1 & 1 & 1 & 0 & 0 & 0 & 0 & 0 & 0 & 0 & 0 & 0 & 0 & 0 & 0 & 0 & 1 & 1 & 0 & 0 \\
\hline & Troglochaetus beraneckei & 1 & 0 & 0 & 0 & 0 & 0 & 0 & 1 & 0 & 0 & 0 & 0 & 0 & 0 & 0 & 0 & 0 & 0 & 0 & 0 & 0 & 1 & 1 & 0 & 0 \\
\hline & Xenonerilla bactericola & 1 & 0 & 0 & 0 & 0 & 0 & 0 & 1 & 0 & 0 & 0 & 0 & 0 & 0 & 0 & 0 & 0 & 0 & 0 & 0 & 0 & 1 & 1 & 0 & 0 \\
\hline
\end{tabular}


Supplementary Table 7. Accession numbers of $18 \mathrm{~S}$ sequences used for the phylogenetic analysis in the analyses comparing Stygocapitella with Orbiniidae and Nerillidae.

\begin{tabular}{|c|c|c|}
\hline Taxon & Species & Accession number \\
\hline \multirow[t]{12}{*}{ Orbiniidae } & Leitoscoloplos fragilis & AY532360 \\
\hline & Leodamas jobnstonei & AF508126 \\
\hline & Methanoaricia dendrobranchiata & AY532357 \\
\hline & Naineris quadricuspida & AY532361 \\
\hline & Orbinia swani & AY532363 \\
\hline & Orbiniella plumisetosa & AY532364 \\
\hline & Pettibonella multiuncinata & AY532359 \\
\hline & Phylo michaelseni & AY532362 \\
\hline & Proscoloplos cygnochaetus & AF448162 \\
\hline & Protoaricia oerstedii & AF508123 \\
\hline & Questa paucibranchiata & AF209464 \\
\hline & Scoloplos armiger & FJ612491 \\
\hline \multirow[t]{9}{*}{ Parergodrilidae } & Stygocapitella minuta & 391_17 \\
\hline & Stygocapitella australis & 392_01 \\
\hline & Stygocapitella EP_A & $432 \_05$ \\
\hline & Stygocapitella EP_C & 430_01 \\
\hline & Stygocapitella EP D & 433_03 \\
\hline & Stygocapitella WA & 427_02 \\
\hline & Stygocapitella EA_A & 439_01 \\
\hline & Stygocapitella EA_B & 396_06 \\
\hline & Stygocapitella EA_C & 422_01 \\
\hline \multirow[t]{11}{*}{ Nerillidae } & Aristonerilla brevis & AY859530 \\
\hline & Leptonerilla prospera & AY834758 \\
\hline & Longipalpa saltatrix & AY859531 \\
\hline & Meganerilla swedmarki & AY859537 \\
\hline & Mesonerilla roscovita & AY834757 \\
\hline & Micronerilla minuta & AY859533 \\
\hline & Nerillidium $s p$ & AY859536 \\
\hline & Paranerilla limicola & AY859539 \\
\hline & Trochonerilla mobilis & AY834759 \\
\hline & Troglochaetus beranecki & AY859534 \\
\hline & Xenonerilla bactericola & AY859535 \\
\hline
\end{tabular}


Supplementary Table 8. Description of the dataset including phylogenetic placement on the various clades. Partitioned refers to the partitioned phylogenetic model. concatenated to the concatenated dataset. Single genes refer to the single genes dataset. We include the length of ITS1 because samples with 1400+ bp were excluded from the analyses. EP_A=Pacific Clade A; EP_B = Pacific Clade B; PA_C = Pacific Clade C; PA_D=Pacific Clade D; WA= Atlantic American clade; EA_A = Europe Clade A; EA_B = Europe Clade B. Australia refers to Australian samples. South Africa to South African Samples. NA = Not Available; indist. = indistinguishable; ITS1 length refers to the total length of ITS1 in the trimmed dataset.

\begin{tabular}{|c|c|c|c|c|c|c|c|}
\hline Site & ID & Combined & COI & $16 S$ & $18 \mathrm{~S}$ & ITS1 & ITS1 length \\
\hline 4th July Beach & 432_01 & PC_D & EP_D & EP_D & NA & EP_D & 938 \\
\hline 4th July Beach & 432_02 & EP_B & EP_B & EP_B & EP_B & EP_B & 759 \\
\hline 4th July Beach & 432_03 & EP_A & EP_A & EP_A & EP_A & EP_A & 725 \\
\hline 4th July Beach & 432_04 & EP_B & NA & EP_B & $\mathrm{NA}$ & EP_B & 759 \\
\hline 4th July Beach & 432_05 & EP_A & EP_A & EP_A & EP_A & EP_A & 725 \\
\hline 4th July Beach & 432_06 & EP_A & EP_A & EP_A & EP_A & EP_A & 725 \\
\hline 4th July Beach & 432_07 & EP_B & EP_B & EP_B & EP_B & EP_B & 759 \\
\hline 4th July Beach & 432_08 & EP_B & EP_B & EP_B & EP_B & NA & 759 \\
\hline 4th July Beach & 432_09 & EP_B & EP_B & EP_B & EP_B & EP_B & 759 \\
\hline 4th July Beach & 432_10 & EP_D & EP_D & EP_D & EP_D & EP_D & 938 \\
\hline Ardtoe & 320_01 & EA_A & EA_A & EA_A & $\mathrm{NA}$ & $\mathrm{NA}$ & NA \\
\hline Ardtoe & 320_02 & EA_B & EA_B & EA_B & NA & NA & NA \\
\hline Ardtoe & 320_03 & EA_A & $\mathrm{NA}$ & EA_A & NA & NA & NA \\
\hline Ardtoe & 320_04 & EA_B & EA_B & EA_B & NA & NA & NA \\
\hline Ardtoe & 320_05 & EA_A & EA_A & EA_A & NA & NA & NA \\
\hline Ardtoe & 320_06 & EA_B & EA_B & EA_B & indist. & NA & 1461 \\
\hline Ardtoe & 320_07 & EA_B & EA_B & EA_B & indist. & NA & 1462 \\
\hline Ardtoe & 320_08 & EA_B & EA_B & EA_B & NA & NA & NA \\
\hline Ardtoe & 320_12 & EA_B & EA_B & EA_B & indist. & NA & 1461 \\
\hline Ardtoe & 320_13 & EA_B & EA_B & EA_B & indist. & NA & 1462 \\
\hline Ardtoe & 320_14 & EA_B & EA_B & EA_B & NA & NA & 1465 \\
\hline Ardtoe & 320_15 & EA_B & $\mathrm{NA}$ & EA_B & NA & NA & 1462 \\
\hline Bakka & 439_01 & EA_A & NA & EA_A & EA_A & NA & NA \\
\hline Bakka & 439_03 & EA_A & EA_A & EA_A & EA_A & NA & NA \\
\hline Bakka & 439_07 & EA_A & NA & EA_A & NA & NA & NA \\
\hline Bakka & 439_08 & EA_A & NA & EA_A & NA & NA & NA \\
\hline Bristol Channel & 422_01 & EA_C & EA_C & EA_C & indist. & EA_C & 954 \\
\hline Bristol Channel & 422_02 & EA_C & $\mathrm{NA}$ & EA_C & indist. & EA_C & 954 \\
\hline Bristol Channel & 422_03 & EA_C & NA & EA_C & indist. & EA_C & 954 \\
\hline Bristol Channel & 422_04 & EA_C & EA_C & EA_C & indist. & EA_C & 952 \\
\hline Bristol Channel & 422_05 & EA_C & NA & EA_C & NA & NA & NA \\
\hline Bristol Channel & 422_06 & EA_C & EA_C & EA_C & NA & EA_C & 954 \\
\hline Bristol Channel & 422_07 & EA_C & EA_C & EA_C & NA & EA_C & 954 \\
\hline Bristol Channel & 422_08 & EA_C & EA_C & EA_C & NA & EA_C & 954 \\
\hline Bristol Channel & 422_09 & EA_C & $\mathrm{NA}$ & EA_C & NA & EA_C & 953 \\
\hline Bristol Channel & 422_10 & EA_C & EA_C & EA_C & NA & EA_C & 954 \\
\hline Bristol Channel & 422_11 & EA_C & EA_C & EA_C & NA & EA_C & 953 \\
\hline Bristol Channel & 422_12 & EA_C & $\mathrm{NA}$ & EA_C & NA & $\mathrm{NA}$ & NA \\
\hline Canoe Beach & 426_01 & WA & WA & $\mathrm{WA}$ & indist. & WA & 944 \\
\hline Canoe Beach & 426_02 & WA & WA & NA & indist. & WA & 943 \\
\hline Canoe Beach & 426_03 & WA & WA & NA & indist. & WA & 943 \\
\hline Canoe Beach & 426_04 & WA & WA & WA & indist. & WA & 943 \\
\hline Canoe Beach & 426_05 & WA & WA & WA & NA & NA & NA \\
\hline Canoe Beach & 426_06 & WA & WA & WA & NA & WA & 943 \\
\hline Canoe Beach & 426_07 & WA & WA & WA & NA & WA & 943 \\
\hline Canoe Beach & 426_08 & WA & WA & WA & NA & WA & 943 \\
\hline Canoe Beach & 426_09 & WA & WA & WA & NA & WA & 944 \\
\hline Canoe Beach & 426_10 & WA & NA & WA & NA & WA & 943 \\
\hline Canoe Beach & 426_11 & WA & NA & WA & NA & WA & 943 \\
\hline Canoe Beach & 426_12 & WA & NA & WA & NA & WA & 944 \\
\hline Cutty Sark & 423_01 & EA_A & NA & $\mathrm{NA}$ & NA & EA_A & 991 \\
\hline Cutty Sark & 423_02 & EA_A & NA & EA_A & NA & EA_A & 991 \\
\hline Cutty Sark & 423_03 & EA_A & EA_A & EA_A & NA & NA & NA \\
\hline Cutty Sark & 423_04 & EA_A & $\mathrm{NA}$ & EA_A & NA & NA & NA \\
\hline Cutty Sark & 423_06 & EA_A & NA & EA_A & NA & NA & NA \\
\hline Cutty Sark & 423_07 & EA_A & EA_A & EA_A & NA & NA & NA \\
\hline Cutty Sark & 423_08 & EA_A & EA_A & EA_A & NA & NA & NA \\
\hline Cutty Sark & 423_09 & EA_A & $\mathrm{NA}$ & EA_A & NA & NA & NA \\
\hline Cutty Sark & 423_10 & EA_A & EA_A & EA_A & NA & EA_A & 991 \\
\hline Ellenbogen & 222_01 & EA_C & EA_C & EA_C & indist. & EA_C & 952 \\
\hline Ellenbogen & 222_02 & EA_C & EA_C & EA_C & indist. & EA_C & 952 \\
\hline Ellenbogen & 222_03 & EA_C & EA_C & EA_C & indist. & EA_C & 952 \\
\hline
\end{tabular}




\begin{tabular}{|c|c|c|c|c|c|c|c|}
\hline Ellenbogen & 222_04 & EA_C & EA_C & EA_C & indist. & EA_C & 952 \\
\hline Ellenbogen & 222_05 & EA_C & EA_C & EA_C & NA & EA_C & 952 \\
\hline Ellenbogen & 222_06 & EA_C & EA_C & NA & NA & EA_C & 952 \\
\hline Ellenbogen & 222_07 & EA_C & EA_C & NA & NA & EA_C & 952 \\
\hline Ellenbogen & 222_08 & EA_C & EA_C & EA_C & NA & EA_C & 952 \\
\hline Ellenbogen & 222_09 & EA_C & EA_C & EA_C & NA & $\mathrm{NA}$ & NA \\
\hline Ellenbogen & 222_10 & EA_C & EA_C & EA_C & NA & NA & NA \\
\hline Ellenbogen & 222_11 & EA_C & EA_C & EA_C & NA & NA & NA \\
\hline Ellenbogen & 222_12 & EA_C & EA_C & EA_C & NA & NA & NA \\
\hline Ellenbogen & 222_13 & EA_C & EA_C & $\mathrm{NA}$ & NA & NA & NA \\
\hline Espegrend & 440_01 & EA_A & EA_A & EA_A & EA_A & EA_A & 991 \\
\hline Espegrend & 440_02 & EA_A & $\mathrm{NA}$ & EA_A & EA_A & EA_A & 992 \\
\hline Espegrend & 440_03 & EA_A & NA & EA_A & $\mathrm{NA}$ & $\mathrm{NA}$ & NA \\
\hline Espegrend & 440_04 & EA_A & NA & EA_A & NA & EA_A & 991 \\
\hline False Bay & 431_01 & EP_B & EP_B & EP_B & EP_B & EP_B & 759 \\
\hline Glenancross & 321_01 & EA_B & EA_B & EA_B & indist. & $\mathrm{NA}$ & NA \\
\hline Glenancross & 321_02 & EA_B & EA_B & EA_B & indist. & NA & NA \\
\hline Glenancross & 321_03 & EA_B & EA_B & EA_B & indist. & NA & NA \\
\hline Glenancross & 321_04 & EA_B & EA_B & EA_B & indist. & NA & NA \\
\hline Glenancross & 321_05 & EA_B & EA_B & EA_B & NA & NA & 1461 \\
\hline Glenancross & 321_06 & EA_B & EA_B & EA_B & NA & NA & NA \\
\hline Glenancross & 321_07 & EA_B & NA & EA_B & NA & NA & 1461 \\
\hline Glenancross & 321_08 & EA_B & NA & EA_B & $\mathrm{NA}$ & NA & NA \\
\hline Glenancross & 321_09 & EA_B & EA_B & EA_B & NA & NA & NA \\
\hline Glenancross & 321_10 & EA_B & EA_B & EA_B & NA & NA & 1461 \\
\hline Glenancross & 321_11 & EA_B & EA_B & EA_B & NA & NA & NA \\
\hline Glenancross & 321_12 & EA_B & EA_B & EA_B & NA & NA & NA \\
\hline Gnarabup Beach & 392_01 & S. australis & S. australis & S. australis & S. australis & NA & NA \\
\hline Gnarabup Beach & 392_03 & S. australis & S. australis & S. australis & NA & NA & NA \\
\hline Gnarabup Beach & 392_04 & S. australis & S. australis & S. australis & S. australis & NA & NA \\
\hline Gnarabup Beach & 392_05 & S. australis & S. australis & S. australis & S. australis & NA & NA \\
\hline Gnarabup Beach & 392_06 & S. australis & S. australis & S. australis & S. australis & NA & NA \\
\hline Gnarabup Beach & 392_07 & S. australis & S. australis & S. australis & S. australis & NA & NA \\
\hline Gravesend & 424_01 & EA_C & EA_C & EA_C & NA & EA_C & 949 \\
\hline Gravesend & 424_02 & EA_C & EA_C & EA_C & NA & $\mathrm{NA}$ & NA \\
\hline Gravesend & 424_03 & EA_C & EA_C & EA_C & NA & NA & NA \\
\hline Gravesend & 424_04 & EA_C & EA_C & EA_C & NA & NA & NA \\
\hline Gravesend & 424_05 & EA_C & EA_C & EA_C & NA & EA_C & 949 \\
\hline Gravesend & 424_06 & EA_C & EA_C & EA_C & NA & EA_C & 949 \\
\hline Gravesend & 424_07 & EA_C & EA_C & EA_C & NA & EA_C & 953 \\
\hline Gravesend & 424_08 & EA_C & EA_C & EA_C & NA & EA_C & 949 \\
\hline Gravesend & 424_09 & EA_C & EA_C & EA_C & NA & EA_C & 949 \\
\hline Gravesend & 424_10 & EA_C & EA_C & EA_C & NA & EA_C & 949 \\
\hline Gravesend & 424_11 & EA_C & EA_C & EA_C & NA & EA_C & 953 \\
\hline Gravesend & 424_12 & EA_C & EA_C & EA_C & NA & EA_C & 949 \\
\hline Gravesend & 424_13 & EA_C & EA_C & EA_C & NA & EA_C & 953 \\
\hline Gravesend & 424_14 & EA_C & EA_C & EA_C & NA & $\mathrm{NA}$ & NA \\
\hline Henningsvær & 437_01 & EA_A & $\mathrm{NA}$ & $\mathrm{NA}$ & NA & EA_A & 998 \\
\hline Henningsvær & 437_02 & EA_A & NA & EA_A & NA & $\mathrm{NA}$ & NA \\
\hline Henningsvær & 437_03 & EA_A & NA & EA_A & NA & EA_A & 992 \\
\hline Henningsvær & 437_05 & EA_A & NA & EA_A & NA & $\mathrm{NA}$ & NA \\
\hline Henningsvær & 437_06 & EA_A & NA & EA_A & NA & NA & NA \\
\hline Henningsvær & 437_07 & EA_A & NA & EA_A & NA & NA & NA \\
\hline Hörnum & 169_06 & EA_C & EA_C & EA_C & NA & EA_C & 952 \\
\hline Hörnum & 169_07 & EA_C & EA_C & EA_C & NA & EA_C & 952 \\
\hline Hörnum & 169_08 & EA_C & EA_C & EA_C & NA & $\mathrm{NA}$ & NA \\
\hline Hörnum & 169_09 & EA_C & EA_C & EA_C & indist. & EA_C & 953 \\
\hline Hörnum & 169_10 & EA_C & EA_C & EA_C & indist. & EA_C & 952 \\
\hline Hörnum & 169_11 & EA_C & EA_C & $\mathrm{NA}$ & indist. & EA_C & 953 \\
\hline Hörnum & 169_12 & EA_C & EA_C & EA_C & indist. & $\mathrm{NA}$ & NA \\
\hline Hörnum & 169_13 & EA_C & EA_C & EA_C & NA & EA_C & 953 \\
\hline Hörnum & 169_14 & EA_C & $\mathrm{NA}$ & EA_C & NA & EA_C & 952 \\
\hline Hörnum & 169_15 & EA_C & EA_C & EA_C & NA & EA_C & 952 \\
\hline Hörnum & 169_16 & EA_C & EA_C & EA_C & NA & EA_C & 952 \\
\hline Hörnum & 169_17 & EA_C & EA_C & $\mathrm{NA}$ & NA & EA_C & 952 \\
\hline Île Callot & 210_10 & EA_B & EA_B & NA & NA & NA & 1461 \\
\hline Île Callot & 210_11 & EA_B & EA_B & EA_B & NA & NA & 1460 \\
\hline Île Callot & 210_12 & EA_B & EA_B & EA_B & NA & EA_B & 942 \\
\hline Île Callot & 210_13 & EA_B & EA_B & EA_B & NA & NA & 1461 \\
\hline Île Callot & 210_14 & EA_B & EA_B & EA_B & NA & NA & 1461 \\
\hline Île Callot & 403_03 & EA_B & EA_B & EA_B & indist. & EA_B & 942 \\
\hline Île Callot & 403_04 & EA_B & EA_B & EA_B & indist. & NA & 1461 \\
\hline Île Callot & 403_05 & EA_B & EA_B & EA_B & indist. & NA & 1461 \\
\hline Île Callot & 403_06 & EA_B & $\mathrm{NA}$ & EA_B & NA & NA & 1461 \\
\hline Île Callot & 403_07 & EA_B & EA_B & EA_B & NA & NA & 1461 \\
\hline Île Callot & 403_08 & EA_B & EA_B & EA_B & NA & NA & NA \\
\hline Île Callot & 403_09 & EA_B & $\mathrm{NA}$ & EA_B & NA & NA & NA \\
\hline
\end{tabular}




\begin{tabular}{|c|c|c|c|c|c|c|c|}
\hline Keitum & 169_28 & EA_B & NA & EA_B & NA & NA & NA \\
\hline Keitum & 169_29 & EA_B & EA_B & EA_B & NA & NA & NA \\
\hline Keitum & 169_30 & EA_B & EA_B & EA_B & NA & NA & NA \\
\hline Keitum & 169_31 & EA_B & $\mathrm{NA}$ & EA_B & NA & NA & NA \\
\hline Keitum & 169_32 & EA_B & NA & EA_B & NA & NA & NA \\
\hline Keitum & 169_33 & EA_B & EA_B & EA_B & NA & NA & NA \\
\hline Keitum & 169_34 & EA_B & EA_B & EA_B & NA & NA & NA \\
\hline Keitum & 169_35 & EA_B & EA_B & EA_B & NA & NA & NA \\
\hline Keitum & 169_36 & EA_B & EA_B & EA_B & NA & NA & NA \\
\hline Keitum & 169_37 & EA_B & $\mathrm{NA}$ & EA_B & indist. & NA & NA \\
\hline Keitum & 169_38 & EA_B & EA_B & EA_B & indist. & NA & 1462 \\
\hline Keitum & 169_39 & EA_B & EA_B & EA_B & indist. & NA & 1460 \\
\hline Keitum & 398_04 & EA_B & EA_B & EA_B & indist. & NA & 1460 \\
\hline Keitum & 398_05 & EA_B & EA_B & EA_B & NA & NA & NA \\
\hline Keitum & 398_06 & EA_B & EA_B & EA_B & NA & NA & NA \\
\hline Keitum & 398_07 & EA_B & EA_B & EA_B & NA & NA & 1460 \\
\hline Keitum & 398_08 & EA_B & EA_B & EA_B & NA & $\mathrm{NA}$ & NA \\
\hline Keitum & 398_09 & EA_B & EA_B & EA_B & NA & NA & NA \\
\hline Keitum & 398_10 & EA_B & EA_B & EA_B & NA & EA_B & 942 \\
\hline Keitum & 398_11 & EA_B & EA_B & EA_B & NA & NA & 1460 \\
\hline Kristineberg & 420_01 & EA_A & EA_A & EA_A & EA_A & NA & NA \\
\hline Kristineberg & 420_02 & EA_A & $\mathrm{NA}$ & EA_A & EA_A & NA & NA \\
\hline Kristineberg & 420_03 & EA_A & NA & EA_A & EA_A & EA_A & 991 \\
\hline Kristineberg & 420_04 & EA_A & NA & EA_A & $\mathrm{NA}$ & EA_A & 993 \\
\hline Kristineberg & 420_05 & EA_A & EA_A & EA_A & NA & EA_A & 993 \\
\hline Kristineberg & 420_06 & EA_A & $\mathrm{NA}$ & EA_A & NA & EA_A & 993 \\
\hline Kristineberg & 420_07 & EA_A & NA & EA_A & NA & EA_A & 991 \\
\hline Kristineberg & 420_09 & EA_A & NA & EA_A & NA & $\mathrm{NA}$ & NA \\
\hline Kristineberg & 420_10 & EA_A & NA & EA_A & NA & NA & NA \\
\hline Kristineberg & 420_12 & EA_A & NA & EA_A & NA & EA_A & 993 \\
\hline Langebaan & 327_01 & S. minuta & S. minuta & S. minuta & $\mathrm{NA}$ & $\mathrm{NA}$ & NA \\
\hline Langebaan & 327_02 & S. minuta & S. minuta & S. minuta & NA & NA & NA \\
\hline Langebaan & 327_03 & S. minuta & S. minuta & S. minuta & $\mathrm{NA}$ & NA & NA \\
\hline Langebaan & 327_04 & S. minuta & S. minuta & S. minuta & NA & NA & NA \\
\hline Langebaan & 327_05 & S. minuta & S. minuta & S. minuta & NA & $\mathrm{NA}$ & NA \\
\hline Langebaan & $327-06$ & S. minuta & S. minuta & S. minuta & NA & $\mathrm{NA}$ & NA \\
\hline Langebaan & 327_07 & S. minuta & S. minuta & S. minuta & NA & NA & NA \\
\hline Langebaan & 327_08 & S. minuta & S. minuta & S. minuta & NA & NA & NA \\
\hline Langebaan & $327 \_10$ & S. minuta & S. minuta & S. minuta & NA & NA & NA \\
\hline Langebaan & $327 \_11$ & S. minuta & S. minuta & S. minuta & NA & NA & NA \\
\hline Langebaan & $327 \_16$ & S. minuta & NA & NA & NA & NA & NA \\
\hline Langebaan & $327 \_17$ & S. minuta & NA & S. minuta & NA & NA & NA \\
\hline Langebaan & $327 \_18$ & S. minuta & NA & NA & NA & NA & NA \\
\hline Langebaan & 327_19 & S. minuta & NA & S. minuta & NA & $\mathrm{NA}$ & NA \\
\hline Langebaan & 391_16 & S. minuta & S. minuta & S. minuta & NA & $\mathrm{NA}$ & NA \\
\hline Langebaan & 391_17 & S. minuta & S. minuta & S. minuta & S. minuta & NA & NA \\
\hline Langebaan & 391_18 & S. minuta & S. minuta & S. minuta & S. minuta & NA & NA \\
\hline Langebaan & 391_19 & S. minuta & S. minuta & NA & NA & NA & NA \\
\hline List & 169_54 & EA_C & EA_C & EA_C & NA & EA_C & 953 \\
\hline List & 169_55 & EA_B & EA_B & $\mathrm{NA}$ & NA & $\mathrm{NA}$ & 1460 \\
\hline List & 169_56 & EA_C & EA_C & EA_C & indist. & EA_C & 952 \\
\hline List & 169_57 & EA_B & EA_B & EA_B & NA & NA & 1460 \\
\hline List & 169_58 & EA_C & EA_C & EA_C & indist. & EA_C & 952 \\
\hline List & 219_02 & EA_C & $\mathrm{NA}$ & EA_C & indist. & $\mathrm{NA}$ & NA \\
\hline List & 219_03 & EA_C & EA_C & EA_C & NA & EA_C & 952 \\
\hline List & 219_04 & EA_C & $\mathrm{NA}$ & EA_C & NA & EA_C & 952 \\
\hline List & 219_05 & EA_C & EA_C & EA_C & NA & EA_C & 952 \\
\hline List & 219_06 & EA_C & EA_C & EA_C & NA & EA_C & 952 \\
\hline List & 219_07 & EA_C & $\mathrm{NA}$ & EA_C & NA & EA_C & 952 \\
\hline List & 219_08 & EA_C & EA_C & EA_C & NA & EA_C & 952 \\
\hline List & 219_09 & EA_C & $\mathrm{NA}$ & EA_C & NA & EA_C & 953 \\
\hline List & 219_10 & EA_C & EA_C & EA_C & NA & $\mathrm{NA}$ & NA \\
\hline List & 219_11 & EA_C & EA_C & $\mathrm{NA}$ & NA & NA & NA \\
\hline List & 219_12 & EA_C & $\mathrm{NA}$ & EA_C & NA & NA & NA \\
\hline List & 219_13 & EA_C & NA & EA_C & NA & NA & NA \\
\hline Little Gruinard & 322_01 & EA_B & EA_B & EA_B & NA & NA & NA \\
\hline Little Gruinard & 322_02 & EA_B & EA_B & EA_B & NA & NA & NA \\
\hline Lødingen & 436_01 & EA_A & NA & EA_A & NA & NA & NA \\
\hline Lødingen & 436_02 & EA_A & NA & EA_A & NA & NA & NA \\
\hline Lødingen & 436_03 & EA_A & NA & EA_A & $\mathrm{NA}$ & EA_A & 991 \\
\hline Lødingen & 436_04 & EA_A & NA & EA_A & NA & $\mathrm{NA}$ & NA \\
\hline Lødingen & 436_05 & EA_A & NA & EA_A & NA & NA & NA \\
\hline Lødingen & 436_07 & EA_A & NA & EA_A & NA & EA_A & 991 \\
\hline Lubec & 429_01 & $\mathrm{EA}_{-}^{-} \mathrm{C}$ & EA_C & EA_C & indist. & EA_C & 949 \\
\hline Lubec & 429_02 & WA & WA & $\mathrm{NA}$ & indist. & WA & 943 \\
\hline Lubec & 429_03 & WA & NA & WA & NA & WA & 943 \\
\hline Lubec & 429_04 & WA & NA & WA & NA & NA & NA \\
\hline
\end{tabular}




\begin{tabular}{|c|c|c|c|c|c|c|c|}
\hline Lubec & 429_05 & WA & NA & WA & NA & WA & 943 \\
\hline Lubec & 429_06 & WA & NA & WA & NA & WA & 943 \\
\hline Lubec & 429_07 & WA & NA & NA & NA & WA & 943 \\
\hline Lubec & 429_08 & EA_C & EA_C & EA_C & indist. & EA_C & 949 \\
\hline Lubec & 429_09 & WA & WA & WA & NA & WA & 943 \\
\hline Lubec & 429_10 & WA & WA & WA & NA & WA & 943 \\
\hline Lubec & 429_11 & WA & WA & WA & NA & WA & 943 \\
\hline Lubec & 429_12 & WA & WA & WA & NA & NA & NA \\
\hline Morsum & 227_01 & EA_B & EA_B & EA_B & indist. & NA & 1460 \\
\hline Morsum & $227-02$ & EA_B & EA_B & EA_B & indist. & NA & NA \\
\hline Morsum & 227_03 & EA_B & EA_B & EA_B & indist. & NA & NA \\
\hline Morsum & 227_04 & EA_B & EA_B & EA_B & indist. & NA & 1460 \\
\hline Morsum & 227_05 & EA_B & EA_B & EA_B & indist. & NA & NA \\
\hline Morsum & 227_06 & EA_B & EA_B & EA_B & NA & NA & 1460 \\
\hline Morsum & $227 \_07$ & EA_B & EA_B & EA_B & NA & NA & 1460 \\
\hline Morsum & $227-08$ & EA_B & EA_B & EA_B & NA & indist. & 941 \\
\hline Morsum & 227_09 & EA_B & NA & EA_B & NA & NA & 1460 \\
\hline Morsum & 227_10 & EA_B & EA_B & EA_B & NA & NA & NA \\
\hline Morsum & 227_14 & EA_A & NA & EA_A & NA & NA & NA \\
\hline Morsum & 227_15 & EA_A & NA & EA_A & NA & NA & NA \\
\hline Musselburgh & 324_01 & EA_C & EA_C & EA_C & NA & NA & NA \\
\hline Musselburgh & 324_02 & EA_C & EA_C & EA_C & NA & NA & NA \\
\hline Musselburgh & 324_03 & EA_B & EA_B & EA_B & NA & NA & NA \\
\hline Musselburgh & 324_04 & EA_A & EA_A & EA_A & EA_A & EA_A & 991 \\
\hline Musselburgh & 324_05 & EA_B & EA_B & EA_B & NA & EA_B & 942 \\
\hline Musselburgh & 324_06 & EA_C & EA_C & EA_C & NA & EA_C & 952 \\
\hline Musselburgh & 324_07 & EA_C & EA_C & EA_C & NA & $\mathrm{NA}$ & NA \\
\hline Musselburgh & 324_08 & EA_C & EA_C & EA_C & NA & NA & NA \\
\hline Musselburgh & 324_09 & EA_C & EA_C & EA_C & NA & NA & NA \\
\hline Musselburgh & 324_10 & EA_C & EA_C & EA_C & NA & NA & NA \\
\hline Musselburgh & 324_11 & EA_C & EA_C & EA_C & NA & NA & NA \\
\hline Musselburgh & 324_12 & EA_C & EA_C & EA_C & NA & NA & NA \\
\hline Musselburgh & $324 \_52$ & EA_C & EA_C & EA_C & NA & NA & NA \\
\hline Nairn & 323_01 & EA_B & EA_B & EA_B & NA & NA & NA \\
\hline Nairn & 323 & EA_B & EA_B & EA_B & NA & NA & NA \\
\hline Nairn & $323 \_03$ & EA_B & EA_B & EA_B & NA & NA & NA \\
\hline Nairn & 323 & EA_B & EA_B & EA_B & indist. & EA_B & 942 \\
\hline Plymouth & 421_01 & EA_C & EA_C & EA_C & indist. & EA_C & 947 \\
\hline Plymouth & 421_02 & EA_C & EA_C & EA_C & NA & NA & NA \\
\hline Plymouth & 421_03 & EA_C & EA_C & EA_C & NA & EA_C & 948 \\
\hline Plymouth & 421_04 & EA_C & EA_C & EA_C & NA & EA_C & NA \\
\hline Plymouth & 421_05 & EA_C & EA_C & EA_C & NA & EA_C & 947 \\
\hline Plymouth & 421_06 & EA_C & EA_C & EA_C & NA & EA_C & 953 \\
\hline Plymouth & 421_07 & EA_C & NA & EA_C & NA & $\mathrm{NA}$ & NA \\
\hline Plymouth & 421_08 & EA_C & EA_C & EA_C & NA & NA & NA \\
\hline Plymouth & 421_09 & EA_C & EA_C & EA_C & NA & NA & NA \\
\hline Plymouth & 421_10 & EA_C & EA_C & EA_C & NA & EA_C & 947 \\
\hline Plymouth & 421_11 & EA_C & NA & EA_C & NA & $\mathrm{NA}$ & NA \\
\hline Plymouth & 421_13 & EA_C & EA_C & EA_C & NA & EA_C & 947 \\
\hline Plymouth & 421_14 & EA_C & EA_C & EA_C & NA & EA_C & 947 \\
\hline Plymouth & 421_15 & EA_C & EA_C & EA_C & NA & $\mathrm{NA}$ & NA \\
\hline Reid State Park & 427_01 & WA & WA & WA & indist. & WA & 943 \\
\hline Reid State Park & 427_02 & WA & WA & WA & indist. & WA & 943 \\
\hline Reid State Park & 427_03 & WA & WA & WA & indist. & WA & 943 \\
\hline Reid State Park & 427_04 & WA & WA & WA & indist. & WA & 943 \\
\hline Reid State Park & 427_05 & WA & WA & WA & NA & NA & NA \\
\hline Reid State Park & 427_06 & WA & WA & WA & NA & WA & 943 \\
\hline Reid State Park & 427_07 & WA & WA & WA & NA & WA & 943 \\
\hline Reid State Park & 427_08 & WA & WA & WA & NA & WA & 943 \\
\hline Reid State Park & 427_09 & WA & WA & WA & NA & WA & 944 \\
\hline Reid State Park & 427_10 & WA & WA & WA & NA & WA & 943 \\
\hline Reuben Tarte & 433_01 & EP_D & EP_D & EP_D & EP_D & EP_D & 938 \\
\hline Reuben Tarte & 433 & EP_D & EP_D & EP_D & EP_D & EP_D & 938 \\
\hline Reuben Tarte & 433_03 & EP_D & EP_D & EP_D & EP_D & EP_D & 938 \\
\hline Reuben Tarte & 433_04 & EP_D & EP_D & EP_D & EP_D & EP_D & 938 \\
\hline Reuben Tarte & 433_05 & EP_D & EP_D & EP_D & EP_D & EP_D & 938 \\
\hline Reuben Tarte & 433 & EP_D & EP_D & EP_D & NA & EP_D & 938 \\
\hline Reuben Tarte & 433_07 & EP_D & EP_D & EP_D & NA & NA & NA \\
\hline Reuben Tarte & 433_08 & EP_D & EP_D & EP_D & NA & EP_D & 938 \\
\hline Reuben Tarte & 433_09 & EP_D & EP_D & EP_D & NA & EP_D & 938 \\
\hline Reuben Tarte & 433_10 & EP_D & EP_D & EP_D & EP_D & NA & NA \\
\hline Reuben Tarte & 433_11 & EP_D & NA & EP_D & NA & EP_D & 939 \\
\hline Reuben Tarte & 433_12 & EP_D & EP_D & EP_D & NA & EP_D & 938 \\
\hline Roche Harbor & 430_01 & EP_C & EP_C & EP_C & EP_C & EP_C & 936 \\
\hline Roche Harbor & 430_02 & EP_C & NA & NA & EP_C & EP_C & 936 \\
\hline Roche Harbor & 430_03 & EP_C & EP_C & EP_C & EP_C & EP_C & 936 \\
\hline Roche Harbor & 430_04 & EP_C & EP_C & EP_C & EP_C & EP_C & 936 \\
\hline
\end{tabular}




\begin{tabular}{|c|c|c|c|c|c|c|c|}
\hline Roche Harbor & 430_05 & EP_C & EP_C & EP_C & EP_C & EP_C & 936 \\
\hline Roche Harbor & 430_06 & EP_C & EP_C & EP_C & NA & EP_C & 942 \\
\hline Roche Harbor & 430_07 & EP_C & EP_C & EP_C & NA & EP_C & 936 \\
\hline Roche Harbor & 430_08 & EP_C & EP_C & EP_C & NA & EP_C & 936 \\
\hline Roche Harbor & 430_09 & EP_C & EP_C & EP_C & NA & EP_C & 936 \\
\hline Roche Harbor & 430_10 & EP_C & EP_C & EP_C & NA & EP_C & 936 \\
\hline Sarge Bay & 393_01 & S. australis & S. australis & S. australis & S. australis & NA & NA \\
\hline Sarge Bay & 393_02 & S. australis & S. australis & S. australis & S. australis & NA & NA \\
\hline Sarge Bay & 393_03 & S. australis & S. australis & S. australis & S. australis & NA & NA \\
\hline Sarge Bay & 393_04 & S. australis & S. australis & S. australis & S. australis & NA & NA \\
\hline Sarge Bay & 393_05 & S. australis & S. australis & S. australis & S. australis & NA & NA \\
\hline Sarge Bay & $393 \_06$ & S. australis & S. australis & S. australis & NA & NA & NA \\
\hline Schilksee & 396_01 & EA_B & EA_B & EA_B & indist. & NA & 1460 \\
\hline Schilksee & 396_02 & EA_B & EA_B & EA_B & indist. & NA & 1460 \\
\hline Schilksee & 396_04 & EA_B & EA_B & EA_B & indist. & EA_B & 942 \\
\hline Schilksee & 396_05 & EA_B & EA_B & EA_B & indist. & EA_B & 942 \\
\hline Schilksee & 396_06 & EA_B & EA_B & EA_B & indist. & $\mathrm{NA}$ & NA \\
\hline Sommarøya & 438_01 & EA_A & NA & EA_A & NA & NA & NA \\
\hline Sommarøya & 438_02 & EA_A & NA & EA_A & EA_A & NA & NA \\
\hline South Lubec & 428_01 & WA & WA & WA & indist. & WA & 943 \\
\hline South Lubec & 428_02 & WA & WA & WA & indist. & WA & 943 \\
\hline South Lubec & 428_03 & WA & WA & WA & indist. & WA & 945 \\
\hline St. Efflam & 210_01 & EA_C & EA_C & NA & indist. & EA_C & 947 \\
\hline St. Efflam & 210_02 & EA_C & EA_C & EA_C & indist. & EA_C & 952 \\
\hline St. Efflam & 210_03 & EA_C & EA_C & EA_C & indist. & EA_C & 947 \\
\hline St. Efflam & 210_04 & EA_C & EA_C & EA_C & NA & EA_C & 947 \\
\hline St. Efflam & 210_05 & EA_C & EA_C & EA_C & NA & $\mathrm{NA}$ & NA \\
\hline St. Efflam & 210_06 & EA_C & EA_C & $\mathrm{NA}$ & NA & EA_C & 947 \\
\hline St. Efflam & 210_07 & EA_C & $\mathrm{NA}$ & EA_C & NA & EA_C & 947 \\
\hline St. Efflam & 401_01 & EA_C & NA & EA_C & NA & EA_C & 948 \\
\hline St. Efflam & 401_02 & EA_C & EA_C & EA_C & NA & EA_C & 947 \\
\hline St. Efflam & 401_03 & EA_C & EA_C & EA_C & NA & $\mathrm{NA}$ & NA \\
\hline St. Efflam & 401_04 & EA_C & EA_C & EA_C & NA & EA_C & 947 \\
\hline St. Efflam & 401_05 & EA_C & EA_C & EA_C & NA & $\mathrm{NA}$ & NA \\
\hline St. Efflam & 401_06 & EA_C & EA_C & EA_C & NA & EA_C & 947 \\
\hline St. Efflam & 401_07 & EA_C & EA_C & EA_C & NA & EA_C & 948 \\
\hline Weststrand & 169_01 & EA_B & EA_B & $\mathrm{NA}$ & NA & $\mathrm{NA}$ & NA \\
\hline
\end{tabular}


Supplementary Table 9. Pairwise contrasts between European clades (red, blue and green) considering various climatic variables. The results of multinomial logistic regression models are presented. Models included only one fixed variable and as a result, 19 models were fit.. Degrees of freedom 1 and 2 (Df1-2), $F$ ratio and $p$ significance values are provided. No statistical significances $(p<0.05)$ were obtained.

\begin{tabular}{|c|c|c|c|c|c|c|c|c|}
\hline \multirow{2}{*}{$\begin{array}{l}\text { Pairwise Contrast } \\
\text { Fixed Variable }\end{array}$} & \multirow[b]{2}{*}{ DfI } & \multirow[b]{2}{*}{$D f 2$} & \multicolumn{2}{|c|}{ EA_A - EA_B } & \multicolumn{2}{|c|}{ EA_A - EA_C } & \multicolumn{2}{|c|}{ EA_B - EA_C } \\
\hline & & & F ratio & $p$ & F ratio & $p$ & F ratio & $p$ \\
\hline Annual Mean Temp. & 1 & 4 & 0.092 & 0.78 & 1.548 & 0.28 & 2.109 & 0.22 \\
\hline Mean Diurnal Range & 1 & 4 & 0.088 & 0.78 & 0.081 & 0.79 & 0.000 & 0.99 \\
\hline Isothermality & 1 & 4 & 0.036 & 0.86 & 0.072 & 0.80 & 0.007 & 0.94 \\
\hline Temp. Seasonality & 1 & 4 & 0.017 & 0.90 & 0.049 & 0.84 & 0.009 & 0.93 \\
\hline Max. Temp. of the Warmest Month & 1 & 4 & 0.027 & 0.88 & 0.260 & 0.64 & 0.433 & 0.55 \\
\hline Min. Temp. of the Coldest Month & 1 & 4 & 0.177 & 0.70 & 0.587 & 0.49 & 1.200 & 0.33 \\
\hline Temp. Annual Range & 1 & 4 & 0.002 & 0.96 & 0.011 & 0.92 & 0.003 & 0.96 \\
\hline Mean Temp. of Wettest Quarter & 1 & 4 & 0.115 & 0.75 & 0.011 & 0.92 & 0.199 & 0.68 \\
\hline Mean Temp. of Driest Quarter & 1 & 4 & 0.040 & 0.85 & 0.160 & 0.71 & 0.042 & 0.85 \\
\hline Mean Temp of Warmest Quarter & 1 & 4 & 0.041 & 0.85 & 0.738 & 0.44 & 0.929 & 0.39 \\
\hline Mean Temp. of Coldest Quarter & 1 & 4 & 0.183 & 0.69 & 0.253 & 0.64 & 0.768 & 0.43 \\
\hline Annual Precipitation & 1 & 4 & 0.020 & 0.89 & 0.155 & 0.71 & 0.070 & 0.80 \\
\hline Precipitation of Wettest Month & 1 & 4 & 0.006 & 0.94 & 0.130 & 0.74 & 0.086 & 0.78 \\
\hline Precipitation of Driest Month & 1 & 4 & 0.031 & 0.87 & 0.123 & 0.74 & 0.034 & 0.86 \\
\hline Precipitation Seasonality & 1 & 4 & 0.048 & 0.84 & 0.057 & 0.82 & 0.000 & 0.99 \\
\hline Precipitation of Wettest Quarter & 1 & 4 & 0.020 & 0.89 & 0.130 & 0.74 & 0.053 & 0.83 \\
\hline Precipitation of Driest Quarter & 1 & 4 & 0.024 & 0.88 & 0.127 & 0.74 & 0.045 & 0.84 \\
\hline Precipitation of Warmest Quarter & 1 & 4 & 0.043 & 0.85 & 0.279 & 0.63 & 0.117 & 0.75 \\
\hline Precipitation of Coldest Quarter & 1 & 4 & 0.034 & 0.86 & 0.073 & 0.80 & 0.008 & 0.93 \\
\hline
\end{tabular}


Supplementary Table 10. Calculations of Tajima's D and its correspondent P-value for the three studied European clades. The Atlantic Pacific America is excluded due to the complete absence of polymorphisms in all four populations. Tajima's $\mathrm{D}$ was not calculated for populations with less than 4 individuals were ("Not enough samples"), and populations without no data polymorphism (i.e. all individual sequences being exactly identical) are signaled ("all data identical").

\begin{tabular}{|c|c|c|c|c|c|c|}
\hline & \multicolumn{2}{|c|}{ EA_A } & \multicolumn{2}{|c|}{ EA_B } & \multicolumn{2}{|c|}{ EA_C } \\
\hline & Tajima's D & $p$ & Tajima's D & $p$ & Tajima's D & $p$ \\
\hline $\begin{array}{l}\text { Ardtoe } \\
\text { Bakka }\end{array}$ & \multicolumn{2}{|c|}{$\begin{array}{l}\text { Not enough samples } \\
\text { All data identical }\end{array}$} & 1.26455 & $>0.1$ & & \\
\hline $\begin{array}{l}\text { Bristol Channel } \\
\text { Cutty Sark }\end{array}$ & 0.20364 & $>0.1$ & & & -1.79631 & $<0.05$ \\
\hline Ellenbogen & & & & & -0.27492 & $>0.1$ \\
\hline $\begin{array}{l}\text { Espegrend } \\
\text { Glenancross }\end{array}$ & Not enough & mples & -1.89423 & $<0.05$ & & \\
\hline $\begin{array}{l}\text { Gravesend } \\
\text { Henningsvær }\end{array}$ & -0.81650 & $>0.1$ & & & 0.51918 & $>0.1$ \\
\hline Hörnum & & & & & -1.23716 & $>0.1$ \\
\hline Île Callot & & & All data & entical & & \\
\hline Keitum & & & -1.76237 & $0.05-0.1$ & & \\
\hline Kristineberg & All data id & tical & & & & \\
\hline List & & & Not enoug & samples & 0.81980 & $>0.1$ \\
\hline $\begin{array}{l}\text { Little Gruinard } \\
\text { Lødingen }\end{array}$ & All data id & tical & Not enoug & samples & & \\
\hline Lubec & & & & & Not enoug & samples \\
\hline Morsum & & & All data & entical & & \\
\hline $\begin{array}{l}\text { Musselburgh } \\
\text { Nairn }\end{array}$ & Not enough & mples & $\begin{array}{l}\text { Not enoug } \\
\text { All data }\end{array}$ & $\begin{array}{l}\text { samples } \\
\text { entical }\end{array}$ & -1.11173 & $>0.1$ \\
\hline Plymouth & & & & & 1.95522 & $0.05-0.1$ \\
\hline St. Efflam & & & & & -1.19267 & $>0.1$ \\
\hline Schilksee & & & Not enoug & samples & & \\
\hline Sommarøya & Not enough & mples & & & & \\
\hline
\end{tabular}


Supplementary Figure 1: Maximum Likelihood Phylogram of the partitioned dataset including the four genes. Bootstrap support values are included for every branch.

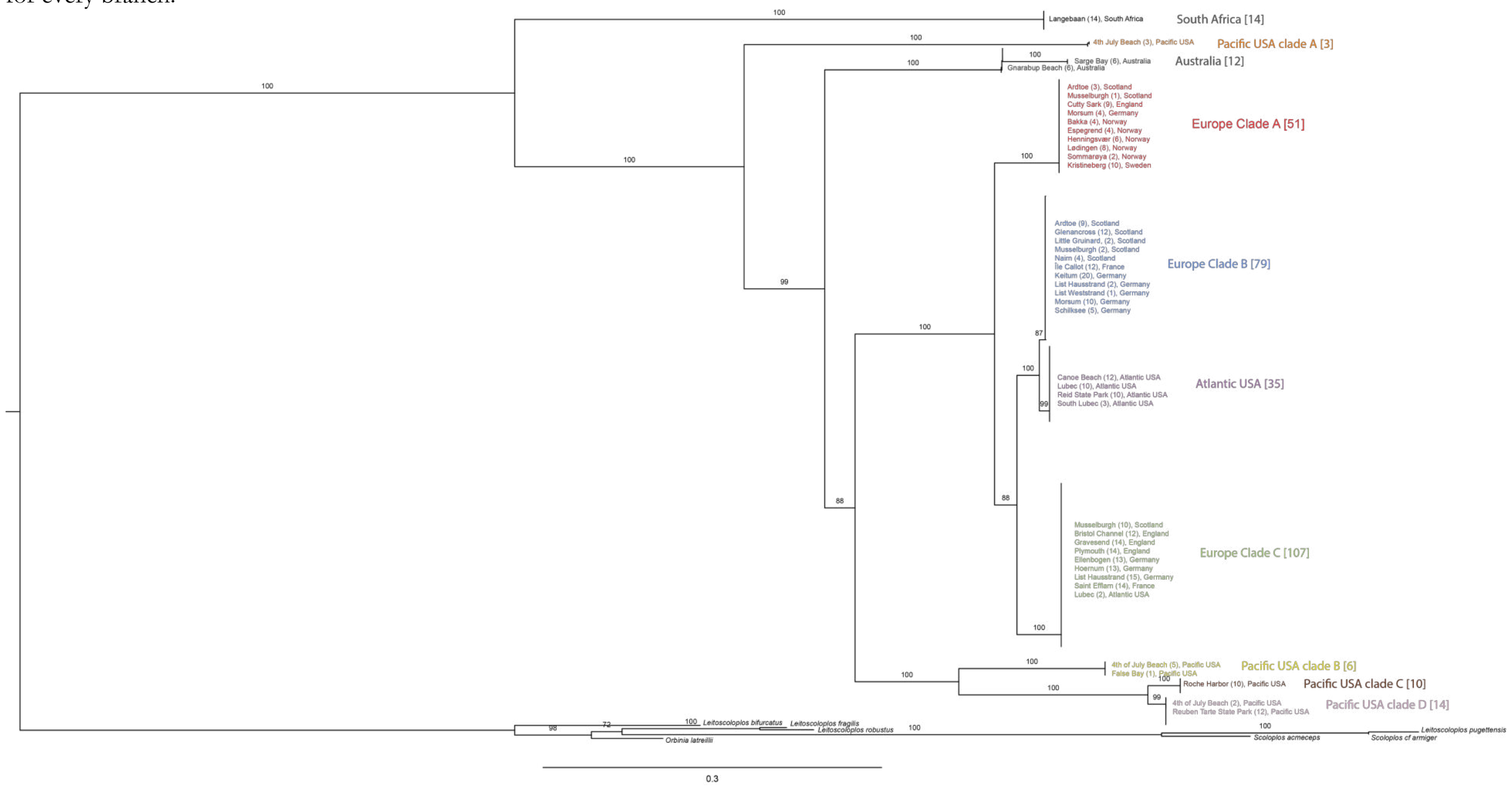


Supplementary Figure 2: Maximum Likelihood Phylogram of the $18 \mathrm{~S}$ gene dataset. Bootstrap support values are included for every branch.

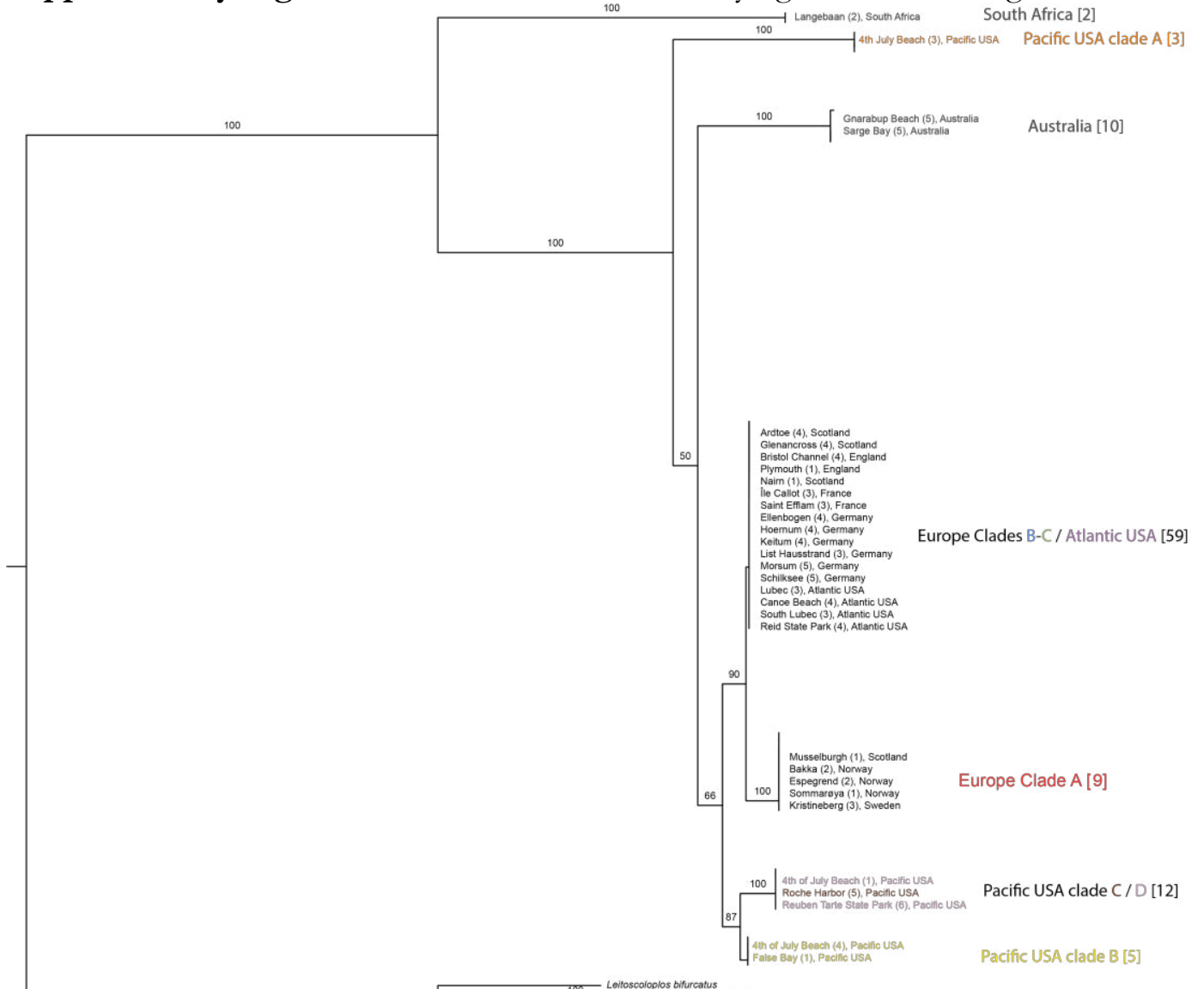


Supplementary Figure 3: Maximum Likelihood Phylogram of the ITS1 dataset. Bootstrap support values are included for every branch.

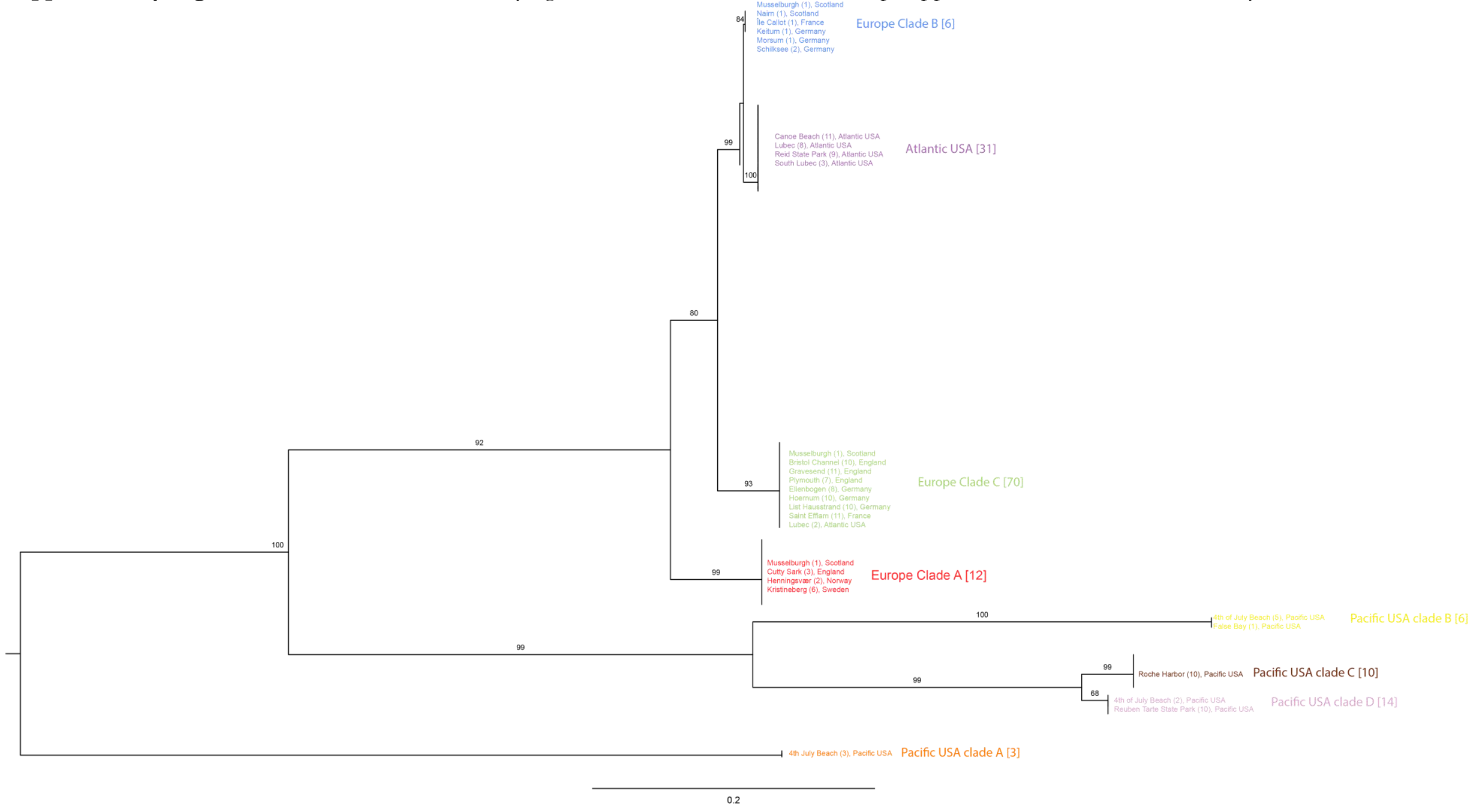


Supplementary Figure 4: Maximum Likelihood Phylogram of the COI dataset. Bootstrap support values are included for every branch.

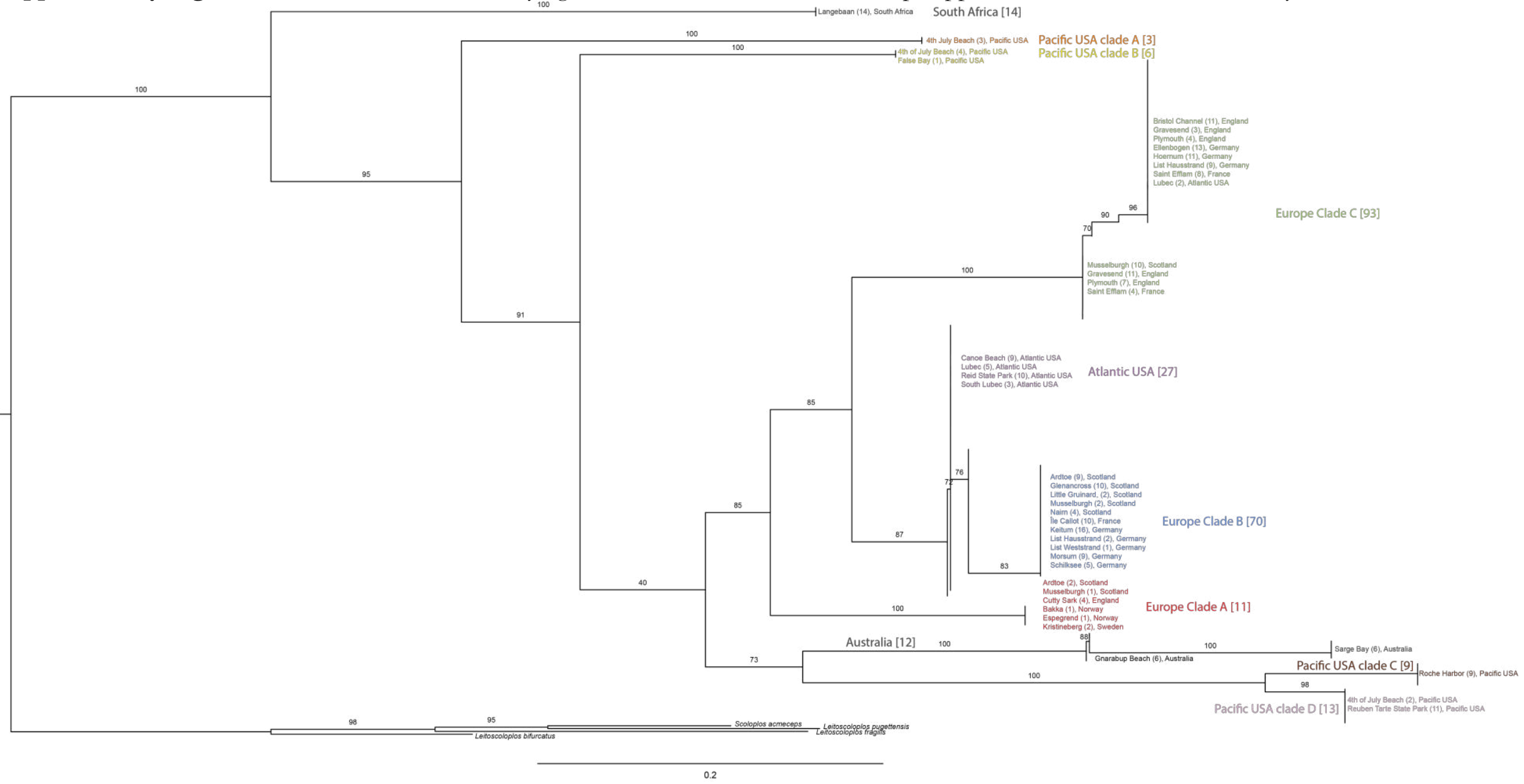


Supplementary Figure 5: Maximum Likelihood Phylogram of the 16S dataset. Bootstrap support values are included for every branch.

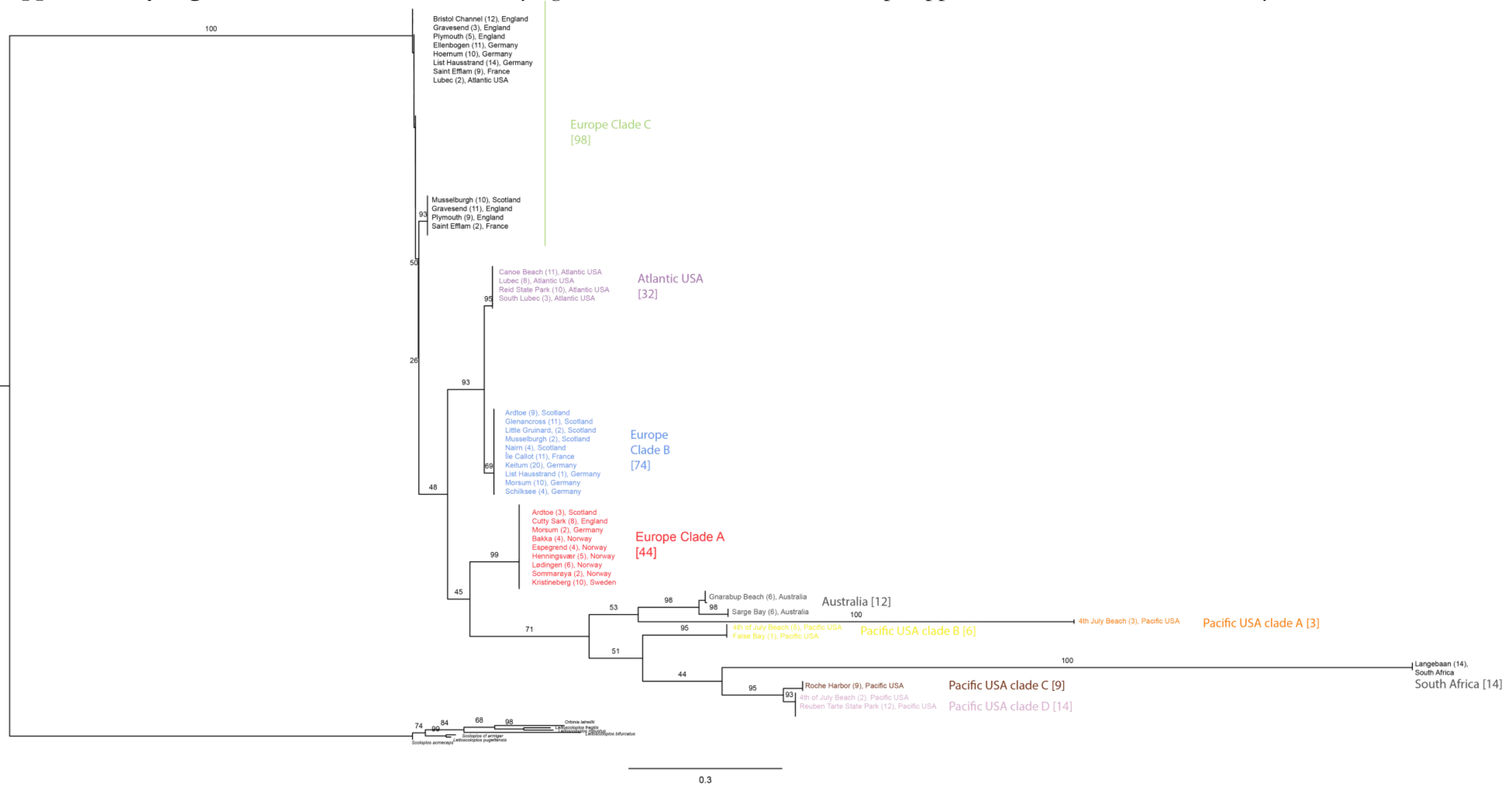


Supplementary Figure 6: Ancestral character reconstruction of morphological characters. Four phenotypes based on the chaetal pattern of the first three chaetae can be distinguished (top left). Red denotes phenotype \#1, green denotes phenotype \#2, blue denotes phenotype 3, yellow denotes phenotype \#4. On the tips we include information of the sampling site, aswell as the country. EC_A = Europe Clade A; EC_B = Europe Clade B; EC_C = Europe Clade C; AA = Atlantic America; PC_A = Pacific Clade A; PC_B = Pacific Clade B; PC_C = Pacific Clade C; PC_D = Pacific clade D

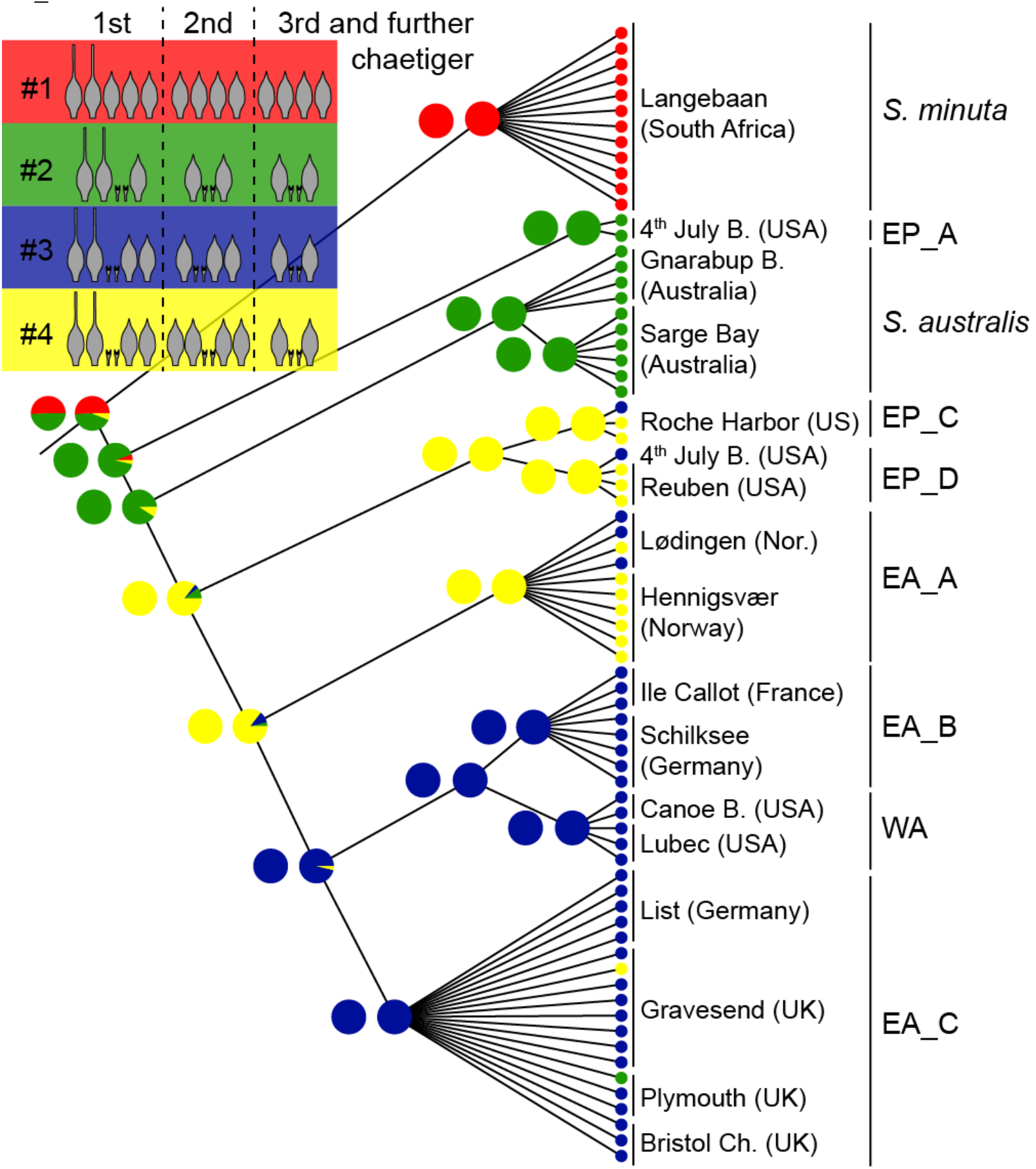


Supplementary Figure 7: Phenotypic and genetic divergence in Stygocapitella. A) Morphological disparity for qualitative traits; B) Morphological disparity for quantitative traits. These values result from a Multidimensional morphological disparity (MMD) index plotted against uncorrelated genetic distances of the $18 \mathrm{~S}$ gene. Red, green, blue and yellow diamonds correspond to different morphortypes (\#1, \#2, \#3, \#4), see main text for a through description.

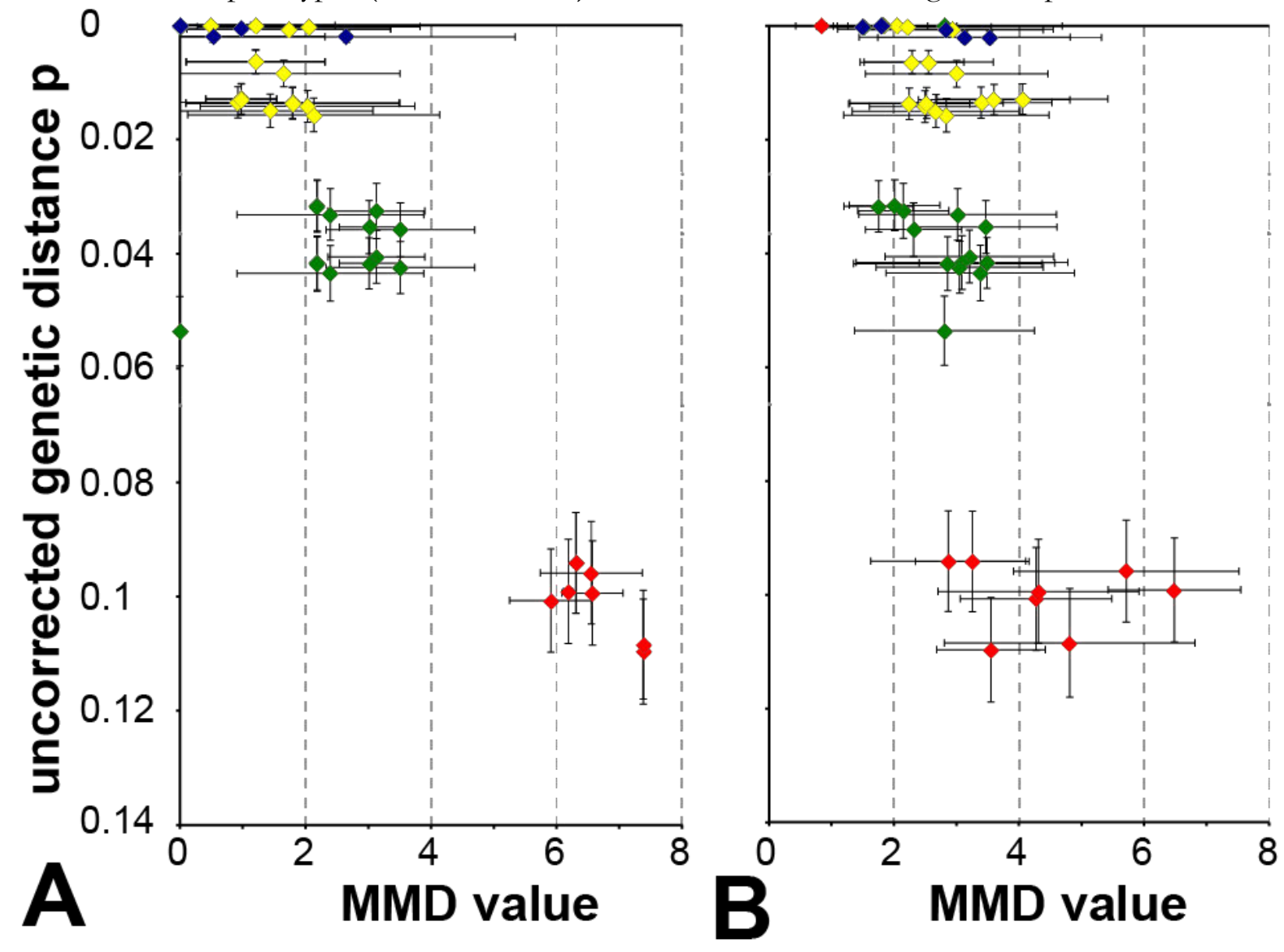


Supplementary Figure 8: ITS length across different clades. EC_A = Europe Clade A; EC_B = Europe Clade B; EC_C = Europe Clade C; AA = Atlantic America; PC_A = Pacific Clade A; PC_B = Pacific Clade B; PC_C = Pacific Clade C; PC_D = Pacific Clade D. In Europe Clade B we display only sequences with $900-1000$ basepairs (see main text)

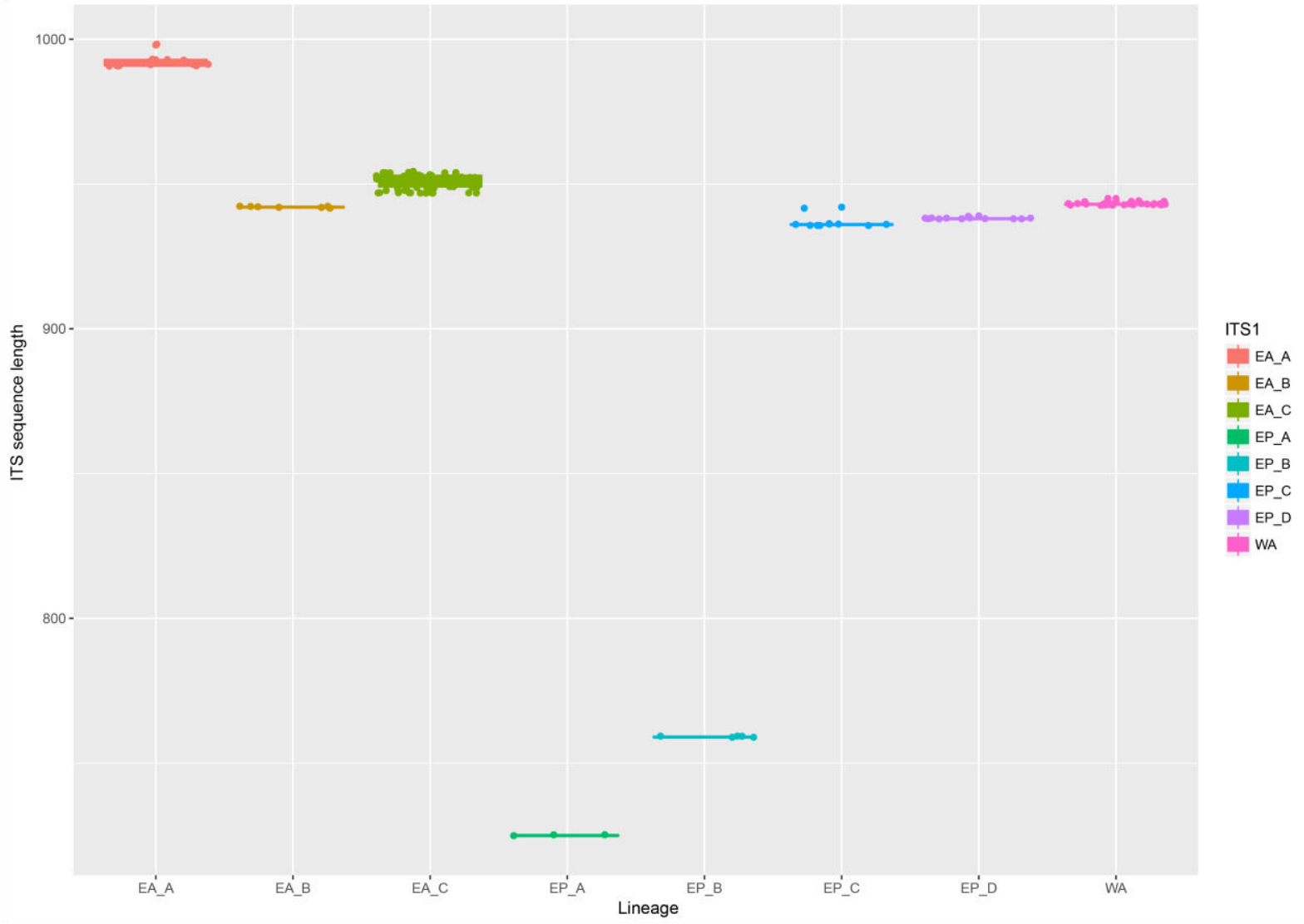


José Cerca - On the Origin of Cryptic Species: Insights from the Stygocapitella species complex

\section{Manuscript 4}

Delimitation of cryptic species drastically reduces the geographical of marine interstitial ghost-worms (Stygocapitella; Annelida, Sedentaria) 


\section{Molecular phylogenetics and evolution}

2 Delimitation of cryptic species drastically reduces the geographical ranges of marine

3 interstitial ghost-worms (Stygocapitella; Annelida, Sedentaria)

4 José Cerca $^{\mathrm{a} *}$, Christian Meyer ${ }^{\mathrm{b}}$, Günter Purschke ${ }^{\mathrm{b}}$, Torsten H. Struck ${ }^{\mathrm{a}}$

$5 \quad{ }^{a}$ Frontiers of Evolutionary Zoology Research Group, Natural History Museum, University of

6 Oslo, 0562 Oslo, Norway

$7 \quad{ }^{\mathrm{b}}$ Zoology and Developmental Biology, Department of Biology and Chemistry, University of

8 Osnabrück, Barbarastr. 11, 49069 Osnabrück, Germany

9 * Corresponding author: José Cerca; jose.cerca@gmail.com; ORCID 0000-0001-7788-4367

10 Abstract

11 The recognition of cryptic species concealed in traditionally established species can reveal new 12 biogeographical patterns and alter the understanding of how biodiversity is geographically 13 distributed. This is particularly relevant for marine ecosystems where the incidence of cryptic 14 species is high and where species distribution data are often challenging to collect and interpret. 15 Here, we studied specimens of the 'cosmopolitan' interstitial meiofaunal annelid Stygocapitella 16 subterranea Knöllner, 1934 (Parergodrilidae, Orbiniida), obtaining data from four coastlines in the 17 Northern hemisphere. Using phylogenetic tools and several species-delimitation methods 18 (haplotype networks, GMYC, bPTP, maximum likelihood, posterior probability and morphology) 19 we describe eight new Stygocapitella species. With one exception, all species are present along a single coastline, ultimately challenging the idea that Stygocapitella subterranea has a cosmopolitan distribution. We found evidence for several oceanic transitions having occurred in the past as well as a recent translocation, potentially due to human activity. No diagnostic characters were found, and qualitative and quantitative morphological data do not allow an unequivocal differentiation of the identified cryptic species. This suggests that (i) neither traditional diagnostic features nor quantitative morphology suffice to recognise species boundaries in cryptic species complexes, such as the Stygocapitella species complex; and that (ii) the recognition and description of cryptic species is of seminal importance for biodiversity assessments, biogeography and evolutionary 28 biology.

\section{Keywords}

30 Sibling species; biogeography; marine connectivity; phylogenetics; distribution range; dispersal 
Species distribution data provide a valuable proxy to understand patterns of biodiversity occurrence across the globe, the influence of past geological events on taxa, but also of human impact on biological communities (Holt et al., 2013). However, quantifying biodiversity and species distributions can be challenging (Knowlton, 2000, 1993; Leray and Knowlton, 2016). For instance, in marine environments, sampling of biodiversity often requires expensive equipment and big teams. Boundaries and biogeographic barriers are often hard to determine, and the patchiness of marine populations combined with the wide area occupied by oceans contributes to difficult sampling and collection. Species delimitation and identification are often compromised because organisms can be deformed following their collection and extraction from the water, due to preservation practices, or because they require sound taxonomic expertise, including adult features and unequivocal diagnostic characters (Cerca et al., 2018; Hellberg, 2009; Knowlton, 1993; Sterrer, 1973). As a result, our understanding of evolutionary and ecological processes as well as biogeographic patterns at the sea is severely diminished (Hellberg, 2009; Johannesson, 1988; Knowlton, 1993).

Cryptic species add another layer of complexity to biodiversity assessments (Knowlton, 1993; Pante et al., 2015) and to the determination of species' distributions (Cerca et al., 2018; Knowlton, 2000, 1993). The debate whether cryptic species result from natural phenomena or taxonomic artefacts has recently sparked attention (Fišer et al., 2018; Korshunova et al., 2019, 2017; Pante et al., 2015). A recent view has argued that the uncertainty in this debate essentially derives from placing the focus on the taxonomic history of the species complex, rather than focusing on the accumulation of morphological disparity through time or lack thereof (Struck et al., 2018a, 2018b; Struck and Cerca, 2019). To distinguish between these two aspects, it was suggested that species should be first investigated and delimited using all available data (e.g. morphological, ecological and behavioural data). The assignment of the 'cryptic' status, should then follow, but only after and independent from the species delimitation process. In this step, one should quantify morphological disparity. The status of 'cryptic species' should only be attributed if the species under consideration are morphologically more similar to each other than expected, given the time since species divergence. The comparison with closely related outgroups, displaying clear morphological differences is beneficial to this procedure as it allows gauging the degree of morphological disparity in closely related lineages (for a more detailed discussion of the problems in assigning cryptic species please see (Struck et al., 2018a, 2018b;

63 Struck and Cerca, 2019). These guidelines allow distinguishing species which are morphologically 
decelerated (i.e., cryptic species) from cryptic species complexes resulting from taxonomic artefacts such as erroneous descriptions, or from poorly sampled and preserved data. Importantly, distinguishing between both opens the possibility to study processes leading to the deceleration of morphological evolution and its underlying causes.

One particularly interesting group of marine organisms with a high incidence of cryptic species and little-known distribution is the interstitial fauna of coastal sediments (Cerca et al., 2018; Giere, 2009; Westheide, 1977). These habitats harbour a rich biodiversity, with organisms being typically found in the space between sand grains in beaches along continental coastlines (Giere, 2009). The overall convergence of body plan, and the suggested occurrence of high rates of morphological stasis (i.e. retention of the same ancestral character state over an extended period) results in high incidences of cryptic species in this group (Cerca et al., 2018; Jörger and Schrödl, 2013; Westheide, 1987). Taken together, these have been suggested to confound the study of meiofauna species' distribution (Cerca et al., 2018; Leasi and Norenburg, 2016). For instance, Stygocapitella subterranea was first described from the Baltic coastline of Germany (Knöllner, 1934). It was later found in numerous places across European coastlines including the Mediterranean and Black Sea, Northern America, as well as New Zealand and Australia (Purschke et al., 2019; Westheide, 2008, 1990), leading to the interpretation that S. subterranea is a cosmopolitan-distributed species (Riser, 1984). Recent investigations using a combination of genetic and morphological data from the Southern hemisphere led to the description of two new Stygocapitella species, S. minuta Struck et al., 2017 and S. australis Struck et al., 2017 (Fig. 1). RAPDPCR data suggested that three different lineages of $S$. subterranea from different coastlines of the Northern hemisphere are genetically distinct (Schmidt and Westheide, 2000), with specimens from Europe and North America (Atlantic) grouping together, and specimens from the Pacific being distantly related to this group (Schmidt and Westheide, 2000). Hence, it is uncertain if $S$. subterranea has a distribution with population structure, or whether these are potentially different species.

The aim of this study is to do a phylogeographic reconstruction of lineages belonging to Stygocapitella, including data from S. subterranea specimens occurring along the Northern European, East-Northern American, West-Northern American, and Far-Eastern Russian coastlines. We complement this with data from the $S$. australis and $S$. minuta which respectively occur in the Australian and South African coastlines, to determine genetic and morphological differences between lineages, and whether these are different species. We (i) delimitate species using phylogenetic tools, species delimitation algorithms and haplotype networks and follow the 
phylogenetic species concept; and (ii) assess morphological similarity between Stygocapitella species. We find evidence for several morphologically similar or identical species (i.e. cryptic species), which differ only in their geographic distribution at different coastlines. In addition, we

100 find evidence for the occurrence of several oceanic translocations, including one potentially due to human activity. We discuss the importance of recognising and delimiting cryptic species, as well as the role of morphological-oriented practices in cryptic species complexes.

\subsection{Field work and species identification}

Stygocapitella spp. are interstitial annelids generally found around and above the high-water line of stable, sheltered gravel or sandy beaches (Purschke et al., 2019). To collect specimens, we selected beaches based on old records or by assessment of the area using google maps (Supplementary Table 1). At each site, we drew a transect roughly perpendicular to the coastline from the high-water line to the foot of the dune. After drawing the transect, we dug a hole every meter and collected sediment samples in plastic bags (volume of $375 \mathrm{~cm}^{3}$ ) at intervals of $15 \mathrm{~cm}$ $(0-15 ; 15-30 ; \ldots)$ until approximately $60-75 \mathrm{~cm}$ depth or till the ground water. Interstitial invertebrate communities were then extracted using the $\mathrm{MgCl}_{2}$ method and sorted under a dissecting microscope (Westheide and Purschke, 1988). After identification, we preserved

114 specimens for molecular biology and for morphological analyses, either by transferring these to a 115 solution of $\sim 70 \%$ ethanol or to a fixative containing picric acid, formaldehyde and glutaraldehyde 116 adjusted with sucrose to sea water osmolality (Sucrose-picric-acid-parafolmaldehyde-

117 glutaraldehyde; SPAFG) following Westheide and Purschke (1988), respectively. Lists of 118 individuals used for molecular and for quantitative morphological analyses are provided in 119 Supplementary Tables 2 and 3, respectively.

\subsection{DNA extraction and amplification}

DNA extractions were carried out using either phenol-chloroform or the E.Z.N.A Tissue

122 DNA Kit (Omega Bio-Tek). The nuclear markers 18S (complete) and ITS1 and the

123 mitochondrial CO1 were amplified using the QIAGEN® Multiplex PCR Kit (Qiagen, Hilden,

124 Germany) in a $10 \mu \mathrm{l}$ reaction-mix containing $5 \mu$ l of multiplex mix, $1 \mu \mathrm{l}$ Q-solution, $0.8 \mu \mathrm{l} 10 \mu \mathrm{M}$

125 of both forward and reverse primer, $1 \mu l$ genomic DNA and $1.4 \mu l$ deionized water. The mitochondrial gene $16 \mathrm{~S}$ was amplified using a $25 \mu \mathrm{l}$ reaction-mix, which included $15.2 \mu \mathrm{l}$ of $\mathrm{H}_{2} \mathrm{O}$, 
$12810 \mathrm{mM}$ dNTPs, $1.6 \mu \mathrm{l} 10 \mu \mathrm{M}$ of both forward and reverse primer and $0.13 \mu \mathrm{l}$ of amplitaq gold

129 (Applied Biosystems). For COI, we used the primers LCO1490-JJ

130 (CHACWAAYCATAAAGATARYGG) and HCO2198-JJ

131 (AWACTTCVGGRTGVCCAAARAATCA; both Astrin \& Stüben, 2008), for 18S 18e

132 (CTGGTTGATCCTGCCAGT, Hillis \& Dixon, 2018) and 18R1779

133 (TGTTACCGACTTTTACTTCCTCTA; (Struck et al., 2002), and for ITS1 species-specific

134 primers Stygo_ITS1_F (TGTTGATTACGTCCCTGCCC; this study) and Stygo_ITS1_R

135 (GTCAACCGACCCTGAGACAG; this study), and for 16S 16SarL

136 (CGCCTGTTTTATCAAAAACAT; Palumbi et al., 1991) and 16S_AN-R

137 (GCTTACGCCGGTCTGAACTCAG; (Zanol et al., 2010). Exceptionally, polyLCO

138 (GAYTATWTTCAACAAATCATAAAGATATTGG) and polyHCO

139 (TAMACTTCWGGGTGACCAAARAATC; both Lobo et al., 2016) were used for individuals

140 from the Atlantic-American sites as they yielded better results. PCR conditions for ITS1 included:

141 an initial denaturation: $15^{\prime} 95^{\circ} \mathrm{C} ; 40$ cycles: $30^{\prime \prime} 95^{\circ} \mathrm{C}, 30^{\prime \prime} 66^{\circ} \mathrm{C}, 1^{\prime} 72^{\circ} \mathrm{C}$; and a final elongation:

$14220^{\prime} 72^{\circ} \mathrm{C}$; for $16 \mathrm{~S}$ we included a touchdown procedure: an initial denaturation: $15^{\prime} 95^{\circ} \mathrm{C}$; 40 cycles:

$14330^{\prime \prime} 94^{\circ} \mathrm{C}, 30^{\prime \prime} 51^{\circ} \mathrm{C}$ (touchdown: $-0.2^{\circ} \mathrm{C}$ per cycle), $2^{\prime} 65^{\circ} \mathrm{C}$; final elongation: $7^{\prime} 65^{\circ} \mathrm{C}$; for $18 \mathrm{~S}$ a

144 touchdown/touch-up: initial denaturation: $15^{\prime} 95^{\circ} \mathrm{C} ; 15$ cycles: $35^{\prime \prime} 94^{\circ} \mathrm{C}, 90^{\prime \prime} 55^{\circ} \mathrm{C}$

145 (touchdown: $-1^{\circ} \mathrm{C}$ per cycle), $2.5^{\prime} 72^{\circ} \mathrm{C} ; 25$ cycles: $35^{\prime \prime} 94^{\circ} \mathrm{C}, 90^{\prime \prime} 50^{\circ} \mathrm{C}, 2.5^{\prime} 72^{\circ} \mathrm{C}$; final elongation:

$14610^{\prime} 72^{\circ} \mathrm{C}$. Finally, for COI: initial denaturation of: $15^{\prime} 95^{\circ} \mathrm{C} ; 15$ cycles: $35^{\prime \prime} 94^{\circ} \mathrm{C}, 90^{\prime \prime} 55^{\circ} \mathrm{C}$

147 (touchdown: $-1^{\circ} \mathrm{C}$ per cycle), $1.5^{\prime} 72^{\circ} \mathrm{C} ; 25$ cycles: $35^{\prime \prime} 94^{\circ} \mathrm{C}, 90^{\prime \prime} 50^{\circ} \mathrm{C}, 1.5^{\prime} 72^{\circ} \mathrm{C}$; final elongation:

$14810^{\prime} 72^{\circ} \mathrm{C}$. PCR fragments were purified using a 10 times dilution of a phosphatase-exonuclease

149 mix and Sanger-sequenced by Macrogen-Europe. Considering the length of the $18 \mathrm{~S}$ fragment,

150 four additional sequencing primers were included as sequencing primers: $18 \mathrm{r}$

151 (CTCTAAT'TTT'TTCAAAGTAAAC), 18L (AGCTCTCAATCTGTCAATCCT; both Hillis \&

152 Dixon, 1991), 18F997 (TTCGAAGACGATCAGATACCG; Struck et al., 2002) and

153 18SF3_Stygo (CCTCGGGATTGGAATGAGTAC; Struck et al., 2017). After sequencing, we

154 assembled sequences using Geneious (v6.8.1). The ends of sequences were automatically trimmed

155 to remove the primers, visually checked, and manually trimmed to account for low quality ends.

156 Finally, consensus sequences were blasted using NCBI database to exclude contamination.

$157 \quad 2.3$ Phylogenetic and molecular clock analyses

158 In total, we included sequence information for 353 specimens belonging to 33 sites in the

159 Northern Hemisphere, as well as data from other Stygocapitella species of the Southern

160 Hemisphere and species of Orbiniidae, the sister group of Parergodrilidae (Supplementary Tables 
1611 and 2; Supplementary Figure 1). We aligned COI, 16S and 18S sequences using MAFFT v7.310, 162 with a maximum of 1,000 iterations and using the local pair alignment algorithm (mafft -163 maxiterate 1000 --localpair -reorder input.fa > output.fa) (Katoh and Standley, 2013). For ITS1 164 sequences, we adopted a different strategy as these sequences ranged from $750-1600 \mathrm{bp}$, 165 resulting from tandem repeats. As we were not able to align these initially, we removed sequences 166 longer than 1100 bp. This allowed aligning ITS1 using the global pair alignment algorithm (-167 globalpair), which accounts for gap-rich sequences. After aligning sequences and removing about $1685 \%$ of the sequences due to long missing-ends, both ends were trimmed until the first position 169 without missing data. To inspect congruence of the datasets (i.e. if separate genes cluster 170 individuals and species similarly), we performed separate maximum likelihood analyses of each 171 gene (Supplementary Figures 2-5). Single gene analyses were conducted using IQ-tree v1.6.7

172 (Chernomor et al., 2016; Nguyen et al., 2015) with an automatic determination of the best 173 substitution model for each gene, 300 initial parsimony trees, 15 best trees retained during search 174 and 1,000 ultrafrast bootstrap replicates (iqtree -s input.fa -nt AUTO -ninit 300 -nbest 15 -bb 1751000 -wbtl) (Hoang et al., 2017). Finally, we concatenated the four genes into a single multi-gene 176 alignment using FASconCAT v1.1 (Kück and Meusemann, 2010), and did a partitioned 177 Maximum Likelihood (ML) analysis using IQ-tree as described for the single-gene analyses (Fig. 178 2). Bayesian inference (BI) was applied using BEAST v2.4.7 (Bouckaert et al., 2014). Before running any analyses we determined substitution models that best fit the data using IQ-tree's

181 ModelFinder (Kalyaanamoorthy et al., 2017). After performing several runs using combinations

182 of different prior models and genes, we opted to remove 16S and ITS1 from further analyses

183 because chain convergence could not be achieved. After this, we ran several analyses, some 184 including missing data for either COI or 185 or without missing data (i.e. including only 185 specimens for which both genes were present). Given the substantial differences in chain 186 convergence we opted for the latter strategy. For the final analysis, the trees of COI and $18 \mathrm{~S}$ were 187 linked and the best fitting-models were TNe+I (Model TN93; Frequencies: All equal) for 18S and 188 TIM+F+I+G4 (F= Empirical base frequencies; I = Invariable sites; $\mathrm{G}=$ Gamma model) for 189 COI. To apply the TIM model in BEAST we selected the GTR model, with all frequencies to be 190 estimated, apart for AG and CT, and 4 gamma categories. A relaxed, log-normal clock was 191 applied with a substitution rate of 0.0001425 for $18 S$ (Struck et al., 2017) and 0.0176 for COI 192 (Lehmacher et al., 2016). We selected a birth-death model and a MCMC run for 100,000,000 193 generations sampling every 100,000 generation. Convergence was confirmed using Tracer v1.6 
194 (Rambaut et al., 2007). A Maximum Credibility Consensus Tree was obtained using

195 TreeAnnotator, with a 10\% burn-in (Bouckaert et al., 2014).

\subsection{Haplotype networks and species delineation}

Haplotype networks of each separate genetic marker were build using TCS (Clement et al., 2000), with a connection limit of $95 \%$. Gaps were considered as a fifth state. Graphical

199 representation was done with tcsBU (Múrias Dos Santos et al., 2015), and then redesigned using 200 Adobe Illustrator. We have adopted several species delineation approaches as suggested as best 201 practice (Carstens et al., 2013). These included a GMYC model at https://species.h-

202 its.org/gmyc/ (Fujisawa and Barraclough, 2013), a bPTP model at https://species.h-its.org/ptp/

203 (Zhang et al., 2013), 16S- and COI-based 95\% connection limits using TCS (Clement et al., 204 2000), a posterior probability cut-off of 0.9 based on the generated Bayesian tree and a bootstrap 205 cut-off of 95\% based on the ML tree. The GMYC analysis was performed based on the obtained 206 Bayesian tree (based on 18S and COI) and the bPTP on the obtained ML tree (concatenated, 207 partitioned dataset including 16S, 18S, COI and ITS1). In addition to the genetic data, we did a 208 'morphological species delineation' with the aim of obtaining diagnostic features, based on the 209 presence of certain chaetal types on the $1^{\text {st }}, 2^{\text {nd }}, 3^{\text {rd }}$ and consecutive segments - the only variable 210 morphological features we were able to obtain in our data.

\subsection{Morphological data analysis}

We investigated morphological disparity by using morphological measurement data 213 obtained via light microscopy. To do so, we photographed single Stygocapitella specimens at 10X 214 amplification. Because this resulted in multiple photos, we stitched photos together to form a 215 whole-organism photograph using Photoshop. We then used ImageJ to measure body length and 216 width, prostomium length and width, and pygidium length and width. In total, we obtained 217 measures from 133 Stygocapitella specimens (Supplementary Table 3). Measurements were analysed 218 using general linear models (GLM), Least Square Means analyses (Lenth, 2013) and principal 219 component analyses. For each measurement, we fit a GLM model, using "measurement" as the dependent variable and "Stygocapitella lineage" as the independent variable. Because GLM models do not allow assessing differences between factorial variables (in this case "Stygocapitella lineage”), we fit a Least Square Means analysis to each model. This analysis provides pairwise statistical comparisons between factorial variables (i.e. "Stygocapitella lineage”), providing $p$-value evaluations between factors. Significance thresholds were then obtained with a Likelihood ratio test using the 
principal component analyses using all six measurements and the function prcomp included in 227 R's stats-package (R Core Team, 2013). Plotting of results was done using the ggplot2 package 228 (Wickham, 2016) and the Hmisc package (Harrell Jr and Many Others, 2019).

In addition to morphological measurements, we looked for presence of chaetal 230 differences using scanning electron microscopy (SEM). Specimens selected for SEM were rinsed 231 in phosphate buffer and then treated with a buffered $1 \% \mathrm{OsO}_{4}$ solution for one hour at ambient temperature. This was followed by dehydration in a graded ethanol series starting in $30 \%$ ethanol and finishing in 100\% ethanol. Dehydrated specimens were then critically-point-dried with $\mathrm{CO}_{2}$, mounted on aluminium stubs and sputter-coated with platinum. SEM photographs from (i) the whole body, (ii) segments with chaetae (chaetiger), and (iii) the type and number of chaetae in each chaetiger were obtained using a Zeiss Auriga field emission SEM.

\section{Results}

\subsection{Phylogenetic analyses}

The dataset of 353 specimens comprised 332 16S, 273 COI, 12518 S and 177 ITS1 sequences. Partitioned ML (Fig. 2) and BI (Fig. 3) of the concatenated data generally resulted in the same topology. Monophyly of both $S$. minuta and $S$. australis is supported by bootstrap support values (BS) of 100 and posterior probabilities (PP) of 1 . The species S. subterranea sensu lato from the Northern hemisphere was not recovered as monophyletic and is separated into eight

244 lineages (BS = 99-100 \& PP = 0.928-1; Fig. 2). Specimens from Volchanets (Russia; new record

245 in Fig. 1) split into two separate lineages (BS = $100 \& \mathrm{PP}=0.997$; one lineage was only

246 represented by one specimen in the BI). Single-gene ML phylogenies retrieved the same lineages

247 as the concatenated datasets, demonstrating congruence between the genes in the dataset. The 248 only exception was the highly conserved $18 \mathrm{~S}$ gene that did not unambiguously distinguish the 249 most recent divergences between closely related species (Supplementary Figures 2-5). Eight of 250 the lineages in the tree are formally described as new species below, following species delimitation analyses (see below), and for the sake of clarity we use their new species names $(S$. pacifica sp. nov., S. furcata sp. nov., S. berniei sp. nov., S. americae sp. nov., S. budaevae sp. nov., S. zecai sp. nov., S. josemariobrancoi sp. nov., and S. westheidei sp. nov.) in the following sections, as well as in Figs. 2 \& 3. Stygocapitella westheidei sp. nov. is sister to the amended S. subterranea sensu stricto, and S. josemariobrancoi sp. nov. is sister to these two $(\mathrm{BB}=100$ and $96 \& \mathrm{PP}=0.991$ and 0.998 , respectively). These three species are sister to Stygocapitella zecai sp. nov., and together they form the North Atlantic clade $(\mathrm{BB}=100 \& \mathrm{PP}=1)$. 
Stygocapitella budaevae sp. nov. is sister to a species which remains undescribed due to the

259 lack of type material and to which we will refer as undescribed species A (BS = $100 \& \mathrm{PP}=1)$,

260 Stygocapitella berniei sp. nov. is sister to S. americae sp. nov. (BS = 100 \& 1). Stygocapitella berniei sp.

261 nov., S. americae sp. nov, S. budaevae sp. nov. and Spec. A form a clade (BS = 100 \& 0.987), which

262 is sister to $S$. australis in the ML analysis (BS = 83, Fig. 2), yet it is sister to the Northern Atlantic

263 clade in the $\mathrm{BI}$ analysis $(\mathrm{PP}=0.987$, Fig. 3). In both analyses all species so far mentioned form a

264 monophyletic group (BS $=100 \& \mathrm{PP}=0.948)$. Stygocapitella pacifica sp. nov. is sister to S. furcata

265 sp. nov. (BS = $100 \& \mathrm{PP}=1)$, together comprising a clade which is sister to all aforementioned

266 species. All these species form a monophyletic clade, which is sister to $S$. minuta which is the first

267 to branch off in the Stygocapitella radiation $(\mathrm{BS}=100 \& \mathrm{PP}=0.656)$.

\subsection{Network analyses}

We retrieved haplotype-networks of COI, 16S and ITS1 focusing on the Northern

270 Atlantic, where we did the majority of the sampling efforts (29 sites; Fig. 4), and for all locations

271 (35 sites; Supplementary Figure 6). Haplotype networks are congruent with phylogenetic results

272 recognizing twelve separate lineages. S. australis displays two unconnected haplotypes, separating

273 specimens geographically. For S. zecai sp. nov., the 16S haplotype network is divided into two

274 dominant haplotypes which are mostly represented in Scandinavia and Scotland and separated by

275 only one substitution. One of the haplotypes is also present in the North Sea and in Eastern

276 England (Fig. 4). For COI, we were unable to obtain as many sequences as for 16S, yet we

277 observe a network comprising five haplotypes, with six substitution differences between the two

278 most distant haplotypes. For ITS1, specimens in different areas have distinct haplotypes.

279 Individuals from Scandinavian regions are separated by up to 25 substitution differences. In $S$.

280 josemariobrancoi sp. nov. one ITS1, two $16 \mathrm{~S}$ and three COI haplotype networks are unconnected at

$28195 \%$ thresholds. Differences in COI and 16S are probably due to differences in variability in two

282 genetic markers. For ITS1, the most common haplotype is present in Germany (North Sea),

283 Scotland and France. Specimens from West England have multiple haplotypes, separated

284 between a single substitution up to 31 substitutions. Haplotypes found in East England are

285 subdivided into three closely-related haplotypes, which are 11 substitution away from the

286 dominant haplotype, and by three specimens which are one and three substitutions away from

287 the dominant haplotype. The two specimens from the USA are nested between the two most

288 common haplotypes. For 16S, one of the two haplotype networks displays a major haplotype

289 present in France, Eastern England and Scotland. The second biggest haplotype in this network

290 is 6 substitutions away from the major haplotype and only occurs in Western England. The 
second haplotype network occurs in France, Germany (North Sea), the USA and Western

292 England and has two major haplotypes, which are only separated by a single substitution. Rarer

293 haplotypes occur mostly in Germany (North Sea), being up to eight substitutions different from

294 one of the major haplotypes. In COI, one of the three networks is represented by a single

295 specimen from Bristol Channel. Another is comprised by a dominant haplotype which is present

296 in Germany (North Sea), France, USA and Western England, and by several haplotypes separated

297 by only one or two substitutions. The third and remaining COI network is comprised by two

298 dominant haplotypes, one occurring in Western England and the other occurring in Eastern

299 England, France and Scotland. This haplotype network is congruent between COI and 16S. 16S

300 and COI retrieve similar networks for S. subterranea, revealing a dominant haplotype occurring in

301 Germany (North Sea), Scotland, and France as well as in COI in Germany (Baltic Sea) and

302 Eastern England (Fig. 4). In both genes, S. subterranea has haplotypes separated by 5-19

303 substitutions from the dominant haplotype, which occurs in Germany (Baltic and North Sea),

304 Scotland and France. For ITS1 in S. subterranea, we were unable to amplify this marker in multiple

305 specimens (Supplementary Table 2). However, 17 substitutions separate the two most distant

306 haplotypes, which occur in Germany (North Sea), and another in Germany (Baltic Sea) and

307 France. In S. westheidei sp. nov., COI and 16S present a very distinct haplotype structure. In 16S a

308 single haplotype is present at all sites from the USA (circa $400 \mathrm{~km}$ ) while, on the other hand, COI

309 shows six co-occurring haplotypes without geographic structuring. Four of these haplotypes are

310 present in Canoe Beach, three in Reid State Park and two in Lubec (Supplementary Figure 6). For

311 ITS1, a major haplotype exists, with two minor haplotypes separated by only one substitution

312 from the major haplotype.

\section{$313 \quad 3.3$ Morphological measurements and morphotypes}

A total of four morphotypes can be identified in Stygocapitella based on chaetal composition. All these morphotypes can be distinguished by chaetae number and composition of 316 chaetae present in the first two chaetigers (Fig. 5). The first morphotype is specific to S. minuta 317 (see Struck et al., 2017). It comprises two whip-like and three bilimbate chaetae in the first and 318 four bilimbates in the second chaetinger. The second morphotype consists of two whip-like, two 319 forked and one bilimbate chaetae in the first, and one bilimbate, two forked and one bilimbate 320 chaetae in the second chaetiger (red morphotype in Fig. 5). This morphotype is seen in S. pacifica 321 sp. nov., S. furcata sp. nov., and S. australis. The third morphotype is distinguished by its two 322 whip-like, two forked and two bilimbate chaetae in the first and two bilimbate, two forked and 323 two bilimbate chaetae in the second chaetiger (blue in Fig. 5). This morphotype is present in $S$. 
berniei sp. nov., S. americae sp. nov., S. budaevae sp. nov., $S$. zecai sp. nov. and presumably in Stygocapitella sp. A, for which we lack morphological data. The fourth morphotype is identified by two whip-like, two forked and two bilimbate chaetae in the first and one bilimbate chaetae, two forked and two bilimbate chaetae in the second chaetiger (green in Fig. 5). This morphotype is present in $S$. josemariobrancoi sp. nov., S. westheidei sp. nov., and S. subterranea. All morphotypes have one bilimbate, two forked and one bilimbate chaetae in the third and following chaetigers except for that present in $S$. minuta which only has bilimbate chaetae in these chaetingers.

General Linear Models demonstrate significant differences in measurements: body length (Likelihood Ratio Test scaled dev. $=124.72, p<0.001)$, body width (LRT scaled dev. $=118.3$, $p$ $<0.001$ ), prostomium length (LRT scaled dev. $=76.5, p<0.001$ ), prostomium width (LRT scaled dev. $=122.8, p<0.001$ ), pygidium length (LRT scaled dev. $=45.4, p<0.001)$, and pygidium width (LRT scaled dev. $=140.5, p<0.001)$. Results from the morphological measurements show that pairwise differences in body length between species are also roughly reflected in the remaining five measurements (Fig. 6, Supplementary Table 4). Considering this, we will concentrate on body length in the following section. Most notably, S. minuta is significantly shorter in body length (mean 1046.88; SD 76.29) when compared to the remaining species, with the exception of S. pacifica sp. nov. (mean 1261.47; SD 52.21) and S. budaevae sp. nov. (mean 1368.49; SD 164.53). For the second morphotype mentioned above we lack light microscopybased measurement data for S. furcata sp. nov.. Within this morphotype, S. pacifica sp. nov. is smaller than S. australis (mean 1933.61; SD 218.01), but this difference is not statistically significant. For the third morphotype, S. budaevae sp. nov. has the shortest body length, followed by S. berniei sp. nov. (mean 2006.98; SD 436.99), whereas S. americae sp. nov. (mean 2550.4; SD 229.74) has the largest body length, followed by $S$. zecai sp. nov. (mean 2238.23; SD 322.48). In this way, $S$. budaevae sp. nov. is not significantly different in body length from S. berniei sp. nov.,

348 but it is significantly different from $S$. americae sp. nov. and S. zecai sp. nov.. Interestingly, S. berniei 349 sp. nov. is not significantly different from all species with the third morphotype in any of the 350 characters except for pygidium width, which is significantly different to S. budaevae sp. nov. 351 (Suppl. Table 4). Stygocapitella americae sp. nov. and S. zecai sp. nov. are not significantly different in 352 body length, but in prostomium length and width and pygidium width. Within the fourth 353 morphotype from above, S. josemariobrancoi sp. nov. (mean 2409.7; SD 472.15) is clearly the 354 longest species, while S. subterranea (mean 1703.7; SD 380.68) and S. westheidei sp. nov. (mean 355 1820.2; SD 293.68) have overlapping body length values. Accordingly, S. josemariobrancoi sp. nov. 356 is significantly different from S. subterranea and S. westheidei sp. nov., but the latter two are not separated from each other. 
Finally, we decomposed the variance in all data using principal component analyses.

359 Considering all species together the first principal component separates only S. minuta from the remaining species (PC1 explains $75.4 \%$ of the variance; Fig. 7A). The second and third principal components explained $11.9 \%$ and $5.4 \%$ of the variance, respectively, but could not separate any of the species (data for third component not shown). However, when considering the variance within morphotypes, the results are slightly more informative. In the second morphotype, $S$. pacifica sp. nov. is clearly separated from $S$. australis based on the first principal component (Fig. 7B). However, S. pacifica sp. nov. is only represented by two specimens. In the third morphotype, the first principal component separates $S$. budaevae sp. nov. from the remaining three species (Fig. 7C). S. zecai sp. nov. can also be separated from $S$. americae sp. nov. based on the first two principal components, but both overlap substantially with S. berniei sp. nov.. Finally, in the fourth morphotype all three species overlap substantially, so that they cannot be separated based on the PCA analysis (Fig. 7D). This is not due to the lack of data as these are the three species with highest number of sampled specimens.

\subsection{Species delimitation}

The complementary approaches to species delimitation were generally concordant (Fig. 2). With a total of 16 species, the GMYC algorithm (based on the Bayesian tree) was the method suggesting the most species, while, on the other hand, bPTP (based on the ML tree) proposed the least number of species (13). Every approach suggested that S. pacifica sp. nov., S. furcata sp. nov., S. bermiei sp. nov., S. americae sp. nov., S. spec. A, and $S$. zecai sp. nov. all represent single taxonomic units. Stygocapitella minuta and S. budaevae sp. nov. are consistently considered as single species in all the approaches with the exception of COI networks which suggest the presence of two species in each of these lineages (Fig. 2). GMYC, bPTP, and network approaches suggest that $S$. australis represent two separate species. For $S$. josemariobrancoi sp. nov., W COI networks and GMYC suggest the occurrence of three species, which also obtain support by posterior probabilities above 0.90 . On the other hand, $16 \mathrm{~S}$ networks suggest the occurrence of two species, but these were not recovered as monophyletic in the ML tree. Finally, bPTP suggests the occurrence of a single species. In both $S$. westheidei sp. nov. and $S$. subterranea, GMYC suggest two separate species, each of which also obtain posterior probabilities above 0.90 , whereas the remaining methods suggest the occurrence of only one species. To avoid over splitting, we have opted for a conservative in species recognition approach which consisted in selecting species based on a most inclusive approach. That is, if one approach found a clade as single species, while another one as more than one the clade, we regarded this clade as a single species. 
Additionally, the recognized species had to be retrieved as monophyletic, and strongly supported in all phylogenetic reconstructions of the concatenated datasets (for more details see Taxonomic account).

\section{Discussion}

Here, we described the genetic divergence and morphological disparity among species in the Stygocapitella genus. We find four morphotypes based on chaetal number and composition in a total of 12 species, rendering some species morphological identical. Even considering chaetal pattern (diagnostic feature) and light microscopy measurements (quantitative data), we are unable to distinguish species, which can only be distinguished using molecular tools. The morphological evolution of this species complex is exceptionally slow, as expected for cryptic species under morphological stasis (Cerca et al., 2018; Struck et al., 2018a; Struck and Cerca, 2019). With one exception, all Stygocapitella species occur in a single coastline, yet some of them are widely distributed spanning hundreds or thousands of kilometres. The discovery of cryptic species drastically reduced the cosmopolitan distribution of $S$. subterranea sensu lato (e.g. Purschke et al., 2019; Schmidt and Westheide, 2000; Westheide, 1990). We find indirect evidence for a potential oceanic translocation due to human activity in $S$. josemariobrancoi sp. nov. We discuss the relevance of morphology in taxonomy and the impact of cryptic species in marine biogeography.

\subsection{Cryptic species: Taxonomic artefacts or evolutionary phenomena?}

We describe eight new Stygocapitella species, totalling to eleven species in the genus. Additionally, one species is not yet formally described due to lack of type material, as required by the ICZN. While we find evidence for several morphologically similar species to occur, we identified 4 morphotypes based on the number and composition of chaetae in the first three chaetingers. Within each morphotype, clear differences in body measurements were found only between some certain species, but not all. For example, S. americae sp. nov. and S. berniei sp. nov. co-occur at the Pacific coastline of the US (Friday Harbor, Washington state) share the same morphotype and display no significant differences in quantitative measurements. The same is true for $S$. recai sp. nov. and $S$. berniei sp. nov.. The only diagnosable difference between these two species is molecular divergence, and potentially their geographic distribution, yet considering the global raise in species introduction by humans (Barnes, 2002; Mack and Lonsdale, 2001; Radziejewska et al., 2006) this cannot be taken as a rigorous diagnostic character. A similar example occurs between $S$. subterranea and $S$. westheidei sp. nov., which cannot be differentiated from each other neither based on morphotype nor morphometrics, but only by molecular data. 
423 Finally, so far $S$. pacifica sp. nov., S. furcata sp. nov. and $S$. australis can also only be separated by 424 molecular tools. We have thus provided evidence that in Stygocapitella morphology is very similar 425 across different species and that some species are even impossible to be identified based on 426 morphology alone. This calls into question whether these species can be called cryptic species or 427 not.

The most often applied definition of cryptic species requires that a given group of species has been recognized as single species before: "two or more distinct species that are erroneously classified (and hidden) under one species name" (Bickford et al., 2007). This definition places the focus in the taxonomic history of the cryptic species complex (Struck and Cerca, 2019). Strictly under this definition, from the 8 Stygocapitella species herein described (and the undescribed species), only seven could be considered cryptic species. These seven represent populations/sites which have been considered to be S. subterranea before in the literature (Karling, 1958; Knöllner, 1934; Purschke, 2006, 1999, 1987, 1986; Purschke et al., 2019; Purschke and Fursman, 2005; Purschke and Jördens, 2007; Riser, 1980; Schmidt and Westheide, 2000; Schmidt, 1972a, 1970, 1969; Struck et al., 2017; Westheide, 2008, 1966; Worsfold, 2008). The two only exceptions would be $S$. pacifica sp. nov. and $S$. budaevae sp. nov. which represent new records and have therefore never been identified as $S$. subterranea. This exposes the arbitrary nature of this definition, which has led some workers to argue that cryptic species are not a natural phenomenon, but rather artefacts of taxonomic practices such as, for instance, the lack or inappropriate resolution of morphological data to determine species boundaries (Korshunova et al., 2019, 2017).

It has been suggested that cryptic species should only be considered as a "temporary formalization of the problems with delineation of the species from the same geographic region, when those species demonstrate significant molecular phylogenetic differences, but are hardly distinguished morphologically, ethologically, etc.” (Korshunova et al. 2017). Given this definition, which considers cryptic species as a problem, not all Stygocapitella species could be considered cryptic species. For instance, S. westheidei sp. nov. and $S$. subterranea are morphologically indistinguishable but are present at different coastlines. Following this definition would not solve the "problem" of morphological similarity between these two species because they do not geographically overlap. Importantly, and despite the efforts herein included to determine morphological differences between species, most Stygocapitella species lack diagnostic characters and morphological differences which allow an unambiguous identification to the species level.

455 Indeed, only when using molecular data, one is able to distinguish these species. Even when 
length measurements are significantly different between species, a substantial overlap between

457 specimens often exists, which does not allow to unambiguously assign an individual to a species 458 and is prone to errors if juveniles get measured. This is evidenced from the PCA, which considers 459 all measurements simultaneously, yet species substantially overlap and are thus unable to be 460 identified. A second critical aspect of this definition is its reliance on sympatry and geography. As we discuss below, we find potential evidence for a recent trans-oceanic translocation by human activity. While we are able to distinguish species based on measurements, if translocated specimens would have been from $S$. subterranea and not $S$. josemariobrancoi sp. nov. it would not be possible to distinguish them from the putatively native species $S$. westheidei sp. nov. without molecular data. Considering its reliance on geography, this definition fails to detect introduced species, when these are morphologically indistinguishable and creates arbitrary challenges on whether species are sympatric or not. Finally, an implicit assumption of this definition is that substantial phenotypic differences will accumulate between species, given enough evolutionary time. This is not the case, as shown by the evidence for long-lasting stasis in palaeontology (Eldredge and Gould, 1972; Futuyma, 2010), as well as in cryptic species complexes (Lee and Frost, 2002; Struck et al., 2017; Swift et al., 2016; Wada et al., 2013). This is evident after contrasting the genetic differences of Stygocapitella with its morphological evolution, hence being in line with the hypothesis of cryptic species complexes under stasis, as enough time has passed to allow for the accumulation of phenotypic differences. Despite this, few or no phenotypic differences can be observed. Treating these cases just as a taxonomic problems would overlook the phenomenon of morphological stasis (Lee and Frost, 2002; Struck et al., 2017; Swift et al., 2016; Wada et al., 2013).

An entirely different approach to delimit and understand cryptic species consists in recognising these as the result of evolutionary phenomena resulting in the deceleration of morphological evolution (Struck et al., 2018a, b). Based on this approach, first, a regular species delineation process takes place. This delimitation-step should focus on detecting differences between putative species and include various sorts of data such as ecological, behaviour and morphological data, being as scrupulous as possible. In a second step, an assessment of the species' morphological similarity should be done. This second step allows evaluating whether the species complex is indeed comprised of cryptic species (i.e. species morphologically more similar than expected). To determine if a set of species are more similar than expected, workers should focus on obtaining the time of divergence of the species complex, and, when possible, compare it with a closely related taxon/taxa (i.e. outgroup). By separating the species-delimitation (step 1), 
the degree of morphological disparity, and on the time of divergence. This allows differentiating

491 between taxonomic artefacts and the deceleration of morphological evolution as seen in cryptic 492 species (Struck et al., 2018a). On the negative side, it requires an exhaustive understanding of the 493 species complex as well as meticulous sampling and knowledge of the study system (Korshunova 494 et al., 2019). While this might not be possible in every case, a scrupulous and meticulous approach is essential to define species, be it cryptic species or not. In Stygocapitella, as outlined above, only very little morphological differences can be observed despite pronounced genetic divergence. Treating these as mere taxonomic oddities would conceal a true biological phenomenon: morphological stasis (Struck et al., 2018a; Struck and Cerca, 2019; Swift et al., 2016; Wada et al., 2013). Recent estimates suggest that the evolution of the Stygocapitella genus has occurred in $>200$ million years and S. australis has been separated from S. subterranea for more than 80 million years (Struck et al., 2017). To put this into perspective, the whole radiation of mammals took place in less time. Orbiniidae, which is the sister family to Parergrodiliidae (which includes Stygocapitella), comprises 21 genera (Horton and Et. Al., 2019). This family has accumulated much more phenotypic differences in the same time than Stygocapitella. Therefore, Stygocapitella spp. are a textbook example of cryptic species.

\subsection{Delimiting cryptic species and biological diversity}

Six of the newly described Stygocapitella species were originally considered to be Stygocapitella subterranea, highlighting the necessity of proper species description in understanding marine biodiversity. The lack of taxonomic knowledge has consequences for marine conservation (Bernardo, 2011; Bickford et al., 2007; Costa and Carvalho, 2010; Schonrogge et al., 2002), biodiversity assessments (Appeltans et al., 2012; Hawksworth and Lücking, 2017; MeyerWachsmuth et al., 2014) and species distribution (Cerca et al., 2018). Ratios of 'crypticness' (i.e. proportion of cryptic species within described species) (Kon et al., 2007) seem to be high in the sea (Cerca et al., 2018; Knowlton, 1993). To name a few examples, 14 cryptic species in Brachionus plicatilis (Rotifera) (Suatoni et al., 2006), 10 cryptic species in Eumida sanguinea (phyllodocidan 516 polychaetes) (Nygren and Pleijel, 2011), and 25 in 4 described Terebellides polychaete species 517 (Nygren et al., 2018). These uncommonly high numbers result from issues related to the 518 obstacles in sampling, re-sampling and identifying marine species (Hellberg, 2009; Knowlton, 519 2000, 1993) which ultimately jeopardize the understanding of basic biology, such as species 520 distribution and life cycle. Cryptic species should be taken into account when protecting marine 521 biodiversity as these contribute to overlooked species richness (Pante et al., 2015). Yet, we must 522 point that we can only be led to speculate how much biological diversity is missed due to the 
occurrence of cryptic species, especially having in mind that we cannot yet determine the proportion of cryptic species which are only taxonomic artefacts (Korshunova et al., 2017; Struck et al., 2018b). Nonetheless, it is worth noticing that morphologically-based practices have failed to report this diversity. Estimations suggest that there might be ca. 9,000 - 36,000 cryptic species in the sea, comprising 3-12\% of marine biodiversity (Appeltans et al., 2012). The development of new tools, including recent genomic approaches which have contributed towards closing the gap between population genetics and phylogenetics, is likely to benefit and improve species delimitation, including the delimitation of cryptic species (Singhal et al., 2018; Struck et al., 2018a). For example, new demographic tools allow distinguishing the contribution of gene flow and incomplete lineage sorting. In the brittle star Ophioderma longicauda the modelling of relatively complex demographic scenarios led to the delimitation of cryptic species in the face of strong incomplete lineage sorting and past hybridization events (Weber et al., 2019).

\subsection{Implications of cryptic species to marine biogeography}

The splitting of Stygocapitella subterranea sensu lato, originally described as a cosmopolitan species, into nine species with reduced geographical distributions suggests that overlooking cryptic species tends to inflate the distribution of marine organisms (Knowlton, 1993; Struck et al., 2018a). The wide distribution of many marine species (Cerca et al., 2018; Johannesson, 1988), and the paradoxical distribution of species with non-pelagic and pelagic larvae (Hellberg, 2009) remains as one of the most puzzling observations in marine biology. The potential high number and influence of cryptic species with reduced distribution ranges provides a further step to solve these issues. The results herein found are in line with evidence from other meiofaunal taxa, which demonstrate that delimitated cryptic species often have geographically restricted distributions and the range of individual species is smaller than the originally described species (Cerca et al., 2018). For instance, in the rotifer Brachionus plicatilis, the discovery of 14 cryptic species led to the reduction of the distribution of the originally described species. While the originally described species was recognised as a cosmopolitan species, cryptic lineages demonstrate a rather localized distribution (Suatoni et al., 2006). Similarly, the gastropod Pontohedyle milaschewitchii had been reported in the Indian Ocean, Central Pacific, Western Pacific, Eastern Pacific, Western Atlantic, and Eastern Atlantic including the Mediterranean and Black Sea. The splitting and discovery of 6 cryptic species led to the circumscription of one species to the Western Atlantic, another to the Indian Ocean, Central Pacific, Western Pacific, another to the Central Pacific, one to the Eastern Pacific, another to the Mediterranean and Black Sea, and yet another to the Eastern Atlantic (Jörger et al., 2012). 
Despite the observed reduction of geographical distribution, Stygocapitella species still maintain wide distributions suggesting wide dispersal capacities. Species for which we obtained multiple specimens show no association between population structure and geography. For example, $S$. zecai sp. nov. is distributed from Northern Norway to Southern England and a $16 \mathrm{~S}$ haplotype is shared between specimens from Henningsvær and Lødingen (Northern Norway), Ardtoe (Western Scotland) and Cutty Sark (England) suggesting that no population structure occurs for about $\sim 400 \mathrm{~km}$ distance. Similarly, the two remaining species occurring in Europe $(S$. subterranea and S. josemariobrancoi sp. nov) have wide distributions ranging from Scotland to

564 Germany and France, with haplotypes occurring over long distances. Finally, S. westheidei sp. nov.

565 has only a single 16S haplotype along the entire North-western Atlantic coastline in the USA 566 spanning $\sim 450 \mathrm{~km}$ (but notice COI). These distributions are coherent with recent evidence from 567 meiofaunal nematodes (Derycke et al., 2008), nemerteans (Leasi and Norenburg, 2016, 2014), 568 xenacoelomorphans (Meyer-Wachsmuth et al., 2014) and molluscs (Jörger et al., 2012), even after 569 the discovery of cryptic species. Generally, the discovery of cryptic species in these groups led to 570 the reduction of the first assigned distribution, but these lineages still maintain wide distribution 571 ranges (Cerca et al., 2018).

The phylogeny of Stygocapitella displays a biogeographic signal related to oceanic water 573 bodies. All Northern Atlantic species form a monophyletic group in all analyses. Interestingly, $S$. westheidei sp. nov., which occurs at the North-western Atlantic (American coastline), is nested within the remaining North-eastern Atlantic species (European coastline), suggesting a relatively recent oceanic transition. The Northern Atlantic group is placed among species occurring in the Indo-Pacific Oceans. This indicates that a transition from the Indo-Pacific to the Atlantic has occurred only once. Most prominently, we find evidence for sister species occurring in opposite sides of the Northern Pacific Ocean, with S. furcata sp. nov. and S. pacifica sp. nov. as well as Stygocapitella spec. A and S. budaevae sp. nov. occurring in Northern America and Russia, respectively. This potentially reveals that the ancient lineage of each pair could transverse the Pacific Ocean, or speciated allopatrically following vicariance. Pacific ones, while S. minuta, from South Africa, is the first to branch off in the phylogenetic tree. This suggests that at least two equatorial transitions must have occurred in addition to the oceanic transitions in the Northern hemisphere. Two major hypotheses have been suggested to explain the distribution of meiofaunal groups. These include the strict vicariance hypothesis, which assumes that these organisms are poor dispersers, and the long-distance dispersal 
hypothesis. Evidence gathered from this work is congruent with a previous analysis (Struck et al.,

590 2017), which together suggest that a strict vicariance hypothesis does neither fit the observed

591 distribution pattern, neither the phylogeny of these meiofaunal organisms. We find evidence for

592 several events of long-distance dispersal (Westheide, 1991, 1977), which have an important role

593 in establishing new populations across oceans and spreading along coastlines (Derycke et al.,

594 2008; Schmidt and Westheide, 2000).

595

596

597

598

599

600

601

602

603

604

605

606

607

608

609

610

611

612

613

614

615

616

617

618

Two specimens collected in Lubec (Maine, USA) at the North-Western Atlantic coastline were identified as S. josemariobrancoi sp. nov. using molecular tools. This species is elsewhere only present along the Northern European coastline (Supplementary Figure 1). The specimens from Lubec share a 16S haplotype with specimens from England, France and Germany. This suggests a very recent dispersal event possibly due to trans-Atlantic trade. Even though we have no evidence to conclude that this translocation was human-based, this result is in line with evidence suggesting that meiofaunal specimens can be dispersed by ballast water or sand translocations (Radziejewska et al., 2006).

\section{Taxonomic account}

We did not take any formal taxonomic actions for Stygocapitella spec. A as we lack material for morphological studies and hence cannot assign type material for this species. We do not take any taxonomic actions on $S$. australis despite some analyses suggesting they are potentially different species. Describing both as separate species could entail that one of them would be non-monophyletic (see Fig. 2). More Western Australian data are needed to solve this issue. Records from New Zealand (Riser, 1984) should also to be taken into account by collection of fresh material for molecular analyses. Interspecific pairwise genetic distances between the species are found in Supplementary Table 5, intraspecific genetic distances are found in Supplementary Table 6. Described species have been registered in in Zoobank.org.

\section{Genus Stygocapitella Knöllner, 1934}

Type species Stygocapitella subterranea Knöllner, 1934 (sensu stricto)

Stygocapitella subterranea (Karling, 1958; Knöllner, 1934; Purschke, 2006, 1999, 1987, 1986; Purschke et al., 2019; Purschke and Fursman, 2005; Purschke and Jördens, 2007; Schmidt and Westheide, 2000; Schmidt, 1969, 1970; Struck et al., 2017; Westheide, 2008, 1966)

Types and material examined. See Struck et al. (2017). 
Description. See Struck et al. (2017) except for size:bbody length: mean $1703.7 \mu \mathrm{m}$ (range 2441.8- $1099.2 \mu \mathrm{m})$ and width $185.8 \mu \mathrm{m}(285.8-121.3 \mu \mathrm{m})$; prostomium length $62.4 \mu \mathrm{m}$ $622(90-33.1 \mu \mathrm{m})$ and width $117 \mu \mathrm{m} 167.8-82.6 \mu \mathrm{m})$; pygidium length $45.6 \mu \mathrm{m}(64.7-33.9 \mu \mathrm{m})$ and 623 width $86.6 \mu \mathrm{m}(160.3-54.1 \mu \mathrm{m})$ (Fig. 6).

Habitat. See Struck et al. (2017).

Distribution. Restricted to the North-eastern Atlantic comprising the North Sea (British \& German coast), the Baltic Sea (German \& Southern Swedish coast), and the Eastern Atlantic Ocean (British \& French coast; Suppl. Fig 1, Suppl. Table 1).

Remarks. The records from the Mediterranean Sea (French \& Tunisian coast), the Black Sea (Romanian coast) and New Zealand in the Southern hemisphere have also been assigned to

$630 S$ subterranea before, but given the results herein it is uncertain whether these records belong to $S$. subterranea, S. josemariobrancoi sp. nov., S. westheidei sp. nov. or $S$. australis or even constitute new species. Therefore, these records should be considered as Stygocapitella sp. for the time being.

\section{Stygocapitella pacifica sp. nov.}

'Types and material examined. Holotype: Volchanets, Russia, N $42^{\circ} 54^{\prime} 37.7^{\prime \prime} / \mathrm{E}$ $132^{\circ} 44^{\prime} 25.0^{\prime \prime}, 5.5 \mathrm{~m}$ above high-water line at a depth of 0-15 cm, Coll. Natural History Museum of the University of Oslo (NHMO C6996). Additional material: 1 paratype from Volchanets, Russia, N 42 $54^{\prime} 37.7^{\prime \prime} / \mathrm{E} 132^{\circ} 44^{\prime} 25.0^{\prime \prime}, 5.5 \mathrm{~m}$ above high-water line at a depth of 0-15 centimetres, Coll. Natural History Museum of the University of Oslo (NHMO C69967).

Diagnosis. Morphology: The first chaetiger possesses two bilimbate chaetae with a whiplike extension, one bilimbate and two forked chaetae, and all following ones two bilimbate and two forked chaetae. For genetic data see Genbank ID MN158611 (COI), MN164341 (16S).

Description. Color: White-transparent with a slightly iridescence surface. Size: body 644 length: mean $1261.5 \mu \mathrm{m}$ (range 1298.4 - $1224.6 \mu \mathrm{m}$ ) and width $137.5 \mu \mathrm{m}(141.1-133.9 \mu \mathrm{m})$; prostomium length $56 \mu \mathrm{m}(62.9-49.2 \mu \mathrm{m})$ and width $87.1 \mu \mathrm{m}(92.7-81.5 \mu \mathrm{m})$; pygidium length $34.3 \mu \mathrm{m}(38.7-29.8 \mu \mathrm{m})$ and width $58.5 \mu \mathrm{m}(58.9-58.1 \mu \mathrm{m})$ (Fig. 6). The body comprises a 
648 round pygidium. $1^{\text {st }}$ to $12^{\text {th }}$ segment biannulated. Chaetae in pairs of ventrolateral bundles are 649 present at segments 2 to 11 in the first ring of each segment. First chaetiger with two bilimbate 650 chaetae with whip-like extensions, two forked chaetae and one bilimbate chaeta in each bundle. 651 All following chaetigers possess two bilimbate and two forked chaetae in each bundle.

652 Habitat: We found specimens at a beach with medium-sized sand grains at or above the 653 high water level down to a depth of $20 \mathrm{~cm}$.

654 Distribution: Volchanets (Primorsky Krai region, Russia)

655 Etymology. The species name derives from presence in the Pacific Ocean.

\section{Stygocapitella furcata sp. nov.} Westheide, 2000; Struck et al., 2017; Westheide, 2008), not Köllner 1934. W $123^{\circ} 00^{\prime} 10.7^{\prime \prime}$, between $5 \mathrm{~m}$ above high-water line and the high-water line, at a depth of 0-15 cm, Coll. Natural History Museum of the University of Oslo (NHMO C7010). Additional material: 1 paratype from Roche Harbor, USA (WA), N 48 35' 46.0" / W $123^{\circ} 10^{\prime} 12.03 \mathrm{~m}$ above high-water line, at a depth of 0-20 centimetres. Coll. Natural History Museum of the

664 University of Oslo (NHMO C7009). Besides the holotype and paratype, two specimens for 665 molecular work have been examined. MN158612 (COI), MN164343 (16S).

Description. Color: White-transparent with a slightly iridescence surface. The body comprises a prostomium without appendages, a peristomium bearing the mouth opening, 13 segments and a round pygidium. $1^{\text {st }}$ to $12^{\text {th }}$ segment biannulated. Chaetae in pairs of ventrolateral

672 bundles are present at segments 2 to 11 in the first ring of each segment. First chaetiger with two 673 bilimbate chaetae with whip-like extensions, two forked chaetae and one bilimbate chaeta in each 674 bundle. All following chaetigers possess two bilimbate and two forked chaetae in each bundle. 675 No measurements were obtained for this species. 
Habitat. Specimens predominantly occur at beaches with medium-sized sand grains at or 677 above the higher water level up.

678

679

680

681

682

683

684

685

686

687

688

689

690

691

692

693

694

695

696

697

698

699

700

701

702

703

704

705

Distribution. San Juan Island (WA, USA). If the additional records from the NorthEastern Pacific along the US and Canadian Pacific coast (Purschke, 2006, 1999; Purschke et al., 2019; Schmidt and Westheide, 2000; Westheide, 2008) belong to this species, S. berniei sp. nov., or S. americae sp. nov. or constitute new species altogether is uncertain. Therefore, these records should be considered as Stygocapitella sp. for the time being.

Etymology. The species name reflects its having forked chaetae.

\section{Stygocapitella berniei sp. nov.}

Stygocapitella subterranea partim (Purschke, 2006, 1999; Purschke et al., 2019; Schmidt and Westheide, 2000; Struck et al., 2017; Westheide, 2008), not Köllner 1934.

Types and material examined. Holotype: Roche Harbor, USA (WA), N 48 35' 46.0" / W $123^{\circ} 10^{\prime} 12.0^{\prime \prime}$, between $3 \mathrm{~m}$ above high-water line and the high-water line, at a depth of 0 20 centimetres, Coll. Natural History Museum of the University of Oslo (NHMO C6994). Aditional material: 1 paratype Roche Harbor, USA (WA), N 48 35' 46.0" / W $123^{\circ} 10^{\prime} 12.0^{\prime \prime}$, between $3 \mathrm{~m}$ above high-water line and the high-water line, at a depth of 0-20 centimetres, Coll. Natural History Museum of the University of Oslo (NHMO C6995). Besides the holotype and the paratype, 10 specimens for molecular work and two for SEM have examined.

Type locality. Roche Harbor, USA (WA), N $48^{\circ} 35^{\prime} 46.0^{\prime \prime}$ / W $123^{\circ} 10^{\prime} 12.0^{\prime \prime}$

Diagnosis. Morphology: The first chaetigerous segment possesses two bilimbate chaetae with a whip-like extension, two bilimbate and two forked chaetae. The second segment possesses two bilimbate, followed by two forked, followed by two bilimbate chaetae. The third and remaining segments have two bilimbate and two forked chaetae organized in a bilimbate-forkedforked-bilimbate arrangement. For genetic data please see genbank IDs MN158602 (COI), MN164081 (16S).

Description. Color: White-transparent with a slightly iridescence surface. Size: body length: mean $1926.3 \mu \mathrm{m}$ (range 2552.8 - $1680.1 \mu \mathrm{m}$ ) and width $217.5 \mu \mathrm{m}(273.7$ - $203.63 \mu \mathrm{m})$; prostomium length $67.7 \mu \mathrm{m}(95.5-42.9 \mu \mathrm{m})$ and width $132.7 \mu \mathrm{m}(182.2-86.7 \mu \mathrm{m})$; pygidium length $52.6 \mu \mathrm{m}(70.9-48 \mu \mathrm{m})$ and width $112.3 \mu \mathrm{m}(145.8-95.9 \mu \mathrm{m})$ (Fig. 6). The body comprises a prostomium without appendages, a peristomium bearing the mouth opening, 13 
segments and a round pygidium. $1^{\text {st }}$ to $12^{\text {th }}$ segment biannulated. Chaetae in pairs of ventrolateral

707 bundles are present at segments 2 to 11 in the first ring of each segment. First chaetiger with two 708 bilimbate chaetae with whip-like extensions, two forked chaetae and two bilimbate chaeta in each 709 bundle. All following chaetigers possess two bilimbate and two forked chaetae in each bundle, except for the second one with four bilimbate chaetae.

Habitat. Specimens predominantly occur at beaches with medium-sized sand grains at or above the high-water line.

Distribution. San Juan Island (WA, USA). If the additional records from the NorthEastern Pacific along the US and Canadian Pacific coast (Purschke, 2006, 1999; Purschke et al., 2019; Schmidt and Westheide, 2000; Westheide, 2008) belong to S. furcata sp. nov., or S. americae sp. nov. or constitute new species altogether is uncertain. Therefore, these records should be considered as Stygocapitella sp. for the time being.

Etymology. The species name reflects upon field collection. The field collection site is in a private property, and while collecting, the caretaker of the property mentioned we could collect sand as long as we would support a progressive such as Bernie Sanders. The species honours Bernie Sanders for his efforts of inclusiveness, diversity and protection of minorities and underrepresented groups.

\section{Stygocapitella americae sp. nov.} Westheide, 2000; Struck et al., 2017; Westheide, 2008), not Köllner 1934. 28' 05.6" / W $123^{\circ} 00^{\prime} 10.7^{\prime \prime}$, between $5 \mathrm{~m}$ above high-water line and the high-water line, at a depth of 0-15 centimetres Coll. Natural History Museum of the University of Oslo (NHMO C6992). Additional material: 1 paratype from Reuben Tarte State Park, USA (WA), N $48^{\circ} 28^{\prime}$ 05.6" / W $123^{\circ} 00^{\prime} 10.7^{\prime \prime}$, between $5 \mathrm{~m}$ above high-water line and the high-water line, at a depth of 0-15 centimetres. Coll. Natural History Museum of the University of Oslo (NHMO C6993).

732 Besides the holotype and the paratype, 14 specimens for molecular work and two for SEM have 733 examined. 
Diagnosis. For morphology see $S$. berniei sp. nov.. For genetic data see Genbank ID: MN158590 (COI); MN164069 (16S).

Description. Color: White-transparent with a slightly iridescence surface. Size: body

738

739

740

741

742

743

744

745

746

747

748

749

750

751

752

753

754

755

756

757

758

759

760 length: mean $2007 \mu \mathrm{m}$ (range 2552.8 - $1342.9 \mu \mathrm{m}$ ) and width $227.6 \mu \mathrm{m}(273.7$ - $166.7 \mu \mathrm{m})$; prostomium length $69.9 \mu \mathrm{m}(95.5-42.9 \mu \mathrm{m})$ and width $138 \mu \mathrm{m}(182.2-86.7 \mu \mathrm{m})$; pygidium length $53.5 \mu \mathrm{m}(70.9-39.4 \mu \mathrm{m})$ and width $116.5 \mu \mathrm{m}(145.8-74.9 \mu \mathrm{m})$ (Fig. 6). The body comprises a prostomium without appendages, a peristomium bearing the mouth opening, 13 segments and a round pygidium. $1^{\text {st }}$ to $12^{\text {th }}$ segment biannulated. Chaetae in pairs of ventrolateral bundles are present at segments 2 to 11 in the first ring of each segment. First chaetiger with two bilimbate chaetae with whip-like extensions, two forked chaetae and two bilimbate chaeta in each bundle. All following chaetigers possess two bilimbate and two forked chaetae in each bundle, except for the second one with four bilimbate chaetae.

Habitat. Specimens predominantly occur at beaches with medium-sized sand grains at or above the high-water line.

Distribution: San Juan Island (WA, USA). If the additional records from the NorthEastern Pacific along the US and Canadian Pacific coast (Purschke, 2006, 1999; Purschke et al., 2019; Schmidt and Westheide, 2000; Westheide, 2008) belong to this species, S. furcata sp. nov., or S. berniei sp. nov. or constitute new species altogether is uncertain. Therefore, these records should be considered as Stygocapitella sp. for the time being.

Etymology. The species name follows the American continent, where it was collected.

Stygocapitella budaevae sp. nov.

Types and material examined. Holotype: Volchanets, Russia, N $42^{\circ} 54^{\prime} 37.7^{\prime \prime} / \mathrm{E}$ $132^{\circ} 44^{\prime} 25.0^{\prime \prime}, 4.0 \mathrm{~m}$ above high-water line at a depth of 15-30 centimetres, Coll. Natural History Museum of the University of Oslo (NHMO C6990). Additional material: 1 paratype Volchanets, Russia, N 42 $54^{\prime} 37.7^{\prime \prime}$ / E $132^{\circ} 44^{\prime} 25.0^{\prime \prime}, 4.0 \mathrm{~m}$ above high-water line at a depth of 0-15 centimetres. Coll. Natural History Museum of the University of Oslo (NHMO C6991). Besides the holotype and paratype, 18 specimens for molecular work and two for SEM have examined.

Type locality. Volchanets, Russia, N 42 54' $37.7^{\prime \prime}$ / E $132^{\circ} 44^{\prime} 25.0^{\prime \prime}$

Diagnosis: For morphology see S. berniei sp. nov. For genetic data check genbank Ids MN158380 (COI), MN164048 (16S) 
Description. Color: White-transparent with a slightly iridescence surface. Size: body 766 length: mean $1368.5 \mu \mathrm{m}$ (range 1655 - $1141 \mu \mathrm{m}$ ) and width $152.2 \mu \mathrm{m}$ (167.7 - $131.5 \mu \mathrm{m}$ ); 767 prostomium length $55 \mu \mathrm{m}(62.1-46.8 \mu \mathrm{m})$ and width $92 \mu \mathrm{m}(97.6-87.9 \mu \mathrm{m})$; pygidium length $76842.4 \mu \mathrm{m}(62.9-28.2 \mu \mathrm{m})$ and width $61.1 \mu \mathrm{m}(76.6-45.2 \mu \mathrm{m})$ (Fig. 6). The body comprises a prostomium without appendages, a peristomium bearing the mouth opening, 13 segments and a round pygidium. $1^{\text {st }}$ to $12^{\text {th }}$ segment biannulated. Chaetae in pairs of ventrolateral bundles are present at segments 2 to 11 in the first ring of each segment. First chaetiger with two bilimbate chaetae with whip-like extensions, two forked chaetae and two bilimbate chaeta in each bundle. All following chaetigers possess two bilimbate and two forked chaetae in each bundle, except for the second one with four bilimbate chaetae.

Habitat: Specimens occurred at a beach with medium-sized sand grains at or above the higher water level up to a depth of $20 \mathrm{~cm}$.

Distribution. Volchanets (Primorsky Krai region, Russia)

Etymology. The species name honours the Russian polychaete biologist Nataliya Budaeva for her contributions to Annelid systematics.

\section{Stygocapitella zecai sp. nov.}

Stygocapitella subterranea partim (Purschke, 2006, 1999; Purschke et al., 2019; Schmidt, 1972b, 1970, 1969; Struck et al., 2017; Westheide, 2008; Worsfold, 2008), not Köllner 1934.

Types and material examined. Holotype: Henningsvær, Norway, 68¹5'38.8"N $14^{\circ} 16^{\prime} 06.1^{\prime \prime E}$ between high-water line and $6 \mathrm{~m}$ above the high-water line, at a depth of 0-15 centimetres Coll. Natural History Museum of the University of Oslo (NHMO C6988). Additional

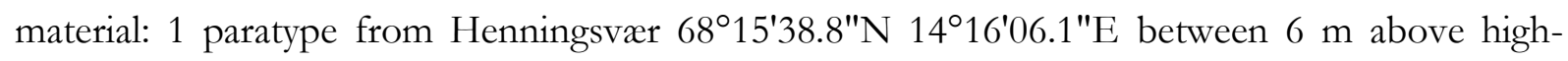
water line and high-water line, at a depth of 0-15 centimetres. Coll. Natural History Museum of the University of Oslo (NHMO C6989). Besides the holotype and paratype, 47 specimens for molecular work and two for SEM have examined.

Type locality. Henningsvær, Norway, 68²15'38.8"N 14¹6'06.1"E

Diagnosis. For morphology see S. berniei sp. nov.. For genetic data please see Genbank ID MN164099 (16S). 
Description. Color: White-transparent with a slightly iridescence surface. Size: body 794 length: mean $2238.2 \mu \mathrm{m}$ (range 2573.3 - $1514.3 \mu \mathrm{m}$ ) and width $236.6 \mu \mathrm{m}(295.5-170.5 \mu \mathrm{m})$; 795 prostomium length $63.1 \mu \mathrm{m}(85.3-44.3 \mu \mathrm{m})$ and width $117.8 \mu \mathrm{m}(147.9-96.7 \mu \mathrm{m})$; pygidium 796 length $61.2 \mu \mathrm{m}(100.8-45.9 \mu \mathrm{m})$ and width $101.4 \mu \mathrm{m}(126-69.7 \mu \mathrm{m})$ (Fig. 6). The body 797 comprises a prostomium without appendages, a peristomium bearing the mouth opening, 13 segments and a round pygidium. $1^{\text {st }}$ to $12^{\text {th }}$ segment biannulated. Chaetae in pairs of ventrolateral bundles are present at segments 2 to 11 in the first ring of each segment. First chaetiger with two bilimbate chaetae with whip-like extensions, two forked chaetae and two bilimbate chaeta in each bundle. All following chaetigers possess two bilimbate and two forked chaetae in each bundle, except for the second one with four bilimbate chaetae. above the high-water line. Especially at beaches with low tidal exposure. Northern and North Seas (Scandinavian, British \& German coast) (Supplementary Fig. 1). freedom fighter whose songs inspired generations. The name honors him.

\section{Stygocapitella josematiobrancoi sp. nov.} 1969; Struck et al., 2017; Westheide, 2008, 1966; Worsfold, 2008), not Köllner 1934. 815 Plymouth Bay, between high-water line and one meter above, at a depth of 0-15 centimetres, $81650^{\circ} 20^{\prime} 55.0^{\prime \prime} \mathrm{N} 4^{\circ} 12^{\prime} 02.6^{\prime \prime W}$. Coll. Natural History Museum of the University of Oslo (NHMO 817 C6987). Besides the holotype, paratype and mature additional material 97 specimens for 818 molecular work and two for SEM have examined. 
823 length: mean $2409.7 \mu \mathrm{m}$ (range 3751.9 - $1317 \mu \mathrm{m}$ ) and width $257.8 \mu \mathrm{m} 423.7$ - $159.6 \mu \mathrm{m}$ ); 824 prostomium length $84.5 \mu \mathrm{m}(153.3-48 \mu \mathrm{m})$ and width $157.7 \mu \mathrm{m}(222.1-104.5 \mu \mathrm{m})$; pygidium 825 length $61.5 \mu \mathrm{m}(160.3-39.1 \mu \mathrm{m})$ and width $127.6 \mu \mathrm{m}(163.4-97.4 \mu \mathrm{m})$ (Fig. 6). The body

826

827 comprises a prostomium without appendages, a peristomium bearing the mouth opening, 13 segments and a round pygidium. $1^{\text {st }}$ to $12^{\text {th }}$ segment biannulated. Chaetae in pairs of ventrolateral bundles are present at segments 2 to 11 in the first ring of each segment. First chaetiger with two bilimbate chaetae with whip-like extensions, two forked chaetae and two bilimbate chaeta in each bundle. The second chaetiger with three bilimbate and two forked chaetae and all following ones with two bilimbate and two forked.

Habitat. Specimens predominantly occur at beaches with medium-sized sand grains at or above the high-water line. Especially at beaches with low tidal exposure.

Distribution. The distribution is predominantly in the North Sea (British \& German coast) and the Channel (British \& French coast) (Supplementary Fig. 1). Two individuals were also found in Lubec (ME, USA).

Etymology. The name honors José Mário Branco, an important Portuguese singer whose music inspired whole generations. JC was hearing his music in the field.

\section{Stygocapitella westheidei sp. nov.}

Stygocapitella subterranea partim, (Purschke, 2006, 1999; Purschke et al., 2019; Riser, 1980; Schmidt and Westheide, 2000; Struck et al., 2017; Westheide, 2008) not Köllner 1934.

Types and material examined. Holotype: Canoe beach, 42²5'10.6"N 7054'24.6"W between 5 and $7 \mathrm{~m}$ above high-water line in a depth of 0-30 cm, Coll. Natural History Museum of the University of Oslo (NHMO C6984). Additional material: 1 paratype Canoe beach, $42^{\circ} 25^{\prime} 10.6^{\prime \prime} \mathrm{N} 70^{\circ} 54^{\prime} 24.6^{\prime \prime} \mathrm{W}$ between 5 and $7 \mathrm{~m}$ above high-water line in a depth of $0-30 \mathrm{~cm}$. Coll. Natural History Museum of the University of Oslo (NHMO C 6985). Besides the holotype, and paratype, 36 specimens for molecular work and two for SEM have examined.

Type locality. Canoe beach, $42^{\circ} 25^{\prime} 10.6^{\prime \prime} \mathrm{N} 70^{\circ} 54^{\prime} 24.6^{\prime \prime} \mathrm{W}$

Diagnosis. For morphology see S. subterranea. For genetic data see Genbank IDs MN158481 (COI) and MN164233 (16S) 
Description. Color: White-transparent with a slightly iridescence surface. Size: body 852 length: mean $1820.2 \mu \mathrm{m}$ (range 2299- $1521.3 \mu \mathrm{m}$ ) and width $188.5 \mu \mathrm{m}(237.2-147.4 \mu \mathrm{m})$; 853 prostomium length $63.8 \mu \mathrm{m}(73.4-49.2 \mu \mathrm{m})$ and width $127.6 \mu \mathrm{m}(168.3-105.9 \mu \mathrm{m})$; pygidium 854 length $48.6 \mu \mathrm{m}(59.3$ - $34.9 \mu \mathrm{m})$ and width $94.5 \mu \mathrm{m}(121.9$ - $72.2 \mu \mathrm{m})$ (Fig. 6). The body 855 comprises a prostomium without appendages, a peristomium bearing the mouth opening, 13 segments and a round pygidium. $1^{\text {st }}$ to $12^{\text {th }}$ segment biannulated. Chaetae in pairs of ventrolateral bundles are present at segments 2 to 11 in the first ring of each segment. First chaetiger with two bilimbate chaetae with whip-like extensions, two forked chaetae and two bilimbate chaeta in each bundle. The second chaetiger with three bilimbate and two forked chaetae and all following ones with two bilimbate and two forked. above the high-water line. Especially at beaches with low tidal exposure. (Supplementary Fig. 1).

Etymology. The species name honours the polychaete biologist and invertebrate specialist Wilfried Westheide for his numerous contributions to systematics of interstitial polychaetes, the cryptic species problem and invertebrate systematics, and also for his mentorship.

\section{Acknowledgments}

JC is grateful to Gustav Paulay, Claudia E. Mills, Bernadette Holthuis and Tim Miller for field site suggestions in the USA. JC is thankful to Tim Worsfold, Andy Mackie, Henning Reiss,

872 Lis Jørgensen for laboratory space in the UK and Norway. JC and THS are grateful to Vasily

873 Radashevsky for hosting us in Russia, and to Nataliya Budaeva for support in obtaining Russian

874 VISAs and funding. JC was partly funded by the Ragen Award from Friday Harbor Laboratories, 875 a Den Grevelige Hjelmstjerne-Rosencroneske Stiftelse ved UiOslo. Funding from FORBIO 876 Research school in biosystematics (JC) was seminal to obtain photographs as part of a visit to 877 Osnabrück. Funding from the ASSEMBLE project, an EU FP7 research infrastructure initiative, 878 funded the collecting trip to Scotland (THS). JC and THS were partly supported by the SIU879 funded MEDUSA project (Multidisciplinary EDUcation and reSearch in mArine biology in 880 Norway and Russia). We acknowledge the use of the Norwegian national e-infrastructure for 881 high-performance computing and storage via the projects NN9408K and NS9408K, respectively. 
882 The authors would like to thank two anonymous reviewers for their comments which have

883 substantially improved a previous version of this manuscript. the This is NHM Evolutionary 884 Genomics lab contribution nr XX.

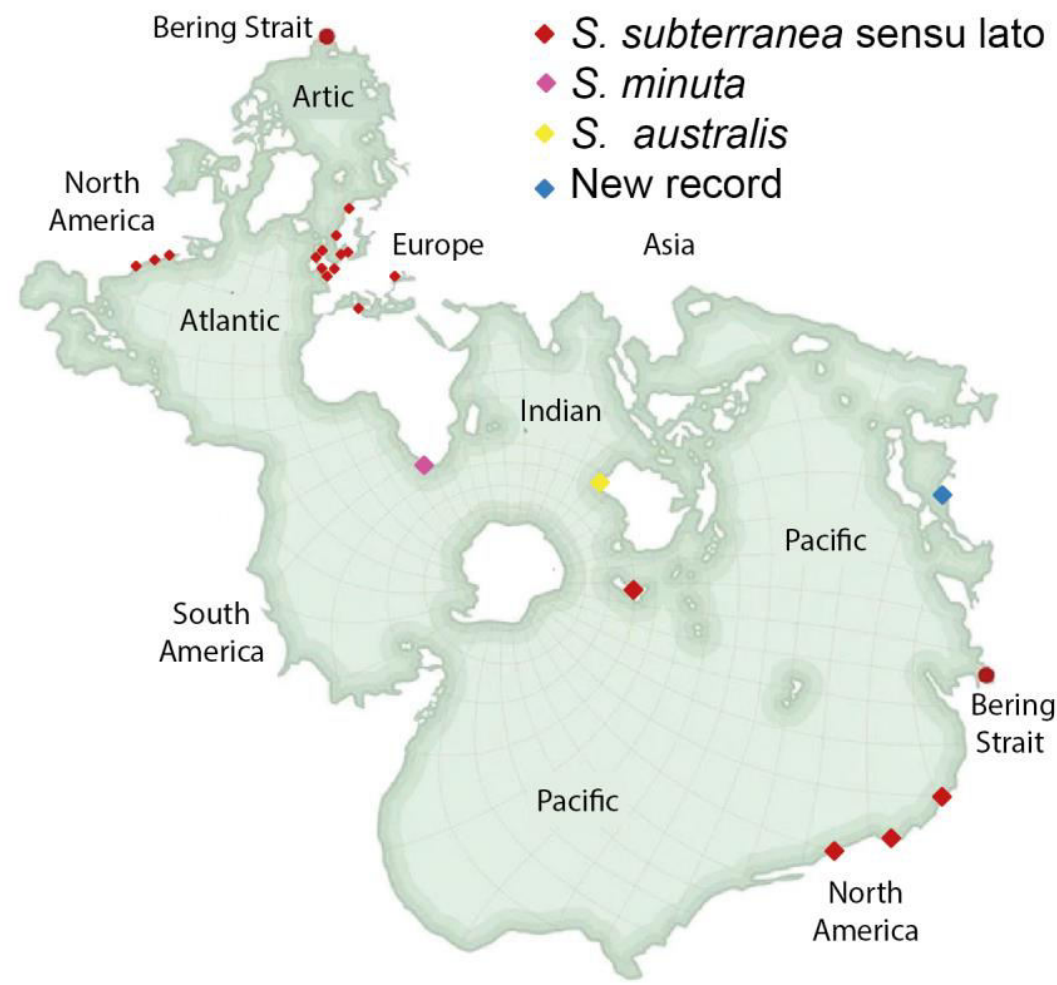

Figure 1: Stygocapitella records considered to date. Stygocapitella subterranea (red diamond; 888 sensu lato) has been recognised as a cosmopolitan species, S. minuta (purple diamond) is found in 889 South Africa and S. australis (yellow diamond) in Australia. As part of this work we report 890 Stygocapitella occurring in Volchanets (Far-east Russia; blue diamond). 


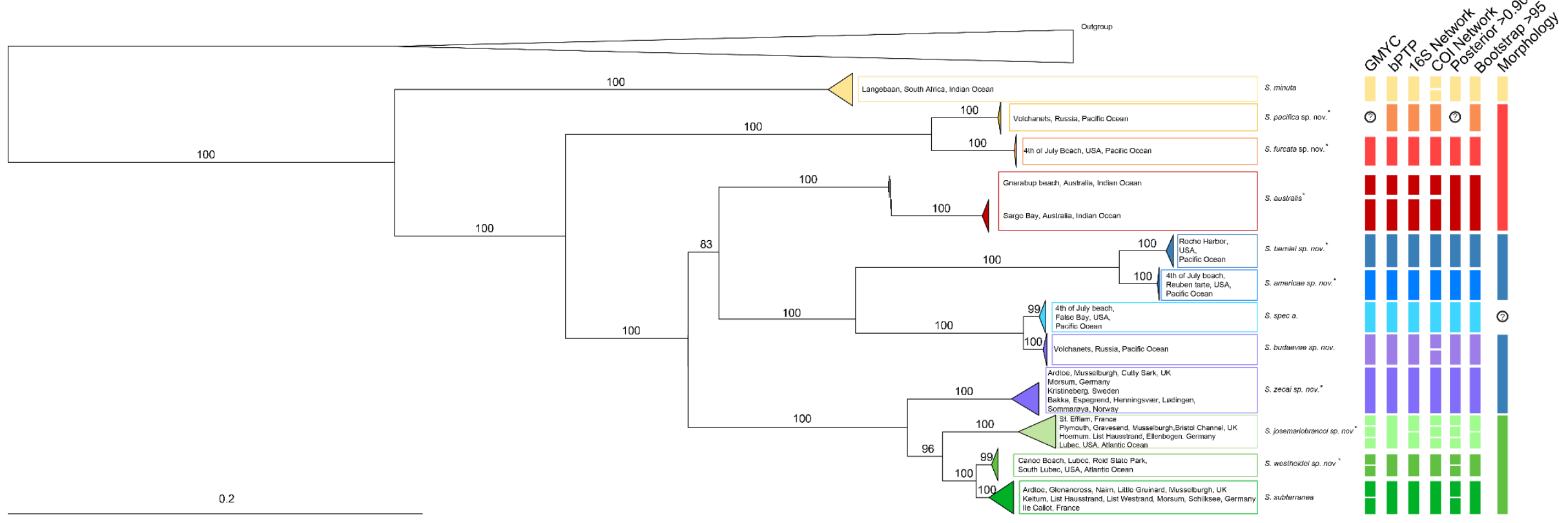

Figure 2: Maximum likelihood phylogeny and species delimitation approach. Phylogenetic tree was obtained using a concatenated-partitioned dataset including COI, 16S, 18S and ITS1. Bootstrap support is included above each branch. Sampling locations, as well as species names are included after each edge. Species delimitation analysis include several approaches: Generalized Mixed Yule Coalescent Approach (GMYC; after a Bayesian tree of the concatenated COI and 18S dataset), bPTP (Bayesian Poisson Tree Processes; of the ML tree using the concatenated 18S, COI, 16S and ITS1 dataset), 16S network using a 95\% cut-off, COI network using a 95\% cut-off, posterior probabilities of $>0.90$, bootstrap support $>95$ and morphology. Question marks highlight cases where models did not run. In specific, because we had only one specimen for the final Bayesian analysis, we were unable to obtain posterior probabilities and to run GMYC (question mark in GMYC and posterior columns). The question mark in the morphology column indicates the species in which we were unable to obtain morphological data (SEM photographs). The scale bar shows substitutions per site. Species followed by an asterisk (*) represent species which were previously considered as Stygocapitella subterranea (sensu lacto). 


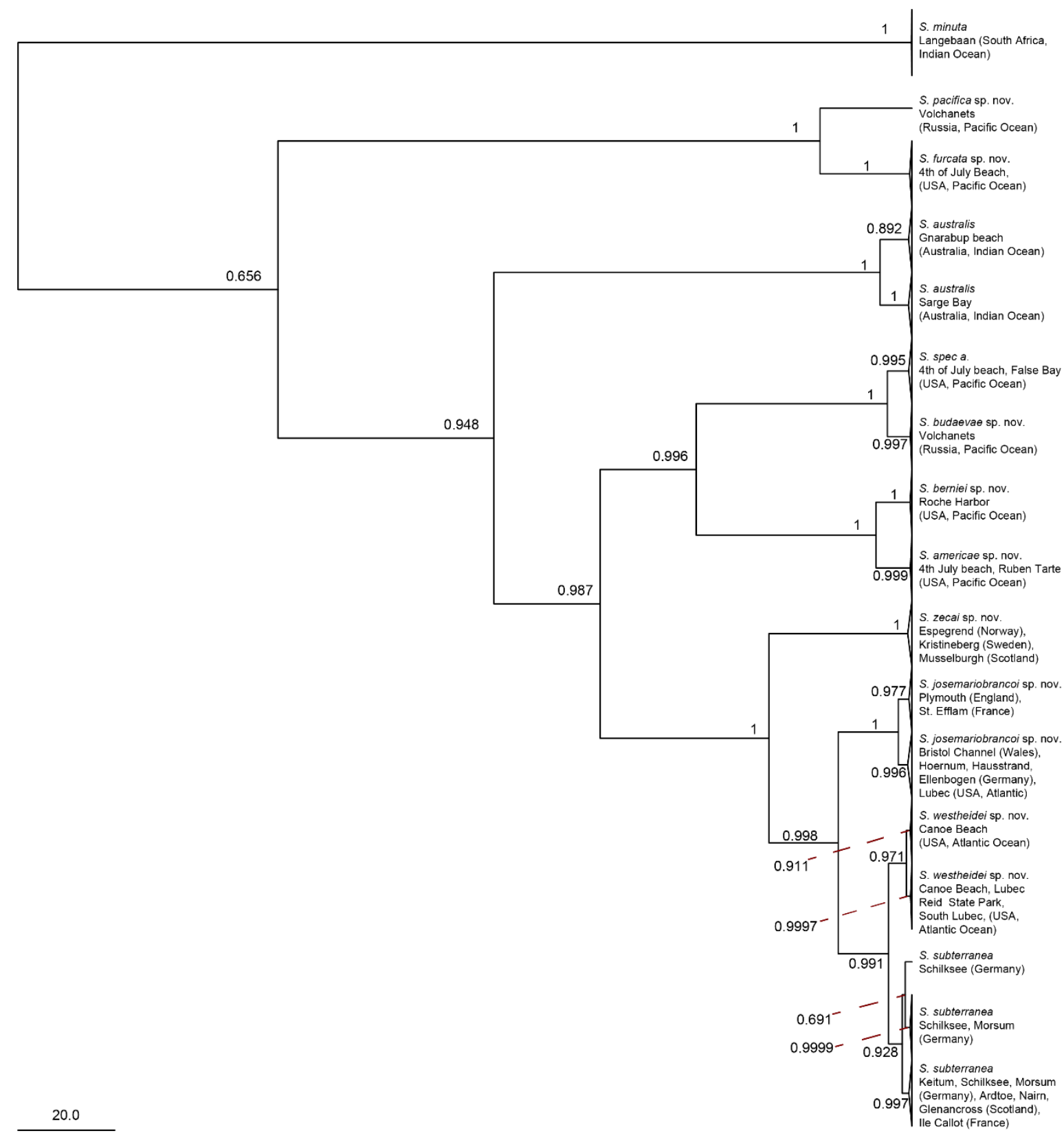

$903 \quad$ Figure 3: Bayesian phylogenetic tree based on concatenated $18 \mathrm{~S}$ and COI. Posterior 904 probability is displayed at each branch. Species names and sampling locations are displayed on 905 the species edges. 


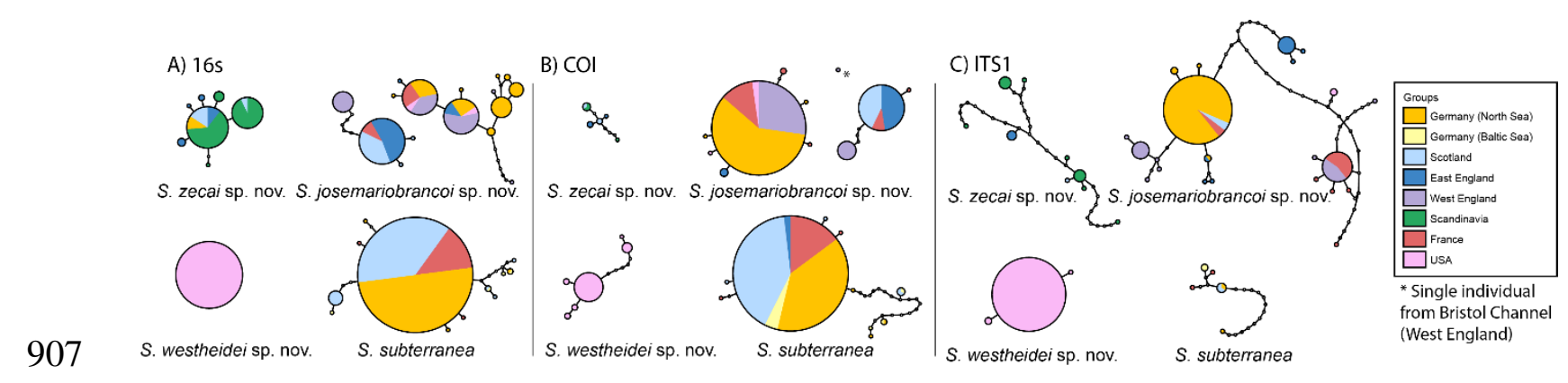

908 Figure 4: Haplotype networks. 16S (A), COI (B), ITS1 (C) based haplotype network of 909 the species present in the Atlantic Ocean (S. zecai sp. nov., S. subterranea, S. westheidei sp. nov., S. 910 josemariobrancoi). Haplotype sp. nov. networks are colored based on countries and regions. 


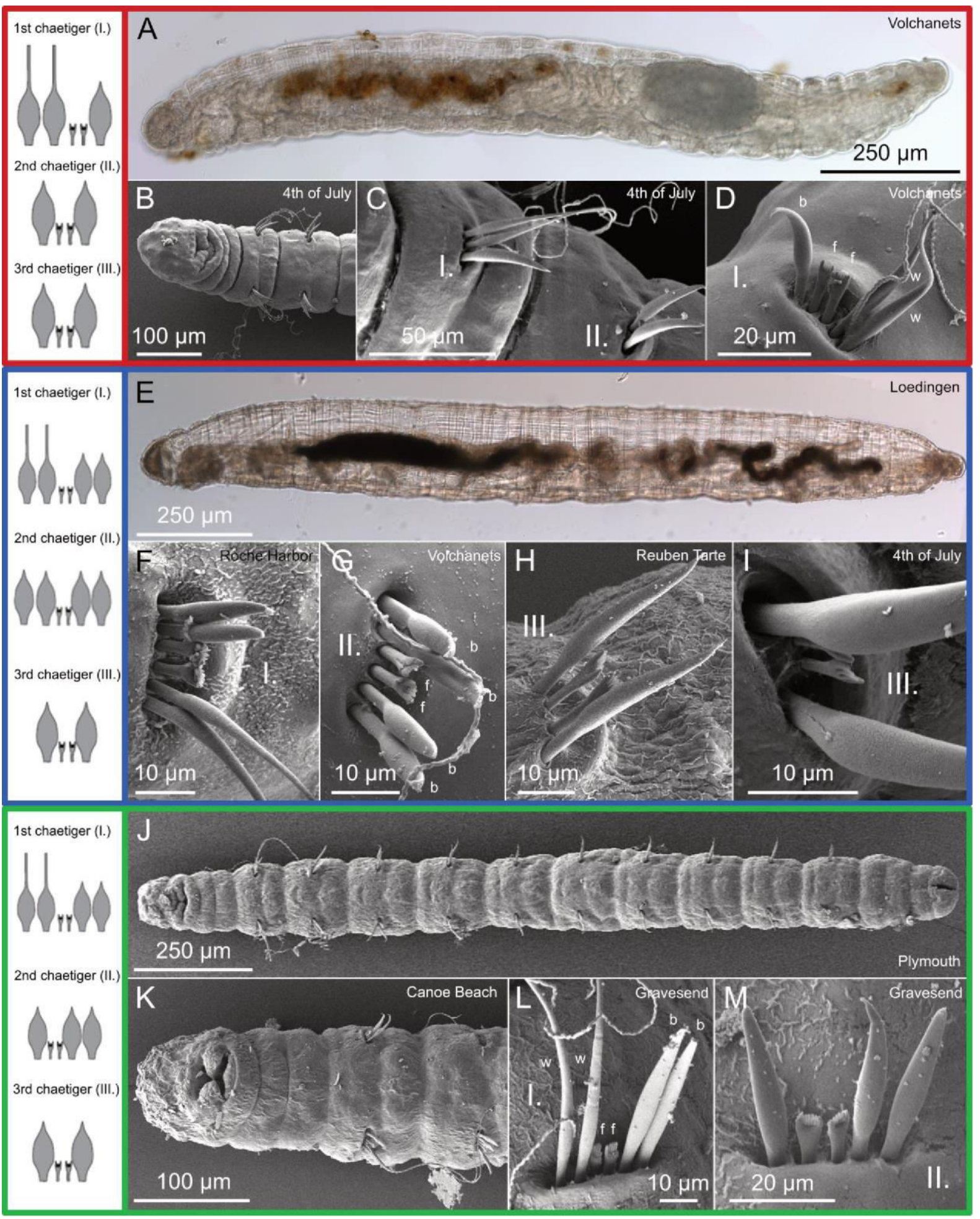

Figure 5: Scanning electron microscopy and light microscopy images of Stygocapitella.

914 Three morphotypes are represented in red, blue and green boxes (for species delimitation see also

915 Figure 2). A) Light microscopy photograph of S. pacifica sp. nov. from Volchanets. B \& C) SEM

916 images of S. furcata sp. nov. from 4th of July Beach with first (I.) and second (II.) chaetae bearing

917 chaetiger. D) 1 st chaetiger of $S$. pacifica sp. nov. with 2 whip-like (w), two forked (f) and 1

918 bilimbate (b) chaetae. E) Light microscopy photograph of S. zecai sp. nov. from Lødingen. F) 1st 
919 chaetiger of $S$. berniei sp. nov. from Roche Harbor with 2 whip-like, 2 forked and 2 bilimbate 920 chaetae. G) 2nd chaetiger of $S$. budaevae sp. nov. from Volchanets with 2 bilimbate (b), 2 forked 921 (f) and 2 bilimbate (b) chaetae. H) 3rd chaetiger of S. americae sp. nov. from Reuben Tarte. I) 3rd 922 chaetiger of Stygocapitella from 4th of July Beach. J) SEM images of whole S. josemariobrancoi sp. 923 nov. from Plymouth. K) Anterior end of S. westheidei sp. nov. from Canoe Beach. L \& M) First 924 two chaetigers of $S$. josemariobrancoi sp. nov. from Gravesend. 1st chaetiger with 2 whip-like (w), 2 925 forked (f) and 2 bilimbate (b) chaetae. 2nd chaetiger with 1 bilimbate (b), two forked (f) and 2 926 bilimbate (b) chaetae. 
A)

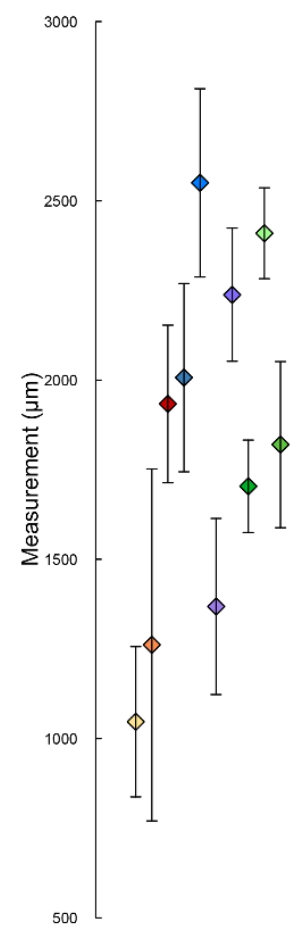

Body Length
B)

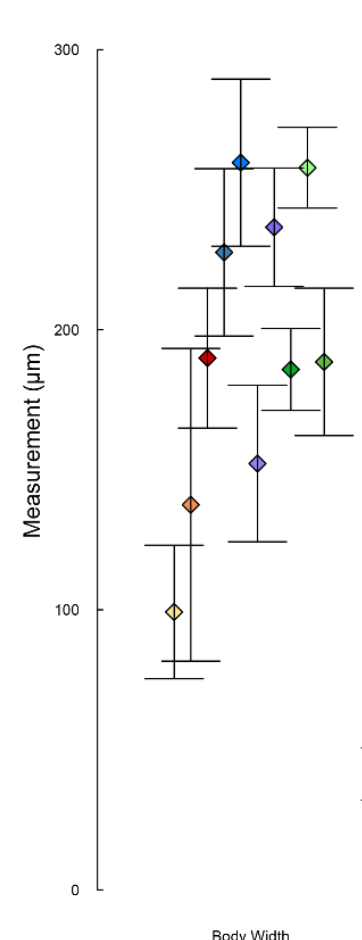

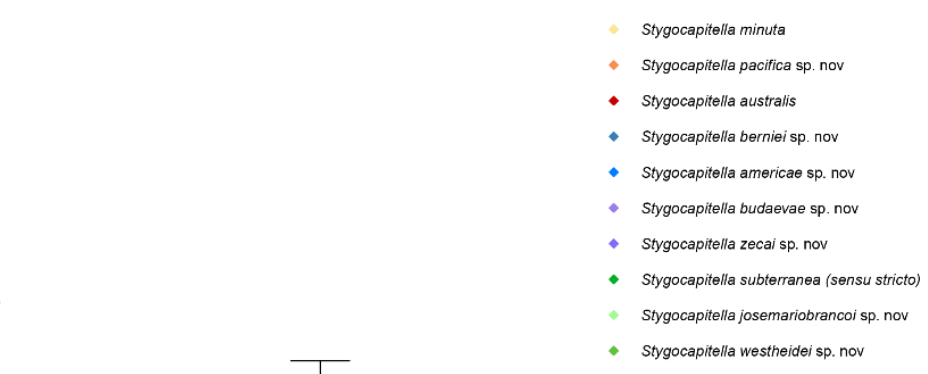

928

Figure 6: Morphometric analysis. Panel A displays body length measurements $(\mu \mathrm{m})$ and
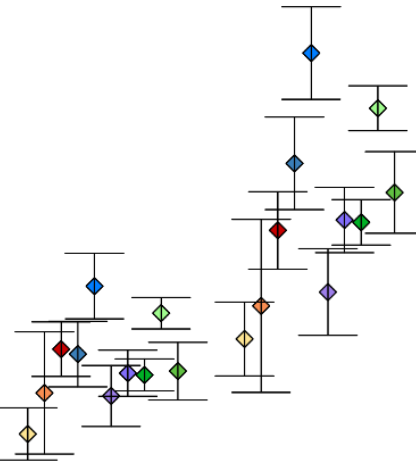

Prostomium Width

Different measurements

Pigidium Length Pigidium Width

Pigidium Length Pigidium Width

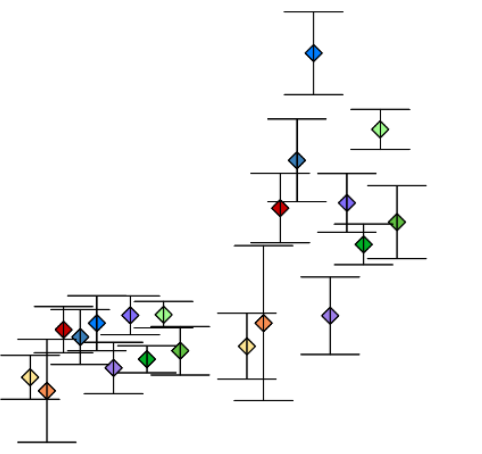

930 panel B) displays body width, prostomium length and width, and pygidium length and width $931(\mu \mathrm{m})$. 

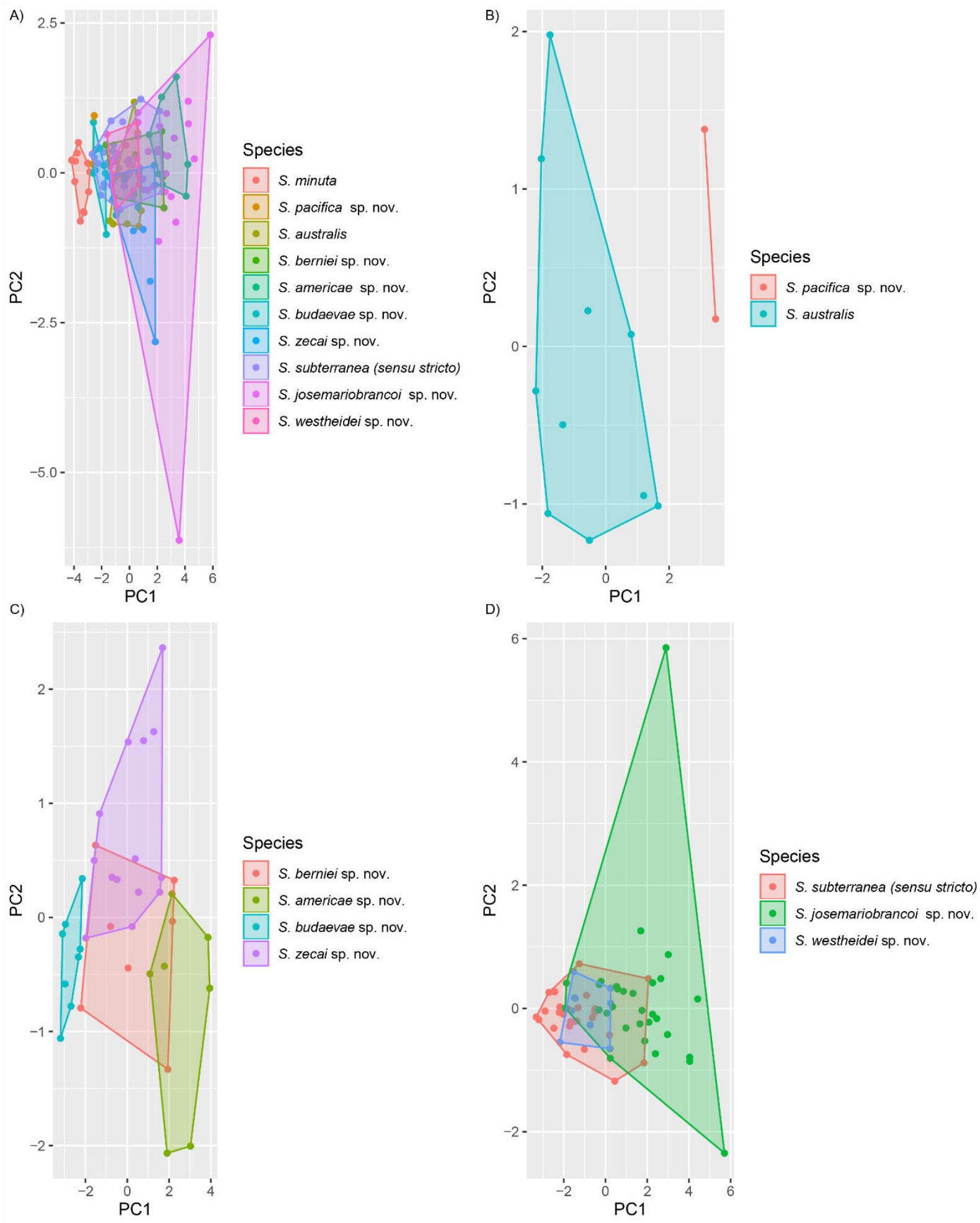

Figure 7: Principal component analysis of morphological measurements. Every panel 935 displays the first two principal components (PC1-PC2). Panel A) displays all species. Panel B), C) 936 and D) display only species from separate morphotypes (see figure 5). 
Appeltans, W., Ahyong, S.T., Anderson, G., Angel, M. V., Artois, T., Bailly, N., Bamber, R., Barber, A., Bartsch, I., Berta, A., Błazewicz-Paszkowycz, M., Bock, P., Boxshall, G., Boyko, C.B., Brandão, S.N., Bray, R.A., Bruce, N.L., Cairns, S.D., Chan, T.Y., Cheng, L., Collins, A.G., Cribb, T., Curini-Galletti, M., Dahdouh-Guebas, F., Davie, P.J.F., Dawson, M.N., De Clerck, O., Decock, W., De Grave, S., De Voogd, N.J., Domning, D.P., Emig, C.C., Erséus, C., Eschmeyer, W., Fauchald, K., Fautin, D.G., Feist, S.W., Fransen, C.H.J.M., Furuya, H., Garcia-Alvarez, O., Gerken, S., Gibson, D., Gittenberger, A., Gofas, S., Gómez-Daglio, L., Gordon, D.P., Guiry, M.D., Hernandez, F., Hoeksema, B.W., Hopcroft, R.R., Jaume, D., Kirk, P., Koedam, N., Koenemann, S., Kolb, J.B., Kristensen, R.M., Kroh, A., Lambert, G., Lazarus, D.B., Lemaitre, R., Longshaw, M., Lowry, J., MacPherson, E., Madin, L.P., Mah, C., Mapstone, G., McLaughlin, P.A., Mees, J., Meland, K., Messing, C.G., Mills, C.E., Molodtsova, T.N., Mooi, R., Neuhaus, B., Ng, P.K.L., Nielsen, C., Norenburg, J., Opresko, D.M., Osawa, M., Paulay, G., Perrin, W., Pilger, J.F., Poore, G.C.B., Pugh, P., Read, G.B., Reimer, J.D., Rius, M., Rocha, R.M., Saiz-Salinas, J.I., Scarabino, V., Schierwater, B., Schmidt-Rhaesa, A., Schnabel, K.E., Schotte, M., Schuchert, P., Schwabe, E., Segers, H., Self-Sullivan, C., Shenkar, N., Siegel, V., Sterrer, W., Stöhr, S., Swalla, B., Tasker, M.L., Thuesen, E. V., Timm, T., Todaro, M.A., Turon, X., Tyler, S., Uetz, P., Van Der Land, J., Vanhoorne, B., Van Ofwegen, L.P., Van Soest, R.W.M., Vanaverbeke, J., Walker-Smith, G., Walter, T.C., Warren, A., Williams, G.C., Wilson, S.P., Costello, M.J., 2012. The magnitude of global marine species diversity. Curr. Biol. 22, 2189-2202. https://doi.org/10.1016/j.cub.2012.09.036

Astrin, J.J., Stüben, P.E., 2008. Phylogeny in cryptic weevils: Molecules, morphology and new genera of western Palaearctic Cryptorhynchinae (Coleoptera: Curculionidae). Invertebr. Syst. 22, 503-522. https://doi.org/10.1071/IS07057

Barnes, D.K.A., 2002. Invasions by marine life on plastic debris. Nature 416, 808-809. https://doi.org/10.1038/416808a

Bernardo, J., 2011. A critical appraisal of the meaning and diagnosability of cryptic evolutionary diversity, and its implications for conservation in the face of climate change. Clim. Chang. Ecol. Syst. 380-438. https://doi.org/10.1017/CBO9780511974540.019 

148-155. https://doi.org/10.1016/j.tree.2006.11.004

971 Bouckaert, R., Heled, J., Kühnert, D., Vaughan, T., Wu, C.H., Xie, D., Suchard, M.A., Rambaut, 972 A., Drummond, A.J., 2014. BEAST 2: A software platform for bayesian evolutionary 973 analysis. PLoS Comput. Biol. 10,1-6. https://doi.org/10.1371/journal.pcbi.1003537

974 Carstens, B.C., Pelletier, T.A., Reid, N.M., Satler, J.D., 2013. How to fail at species delimitation. 975 Mol. Ecol. 22, 4369-4383. https://doi.org/10.1111/mec.12413

976 Cerca, J., Purschke, G., Struck, T.H., 2018. Marine connectivity dynamics: clarifying 977 cosmopolitan distributions of marine interstitial invertebrates and the meiofauna paradox. 978 Mar. Biol. 165, 123. https://doi.org/10.1007/s00227-018-3383-2

979 Chernomor, O., Von Haeseler, A., Minh, B.Q., 2016. Terrace aware data structure for 980 phylogenomic inference from supermatrices. Syst. Biol. 65, 997-1008. https://doi.org/10.1093/sysbio/syw037

Clement, M., Posada, D., Crandall, K.A., 2000. TCS: a computer program to estimate gene 983 genealogies. Mol. Ecol. 9, 1657-1660. https://doi.org/10.1046/j.1365-294x.2000.01020.x

Costa, F.O., Carvalho, G.R., 2010. New insights into molecular evolution: Prospects from the barcode of life initiative (BOLI). Theory Biosci. 129, 149-157. https://doi.org/10.1007/s12064-010-0091-y

Derycke, S., Remerie, T., Backeljau, T., Vierstraete, A., Vanfleteren, J., Vincx, M., Moens, T., 2008. Phylogeography of the Rhabditis (Pellioditis) marina species complex: Evidence for long-distance dispersal, and for range expansions and restricted gene flow in the northeast Atlantic. Mol. Ecol. 17, 3306-3322. https://doi.org/10.1111/j.1365-294X.2008.03846.x

Eldredge, N., Gould, S.J., 1972. Punctuated Equilibria: An alternative to phylogetic gradualism, in: Schopf, T.J.M. (Ed.), Models in Paleobiology. Freeman, Cooper and Co., San Francisco., pp. $82-115$. of the species concept. Mol. Ecol. 27, 613-635. https://doi.org/10.1111/mec.14486 
generalized mixed yule coalescent approach: A revised method and evaluation on simulated data sets. Syst. Biol. 62, 707-724. https://doi.org/10.1093/sysbio/syt033

999 Futuyma, D.J., 2010. Evolutionary constraint and ecological consequences. Evolution (N. Y). 64, 1865-1884. https://doi.org/10.1111/j.1558-5646.2010.00960.x

1001 Giere, O., 2009. Meiobenthology: the microscopic motile fauna of aquatic sediments, 2nd ed.

1002 Springler-Verlag, Berlin Heidelberg. https://doi.org/10.1016/0022-0981(94)90135-X

1003 Harrell Jr, F.E., Many Others, contributions from, 2019. Hmisc: Harrell Miscellaneous. R 1004 package.

1005 Hawksworth, D.L., Lücking, R., 2017. Fungal diversity revisited : 2.2 to 3.8 million species.

1006 Microbiol. Spetrum 5,1-17. https://doi.org/10.1128/microbiolspec.FUNK-0052-

1007 2016.Correspondence

1008 Hellberg, M.E., 2009. Gene flow and isolation among populations of marine animals. Annu. Rev.

1009 Ecol. Evol. Syst. 40, 291-310. https://doi.org/10.1146/annurev.ecolsys.110308.120223

1010 Hillis, D.M., Dixon, M.T., 1991. Ribosomal DNA: Molecular evolution and phylogenetic

1011 inference. Q. Rev. Biol. 66, 411-453.

1012 Hoang, D.T., Chernomor, O., von Haeseler, A., Quang Minh, B., Sy Vinh, L., 2017. Ufboot2:

$1013 \quad$ Improving the ultrafast bootstrap approximation 35, 518-522.

1014 https://doi.org/10.5281/zenodo.854445

1015 Holt, B.G., Lessard, J.-P., Borregaard, M.K., Fritz, S.A., Araújo, M.B., Dimitrov, D., Fabre, P.-H., 1016 Graham, C.H., Graves, G.R., Jønsson, K.A., Nogués-Bravo, D., Wang, Z., Whittaker, R.J., 1017 Fjeldså, J., Rahbek, C., 2013. An update of Wallace's zoogeographic regions of the world. 1018 Science (80-. ). 339, 74-79. https://doi.org/10.1590/S1413-81232011000600020

1019 Horton, T., Et. Al., 2019. World Register of Marine Species, taxon details for Orbiniidae Hartman, 1942 [WWW Document]. http://www.marinespecies.org/aphia.php?p=taxdetails\&id=902\&allchildren=1.

1022 Johannesson, K., 1988. The paradox of Rockall: why is a brooding gastropod (Littorina saxatilis) 1023 more widespread than one having a planktonic larval dispersal stage (L. littorea)? Mar. Biol. 99, 507-513. https://doi.org/10.1007/BF00392558 
1025 Jörger, K.M., Norenburg, J.L., Wilson, N.G., Schrödl, M., 2012. Barcoding against a paradox?

1026 Combined molecular species delineations reveal multiple cryptic lineages in elusive

1027 meiofaunal sea slugs. BMC Evol. Biol. 12, 245. https://doi.org/10.1186/1471-2148-12-245

1028 Jörger, K.M., Schrödl, M., 2013. How to describe a cryptic species? Practical challenges of

1029 molecular taxonomy. Front. Zool. 10, 59. https://doi.org/10.1186/1742-9994-10-59

1030 Kalyaanamoorthy, S., Minh, B.Q., Wong, T.K.F., Von Haeseler, A., Jermiin, L.S., 2017.

1031 ModelFinder: Fast model selection for accurate phylogenetic estimates. Nat. Methods 14, 1032 587-589. https://doi.org/10.1038/nmeth.4285

1033 Karling, T.G., 1958. Zur Kenntnis von Stygocapitella subterranea Knöllner und Parergodrilus heideri 1034 Reisinger. Ark. för Zool. 1, 307-324.

1035 Katoh, K., Standley, D.M., 2013. MAFFT multiple sequence alignment software version 7:

1036 Improvements in performance and usability. Mol. Biol. Evol. 30, 772-780.

1037 https://doi.org/10.1093/molbev/mst010

1038 Knöllner, F., 1934. Stypocapitella subterranea nov.gen. nov.spec. Schriften der

1039 Naturwissenschaftlichen Vereins für Schleswig-Holstein 20, 468-472.

1040 Knowlton, N., 2000. Molecular genetic analyses of species boundaries in the sea. Hydrobiologia 420, 73-90. https://doi.org/10.1023/A:1003933603879

1042 Knowlton, N., 1993. Sibling species in the sea. Annu. Rev. Ecol. Syst. 24, 189-216.

1043 Kon, T., Yoshino, T., Mukai, T., Nishida, M., 2007. DNA sequences identify numerous cryptic 1044 species of the vertebrate: A lesson from the gobioid fish Schindleria. Mol. Phylogenet. Evol. 1045 44, 53-62. https://doi.org/10.1016/j.ympev.2006.12.007

1046 Korshunova, T., Martynov, A., Bakken, T., Picton, B., 2017. External diversity is restrained by 1047 internal conservatism: New nudibranch mollusc contributes to the cryptic species problem. 1048 Zool. Scr. 46, 683-692. https://doi.org/10.1111/zsc.12253

1049 Korshunova, T., Picton, B., Furfaro, G., Mariottini, P., Pontes, M., Prkić, J., Fletcher, K., 1050 Malmberg, K., Lundin, K., Martynov, A., 2019. Multilevel fine-scale diversity challenges the 1051 'cryptic species’ concept. Sci. Rep. 9, 6732. https://doi.org/10.1038/s41598-019-42297-5

1052 Kück, P., Meusemann, K., 2010. FASconCAT: Convenient handling of data matrices. Mol. 
1054

1055

1056

1057

1058

1059

1060

1061

1062

1063

1064

1065

1066

1067

1068

1069

1070

1071

1072

1073

1074

1075

1076

1077

1078

1079

1080

1081

Leasi, F., Norenburg, J.L., 2016. At least some meiofaunal species are not everywhere. Indication of geographic, ecological and geological barriers affecting the dispersion of species of Ototyphlonemertes (Nemertea, Hoplonemertea). Mol. Ecol. 25, 1381-1397. https://doi.org/10.1111/mec.13568

Leasi, F., Norenburg, J.L., 2014. The necessity of DNA taxonomy to reveal cryptic diversity and spatial distribution of meiofauna, with a focus on Nemertea. PLoS One 9. https://doi.org/10.1371/journal.pone.0104385

Lee, C.E., Frost, B.W., 2002. Morphological stasis in the Eurytemora affinis species complex (Copepoda: Temoridae). Hydrobiologia 480, 111-128. https://doi.org/10.1023/A:1021293203512

Lehmacher, C., Ramey-balci, P.A., Wolff, L.I., Fiege, D., 2016. Ultrastructural differences in presumed photoreceptive organs and molecular data as a means for species discrimination in Polygordius (Annelida, Protodriliformia , Polygordiidae). Org. Divers. Evol. https://doi.org/10.1007/s13127-016-0272-8

Lenth, R. V., 2013. Lsmeans: Least-squares means. R package version 1.10-4. http://CRAN.Rproject.org $/$ package $=$ lsmeans [WWW Document].

Leray, M., Knowlton, N., 2016. Censusing marine eukaryotic diversity in the twenty-first century. Philos. Trans. R. Soc. B Biol. Sci. 371, 20150331. https://doi.org/http://dx.doi.org/10.1098/rstb.2015.0331

Lobo, J., Teixeira, M.A.L., Borges, L.M.S., Ferreira, M.S.G., Hollatz, C., Gomes, P.T., Sousa, R., Ravara, A., Costa, M.H., Costa, F.O., 2016. Starting a DNA barcode reference library for shallow water polychaetes from the southern European Atlantic coast. Mol. Ecol. Resour. 16, 298-313. https://doi.org/10.1111/1755-0998.12441

Mack, R.N., Lonsdale, W.M., 2001. Humans as global plant dispersers: getting more than we bargained for. Bioscience 51, 95. https://doi.org/10.1641/00063568(2001)051[0095:hagpdg]2.0.co;2

Meyer-Wachsmuth, I., Curini Galletti, M., Jondelius, U., 2014. Hyper-cryptic marine meiofauna: Species complexes in Nemertodermatida. PLoS One 9. 
Múrias Dos Santos, A., Cabezas, M.P., Tavares, A.I., Xavier, R., Branco, M., 2015. TcsBU: A tool to extend TCS network layout and visualization. Bioinformatics 32, 627-628. https://doi.org/10.1093/bioinformatics/btv636 effective stochastic algorithm for estimating maximum-likelihood phylogenies. Mol. Biol. Evol. 32, 268-274. https://doi.org/10.1093/molbev/msu300

Nygren, A., Pleijel, F., 2011. From one to ten in a single stroke - resolving the European Eumida sanguinea (Phyllodocidae, Annelida) species complex. Mol. Phylogenet. Evol. 58, 132-141.

Palumbi, S., Martin, A., Romano, S., McMillan, W.O., Stice, L., Grabowski, G., 1991. The simple fool's guide to PCR, version 2.

Pante, E., Puillandre, N., Viricel, A., Arnaud-Haond, S., Aurelle, D., Castelin, M., Chenuil, A., Destombe, C., Forcioli, D., Valero, M., Viard, F., Samadi, S., 2015. Species are hypotheses: avoid connectivity assessments based on pillars of sand. Mol. Ecol. 24, 525-544.

Purschke, G., 2006. Problematic Annelid Groups, in: Rouse, G.W., Pleijel, F. (Eds.), Plymouth, pp. 639-667. (Annelida)? Hydrobiologia 406, 87-99. https://doi.org/10.1023/A:1003780032497 phylogenetic importance in Polychaeta (Annelida) - III. The pharynx of the Parergodrilidae. Zool. Jahrbücher Anat. 115, 331-362. 
1110 Purschke, G., 1986. Ultrastructure of the nuchal organ in the interstitial polychaete Stygocapitella 1111 subterranea (Parergodriilidae). Zool. Scr. 15, 13-20.

1112 Purschke, G., Böggemann, M., Westheide, W., 2019. Parergodrilidae Reisinger, 1925, in:

1113 Purschke, G., Böggemann, M., Westheide, W. (Eds.), Annelida, Volume 1: Annelida Basal 1114 Groups and Pleistoannelida, Sedentaria. De Gruyter, Berlin, Boston, pp. 237-250.

1115 Purschke, G., Fursman, M.C., 2005. Spermatogenesis and Spermatozoa in Stygocapitella subterranea 1116 (Annelida, Parergodrilidae), an Enigmatic Supralittoral Polychaete. Zoomorphology 124, 1117 137-148. https://doi.org/10.1007/s00435-005-0001-x

1118 Purschke, G., Jördens, J., 2007. Male genital organs in the eulittoral meiofaunal polychaete stygocapitella subterranea (Annelida, Parergodrilidae): Ultrastructure, functional and

1122 R Core Team, 2013. R: A language and environment for statistical computing. R Foundation for Statistical Computing, Vienna, Austria. URL http://www.R-project.org/. [WWW

Radziejewska, T., Gruszka, P., Rokicka-Praxmajer, J., 2006. A home away from home: A meiobenthic assemblage in a ship's ballast water tank sediment. Oceanologia 48, 259-265.

Rambaut, A., Drummond, A.J., Suchard, M.A., 2007. Tracer v1.6.

1128 Riser, N.W., 1984. General observations on the intertidal interstitial fauna of New Zealand. Tane $30,239-250$.

1130 Riser, N.W., 1980. The aberrant polychaete Stygocapitella from some American beaches. Wasmann J. Biol. 38, 10-17.

1132 Schmidt, H., Westheide, W., 2000. Are the meiofaunal polychaetes Hesionides arenaria and Stygocapitella subterranea true cosmopolitan species? - results of RAPD-PCR investigations. Zool. Scr. 29, 17-27. https://doi.org/doi:10.1046/j.1463-6409.2000.00026.x

1135 Schmidt, P., 1972a. Zonierung und jahreszeitliche Fluktuationen des Mesopsammons im Sandstrand von Schilksee. Mikrofauna des Meeresbodens 10, 1-60.

1137 Schmidt, P., 1972b. Zonierung und jahreszeitliche Fluktuationen des Mesopsammons im 
1139 Schmidt, P., 1970. Zonation of the interstitial polychaete Stygocapitella subterranea

1140 (Stygocapitellidae) in European sandy beaches. Mar. Biol. 7, 319-323.

1141 Schmidt, P., 1969. Die quantitative Verteilung und Populationdynamik des Mesopsammons am 1142 Gezeiten-Sandstrand der Nordseeinsel Sylt - II. Quantitative verteilung und populationsdynamik einzelner Arten. Int. Rev. der gesamten Hydrobiol. und Hydrogr. 54, 95-174.

Schonrogge, K., Barr, B., Wardlaw, J., Napper, E., Gardner, M., Breen, J., Elmes, G., Thomas, J.A., 2002. When rare species become endangered: Cryptic speciation in myrmecolphilous hoverflies. J. Linn. Soc. 75, 291-300. https://doi.org/10.1046/j.1095-8312.2002.00019.x

Singhal, S., Hoskin, C.J., Couper, P., Potter, S., Moritz, C., 2018. A framework for resolving cryptic species: a case study from the lizards of the Australian Wet Tropics. Syst. Biol. https://doi.org/10.1093/sysbio/syy026/4960881

Sterrer, W., 1973. Plate tectonics as a mechanism for dispersal and speciation in interstitial sand fauna. Netherlands J. Sea Res. 7, 200-222.

Struck, T.H., Cerca, J., 2019. Cryptic species and their Evolutionary significance. eLS 1-9. https://doi.org/10.1002/9780470015902.a0028292

Struck, T.H., Feder, J.L., Bendiksby, M., Birkeland, S., Cerca, J., Gusarov, V.I., Kistenich, S., Larsson, K.-H.H., Liow, L.H., Nowak, M.D., Stedje, B., Bachmann, L., Dimitrov, D., 2018a. Finding evolutionary processes hidden in cryptic species. Trends Ecol. Evol. 1-11.

Struck, T.H., Feder, J.L., Bendiksby, M., Birkeland, S., Cerca, J., Gusarov, V.I., Kistenich, S., Larsson, K.-H.H., Liow, L.H., Nowak, M.D., Stedje, B., Bachmann, L., Dimitrov, D., 2018b. Cryptic Species - More Than Terminological Chaos: A Reply to Heethoff. Trends Ecol. Evol. 33, 310-312. https://doi.org/10.1016/j.tree.2018.02.008 
Struck, T.H., Westheide, W., Purschke, G., 2002. Progenesis in Eunicida ("Polychaeta," Annelida) - Separate evolutionary events? Evidence from molecular data. Mol. Phylogenet. Evol. 25, 190-199. https://doi.org/10.1016/S1055-7903(02)00231-2

Suatoni, E., Vicario, S., Rice, S., Snell, T., Caccone, A., 2006. An analysis of species boundaries and biogeographic patterns in a cryptic species complex: The rotifer-Brachionus plicatilis. Mol. Phylogenet. Evol. 41, 86-98. https://doi.org/10.1016/j.ympev.2006.04.025

Swift, H.F., Daglio, L.G., Dawson, M.N., 2016. Three routes to crypsis: stasis, convergence, and parallelism in the Mastigias species complex (Scyphozoa, Rhizostomeae). Mol. Phylogenet. Evol. 99, 103-115. https://doi.org/10.1016/j.ympev.2016.02.013

Wada, S., Kameda, Y., Chiba, S., 2013. Long-term stasis and short-term divergence in the phenotypes of microsnails on oceanic islands. Mol. Ecol. 22, 4801-10. https://doi.org/10.1111/mec.12427

Weber, A.A.-T., Stöhr, S., Chenuil, A., 2019. Species delimitation in the presence of strong incomplete lineage sorting and hybridization. Mol. Phylogenet. Evol. 131, 240218. https://doi.org/10.1101/240218

Westheide, W., 2008. Polychaetes: Interstitial families., 2nd Editio. ed. Field Studies Council, Shrewsbury, 169 pp.

Westheide, W., 1991. The meiofauna of the Galapagos: a review, in: Mathew J. James (Ed.), Galápagos Marine Invertebrates. Springler, New York, pp. 37-69.

Westheide, W., 1990. Polychaetes: interstitial families. Keys and notes for the identification of the species., Universal. ed.

Westheide, W., 1987. Progenesis as a principle in meiofauna evolution. J. Nat. Hist. 21, 843-854. https://doi.org/10.1080/00222938700770501

Westheide, W., 1977. The geographical distribution of interstitial polychaetes. Mikrofauna Meeresb. 61, 287-302.

Westheide, W., 1966. On the polychaete fauna of the eulitoral of the North Sea island Sylt. Zur Polychaetenfauna des Eulitorals der Nord. Sylt 13, 203-209.

Westheide, W., Purschke, G., 1988. Organism processing, in: Higgins, R.P., Thiel, H. (Eds.), 
1194 Introduction to the Study of Meiofauna. Smithsonian Institution Press, Washington, pp.

1195 146-160.

1196 Wickham, H., 2016. ggplot2: Elegant Graphics for Data Analysis. Springer-Verlag, New York.

1197 Worsfold, T.M., 2008. British records of the interstitial polychaete Stygocapitella subterranea

1198 (Annelida: Parergodrilidae). Mar. Biodivers. Rec. 1, 50-52.

1199 https://doi.org/10.1017/S1755267206004295

1200 Zanol, J., Halanych, K.M., Struck, T.H., Fauchald, K., 2010. Phylogeny of the bristle worm family Eunicidae (Eunicida, Annelida) and the phylogenetic utility of noncongruent 16S, COI and $18 \mathrm{~S}$ in combined analyses. Mol. Phylogenet. Evol. 55, 660-676.

1203 https://doi.org/10.1016/j.ympev.2009.12.024

1204 Zhang, J., Kapli, P., Pavlidis, P., Stamatakis, A., 2013. A general species delimitation method with applications to phylogenetic placements. Bioinformatics 29, 2869-2876.

1206 https://doi.org/10.1093/bioinformatics/btt499 


\section{Supplementary data for manuscript 4}

Supplementary Table 1: Sampling locations including GPS coordinates for this work.

\begin{tabular}{|c|c|c|c|}
\hline Site & Coastline (Country) & Latitude & Longitude \\
\hline $4^{\text {th }}$ July Beach & Eastern Pacific (USA) & 48.46822 & -123.00298 \\
\hline False bay & Eastern Pacific (USA) & 48.49026 & -123.06598 \\
\hline Roche Harbor & Eastern Pacific (USA) & 48.59612 & -123.16999 \\
\hline Reuben Tarte State Park & Eastern Pacific (USA) & 48.61281 & -123.09838 \\
\hline Canoe Beach & Western Atlantic (USA) & 42.41962 & -70.90684 \\
\hline Reid State Park & Western Atlantic (USA) & 43.77628 & -69.73121 \\
\hline Lubec & Western Atlantic (USA) & 44.85482 & -66.98179 \\
\hline South Lubec & Western Atlantic (USA) & 44.82476 & -66.98917 \\
\hline Île Callot & Eastern Atlantic (France) & 48.68713 & -3.92439 \\
\hline Saint Efflam & Eastern Atlantic (France) & 48.684609 & -3.62247 \\
\hline Hörnum & Eastern Atlantic (Germany) & 54.75619 & 8.29466 \\
\hline Morsum & Eastern Atlantic (Germany) & 54.87822 & 8.46527 \\
\hline Ellenbogen & Eastern Atlantic (Germany) & 55.04397 & 8.45172 \\
\hline Keitum & Eastern Atlantic (Germany) & 54.902 & 8.36766 \\
\hline List Hausstrand & Eastern Atlantic (Germany) & 55.01556 & 8.43736 \\
\hline List Westland & Eastern Atlantic (Germany) & 55.040667 & 8.386944 \\
\hline Schilksee & Eastern Atlantic (Germany) & 54.42386 & 10.17473 \\
\hline Kristineberg & Eastern Atlantic (Sweden) & 58.24774 & 11.44598 \\
\hline Bakka & Eastern Atlantic (Norway) & 60.920192 & 6.867506 \\
\hline Henningsvær & Eastern Atlantic (Norway) & 68.26079 & 14.26836 \\
\hline Lødingen & Eastern Atlantic (Norway) & 68.56414 & 16.49406 \\
\hline Sommarøya & Eastern Atlantic (Norway) & 69.63179 & 18.02713 \\
\hline Espegrend & Eastern Atlantic (Norway) & 60.26637 & 5.22234 \\
\hline Bristol Channel & Eastern Atlantic (Wales) & 51.39973 & -3.19606 \\
\hline Plymouth & Eastern Atlantic (England) & 50.34861 & -4.20071 \\
\hline Cutty Sark & Eastern Atlantic (England) & 51.48294 & -0.0137 \\
\hline Gravesend & Eastern Atlantic (England) & 51.44443 & 0.37764 \\
\hline Ardtoe & Eastern Atlantic (Scotland) & 56.76923 & -5.88361 \\
\hline Glenancross & Eastern Atlantic (Scotland) & 56.94472 & -5.85347 \\
\hline Nairn & Eastern Atlantic (Scotland) & 57.59653 & -3.84176 \\
\hline Musselburgh & Eastern Atlantic (Scotland) & 55.94645 & -3.07624 \\
\hline Little Gruinard & Eastern Atlantic (Scotland) & 57.85223 & -5.4533 \\
\hline Volchanets & Western Pacific (Russia) & 42.910472 & 132.7402 \\
\hline
\end{tabular}


Supplementary Table 2: Accession numbers of sequences used for phylogenetic analyses. Sequences obtained for this study are in bold. For information on sampling sites see Supplementary Table 2.

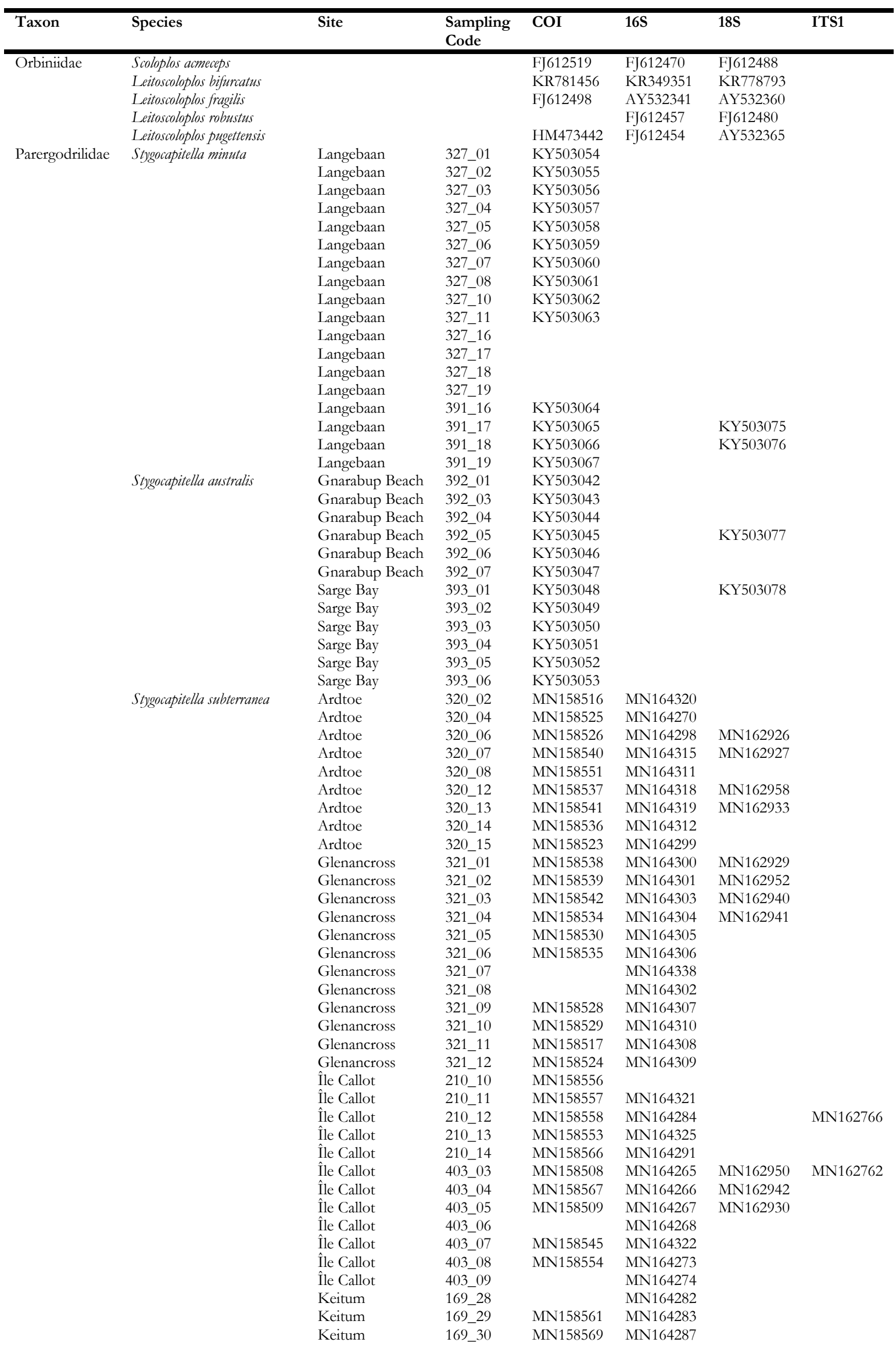




\begin{tabular}{|c|c|c|c|c|c|c|}
\hline & Keitum & 169_31 & & MN164288 & & \\
\hline & Keitum & 169_32 & & MN164323 & & \\
\hline & Keitum & 169_33 & MN158562 & MN164293 & & \\
\hline & Keitum & 169_34 & MN158518 & MN164326 & & \\
\hline & Keitum & 169_35 & MN158563 & MN164289 & & \\
\hline & Keitum & 169_36 & MN158560 & MN164324 & & \\
\hline & Keitum & 169_37 & & MN164295 & MN162953 & \\
\hline & Keitum & $169+38$ & MN158568 & MN164281 & MN162949 & \\
\hline & Keitum & 169_39 & MN158564 & MN164290 & MN162954 & \\
\hline & Keitum & 398_04 & MN158510 & MN164275 & MN162956 & \\
\hline & Keitum & 398_05 & MN158546 & MN164276 & & \\
\hline & Keitum & 398_06 & MN158550 & MN164277 & & \\
\hline & Keitum & 398_07 & MN158511 & MN164278 & & \\
\hline & Keitum & 398_08 & MN158512 & MN164297 & & \\
\hline & Keitum & 398_09 & MN158544 & MN164279 & & \\
\hline & Keitum & 398_10 & MN158513 & MN164269 & & MN162763 \\
\hline & Keitum & 398_11 & MN158547 & MN164280 & & \\
\hline & Little Gruinard & $322 \_01$ & MN158576 & MN164314 & & \\
\hline & Little Gruinard & $322 \_02$ & MN158577 & MN164335 & & \\
\hline & Morsum & 227_01 & MN158519 & MN164285 & MN162935 & \\
\hline & Morsum & 227_02 & MN158520 & MN164286 & MN162951 & \\
\hline & Morsum & 227_03 & MN158573 & MN164271 & MN162955 & \\
\hline & Morsum & 227_04 & MN158521 & MN164272 & MN162936 & \\
\hline & Morsum & 227_05 & MN158522 & MN164316 & MN162961 & \\
\hline & Morsum & 227_06 & MN158527 & MN164294 & & \\
\hline & Morsum & 227_07 & MN158543 & MN164292 & & \\
\hline & Morsum & 227_08 & MN158555 & MN164340 & & MN162767 \\
\hline & Morsum & 227_09 & & MN164296 & & \\
\hline & Morsum & 227_10 & MN158559 & MN164317 & & \\
\hline & Morsum & 227_14 & & MN164129 & & \\
\hline & Morsum & 227_15 & & MN164130 & & \\
\hline & Musselburgh & $324 \_03$ & MN158565 & MN164331 & & \\
\hline & Musselburgh & $324 \_05$ & MN158549 & MN164332 & & MN162764 \\
\hline & Nairn & 323_01 & MN158531 & MN164329 & & \\
\hline & Nairn & $323 \_02$ & MN158533 & MN164333 & & \\
\hline & Nairn & 323_03 & MN158552 & MN164330 & & \\
\hline & Nairn & 323_04 & MN158532 & MN164334 & MN162957 & MN162765 \\
\hline & Schilksee & 396_01 & KY503068 & MN164336 & KY503073 & \\
\hline & Schilksee & $396 \_02$ & KY503069 & MN164339 & KY503074 & \\
\hline & Schilksee & 396_04 & KY503070 & MN164327 & MN162938 & MN162761 \\
\hline & Schilksee & 396_05 & KY503071 & MN164313 & MN162962 & MN162760 \\
\hline & Schilksee & $396 \_06$ & KY503072 & MN164328 & MN162959 & \\
\hline & Weststrand & 169_01 & MN158574 & & & \\
\hline Stygocapitella zecai & Ardtoe & 320_01 & MN158583 & MN164132 & & \\
\hline & Ardtoe & 320_03 & & MN164133 & & \\
\hline & Ardtoe & 320_05 & MN158584 & MN164134 & & \\
\hline & Bakka & 439_01 & & MN164090 & MN162985 & \\
\hline & Bakka & 439_03 & MN158582 & MN164093 & MN162989 & \\
\hline & Bakka & 439_07 & & MN164091 & & \\
\hline & Bakka & 439_08 & & MN164094 & & \\
\hline & Cutty Sark & 423_01 & & & & MN162869 \\
\hline & Cutty Sark & $423 \_02$ & & MN164109 & & MN162870 \\
\hline & Cutty Sark & 423_03 & MN158578 & MN164127 & & \\
\hline & Cutty Sark & 423_04 & & MN164095 & & \\
\hline & Cutty Sark & 423_06 & & MN164128 & & \\
\hline & Cutty Sark & 423_07 & MN158579 & MN164110 & & \\
\hline & Cutty Sark & 423_08 & MN158580 & MN164111 & & \\
\hline & Cutty Sark & 423_09 & & MN164096 & & \\
\hline & Cutty Sark & 423_10 & MN158581 & MN164112 & & MN162871 \\
\hline & Espegrend & 440_01 & MN158588 & MN164092 & MN162986 & MN162872 \\
\hline & Espegrend & 440_02 & & MN164097 & MN162993 & MN162878 \\
\hline & Espegrend & 440_03 & & MN164098 & & \\
\hline & Espegrend & 440_04 & & MN164113 & & MN162875 \\
\hline & Henningsvær & 437_01 & & & & MN162885 \\
\hline & Henningsvær & 437_02 & & MN164099 & & \\
\hline & Henningsvær & 437_03 & & MN164114 & & MN162877 \\
\hline & Henningsvær & 437_05 & & MN164105 & & \\
\hline & Henningsvær & 437_06 & & MN164100 & & \\
\hline & Henningsvær & 437_07 & & MN164103 & & \\
\hline & Kristineberg & 420_01 & MN158585 & MN164115 & MN162987 & \\
\hline & Kristineberg & 420_02 & & MN164116 & MN162988 & \\
\hline & Kristineberg & 420_03 & & MN164124 & MN162990 & MN162873 \\
\hline & Kristineberg & 420_04 & & MN164117 & & MN162880 \\
\hline & Kristineberg & 420_05 & MN158586 & MN164118 & & MN162882 \\
\hline & Kristineberg & 420_06 & & MN164119 & & MN162881 \\
\hline & Kristineberg & 420_07 & & MN164120 & & MN162874 \\
\hline & Kristineberg & 420_09 & & MN164125 & & \\
\hline
\end{tabular}




\begin{tabular}{|c|c|c|c|c|c|c|}
\hline & Kristineberg & 420_10 & & MN164122 & & \\
\hline & Kristineberg & 420_12 & & MN164123 & & MN162883 \\
\hline & Lødingen & 436_01 & & MN164106 & & \\
\hline & Lødingen & 436_02 & & MN164107 & & \\
\hline & Lødingen & 436_03 & & MN164101 & & MN162884 \\
\hline & Lødingen & 436_04 & & MN164102 & & \\
\hline & Lødingen & 436_05 & & MN164104 & & \\
\hline & Lødingen & 436_07 & & MN164108 & & MN162879 \\
\hline & Musselburgh & $324 \_04$ & MN158587 & MN164131 & MN162992 & MN162876 \\
\hline & Sommarøya & 438_01 & & MN164121 & & \\
\hline & Sommarøya & 438_02 & & MN164126 & MN162991 & \\
\hline Stygocapitella josemariobrancoi & Bristol Channel & 422_01 & MN158387 & MN164135 & MN162970 & MN162799 \\
\hline & Bristol Channel & $422 \_02$ & MN158399 & MN164136 & MN162971 & MN162803 \\
\hline & Bristol Channel & $422 \_03$ & MN158400 & MN164144 & MN162972 & MN162805 \\
\hline & Bristol Channel & 422_04 & MN158388 & MN164148 & MN162978 & MN162808 \\
\hline & Bristol Channel & $422 \_05$ & MN158413 & MN164176 & & \\
\hline & Bristol Channel & $422 \_06$ & MN158401 & MN164183 & & MN162802 \\
\hline & Bristol Channel & $422 \_07$ & MN158389 & MN164177 & & MN162800 \\
\hline & Bristol Channel & 422_08 & MN158435 & & & MN162804 \\
\hline & Bristol Channel & $422 \_09$ & MN158415 & MN164184 & & MN162807 \\
\hline & Bristol Channel & 422_10 & MN158480 & MN164200 & & MN162801 \\
\hline & Bristol Channel & 422_11 & MN158390 & MN164178 & & MN162806 \\
\hline & Bristol Channel & 422_12 & & MN164149 & & \\
\hline & Ellenbogen & 222_01 & MN158440 & MN164199 & MN162982 & MN162809 \\
\hline & Ellenbogen & $222 \_02$ & MN158418 & MN164153 & MN162975 & MN162810 \\
\hline & Ellenbogen & 222_03 & MN158396 & MN164171 & MN162979 & MN162832 \\
\hline & Ellenbogen & $222 \_04$ & MN158416 & MN164142 & MN162984 & MN162811 \\
\hline & Ellenbogen & $222 \_05$ & MN158428 & MN164195 & & MN162812 \\
\hline & Ellenbogen & $222 \_06$ & MN158419 & & & MN162820 \\
\hline & Ellenbogen & 222_07 & MN158412 & & & MN162816 \\
\hline & Ellenbogen & 222_08 & MN158421 & MN164154 & & MN162821 \\
\hline & Ellenbogen & 222_09 & MN158422 & MN164155 & & \\
\hline & Ellenbogen & 222_10 & MN158420 & MN164172 & & \\
\hline & Ellenbogen & 222_11 & MN158397 & MN164173 & & \\
\hline & Ellenbogen & 222_12 & MN158423 & MN164175 & & \\
\hline & Ellenbogen & 222_13 & XX000000 & MN164143 & & \\
\hline & Gravesend & 424_01 & MN158447 & MN164201 & & MN162842 \\
\hline & Gravesend & 424_02 & MN158436 & MN164151 & & \\
\hline & Gravesend & 424_03 & MN158463 & MN164211 & & \\
\hline & Gravesend & 424_04 & MN158448 & MN164202 & & \\
\hline & Gravesend & 424_05 & MN158449 & MN164213 & & MN162843 \\
\hline & Gravesend & 424_06 & MN158450 & MN164203 & & MN162846 \\
\hline & Gravesend & 424_07 & MN158451 & MN164212 & & MN162841 \\
\hline & Gravesend & 424_08 & MN158452 & MN164209 & & MN162848 \\
\hline & Gravesend & 424_09 & MN158461 & MN164204 & & MN162849 \\
\hline & Gravesend & 424_10 & MN158479 & MN164205 & & MN162844 \\
\hline & Gravesend & 424_11 & MN158453 & MN164206 & & MN162838 \\
\hline & Gravesend & $424 \_12$ & MN158431 & MN164179 & & MN162847 \\
\hline & Gravesend & 424_13 & MN158432 & MN164191 & & MN162840 \\
\hline & Gravesend & 424_14 & MN158462 & MN164207 & & MN162845 \\
\hline & Hörnum & 169_06 & MN158391 & MN164180 & & MN162828 \\
\hline & Hörnum & 169_07 & MN158404 & MN164192 & & MN162822 \\
\hline & Hörnum & 169_08 & MN158439 & MN164159 & & \\
\hline & Hörnum & 169_09 & MN158424 & MN164165 & MN162973 & MN162839 \\
\hline & Hörnum & 169_10 & MN158392 & MN164174 & MN162974 & MN162825 \\
\hline & Hörnum & 169_11 & MN158441 & & MN162981 & MN162835 \\
\hline & Hörnum & 169_12 & MN158433 & MN164190 & MN162977 & \\
\hline & Hörnum & 169_13 & MN158393 & MN164198 & & MN162836 \\
\hline & Hörnum & 169_14 & & MN164157 & & MN162829 \\
\hline & Hörnum & 169_15 & MN158430 & MN164181 & & MN162826 \\
\hline & Hörnum & 169_16 & MN158405 & MN164147 & & MN162823 \\
\hline & Hörnum & 169_17 & MN158394 & & & MN162830 \\
\hline & List & 169_54 & MN158446 & MN164156 & & MN162837 \\
\hline & List & 169_55 & MN158548 & & & \\
\hline & List & $169 \_56$ & MN158406 & MN164160 & MN162980 & MN162817 \\
\hline & List & 169_57 & MN158571 & MN164337 & & XX000000 \\
\hline & List & 169_58 & MN158417 & MN164164 & MN162976 & MN162813 \\
\hline & List & 219_02 & & MN164161 & MN162983 & \\
\hline & List & 219_03 & MN158408 & MN164193 & & MN162824 \\
\hline & List & 219_04 & & MN164168 & & MN162819 \\
\hline & List & 219_05 & MN158442 & MN164170 & & MN162818 \\
\hline & List & 219_06 & MN158443 & MN164163 & & MN162814 \\
\hline & List & 219 & & MN164158 & & MN162827 \\
\hline & List & 219_08 & MN158410 & MN164150 & & MN162831 \\
\hline & List & 219_09 & & MN164166 & & MN162833 \\
\hline & List & 219_10 & MN158425 & MN164169 & & \\
\hline & List & 219_11 & MN158427 & & & \\
\hline
\end{tabular}




\begin{tabular}{|c|c|c|c|c|c|c|}
\hline & List & 219_12 & & MN164162 & & \\
\hline & List & 219_13 & & MN164182 & & \\
\hline & Lubec & 429_01 & MN158444 & MN164138 & MN162963 & MN162850 \\
\hline & Lubec & 429_08 & MN158429 & MN164185 & MN162967 & MN162851 \\
\hline & Plymouth & 421_01 & MN158471 & MN164224 & MN162964 & MN162852 \\
\hline & Plymouth & 421_02 & MN158474 & MN164225 & & \\
\hline & Plymouth & 421_03 & MN158473 & MN164228 & & MN162865 \\
\hline & Plymouth & 421_04 & MN158438 & MN164186 & & \\
\hline & Plymouth & 421_05 & MN158475 & MN164229 & & MN162853 \\
\hline & Plymouth & 421_06 & MN158403 & MN164187 & & MN162867 \\
\hline & Plymouth & 421_07 & & MN164226 & & \\
\hline & Plymouth & 421_08 & MN158472 & MN164232 & & \\
\hline & Plymouth & 421_09 & MN158476 & MN164227 & & \\
\hline & Plymouth & 421_10 & MN158478 & MN164230 & & MN162862 \\
\hline & Plymouth & 421_11 & & MN164188 & & \\
\hline & Plymouth & 421_13 & MN158414 & MN164189 & & MN162855 \\
\hline & Plymouth & 421_14 & MN158426 & MN164167 & & MN162858 \\
\hline & Plymouth & 421_15 & MN158477 & MN164231 & & \\
\hline & Musselburgh & 324_01 & MN158455 & MN164223 & & \\
\hline & Musselburgh & 324_02 & MN158457 & MN164215 & & \\
\hline & Musselburgh & 324_06 & MN158466 & MN164216 & & MN162834 \\
\hline & Musselburgh & 324_07 & MN158458 & MN164217 & & \\
\hline & Musselburgh & 324_08 & MN158464 & MN164222 & & \\
\hline & Musselburgh & 324_09 & MN158460 & MN164219 & & \\
\hline & Musselburgh & 324_10 & MN158459 & MN164220 & & \\
\hline & Musselburgh & 324_11 & MN158465 & MN164218 & & \\
\hline & Musselburgh & 324_12 & MN158456 & MN164221 & & \\
\hline & Musselburgh & 324_52 & MN158468 & MN164208 & & \\
\hline & St. Efflam & 210_01 & MN158470 & & & MN162864 \\
\hline & St. Efflam & 210_02 & MN158409 & MN164197 & & MN162815 \\
\hline & St. Efflam & 210_03 & MN158395 & & & MN162860 \\
\hline & St. Efflam & 210_04 & MN158467 & MN164152 & & MN162863 \\
\hline & St. Efflam & 210_05 & MN158407 & MN164196 & & \\
\hline & St. Efflam & 210_06 & MN158411 & & & MN162856 \\
\hline & St. Efflam & 210_07 & & MN164141 & & MN162868 \\
\hline & St. Efflam & 401_01 & & MN164139 & MN162968 & MN162861 \\
\hline & St. Efflam & 401_02 & MN158398 & MN164140 & MN162966 & MN162854 \\
\hline & St. Efflam & 401_03 & MN158454 & MN164214 & MN162965 & \\
\hline & St. Efflam & 401_04 & MN158437 & MN164194 & & MN162857 \\
\hline & St. Efflam & 401_05 & MN158434 & MN164146 & & \\
\hline & St. Efflam & 401_06 & MN158445 & MN164145 & & MN162859 \\
\hline & St. Efflam & 401_07 & MN158469 & MN164210 & & MN162866 \\
\hline Stygocapitella westheidei & Canoe Beach & 426_01 & MN158481 & MN164233 & MN162928 & MN162768 \\
\hline & Canoe Beach & 426_02 & MN158503 & & MN162960 & MN162770 \\
\hline & Canoe Beach & 426_03 & MN158504 & MN164234 & MN162939 & MN162794 \\
\hline & Canoe Beach & 426_04 & MN158502 & MN164235 & MN162948 & MN162784 \\
\hline & Canoe Beach & 426_05 & MN158507 & MN164236 & & \\
\hline & Canoe Beach & 426_06 & MN158486 & MN164237 & & MN162795 \\
\hline & Canoe Beach & 426_07 & MN158501 & MN164254 & & MN162771 \\
\hline & Canoe Beach & 426_08 & MN158505 & MN164238 & & MN162785 \\
\hline & Canoe Beach & 426_09 & MN158506 & MN164264 & & MN162796 \\
\hline & Canoe Beach & 426_10 & & MN164239 & & MN162774 \\
\hline & Canoe Beach & 426_11 & & MN164249 & & MN162788 \\
\hline & Canoe Beach & 426_12 & & MN164250 & & MN162797 \\
\hline & Lubec & 429_02 & MN158482 & & MN162934 & MN162775 \\
\hline & Lubec & 429_03 & & MN164255 & & MN162776 \\
\hline & Lubec & 429_04 & & MN164240 & & \\
\hline & Lubec & 429_05 & & MN164256 & & MN162777 \\
\hline & Lubec & 429_06 & & MN164251 & & MN162778 \\
\hline & Lubec & 429_07 & & & & MN162793 \\
\hline & Lubec & 429_09 & MN158490 & MN164257 & & MN162779 \\
\hline & Lubec & 429_10 & MN158489 & MN164241 & & MN162783 \\
\hline & Lubec & 429_11 & MN158483 & MN164242 & & MN162780 \\
\hline & Lubec & 429_12 & MN158497 & MN164258 & & \\
\hline & Reid State Park & 427_01 & MN158484 & MN164259 & MN162943 & MN162781 \\
\hline & Reid State Park & 427_02 & MN158495 & MN164260 & MN162931 & MN162772 \\
\hline & Reid State Park & 427_03 & MN158487 & MN164243 & MN162937 & MN162773 \\
\hline & Reid State Park & 427_04 & MN158485 & MN164252 & MN162944 & MN162786 \\
\hline & Reid State Park & 427_05 & MN158499 & MN164244 & & \\
\hline & Reid State Park & 427_06 & MN158500 & MN164245 & & MN162787 \\
\hline & Reid State Park & 427_07 & MN158492 & MN164261 & & MN162789 \\
\hline & Reid State Park & 427_08 & MN158493 & MN164262 & & MN162792 \\
\hline & Reid State Park & 427_09 & MN158494 & MN164246 & & MN162798 \\
\hline & Reid State Park & 427_10 & MN158496 & MN164253 & & MN162782 \\
\hline & South Lubec & 428_01 & MN158491 & MN164263 & MN162946 & MN162791 \\
\hline & South Lubec & 428_02 & MN158498 & MN164247 & MN162969 & MN162790 \\
\hline & South Lubec & 428_03 & MN158488 & MN164248 & MN162947 & MN162769 \\
\hline
\end{tabular}




\begin{tabular}{|c|c|c|c|c|c|c|}
\hline \multirow[t]{6}{*}{ Stygocapitella spec. $A$. } & 4th July Beach & 432_02 & MN158382 & MN164061 & MN162897 & MN162736 \\
\hline & 4th July Beach & 432_04 & & MN164062 & & MN162738 \\
\hline & 4th July Beach & 432_07 & MN158385 & MN164063 & MN162909 & MN162739 \\
\hline & 4th July Beach & 432_08 & MN158383 & MN164065 & MN162895 & MN162737 \\
\hline & 4th July Beach & 432_09 & MN158384 & MN164064 & MN162911 & MN162741 \\
\hline & False Bay & 431_01 & MN158386 & MN164066 & MN162910 & MN162740 \\
\hline \multirow[t]{14}{*}{ Stygocapitella americae } & 4th July Beach & 432_01 & MN158589 & MN164067 & & MN162714 \\
\hline & 4th July Beach & 432_10 & MN158597 & MN164068 & MN162914 & MN162724 \\
\hline & Reuben Tarte & $433 \_01$ & MN158590 & MN164069 & MN162917 & MN162720 \\
\hline & Reuben Tarte & $433 \_02$ & MN158591 & MN164075 & MN162918 & MN162722 \\
\hline & Reuben Tarte & 433_03 & MN158599 & MN164070 & MN162915 & MN162715 \\
\hline & Reuben Tarte & 433_04 & MN158600 & MN164076 & MN162920 & MN162716 \\
\hline & Reuben Tarte & 433_05 & MN158601 & MN164071 & MN162919 & MN162721 \\
\hline & Reuben Tarte & 433_06 & MN158592 & MN164077 & & MN162717 \\
\hline & Reuben Tarte & 433_07 & MN158593 & MN164078 & & \\
\hline & Reuben Tarte & 433_08 & MN158594 & MN164072 & & MN162719 \\
\hline & Reuben Tarte & 433_09 & MN158595 & MN164079 & & MN162723 \\
\hline & Reuben Tarte & 433_10 & MN158596 & MN164080 & MN162916 & \\
\hline & Reuben Tarte & 433_11 & & MN164073 & & MN162725 \\
\hline & Reuben Tarte & 433_12 & MN158598 & MN164074 & & MN162718 \\
\hline \multirow[t]{10}{*}{ Stygocapitella berniei } & Roche Harbor & 430_01 & MN158602 & MN164081 & MN162921 & MN162726 \\
\hline & Roche Harbor & 430_02 & & & MN162925 & MN162727 \\
\hline & Roche Harbor & 430_03 & MN158603 & MN164082 & MN162922 & MN162731 \\
\hline & Roche Harbor & 430_04 & MN158604 & MN164083 & MN162923 & MN162728 \\
\hline & Roche Harbor & 430_05 & MN158605 & MN164084 & MN162924 & MN162729 \\
\hline & Roche Harbor & 430_06 & MN158609 & MN164089 & & MN162735 \\
\hline & Roche Harbor & 430_07 & MN158606 & MN164085 & & MN162733 \\
\hline & Roche Harbor & 430_08 & MN158608 & MN164086 & & MN162730 \\
\hline & Roche Harbor & 430_09 & MN158607 & MN164087 & & MN162734 \\
\hline & Roche Harbor & 430_10 & MN158610 & MN164088 & & MN162732 \\
\hline \multirow[t]{18}{*}{ Stygocapitella budaevae } & Volchanets & $442 \_1$ & & MN164047 & MN162891 & MN162742 \\
\hline & Volchanets & $442 \_4$ & MN158372 & & MN162898 & MN162750 \\
\hline & Volchanets & $442 \_5$ & MN158380 & MN164048 & MN162899 & MN162745 \\
\hline & Volchanets & $442 \_6$ & MN158374 & MN164060 & MN162912 & MN162744 \\
\hline & Volchanets & $442 \_7$ & MN158375 & & MN162913 & MN162751 \\
\hline & Volchanets & $442 \_8$ & MN158378 & MN164049 & MN162900 & MN162752 \\
\hline & Volchanets & 442_9 & MN158373 & MN164050 & MN162901 & MN162747 \\
\hline & Volchanets & 442_12 & MN158379 & & MN162904 & MN162757 \\
\hline & Volchanets & 442_15 & MN158376 & MN164051 & MN162892 & MN162758 \\
\hline & Volchanets & $442 \_16$ & & MN164052 & MN162896 & MN162748 \\
\hline & Volchanets & 442_18 & & MN164057 & MN162905 & MN162753 \\
\hline & Volchanets & 442_19 & & MN164053 & MN162902 & MN162754 \\
\hline & Volchanets & 442_20 & MN158381 & MN164054 & MN162903 & MN162746 \\
\hline & Volchanets & 442_21 & & MN164055 & MN162893 & MN162749 \\
\hline & Volchanets & $442 \_22$ & MN158377 & MN164059 & MN162906 & MN162743 \\
\hline & Volchanets & $442 \_23$ & & MN164058 & MN162907 & MN162755 \\
\hline & Volchanets & $442 \_24$ & & & MN162894 & MN162759 \\
\hline & Volchanets & $442 \_25$ & & MN164056 & MN162908 & MN162756 \\
\hline \multirow[t]{3}{*}{ Stygocapitella furcata } & 4th July Beach & 432_03 & MN158612 & MN164343 & MN162996 & MN162886 \\
\hline & 4th July Beach & 432_05 & MN158613 & MN164345 & MN162997 & MN162887 \\
\hline & 4th July Beach & 432_06 & MN158614 & MN164344 & MN162998 & MN162888 \\
\hline \multirow[t]{2}{*}{ Stygocapitella pacifica } & Volchanets & $442 \_10$ & MN158611 & MN164341 & MN162994 & MN162889 \\
\hline & Volchanets & 442_11 & & MN164342 & MN162995 & MN162890 \\
\hline
\end{tabular}


Supplementary Table 3. Morphometric measurements. BodyLength = Length of entire body;

BodyWidth $=$ Width of entire body; ProstomiumLength $=$ Length of prostomium; ProstomiumWidth $=$ Width of prostomium; PeristomiumLength $=$ Length of peristomium; PeristomiumWidth $=$ Width of peristomium. All measurements are in $\mu \mathrm{m}$.

\begin{tabular}{|c|c|c|c|c|c|c|c|c|c|}
\hline Site & Clade & Individual & ID & 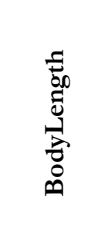 & $\begin{array}{l}\frac{1}{ \pm} \\
0 \\
0 \\
0 \\
0 \\
0 \\
0 \\
0\end{array}$ & 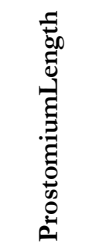 & 吾 & 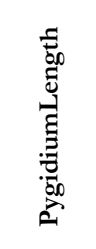 & 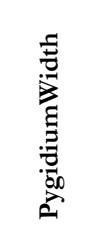 \\
\hline Langebaan & S. minuta & Holotype & SA_LGB_Holo & 1010.74 & 104.54 & 46.6 & 78.89 & 30.95 & 35.21 \\
\hline Langebaan & S. minuta & Lost Male & SA_LGB_LostM1 & 992.34 & 91.11 & 39.61 & 75.01 & 33.51 & 37.7 \\
\hline Langebaan & S. minuta & Paratype +1 & SA_LGB_ParaF1 & 977.69 & 87.79 & 46.46 & 75.88 & 33.13 & 39.6 \\
\hline Langebaan & S. minuta & Paratype 93 & SA_LGB_ParaF3 & 999.66 & 97.2 & 33.13 & 66.02 & 47.41 & 59.72 \\
\hline Langebaan & S. minuta & Paratype 94 & SA_LGB_ParaF4 & 912.97 & 81.1 & 35.07 & 72.96 & 37.35 & 47.75 \\
\hline Langebaan & S. minuta & Paratype 95 & SA_LGB_ParaF5 & 1143.29 & 117.07 & 46.6 & 85.51 & 37.51 & 55.87 \\
\hline Langebaan & S. minuta & Paratype 96 & SA_LGB_ParaF6 & 1059.66 & 89.71 & 39.8 & 52.27 & 30.9 & 38.53 \\
\hline Langebaan & S. minuta & Paratype $\delta 1$ & SA_LGB_ParaM1 & 1155.68 & 102.67 & 38.44 & 69.19 & 46.86 & 54.27 \\
\hline Langebaan & S. minuta & Paratype $\delta^{\lambda} 2$ & SA_LGB_ParaM2 & 1099 & 110.27 & 43.24 & 85.35 & 44.31 & 63.48 \\
\hline Langebaan & S. minuta & Paratype $\bar{\delta} 3$ & SA_LGB_ParaM3 & 1117.34 & 110.65 & 47.34 & 90.44 & 40.46 & 62.76 \\
\hline Langebaan & S. minuta & Paratype $\widehat{\delta} 4$ & SA_LGB_ParaM4 & 1047.34 & 99.21 & 38.6 & 76.46 & 47.71 & 57.39 \\
\hline Gnarabup Beach & S. australis & Holotype & AUS_GNB_HoloM & 2019.02 & 209.21 & 73.84 & 115.29 & 67.47 & 123.95 \\
\hline Gnarabup Beach & S. australis & Paratype +1 & AUS_GNB_ParaF1 & 1900.44 & 196.75 & 89.21 & 138.95 & 47.87 & 114.86 \\
\hline Gnarabup Beach & S. australis & Paratype $\delta 1$ & AUS_GNB_ParaM1 & 1808 & 224.39 & 81.89 & 130.51 & 67.19 & 115.27 \\
\hline Gnarabup Beach & S. australis & Paratype $\delta^{\lambda} 2$ & AUS_GNB_ParaM2 & 2312.6 & 235.11 & 80.59 & 131.72 & 37.62 & 84.99 \\
\hline Sarge Bay & S. australis & Paratype +2 & AUS_SAB_ParaF2 & 2008.77 & 202.73 & 76.18 & 104.79 & 53.32 & 89.06 \\
\hline Sarge Bay & S. australis & Paratype 93 & AUS_SAB_ParaF3 & 1650.14 & 172.52 & 64.76 & 104.79 & 49.6 & 84.56 \\
\hline Sarge Bay & S. australis & Paratype 94 & AUS_SAB_ParaF4 & 2130.8 & 185.77 & 54.33 & 113.22 & 61.04 & 106.34 \\
\hline Sarge Bay & S. australis & Paratype +5 & AUS_SAB_ParaF5 & 2079.81 & 204.69 & 69.79 & 114.52 & 57.38 & 117.42 \\
\hline Sarge Bay & S. australis & Paratype $\delta 3$ & AUS_SAB_ParaM3 & 1804.37 & 145.06 & 59.7 & 98.88 & 60.3 & 75.89 \\
\hline Sarge Bay & S. australis & Paratype $\widehat{\delta} 4$ & AUS_SAB_ParaM4 & 1622.17 & 122.31 & 66.23 & 87.96 & 59.36 & 82.77 \\
\hline 4th July Beach & S. furcata & Individual 2 & USA_4JB_Ind2 & 2075.61 & 283.45 & 143.15 & 240.08 & 71.07 & 126.86 \\
\hline 4th July Beach & S. furcata & Individual 3 & USA_4JB_Ind3 & 1669.4 & 200.72 & 87.72 & 111.82 & 37.54 & 82.19 \\
\hline 4th July Beach & S. furcata & Individual 4 & USA_4JB_Ind4 & 1837.43 & 214.65 & 79.28 & 137.85 & 68.51 & 84.66 \\
\hline 4th July Beach & S. furcata & Individual 5 & USA_4JB_Ind5 & 1718.05 & 218.64 & 78.05 & 130.88 & 55.85 & 86.03 \\
\hline 4th July Beach & S. furcata & Individual 6 & USA_4JB_Ind6 & 2535.21 & 308.11 & 104.79 & 177.73 & 77.18 & 123.73 \\
\hline 4th July Beach & S. furcata & Individual 7 & USA_4JB_Ind7 & 1217.05 & 154.59 & 84.29 & 108.99 & 27.46 & 89.47 \\
\hline Roche Harbor & S. berniei & Individual 1 & USA_ROH_Ind1 & 1342.86 & 166.72 & 60.45 & 106.08 & 39.35 & 74.9 \\
\hline Roche Harbor & S. berniei & Individual 2 & USA_ROH_Ind2 & 1874.94 & 203.63 & 42.85 & 86.68 & 47.96 & 101.62 \\
\hline Roche Harbor & S. berniei & Individual 3 & USA_ROH_Ind3 & 1680.1 & 216.92 & 58.03 & 125.91 & 50.54 & 95.9 \\
\hline Roche Harbor & S. berniei & Individual 4 & USA_ROH_Ind4 & 2406.77 & 273.1 & 81.79 & 162.75 & 70.9 & 143.44 \\
\hline Roche Harbor & S. berniei & Individual 5 & USA_ROH_Ind5 & 2326.9 & 226.89 & 95.54 & 182.19 & 54.18 & 145.75 \\
\hline Roche Harbor & S. berniei & Individual 6 & USA_ROH_Ind6 & 2552.82 & 273.68 & 91.58 & 148.79 & 63.5 & 138.1 \\
\hline Roche Harbor & S. berniei & Individual 7 & USA_ROH_Ind7 & 1864.44 & 232.47 & 58.96 & 153.64 & 47.97 & 116.03 \\
\hline Reuben Tarte & S. americae & Individual 1 & USA_RSP_Ind1 & 2409.03 & 256.93 & 71.27 & 147.03 & 45.67 & 137.85 \\
\hline Reuben Tarte & S. americae & Individual 2 & USA_RSP_Ind2 & 2787.72 & 261.71 & 78.35 & 165.59 & 64.01 & 131.26 \\
\hline Reuben Tarte & S. americae & Individual 3 & USA_RSP_Ind3 & 2733.84 & 283.71 & 103.84 & 189.07 & 76.45 & 174.35 \\
\hline Reuben Tarte & S. americae & Individual 4 & USA_RSP_Ind4 & 2181.42 & 224.14 & 114.39 & 184.93 & 50.12 & 129.56 \\
\hline Reuben Tarte & S. americae & Individual 5 & USA_RSP_Ind5 & 2787.91 & 284.27 & 95.39 & 197.67 & 65.89 & 200.81 \\
\hline Reuben Tarte & S. americae & Individual 6 & USA_RSP_Ind6 & 2516.54 & 275.45 & 109.05 & 193.42 & 44.71 & 171.26 \\
\hline Reuben Tarte & S. americae & Individual 7 & USA_RSP_Ind7 & 2436.34 & 231.51 & 86.84 & 164.01 & 62.08 & 138.87 \\
\hline Canoe Beach & S. westheidei & Individual 1 & USA_CAB_Ind1 & 1570.1 & 168.64 & 73.11 & 107.38 & 51.41 & 86.24 \\
\hline Canoe Beach & S. westheidei & Individual 2 & USA_CAB_Ind2 & 1632.26 & 182.2 & 66.42 & 105.87 & 59.28 & 72.17 \\
\hline Lubec & S. westheidei & Individual 1 & USA_LUB_Ind1 & 2013.09 & 222.07 & 68.53 & 136.84 & 56.89 & 121.91 \\
\hline Lubec & S. westheidei & Individual 2 & USA_LUB_Ind2 & 1851.4 & 184.65 & 63.18 & 136.1 & 43.68 & 106.07 \\
\hline Lubec & S. westheidei & Individual 3 & USA_LUB_Ind3 & 2227.13 & 198.78 & 71.97 & 168.34 & 43.75 & 98.99 \\
\hline Lubec & S. westheidei & Individual 4 & USA_LUB_Ind4 & 1620.44 & 171.11 & 49.22 & 118.02 & 34.88 & 72.28 \\
\hline Lubec & S. westheidei & Individual 5 & USA_LUB_Ind5 & 1647.19 & 147.38 & 73.39 & 113.84 & 48.14 & 77.73 \\
\hline Lubec & S. westheidei & Individual 6 & USA_LUB_Ind6 & 2298.89 & 237.15 & 56.89 & 139.88 & 51.96 & 116.73 \\
\hline Lubec & S. westheidei & Individual 7 & USA_LUB_Ind7 & 1521.28 & 184.64 & 51.68 & 122.04 & 47.11 & 98.58 \\
\hline Lødingen & S. zecai & 436.29 & NOR_LOE_A436.29 & 2365.12 & 245.9 & 82.79 & 127.87 & 59.84 & 79.51 \\
\hline Lødingen & S. zecai & 436.30 & NOR_LOE_A436.30 & 1766.87 & 198.36 & 49.18 & 105.74 & 52.46 & 69.67 \\
\hline Lødingen & S. zecai & 436.31 & NOR_LOE_A436.31 & 2005.23 & 202.46 & 45.08 & 96.72 & 54.92 & 82.79 \\
\hline Lødingen & S. zecai & 436.32 & NOR_LOE_A436.32 & 2388.31 & 195.87 & 51.65 & 123.14 & 50 & 80.58 \\
\hline Lødingen & S. zecai & 436.33 & NOR_LOE_A436.33 & 2277.61 & 250 & 61.16 & 147.93 & 100.83 & 116.94 \\
\hline Lødingen & S. zecai & 436.34 & NOR_LOE_A436.34 & 2456.69 & 241.32 & 73.55 & 112.81 & 83.47 & 123.55 \\
\hline Henningsvær & S. zecai & 437.21 & NOR_HEN_A437.21 & 2293.93 & 221.9 & 57.85 & 118.18 & 50 & 83.47 \\
\hline Henningsvær & S. zecai & 437.23 & NOR_HEN_A437.23 & 2500.06 & 295.46 & 84.71 & 123.55 & 56.41 & 126.03 \\
\hline
\end{tabular}




\begin{tabular}{|c|c|c|c|c|c|c|c|c|c|}
\hline Henningsvær & S. zecai & 437.24 & NOR_HEN_A437.24 & 2572.16 & 280.99 & 54.55 & 102.07 & 63.64 & 123.97 \\
\hline Henningsvær & S. zecai & 437.25 & NOR_HEN_A437.25 & 1876.3 & 198.36 & 85.25 & 121.31 & 65.57 & 114.75 \\
\hline Henningsvær & S. zecai & 437.26 & NOR_HEN_A437.26 & 2573.28 & 255.37 & 57.85 & 118.18 & 49.59 & 113.22 \\
\hline Henningsvær & S. zecai & 437.28 & NOR_HEN_A437.28 & 1514.25 & 170.49 & 50.82 & 108.2 & 45.9 & 81.15 \\
\hline Henningsvær & S. zecai & 437.29 & NOR_HEN_A437.29 & 2392.82 & 262.3 & 44.26 & 107.38 & 61.48 & 104.1 \\
\hline Henningsvær & S. zecai & 437.30 & NOR_HEN_A437.30 & 2352.62 & 293.44 & 84.43 & 136.07 & 63.12 & 119.67 \\
\hline Schilksee & S. subterranea & Neotype & GER_SCS_NeoF & 1692.39 & 140.99 & 54.12 & 82.56 & 46.55 & 77.55 \\
\hline Schilksee & S. subterranea & Paratype +1 & GER_SCS_ParaF1 & 1801.36 & 218.75 & 65.31 & 121.51 & 55.29 & 76.76 \\
\hline Schilksee & S. subterranea & Paratype +2 & GER_SCS_ParaF2 & 1407.97 & 159.51 & 48.13 & 99.11 & 45.94 & 81.02 \\
\hline Schilksee & S. subterranea & Paratype 33 & GER_SCS_ParaM3 & 1841.37 & 171.13 & 33.07 & 93.32 & 45.23 & 58.33 \\
\hline Schilksee & S. subterranea & Paratype $\delta 4$ & GER_SCS_ParaM4 & 1608.5 & 185.78 & 61.52 & 109.71 & 33.85 & 80.41 \\
\hline Île Callot & S. subterranea & Individual 1 & FRA_ILE_Ind1 & 1772.15 & 186.94 & 51.36 & 104.66 & 38.91 & 92.79 \\
\hline Île Callot & S. subterranea & Individual 2 & FRA_ILE_Ind2 & 2074.69 & 233.75 & 66.39 & 109.72 & 50.68 & 98.79 \\
\hline Île Callot & S. subterranea & Individual 3 & FRA_ILE_Ind3 & 2329.07 & 277.84 & 79.73 & 152.68 & 64.65 & 160.32 \\
\hline Île Callot & S. subterranea & Individual 4 & FRA_ILE_Ind4 & 2507.08 & 251.73 & 70.58 & 153.04 & 36.65 & 95.99 \\
\hline Île Callot & S. subterranea & Individual 5 & FRA_ILE_Ind5 & 2441.76 & 285.81 & 89.96 & 167.84 & 47.14 & 125.71 \\
\hline Île Callot & S. subterranea & Individual 6 & FRA_ILE_Ind6 & 1958.52 & 233.13 & 72.9 & 140.66 & 45.31 & 118.62 \\
\hline Glenancross & S. subterranea & 321.51 & UK_GLE_A321.51 & 1352.02 & 204.92 & 88.53 & 126.23 & 43.44 & 78.69 \\
\hline Glenancross & S. subterranea & 321.52 & UK_GLE_A321.52 & 1277.24 & 217.36 & 54.96 & 114.05 & 45.87 & 63.22 \\
\hline Glenancross & S. subterranea & 321.53 & UK_GLE_A321.53 & 1617.29 & 183.88 & 66.53 & 121.49 & 45.46 & 82.23 \\
\hline Glenancross & S. subterranea & 321.55 & UK_GLE_A321.55 & 1219.04 & 143.8 & 54.13 & 91.32 & 39.26 & 54.13 \\
\hline Glenancross & S. subterranea & 321.56 & UK_GLE_A321.56 & 1201.2 & 142.88 & 54.96 & 102.07 & 42.15 & 61.57 \\
\hline Glenancross & S. subterranea & 321.57 & UK_GLE_A321.57 & 1545.18 & 176.03 & 51.24 & 104.13 & 39.26 & 60.33 \\
\hline Glenancross & S. subterranea & 321.59 & UK_GLE_A321.59 & 1358.37 & 185.73 & 52.89 & 104.55 & 42.98 & 76.86 \\
\hline Glenancross & S. subterranea & 321.60 & UK_GLE_A321.60 & 1099.18 & 121.31 & 45.9 & 105.74 & 36.89 & 63.93 \\
\hline Keitum & S. subterranea & 398.1_1 & GER_KEI__A398.1_1 & 1944.72 & 188.84 & 71.49 & 126.45 & 49.17 & 104.55 \\
\hline Keitum & S. subterranea & 398.1_2 & GER_KEI_A398.1_2 & 1427.03 & 146.69 & 66.12 & 118.18 & 45.87 & 86.36 \\
\hline Keitum & S. subterranea & 398.1_3 & GER_KEI_A398.1_3 & 1909.69 & 231.41 & 57.03 & 130.58 & 47.11 & 95.46 \\
\hline Keitum & S. subterranea & 398.1_4 & GER_KEI_A398.1_4 & 2050.62 & 180.58 & 72.31 & 127.27 & 50.83 & 99.59 \\
\hline Keitum & S. subterranea & 398.2_1 & GER_KEI_A398.2_1 & 2185.57 & 149.59 & 61.57 & 108.26 & 43.39 & 78.93 \\
\hline Keitum & S. subterranea & 398.2_2 & GER_KEI_A398.2_2 & 1452 & 151.65 & 61.98 & 111.98 & 45.04 & 83.06 \\
\hline Keitum & S. subterranea & $398.2 \_3$ & GER_KEI_A398.2_3 & 1921.13 & 161.57 & 64.88 & 117.36 & 48.35 & 84.3 \\
\hline Keitum & S. subterranea & 398.2_4 & GER_KEI_A398.2_4 & 1401.46 & 135.95 & 63.22 & 108.26 & 44.63 & 82.23 \\
\hline Keitum & S. subterranea & 398.16 & GER_KEI_A398.16 & 1396.82 & 145.9 & 70.49 & 124.59 & 43.44 & 88.53 \\
\hline Keitum & S. subterranea & 398.17 & GER_KEI_A398.17 & 1613.95 & 174.79 & 58.68 & 114.46 & 57.85 & 100 \\
\hline Bristol Channel & S. josemariobrancoi & Individual 1 & UK_BCH_Ind1 & 1873.11 & 207.79 & 88.07 & 111.54 & 54.05 & 99.27 \\
\hline Bristol Channel & S. josemariobrancoi & Individual 2 & UK_BCH_Ind2 & 2149.73 & 227.91 & 67.44 & 146.56 & 53.36 & 113.37 \\
\hline Bristol Channel & S. josemariobrancoi & Individual 3 & UK_BCH_Ind3 & 1998.95 & 226.25 & 66.45 & 139.53 & 54.81 & 145.95 \\
\hline Bristol Channel & S. josemariobrancoi & Individual 4 & UK_BCH_Ind4 & 2294.3 & 248.21 & 76.08 & 147.1 & 76.32 & 149.98 \\
\hline Bristol Channel & S. josemariobrancoi & Individual 5 & UK_BCH_Ind5 & 1829.39 & 227.4 & 71.96 & 141.17 & 51.03 & 114.78 \\
\hline Gravesend & S. josemariobrancoi & Individual 1 & UK_GRA_Ind1 & 2661.38 & 338.49 & 84.97 & 164.24 & 64.46 & 105.47 \\
\hline Gravesend & S. josemariobrancoi & Individual 2 & UK_GRA_Ind2 & 2275.83 & 226.1 & 67.52 & 145.55 & 59.35 & 114.8 \\
\hline Gravesend & S. josemariobrancoi & Individual 3 & UK_GRA_Ind3 & 2644.38 & 267.09 & 81.52 & 139.92 & 52.82 & 142.71 \\
\hline Gravesend & S. josemariobrancoi & Individual 4 & UK_GRA_Ind4 & 2637.59 & 291.42 & 90.99 & 161.94 & 59.33 & 144.71 \\
\hline Gravesend & S. josemariobrancoi & Individual 5 & UK_GRA_Ind5 & 2493.57 & 264.58 & 71.32 & 144.94 & 50.62 & 118.22 \\
\hline Gravesend & S. josemariobrancoi & Individual 6 & UK_GRA_Ind6 & 3751.87 & 423.71 & 153.28 & 206.36 & 51.2 & 115.59 \\
\hline Gravesend & S. josemariobrancoi & Individual 7 & UK_GRA_Ind7 & 2549.49 & 189.77 & 63.13 & 115.96 & 56.95 & 97.98 \\
\hline Gravesend & S. josemariobrancoi & Individual 8 & UK_GRA_Ind8 & 2625.56 & 234.9 & 85.71 & 110.32 & 61.09 & 119.39 \\
\hline Gravesend & S. josemariobrancoi & Individual 9 & UK_GRA_Ind9 & 2499.99 & 297.56 & 84.72 & 164.46 & 57.75 & 131.38 \\
\hline Plymouth & S. josemariobrancoi & Individual 1 & UK_PLY_Ind1 & 1595.9 & 169.31 & 47.96 & 106.38 & 41.61 & 97.98 \\
\hline Plymouth & S. josemariobrancoi & Individual 2 & UK_PLY_Ind2 & 1317 & 159.65 & 56.13 & 104.45 & 48.81 & 105.2 \\
\hline Plymouth & S. josemariobrancoi & Individual 3 & UK_PLY_Ind3 & 2903.19 & 284.06 & 89.94 & 161.34 & 77.43 & 153.36 \\
\hline Plymouth & S. josemariobrancoi & Individual 4 & UK_PLY_Ind4 & 1713.76 & 225.3 & 62.55 & 130.77 & 56.28 & 120.45 \\
\hline Plymouth & S. josemariobrancoi & Individual 5 & UK_PLY_Ind5 & 3021.08 & 367.8 & 105.95 & 200.45 & 60.57 & 132.59 \\
\hline Plymouth & S. josemariobrancoi & Individual 6 & UK_PLY_Ind6 & 2093.62 & 229.65 & 77.32 & 133.1 & 39.05 & 123.48 \\
\hline Plymouth & S. josemariobrancoi & Individual 7 & UK_PLY_Ind7 & 2689.28 & 312.04 & 93.96 & 171.86 & 56.55 & 156.02 \\
\hline Ellenbogen & S. josemariobrancoi & Individual 1 & GER_ELL_Ind1 & 2386.98 & 255.15 & 70.92 & 160.32 & 160.32 & 126.17 \\
\hline Ellenbogen & S. josemariobrancoi & Individual 2 & GER_ELL_Ind 2 & 2524.11 & 247.34 & 75.37 & 175.99 & 64.66 & 97.37 \\
\hline Ellenbogen & S. josemariobrancoi & Individual 3 & GER_ELL_Ind3 & 2780.02 & 277.53 & 126.13 & 222.07 & 59.78 & 145.03 \\
\hline Ellenbogen & S. josemariobrancoi & Individual 5 & GER_ELL_Ind5 & 2324.45 & 213.18 & 81.59 & 172.38 & 53.95 & 163.36 \\
\hline Ellenbogen & S. josemariobrancoi & Individual 6 & GER_ELL_Ind6 & 2372.22 & 251.88 & 87.12 & 180.05 & 50.92 & 137.65 \\
\hline Ellenbogen & S. josemariobrancoi & Individual 7 & GER_ELL_Ind7 & 2283.45 & 280.01 & 100.28 & 190.78 & 52.69 & 133 \\
\hline Ellenbogen & S. josemariobrancoi & Individual 8 & GER_ELL_Ind8 & 2674.36 & 270.7 & 92.9 & 183.6 & 73.28 & 127.54 \\
\hline Ellenbogen & S. josemariobrancoi & Individual 9 & GER_ELL_Ind9 & 2732.56 & 264.3 & 73.54 & 178.41 & 65.86 & 140.89 \\
\hline Ellenbogen & S. josemariobrancoi & Individual 10 & GER_ELL_Ind 10 & 2593.88 & 256.32 & 140.17 & 219.23 & 78.67 & 155.39 \\
\hline
\end{tabular}


Supplementary Table 4: Least-Square means contrasts in morphological measurements of Stygocapitella species for different measurements including body length and width, Prostomium length and width and pygidium length and width. Z-ratio ( $Z$ ) and p-values $(p)$ associated to each contrast are presented. Statistically significant values $(<0.001)$ are marked in bold.

\begin{tabular}{|c|c|c|c|c|c|c|c|c|c|c|c|c|c|}
\hline \multirow[b]{2}{*}{ Species 1} & \multirow[b]{2}{*}{ Species 2} & \multicolumn{2}{|c|}{$\begin{array}{l}\text { Body } \\
\text { length }\end{array}$} & \multicolumn{2}{|c|}{ Body width } & \multicolumn{2}{|c|}{ Prostomium length } & \multicolumn{2}{|c|}{ Prostomium width } & \multicolumn{2}{|c|}{ Pygidium length } & \multicolumn{2}{|c|}{ Pygidium width } \\
\hline & & Z & $p$ & Z & $p$ & Z & $p$ & Z & $p$ & $\mathrm{Z}$ & $p$ & $\mathrm{Z}$ & $p$ \\
\hline \multirow[t]{9}{*}{ S. minuta } & S. pacifica & -0.79 & 1 & -1.24 & 0.97 & -1.21 & 0.97 & -0.69 & 1 & 0.47 & 1 & -0.54 & 1 \\
\hline & S. australis & -5.72 & $<0.001$ & -5.15 & $<0.001$ & -4.40 & $<0.001$ & -3.98 & 0.003 & -2.94 & 0.1 & -5.65 & $<0.001$ \\
\hline & S. berniei & -5.60 & $<0.001$ & -6.59 & $<0.001$ & -3.75 & $<0.01$ & -5.82 & $<0.001$ & -2.24 & 0.43 & -6.87 & $<0.001$ \\
\hline & S. americae & -8.77 & $<0.001$ & -8.24 & $<0.001$ & -6.94 & $<0.001$ & -9.47 & $<0.001$ & -3.01 & 0.08 & -10.84 & $<0.001$ \\
\hline & S. budaevae & -1.95 & 0.63 & -2.83 & 0.13 & -1.86 & 0.70 & -1.62 & 0.84 & -0.54 & 1 & -1.17 & 0.98 \\
\hline & S. zесаi & -8.34 & $<0.001$ & -8.46 & $<0.001$ & -3.43 & 0.02 & -4.73 & $<0.001$ & -4.14 & 0.01 & -6.36 & $<0.001$ \\
\hline & S. subterranea & -5.23 & $<0.001$ & -6.07 & $<0.001$ & -3.78 & $<0.01$ & -5.28 & $<0.001$ & -1.38 & 0.93 & -5.14 & $<0.001$ \\
\hline & S. josemariobrancoi & -10.91 & $<0.001$ & -11.17 & $<0.001$ & -7.78 & $<0.001$ & -10.48 & $<0.001$ & -4.78 & $<0.001$ & -11.01 & $<0.001$ \\
\hline & S. westheidei & -4.85 & $<0.001$ & -4.93 & $<0.001$ & -3.18 & 0.048 & -5.22 & $<0.001$ & -1.59 & 0.85 & -4.94 & $<0.001$ \\
\hline \multirow{8}{*}{ S. pacifica } & S. australis & -2.45 & 0.30 & -1.68 & 0.81 & -1.28 & 0.96 & -1.56 & 0.87 & -2.13 & 0.51 & -2.66 & 0.19 \\
\hline & S. berniei & -2.62 & 0.21 & -2.79 & 0.14 & -1.10 & 0.99 & -2.85 & 0.12 & -1.81 & 0.73 & -3.6 & 0.01 \\
\hline & S. americae & -4.53 & $<0.001$ & -3.78 & $<0.001$ & -3.02 & 0.08 & -5.05 & $<0.001$ & -2.27 & 0.41 & -6.02 & $<0.001$ \\
\hline & S. budaevae & -0.38 & 1 & -0.46 & 1 & 0.09 & 1 & -0.28 & 1 & -0.78 & 1 & -0.16 & 1 \\
\hline & S. zecai & -3.64 & 0.01 & -3.25 & 0.04 & -0.59 & 1 & -1.82 & 0.72 & -2.69 & 0.18 & -2.84 & 0.12 \\
\hline & S. subterranea & -1.71 & 0.79 & -1.64 & 0.83 & -0.55 & 1 & -1.83 & 0.72 & -1.16 & 0.98 & -1.93 & 0.65 \\
\hline & S. josemariobrancoi & -4.43 & $<0.001$ & -4.09 & $<0.01$ & -2.47 & 0.28 & -4.33 & $<0.001$ & -2.81 & 0.13 & -4.75 & $<0.001$ \\
\hline & S. westheidei & -2.02 & 0.59 & -1.62 & 0.84 & -0.63 & 1 & -2.32 & 0.37 & -1.38 & 0.93 & -2.31 & 0.38 \\
\hline \multirow[t]{7}{*}{ S. australis } & S. berniei & -0.42 & 1 & -1.90 & 0.67 & 0.23 & 1 & -2.18 & 0.47 & 0.40 & 1 & -1.73 & 0.78 \\
\hline & S. americae & -3.53 & 0.02 & -3.52 & 0.02 & -2.90 & 0.10 & -5.76 & $<0.001$ & -0.35 & 1 & -5.63 & $<0.001$ \\
\hline & S. budaevae & 3.36 & 0.03 & 1.97 & 0.62 & 2.24 & 0.43 & 2.08 & 0.54 & 2.17 & 0.47 & 4.06 & $<0.01$ \\
\hline & S. zecai & -2.08 & 0.55 & -2.80 & 0.14 & 1.32 & 0.95 & -0.40 & 1 & -0.93 & 1 & -0.23 & 1 \\
\hline & S. subterranea & 1.77 & 0.76 & 0.27 & 1 & 1.60 & 0.85 & -0.35 & 1 & 2.17 & 0.48 & 1.77 & 0.75 \\
\hline & S. josemariobrancoi & -3.68 & $<0.01$ & -4.62 & $<0.001$ & -2.24 & 0.43 & -5.36 & $<0.001$ & -1.10 & 0.98 & -3.86 & $<0.01$ \\
\hline & S. westheidei & 0.70 & 1 & 0.07 & 1 & 1.08 & 0.99 & -1.32 & 0.95 & 1.24 & 0.97 & 0.54 & 1 \\
\hline \multirow[t]{6}{*}{ S. berniei } & S. americae & -2.87 & 0.11 & -1.49 & 0.90 & -2.88 & 0.11 & -3.30 & 0.03 & -0.70 & 1 & -3.59 & 0.01 \\
\hline & S. budaevae & 3.48 & 0.02 & 3.62 & 0.01 & 1.83 & 0.71 & 3.98 & $<0.01$ & 1.61 & 0.84 & 5.37 & $<0.001$ \\
\hline & S. zecai & -1.41 & 0.92 & -0.48 & 1 & 0.93 & 1 & 1.96 & 0.63 & -1.26 & 0.96 & 1.64 & 0.83 \\
\hline & S. subterranea & 2.03 & 0.58 & 2.47 & 0.29 & 1.13 & 0.99 & 2.24 & 0.43 & 1.42 & 0.92 & 3.57 & 0.01 \\
\hline & S. josemariobrancoi & -2.71 & 0.17 & -1.79 & 0.74 & -2.21 & 0.45 & -2.10 & 0.53 & -1.43 & 0.92 & -1.33 & 0.95 \\
\hline & S. westheidei & 1.05 & 0.99 & 1.93 & 0.65 & 0.76 & 1 & 0.93 & 1 & 0.74 & 1 & 2.19 & 0.46 \\
\hline \multirow[t]{5}{*}{ S. americae } & S. budaevae & 6.44 & $<0.001$ & 5.15 & $<0.001$ & 4.81 & $<0.001$ & 7.39 & $<0.001$ & 2.33 & 0.37 & 9.08 & $<0.001$ \\
\hline & S. zесаi & 1.90 & 0.67 & 1.24 & 0.97 & 4.27 & $<0.001$ & 5.77 & $<0.001$ & -0.46 & 1 & 5.79 & $<0.001$ \\
\hline & S. subterranea & 5.67 & $<0.001$ & 4.35 & $<0.001$ & 4.79 & $<0.001$ & 6.43 & $<0.001$ & 2.30 & 0.39 & 8.13 & $<0.001$ \\
\hline & S. josemariobrancoi & 0.95 & 0.99 & 0.11 & 1 & 1.46 & 0.91 & 2.10 & 0.53 & -0.55 & 1 & 3.25 & 0.04 \\
\hline & S. westheidei & 4.09 & $<0.01$ & 3.51 & 0.02 & 3.82 & $<0.01$ & 4.43 & $<0.001$ & 1.47 & 0.90 & 6.00 & $<0.001$ \\
\hline \multirow[t]{4}{*}{ S. budaevae } & S. zecai & -5.54 & $<0.001$ & -4.72 & $<0.001$ & -1.17 & 0.98 & -2.60 & 0.22 & -3.20 & 0.045 & -4.56 & $<0.001$ \\
\hline & S. subterranea & -2.37 & 0.35 & -2.09 & 0.54 & -1.19 & 0.97 & -2.80 & 0.14 & -0.59 & 1 & -3.2 & 0.045 \\
\hline & S. josemariobrancoi & -7.38 & $<0.001$ & -6.59 & $<0.001$ & -4.702 & $<0.001$ & -7.40 & $<0.001$ & -3.60 & 0.01 & -8.38 & $<0.001$ \\
\hline & S. westheidei & -2.62 & 0.21 & -1.85 & 0.70 & -1.16 & 0.98 & -3.28 & 0.03 & -0.95 & 0.99 & -3.45 & 0.02 \\
\hline
\end{tabular}




\begin{tabular}{|c|c|c|c|c|c|c|c|c|c|c|c|c|c|}
\hline \multirow[t]{3}{*}{ S. zесаi } & S. subterranea & 4.63 & $<0.001$ & 3.87 & $<0.01$ & 0.13 & 1 & 0.12 & 1 & 3.63 & 0.01 & 2.29 & 0.40 \\
\hline & S. josemariobrancoi & -1.49 & 0.89 & -1.63 & 0.83 & -4.20 & 0.001 & -5.52 & $<0.001$ & -0.05 & 1 & -4.06 & $<0.01$ \\
\hline & S. westheidei & 2.79 & 0.15 & 2.79 & 0.14 & -0.11 & 1 & -1.03 & 0.99 & 2.24 & 0.43 & 0.80 & 1 \\
\hline \multirow{2}{*}{ S. subterrant } & S. josemariobrancoi & -7.65 & $<0.001$ & -6.87 & $<0.001$ & -5.39 & $<0.001$ & -7.01 & $<0.001$ & -4.60 & $<0.001$ & -7.90 & $<0.001$ \\
\hline & S. westheidei & -0.86 & 1 & -0.18 & 1 & -0.23 & 1 & -1.25 & 0.96 & -0.59 & 1 & -1.05 & 0.99 \\
\hline S. westheidei & S. josemariobrancoi & 4.38 & $<0.001$ & 4.53 & $<0.001$ & 3.46 & 0.02 & 3.55 & 0.01 & 2.56 & 0.24 & 4.37 & $<0.001$ \\
\hline
\end{tabular}


Supplementary Table 5: Pairwise interspecific genetic distances using the COI dataset for the studied Stygocapitella species. These distances were computed using MEGA X. After defining groups (species), we calculated distances between group mean differences after the bootstrap method (500 replications), model TN-93, Rates among Sites Gamma Distribution, Gamma Parameter 1,00. Values on the lower end of the matrix represent genetic distances, values on the upper end of the matrix represent the standard deviation.

\begin{tabular}{|c|c|c|c|c|c|c|c|c|c|c|c|c|}
\hline & S. budaevae & S. pacifica & S. josemariobrancoi & S. westheidei & S. subterranea & S. australis & S. berniei & S. americae & S. zecai & S. minuta & $\operatorname{S.spec} A$ & S. furcata \\
\hline S. budaevae & & 0.0275 & 0.0289 & 0.0253 & 0.0262 & 0.0272 & 0.0308 & 0.0301 & 0.0261 & 0.0408 & 0.0108 & 0.0284 \\
\hline S. pacifica & 0.2944 & & 0.0305 & 0.0287 & 0.0290 & 0.0290 & 0.0329 & 0.0342 & 0.0303 & 0.0362 & 0.0291 & 0.0227 \\
\hline S. josemariobrancoi & 0.3034 & 0.3405 & & 0.0171 & 0.0173 & 0.0246 & 0.0278 & 0.0281 & 0.0231 & 0.0398 & 0.0282 & 0.0288 \\
\hline S. westheidei & 0.2545 & 0.3157 & 0.1639 & & 0.0095 & 0.0227 & 0.0263 & 0.0263 & 0.0186 & 0.0366 & 0.0248 & 0.0282 \\
\hline S. subterranea & 0.2565 & 0.3194 & 0.1634 & 0.0577 & & 0.0222 & 0.0269 & 0.0269 & 0.0202 & 0.0374 & 0.0251 & 0.0278 \\
\hline S. australis & 0.2975 & 0.3208 & 0.2690 & 0.2450 & 0.2356 & & 0.0302 & 0.0276 & 0.0239 & 0.0379 & 0.0262 & 0.0308 \\
\hline S. berniei & 0.3342 & 0.3768 & 0.2949 & 0.2816 & 0.3013 & 0.3322 & & 0.0144 & 0.0282 & 0.0393 & 0.0287 & 0.0348 \\
\hline S. americae & 0.3202 & 0.3784 & 0.3029 & 0.2692 & 0.2825 & 0.2983 & 0.1180 & & 0.0279 & 0.0404 & 0.0299 & 0.0352 \\
\hline S. zecai & 0.2629 & 0.3291 & 0.2371 & 0.1741 & 0.1846 & 0.2555 & 0.3019 & 0.3044 & & 0.0357 & 0.0255 & 0.0307 \\
\hline S. minuta & 0.4096 & 0.4043 & 0.3961 & 0.3824 & 0.3940 & 0.3870 & 0.4205 & 0.4264 & 0.3814 & & 0.0392 & 0.0381 \\
\hline S. spec $A$ & 0.0694 & 0.3227 & 0.2967 & 0.2449 & 0.2477 & 0.2961 & 0.3005 & 0.3017 & 0.2574 & 0.4012 & & 0.0293 \\
\hline S. furcata & 0.2885 & 0.2303 & 0.3298 & 0.2956 & 0.3093 & 0.3593 & 0.3748 & 0.3851 & 0.3337 & 0.4107 & 0.3132 & \\
\hline
\end{tabular}


Supplementary Table 6: Intraspecific genetic distances using the COI dataset for the studied Stygocapitella species. These distances were computed using MEGA X. After defining groups (species), we calculated genetic distances for each group after the bootstrap method (500 replications), model TN-93, Rates among Sites Gamma Distribution, Gamma Parameter 1,00. ' $\mathrm{n} / \mathrm{c}$ ' stands for non-calculated due to a reduced number of individuals.

\begin{tabular}{lll} 
& Distance & Standard Error \\
\hline S. budaevae & 0.001961233 & 0.000949231 \\
S. pacifica & $\mathrm{n} / \mathrm{c}$ & $\mathrm{n} / \mathrm{c}$ \\
S. josemariobrancoi & 0.01622295 & 0.003269977 \\
S. westheidei & 0.004264828 & 0.001335192 \\
S. subterranea & 0.005740379 & 0.001110693 \\
S. australis & 0.067016213 & 0.008159899 \\
S. berniei & 0.001071403 & 0.000580938 \\
S. americae & 0 & 0 \\
S. zecai & 0.004776885 & 0.001455438 \\
S. minuta & 0.009434387 & 0.002140802 \\
S. spec A & 0.003217497 & 0.001383465 \\
S. furcata & 0.004283353 & 0.002097259
\end{tabular}



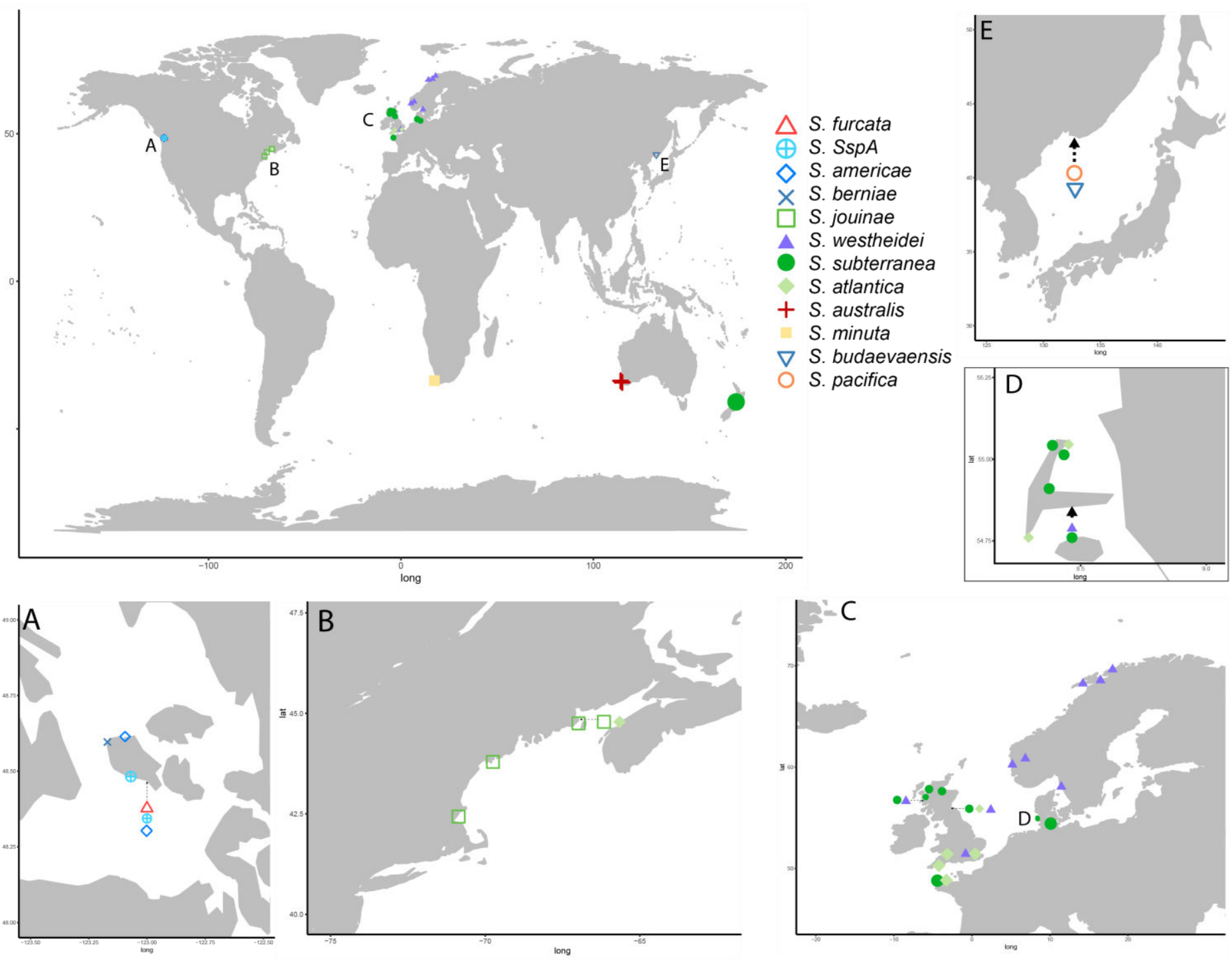

Supplementary Figure 1: World-map with sampling locations included as part of Cerca et al.. The world-view panel displays sampling locations as well as symbols for every species included in this study. As part of this panel, we provide indications of: Panel A) sampling area in the Pacific US; Panel B) sampling locations in the Atlantic coastline of the USA; Panel C) sampling locations in European coastline; Panel D) displays the island of Sylt in Northern Germany; Panel E) displays sampling locations in Far-East-Russia. 


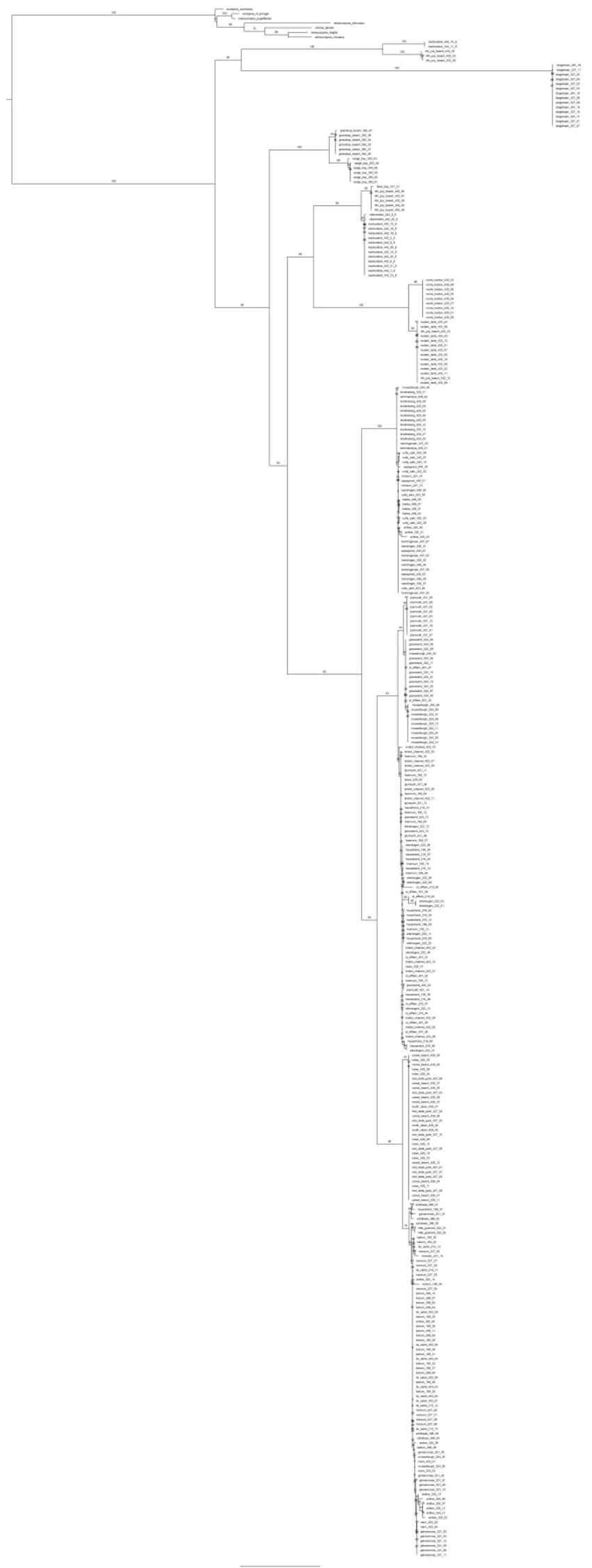

Supplementary Figure 2: Maximum Likelihood Phylogram of the 16S dataset. Bootstrap support values are included for every branch. 


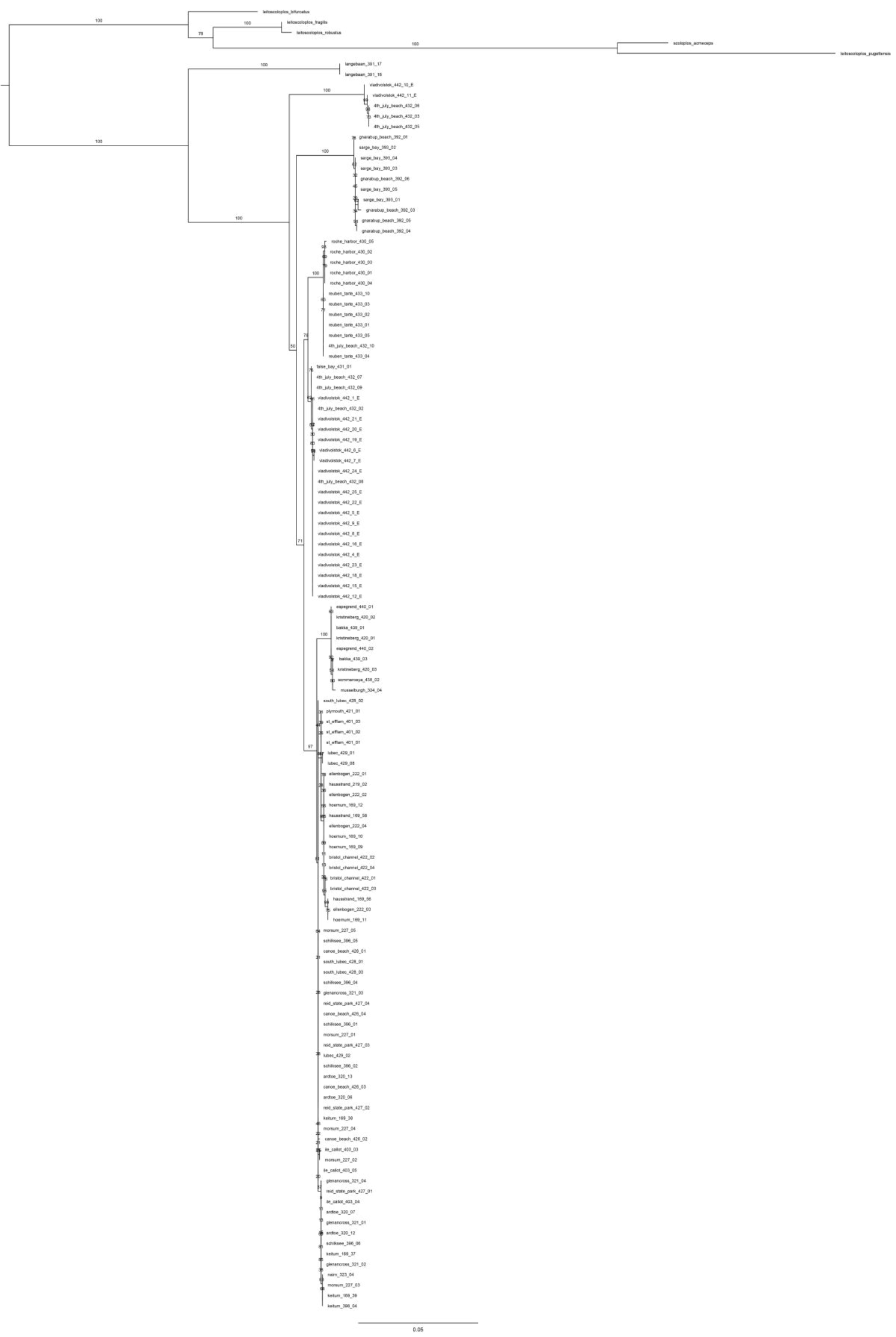

Supplementary Figure 3: Maximum Likelihood Phylogram of the 18S dataset. Bootstrap support values are included for every branch. 


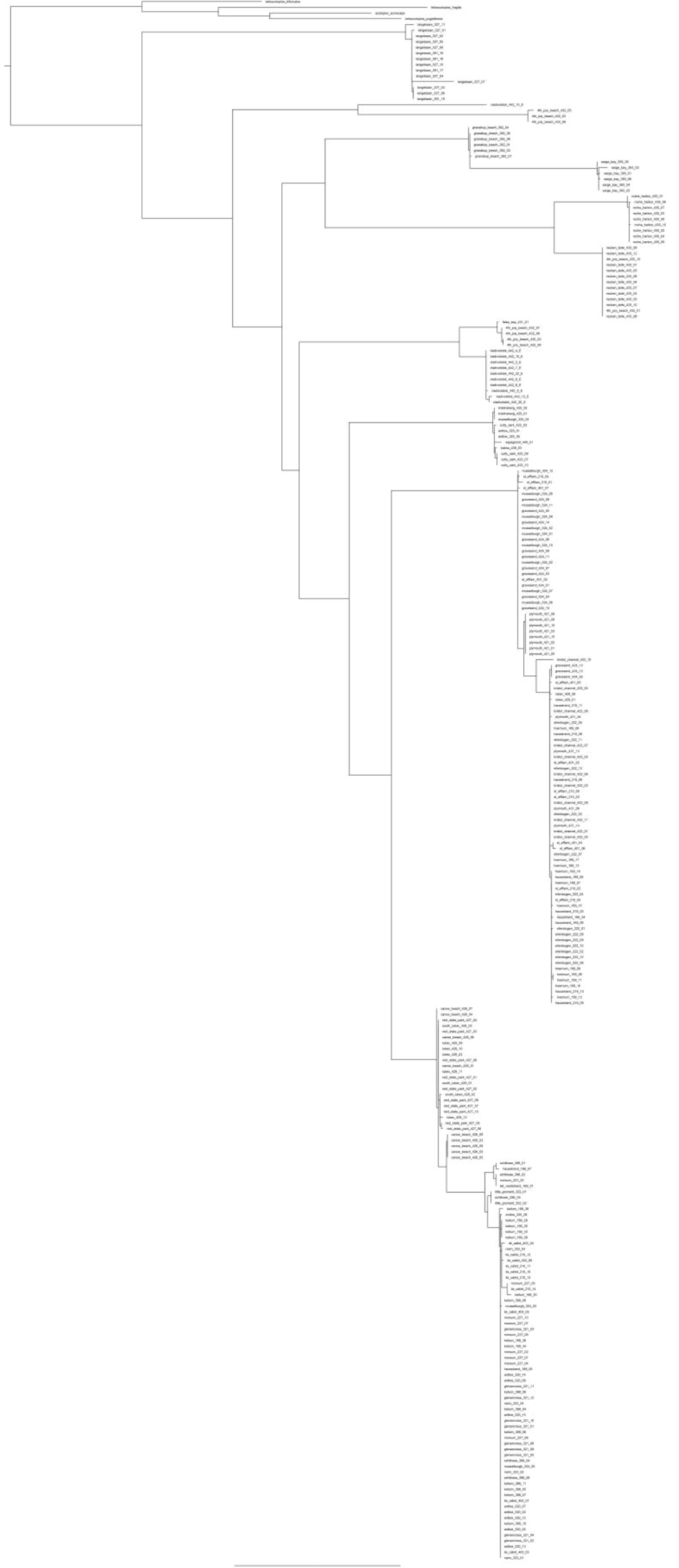

Supplementary Figure 4: Maximum Likelihood Phylogram of the COI dataset. Bootstrap support values are included for every branch. 


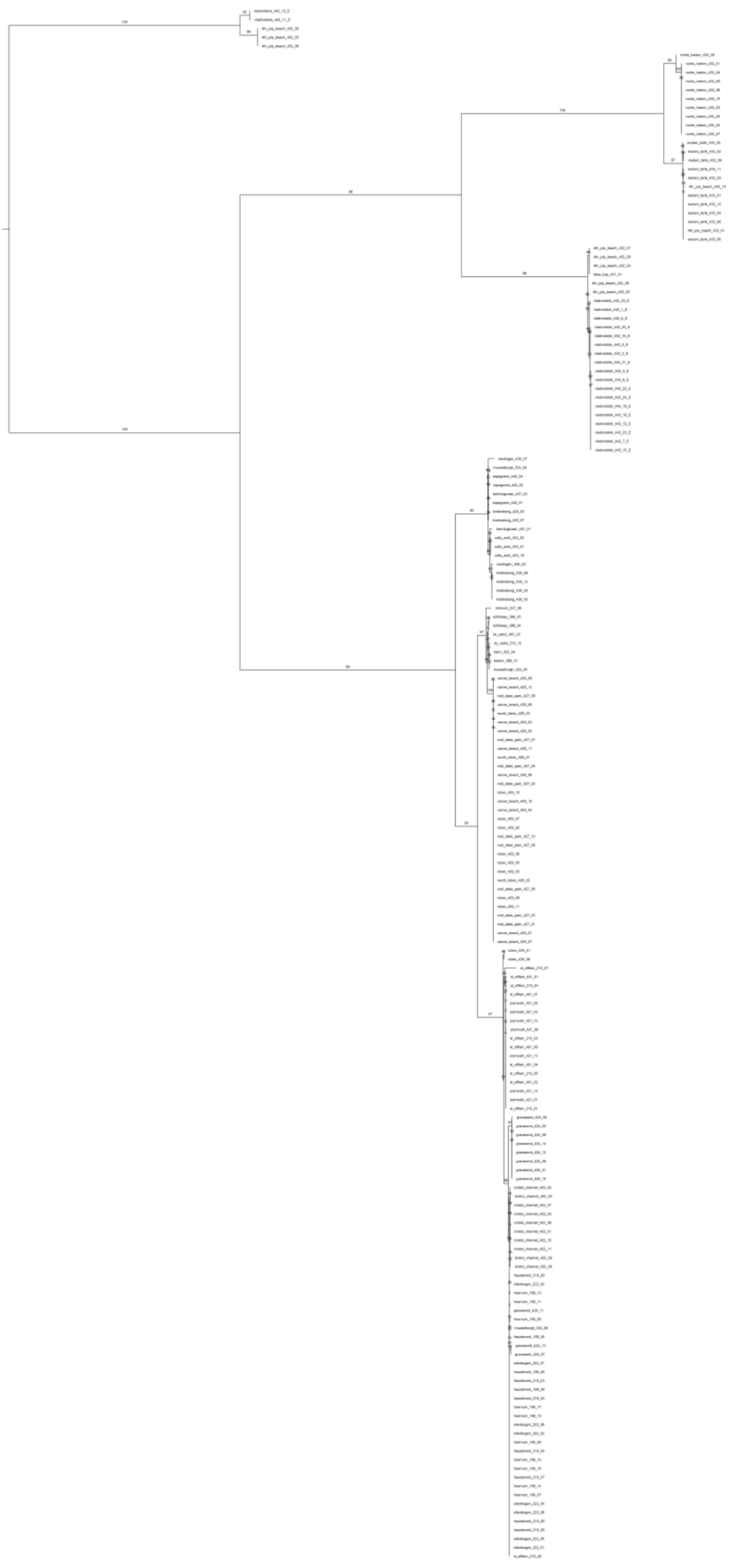

Supplementary Figure 5: Maximum Likelihood Phylogram of the ITS1 dataset. Bootstrap support values are included for every branch. 
A) $16 \mathrm{~S}$

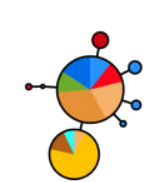

S. zecai sp. nov.

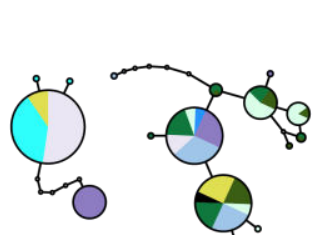

S. josemariobrancoi sp. nov.

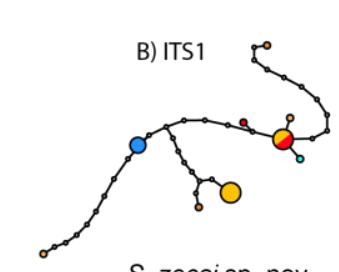

S. zecai sp. nov.

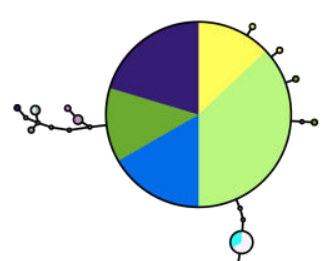

S. subterranea sensu stricto

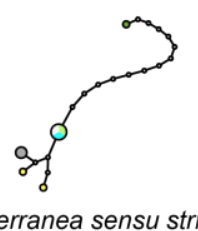

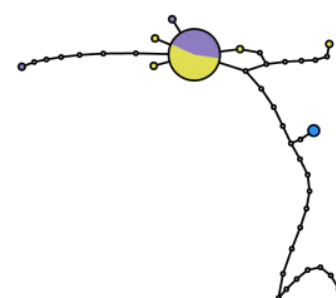

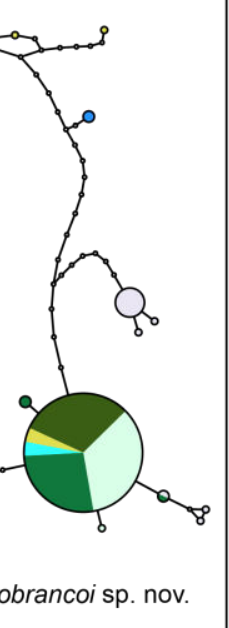

S. subterranea sensu stricto S. josemariobrancoi sp. nov.

C) $\mathrm{COI}$

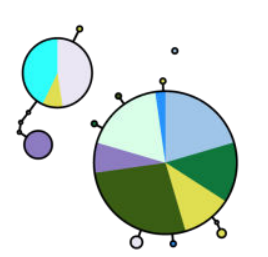

S. zecai sp. nov

S. josemariobrancoi sp. nov.

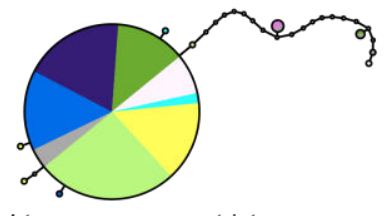

S. subterranea sensu stricto

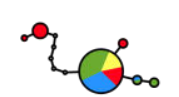

S. westheidei sp. nov.

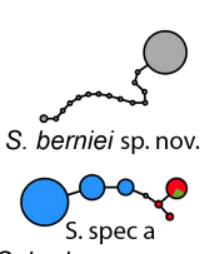

S. budaevae sp. nov. $\rightarrow$

S. pacifica sp. nov.
S. westheideisp nov.

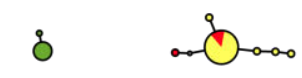

S. minuta S. americae sp. nov. $\circ$

S. furcata sp. nov.

S. speca $\quad$ S. australis S. furcata sp. nov.

O.

S. budaevae sp. nov.

S. pacifica sp. nov.

Supplementary Figure 6: Haplotype networks colored by sampling location. Panel A) displays 16S; Panel B) displays ITS1; Panel C) displays COI. Networks are divided by ocean and coastlines (horizontal divisions) including the North European coastline, the East American Coastline and the Pacific Ocean. 

José Cerca - On the Origin of Cryptic Species: Insights from the Stygocapitella species complex

Appendices including non-peer reviewed replies and book chapters 1-2 
José Cerca - On the Origin of Cryptic Species: Insights from the Stygocapitella species complex

\section{Appendix 1}

Cryptic Species - more than terminological chaos: A reply to Heethoff 
References

1. Kuparinen, A. and Uusi-Heikkilä, S. (2018) Sustainability of fishing is about abundance: a response to Bernatchez et al. Trends Ecol. Evol. 33, 307-308

2. Bernatchez, L. et al. (2017) Harnessing the power of genomics to secure seafood future. Trends Ecol. Evol. 9, 665680

3. Willette, D. et al. (2014) So, you want to use next-generation sequencing in marine systems? Insight from the Pan-Pacific Advanced Studies Institute. Bull. Mar. Sci. 90, 79-122

4. Pearse, D. (2016) Saving the spandrels? Adaptive genomic variation in conservation and fisheries management. J. Fish Biol. 89, 2697-2716

5. Kelley, J.L. et al. (2016) The life aquatic: advances in marine vertebrate genomics. Nat. Rev. Genet. 4, 523-534

6. Waples, R.S. et al. (2008) Integrating genetic data into management of marine resources: how can we do it better? Fish Fish. 9, 423-449

\section{Letter}

Cryptic Species Conceptual or

Terminological Chaos? A Response to Struck et al.

\section{Michael Heethoff ${ }^{1, \star}$}

In a recent article, Struck et al. [1] aimed at finding evolutionary processes hidden in cryptic species. They provided a broad overview on the different usage of the term 'cryptic species' and called for a more rigorous definition by comparing phenotypic (morphological) disparity with the degree of genetic differentiation. They conclude 'if biologists cannot even agree on what to consider different species, then how can we reach consensus on what represents cryptic species?' I argue that there is only one solution to both of these issues and that cryptic species represent nothing more than an incompatibility of species 'concepts' in applied taxonomy. Hence, 'cryptic species' can neither be defined nor are they outcomes of an evolutionary process like 'cryptic speciation'.

Species delimitation has been confused with species conceptualization, leading to a controversy on what the species category is and how species can be delineated [2]. The evolutionary species concept [3] represents a general primary concept, however, without much value for applied taxonomy. Applied taxonomy mostly refers to the morphological species concept, although there is no clearly defined workflow for species delineation [4]. In this context, Struck et al. suggest that 'morphological variation needs to be explicitly quantified', and I could not agree more. The biological species concept [5] is often used to confirm or reject morphospecies hypotheses, but is only applicable to sexually reproducing organisms. Using genetic differences for species delineation has also been proposed (e. g., [6]), and has recently been applied to split giraffes into four distinct species despite them interbreeding in captivity [7]. Hence, whether a species is cryptic or not depends on nothing else than the underlying species concept. Struck et al. implicitly used the morphological species concept and 'tested' it against genetic divergence. Hence, they compared two classes of species concepts (morphological vs. genetical) regarding their compatibility (i.e., supporting the same boundaries of species), and 'define' species to be cryptic when they are morphologically similar but genetically distinct (which is here taken as a proxy for 'reduced gene flow' and 'reproductive isolation' and would thus confirm the biological species hypothesis). This approach prioritizes the 'evolutionary truth' of genetic over morphological species concepts - probably a valid approach in many if not most cases. Ten years ago, Bickford and colleagues defined cryptic species as "two or more distinct species classified as a single species' [8], rendering 'cryptic' species as nothing more than grouping artifacts. I agree and conclude that cryptic species do not exist as a concept, but that the term 'cryptic' is only used to prioritize one species concept over others. Eventually, it may turn out that cryptic species are not so cryptic at all [9].

Hence, we should not aim at defining what 'cryptic species' are, but what species concept we believe to represent evolutionary entities that we can use as fundamental units in biology - even if such a concept may lack clear instructions for applied taxonomy.

${ }^{1}$ Ecological Networks, Technische Universität Darmstadt, Schnittspahnstraße 3, 64287 Darmstadt, Germany

${ }^{*}$ Correspondence:

heethoff@bio.tu-darmstadt.de34 (M. Heethoff).

https://doi.org/10.1016/j.tree.2018.02.006

References

1. Struck, T.H. et al. (2017) Finding evolutionary processes hidden in cryptic species. Trends Ecol. Evol. 33, 153-163

2. De Queiroz, K. (2007) Species concepts and species delimitation. Syst. Biol. 56, 879-886

3. Simpson, G.G. (1951) The species concept. Evolution V, 285-298

4. Mayden, R.L. et al. (1997) A hierarchy of species concepts: the denouement in the saga of the species problem. In Species: The Units of Biodiversity (Claridge, M.F., ed.), pp. 381-424, Chapman \& Hal

5. Mayr, E. (1940) Speciation phenomena in birds. Am. Nat. 74, 249-278

6. Birky, C.W. et al. (2010) Using population genetic theory and DNA sequences for species detection and identification in asexual organisms. PLoS One 5, e1060951

7. Fennessy, J. et al. (2016) Multi-locus analyses reveal four giraffe species instead of one. Curr. Biol. 26, 2543-2549

8. Bickford, D. et al. (2007) Cryptic species as a window on diversity and conservation. Trends Ecol. Evol. 22, 148-155

9. Sykes, B.C. et al. (2014) Genetic analysis of hair samples attributed to yeti, bigfoot and other anomalous primates. Proc. Biol. Sci. 281, 20140161

\section{Letter}

Cryptic Species More Than

Terminological Chaos: A Reply to Heethoff
Torsten H. Struck, ${ }^{1, \star}$ Jeffrey L. Feder, ${ }^{2}$ Mika Bendiksby, ${ }^{1,3}$ Siri Birkeland, ${ }^{1}{ }^{1}$ Jose Cerca, ${ }^{1}$ Vladimir I. Gusarov, ${ }^{1}$ Sonja Kistenich, ${ }^{1}$ 


\author{
Karl-Henrik Larsson, ${ }^{1}$ \\ Lee Hsiang Liow, ${ }^{1,4}$ \\ Michael D. Nowak, ${ }^{1}$ \\ Brita Stedje, ${ }^{1}$ Lutz Bachmann, ${ }^{1}$ \\ and Dimitar Dimitrov ${ }^{1,5}$
}

Recently we discussed problems and challenges associated with inconsistent definitions and methods used to identify cryptic species, and how these hamper studies of their evolutionary significance. We proposed a conceptual framework that is focussed on evolutionary processes and advocated for a shift from pattern- to process-driven research concerning cryptic species, in order to circumvent these issues [1]. In his response, Heethoff [2] argued that cryptic species are merely a reflection of the limitations of applied taxonomy. Hestated that cryptic species 'represent nothing more than an incompatibility of species "concepts" in applied taxonomy'. As such, he rejected our proposed framework as an approach that "prioritizes the "evolutionary truth" of genetic over morphological species concepts'. In our opinion Heethoff's conclusions are based on his misconceptions about the proposed framework.

In essence, Heethoff repeats the oftencited opinion that cryptic species are only a temporary taxonomical formalization problem of species delineation $[3,4]$ and not a natural phenomenon. He supports this view with examples of diverging species in the so-called grey zone of speciation $[5,6]$, like the giraffe, and ignores many examples of good species with unusually high phenotypic similarity despite restricted gene flow, sometimes over long time periods [7-11]. Importantly, our survey of the literature revealed that there are as many old cryptic species reported as young ones [1]. However, the current taxonomic practice makes it difficult to differentiate between these two cases and to understand the evolutionary processes and mechanisms underlying their origins.
Thus, we proposed a framework that in contrast to previous approaches explicitly separated the two steps, that is, species delineation and assignment of the status cryptic. Specifically, we concluded that what is needed is a rigorous quantitative assessment of phenotypic similarity in an evolutionary context [1]. To this end, our framework provides explicit means of differentiating taxonomical errors from true cryptic biodiversity. The first basic requirement of our framework is to show that the lineages in question are clearly separate species [5]. This can be achieved by applying any species concept. We provided examples based on molecular approaches, but we did not advocate for any particular species concept, as presumed by Heethoff. In fact, our proposed call for proof of species being distinct is not different from any other species delineation attempt, and evidence should be based on as many sources of information as possible [5].

The second step of assigning the status cryptic implies that a null expectation (hypothesis) is to be formulated and tested. Specifically, it requires evidence for substantially higher degrees of phenotypic similarity between species in question than expected. This can, for example, be achieved by comparing evolutionary rates to other species pairs within the lineage. If the homogenizing effect of gene flow is shown to be low or absent, high phenotypic similarity becomes less likely with increasing divergence time. Hence, only species exhibiting statistically lower degrees of phenotypic disparity than expected for a given divergence time are accepted as cryptic in the proposed framework. Genetic divergence was proposed as a proxy, when actual divergence times cannot be determined with high confidence. This proposal offers further advantages because genetic divergence estimates can also serve as proxy for the degree of gene flow. However, this does not mean that genetic divergence serves as a proxy for the biological species concept, as implied by Heethoff. Species delineation is done in the first step from the sum whole of information, including genetic data, before cryptic status is assigned.

Finally, it is important to note that we did not advocate that cryptic species are the outcome 'of an evolutionary process like cryptic speciation'. We clearly stated that this term is misleading and should not be used. When it comes to cryptic species, only recent divergence can be directly related to the speciation processes. Other processes such as convergence, parallelism, and stasis are not related to the speciation process itself, but describe macroevolutionary processes that have led to high phenotypic similarity as the outcome of evolution. We explicitly outlined the advantages of cryptic species as models for understanding these processes [1], an end goal of our proposed framework.

Responding to concerns raised by Heethoff [2], we conclude that they are the result of misconceptions about our framework. We reaffirm that our approach to evaluating whether species are cryptic is transparent, repeatable, and independent of taxonomic treatment (e.g., usage of species concepts and history of synonymies). We all make errors and overlook things sometimes, taxonomists included, but cryptic species are more than errors. If we take the time to define and quantify cryptic species with rigor, then they have potentially much to teach us about evolution beyond just learning from our mistakes.

\footnotetext{
${ }^{1}$ Natural History Museum, University of Oslo, 0318 Oslo, Norway

${ }^{2}$ Department of Biological Sciences, University of Notre Dame, Notre Dame, IN 46556, USA ${ }^{3}$ NTNU University Museum, Norwegian University of Science and Technology, 7491 Trondheim, Norway ${ }^{4}$ Centre for Ecological \& Evolutionary Synthesis (CEES), Department of Biosciences, University of Oslo, 0316 Oslo, Norway
} 
${ }^{5}$ Center for Macroecology, Evolution and Climate, Natural History Museum of Denmark, University of Copenhagen,

Copenhagen, Denmark

*Correspondence: t.h.struck@nhm.uio.no (T.H. Struck).

https://doi.org/10.1016/j.tree.2018.02.008

References

1. Struck, T.H. et al. (2018) Finding evolutionary processes hidden in cryptic species. Trends Ecol. Evol. 33, 153-163

2. Heethoff, M. (2018) Cryptic species - conceptual or terminological chaos? A response to Struck et al. Trends Ecol. Evol. 33, 310

3. Korshunova, T. et al. (2017) External diversity is restrained by internal conservatism: new nudibranch mollusc contributes to the cryptic species problem. Zool. Scripta 46, 683-692

4. Bickford, D. et al. (2007) Cryptic species as a window on diversity and conservation. Trends Ecol. Evol. 22, 148-155

5. Pante, E. et al. (2015) Species are hypotheses: avoid connectivity assessments based on pillars of sand. $\mathrm{Mol}$. Ecol. 24, 525-544

6. Sukumaran, J. and Knowles, L.L. (2017) Multispecies coalescent delimits structure, not species. Proc. Natl. Acad. Sci. U. S. A. 114, 1607-1612

7. Smith, K.L. et al. (2011) Evidence of constrained phenotypic evolution in a cryptic species complex of agamid lizards. Evolution 65, 976-992
8. Struck, T.H. et al. (2017) Two new species in the annelid genus Stygocapitella (Orbiniida, Parergodrilidae) with comments on their biogeography. Zootaxa 4286, 301-332

9. Wada, S. et al. (2013) Long-term stasis and short-term divergence in the phenotypes of microsnails on oceanic islands. Mol. Ecol. 22, 4801-4810

10. Swift, H.F. et al. (2016) Three routes to crypsis: stasis, convergence, and parallelism in the Mastigias species complex (Scyphozoa, Rhizostomeae). Mol. Phylogenet. Evol. 99, 103-115

11. Cursino, M. et al. (2014) The role of chromosome variation in the speciation of the red brocket deer complex: the study of reproductive isolation in females. BMC Evol. Biol. 14,40 
José Cerca - On the Origin of Cryptic Species: Insights from the Stygocapitella species complex

\section{Appendix 2}

Cryptic species and their evolutionary significance 


\section{Evolutionary Significance}

Torsten H Struck, Natural History Museum, University of Oslo, Oslo, Norway

José Cerca, Natural History Museum, University of Oslo, Oslo, Norway

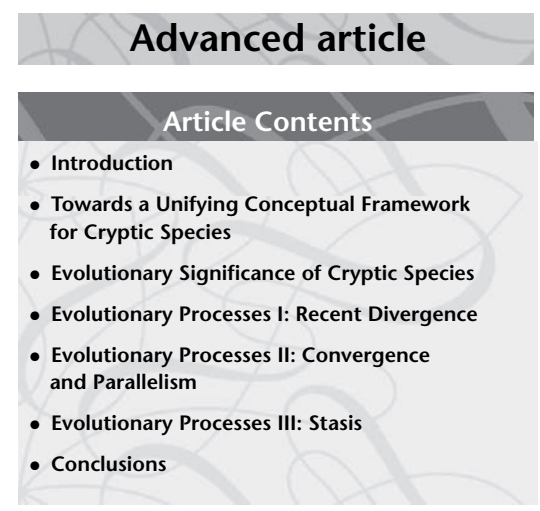

Online posting date: $16^{\text {th }}$ January 2019

\begin{abstract}
Cryptic species are detected at an ever-increasing rate, mainly due to the application of molecular data. While the impact of this hidden diversity on macro-ecology and conversation biology is widely recognized, its evolutionary significance is rarely. In recent years, it became apparent that definitions of cryptic species are too ambiguous to allow the differentiation between natural phenomena from human-made artefacts. Hence, recently, a unifying conceptual framework has been proposed highlighting the necessity to test the degree of reduced phenotypic disparity in cryptic species. Within this reduced disparity also lies the evolutionary significance, as cryptic species can be regarded as the opposite of adaptive radiations. Specifically, studies on evolutionary stasis can substantially benefit from including these by addressing both patterns of reduced disparity and processes resulting in the lack of phenotypic evolution. In addition, this will allow connecting macro-evolutionary and paleontological studies with micro-evolutionary investigations of genotype-phenotype linkage.
\end{abstract}

\section{Introduction}

Taxonomy, the discipline dealing with the delimitation of biological units, remains one of the most contentious and laborious disciplines in biology, yet it represents a fundamental step before understanding underlying evolutionary processes. Interestingly, taxonomical considerations already had a strong impact on Darwin's line of argument concerning evolution (Darwin,

eLS subject area: Evolution \& Diversity of Life

How to cite:

Struck, Torsten $\mathrm{H}$ and Cerca, José (January 2019) Cryptic

Species and Their Evolutionary Significance. In: eLS. John Wiley \& Sons, Ltd: Chichester.

DOI: 10.1002/9780470015902.a0028292
1859). He had already pointed out the problem of delineating species properly, and that the progress from populations to species is a contiguous scale with respect to the variability that can be observed at different levels, rendering it difficult to delineate species boundaries with certainty. The debate about this problem is still vibrant today and the debate about species concepts and how to apply them is in full fledge (for details see also: Species Concepts). In the last decades, the discussion about cryptic species has been added to this debate, highlighting the necessity to delimitate independently evolving units to understand evolutionary processes.

The concept of cryptic species has been applied as early as 1718 by the English clergyman William Derham focusing on the avian genus Phylloscopus (Winker, 2005) and Mayr (1963) coined the term sibling species for cases, where the species are either sister or very closely related to each other. However, the detection of cryptic species really took off with the advent of employing sequence data in delineating species boundaries on a much broader scale since the early 1990s (Struck et al., 2018b; see also: Systematics: Relevance to the Twenty-first Century on barcoding). Since then, cryptic species have been detected at an ever-increasing pace and across all habitats on Earth and the entire tree of life including fungi, algae, plants, protists, invertebrates, but also primates, amphibia, reptiles and crustaceans (Bickford et al., 2007; Pfenninger and Schwenk, 2007; Perez-Ponce de Leon and Poulin, 2016; Hawksworth and Lücking, 2017). Accordingly, cryptic species seem to represent an overlooked, yet substantial part of biodiversity with far-reaching implications for ecological research such as diversity estimates, pest control, fisheries management and conservation efforts as well as research in model systems (Bickford et al., 2007; Caputi et al., 2007; Bernardo, 2011; Pante et al., 2015; Fišer et al., 2018). However, like with any new emerging concept in biology, the term cryptic species is often applied with very different meanings and hence has different implications. This, among others, affects the general conclusions, which can be drawn concerning cryptic species. Owing to the different meanings the conducted meta-analyses usually compare apples with oranges (Struck et al., 2018a; Struck et al., 2018b). Therefore, it became noticeable that a unifying theoretical framework is needed for studying cryptic species, which then would also allow for drawing more general and solid conclusions about the ecological and evolutionary 
significance of cryptic species. Only such conclusions are then able to provide meaningful contributions to, for example conversation management or health issues stemming from cryptic species.

\section{Towards a Unifying Conceptual Framework for Cryptic Species}

The first attempt towards a unifying conceptual framework of cryptic species was accomplished by Bickford et al. (2007). They defined cryptic species as 'two or more distinct species that are erroneously classified (and hidden) under one species name'. This broad definition was quickly applied in several studies and became the most commonly used one, as it is easily applicable due to its tight link to the taxonomic history of the species. That is, it strictly requires that the species complex is formally described as a single species before. However, this also entails a caveat associated with different schools of taxonomic practice (see also: History of Taxonomy). For instance, in taxonomy, some schools favour splitting species even in cases of only little support, while others would rather lump these together as a single species (the splitter vs. lumper debate). Hence, some groups would be more prone to have cryptic species only due to different taxonomic practices. For example, the newly described Marphysa aegypti (Annelida) from Egyptian waters was previously recorded as Marphysa sanguinea (Elgetany et al., 2018). Even though both species are morphologically substantially different from each other, they could be called cryptic species or at least pseudo-cryptic species, while in truth the previous records suggest only sloppy taxonomic practices. On the other hand, molecular data supported the traditional assignment of species within the genus Polygordius (Annelida) based on geographic regions (Ramey-Balc1 et al., 2018), despite the indistinguishable adult morphology of Polygordius lacteus from Polygordius neapolitanus and Polygordius jouinae from Polygordius triestinus. Nonetheless, both species pairs could not be considered cryptic species given the provided definition by Bickford et al. (2007). Moreover, others pointed out that recent definitions of cryptic species are often linked to and depend on the applied species concept (Pante et al., 2015; Sukumaran and Knowles, 2017; Fišer et al., 2018; Heethoff, 2018). Given these nonbiological aspects, several studies introduced slightly different concepts such as pseudo-cryptic, hyper- or mega-cryptic species (e.g. Adams et al., 2014; Cornils and Held, 2014; Nygren et al., 2018).

Hence, in recent years, there has been an increased debate again what constitutes a cryptic species. Ultimately, Korshunova et al. (2017) argued "to avoid the terms "cryptic"/"pseudocryptic" species as a reference to a "natural phenomenon" because it is obscuring multilevel character diversity within a complicated taxonomy-dependent framework' and instead 'to use the term "cryptic species" only for a temporary formalization of the problems with delineation of the species from the same geographic region, when those species demonstrate significant molecular phylogenetic differences, but are hardly distinguished morphologically, ethologically, etc.' A recent literature survey found that only $14 \%$ of the studies actually provided or applied an explicit definition of cryptic species adding to the problem of uncertainty in the assignment of cryptic species (Struck et al., 2018b). Of these, all were explicitly or implicitly taxonomy-based like the Bickford et al. (2007) definition. Additional criteria such as usage of molecular data, sympatric occurrence, reproductive isolation, reduced gene flow, or no morphological differences were included in the definitions. Moreover, another problem of assigning cryptic species based on these definitions is that the species delineation process is intermingled with the assignment of the term 'cryptic'. As a consequence, all problems associated with species delineation (see also: Species Problem - A Philosophical Analysis) also automatically apply to the assignment. In summary, the assignment of a species as cryptic species depends on many nonbiological factors such as the applied definition and species concept as well as the taxonomic tradition resulting in much uncertainty about what constitutes a cryptic species and if it is a natural phenomenon or only a human-made artefact. This problem has dire consequences for meta-analyses investigating the impact of cryptic species in biodiversity studies (Perez-Ponce de Leon and Poulin, 2016; Poulin and Pérez-Ponce de León, 2017), and for the understanding of biological processes.

Two general assumptions, which were at least implicitly applied in the practical procedures, were evident from the literature (Struck et al., 2018b). First, given the species concept, cryptic species were generally thought to be 'true' species and, second, these species were so similar in the taxonomically relevant phenotypic characters that they were not or hardly distinguishable from each other. Therefore, Struck et al., 2018b provided a new definition for cryptic species reflecting these two assumptions. The process of assigning cryptic species was separated into two clearly separated steps in contrast to the previous attempts. At the first step, it has to be established that the species are truly species given the applied species concept. In Figure 1, the white circles indicate cases, which would not be considered species and accordingly also not cryptic species. Hence, this first step is not different from any other species delineation process, independent if these entities are cryptic or not, but it has the advantage that the pitfalls associated with this process are confined to the proper step and are not carried over to the next step. The second step consists in showing that the species are phenotypically more similar to each other than one would expect given the time that has passed since their last common ancestor (or the level of genetic divergence as a proxy for time). These species should hence be called cryptic species only if this level of phenotypic disparity is significantly lower than expected. The red circles in Figure 1 represent such cases, while the orange and yellow circles do not. This second step is the crucial step in the framework with respect to cryptic species as here the actual assignment occurs. The definition is property-based and independent of the taxonomic history of the species at hand. Specifically, it does not matter if the species have been described as only one before or not. Studies across taxa, habitats, life strategies and so forth can be based on comparable categories like similar applied species concepts, levels of disparity or genetic divergence instead of taking cryptic species at face value allowing more robust conclusions about the impact of cryptic species. 


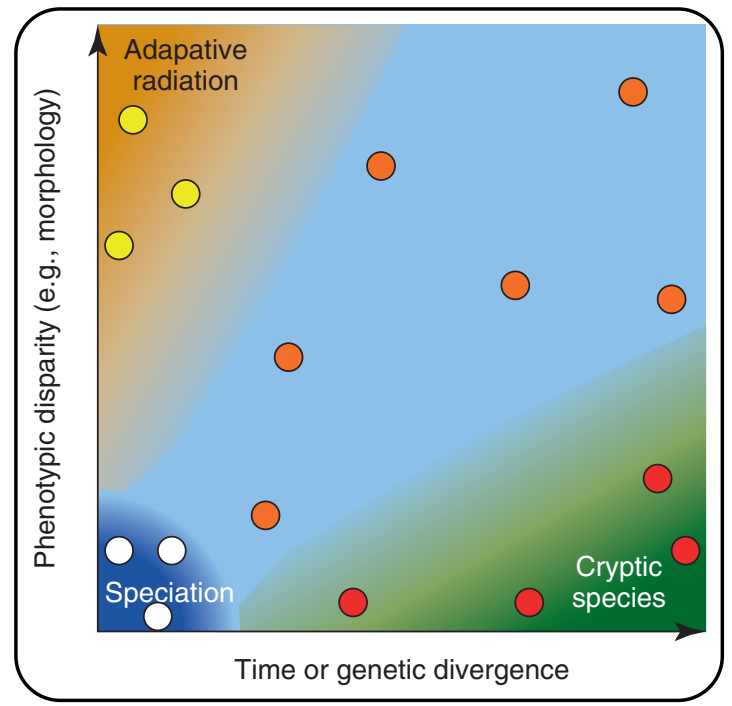

Figure 1 Unifying conceptual framework based on Struck et al. (2018b). The $x$-axis represent time since divergence from the last common ancestor. Often genetic divergence is used as proxy for this. The $y$-axis represents the degree of phenotypic disparity. The dark blue area is the area of ongoing speciation and hence no species boundaries have been established yet (white circles). The light blue area indicates evolution between pairs of species (orange circles) as it is intuitively assumed. That is phenotypic disparity more or less increases linear with time. The orange area reflects cases (yellow circles) in which phenotypic evolution occurs at a much higher rate than anticipated such as in adaptive radiations. The green area represents cases (red circles) of significantly reduced phenotypic disparity given time as it is the case in cryptic species.

\section{Evolutionary Significance of Cryptic Species}

Understanding the tempo and mode of speciation, and the drivers of phenotypic diversification are major objectives in biology (Rabosky and Adams, 2012). Therefore, identifying and quantifying contrasts between phenotypic disparity and genetic divergence has become popular in recent decades. Cases such adaptive radiations where morphological disparity outpaces genetic divergence received considerable attention (see also: Adaptive Radiation). Adaptive radiations generally rely on open ecological opportunities like appearance of new resources, evolution of key innovations or colonization of new areas followed by specialization to the open niches and speciation (Losos, 2010). Cryptic species as defined by the aforementioned framework can be regarded as the exact opposite to these radiations, being characterized by a strongly reduced phenotypic or at least morphological disparity in comparison to the observed genetic divergence (yellow vs. red circles in Figure 1).

If high rates of phenotypic variation have the potential to result in radiation of organisms and occupation of different evolutionary niches - 'high evolvability' - then low phenotypic disparity as observed in cryptic species can be seen as a paradox as theory predicts that clades with high evolvability supersede clades with low evolvability (Estes and Arnold, 2007; Rabosky and Adams,
2012). Clades of cryptic species should have a lower 'adaptive zone' and occupy less ecological space and, hence, be replaced by clades with a potential to evolve and adapt faster (Rabosky and Adams, 2012). As evolvability is generally considered as a measure of evolutionary success (Rabosky and Adams, 2012), the question arises why so many cryptic species are observed nowadays, which supposedly lack any phenotypic or at least morphological evolution. Several suggestions have been put forth to explain lack of phenotypic evolution in general and especially considering macro-evolutionary patterns (Futuyma, 2010). These include, among others, genetic and developmental constraints, source populations impeding specialization (meta-population dynamics), repeated bottlenecks decreasing standing genetic variation, large populations, stabilizing selection, ephemeral, stressful or fluctuating environments, evolutionary stable configurations or niche conservationism (Maynard Smith, 1983; Eldredge et al., 2005; Futuyma, 2010; Haller and Hendry, 2014; Chomicki and Renner, 2017). However, the lack of phenotypic evolution has received considerably less attention in evolutionary biology than its opposite, adaptive radiations, especially at the microevolutionary level, and empirical and experimental evidence for any of the suggestions is low so far. While cryptic species can be ideal systems to inform us on the causes of reduced phenotypic disparity, much needs to be done. First, the evolutionary processes resulting in cryptic species must be identified. Then it can be investigated in how far the different causes mentioned above influenced these processes. Four different processes have been suggested to result in cryptic species: recent divergence, convergence, parallelism and stasis (Swift et al., 2016; Struck et al., 2018b).

\section{Evolutionary Processes I: Recent Divergence}

The most common, but unproven assumption is that cryptic species follow recent speciation and that they did not yet have enough time to accumulate substantial phenotypic, especially morphological differences (Knowlton, 1993; Reidenbach et al., 2012). For example (Figure 2), in the malaria vector Anopheles gambiae (Hexapoda) two forms, the $\mathrm{M}$ (now recognized as Anopheles coluzzii) and S form, are recognized, which seem to be reproductively isolated (Reidenbach et al., 2012). They are at an early stage after speciation differing in an inversion on chromosome-2, which seems to be associated with their ecological differences (Simard et al., 2009). The M form mainly exploits stable larval habitats with high level of stressors; the $\mathrm{S}$ form exploits unpolluted, predator-free, ephemeral habitats associated with seasonal rainfall (Reidenbach et al., 2012). Ecological experiments suggest that these forms seem to outcompete each other in their respective environment and respond to predation differently (Diabaté et al., 2008). Hence, in the $\mathrm{M}$ and $\mathrm{S}$ forms, other traits than morphology are under selection.

Speciation is not necessarily accompanied by morphological change in the early stages as selection acts largely on physiological, immunological, reproductive or behavioural traits (Bensch et al., 2004; Damm et al., 2010; Derycke et al., 2016). Allopatric 


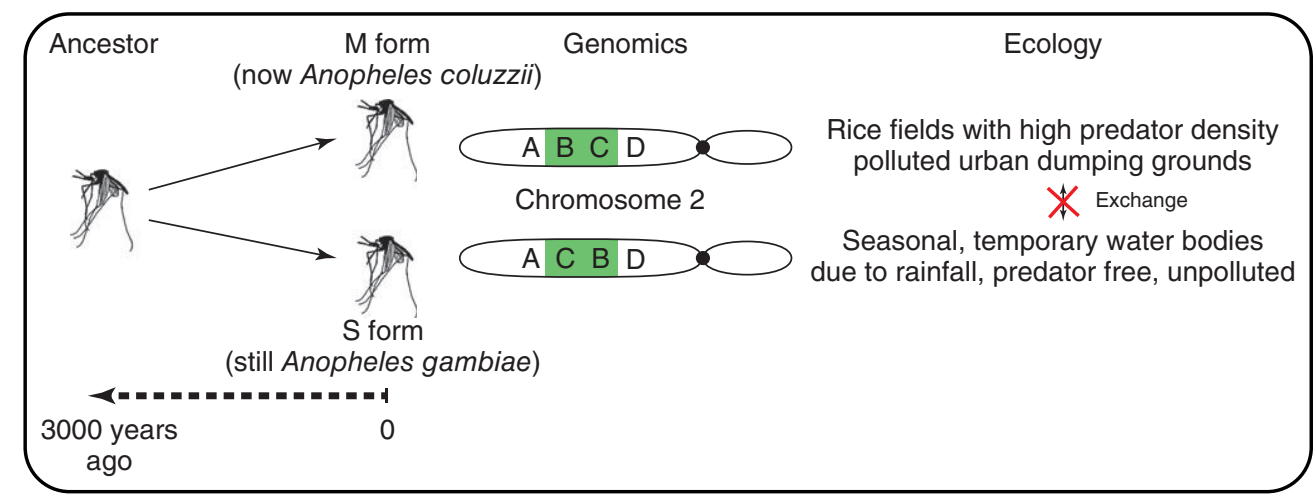

Figure 2 Schematic representation of the Anopheles example for recent divergence (based on the results of Reidenbach et al., 2012). The left panel exemplifies the recent divergence of the two cryptic species. In the middle, the genomic inversion at chromosome 2 is shown and the right one lists the ecological differences observed between the two species.

speciation while remaining in one particular ecological niche or habitat might lead to the building-up of nonadaptive divergence without morphological change. As a result, recently diverged species can remain morphologically identical following initial divergence (Korshunova et al., 2017). In these cases of recent divergence, cryptic species are nothing special to other species pairs as the speciation event is very recent and generally no or little phenotypic change, particularly in morphology, is expected this shortly after the speciation unless there is a strong selection towards different adaptive optima. Moreover, such cases cannot provide much insight into the supposed lack of phenotypic evolution.

\section{Evolutionary Processes II: Convergence and Parallelism}

Phenotypic similarity could also stem from convergence or parallelism (Swift et al., 2016; Struck et al., 2018b). In both cases, the cryptic species evolved the same phenotypes independently of each other. While for convergence the immediate ancestors of the cryptic species were dissimilar from each other as well as to the extant cryptic species, for parallelism the ancestors were similar to each other, but dissimilar to the extant cryptic species. One example (Figure 3) comprising both convergence and parallelism occurs in the Mastigias species complex (Scyphozoa) (Swift et al., 2016). Mastigias species occur in both coastal waters including coves and lagoons ('ocean' phenotypes), and in small-bodies of salt water without an open connection to the ocean ('lake' phenotypes). The 'lake' phenotypes evolved both by parallelism and convergence from the 'ocean' phenotypes. In some cases, the 'lake' phenotypes evolved from the same 'ocean' phenotype (parallelism) and in others from different 'ocean' phenotypes (convergence). Similarly, selective pressures from predators led to parallelism in the Holarctic Enallagma species (Hexapoda) (Stoks et al., 2005). Cases of convergence of cryptic species were also found in the Deep Sea (Vrijenhoek, 2009).

As for the case of recent divergence, the evolutionary processes of convergence and parallelism cannot contribute to our understanding of the lack of phenotypic evolution, as phenotypic change occurred. Nonetheless, these cases can help us understand how reduced phenotypic disparity evolves. Importantly, it indicates that reduced phenotypic disparity and lack of phenotypic evolution are not necessarily the same. For convergence and parallelism specifically, the question arises what are the driving factors that the cryptic species independently evolved to the same phenotypes? Is it due to intrinsic (e.g. developmental constraints) or extrinsic ones (e.g. extreme environments) confining the available phenotypic landscape to only one solution in the respective situation? Contrary to parallelism, intrinsic factors are expected to be less influential than extrinsic ones in convergence, as evolution starts from more distinct genetic backgrounds. However, maybe even for convergence developmental constraints constrict the available phenotypic landscape more than expected.

\section{Evolutionary Processes III: Stasis}

In contrast to the other three processes, under phenotypic stasis, cryptic species retain similar phenotypes for millions of years. The literature survey by Struck et al. (2018b) revealed that stasis in cryptic species may occur at least not substantially less than recent divergence and seems to be an important process in the evolution of cryptic species. A prominent example (Figure 4) is provided by the Cavernacmella complex (Gastropoda) on the Ogasawara Islands (Japan) (Wada et al., 2013). The 'Cavernacmella minima' phenotype occurs in five clades on the different islands of the archipelago (i.e. Mukojima, Chichijima and Hahajima). These represent cryptic species and are unaltered for over 3 million years. In contrast, within the clade of these cryptic species are also five species, which are morphologically distinct from the ' $C$. minima' phenotype. This indicates that enough time passed to accumulate morphological differences under certain conditions. This release from morphological arrest might indicate the absence of developmental constraints. Similarly, cichlids have demonstrated the potential for burst of morphological evolution and stasis (Seehausen, 2006). Other examples of stasis comprise Stygocapitella (Annelida), 


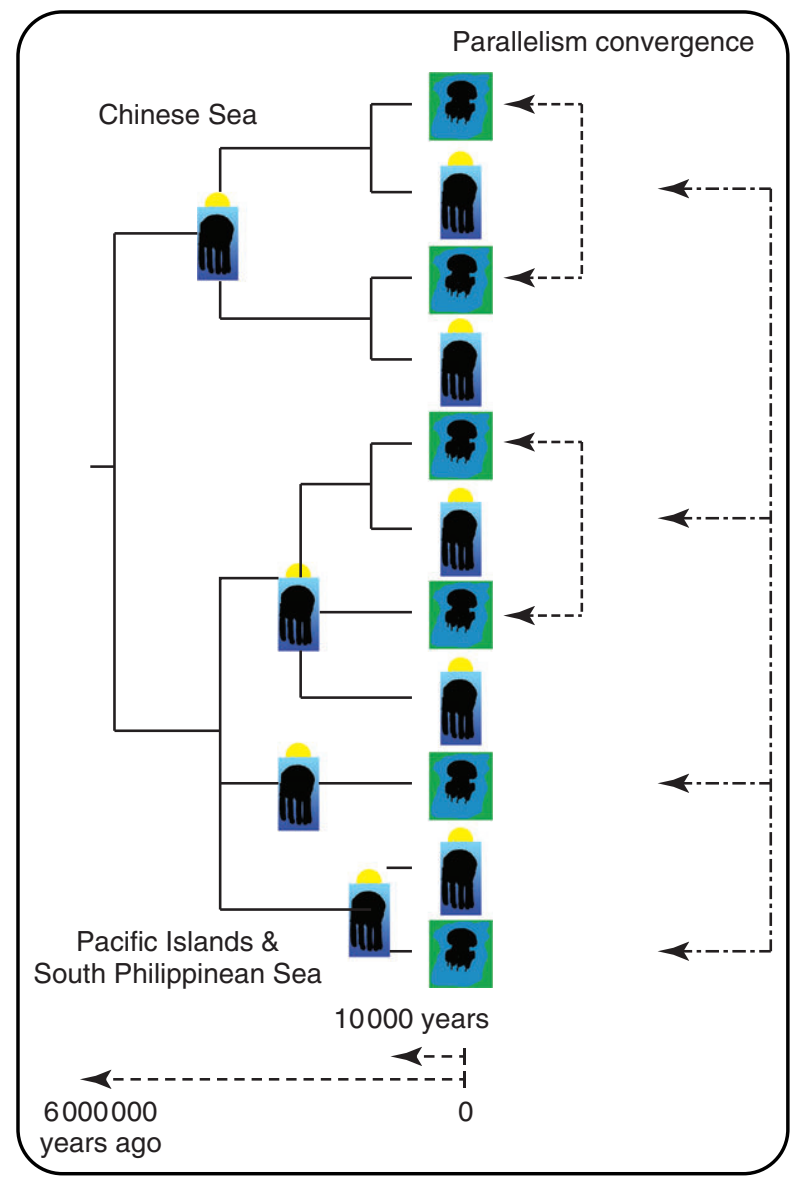

Figure 3 Schematic representation of the Mastigias example of parallelism and convergence based on the results by Swift et al. (2016). The phylogenetic relationship between the two morphotypes (oceanic and lake; indicated by the two icons) is shown to the left. Swift et al. (2016) regarded the origin of the two lake morphotypes within the Chinese Sea as well as two within the Pacific Islands \& South Philippinean Seas as examples of parallelism as they originated from the same oceanic species. In contrast, they concluded that the other lake morphotypes to each other as well as to these previous ones evolved by convergence as they originated from different oceanic species.

Diporiphora (Squamata), Mastigias (Scyphozoa) or Cletocamptus (Crustacea) species complexes (Rocha-Olivares et al., 2001; Smith et al., 2011; Swift et al., 2016; Struck et al., 2017). Stygocapitella is an example of long-lasting morphological stasis. Stygocapitella individuals live between sand grains, by the foot of the dune, at a depth of about $0.5-1$ meter and can be found on beaches in all major coastlines with the exception of tropical regions (Westheide, 2008). Molecular data suggest the presence of several cryptic species at the different coastlines and even though rigorous morphological reinvestigations discovered minimal phenotypic differences among the deeply divergent clades, these are estimated to have diverged about 300 to 100 million years ago (Struck et al., 2017). As such, the Stygocapitella complex seems to be under morphological stasis with slight morphological differentiations having occurred more than 100 million years ago. It is certainly challenging to address why these species did not change morphologically while closely related ones did, and why no phenotypic differences became fixed in the gene pools just by chance (e.g. due to recurrent bottlenecks).
Hence, cryptic species such as the presented examples are ideal systems to investigate stasis using extant taxa. These systems allow addressing both patterns of reduced phenotypic disparity and the process leading to the absence of phenotypic evolution. The term stasis is most often used in macro-evolutionary and paleontological studies and less in micro-evolutionary ones using extant taxa. In macroevolution and palaeontology, it became popularized as an argument for punctuated equilibria (see also: Punctuated Equilibrium and Phyletic Gradualism), where evidence from fossil timelines lasting for millions of years questioned the power of selection. However, recent efforts have focused on integrating stasis at the microevolutionary level (e.g. Hansen and Houle, 2004; Estes and Arnold, 2007). Futuyma (2010) reviewed many of these models including stabilizing selection, lack of genetic diversity, genetic and developmental constraints, ecological niche tracking and niche conservatism. Other potential, nonexclusive explanations for stasis or arrested evolution have been put forward specifically for more specific scenarios or habitats. For example, for the interstitial realm, that is the space 


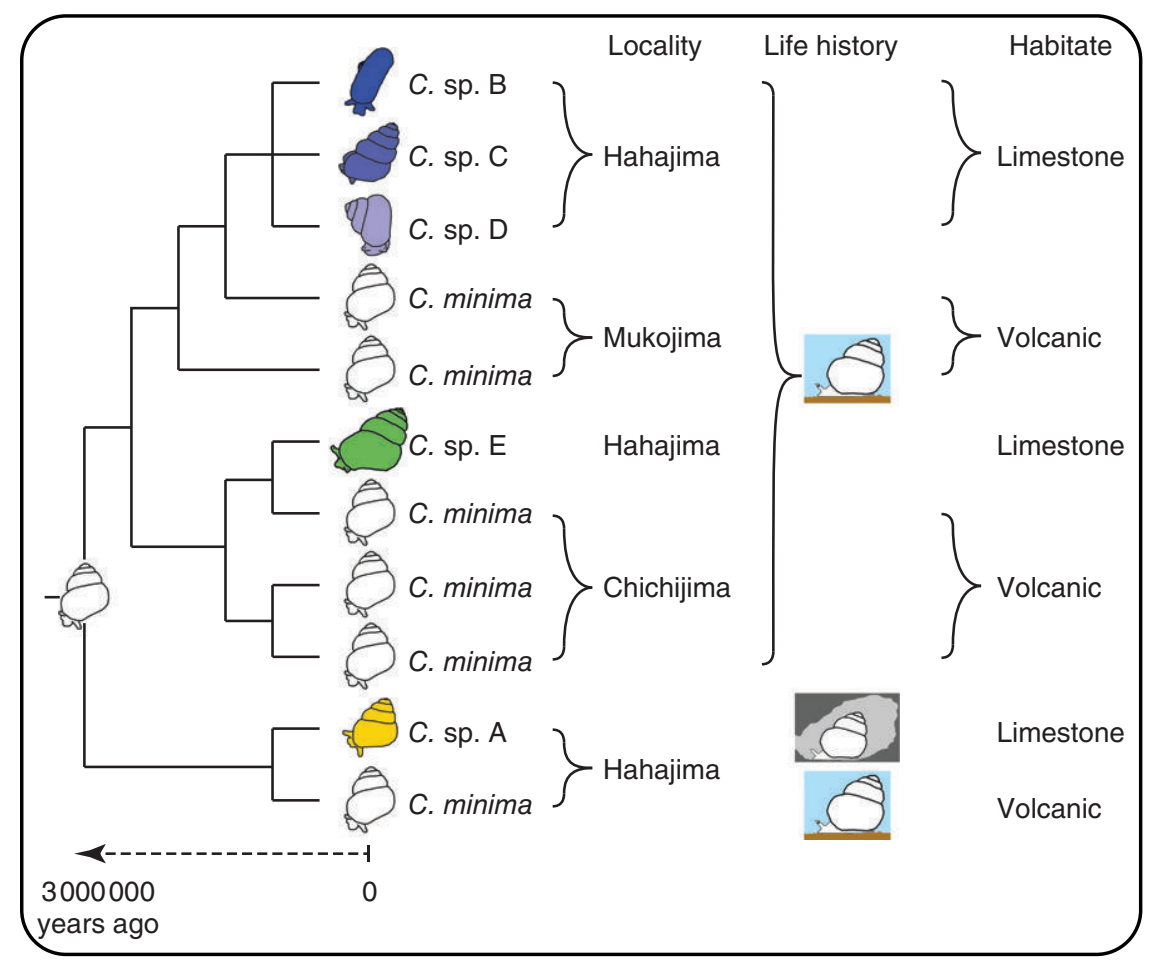

Figure 4 Schematic representation of the Cavernacmella example for stasis given the results of Wada et al. (2013). Wada et al. (2013) recognized a total five cryptic species as well as five morphologically distinct, noncryptic species within them (indicated by the different forms and colours; icons are relative in size to each other). The occurrence of these ten species is indicated as well as their life-history and habitat (epigenean and cave-dwelling; indicated by the two icons).

between the sand grains in marine sediments, one potential explanation stems from the 'plus ça change, plus c'est la même chose' (The more it changes, the more it is the same) model (Sheldon, 1996). This model regards morphological stasis as a response to widely fluctuating physical conditions, which are stable on geological timescales. This fits the interstitial realm, as this is characterized by wide variations in $\mathrm{pH}$, salinity and moisture at short timescales, but this fluctuating characteristic has remained similar for millions of years ago (e.g. Westheide, 1977). It has also been suggested that the phenotypic landspace of species with limited morphological differentiation such as, for example some worms or fungi are too small to allow for change (Bickford et al., 2007). In contrast, another suggestion is that intraspecific variation of traits is high and allows for coping with broader ranges of ecological differences, while the traits fluctuate around a stable mean (Voje, 2016).

\section{Conclusions}

Studying cryptic species has great potential to further our understanding of evolutionary processes as outlined earlier, but also with respect to research in macroecology and conservation biology (Figure 5) (Bickford et al., 2007; Bernardo, 2011; Pante et al., 2015; Fišer et al., 2018). However, to accomplish these goals a pre-requisite is that what is a cryptic species can be determined with certainty. It is important to differentiate cryptic species complexes from those complexes arising from taxonomic biases or malpractice. Only the former will be able to inform us on biological processes in evolution and ecology as they reflect true natural properties. A two-step conceptual framework to accomplish this has been provided and hence the theoretical foundation been laid. However, the literature survey by Struck et al. (2018b) also clearly showed that methodological improvement is needed in all aspects to achieve this. Often the phenotype is not studied at all, only a single, uni-parentally inherited genetic marker is used, and/or the results are not set in relation to time or other noncryptic species to assess if they are really exceptionally different from them. Moreover, biology is transforming into a 'big data' science including among others high-throughput sequencing technologies, which allows us to apply population genomic and phylogenomic methods independent of the study object and hence provide much broader data basis for their conclusions (Figure 5).

On the other hand, improved delineations of cryptic species will result in and contribute to an improved understanding of the causes of evolutionary processes like convergence, parallelism and stasis (Figure 5). Again, the applications of genomic and transcriptomic approaches studies on cryptic species can aid in linking genotypic change to phenotypic alterations or lack thereof. Similarly, improved delineations will result in improved biodiversity assessments allowing better modelling of 


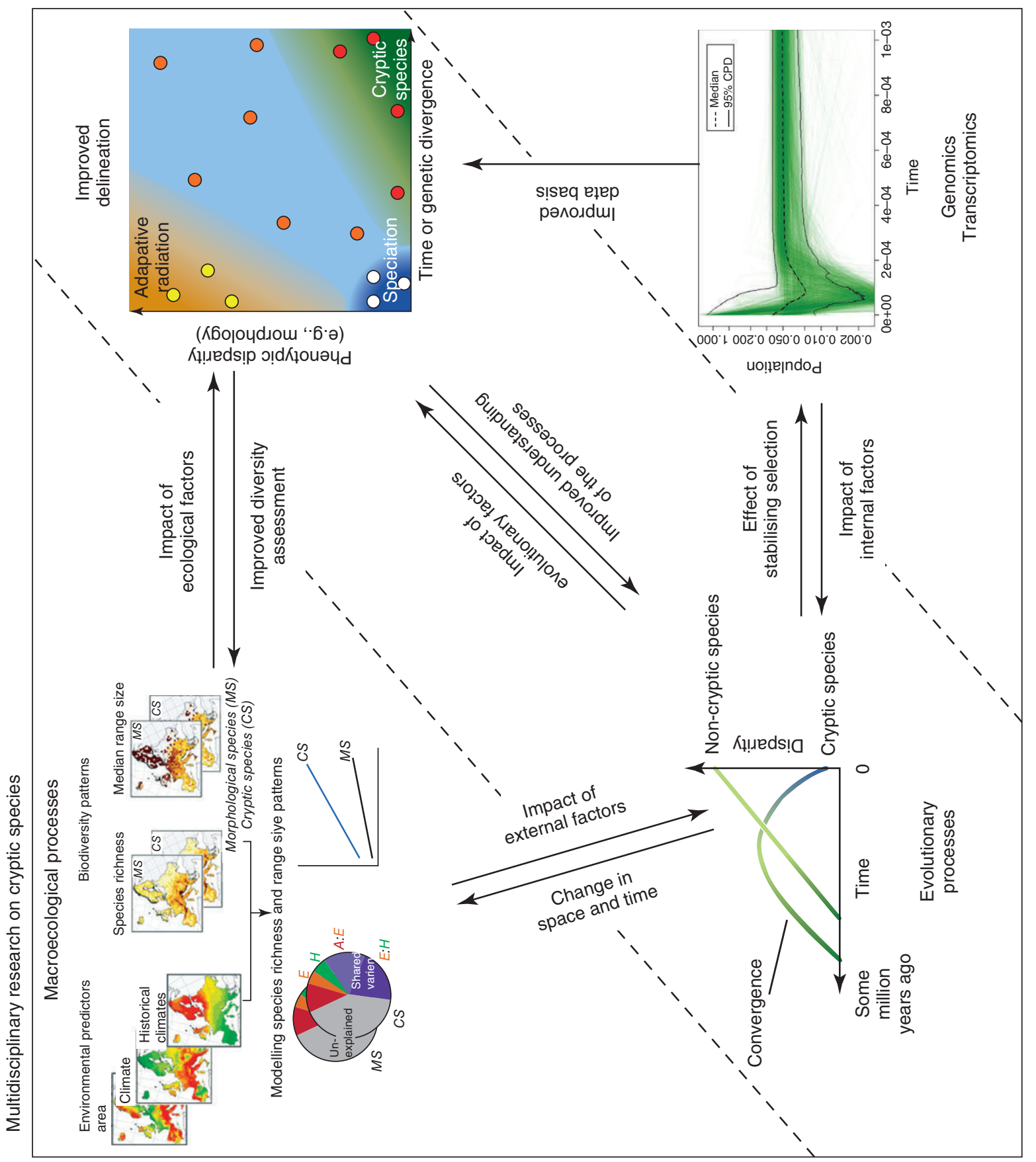

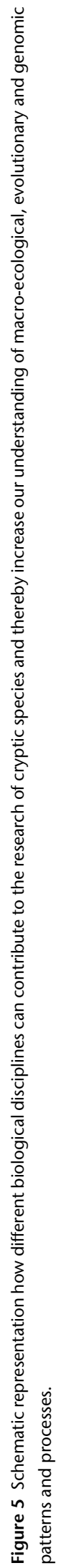


macroecological processes. Moreover, an improved understanding of the evolutionary processes shaping cryptic species allows a better assessment of ecological changes and its evolutionary consequences over space and time. Summarizing the research on cryptic species should address the following questions to contribute to our understanding of the evolution of reduced phenotypic disparity and how this affects the macroecological processes in different habitats:

1. Which species complexes are only taxonomic oddities, and which are truly cryptic?

2. Which cryptic species are the results of recent speciation, parallelism, convergence or stasis, and how common are they?

3. What are the relevant intrinsic and extrinsic factors affecting phenotypic evolution of cryptic species and to what degree do they affect their phenotypic landscape?

4. Are there more cryptic species in certain branches of the tree of life, among taxa with certain life histories (e.g. generalists vs. specialists), or in certain habitats?

5. How affect cryptic species the composition and stability of ecosystems or vice versa how vulnerable are cryptic species due to these effects?

\section{Glossary}

Convergent evolution Evolution of the same set of morphological traits from different ancestral set of traits.

Cryptic species Different species, which are morphologically very similar or identical.

Morphology The form or structure of the external characters of an organism.

Parallel evolution Evolution of the same set of morphological traits from one ancestral set of traits.

Stasis Maintenance of morphological similarity during long timescales.

\section{References}

Adams M, Raadik TA, Burridge CP and Georges A (2014) Global biodiversity assessment and hyper-cryptic species complexes: more than one species of elephant in the room? Systematic Biology 63 (4): 518-533.

Bensch S, Pérez-Tris J, Waldenström J and Hellgren O (2004) Linkage between nuclear and mitochondrial DNA sequences in avian malaria parasites: multiple cases of cryptic speciation? Evolution 58 (7): 1617-1621.

Bernardo J (2011) A critical appraisal of the meaning and diagnosability of cryptic evolutionary diversity, and its implications for conservation in the face of climate change. In: Hodkinson TR, Jones MB, Waldren S and Parnell JAN (eds) Climate Change, Ecology and Systematics, pp. 380-438. Cambridge, UK: Cambridge University Press.

Bickford D, Lohman DJ, Sodhi NS, et al. (2007) Cryptic species as a window on diversity and conservation. Trends in Ecology \& Evolution 22 (3): 148-155.
Caputi L, Andreakis N, Mastrototaro F, et al. (2007) Cryptic speciation in a model invertebrate chordate. Proceedings of the National Academy of Sciences 104 (22): 9364-9369.

Chomicki G and Renner SS (2017) Partner abundance controls mutualism stability and the pace of morphological change over geologic time. Proceedings of the National Academy of Sciences 114 (15): 3951-3956.

Cornils A and Held C (2014) Evidence of cryptic and pseudocryptic speciation in the Paracalanus parvus species complex (Crustacea, Copepoda, Calanoida). Frontiers in Zoology 11: 19.

Damm S, Schierwater B and Hadrys H (2010) An integrative approach to species discovery in odonates: from character-based DNA barcoding to ecology. Molecular Ecology 19: 3881-3893.

Darwin C (1859) On the Origin of Species by Means of Natural Selection: Or the Preservation of Favoured Races in the Struggle of Life. London: John Murray.

Derycke S, De Meester N, Rigaux A et al. (2016) Coexisting cryptic species of the Litoditis marina complex (Nematoda) show differential resource use and have distinct microbiomes with high intraspecific variability. Molecular Ecology 25: 2093-2110

Diabaté A, Dabiré RK, Heidenberger K, et al. (2008) Evidence for divergent selection between the molecular forms of Anopheles gambiae: role of predation. BMC Evolutionary Biology 8 (1): 5.

Eldredge N, Thompson JN, Brakefield PM, et al. (2005) The dynamics of evolutionary stasis. Paleobiology 31 (5): 133-145.

Elgetany AH, El-Ghobashy AE, Ghoneim AM and Struck TH (2018) Description of a new species of the genus Marphysa (Eunicidae), Marphysa aegypti sp.n., based on molecular and morphological evidence. Invertebrate Zoology 15 (1): 71-84.

Estes S and Arnold SJ (2007) Resolving the paradox of stasis: models with stabilizing selection explain evolutionary divergence on all timescales. The American Naturalist 169 (2): 227-244.

Fišer C, Robinson CT and Malard F (2018) Cryptic species as a window into the paradigm shift of the species concept. Molecular Ecology 27: 613-635.

Futuyma DJ (2010) Evolutionary constraint and ecological consequences. Evolution 64 (7): 1865-1884.

Haller BC and Hendry AP (2014) Solving the paradox of stasis: squashed stabilizing selection and the limits of detection. Evolution 68 (2): 483-500.

Hansen TF and Houle D (2004) Evolvability, stabilizing selection, and the problem of stasis. In: Pigliucci M and Preston K (eds) Phenotypic Integration: Studying the Ecology and Evolution of Complex Phenotypes, pp. 130-154. Oxford: Oxford University Press.

Hawksworth DL and Lücking R (2017) Fungal diversity revisited: 2.2 to 3.8 million species. Microbiology Spectrum 5 (4): FUNK-0052-2016.

Heethoff M (2018) Cryptic species - conceptual or terminological chaos? A response to Struck et al. Trends in Ecology \& Evolution 33 (5): 310.

Knowlton N (1993) Sibling species in the sea. Annual Review of Ecology and Systematics 24 (1): 189-216.

Korshunova T, Martynov A, Bakken T and Picton B (2017) External diversity is restrained by internal conservatism: new nudibranch mollusc contributes to the cryptic species problem. Zoologica Scripta 46: 692-683.

Losos JB (2010) Adaptive radiation, ecological opportunity, and evolutionary determinism. The American Naturalist 175 (6): 623-639.

Maynard Smith J (1983) The genetics of stasis and punctuation. Annual Review of Genetics 17 (1): 11-25. 
Mayr E (1963) Animal Species and Evolution. Cambridge: Belknap Press of Harvard University.

Nygren A, Parapar J, Pons J, et al. (2018) A mega-cryptic species complex hidden among one of the most common annelids in the North East Atlantic. PLoS ONE 13 (6): e0198356.

Pante E, Puillandre N, Viricel A, et al. (2015) Species are hypotheses: avoid connectivity assessments based on pillars of sand. Molecular Ecology 24 (3): 525-544.

Perez-Ponce de Leon G and Poulin R (2016) Taxonomic distribution of cryptic diversity among metazoans: not so homogeneous after all. Biology Letters 12: 20160371.

Pfenninger M and Schwenk K (2007) Cryptic animal species are homogeneously distributed among taxa and biogeographical regions. BMC Evolutionary Biology 7 (1): 121.

Poulin R and Pérez-Ponce de León G (2017) Global analysis reveals that cryptic diversity is linked with habitat but not mode of life. Journal of Evolutionary Biology 30 (3): 641-649.

Rabosky DL and Adams DC (2012) Rates of morphological evolution are correlated with species richness in salamanders. Evolution 66 (6): 1807-1818.

Ramey-Balc1 P, Fiege D and Struck TH (2018) Molecular phylogeny, morphology, and distribution of Polygordius (Polychaeta: Polygordiidae) in the Atlantic and Mediterranean. Molecular Phylogenetics and Evolution 127: 919-930.

Reidenbach KR, Neafsey DE, Costantini C, et al. (2012) Patterns of genomic differentiation between ecologically differentiated $\mathrm{M}$ and $\mathrm{S}$ forms of Anopheles gambiae in West and Central Africa. Genome Biology and Evolution 4 (12): 1202-1212.

Rocha-Olivares A, Fleeger JW and Foltz DW (2001) Decoupling of molecular and morphological evolution in deep lineages of a meiobenthic harpacticoid copepod. Molecular Biology and Evolution 18: 1088-1102.

Seehausen O (2006) African cichlid fish: a model system in adaptive radiation research. Proceedings of the Royal Society B: Biological Sciences 273 (1597): 1987-1998.

Sheldon PR (1996) Plus ça change-A model for stasis and evolution in different environments. Palaeogeography, Palaeoclimatology, Palaeoecology 127 (1): 209-227.

Simard F, Ayala D, Kamdem GC, et al. (2009) Ecological niche partitioning between Anopheles gambiae molecular forms in Cameroon: the ecological side of speciation. BMC Ecology 9 (1): 17.

Smith KL, Harmon LJ, Shoo LP and Melville J (2011) Evidence of constrained phenotypic evolution in a cryptic species complex of agamid lizards. Evolution 65 (4): 976-992.

Stoks R, Nystrom JL, May ML, McPeek MA and Benkman C (2005) Parallel evolution in ecological and reproductive traits to produce cryptic damselfly species across the Holarctic. Evolution 59 (9): 1976-1988.

Struck TH, Feder JL, Bendiksby M, et al. (2018a) Cryptic species - more than terminological chaos: a reply to Heethoff. Trends in Ecology \& Evolution 33 (5): 310-312.

Struck TH, Feder JL, Bendiksby M, et al. (2018b) Finding evolutionary processes hidden in cryptic species. Trends in Ecology \& Evolution 33 (3): 153-163.

Struck TH, Koczula J, Stateczny D, Meyer C and Purschke G (2017) Two new species in the annelid genus Stygocapitella (Orbiniida, Parergodrilidae) with comments on their biogeography. Zootaxa 4286 (3): 301-332.
Sukumaran J and Knowles LL (2017) Multispecies coalescent delimits structure, not species. Proceedings of the National Academy of Sciences 114 (7): 1607-1612.

Swift HF, Gómez Daglio L and Dawson MN (2016) Three routes to crypsis: stasis, convergence, and parallelism in the Mastigias species complex (Scyphozoa, Rhizostomeae). Molecular Phylogenetics and Evolution 99: 103-115.

Voje KL (2016) Tempo does not correlate with mode in the fossil record. Evolution 70 (12): 2678-2689.

Vrijenhoek RC (2009) Cryptic species, phenotypic plasticity, and complex life histories: assessing deep-sea faunal diversity with molecular markers. Deep Sea Research Part II: Topical Studies in Oceanography 56 (19): 1713-1723.

Wada S, Kameda Y and Chiba S (2013) Long-term stasis and short-term divergence in the phenotypes of microsnails on oceanic islands. Molecular Ecology 22 (18): 4801-4810.

Westheide W (1977) The geographical distribution of interstitial polychaetes. Mikrofauna Meeresboden 61: 287-302.

Westheide W (2008) Polychaetes: Interstitial Families. Shrewsbury: Field Studies Council.

Winker K (2005) Sibling species were first recognized by William Derham (1718). The Auk 122: 706-707.

\section{Further Reading}

Appeltans W, Ahyong Shane T, Anderson G, et al. (2012) The magnitude of global marine species diversity. Current Biology 22 (23): 2189-2202.

Cerca J, Purschke G and Struck TH (2018) Marine connectivity dynamics: clarifying cosmopolitan distributions of marine interstitial invertebrates and the meiofauna paradox. Marine Biology 165 : 123.

Charlesworth B, Lande R and Slatkin M (1982) A Neo-Darwinian commentary on macroevolution. Evolution 36: 474-498.

Coyne J and Orr H (2004) Speciation. Sunderland, MA: Sinauer Associates.

Giere O (2009) Meiobenthology-The Microscopic Motile Fauna of Aquatic Sediments. Berlin Heidelberg: Springer-Verlag.

Karanovic T, Djurakic M and Eberhard SM (2016) Cryptic species or inadequate taxonomy? Implementation of 2D geometric morphometrics based on integumental organs as landmarks for delimitation and description of copepod taxa. Systematic Biology 65 (2): 304-327.

Meleg IN, Zakšek V, Fišer C, Kelemen BS and Moldovan OT (2013) Can environment predict cryptic diversity? The case of Niphargus inhabiting western Carpathian groundwater. PLOS ONE 8 (10): e76760.

Nygren A (2013) Cryptic polychaete diversity: a review. Zoologica Scripta 43: 172-183.

Schwenk K and Wagner GP (2001) Function and the evolution of phenotypic stability: connecting pattern to process. American Zoologist 41 (3): 552-563.

Winston JE (1999) Describing Species-Practical Taxonomic Procedure for Biologists. New York: Columbia University Press. 